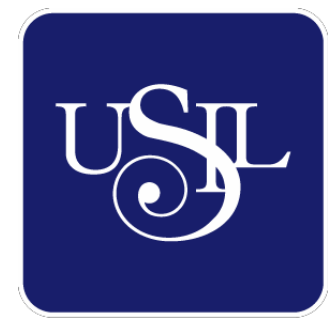

UNIVERSIDAD

SAN IGNACIO

DE LOYOLA

ESCUELA DE POSTGRADO

Maestría en Administración de Negocios (MBA)

\title{
PLAN DE NEGOCIO PARA LA CREACIÓN DE UNA GUARDERÍA INFANTIL PARA NIÑOS DE 3 A 36 MESES APLICANDO LA METODOLOGÍA DOMAN
}

Trabajo de Investigación para optar el grado de Maestro en Administración de Negocios (MBA)

\section{KELLY ARACELLY BASUALDO AGUILAR ALVARO RICARDO MELGAREJO FARIAS ANA MARIELA PRADERA MENDOZA}

Asesor:

Patricia Mercedes Rodríguez Román

$$
\text { Lima - Perú }
$$




\section{Dedicatoria}

Agradecemos a Dios por permitirnos culminar satisfactoriamente esta etapa de nuestras vidas, por darnos la oportunidad y las herramientas de desarrollar este plan de negocios.

Dedicamos este Plan de Negocio a las mujeres que cada día luchan por tener igualdad de oportunidades en el mundo laboral, a las familias nuevas que deben buscar alternativas para mantener el mismo estilo de vida (económico) después de la llegada de sus hijos y a las empresas que apuestan por retener a mujeres embarazadas y contratar a madres de niños de la primera infancia.

Lo dedicamos también a nuestros padres por creer en nosotros y por su valioso e incondicional apoyo en nuestro desarrollo personal y profesional, a nuestros hijos por motivarnos e impulsarnos a ser cada día mejores personas y profesionales, a nuestra asesora Dra. Patricia Rodriguez por compartir sus conocimientos y experiencias para poder culminar satisfactoriamente este trabajo y a todas las personas que nos han apoyado a cumplir con el objetivo trazado al iniciar el MBA. 


\section{Resumen Ejecutivo}

El presente proyecto trata sobre la elaboración de un plan de negocios para la creación de una guardería infantil para niños de 3 a 36 meses, aplicando la metodología Doman como parte de la estimulación temprana. El objetivo de este método es desarrollar al máximo la capacidad natural y espontaneo de aprendizaje en lo intelectual, físico y social. Es un método no muy conocido comercialmente; sin embargo, los beneficios que brinda a los infantes son altamente interesantes y contribuyen con la estimulación integral.

El público objetivo del proyecto está conformado por hombre o mujer jefe de familia de 25 años a más perteneciente al nivel socioeconómico B; que trabajan en la zona financiera de San Isidro, con hijos menores y que tienen la necesidad de encargar el cuidado de sus hijos a terceros.

El lugar donde va a estar ubicada la guardería es en el distrito de La Victoria, en la Urbanización Santa Catalina, el cual está ubicado frente a la zona financiera de San Isidro, es importante resaltar que actualmente la municipalidad de San Isidro no viene otorgando licencias municipales para instituciones educativas.

El nombre comercial que se ha considerado para la guardería es Titinos Daycare, el cual nace de un proceso donde se han considerado aspectos estratégicos de marketing que facilite el posicionamiento de la marca, apoyándose también en un adecuado diseño del logo y slogan, los cuales identifican claramente el servicio que se brinda y buscan generar empatía con los padres.

La estrategia en la que se basa el proyecto es el de enfoque de mejor valor, pues según la investigación de mercado realizada, los padres valoran mucho el tiempo por lo que Titinos Daycare permite que estos destinen su tiempo en actividades laborales, de crecimiento profesional y personales, y les ofrece un horario extendido de atención (lunes a viernes en el horario de 8:00 am - 7:00 pm); asimismo, cuenta con alta tecnología de cámaras IP lo cual contribuye a generar la confianza de los padres, ya que pueden observar a sus hijos en todo momento y en tiempo real.

Se ha considerado que el costo del servicio de Guardería incluido la estimulación temprana bajo la metodología Doman es S/ 825 Soles mensuales para los dos primeros años y de S/ 900 Soles a partir del tercer año, también se debe realizar un único pago para todo el ciclo de S/ 400 soles correspondiente al derecho a matrícula, es preciso destacar que el costo está por encima de los costos de empresas que brindan un servicio similar en la zona; sin 
embargo, este precio se justifica ya que Titinos Daycare brinda un horario extendido y la infraestructura es de mejor calidad a las guarderías existentes.

La estructura organizacional se ha dividido en un área administrativa que a su vez realiza gestiones comerciales y un área académica que está conformada por una plana docente y cuenta con la asesoría de un especialista en metodología Doman.

La inversión preoperativa para la implementación de la guardería Titinos Daycare está conformada por activos tangibles, activos intangibles y el capital de trabajo calculado bajo el método de déficit acumulado máximo; los cuales ascienden a S/ 67 828, S/ 28 456, S/ 67005 respectivamente. Por lo tanto, para iniciar la puesta en marcha del proyecto se requiere contar con una inversión total de S/163 279, los cuales el 58.5\% van a ser obtenidos a través de un financiamiento propio, y el $41.5 \%$ será obtenido a través de un financiamiento externo proveniente de una empresa del sistema financiero peruano a una tasa efectiva anual de $32 \%$.

El Costo de capital promedio ponderado o WACC del proyecto es $22.14 \%$, mientras que el Costo de capital del accionista o COK es 21.83\%, asimismo se ha realizado una proyección del Estado de Ganancias y Pérdidas donde se evidencia que el proyecto va a generar utilidad a partir del segundo año de funcionamiento y respecto a los análisis de flujo de caja proyectado a 5 años se ha obtenido que la Tasa Interna de Retorno o TIR del proyecto es $40.94 \%$ y que el Valor Presente Neto o VAN de proyecto es S/ 140899 evidenciando ambos indicadores que el proyecto es rentable y puede implementarse, finalmente se ha realizado un análisis de sensibilidad y otro de escenarios donde se ha corroborado que el proyecto es poco sensible a los cambios de las variables analizadas (precio y costo de alquiler del local) y que aun en un escenario pesimista el proyecto sigue siendo rentable.

Por lo expuesto, se concluye que el proyecto de elaboración de un plan de negocios para la creación de una guardería infantil para niños de 3 a 36 meses, aplicando la metodología Doman; es una buena alternativa de inversión para los accionistas y que adicionalmente contribuye a la sociedad permitiendo el crecimiento profesional de los padres (especialmente de las madres) y el desarrollo integral de sus hijos durante la primera infancia. 
Tabla de Contenido

Lista de Tablas .viii

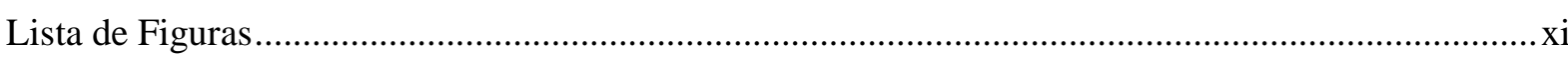

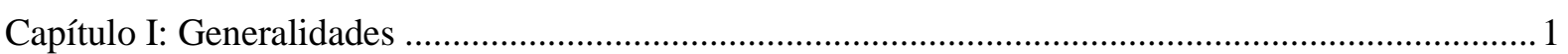

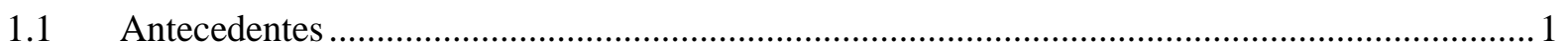

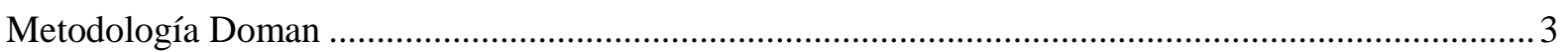

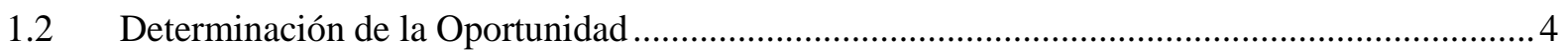

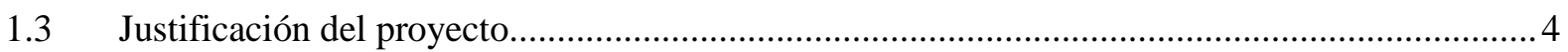

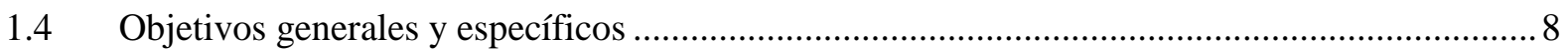

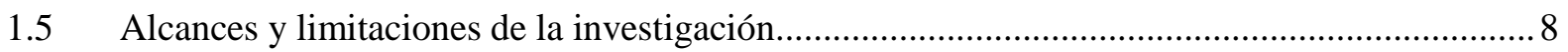

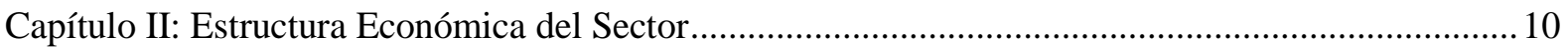

2.1 Descripción del estado actual de la industria ............................................................................... 10

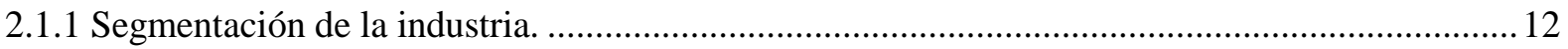

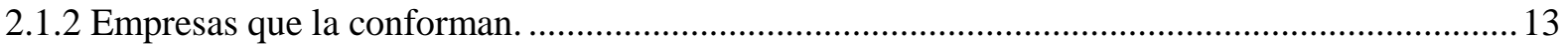

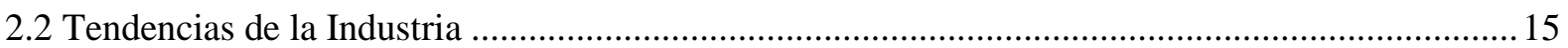

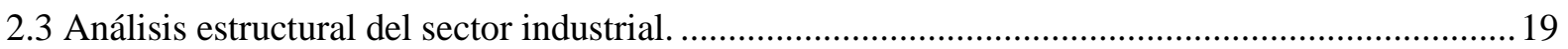

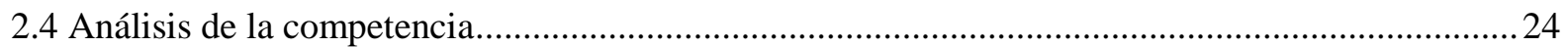

2.4.1 Empresas que ofrecen el mismo servicio, indicando las semejanzas y diferencias que tienen con

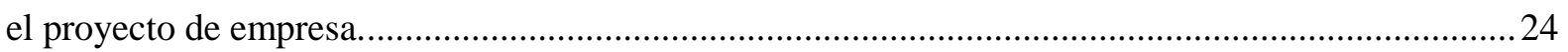

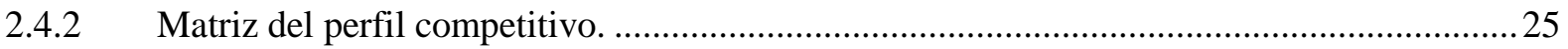

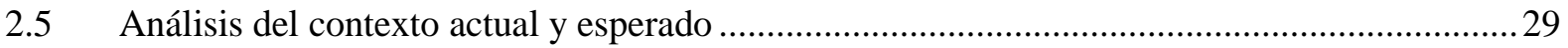

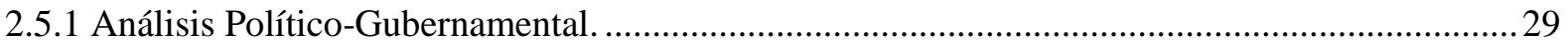

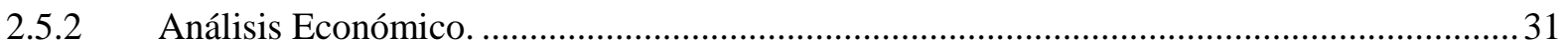

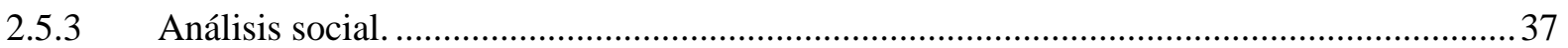

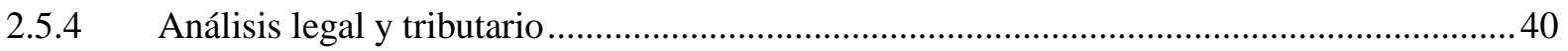

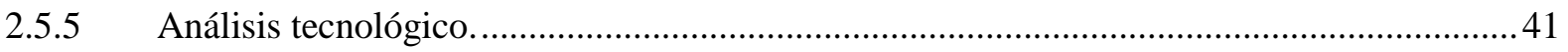

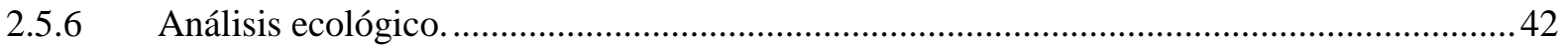

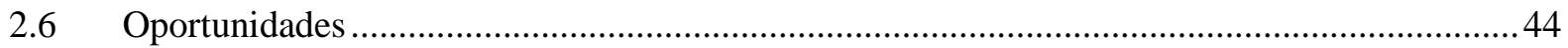

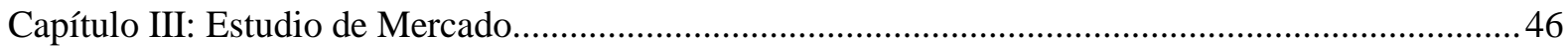

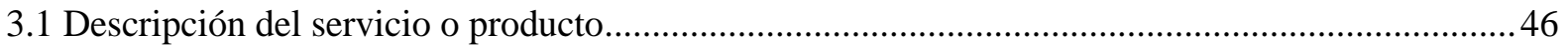

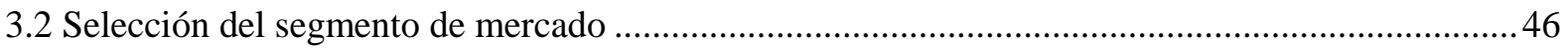

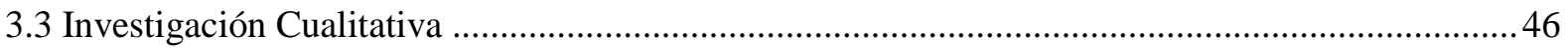

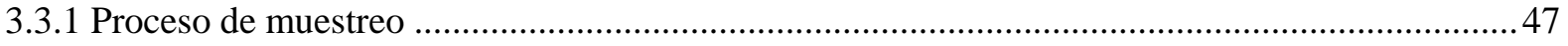

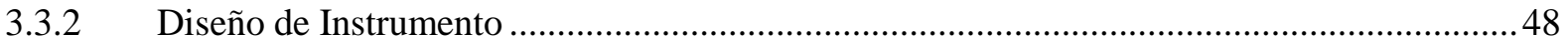

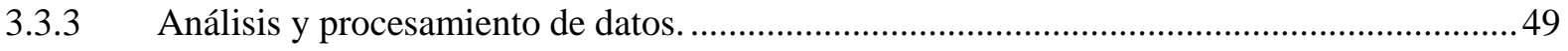

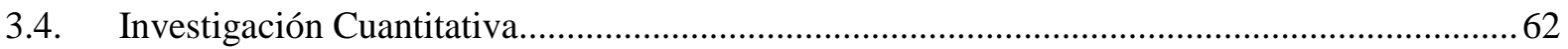




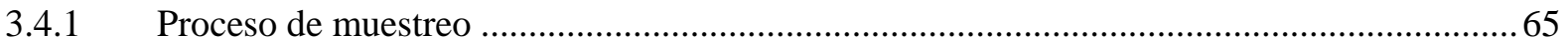

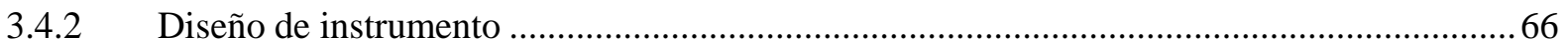

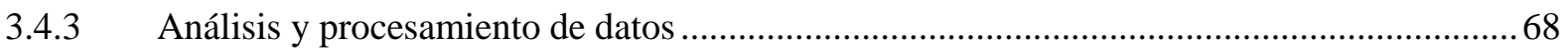

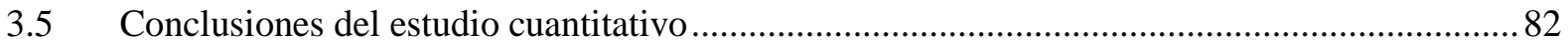

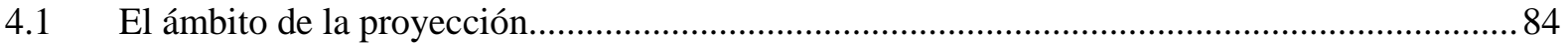

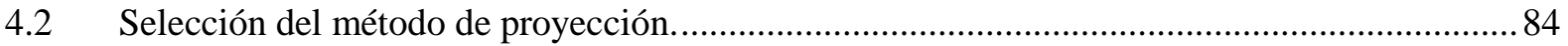

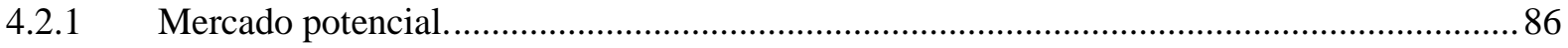

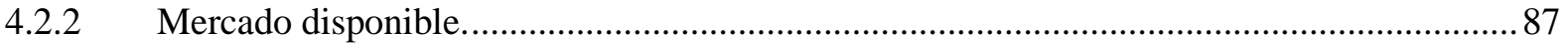

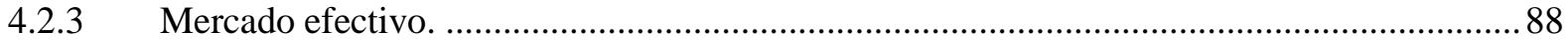

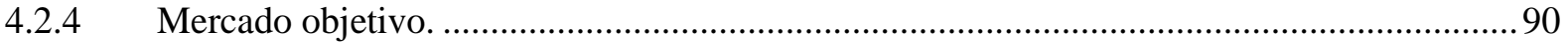

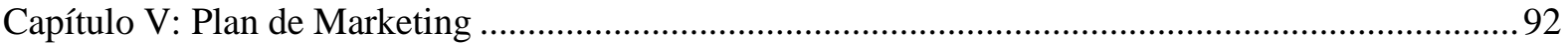

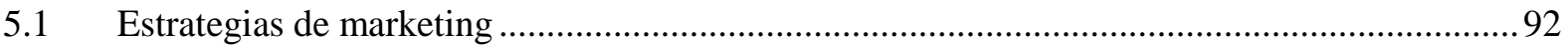

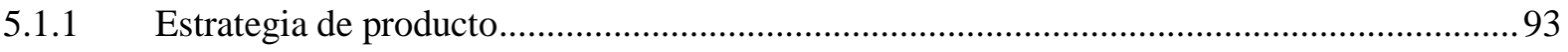

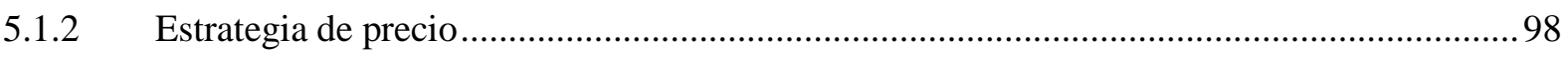

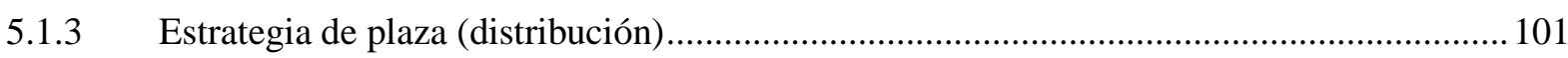

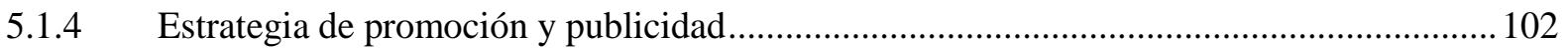

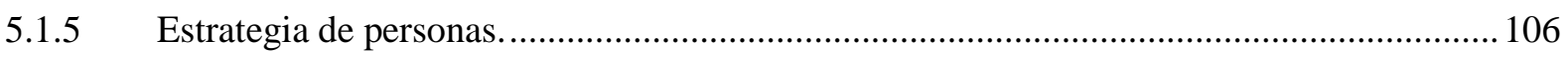

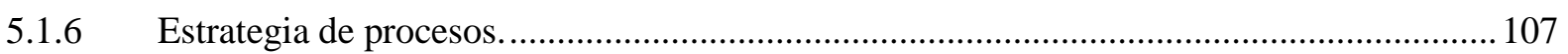

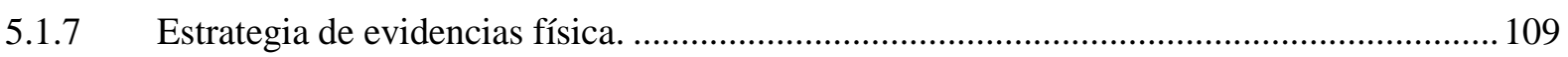

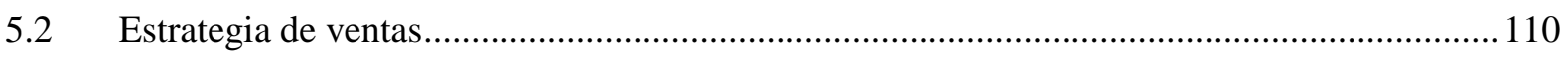

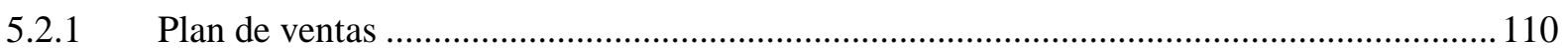

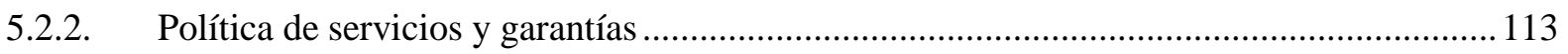

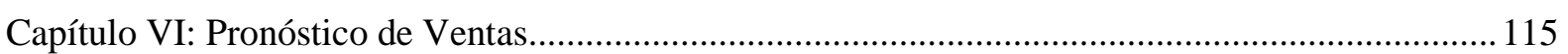

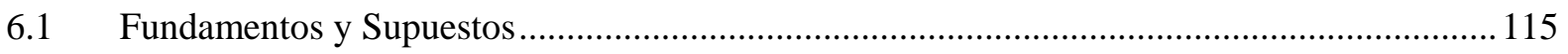

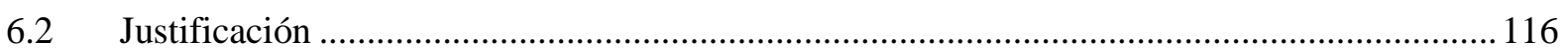

6.3 Análisis de los riesgos y aspectos críticos que impactan en el pronóstico................................ 116

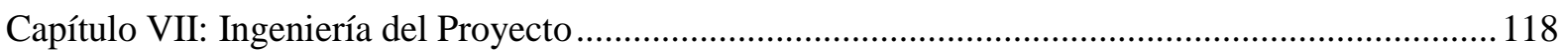

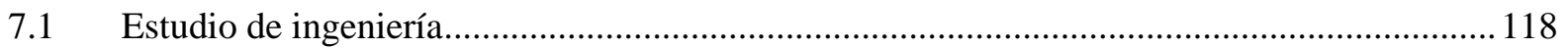

7.1.1 Modelamiento y selección de procesos productivos............................................................ 118

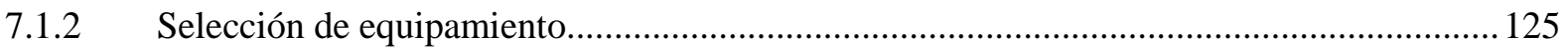

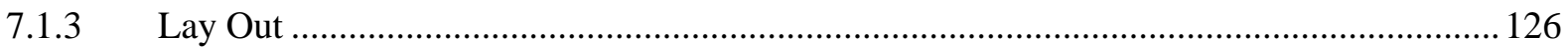

7.1.4 Distribución de equipos, muebles y enseres .................................................................... 128

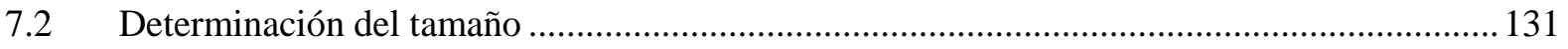

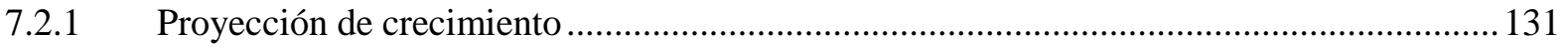

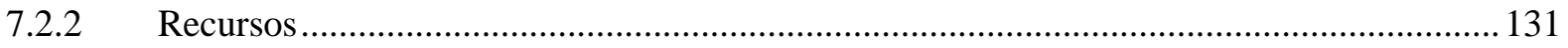

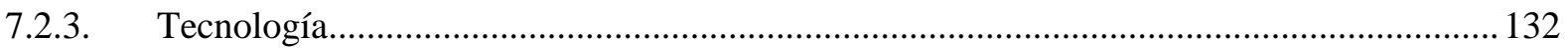




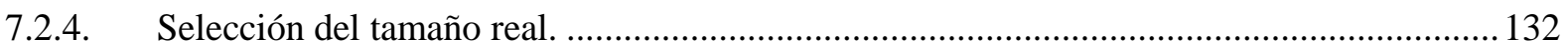

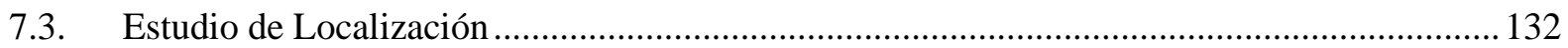

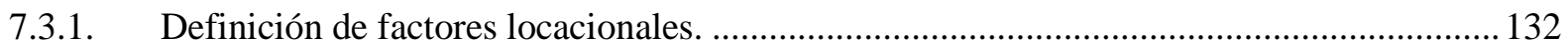

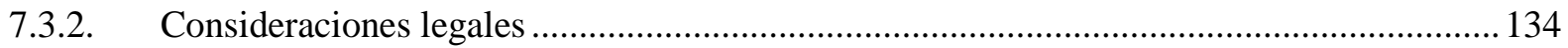

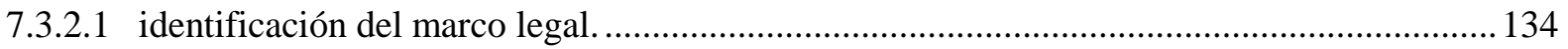

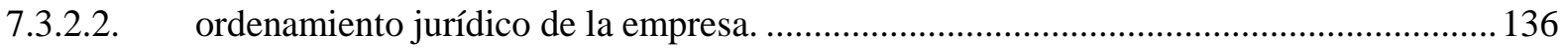

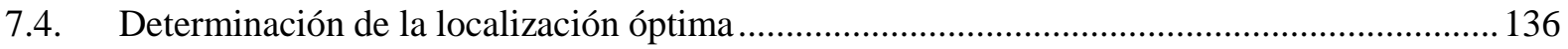

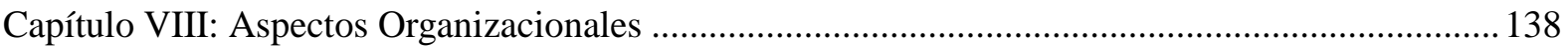

8.1. Caracterización de la cultura organizacional deseada............................................................. 138

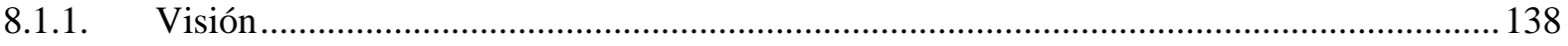

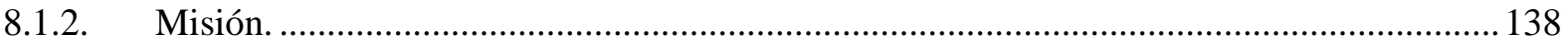

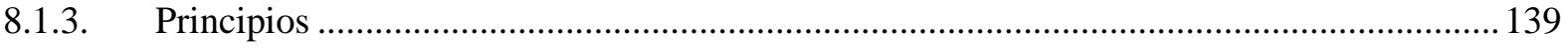

8.2. Formulación de estrategias del negocio ............................................................................... 140

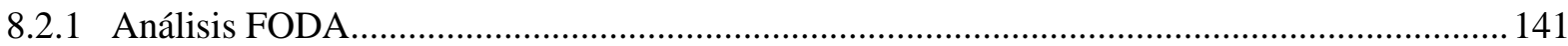

8.3. Determinación de las ventajas competitivas críticas.............................................................. 145

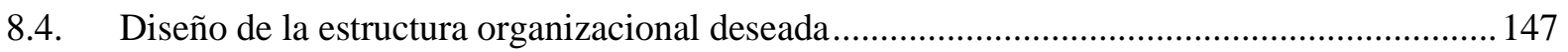

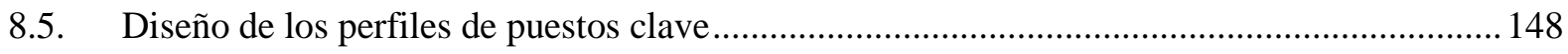

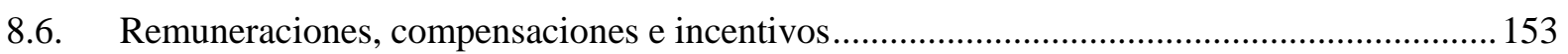

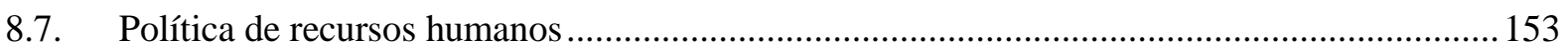

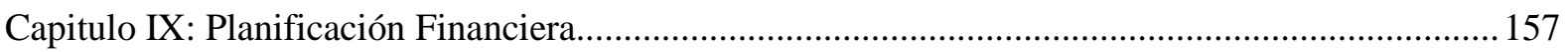

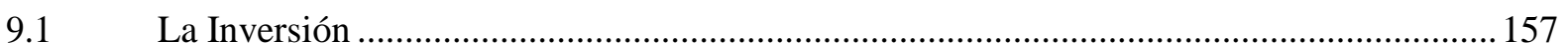

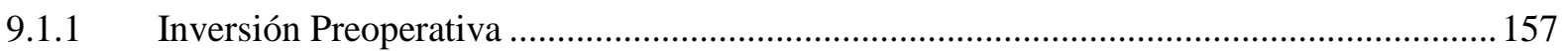

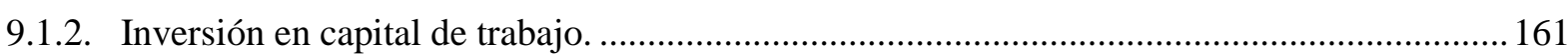

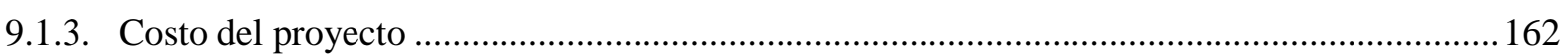

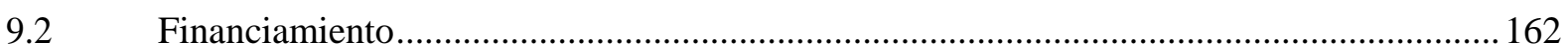

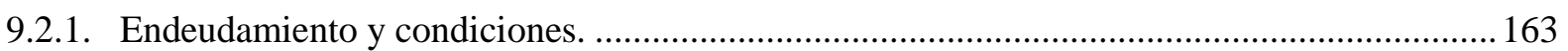

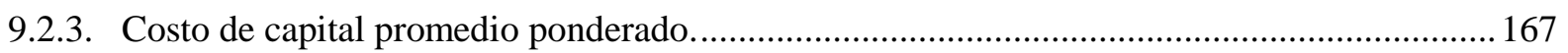

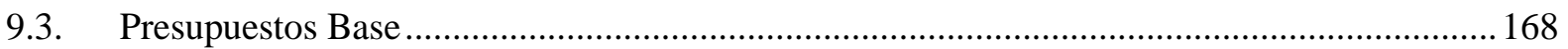

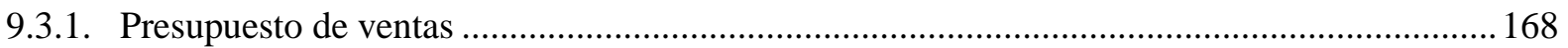

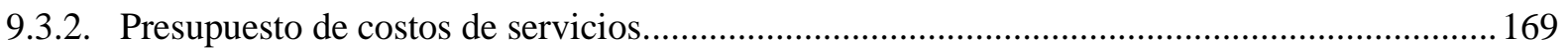

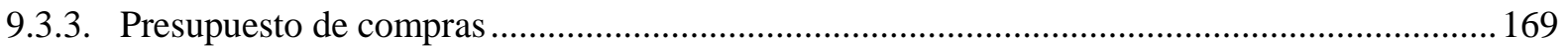

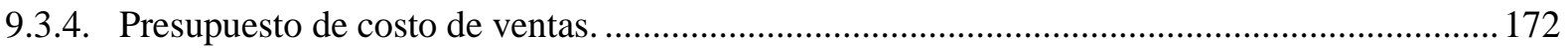

9.3.5. Presupuesto de gastos administrativos y de ventas................................................................ 173

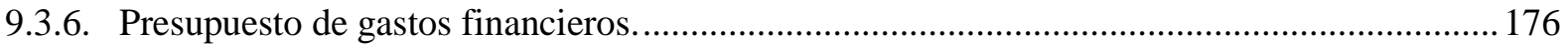

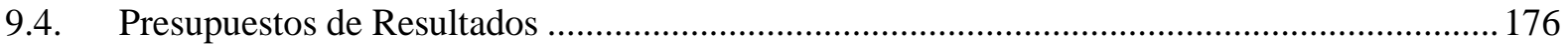

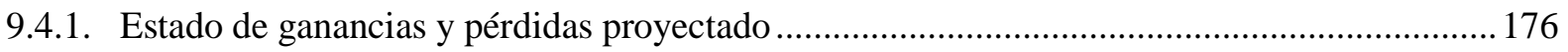


9.4.2. Balance proyectado 177

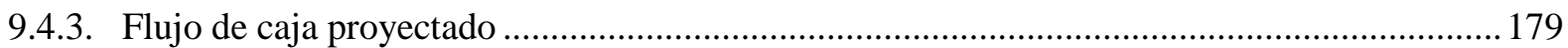

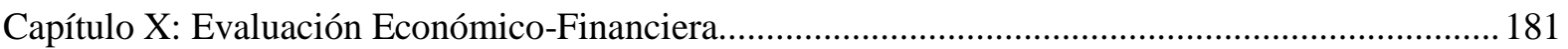

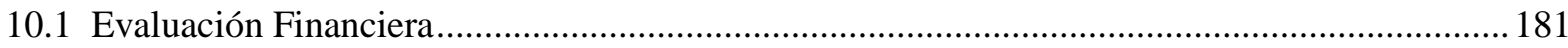

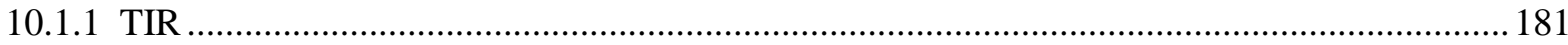

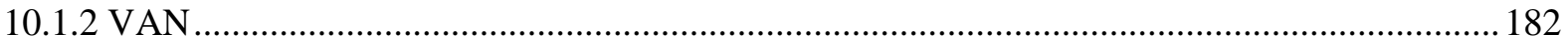

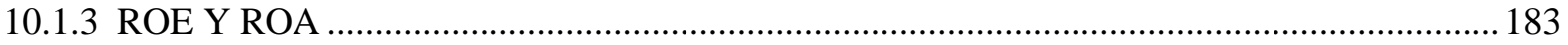

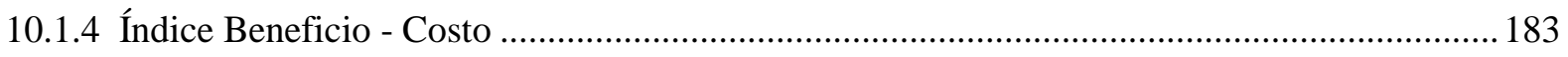

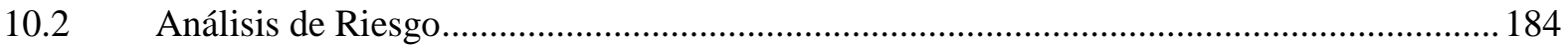

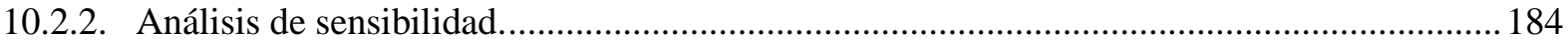

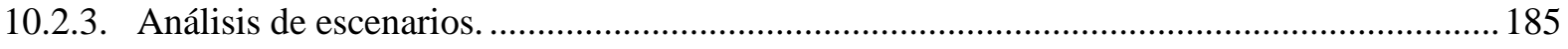

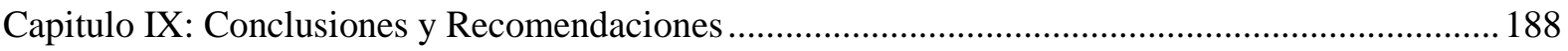

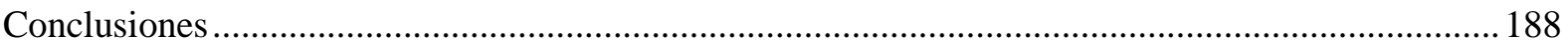

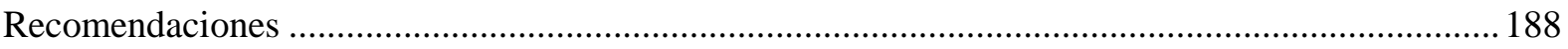

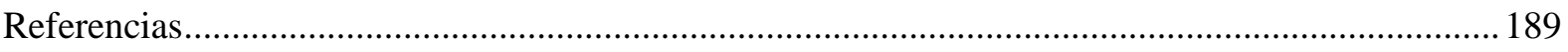

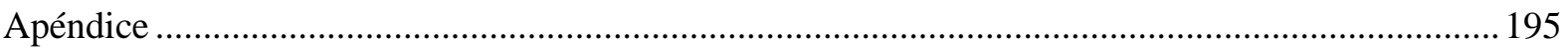




\section{Lista de Tablas}

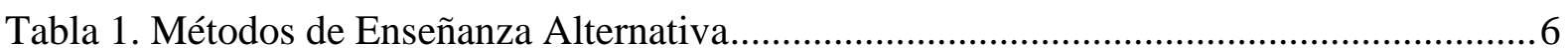

Tabla 2. Empresas Educativas Entre los Distritos de La Victoria y San Isidro........................ 14

Tabla 3. Servicios Ofrecidos por Empresas del Sector ........................................................25

Tabla 4. Matriz Perfil Competitivo de las Guarderías de Santa Catalina ................................27

Tabla 5. Matriz Perfil Competitivo de las Guarderías de San Isidro .......................................27

Tabla 6. Justificación de Ponderaciones de Guarderías de Santa Catalina ..............................28

Tabla 7. Justificación de Ponderaciones de Guarderías de Santa Isidro ..................................29

Tabla 8. Pronostico del Crecimiento Económico para los Países de América Latina y el

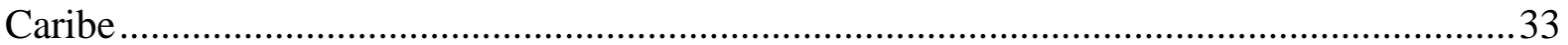

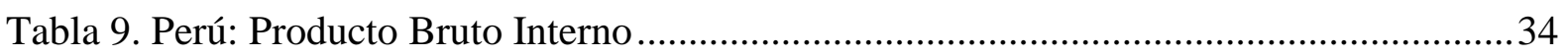

Tabla 10. Perú: Distribución de la PEA Ocupada, Según Sexo y Nivel Educativo,

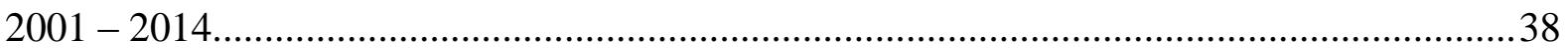

Tabla 11. Distribución Muestral Para el Focus Group ........................................................ 47

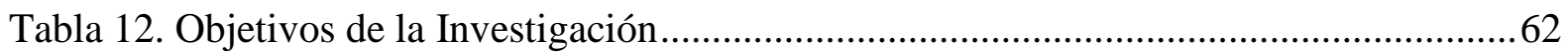

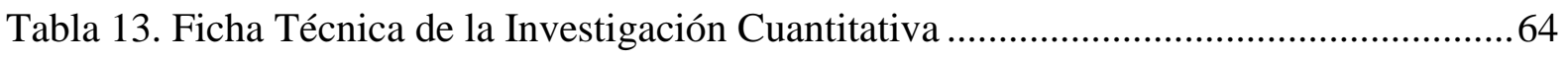

Tabla 14. Operacionalización Para el Diseño del Cuestionario...............................................67

Tabla 15. Tipos de Metodología que se Aplica en Otras Guarderías ......................................73

Tabla 16. San Isidro: Población Flotante 2016 en Miles ........................................................ 85

Tabla 17. Proyección de Crecimiento del Distrito y por Sectores en Miles ..............................86

Tabla 18. Población Proyectada San Isidro en Miles ............................................................ 86

Tabla 19. Población Total Proyectada Niños 0 - 4 Años Lima en Miles .................................. 87

Tabla 20. Mercado Potencial Proyectado de Niños 0 - 4 Años Lima ....................................87

Tabla 21. Mercado Disponible SI Proyectados Niños 0 - 4 Años Lima en Miles ................... 88

Tabla 22. Aplicación de la Teoría McDaniels ..................................................................... 90

Tabla 23. Mercado Efectivo Proyectados Niños 0 - 4 Años Lima en Miles............................90

Tabla 24. Proyección de Crecimiento de la Guardería ........................................................... 91

Tabla 25. Mercado Objetivo Proyectado Niños 0 -4 Años Lima .............................................. 91

Tabla 26. Precios de la Competencia ..................................................................................99

Tabla 27. Resultado de Intención de Pago - Investigación de Mercados................................ 100

Tabla 28. Estrategia de Precios Titinos Daycare ..................................................................... 101

Tabla 29. Objetivos de Ventas en Ingreso de Infantes en Titinos Daycare Año 1 .................111

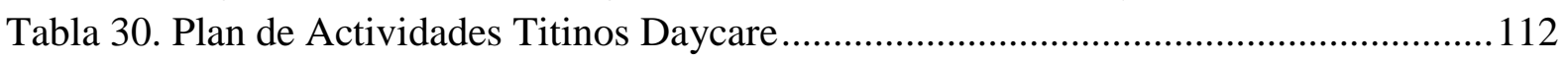

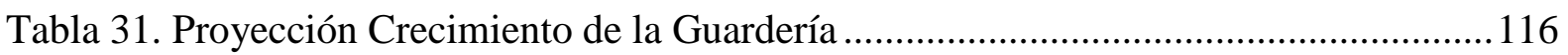

Tabla 32. Mercado Objetivo Proyectado Niños 0 - 4 Años Lima.......................................... 116

Tabla 33. Requerimiento de Muebles, Equipos y Enseres para la Guardería........................ 125

Tabla 34. Requerimiento de Muebles y Equipos de Administración y Ventas ...................... 126

Tabla 35. Descripción de los Espacios por Características de Desplazamiento Nivel Inicial 129

Tabla 36. Características Establecidas para la Pequeña Empresa....................................... 135

Tabla 37. Localización por el Método de Puntos para la Guardería Titinos Daycare ............ 137

Tabla 38. Preguntas y Respuestas para la Definición de la Visión..........................................138

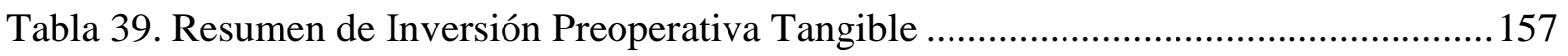

Tabla 40. Inversión Preoperativa Tangible - Equipos y Muebles de Guardería..................... 158 
Tabla 41. Inversión Preoperativa Tangible - Equipos y Muebles de Administración y Ventas

Tabla 42. Inversión Preoperativa Tangible - Equipos y Muebles de Administración y Ventas 159

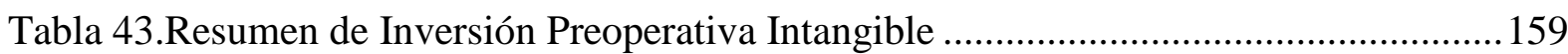

Tabla 44. Inversión Preoperativa Intangible - Constitución de Empresa................................. 160

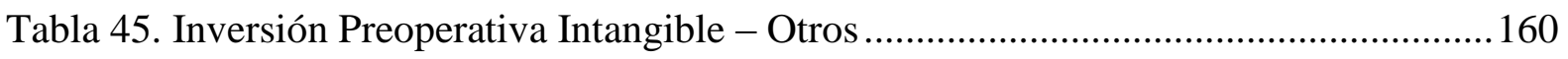

Tabla 46. Inversión Preoperativa Intangible - Otros ............................................................... 161

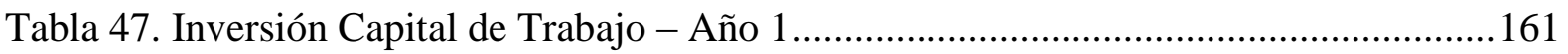

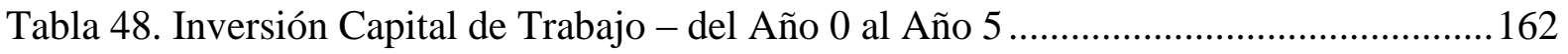

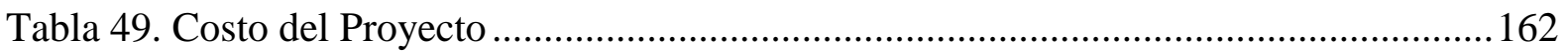

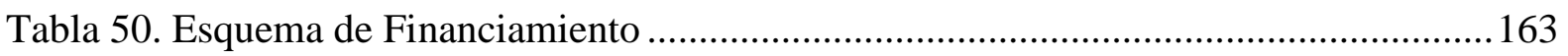

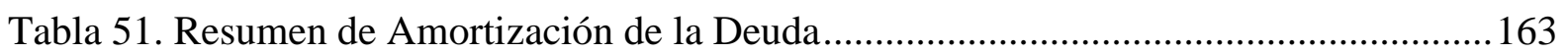

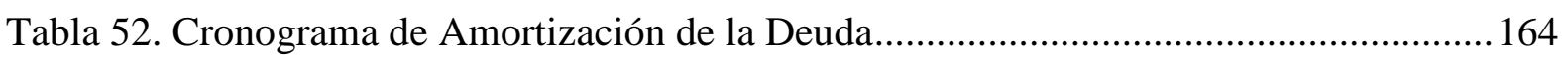

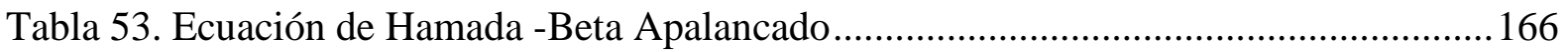

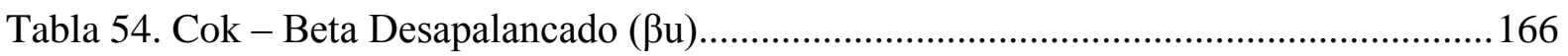

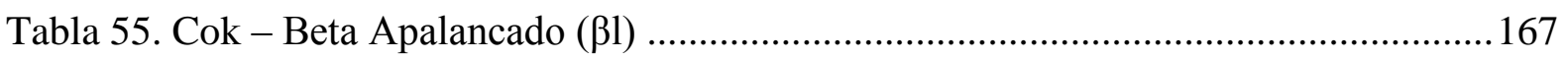

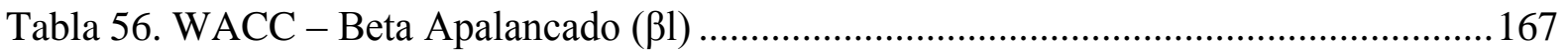

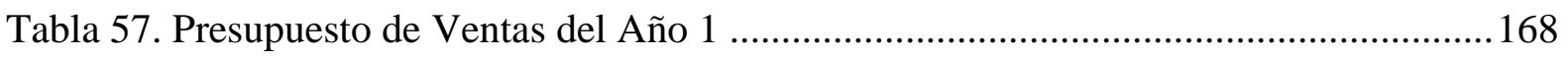

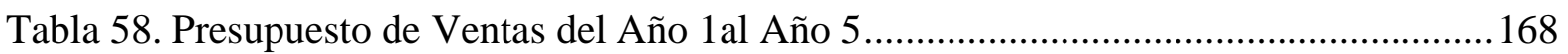

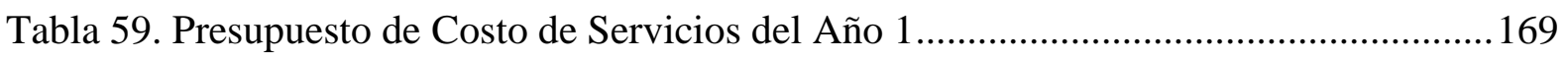

Tabla 60. Presupuesto de Costo de Servicios del Año 1al Año 5 ........................................... 169

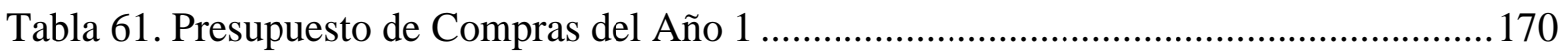

Tabla 62. Presupuesto de Compras del Año 1al Año 5 ........................................................ 171

Tabla 63. Presupuesto de Costo de Ventas del Año 1 ............................................................ 172

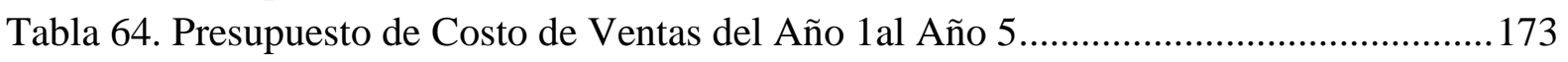

Tabla 65. Presupuesto de Gastos Administrativos y de Ventas del Año 1 ............................. 174

Tabla 66. Presupuesto de Gastos Administrativos y de Ventas del Año 1 al Año 5 .............. 175

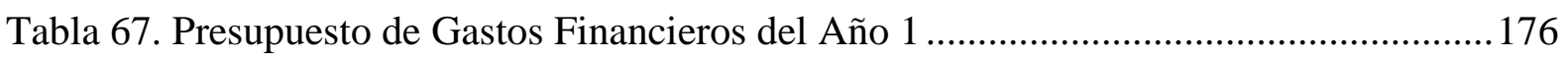

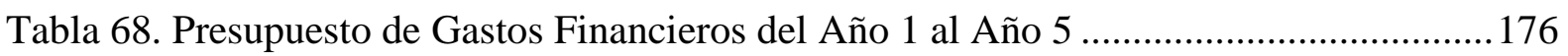

Tabla 69. Estado de Ganancias y Pérdidas Proyectado del Año 1......................................... 177

Tabla 70. Estado de Ganancias y Pérdidas Proyectado del Año 1 al Año 5 ...........................177

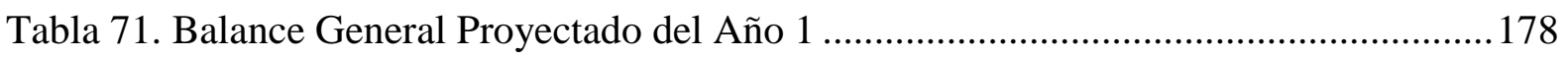

Tabla 72. Balance General Proyectado del Año 0 al Año 5 ............................................... 179

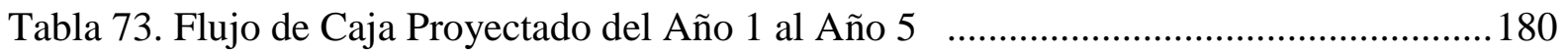

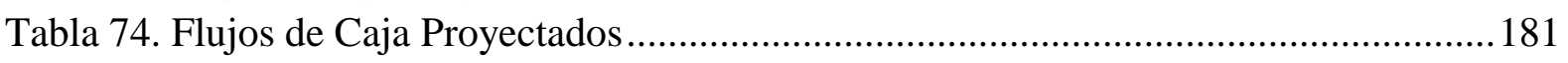

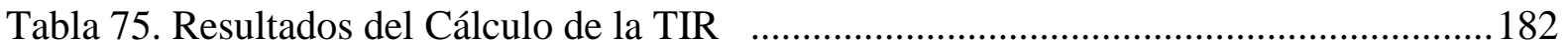

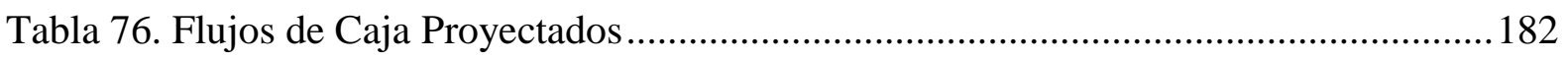

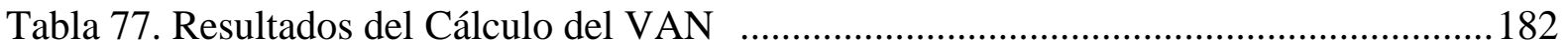

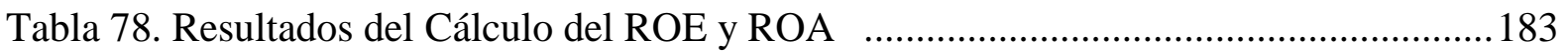

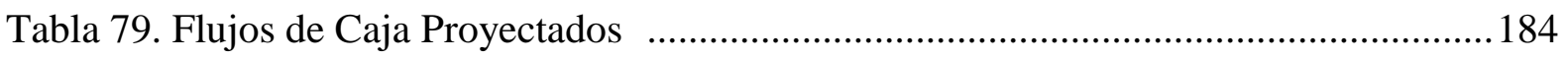

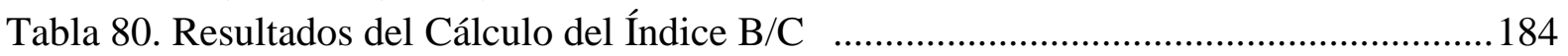

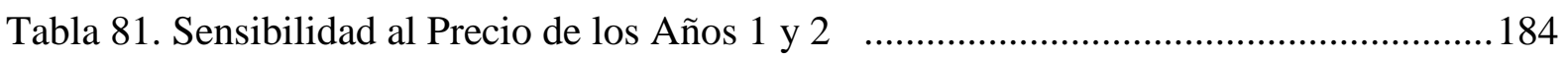

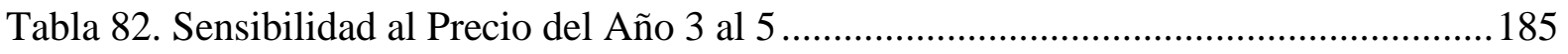




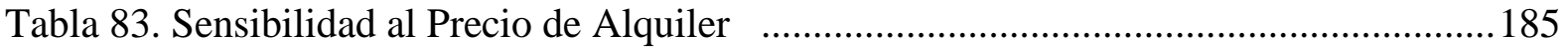

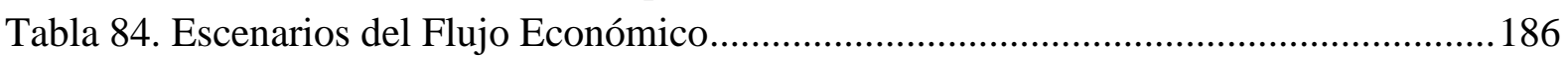

Tabla 85. Escenarios del VAN y TIR Económico (con Deuda) ............................................186

Tabla 86. VAN y TIR Promedio, la Varianza y la Desviación Estándar ............................. 186 


\section{Lista de Figuras}

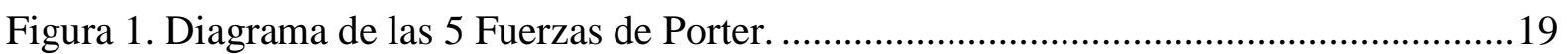

Figura 2. Evolución del PBI Anual (Variación porcentual)-Perú............................................. 32

Figura 3. PEA Ocupada Total y Adecuadamente Empleada de Lima Metropolitana. .............35

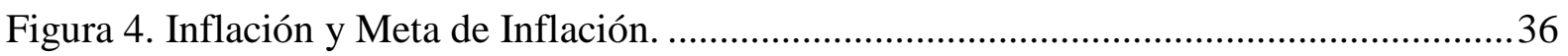

Figura 5. Distribución de hogares según NSE 2017 - Lima Metropolitana............................37

Figura 6. Evaluación OCDE. Tomado de“Perú sale del último lugar en la prueba PISA 2015”.....39

Figura 7. Plano de Límites y sectores del distrito de San Isidro.............................................65

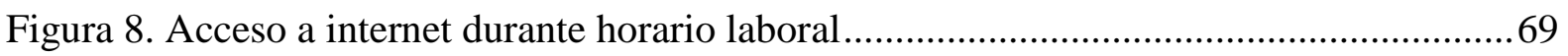

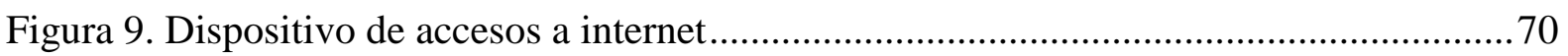

Figura 10. Encargo del cuidado de sus hijos menores de 3 años mientras usted trabaja..........70

Figura 11. Motivo por el cual hasta el día de hoy no ha dejado a su hijo al cuidado de una

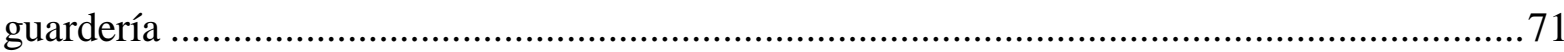

Figura 12. Atributos que considera más importantes para poder escoger una Guardería.........72

Figura 13. Nivel de satisfacción por el servicio recibido en la guardería..............................72

Figura 14. Respuesta a los horarios del servicio de guardería que se adecuan a su horario

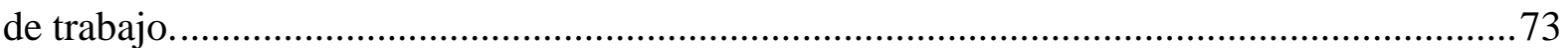

Figura 15. Metodología de enseñanza y estimulación temprana especializada que aplica

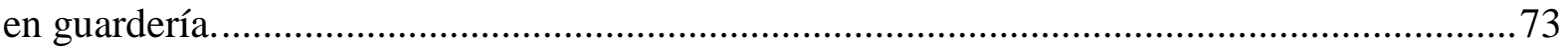

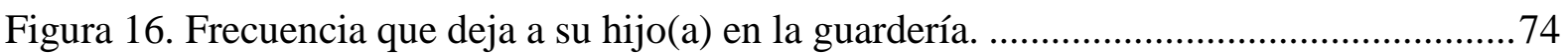

Figura 17. Frecuencia de meses al año que utiliza los servicios de una guardería .................. 74

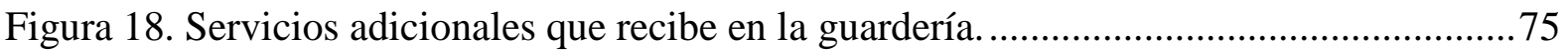

Figura 19. Importe mensual que pagan por el servicio de una guardería .................................75

Figura 20. Intención de propuesta para un nuevo concepto de guardería................................76

Figura 21. Conformidad sobre una Guardería que brindaría un servicio de video vigilancia.76

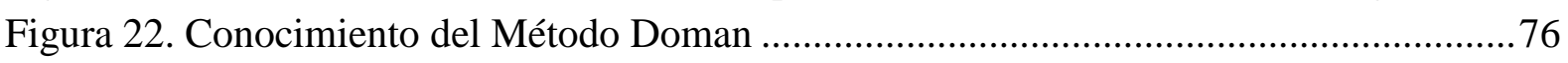

Figura 23. Ventajas más importantes en la aplicación del método Doman ..............................77

Figura 24. Conformidad de la zona de ubicación de la guardería. ............................................ 77

Figura 25. Horario que le parecería adecuado para la atención de la guardería .......................78

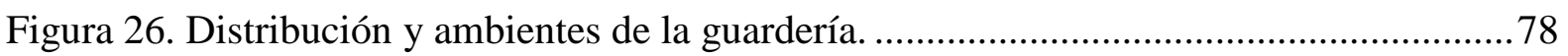

Figura 27. Disposición de pago mensual de guardería ........................................................... 79

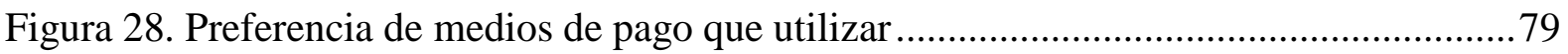

Figura 29. Servicios adicionales de importancia para la implementación de una guardería. ..80

Figura 30. Disposición de pago mensual por servicio adicional ...........................................80

Figura 31. Preferencia del nombre para una guardería .................................................... 81

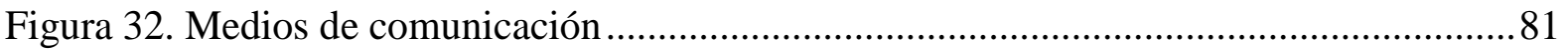

Figura 33. Disposición para el uso de servicio de una guardería..............................................82

Figura 34. Mapa por sector del distrito de San Isidro. Tomado del estudio "Cuantificar y

Caracterizar a la Población Flotante del distrito de San Isidro" ............................................. 84

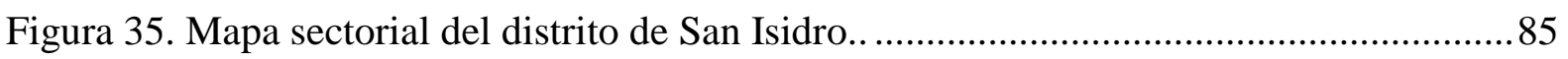

Figura 36. Probabilidad de que las personas encuestadas utilicen la guardería........................ 89

Figura 37. Pirámide de la Motivación de Abraham Maslow...................................................94

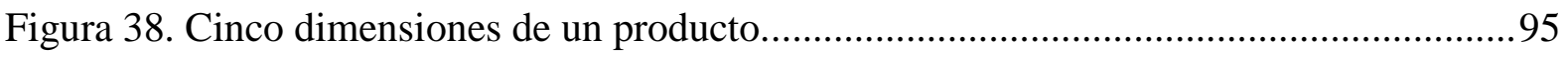




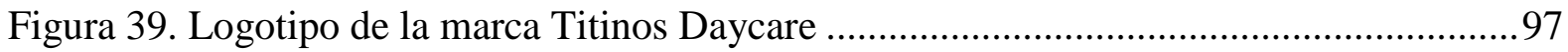

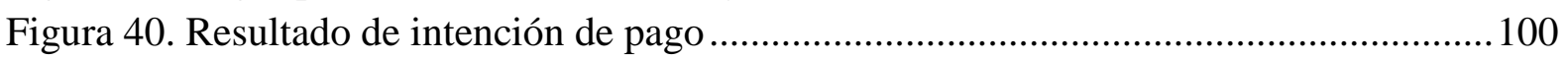

Figura 41. Ubicación de la plaza para el público objetivo................................................. 101

Figura 42. Estrategia de promoción y publicidad -Ubicación................................................ 103

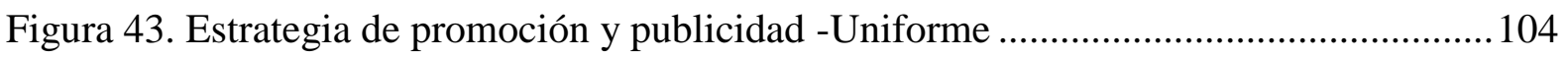

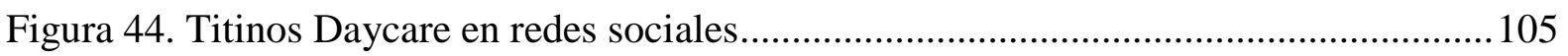

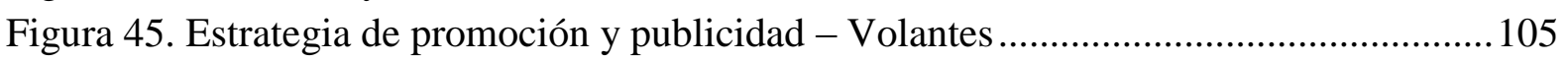

Figura 46. Estrategia de promoción y publicidad - Merchandising ...................................... 106

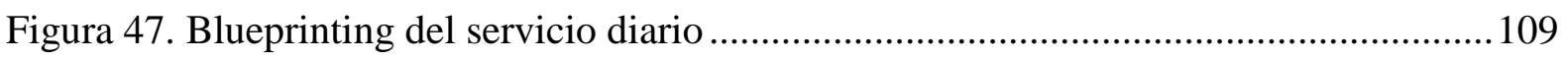

Figura 48. Formato para Personas Autorizadas de Recojo del alumno ................................114

Figura 49. PBI de Economías avanzadas, y economías emergentes y desarrollo. ................. 115

Figura 50. Diagrama general de entrada-proceso-salida para la Guardería Titinos Daycare 118

Figura 51. Flujograma de proceso de selección de personal ............................................. 120

Figura 52. Flujograma del proceso para Inscripción y Matriculas de bebes e infantes......... 122

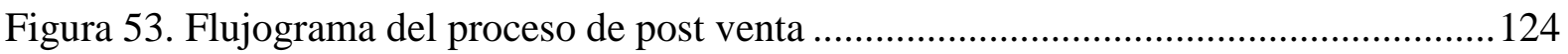

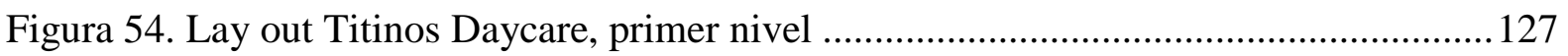

Figura 55. Lay out Titinos Daycare, Segundo nivel ......................................................... 128

Figura 56. Distribución por tipo de desplazamiento de niños nivel Inicial: Cuna y Jardín...130

Figura 57. Distribución Titinos por tipo de desplazamiento de niños ................................. 130

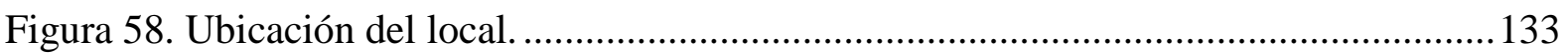

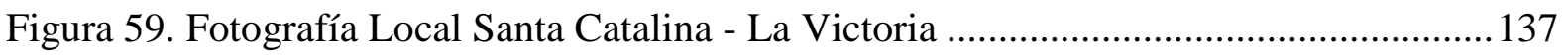

Figura 60. Cadena de valor de la empresa - Adaptado del modelo de Michael Porter......... 147

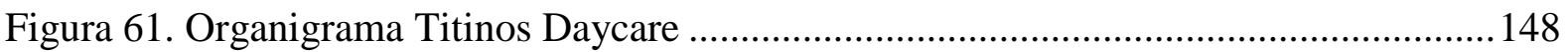

Figura 62. Perfil y funciones del Director General Titinos Daycare ................................... 149

Figura 63. Perfil y funciones del Coordinador Administrativo y Ventas Titinos Daycare.... 150

Figura 64. Perfil y funciones del Contador Titinos Daycare ................................................ 150

Figura 65. Perfil y funciones del Especialista Titinos Daycare .............................................. 151

Figura 66. Perfil y funciones del Maestro Titinos Daycare .................................................. 151

Figura 67. Perfil y funciones del Auxiliar Titinos Daycare .............................................. 152

Figura 68. Perfil y funciones del Asistente de Mantenimiento Titinos Daycare ....................152

Figura 69. Planilla de Remuneraciones personal Titinos Daycare ...................................... 153 


\section{Capítulo I: Generalidades}

\subsection{Antecedentes}

La Convención sobre los Derechos del Niño reconoce como un derecho asistir a la escuela y aprender, este derecho comienza en la primera infancia. Se ha demostrado que las intervenciones integrales que combinan la nutrición, la protección y la estimulación producen beneficios notables en el desarrollo cognitivo de los niños de corta edad. Así pues, el 38\% de los niños salen de la escuela primaria sin aprender a leer, escribir y hacer cálculos aritméticos simples. Estudios practicados en los Estados Unidos atribuyen una rentabilidad a las inversiones en la primera infancia de entre el $7 \%$ y el $10 \%$ anual. (UNICEF, 2016, p.42).

Según el artículo de UNICEF, Estado Mundial de la Infancia 2016 cita lo siguiente: Dado que los primeros años de vida de un niño afectan de manera tan notable al desarrollo del cerebro, la primera infancia ofrece una ventana de oportunidad fundamental para romper los ciclos intergeneracionales de inequidad. Los cuidados, la nutrición y la estimulación en la primera infancia pueden impulsar el desarrollo cerebral, fortalecer la capacidad de aprendizaje de los niños y fomentar su resistencia psicológica y su flexibilidad para adaptarse al cambio. (p.50)

En el Perú, actualmente el Estado a través de los entes encargados como el Ministerio de Educación y el Ministerio de Desarrollo e Inclusión Social (MIDIS), promueve y desarrolla el Programa Cuna Más del MIDIS, que desde su creación atiende a más de 440 mil (Cuna Mas, 2016) niñas y niños entre 6 meses y 2 años de edad, programa que va dirigido solo a familias en condiciones de pobreza y pobreza extrema.

En la misma línea, el Estado no cuenta con otro programa similar para los servicios de cuidados para niños y niñas menores de 3 años de edad de índole contributivo o de condiciones medias, dejando abierta la necesidad de buscar guarderías o cunas privadas que se adecuen a los horarios laborales y que geográficamente se encuentren cerca a sus centros de trabajo o residencia (San Isidro y/o Santa Catalina). Cabe mencionar que actualmente en la ciudad de Lima y Callao funcionan 450 cunas privadas y 174 públicas que cuentan con la resolución de funcionamiento. (El Comercio, 2017, p.1); asimismo, en los alrededores de la zona propuesta para el proyecto existen 7 guarderías (según estudio de campo), de las cuales 3 son de difícil acceso y de limitada infraestructura.

En el aspecto laboral es preciso destacar que en el informe del Programa de las Naciones Unidas para el Desarrollo - PNUD sobre el Desarrollo Humano (2015) señala que: 
Los desequilibrios dejan a las mujeres en situación de desventaja en el ámbito del trabajo, tanto remunerado como no remunerado. En la mayoría de los países de todas las regiones del planeta, las mujeres trabajan más que los hombres. Se estima que la contribución de las mujeres al trabajo mundial es del 52\%, mientras que la de los hombres es del 48\%. En el 2015, la tasa de participación en el mercado laboral a escala mundial fue del $50 \%$ en el caso de las mujeres y del $77 \%$ en el de los hombres. En 2015, a escala mundial, el 72\% de los hombres en edad de trabajar (a partir de 15 años) tenía empleo, frente a solo el $47 \%$ de las mujeres. La participación de las mujeres en el mercado laboral y las tasas de ocupación se ven afectadas en gran medida por cuestiones económicas, sociales y culturales y la distribución del trabajo de cuidados en el hogar. Del 59\% del trabajo remunerado, que se realiza en su mayor parte fuera del hogar, la proporción de hombres es casi el doble que la de mujeres (el $38 \%$ frente al $21 \%$ ). La situación se invierte en el caso del trabajo no remunerado, que en su mayor parte se realiza dentro del hogar y abarca una gran variedad de labores de cuidado: del $41 \%$ del trabajo que no es remunerado, las mujeres representan el triple que los hombres (el 31\% frente al 10\%). (p.11,12)

Frente a esta situación, el Perú no es ajeno a esta realidad, sin embargo, se observa cambios que conllevan a un crecimiento en el empleo de mujeres, en el año 2017 se incrementó en 2.4\% respecto al año anterior. Así también, en el 2017 la población ocupada en Lima aumento en $1.5 \%$ respecto al 2016 y al cierre del 2017 del total de la población ocupada, el 45,4\% (2 millones 200 mil 700) estuvo integrada por mujeres y el 54,6\% (2 millones 645 mil 200) por hombres. (INEI, 2018, p. 1). Según CPI del total de la población de Lima Metropolitana el 13\% vive en Lima Moderna y al no tener información de la PEA ocupada de este sector se procede a efectuar un cálculo estimado donde 286,091 corresponde a las mujeres y 343,876 corresponde a hombres.

Lo expuesto en párrafos anteriores, se evidencia en los cambios sociales ocurridos en los últimos años, donde hay un mayor desarrollo profesional de la mujer que incursiona con más frecuencia en la vida laboral, pasando la Población Económicamente Activa Femenina en Lima Metropolitana de 1,875 millones en el 2007 a 2,200.7 millones en el 2017 (INEI, 2018, p. 1)._Y según cálculos propios la Población Económicamente Activa Femenina en Lima Moderna pasa de 243,750 en el 2007 a 286,091 en el 2017.

“Teresa Hernández, directora de Familia y Comunidad del Ministerio de la Mujer, quien explicó que una de las razones por las que la mayoría de las peruanas decide no trabajar es porque no tiene con quién dejar sus hijos". (Correo, 2015, p.1). 
Por otro lado, La Unidad de Estadística Educativa (Escale) del Minedu, señala que en Lima y Callao funcionan 450 cunas privadas y 174 públicas que cuentan con la resolución de funcionamiento. (El Comercio, 2017, p.1)

“Milagros Millán, especialista de la Dirección de Educación Inicial, consideró que el número es insuficiente para atender la demanda de padres que necesitan trabajar y no tienen otra alternativa para el cuidado de sus menores hijos”. (El Comercio, 2017, p.1) Frente a estos antecedentes y teniendo en cuenta que cada vez la participación femenina en la vida laboral va en aumento, surge la oportunidad de crear alternativas para el cuidado del niño durante la primera infancia, como los servicios que ofrecen las guarderías, cuyo fin es el de ayudar, ofreciendo horarios que puedan adaptarse a los requerimientos y necesidades de las familias modernas y/o trabajadores que tienen que postergar su crecimiento profesional a cambio de no descuidar el cuidado y seguridad de sus pequeños; por ello proponemos el proyecto para la creación de una guardería infantil para niños que se encuentren en el rango de edades de 3 a 36 meses, aplicando la metodología Doman.

\section{Metodología Doman}

El Instituto para el logro del Potencial humano, creado por Glen Doman es conocido internacionalmente por su trabajo pionero en el desarrollo del cerebro infantil. El objetivo es ayudar a todos los niños a alcanzar la excelencia intelectual, física y social. Cuando comenzó hace más de medio siglo, se pensaba que los niños muy pequeños no podían aprender mucho. Muchos pensaron en ese momento que la inteligencia estaba genéticamente determinada y esencialmente inmutable. Glenn Doman y su equipo inicial cuestionaron esta noción. Propusieron que el cerebro tenía un enorme potencial y que este potencial no se estaba realizando plenamente. Querían dar a los niños la oportunidad de ser lo que quisieran y ser lo mejor que pudieran lograr. Los niños sanos alcanzan la excelencia. La Convención sobre los Derechos del Niño reconoce como un derecho asistir a la escuela y aprender, este derecho comienza en la primera infancia.

La lista original de pasajeros estaba constituida por un neurocirujano, un fisíatra (médica especializado en medicina física y rehabilitación), un fisioterapeuta, un foníatra, un psicólogo, un educador y una enfermera. En la actualidad sobrepasamos el centenar, sumándose al grupo muchas otras clases de especialistas (Cómo Enseñar A Leer A Su Bebé p.2)

En su diseño original, los programas Doman fueron creados justamente para ser llevados a cabo por padres y madres, en su hogar, con sus propios hijos. Sólo ahí 
podrían presentarse con la duración, intensidad y frecuencia óptimos, en un ambiente amoroso y familiar, desde el nacimiento del bebé y a lo largo de sus primeros años. Sin embargo, si bien existen diferencias en la aplicación y los resultados, es posible retomar la filosofía Doman para diseñar un programa enriquecido para el desarrollo intelectual, físico y social de los niños en edad preescolar, e incluso llevarlo más allá, a la educación primaria y secundaria. (Blog Educación y Neurodesarrollo, 2013, p.1).

\subsection{Determinación de la Oportunidad}

Situaciones que generan oportunidad.

- La progresiva incorporación de la mujer en el mercado laboral, donde la PEA femenina en Lima Metropolitana creció 15\% del 2007 al 2017 (INEI, 2018, p. 1).

- La existencia de parejas, padres y madres que trabajan y que no están dispuestos a dejar de trabajar para el cuidado de sus hijos, pues no desean sacrificar su desarrollo profesional, así como su estilo de vida y probables deudas financieras les impide prescindir de uno de los sueldos. Según el CPI 286,091 son mujeres que trabajan, y 343,876 corresponde a hombres que trabajan activamente (CPI, 2017, p. 1).

- Las opciones limitadas en el mercado que brinden un lugar seguro, con infraestructura adecuada, confiable y que brinde el cuidado y atención especializada a infantes de 3 a 36 meses durante el horario y que adicionalmente proporcionen una metodología especializada en el aprendizaje.

- La carencia de oferta de guarderías en la ciudad de Lima y la zona en estudio, ya que actualmente en Lima y Callao funcionan 450 cunas privadas y 174 públicas que cuentan con la resolución de funcionamiento. (El Comercio, 2017, p.1) y según el trabajo de campo realizado solo existen 7 guarderías que se encuentran ubicadas alrededor de la zona financiera de San Isidro.

- Por otro lado, el cuidado tradicional de los abuelos hacia los nietos, cuyos padres trabajan, ya no es común por las diferentes actividades que realizan (Cornachione, 2006, P.81); Solo el 18\% de los abuelos a nivel nacional participa del cuidado de menores de edad. (UNFPA, 2015, p.2)

\subsection{Justificación del proyecto}

De acuerdo con los análisis y cifras mostradas en los puntos anteriores se evidencia que existe una oportunidad para la creación de una guardería infantil para niños de 3 a 36 meses. Según el trabajo de campo realizado en las guarderías cercanas a la de este proyecto; 
se observa que se aplican diferentes metodologías, dentro de las más conocidas: Optimist, Montessori, Emilia Reggio, entre otras, y se evidencia que la metodología Doman no es aplicada por ninguna de ellas, por lo que también representa una oportunidad para la implementación.

En la Tabla 1 se detallan las características de los métodos de enseñanza alternativa ofrecidas en el mercado, aplicado en los diferentes nidos-jardín, guarderías y centros educativos de menores. 
Tabla 1

Métodos de Enseñanza Alternativa

\begin{tabular}{|c|c|c|c|c|c|}
\hline Método & Aspectos claves de aprendizaje & Objetivo & Niveles & Técnica & Nacionalidad \\
\hline Doman & Habilidades cognitivas & $\begin{array}{l}\text { Usar la "lectura" como un método } \\
\text { importante para estimular el desarrollo } \\
\text { cerebral y la inteligencia del niño". }\end{array}$ & $\begin{array}{l}\text { Primera Infancia (de } \\
0 \text { a } 6 \text { años) }\end{array}$ & $\begin{array}{l}\text { Tarjeta o cartillas con palabras } \\
\text { grandes de color rojo o negro }\end{array}$ & Norteamericano \\
\hline Kumon & Las matemáticas y la lectura & $\begin{array}{l}\text { Adquirir hábitos de estudio que permitan } \\
\text { trabajar de forma independiente }\end{array}$ & $\begin{array}{l}\text { Educación infantil - } \\
\text { Bachillerato }\end{array}$ & & Japonés \\
\hline Montessori & $\begin{array}{l}\text { Promover que el alumno tenga } \\
\text { libertad de elección, que sea } \\
\text { responsable de las consecuencias de } \\
\text { su elección, con lo cual se pretende } \\
\text { que logre su independencia }\end{array}$ & $\begin{array}{l}\text { Adquirir la máxima independencia física } \\
\text { y Psíquica, descubrir el mundo a través } \\
\text { de sus propias expericiencias }\end{array}$ & $\begin{array}{l}\text { Educación infantil } \\
\text { (mezcla diferentes } \\
\text { edades) }\end{array}$ & Materiales pedagógicos & Italiano \\
\hline Optimist & Desarrollo del circuito neuromotor & $\begin{array}{l}\text { Estimulación organizada para que el niño } \\
\text { pueda desarrollar todas sus capacidades. }\end{array}$ & $\begin{array}{l}\text { Niños de } 2 \text { a } 5 \text { años } \\
\text { (nido) }\end{array}$ & $\begin{array}{l}\text { Entorno lúdico que favorece el } \\
\text { aprendizaje, adquisición de hábitos y } \\
\text { desarrollo sensorial y motriz. } \\
\text { (implicada los padres) }\end{array}$ & Español \\
\hline Reggio Emilia & $\begin{array}{l}\text { Propicia en los niños el interés y la } \\
\text { curiosidad por lo que les rodea, la } \\
\text { experimentación. }\end{array}$ & $\begin{array}{l}\text { Crear una escuela activa, inventiva, } \\
\text { donde predomina la investigación y } \\
\text { reflexión }\end{array}$ & Primera Infancia & $\begin{array}{l}\text { Los niños son motivados a trabajar } \\
\text { en grupo para resolver problemas, } \\
\text { jugar solos o compartir en grandes } \\
\text { grupos. }\end{array}$ & Italiano \\
\hline Waldorf & Intelectuales, artísticas y prácticas & $\begin{array}{l}\text { Capacidad de los niños para imitar, } \\
\text { imaginar y experiencia }\end{array}$ & $\begin{array}{l}\text { Primera infancia, } \\
\text { infancia media y } \\
\text { adolescencia }\end{array}$ & Imitación & Austriaco \\
\hline
\end{tabular}


La Guardería sería un lugar seguro ya que el proyecto plantea la instalación de cámaras IP (también conocidas como cámaras de Web o Red) las cuales permitirán a los padres ver en tiempo real las actividades que desarrollan sus hijos y los cuidados que reciben. Asimismo, se propone la utilización del método Glen Doman como mecanismo de aprendizaje para desarrollar habilidades que les permitan a los infantes tener un desarrollo integral donde se estimularán el aspecto físico, cognitivo, lingüístico, artístico y emocional.

Así también, este plan de negocios permitirá consolidar y aplicar los conocimientos y competencias adquiridas durante el desarrollo de los cursos de la Maestría en Administración de Negocios (MBA); los mismos que servirán de guía para el desarrollo del Plan de Negocios de la Guardería infantil para niños de 3 a 36 meses aplicando la metodología Doman.

Para el desarrollo del Plan de Negocios los conocimientos a aplicar serán los siguientes:

- Análisis del entorno externo - PESTEL; para poder determinar el contexto en el que se desarrollará el plan de negocios identificando las amenazas y oportunidades.

- Estudio de mercados; para poder determinar al público objetivo, sus gustos y preferencias, localización, cuanto está dispuesto a pagar por los servicios, etc.

- Marketing; para poder definir las estrategias adecuadas para los clientes potenciales y la utilización de los medios correctos para hacer un uso eficiente del capital de trabajo.

- Contabilidad y costos; para poder determinar el punto de equilibrio, determinar los costos y gastos atribuibles al proyecto, poder realizar proyecciones y elaborar los Estados Financieros, los mismos que nos permitirán tomar decisiones.

- Finanzas; para poder determinar la rentabilidad, buscar las mejores alternativas de financiamiento y encontrar el mejor grado de apalancamiento.

- Ingeniería del proyecto; para determinar el Lay Out, selección y distribución de recursos.

- Responsabilidad social; para poder dar a los trabajadores estabilidad laboral, seguridad ocupacional y una cultura amigable al medio ambiente.

- Aporte ambiental; el proyecto pondrá énfasis en las practicas sustentables tales como reducir el consumo de agua y energía como por ejemplo la promoción activa del reciclado. 


\subsection{Objetivos generales y específicos}

A continuación, se presenta el objetivo general y los objetivos específicos del proyecto.

\section{Objetivo general}

El presente estudio tiene como objetivo trasladar los conocimientos adquiridos durante el desarrollo de la maestría a la elaboración de un plan de negocios y evaluar su viabilidad.

\section{Objetivos específicos del proyecto}

- Determinar el entorno externo de la industria educativa para la identificación de Oportunidades y Amenazas.

- Analizar el contexto actual y esperado de la economía del sector e industria.

- Desarrollar la investigación de mercado cuantitativa y cualitativa para identificación de la demanda.

- Realizar entrevistas a expertos y focus groups aplicando cuestionarios que permita conocer las necesidades y requerimientos de los potenciales clientes para este proyecto.

- Formular estrategias de marketing y a través del marketing mix analizar el comportamiento de los consumidores para posicionar a la empresa con su público objetivo y que con ello permita presentar con mayor atractivo el proyecto.

- Realizar un pronóstico de ventas.

- Realizar un estudio de ingeniería del proyecto, donde se defina el tamaño, el uso de recursos, la localización y distribución de áreas.

- Definir los aspectos organizacionales del negocio.

- Formular las estrategias del negocio.

- Realizar un adecuado plan financiero de inversión y financiamiento.

- Elaborar presupuestos, estados financieros y flujos de caja proyectados.

- Determinar la evaluación técnica - financiera del negocio de tal manera que nos permita detectar riesgos, punto de equilibrio y analizar diversos escenarios.

\subsection{Alcances y limitaciones de la investigación}

Alcances

- El estudio de mercado será realizado a hombres y mujeres que residen en Lima Moderna de las edades entre los 25 a más años, debido a que es el rango de edad con mayor probabilidad de concepción; del Nivel Socioeconómico (NSE) B que 
laboran principalmente en los distritos de San Isidro, San Borja y La Victoria (Santa Catalina) ya que según los últimos censos económicos son quienes poseen mayor poder adquisitivo y por ende mayor capacidad de gasto.

- Target: Hombre o mujer jefe de familia; con hijos en las edades comprendidas entre 03 y 36 meses de edad, que trabajan y que tienen la necesidad de encargar el cuidado de sus hijos a terceros; que sea el responsable de decidir sobre el cuidado de los niños.

Limitantes:

- Los expertos en la metodología Doman son pocos y debido a ello su tiempo y de disponibilidad es restringida; sin embargo, existe la posibilidad de que uno de los socios se certifique en el método y este sea aplicable.

- Los padres (mamá y papá) de infantes entre 3 y 36 meses, que trabajan durante el día no cuentan con disposición para asistir a los Focus Group, ya que desean emplear su tiempo libre con su familia; sin embargo, se ve la posibilidad de programar los focus en horarios de oficina.

- Limitada información estadística respecto a la población que trabaja en la zona planificada para este proyecto, lo cual obliga a buscar otras fuentes de información para determinar la demanda (Población Flotante).

- Limitada información acerca de los padres con hijos de 0 a 3 años que trabajen en el distrito de San Isidro.

- La falta de información secundaria con respecto a la composición del mercado ya que existen guarderías formales e informales. 


\section{Capítulo II: Estructura Económica del Sector}

\subsection{Descripción del estado actual de la industria}

De acuerdo a unos estudios realizados por el Banco Interamericano de Desarrollo BID (2017) citado en el diario El Comercio (2017), explica que:

El Perú es uno de los países de la región que invierte menos porcentaje del PBI, invirtiendo sólo el 3,7\% el PBI, que si bien es cierto ha tenido un incremento en los últimos 10 años del 3\% al 3,7\%, continúa estando muy por debajo de Países como Bolivia que invierte el 6.5\% y Brasil el 6.1\%. Lo más importante de la inversión que se realiza es que se logre el objetivo trazado, el cual debe ser sustentando en los resultados, siendo uno de los cambios a realizar disminuyendo el número de alumnos por aula, siendo el ideal 20, lo cual incrementará el aprendizaje, adicional a ello los docentes deben contar con guías de estudio y apoyarse en la tecnología para sus estudiantes, pero de forma guiada, lo cual requiere capacitación. (p. 1)

Así también, al analizar los indicadores en Educación del Perú y otros países de América, los expertos señalan,

El ex ministro de educación Jaime Saavedra indicó que la remuneración promedio de los docentes del sector público equivale a U\$ 1,000, lo cual es la tercera parte comparado con lo que se pagaba hace 40 años, asimismo hizo hincapié que se ha logrado incrementar la remuneración a los docentes que lograron pasar por una evaluación meritocrática. (Gestión, Diario, 2016, pág. 1)

En 1902, Juana Alarco de Dammert funda la primera Cuna Infantil Privada "Los Naranjos" para atender a los hijos de las madres obreras en los Barrios Altos. Ese mismo año, Elvira García y García crean el primer Kindergarten privado.

En 1968, por iniciativa de Caritas en Puno, se crearon los primeros "Wawa Wasi” o "Wawa Uta", que, en quechua y aymara, respectivamente, significan "Casa de niños". Estos programas surgieron para hacer frente al problema de muchas familias rurales y propiciaron la generación de un espacio muy similar al doméstico, donde los niños menores de 5 años realizan actividades lúdicas y reciben alimentación complementaria.

El Ministerio de Educación realizó el estudio de educación inicial: un acercamiento a los aprendizajes de niños y niñas de cinco años de edad, dicho estudio se realizó en 16 regiones del País, cuyos participantes fueron 3,520 niños de cinco años de edad, el $50 \%$ varones y el otro 50\% mujeres, con lengua materna el castellano de IEI Públicas 
y PRONOEI, así como docentes de zona urbana y rural. (Ministerio de Educación, 2013, p. 6)

Las capacidades evaluadas fueron: matemática, comunicación y personal social. Para obtener los resultados se establecieron 3 niveles Siendo el III el óptimo, en matemáticas se refiere a cuantificar, clasificar y resolver problemas. En el nivel II realizan actividades sencillas como algunas relaciones entre objetos, pero aún no señalan las razones por las cuales los clasifican y en el nivel I no lograron realizar las actividades más sencillas del estudio. Los resultados fueron: (a) Nivel I: 13,5\%, (b) Nivel II: 72,2\%, (c) Nivel III: 14,3\%. (Ministerio de Educación, 2013, p. 27) En comunicación, el nivel III consiste en comprender los textos que escuchan y brindar razones sobre cómo reconocieron palabras de las láminas, en el nivel II los niños reconocieron la información de las historias narradas, pero aún no relacionan la información ni formulan el título para la historia y en el nivel I los niños no respondieron las preguntas más sencillas de los textos que escucharon ni de las láminas que vieron, los resultados fueron los siguientes: (a) Nivel I: 45,1\%, (b) Nivel II: 44,8\%, (c) Nivel III: 10,1\%. (Ministerio de Educación, 2013, p. 30)

En Personal Social, en el nivel III los niños demuestran equilibrio al desplazarse de diversas maneras, ya sea arrastrándose, caminando en cuclillas o saltando hacia la meta, reconocen características personales y participa en grupo respetando a los demás. En el nivel II los niños emplean una sola forma de desplazamiento para llegar a la meta y lanzan los objetos con cierta dificultad y en el nivel I los niños demuestran dificultad la trasladarse tropezándose y no pueden llegar a la meta y no logran lanzar los objetos con fuerza.

Los resultados obtenidos fueron: (a) Nivel I: 5\%, (b) Nivel II: 17,6\%, (c) Nivel III: 77,4\%. (Ministerio de Educación, 2013, p. 35)

Oportunidad:

Se evidencia que a los 5 años de edad de educación inicial que reciben educación por parte del estado, los niños no logran desarrollar las competencias propias de su edad, lo que se suma a los conocimientos que se le enseñan en casa durante sus primeros años de vida, lo genera una oportunidad para el proyecto, ya que propone métodos de aprendizaje para estimular a menores entre 3 a 36 meses preparándolos para captar los conocimientos que se le impartan en los años posteriores y se logren mejores resultados.

Por otro lado, las estadísticas revelan que en los últimos años la cobertura de servicios de educación inicial que atienden a niños y niñas de 3 a 5 años se ha incrementado, siendo 
una oportunidad al reflejarse mayor interés en la educación en niños pequeños_aun cuando persisten grandes desafíos de equidad. Así, del 65,6\% de cobertura total registrada en el 2005, se pasó a 72,5\% en el 2008. No obstante, las brechas de atención continúan afectando a la población rural (zona urbana: $80,3 \%$; rural: $61,8 \%$ ) y en condiciones de pobreza (no pobre: 81\%; pobre: 69,4\%; pobre extremo: 56,8\%). Por su parte, la evolución de la cobertura de servicios educativos dirigidos a niños y niñas de 0 a 2 años ha sido mínima. Del $4 \%$ de cobertura total registrada en el 2005, solo se incrementó a 4,2\% en el 2008 (zona urbana: 5.3 $\%$; rural: $2 \%$ ). Esto contribuye con el proyecto al mostrar las ventajas que significa que los niños pequeños reciban educación a temprana edad siendo realizada por la empresa privada y el estado se preocupará más por este sector logrando mejorar el nivel de educación estatal.

\subsubsection{Segmentación de la industria.}

El Ministerio de Educación es el encargado de gestionar la educación y garantizar el acceso de todos los peruanos. El sistema educativo se divide en cuatro niveles o etapas, siendo las tres primeras de carácter obligatorio (Ministerio de Educación-Minedu, 2003).

(a) Educación Básica o Inicial, (b) Educación Primaria, (c) Educación Secundaria, (d) Educación superior

A continuación, definiciones para tener en cuenta:

- Básica o Inicial: La Educación Inicial ofrece las denominadas cunas, constituye el primer nivel de la Educación Básica Regular, atiende a niños de 0 a 2 años en forma no escolarizada y de 3 a 5 años en forma escolarizada. Se articula con el nivel de Educación Primaria asegurando coherencia pedagógica y curricular, pero conserva su especificidad y autonomía administrativa y de gestión.

- Primaria: La educación primaria tiene una duración de seis años. Los estudiantes adquieren conocimientos generales de ciencias, matemáticas y lenguaje, teniendo que contar con un promedio de 11 (sistema vigesimal de evaluación) para superarlo.

- Secundaria: La educación secundaria se divide en dos ciclos: el primero, general para todos los alumnos, tiene una duración de dos años y junto con la educación primaria constituyen el bloque de la educación obligatoria; el segundo, con una duración de tres años, es diversificado, con opciones científico-humanista y técnicas. Se ofrece en dos modalidades: para adolescentes (de 12 a 16 años) y para adultos.

- Superior: La educación superior se imparte en escuelas, institutos superiores, 
centros superiores de posgrado y en universidades. Los institutos ofrecen programas de formación de maestros y una variedad de opciones de formación técnica en carreras que tienen una duración entre cuatro y diez semestres académicos. Los institutos y escuelas superiores otorgan títulos de profesional, técnico y experto, y también los de segunda y ulterior especialización profesional. Las universidades otorgan títulos de bachiller, maestro y doctor, así como certificados y títulos profesionales, incluso los de segunda y ulterior especialización.

\subsubsection{Empresas que la conforman.}

En la Tabla 2 se muestran datos de las principales empresas del rubro educativo que se encuentran entre los distritos de La Victoria y San Isidro, los mismos que forman parte de la actual competencia en la zona. 
Tabla 2

Empresas Educativas Entre los Distritos de La Victoria y San Isidro

\begin{tabular}{|c|c|c|c|c|c|c|}
\hline Institución & Tipo & Modalidad & Ubicación & Metodología & Alimentación & Horario \\
\hline Primeros Pasos & Cuna/Guardería, Nido Jardín & Particular & Sta. Catalina La victoria & No & $\mathrm{Si}$ & 8:00 am. a 6:00 pm \\
\hline Verde Limón & Cuna/Guardería & Particular & Sta. Catalina La victoria & No & $\begin{array}{l}\text { En horario de 7:00 - 4:00 } \\
\text { pm y 7:00 -7:00 pm }\end{array}$ & $\begin{array}{l}\text { 7:00 am - 1:00 pm, 7:00 am - } \\
4: 00 \mathrm{pm}, 7: 00 \mathrm{am}-7: 00 \mathrm{pm} .\end{array}$ \\
\hline Star Kids I y II & Cuna, Nido, Guardería & Particular & Sta. Catalina La victoria & Montessori & (Opcional) S/ 150 más & $\begin{array}{l}\text { Nido:8:30 am.-1.15 pm/ } \\
\text { Guardería: } 1.15 \text { pm- 5:30 } \\
\text { pm. }\end{array}$ \\
\hline Palitroques & Cuna/Jardín/Guardería & Particular & San Isidro & Optimist & No & $\begin{array}{l}\text { Nido: 8:30 am.-1:00 pm/ } \\
\text { Guardería: 1pm- 5:30 pm. }\end{array}$ \\
\hline My World & Inicial/Jardín/Guardería & Particular & Urb. Corpac. San Isidro & $\begin{array}{l}\text { Desarrollo } \\
\text { Neuromotor }\end{array}$ & No & 8:00 am. a 2:00 pm \\
\hline Smartd Kid & Cuna/Jardín & Particular & Urb. Corpac. San Isidro & Optimist & No & 8:00 am. a 5:30 pm \\
\hline Mundo de Colores & Cuna/Guardería, Nido Jardín & Particular & $\begin{array}{l}\text { Sta. Catalina - La } \\
\text { Victoria }\end{array}$ & Reggio Emilia & No & 8:00 am. a 6:00 pm \\
\hline
\end{tabular}

Fuente: Elaboración en base a la investigación de campo en las zonas de San Isidro y La Victoria. 


\subsection{Tendencias de la Industria}

Según el Diario el Comercio (2016) al cierre del 2015,

“en Lima Metropolitana existían 5,680 colegios privados versus 1,705 colegios

públicos, siendo importante precisar que en Lima abundan los colegios chicos con

poco alumnado lo cual equipara el número del alumnado total entre ambos, el cual asciende a los $2 \mathrm{~mm} "($ p. 1)

El surgimiento de la oferta masiva de colegios privados responde al déficit de la educación pública lo cual ha privilegiado a la opción privada,

El referido crecimiento se ha dado, en mucho, de manera improvisada y hasta informal, muchos de los colegios se encuentran en casas adaptadas con lo cual no tiene las instalaciones adecuadas. La educación pública, en el actual gobierno, viene desarrollando una serie de acciones como reformas orientadas a mejorar la calidad educativa, incremento en las remuneraciones de los docentes previa evaluación lo cual motiva a su mejor preparación. En el mensaje a la nación, el expresidente Pedro Pablo Kuczynski precisó el compromiso fundamental del gobierno para los próximos cinco años: “educación pública de calidad, que abra el mundo a millones de jóvenes".

"En Lima y Callao existen 450 cunas privadas, de las cuales 7 se encuentran en la zona Financiera de San Isidro, y 174 públicas, que cuentan con la resolución de funcionamiento del Ministerio de Educación” (Diario El Comercio (2017, p. 1) Según la especialista de la Dirección de Educación Inicial del Minedu, Milagros Millán, señala que:

El número es insuficiente para atender la demanda creciente de padres que necesitan trabajar y no cuentan con otra alternativa para el cuidado de sus hijos precisando que, "una cuna es un lugar que se dedica al cuidado integral de niños pequeños y debe contar con docentes de educación inicial, auxiliares, un pediatra y un nutricionista y el ambiente debe contar como mínimo $2 \mathrm{~m} 2$ por cada niño. Además, indicó, deben cumplir estándares de infraestructura, como estar ubicado en un primer piso, tener amplios espacios y mobiliario especial. (p. 1)

Según el diario El Comercio (2017), "La licencia de funcionamiento de las guarderías se ampara en una directiva del Ministerio de Educación por lo que no debería distar mucho del servicio que brindan las cunas" (p. 1)

La educación pública debe mantener una alianza pedagógica con las escuelas privadas para que sus mejores prácticas puedan ser incorporadas en la gestión pública, y que, al mismo tiempo, ellas puedan aprender de los avances de nuestros mejores docentes públicos. 
"La brecha en el sector es enorme, la infraestructura escolar: equivale al 10\% del PBI. Es necesario continuar renovando, sustituyendo y ampliándola a ritmo acelerado. De manera tal que, para el Bicentenario, el 75\% de escuelas del país contarán con todos los servicios básicos" (Andina, Agencia Peruana de Noticias, 2016, p. 1)

Tal y como se menciona en una publicación de la UNESCO (2011),

“La UNESCO y la Educación -Toda persona tiene derecho a la educación”, el recibir una educación de calidad a lo largo de toda la vida es un derecho de cada niño, la cual contribuye a la consecución de todos los objetivos de desarrollo. (p. 1)

Entre los principales métodos de enseñanza que se ha encontrado destacan:

Reggio Emilia; La Metodología Reggio Emilia, que lleva el nombre del pueblo italiano donde se originó en la década de los 70, es un innovador sistema de enseñanza. Fue desarrollado por el pedagogo Loris Malaguzzi, quién introdujo el arte en las escuelas infantiles defendiendo que los alumnos aprenden por medio de la observación para, finalmente, poder desarrollar sus propios proyectos creativos. En los principios Reggianos prevalece "la pedagogía de hablar por la pedagogía de escuchar". Así, se trata de una filosofía educativa elaborada por las personas que forman parte de la educación cotidiana de los niños/as: los padres, educadores, maestros, artistas y, los mismos niños/as.

El medio natural se incorpora, en la medida de lo posible, en todas las actividades educativas y los idiomas constituyen la herramienta para el desarrollo y comprensión del mundo que les rodea. La Metodología Reggio Emilia se basa, según afirmaba Loris Malaguzzi, en que las ideas surgen a partir de experiencias reales que originan consecuencias reales. El Método Reggiano es mucho más que llevar el arte a las aulas. Es un método de enseñanza vivencial que tiene que ver con el compromiso de todos los miembros de la comunidad educativa en la enseñanza de los niños, para conseguir que estrechen lazos de comunicación con el mundo. El papel del docente es escuchar al alumno, dejarlo que lleve la iniciativa y guiarlo de una manera productiva. Es una metodología que orienta y potencia la capacidad intelectual de cada niño/a. El alumno/a se compromete en proyectos a largo plazo que se desarrollan en un ambiente relajado, saludable y lleno de amor. El bienestar del niño/a es considerado muy importante para que pueda aprender. Así, deben tenerse en cuenta los derechos de los niños/as no solo sus necesidades.

Montessori; El método Montessori se caracteriza por proveer un ambiente preparado: ordenado, estético, simple, real, donde cada elemento tiene su razón de ser en el desarrollo de los niños. El aula Montessori integra edades agrupadas en períodos de 3 años, lo que 
promueve naturalmente la socialización, el respeto y la solidaridad. El ambiente preparado ofrece al niño oportunidades para comprometerse en un trabajo interesante, elegido libremente, que propicia prolongados períodos de concentración que no deben ser interrumpidos. La libertad se desarrolla dentro de límites claros que permite a los niños convivir en la pequeña sociedad del aula. Los niños trabajan con materiales concretos científicamente diseñados, que brindan las llaves para explorar el mundo y para desarrollar habilidades cognitivas básicas. Los materiales están diseñados para que el niño pueda reconocer el error por sí mismo y hacerse responsable del propio aprendizaje. El adulto es un observador y un guía; ayuda y estimula al niño en todos sus esfuerzos. Le permite actuar, querer y pensar por sí mismo, ayudándolo a desarrollar confianza y disciplina interior.

Aprendizaje Activo; Basada en el aprendizaje activo, para que niños y niñas desarrollen sus habilidades por medio de experiencias concretas y significativas. Por medio del aprendizaje activo los niños construyen un conocimiento que los ayuda a encontrar sentido a su mundo. Se les estimula cada día para que elijan las actividades y los materiales que van a utilizar. Ellos mismos exploran, hacen preguntas, que muchas veces responden, resuelven problemas e interactúan con sus compañeros. La gran diferencia de este método es que el aprendizaje nace de ellos mismos. El ambiente es fundamental para un buen aprendizaje por esto las salas cuentan con material al alcance de los niños, cuidadosamente seleccionado.

"Reconocemos que la facultad para aprender se encuentra en el niño, de ahí el enfoque en las prácticas del aprendizaje activo. Cuando aceptamos que el aprendizaje proviene del interior, logramos un equilibrio crítico en la educación de los niños. El papel del adulto consiste en apoyar y guiar a los niños a lo largo de sus aventuras y experiencias en el aprendizaje activo." (David P. Wikart, 1995.)

Optimist; Este es un proyecto que ofrece una estimulación organizada para que el niño pueda desarrollar todas sus capacidades. Uno de los pilares fundamentales del Proyecto Optimist es la implicación de los padres. Este proyecto marca un itinerario para estimular al niño, ofrece un marco para que él pueda desarrollar en toda su plenitud las capacidades que le vienen dadas de manera innata.

Capacidades motoras, Capacidades intelectuales, Capacidades afectivas, Capacidades sociales, Capacidades de la voluntad.

El proyecto propone una serie de programas organizados y estipulados para conseguir el pleno desarrollo de las capacidades de los niños. Consiste en los siguientes aspectos: 
Programa Neuromotor; es la práctica de ejercicios de coordinación, equilibrio, control postural para así poder desarrollar la motora fina y gruesa.

Módulo de la Lengua - se desarrollan las capacidades de escucha, verbalización y expresión de sentimientos. Se realizan audiciones musicales, para desarrollar la sensibilidad estética. Programa de Lectura - el aprendizaje de la lectura se realiza a través de bits de imágenes y palabras.

Programas de eficacia visual - se favorece el desarrollo de habilidades visuales necesarias para aprender y dominar la lectura.

Programa crecemos en valores - práctica de hábitos concretos para conformar valores fundamentales.

Programa de Grafomotricidad - desarrolla la coordinación óculo-manual.

Grupo Coloquial - se desarrollan las áreas matemáticas, social, de ciencia, religión y de comunicación integral.

Cada 2 meses se realiza un informe de progreso del niño, que detalla su proceso de aprendizaje de acuerdo con el desarrollo de sus capacidades.

Doman; El Método Doman fue diseñado por un equipo de neurólogos y especialistas en lesiones cerebrales dirigidos por el doctor Glenn Doman, que parten de la premisa de que la capacidad de aprendizaje alcanza su punto más álgido cuanto más pequeño es el niño, siendo esta superior a la que podrá alcanzar el resto de su vida. Tras comprobar en sus numerosas investigaciones los magníficos resultados obtenidos en niños con parálisis cerebral, el equipo de Doman se planteó la posibilidad de adaptar dichos principios, programas, técnicas y métodos a todo tipo de niños, con la finalidad de desarrollar al máximo todas las áreas sensoriales del cerebro. Dicho método ha sido diseñado para que padres y madres puedan ponerlo en práctica con sus bebés, de una forma fácil, amena y adaptada a las características y necesidades del pequeño. Son muchos los programas con los que cuenta, pero los más populares son: bits de inteligencia, lectura y matemáticas. Entre los diferentes beneficios que se pueden obtener cabe destacar que:

- Aumenta la atención y favorece la concentración de los niños en las tareas.

- Desarrolla y estimula el cerebro para ayudar a crear conexiones neuronales.

- Estimula la memoria y el aprendizaje.

- Contribuye al desarrollo visual y auditivo del niño.

Este método puede ponerse en práctica a partir del primer año de vida o incluso antes ya que dicho método contempla las diferentes limitaciones que pueden presentar los niños a dichas edades, como puede ser la agudeza visual, la atención, etc. Es por ello que su práctica 
requiere de muy poco tiempo. Se trabaja con materiales llamativos y cuyo tamaño es el idóneo para que la agudeza visual del pequeño pueda captarlos. Requiere también de una actitud cariñosa y entusiasta por parte de los padres, lo que hará de esta actividad algo divertido y llamativo para el niño deseoso de recibir nueva información.

El programa de lectura se trabajará como si de un tiempo de juego se tratase y teniendo presente: Se presentarán al niño cinco categorías de cinco palabras diferentes cada una (25 palabras). A lo largo de todo el programa y progresivamente mostraremos al niño desde palabras sueltas, parejas de palabras, frases sencillas, oraciones y, por último, sencillos cuentos que serán de su interés. Dichas palabras se mostrarán 3 veces al día durante 5 días (después estas palabras cambiarán). Este proceso no requerirá de mucho más de un minuto por sesión. El tamaño de las letras será el idóneo para satisfacer las necesidades de visión gruesa y fina del niño, y su tamaño irá disminuyendo a lo largo del programa.

\subsection{Análisis estructural del sector industrial.}

El análisis del microentorno se efectuará en base al análisis Porter y Pestel de las cinco fuerzas (ver Figura 1). Este modelo plantea un marco estratégico sistemático a fin de evaluar el valor y la proyección futura del proyecto o unidades de negocio que operan en el sector.

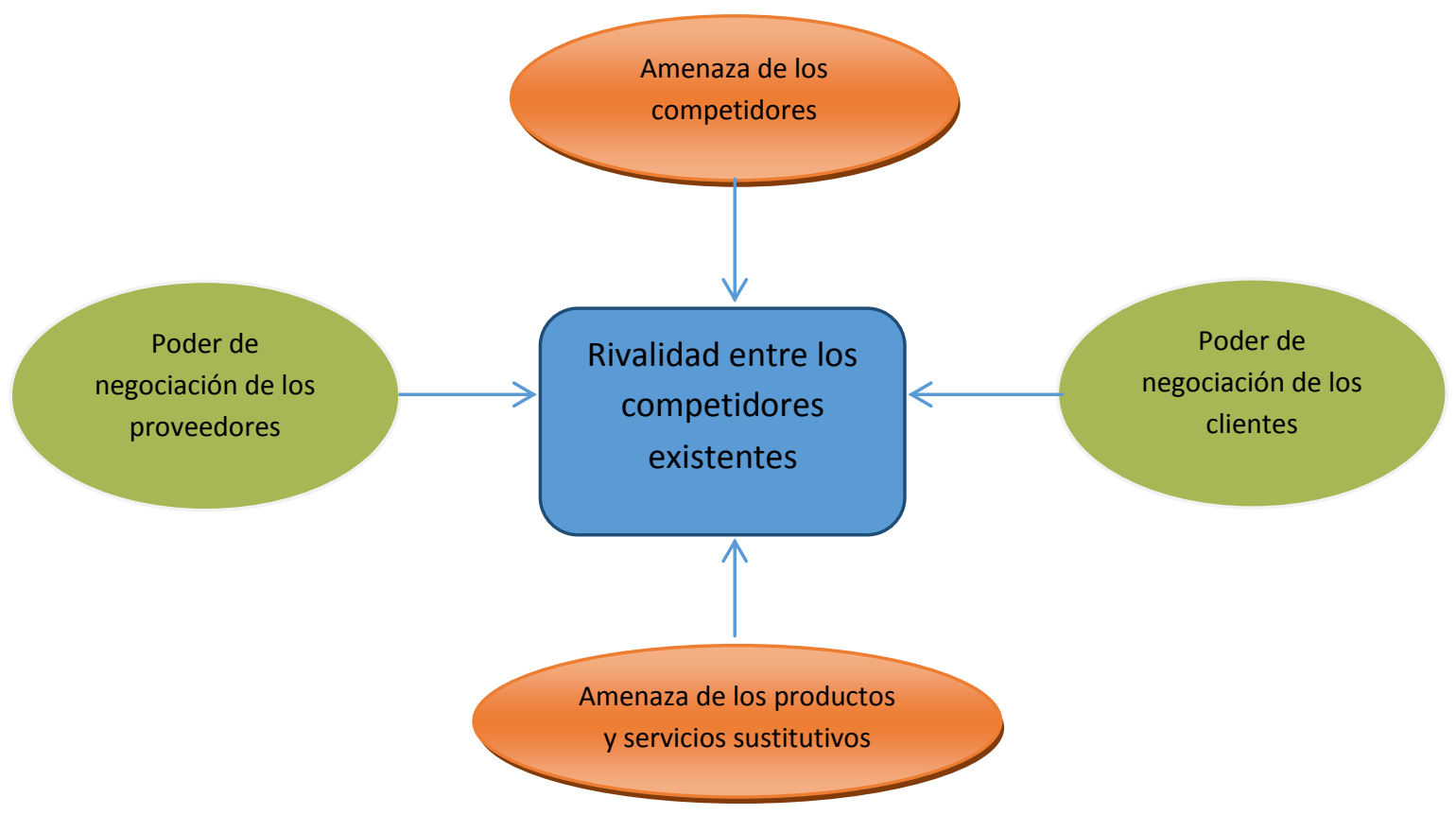

Figura 1. Diagrama de las 5 Fuerzas de Porter. Tomado de "Las 5 Fuerzas de Porter - Clave para el Éxito de la Empresa” por Riquelme. M. Autor, 2015, Santiago, Chile. Recuperado de http://www.5fuerzasdeporter.com/ 


\section{Amenaza de los Competidores}

Para considerar las posibles amenazas de nuevos competidores, se evaluará según factores y dos barreras, las cuales se detallan líneas abajo:

Barreras de entrada; se considera que la experiencia en el sector es determinante, dado que es una trasmisión de datos a niños a través de un modelo ya establecido. Ese "Know how" haría más complicado el ingreso de nuevos competidores; así también el tema de los alquileres para una infraestructura adecuada se considera una amenaza debido a los altos costos y zona de ubicación.

Barreras de salida; se considera que es un sector donde las barreras de salida no son considerables, dado que la inversión en infraestructura no es determinante. Tener presente que el traspaso del conocimiento del método es un bien intangible.

Diferenciación del producto; existe diferenciación en el sector educativo sobre todo en guarderías o cunas, empresas del sector no ofrecen los mismos servicios que la propuesta de proyecto ofrece, tales como: horarios extendidos, metodología especializada, servicio de calidad, personal califica e infraestructura.

2. Poder de Negociación de los Proveedores

Al ser este negocio una empresa de servicios, el principal proveedor estará conformado por el capital humano, el mismo que estará encargado del cuidado y educación de los menores; por lo que los principales proveedores estarán conformados por maestros y auxiliares.

Es preciso destacar que la ley peruana en la DIRECTIVA No 073-2006-DINEBR-DEI establece los requisitos mínimos que necesita tener un maestro y un auxiliar de cuna, los mismos que a continuación se detallan:

\section{Maestro}

- Poseer título profesional pedagógico en la especialidad de Educación Inicial.

- Disposición para el trabajo con menores de tres años, padres de familia y comunidad.

- Estar inscrita en el Colegio de Profesores del Perú.

- Gozar de salud física y mental, acreditada mediante Certificado Médico, renovable cada 3 años.

- No tener antecedentes penales.

Auxiliar

- Poseer formación especializada en Educación Inicial o con estudios en atención 
integral al niño menor de 3 años.

- Acreditar un año de experiencia en el trabajo con menores de tres años, como mínimo.

- Gozar de salud física y mental, acreditada mediante Certificado Médico, renovable cada 3 años.

- No tener antecedentes penales.

Adicionalmente, para el plan de negocio se necesita que los maestros y auxiliares cumplan los siguientes requisitos:

Maestro

- Acreditar especialización en el Método de enseñanza Glenn Doman para niños menores de 3 años.

- Contar con 5 años de experiencia como maestro en el sector educativo en fase inicial, de preferencia haber trabajado con niños menores de 3 años.

- Contar con 2 años de experiencia aplicando el método Doman.

- Ser bilingüe (español e inglés)

Auxiliar

- Tener mínimo un año de experiencia como auxiliar de cuna, de preferencia en sector educativo.

- Tener conocimiento de metodologías de enseñanza en niños menores de 3 años.

- De preferencia mujer entre los 22 y 30 años.

- Conocimiento de inglés básico

Por los requisitos adicionales que el puesto de maestro requiere, el poder de negociación será medio, ya que el método Doman no es muy practicado en nuestro país y son pocos los maestros especializados en este método.

Oportunidad: Si bien es cierto que no hay tantos maestros con esta especialidad con lo cual no hay tanta oferta; sin embargo, la capacitación y actualización del especialista a los demás profesores y auxiliares de la guardería, potencializara el método para su aplicación como ventaja competitiva para este plan de negocio.

3. Poder de negociación de los clientes

Concentración

Los clientes del sector educativo relacionados al negocio de guarderías no están concentrados en San Isidro ni en zonas aledañas, ni se evidencia una posible concertación en 
los precios, lo que es una gran oportunidad en el mercado, ya que no ejercen presión de manera conjunta y tampoco obligan a modificar los precios.

Los potenciales clientes buscan un lugar seguro y adecuado para dejar a sus hijos donde le brinden además del cuidado, una educación y metodología aplicada que les permita desarrollarse y socializarse como si estuvieran en casa.

Diferenciación

Los servicios brindados en el sector educativo se diferencian por su metodología y sistemas de seguridad de acuerdo con el segmento o nivel al que pertenecen. Para el proyecto de guardería aplicar la metodología Doman lo hace diferente al resto ya que no es comúnmente aplicado en este sector, además que contara con un monitoreo a través de cámaras que puede ser visto desde cualquier dispositivo conectado a internet en tiempo real. Los padres pueden percatarse del avance de sus hijos y referenciar la guardería. Los costos por cambiar de proveedor

Los clientes de este sector no son sensibles al precio, siempre y cuando tengan la seguridad que la calidad en el servicio es garantizada, de acuerdo con las encuestas realizadas para el mercado objetivo, trabajadores de San Isidro. Se tiene mucho en mente que cuando un servicio es barato no es bueno.

Se considera que el poder de negociación de los clientes es medio ya que buscan un servicio de alta calidad para sus niños.

Oportunidad: El precio estará justificado con el servicio de calidad que recibirán los niños y el método a utilizar es un valor agregado lo cual lo hace atractivo a los potenciales clientes.

4. Rivalidad entre los competidores existentes

La competencia entre las guarderías que se encuentran alrededor del punto objetivo es media, ya que no existen muchos lugares que ofrecen este servicio como tal, sino como un agregado a negocios como Nido o Jardín, estos poseen ofertas similares en cuanto a precios, mientras que en servicio muy pocos logran una diferenciación notable. Las ventajas de estos centros se centran alrededor de la experiencia en el mercado, su ubicación y metodología aplicada.

Competidores directos o igualmente equilibrados, en la actualidad el sector cuenta con siete ofertantes: hacer un análisis más profundo de cada uno de los competidores, número de locales, metodología, estacionamiento, horarios, instalaciones, ubicación, fotos, etc.

- Mundo de Colores. - Este centro tiene la modalidad de Cuna, Guardería, Jardín; cuenta con la metodología Reggia Emilia cuyo principal objetivo es crear una escuela activa, inventiva, donde predomine la investigación y la reflexión y, un 
lugar que posibilite el bienestar de niños/as, educadores y familias para así intensificar las relaciones entre todos ellos, se encuentra ubicado a tres cuadras de la avenida principal. La vista de sus instalaciones es simple al igual que los servicios de espacio de recreación. El centro no ofrece un servicio diferenciado.

- Star Kids I y II.- Este centro tiene la modalidad de Cuna, Nido, Guardería; cuenta con la metodología Montessori, que permite que el niño experimente la alegría de aprender, el tiempo para disfrutar el proceso y asegure el desarrollo de su autoestima. Proporciona las experiencias a través de las cuales los niños crean sus conocimientos y los prepara para las muchas experiencias que ofrece la vida, se encuentra ubicado a 6 cuadras de la avenida principal. La vista de sus instalaciones es simple al igual que los servicios de espacio de recreación. El centro no ofrece un servicio diferenciado.

- Verde Limón. - Este centro tiene la modalidad de Cuna, Guardería; cuenta con la metodología de aprendizaje activo a través de proyectos de forma participativa, alternativa y personalizada, se encuentra ubicado en la misma avenida principal. La vista de sus instalaciones es simple al igual que los servicios de espacio de recreación. El centro no ofrece un servicio diferenciado.

- Primeros Pasos. - Este centro tiene la modalidad de Cuna, Guardería, Nido, Jardín; cuenta con la metodología de aprendizaje a través de proyectos de forma participativa como "Verde Limón". Se encuentra ubicado a 5 cuadras de la avenida principal. La vista de sus instalaciones es simple al igual que los servicios de espacio de recreación. El centro no ofrece un servicio diferenciado.

- Palitroques. - Este centro tiene la modalidad de Cuna, Jardín, Guardería; cuenta con la metodología Optimist, que ofrece una estimulación organizada para que el niño pueda desarrollar todas sus capacidades. Uno de los pilares fundamentales del Proyecto Optimist es la implicación de los padres. Este proyecto marca un itinerario para estimular al niño, ofrece un marco para que él pueda desarrollar en toda su plenitud las capacidades que le vienen dadas de manera innata. Se encuentra ubicado en el distrito de San Isidro en la misma avenida principal. La vista de sus instalaciones está llena de colores y llama la atención.

- My World. - Este centro tiene la modalidad de Inicial, Guardería, Jardín; cuenta con la metodología del Desarrollo Neuromotor, donde el término motor se refiere a cualquier movimiento ejecutado. El movimiento se constituye en el gran pilar 
del aprendizaje, la afectividad y el desarrollo intelectual. Se encuentra ubicado en el distrito de San Isidro - Corpac en la misma avenida principal. La vista de sus instalaciones está llena de colores y llama la atención.

- Smart Kids. - Este centro tiene la modalidad de Cuna, Jardín; cuenta con la metodología Optimist, que ofrece una estimulación organizada para que el niño pueda desarrollar todas sus capacidades. Uno de los pilares fundamentales del Proyecto Optimist es la implicación de los padres. Este proyecto marca un itinerario para estimular al niño, ofrece un marco para que él pueda desarrollar en toda su plenitud las capacidades que le vienen dadas de manera innata. Se encuentra ubicado en el distrito de San Isidro. La vista de sus instalaciones está llena de colores y llama la atención.

5. Amenaza de productos sustitutos

Se considera que no existen productos sustitutos por lo cual la amenaza seria baja, dado que un servicio de guardería no podría ser reemplazado por otro tipo de cuidado que se les da a los niños. Se podría considerar a los nidos como un semi sustituto; sin embargo, el costo sería mucho mayor y no ofrecerían un tipo de cuidado que requieren los niños menores de 3 años. Finalmente debido al público objetivo al que el proyecto se dirige, no se considera que los abuelos o un familiar puedan ser una opción permanente.

\subsection{Análisis de la competencia}

Para realizar un análisis de la competencia es necesario tener claro el mercado al cual apuntamos como público objetivo. Para la propuesta de proyecto establecido "Guardería Infantil para niños de 3 a 36 meses, aplicando la metodología Doman, del NSE B, que trabajan en la zona de San Isidro", existirían pocos competidores que ofrezcan similar o igual servicio en la zona en estudio.

\subsubsection{Empresas que ofrecen el mismo servicio, indicando las semejanzas y}

\section{diferencias que tienen con el proyecto de empresa.}

En este punto se menciona a otras empresas que ofrecen el mismo producto o servicio, indicando las semejanzas y diferencias que tienen con el proyecto de empresa. Los lugares considerados como competencia directa son las cunas ubicadas en el distrito de La Victoria en la zona de Santa Catalina, dado que las que se encuentran en el distrito de San Isidro se encuentran fuera de los sectores donde se quiere llegar, y adicionalmente son Nidos. Actualmente figuran cuatro empresas en Santa Catalina y tres en San Isidro, pero estas alejadas de la zona financiera y el target al cual se dirige el proyecto; dichas empresas se 
detallan en la Tabla 3, las mismas que han sido seleccionadas de acuerdo con el tipo de servicio ofrecido. Tener en cuenta que "OK” equivale a que cumple con el servicio.

Tabla 3

Servicios Ofrecidos por Empresas del Sector

\begin{tabular}{lccccccc}
\hline Características & $\begin{array}{c}\text { Mundo de } \\
\text { Colores }\end{array}$ & $\begin{array}{c}\text { Star Kids I } \\
\text { y II }\end{array}$ & $\begin{array}{c}\text { Verde } \\
\text { Limón }\end{array}$ & $\begin{array}{c}\text { Primeros } \\
\text { Pasos }\end{array}$ & Palitroques & My World & Smart Kids \\
\hline $\begin{array}{l}\text { Facebook } \\
\text { Página web }\end{array}$ & & OK & & & OK & OK & OK \\
$\begin{array}{l}\text { Correo } \\
\text { Teléfono }\end{array}$ & OK & OK & OK & OK & OK & OK & OK \\
Cámaras IP & & OK & OK & OK & OK & OK & OK \\
Estacionamientos & & & & & & & \\
Aire acondicionado & & & & & OK & & \\
$\begin{array}{l}\text { Detector de humo } \\
\text { Agua Caliente }\end{array}$ & OK & OK & OK & OK & OK & OK & OK \\
Juego para niños & OK & OK & OK & OK & OK & OK & OK \\
\hline
\end{tabular}

Dentro de los métodos que tiene nuestra competencia los dos principales son el Montessori y Reggio, se concluye normalmente, que las escuelas Montessori, basadas en la libertad y el individualismo de la autonomía, originan buenos líderes. Por otro lado, las escuelas con enfoque Reggio a través de sus valores sociales y de cooperación, dan como resultados adultos válidos para el trabajo en equipo. Digamos que en las escuelas Montessori se potencia el enfoque científico, mientras que en las escuelas Reggio se potencia más la parte creativa.

Por su lado en método Doman tiene como objetivo estimular las neuronas de manera que produzcan el mayor número de conexiones posible y el aumento de conexiones neuronales se traduce como un aumento de inteligencia.

\subsubsection{Matriz del perfil competitivo.}

La Matriz del Perfil Competitivo (MPC) identifica a los principales competidores de la empresa, así como sus fortalezas y debilidades particulares, en relación con una muestra de la posición estratégica de la empresa. Los factores de una MPC incluyen cuestiones internas y externas; las calificaciones se refieren a las fuerzas y a las debilidades.

Los Factores Claves o Determinantes para el Éxito son las áreas claves, que deben llevarse al nivel más alto posible de excelencia si la empresa quiere tener éxito en una industria en particular. Estos factores varían entre diferentes industrias o incluso entre diferentes grupos estratégicos e incluyen tanto factores internos como externos. En una MPC 
son amplios, no incluyen datos específicos o concretos, e incluso se pueden concentrar en cuestiones internas. (Elección, México, 2006)

Descripción:

El Peso en la matriz: cada factor crítico de éxito debe tener un peso relativo que oscila entre 0,0 (poca importancia) a 1.0 (alta importancia). El número indica la importancia que tiene el factor en la industria.

El Rating: se refiere a lo bien que lo están haciendo las empresas en cada área. Van desde 4 a 1, en donde 4 significa una gran fortaleza, 3 - fuerza menor, 2 - debilidad menor y 1 - gran debilidad.

Puntaje: es el resultado de la multiplicación del peso por el rating. Cada empresa recibe una puntuación en cada factor. (Zona Económica.com, 2018)

Para realizar la matriz del perfil competitivo nos realizamos las siguientes preguntas:

- ¿Quiénes son nuestros competidores?

- ¿Qué factores claves son los de mayor importancia para tener éxito en la industria?

- ¿Cuál es la importancia relativa de cada factor decisivo para el éxito den la industria?

- ¿Hasta qué punto es importante cada competidor fuerte o débil en cada factor decisivo del éxito?

- En general ¿Qué tan fuerte o débil es cada competidor importante?

Luego, se identifica a los competidores:

- Muy fuertes: Los que están cerca de la calificación 4

- Fuertes: Los que están cerca de la calificación 3

- Los menos débiles: Que están cerca de la 2

- Los débiles: Los que están cerca de la calificación 1

A continuación, se procede a elaborar la matriz del perfil competitivo, en la Tabla 4 Santa Catalina y en la Tabla 5 San Isidro, tomados según criterios de expertos en el sector educativo en la entrevista realizada (véase Apéndice P y Q), escogiendo los factores claves de éxito. 
Tabla 4

Matriz Perfil Competitivo de las Guarderías de Santa Catalina

\begin{tabular}{|c|c|c|c|c|c|c|c|c|c|}
\hline \multirow[b]{3}{*}{ Servicio al Cliente } & \multirow{3}{*}{$\begin{array}{c}\text { Ponderación } \\
0.30\end{array}$} & \multirow{2}{*}{\multicolumn{2}{|c|}{\begin{tabular}{ll}
\multicolumn{2}{c}{ Mundo de Colores } \\
Clasific. & $\begin{array}{l}\text { Resultado } \\
\text { Ponderado }\end{array}$ \\
\end{tabular}}} & \multirow{2}{*}{\multicolumn{2}{|c|}{\begin{tabular}{cl}
\multicolumn{2}{c}{ Star Kids I y II } \\
Clasific. & $\begin{array}{l}\text { Resultado } \\
\text { Ponderado }\end{array}$ \\
& Pond
\end{tabular}}} & \multirow{2}{*}{\multicolumn{2}{|c|}{\begin{tabular}{ll}
\multicolumn{2}{c}{ Verde Limón } \\
Clasific. & $\begin{array}{l}\text { Resultado } \\
\text { Ponderado }\end{array}$
\end{tabular}}} & \multirow{2}{*}{\multicolumn{2}{|c|}{\begin{tabular}{cl}
\multicolumn{2}{c}{ Primeros Pasos } \\
Clasific. & $\begin{array}{l}\text { Resultado } \\
\text { Ponderado }\end{array}$
\end{tabular}}} \\
\hline & & & & & & & & & \\
\hline & & 2 & 0.6 & 2.5 & 0.75 & 2 & 0.6 & & $2 \quad 0.6$ \\
\hline Diferenciación del producto & 0.30 & 2 & 0.6 & 2.5 & 0.75 & 2.5 & 0.75 & & 0.6 \\
\hline Estrategia de Precio & 0.20 & 2 & 0.4 & 2 & 0.4 & 2 & 0.4 & 2 & 0.4 \\
\hline Infraestructura & 0.20 & 2 & 0.4 & 2.5 & 0.5 & 2.5 & 0.5 & 2 & 0.4 \\
\hline Total & 1.00 & & 2.0 & & 2.4 & & 2.25 & & 2.0 \\
\hline
\end{tabular}

Fuente: Elaboración en base a soporte de expertos. (Lizbeth Chavez/Daniella Centurion)

Tabla 5

Matriz Perfil Competitivo de las Guarderías de San Isidro

\begin{tabular}{|c|c|c|c|c|c|c|c|}
\hline Factor clave de éxito & Ponderación & \multicolumn{2}{|c|}{ Palitroques } & \multicolumn{2}{|c|}{ My World } & \multicolumn{2}{|c|}{ Smart Kid } \\
\hline & & Clasific. & $\begin{array}{l}\text { Resultado } \\
\text { Ponderado }\end{array}$ & Clasific. & $\begin{array}{l}\text { Resultado } \\
\text { Ponderado }\end{array}$ & Clasific. & $\begin{array}{l}\text { Resultado } \\
\text { Ponderado }\end{array}$ \\
\hline Servicio al Cliente & 0.30 & 3 & 0.9 & 2.5 & 0.75 & 3 & 0.9 \\
\hline Diferenciación del product & 0.30 & 2.5 & 0.75 & 2.5 & 0.75 & 2.5 & 0.75 \\
\hline Estrategia de Precio & 0.20 & 2 & 0.4 & 2 & 0.4 & 2 & 0.4 \\
\hline Infraestructura & 0.20 & 4 & 0.8 & 3 & 0.6 & 3 & 0.6 \\
\hline Total & 1.00 & & 2.85 & & 2.5 & & 2.65 \\
\hline
\end{tabular}

Fuente: Elaboración en base a soporte de expertos. (Lizbeth Chavez/Daniella Centurion)

Luego de ponderar los factores claves de éxito de acuerdo al soporte brindado por dos expertos en la industria educativa (inicial), se procede a explicar porque se asignaron dichas ponderaciones, las mismas que se muestran en la Tabla 6 para Santa Catalina y la Tabla 7 para San Isidro. 
Tabla 6

Justificación de Ponderaciones de Guarderías de Santa Catalina

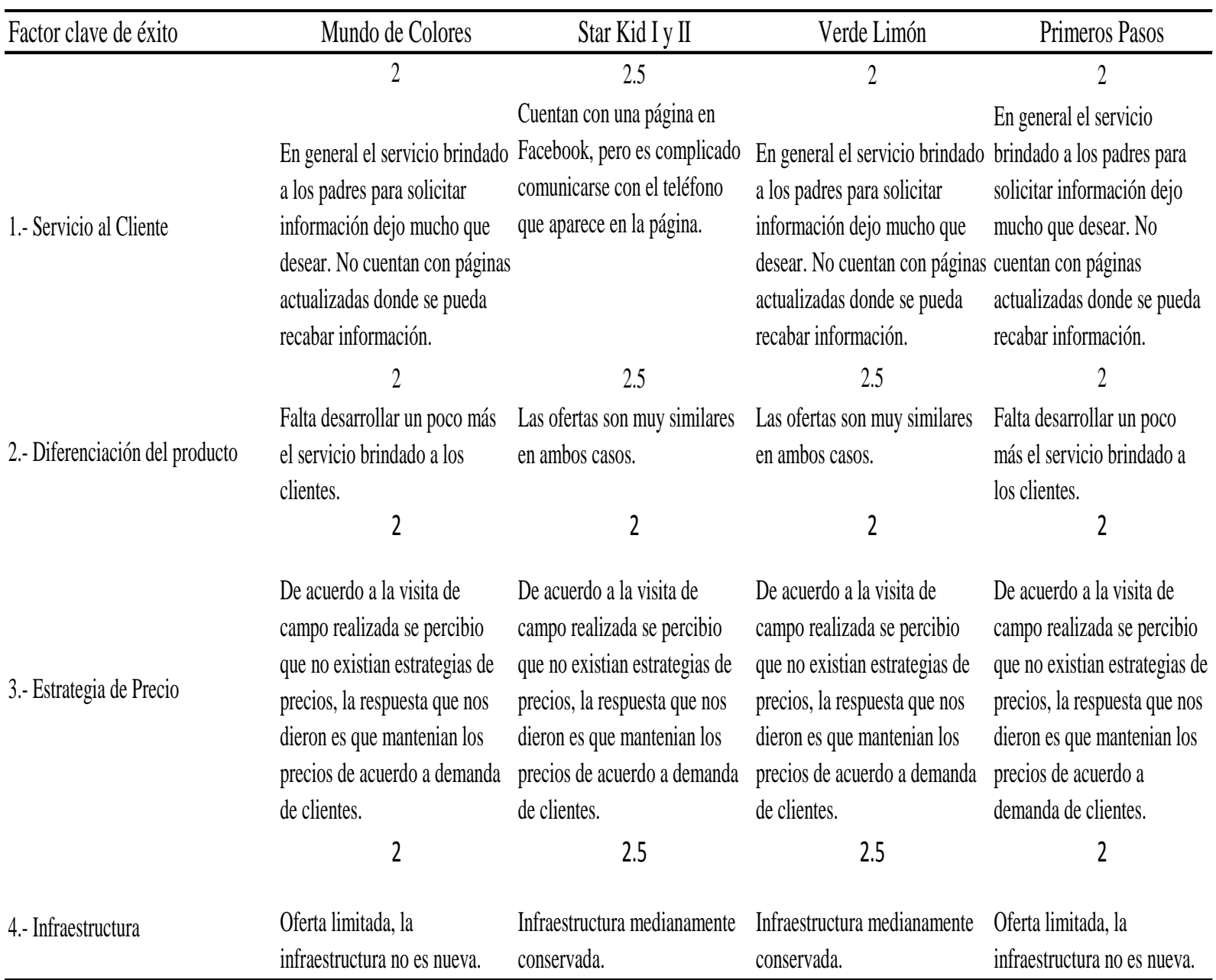

Fuente: Elaboración en base a soporte de expertos 
Tabla 7

Justificación de Ponderaciones de Guarderías de Santa Isidro

\begin{tabular}{|c|c|c|c|}
\hline Factor clave de éxito & Palitroques & My World & Smart Kids \\
\hline \multirow{3}{*}{ 1.- Servicio al Cliente } & 3 & 2.5 & 3 \\
\hline & $\begin{array}{l}\text { Contestaron todas las dudas, } \\
\text { buena comunicación con los } \\
\text { clientes. Página en facebook } \\
\text { actualizada. }\end{array}$ & $\begin{array}{l}\text { Contestaron todas las dudas, } \\
\text { buena comunicación con los } \\
\text { clientes. Página en facebook } \\
\text { actualizada. Un poco difícil de } \\
\text { comunicarse por teléfono. }\end{array}$ & $\begin{array}{l}\text { Contestaron todas las dudas, } \\
\text { buena comunicación con los } \\
\text { clientes. Página en facebook } \\
\text { actualizada. }\end{array}$ \\
\hline & 2.5 & 2.5 & 2.5 \\
\hline 2.- Diferenciación del producto & $\begin{array}{l}\text { Métodos de estimulación } \\
\text { utilizados en la mayoría de } \\
\text { nidos. }\end{array}$ & $\begin{array}{l}\text { Métodos de estimulación } \\
\text { utilizados en la mayoría de } \\
\text { nidos. }\end{array}$ & $\begin{array}{l}\text { Métodos de estimulación } \\
\text { utilizados en la mayoría de } \\
\text { nidos. }\end{array}$ \\
\hline \multirow{3}{*}{ 3.- Estrategia de Precio } & 2 & 2 & 2 \\
\hline & $\begin{array}{l}\text { Precios muy similares en las } \\
\text { tres cunas y / o nidos }\end{array}$ & $\begin{array}{l}\text { Precios muy similares en las } \\
\text { tres cunas y / o nidos }\end{array}$ & $\begin{array}{l}\text { Precios muy similares en las } \\
\text { tres cunas y / o nidos }\end{array}$ \\
\hline & 4 & 3 & 3 \\
\hline 4.- Infraestructura & $\begin{array}{l}\text { Muy bien cuidada, la fachada } \\
\text { se encuentra limpia y parece } \\
\text { recién pintada. }\end{array}$ & $\begin{array}{l}\text { Infraestructura medianamente } \\
\text { conservada. }\end{array}$ & $\begin{array}{l}\text { Mayor oferta, ubicación } \\
\text { estrategica. }\end{array}$ \\
\hline
\end{tabular}

Fuente: Elaboración en base a soporte de expertos

\subsection{Análisis del contexto actual y esperado}

\subsubsection{Análisis Político-Gubernamental.}

El Perú durante el gobierno de Ollanta Humala estuvo en una situación expectante en América Latina, este gobierno destacó dos áreas que son pilares de reconocimiento como: los programas sociales y la educación. Proyectos como Beca 18 y Pensión 65 que han logrado certificación internacional (RPP, 2016, p.1). Así también se ha logrado el avance en la calidad de la educación y su universalización.

En el 2014 según Andina, Agencia Peruana de Noticias:

La Unesco reconoció el desarrollo en la política educativa, Perú ha tenido importantes avances en las tasas de matrícula, y estas se asocian con la meta de la universalización en la educación básica", señaló Robalino. Sin embargo, también hay temas que representan desafíos para el país, como extender más los servicios educativos públicos a la primera infancia. En tal sentido, la especialista también estimó que la existencia del Proyecto Educativo Nacional es muy importante" para el desarrollo de este sector en el país y para la obtención de los logros hasta el momento registrados (p. 1).

Para el año 2018 el Perú se presenta con un mayor nivel de incertidumbre por la crisis política que aqueja, lo que alcanzará a tener un impacto en la economía nacional. En este contexto, aumenta la percepción del riesgo para los inversionistas nacionales e 
internacionales debido a que no se tiene una estabilidad económica, y frente a este horizonte podrían aplazar sus decisiones de inversión reduciendo la posibilidad de generar nuevos empleos.

Actualmente, el país se encuentra en una etapa de transición de cambio de mando que corresponderá asumir el cargo como presidente de la república al primer vicepresidente Martin Vizcarra, a pesar de no contar con una bancada mayoritaria, se espera el respaldo de las diferentes tiendas políticas para con el nuevo jefe de mando.

Según el defensor del Pueblo, Walter Gutiérrez (2018), “consideró que el nuevo gobierno debe estar encaminado a reconciliar a la ciudadanía con sus autoridades, así como cerrar las brechas sociales que existen en el país, debe construir un gobierno amplio y plural que emprenda esa nueva etapa de reconciliación" (p. 1).

El actual presidente de la Republica en su primer mensaje a la Nación manifestó que uno de sus pilares durante su gestión será la Educación. Reconocido por su gestión exitosa y contribución a la Educación cuando se desempeñó como gobernador regional de Moquegua, se espera un gran aporte y acciones inmediatas para este sector, ya que ante la interpelación de los dos anteriores ministros del gobierno saliente de PPK, no ha tenido mayor avance sobre temas en la educación.

Así mismo, en el segundo semestre del 2018 se llevarán a cabo las elecciones regionales y municipales, lo que probablemente también provocaría cierta desaceleración de la inversión pública al interior del país, trayendo consigo demoras o estancamiento en la ejecución de nuevos proyectos o negocios comerciales.

Por lo mencionado en párrafos anteriores, se espera una recuperación y estabilidad del país, la misma que dependerá de cómo se reafirme la confianza en la política económica y en el gobierno actual. Así también, el nuevo Gabinete Ministerial deberá buscar legitimarse con una gestión eficiente, priorizando el dialogo con las distintas fuerzas políticas del Congreso de la Republica y los diferentes sectores que necesitan la activación de proyectos estancados. La importancia de tener un Gabinete Ministerial con un balance entre técnicos y políticos, y con trayectoria en la gestión pública resulta conveniente para tener mayor capacidad de negociación.

Oportunidad:

La política adoptada por el nuevo Ministro de Educación, el de continuar las políticas emprendidas en el sector y de puertas abiertas y dialogo a todos, resulta beneficioso para el proyecto, dado que se mantendría la norma establecida y ratificada con Resolución Ministerial 657-2017-Minedu (El Peruano, 2018, p.1), donde establece los lineamientos para 
el desarrollo del año escolar 2018 y la edad cronológica donde los menores deberán cumplir 3,4 y 5 años antes del 31 de marzo para ingresar al nivel inicial. Esto permitirá que padres con ocupación laboral permanente busquen alternativas como nidos y guarderías para el cuidado y aprendizaje de niños menores de 3 años.

\subsubsection{Análisis Económico.}

Durante los últimos diez años, el Perú en comparación con los países de Sudamérica se ha destacado como una de las economías de más rápido crecimiento, con una tasa de crecimiento anual promedio de 5,9 por ciento en un entorno de baja inflación (2,9 por ciento en promedio). Los últimos gobiernos han llevado a cabo políticas macroeconómicas conservadoras y reformas estructurales en diversos campos más un contexto externo oportuno y favorable lograron llevar al Perú a un país con alto crecimiento con baja inflación (Andina Agencia Peruana de Noticias, 2015). Como resultado de estas medidas económicas se dio un crecimiento del empleo y de los ingresos lo cual llevó a la reducción de los índices de pobreza. Como un indicador, la pobreza moderada (4 dólares diarios a nivel poder adquisitivo - PPA - en 2005) cayó, del 43 por ciento de la población en el año 2004 al 20 por ciento en el año 2014 (Banco Mundial en el Perú [BMP], 2017).

En el año 2015, el producto bruto interno (PBI) tuvo una leve recuperación, llegando a al 3,3 por ciento, el crecimiento se debió al fuerte aumento de los inventarios y a una recuperación de las exportaciones. Sin embargo, las inversiones siguieron contrayéndose debido a una situación económica externa menos favorable y a la lentitud en la ejecución de proyectos de infraestructura a nivel local.

Para el año 2016 el crecimiento del PBI tuvo un aceleramiento debido a los proyectos mineros de gran magnitud que entraron en su fase producción, se estima que la economía tuvo un crecimiento de 3.9 por ciento (ver Figura 2) por un nivel temporal en la producción minera (BMP, 2017). 


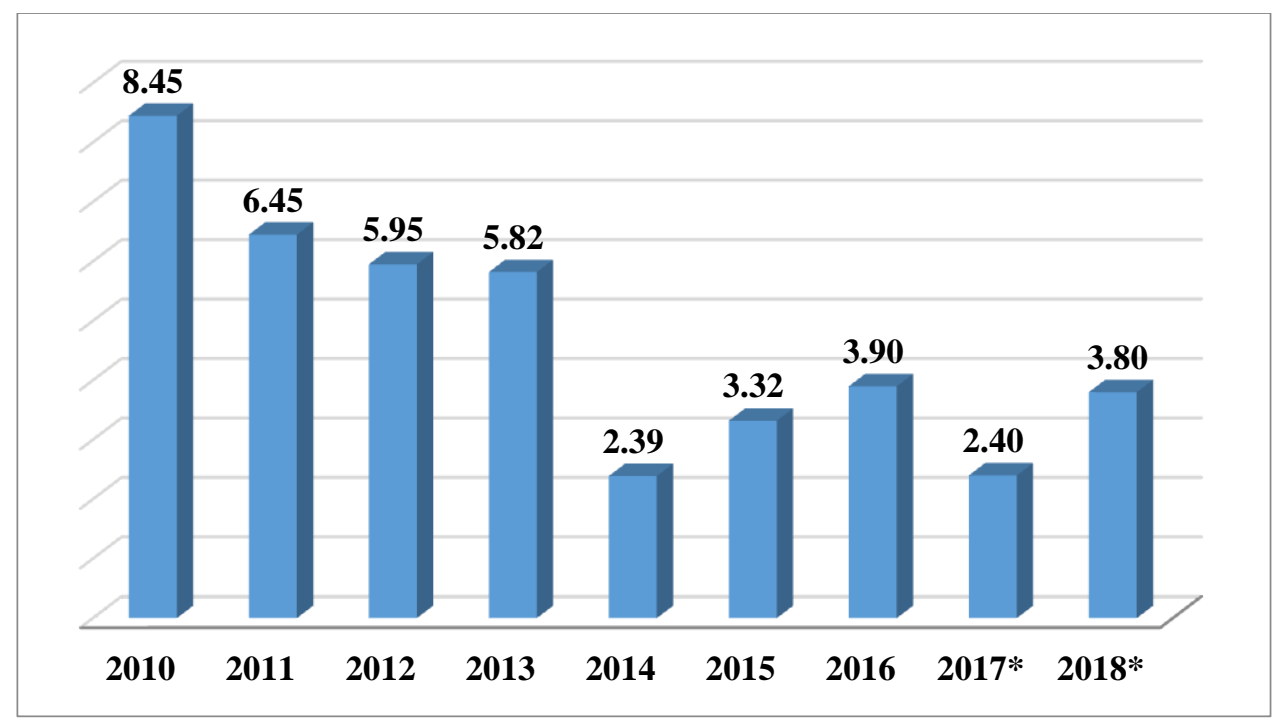

Figura 2. Evolución del PBI Anual (Variación porcentual)-Perú. Tomado de "Perú Económico en el 2018," por Julio Durand Carrión - La Cátedra del Consumidor, 2018. Recuperado de http://blog.pucp.edu.pe/blog/competenciayconsumidor/2018/01/23/peru-economico-en-el-2018analisis-de-la-economia-peruana-a-enero-de-2018/

El Banco Mundial para inicios del 2017 mantuvo una estimación de crecimiento del PBI 3.8 por ciento, sin embargo, tras el fenómeno de El niño costero y la incertidumbre política (Lava Jato) estas cifras se redujeron a las estimadas, llegando al 2.8 por ciento, a pesar de ello se estima un crecimiento económico del PBI en 3.8\% para el 2018 (ver Tabla 8), cifra menores a los estimados por Banco Central de Reserva (BCR) y el Ministerio de Economía y Finanzas (MEF), en 4.2\% y 4\%, respectivamente. (Semana Economica.com, 2018) 
Tabla 8

Pronostico del Crecimiento Económico para los Países de América Latina y el Caribe (Variación porcentual anual, a menos que se indique otra cosa)

\begin{tabular}{lrrrrrr}
\hline & $\mathbf{2 0 1 5}$ & $\mathbf{2 0 1 6}$ & $\mathbf{2 0 1 7 e}$ & $\mathbf{2 0 1 8} \mathbf{2 0 1 9}$ & $\mathbf{2 0 2 0 p}$ \\
\hline PIB a precios de mercado (USD de 2010) & & & & & & \\
Agentina & 2,6 & $-2,2$ & 2,7 & 3,0 & 3,0 & 3,2 \\
Belice & 2,9 & $-0,8$ & 0,8 & 2,2 & 1,7 & 1,7 \\
Bolivia & 4,9 & 4,3 & 3,9 & 3,8 & 3,4 & 3,3 \\
Brasil & $-3,5$ & $-3,5$ & 1,0 & 2,0 & 2,3 & 2,5 \\
Chile & 2,3 & 1,6 & 1,7 & 2,4 & 2,7 & 2,8 \\
Colombia & 3,1 & 2,0 & 1,8 & 2,9 & 3,4 & 3,4 \\
Costa Rica & 4,7 & 4,3 & 3,9 & 3,6 & 3,5 & 3,5 \\
Ecuador & 0,2 & $-1,5$ & 1,4 & 0,8 & 0,9 & 1,0 \\
El Salvador & 2,3 & 2,4 & 2,1 & 1,8 & 1,8 & 1,9 \\
Granada & 6,2 & 3,9 & 2,4 & 2,2 & 2,1 & 2,1 \\
Guatemala & 4,1 & 3,1 & 3,2 & 3,4 & 3,5 & 3,5 \\
Guyana & 3,1 & 3,4 & 2,9 & 3,8 & 3,7 & 3,7 \\
Haiti & 1,2 & 1,4 & 1,1 & 2,2 & 2,5 & 2,5 \\
Honduras & 3,6 & 3,6 & 4,1 & 3,6 & 3,5 & 3,5 \\
Jamaica & 0,9 & 1,4 & 1,4 & 1,8 & 2,0 & 2,0 \\
México & 3,3 & 2,9 & 1,9 & 2,1 & 2,6 & 2,6 \\
Nicaragua & 4,9 & 4,7 & 4,5 & 4,4 & 4,4 & 4,4 \\
Panamá & 5,8 & 4,9 & 5,5 & 5,6 & 5,6 & 5,7 \\
Paraguay & 3,0 & 4,0 & 3,8 & 4,0 & 4,0 & 4,0 \\
Perú & $\mathbf{3 , 3}$ & $\mathbf{4 , 0}$ & $\mathbf{2 , 6}$ & $\mathbf{3 , 8}$ & $\mathbf{3 , 8}$ & $\mathbf{4 , 0}$ \\
República Dominicana & 7,0 & 6,6 & 4,5 & 4,9 & 4,7 & 4,7 \\
San Vicente y las Granadinas & 1,4 & 1,9 & 2,5 & 2,7 & 2,8 & 2,8 \\
Santa Lucía & 2,0 & 0,9 & 2,0 & 2,2 & 1,8 & 1,8 \\
Suriname & $-2,7$ & $-5,1$ & 0,0 & 2,2 & 1,2 & 1,2 \\
Trinidad y Tobago & $-0,6$ & $-5,4$ & $-3,2$ & 1,9 & 2,2 & 1,6 \\
Uruguay & 0,4 & 1,5 & 2,5 & 2,8 & 3,2 & 3,2 \\
Venezuela, Rep. Bol. De & $-8,2$ & $-16,1$ & $-11,9$ & $-4,2$ & 0,6 & 0,9 \\
\hline & & & & & & 3,0
\end{tabular}

Nota. Adaptado de "Banco Mundial mantuvo estimado en el 2018: PBI del Perú crecería 3,8\% este año,” por Banco Mundial en Perú, 2018, Journal SEMANAEconómica.com, (p. 1).

PBI por actividades

El sector Educativo se encuentra en el rubro de actividades de OTROS SERVICIOS, la misma que creció 3.7\% respecto al periodo del año anterior (ver Tabla 9), se explica por la mayor demanda de los servicios de salud y educación privada por parte de los hogares y las instituciones. Así también, los servicios inmobiliarios aumentaron en 0,4\%. Al cuarto trimestre de 2017, el valor agregado bruto de la actividad otros servicios crecieron en 3,8\% (INEI, 2018, p.9, p.24) 
Tabla 9

Perú: Producto Bruto Interno (Variación porcentual del índice de volumen físico respecto al mismo periodo del año anterior). Año Base 2007=100

\begin{tabular}{|c|c|c|c|c|c|c|c|c|c|c|}
\hline \multirow{2}{*}{ Actividad } & \multicolumn{5}{|c|}{$2016 / 2015$} & \multicolumn{5}{|c|}{$2017 / 2016$} \\
\hline & I Trim. & \| Trim. \| & II Trim. & IV Trim. & Año & I Trim. & II Trim. I & III Trim. I & IV Trim. & Año \\
\hline Economía Total (PBI) & 4,5 & 4,0 & 4,4 & 3,0 & 4,0 & 2,3 & 2,6 & 2,9 & 2,2 & 2,5 \\
\hline Agricultura, ganadería, caza y silvicultura & 2,6 & 1,8 & 2,2 & 3,7 & 2,5 & $-0,4$ & 0,5 & 7,0 & 4,0 & 2,6 \\
\hline Pesca y acuicultura & 1,8 & $-56,0$ & 71,5 & 31,1 & $-9,0$ & 36,9 & 124,5 & $-44,5$ & $-51,4$ & 4,7 \\
\hline Extracción de petróleo, gas y minerales & 11,7 & 19,7 & 12,8 & 7,1 & 12,6 & 4,2 & 1,9 & 4,1 & 2,6 & 3,2 \\
\hline Manufactura & $-1,3$ & $-5,5$ & 2,4 & 2,3 & $-0,6$ & 2,3 & 4,5 & $-1,8$ & $-5,5$ & $-0,3$ \\
\hline Electricidad, gas y agua & 10,7 & 7,5 & 6,8 & 5,9 & 7,7 & 1,0 & 1,6 & 1,6 & 0,2 & 1,1 \\
\hline Construcción & 2,9 & 1,8 & $-3,5$ & $-9,2$ & $-2,5$ & $-5,0$ & $-2,7$ & 6,2 & 9,1 & 2,2 \\
\hline Comercio & 3,9 & 3,4 & 2,4 & 1,9 & 2,8 & 0,3 & 1,0 & 1,4 & 1,7 & 1,1 \\
\hline Transporte, almacenamiento, correo y mensajería & 4,3 & 3,5 & 3,7 & 3,6 & 3,8 & 2,5 & 3,0 & 2,0 & 4,2 & 2,9 \\
\hline Alojamiento y restaurantes & 3,1 & 2,8 & 2,9 & 2,5 & 2,8 & 0,8 & 1,3 & 1,4 & 1,7 & 1,3 \\
\hline Telecomunicaciones y otros servicios de información & 8,4 & 11,4 & 7,6 & 7,9 & 8,8 & 8,8 & 6,6 & 8,9 & 7,8 & 8,0 \\
\hline Servicios financieros, seguros y pensiones & 8,6 & 6,6 & 5,0 & 1,0 & 5,4 & $-0,3$ & 0,5 & 1,8 & 2,9 & 1,2 \\
\hline Servicios prestados a las empresas & 3,3 & 2,4 & 2,5 & 1,9 & 2,5 & 0,8 & 0,2 & 1,6 & 1,9 & 1,1 \\
\hline Administración pública y defensa & 4,4 & 4,4 & 4,3 & 3,9 & 4,3 & 3,4 & 3,6 & 3,9 & 3,7 & 3,7 \\
\hline Otros servicios & 4,3 & 4,4 & 4,1 & 4,0 & 4,2 & 3,9 & 3,9 & 3,7 & 3,7 & 3,8 \\
\hline Total Industrias (VAB) & 4,6 & 4,1 & 4,4 & 2,9 & 4,0 & 2,1 & 2,6 & 2,7 & 2,0 & 2,4 \\
\hline Otros impuestos a los productos y DM & 3,3 & 3,0 & 3,9 & 4,4 & 3,6 & 4,2 & 2,5 & 5,5 & 4,6 & 4,2 \\
\hline
\end{tabular}

Nota. Cifras trimestrales ajustadas a las cuentas Nacionales Anuales. Adaptado de "Comportamiento de la Economía Peruana en el cuarto trimestre de 2017," por el Instituto Nacional de Estadística e Informática, 2017, (p. 9).

Recuperado de https://www.inei.gob.pe/media/MenuRecursivo/boletines/01-informe-tecnicon01_producto-bruto-interno-trimestral_-ivtrim2017.pdf

Las proyecciones relacionadas al crecimiento del PBI son vulnerables a lo siguiente:

- Confianza empresarial: se prevé que la confianza empresarial se mantenga dentro del tramo optimista en el horizonte de proyección.

- Inestabilidad política debido a la crisis política y cambio de gobierno

- Un gran porcentaje de la población sigue siendo vulnerable a los choques o remezones y podría volver a caer en la pobreza.

Oportunidad:

Las proyecciones del PBI para el año 2018 tienden a un crecimiento y mejora respecto a periodos pasados, el cierre del primer trimestre ha sido positivo con un 3.8 por ciento, los cambios suscitados no han tenido mayor impacto a pesar que se proyectaba inestabilidad o una crisis política, al contrario, se han recibido positivamente y se espera que sea un crecimiento sostenido y permanente con mayores beneficios para todos los peruanos; la 
oportunidad de enfrentar nuevos negocios en el sector donde se encuentra la educación privada por parte de hogares e instituciones es óptima gracias a la confianza empresarial que se viene mostrando.

Por otro lado, podemos ver que la Población Económicamente Activa (PEA) ocupada de Lima Metropolitana registró un crecimiento de 1,8 por ciento en el trimestre de agostooctubre (ver Figura 3), cifra menor a la registrada en los tres trimestres previos (Banco Central de Reserva del Perú [BCRP], 2017, p.41)

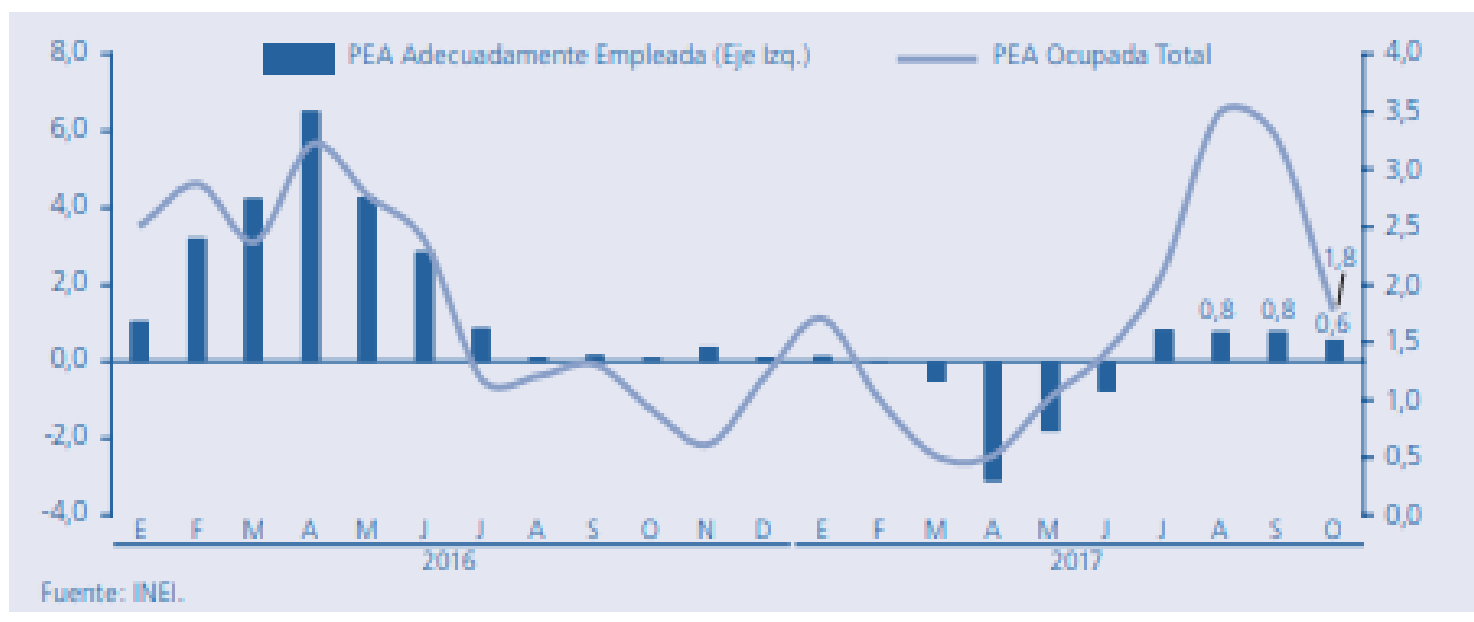

Figura 3. PEA Ocupada Total y Adecuadamente Empleada de Lima Metropolitana (Trimestre móvilVariaciones porcentuales doce meses). Tomado de "Reporte de Inflación, Panorama actual y proyecciones macroeconómicas 2017-2019," por el Banco Central de Reserva del Perú (BCRP), 2017. Recuperado de http://www.bcrp.gob.pe/docs/Publicaciones/ReporteInflacion/2017/diciembre/reporte-de-inflacion-diciembre-2017.pdf

De igual forma, el número de anuncios de empleo a través de páginas web (indicador alternativo construido por el BCRP); para el 2017 se ha visto volatibilidad en cuanto a los registros, se recupera incrementándose en julio e inicios de agosto, con bajas a mediados de agosto y setiembre, resultado que concuerda con la moderación del empleo y la evolución de la PEA ocupada de Lima Metropolitana; sin embargo en octubre vuelve a repuntar significativamente lo que haría pensar una mejor evolución del empleo para los próximos meses (BCRP, 2017, p.42)

Inflación

Con respecto a la inflación en el año del 2017 después de llegar a un punto máximo de 3.17 por ciento en agosto, este disminuyó a 1.54 por ciento en noviembre 2017 (ver Figura 4) debido a la reversión de los choques de oferta asociados a fenómenos climatológicos (déficit hídrico, finales del 2016 y el Fenómeno El Niño Costero a inicios del 2017). Así 
también, el precio del limón disminuyó 62,7 por ciento entre setiembre y noviembre, y los precios de la cebolla y la papa decrecieron 16,4 y 5,7 por ciento, respectivamente (BCRP, 2017, p.98-99)

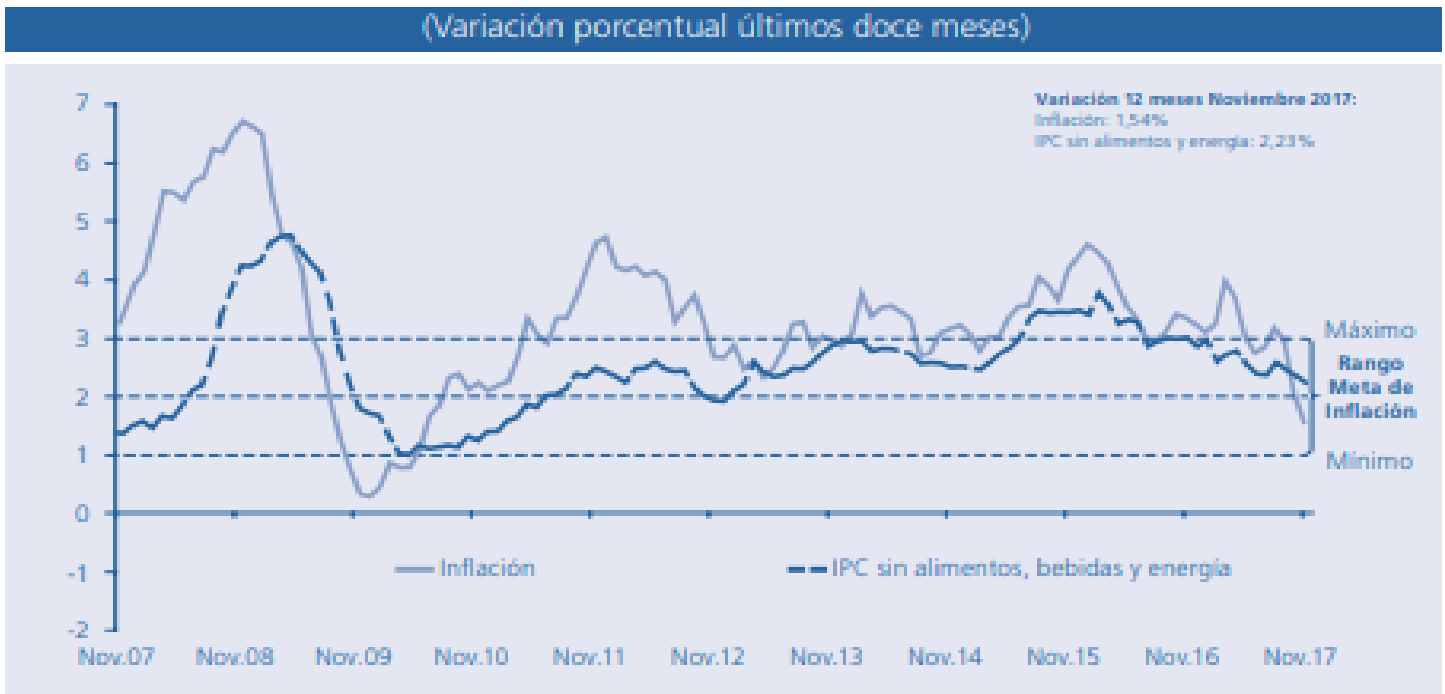

Figura 4. Inflación y Meta de Inflación. Tomado de "Reporte de Inflación, Panorama actual y proyecciones macroeconómicas 2017-2019," por el Banco Central de Reserva del Perú (BCRP), 2017. Recuperado de http://www.bcrp.gob.pe/docs/Publicaciones/ReporteInflacion/2017/diciembre/reporte-de-inflacion-diciembre-2017.pdf

A enero del 2018 el Perú fluctúa en un porcentaje de 1.37\% de inflación. Según el Banco Central de Reserva del Perú (BCR) se espera que este año la inflación sea de $2.0 \%$. Según el Ministerio de Economía y Finanzas en su artículo del 2016, en los próximos dos o tres años (2017-2019), se espera que el inicio de la fase de producción de proyectos mineros a gran escala y la mayor inversión pública y privada en proyectos de infraestructura refuerce la demanda agregada. Además, el país seguirá impulsando reformas estructurales, garantizando con ello la confianza de los inversionistas privados.

Asimismo, la misma fuente afirma que para sostener un crecimiento económico en el mediano plazo mayor al 4,0\%, potencial de crecimiento actual, es imprescindible continuar las reformas estructurales ya iniciadas en la administración de Kuczynski, la misma que deben ser continuadas por el actual presidente de la Republica Martín Vizcarra: capital humano (educación, salud y servicio civil), infraestructura, diversificación productiva, simplificación administrativa e inclusión social. Asimismo, dichas reformas deben ser complementadas con nuevas reformas como la laboral o el proceso de descentralización, entre otras. 
Oportunidad: Con respecto al análisis económico y la relación con el presente proyecto, este tendría con un impacto positivo, a pesar de la crisis política, dado que el gobierno actual está realizando una reestructuración del aparato público y fiscal; así como el destrabe de proyectos y el impulso a las inversiones, lo que resultará en una aceleración del consumo privado y por ello mejores condiciones en el mercado laboral a hombres y mujeres que llevará al incremento de la demanda y la oportunidad de abrirse en el mercado para un servicio como el que el proyecto ofrece.

\subsubsection{Análisis social.}

Como es de conocimiento, el Perú está formado por 24 departamentos; ubicándose en el departamento de Lima, la ciudad de Lima, capital que concentra el 35.1\% del total de la población del país (Compañía Peruana de Estudios de Mercado y Opinión Pública SAC [CPI], 2017) y de acuerdo a un análisis del ranking de las 100 empresas más grandes del Perú de Merco (Monitor Empresarial de Reputación Corporativa) hemos podido comprobar que las oficinas principales de 97 de ellas se encuentran ubicadas en la ciudad de Lima, 39 en el distrito de San Isidro y 4 en Santa Catalina La Victoria

Asimismo, los hogares ubicados en Lima Metropolitana han sido distribuidos por Niveles Socioeconómicos (NSE) A, B, C, D, E; siendo A el NSE con mayores ingresos y E el NSE con menores ingresos. A continuación, se muestra en la Figura 5 la Distribución de Hogares según NSE 2015 - Lima Metropolitana.

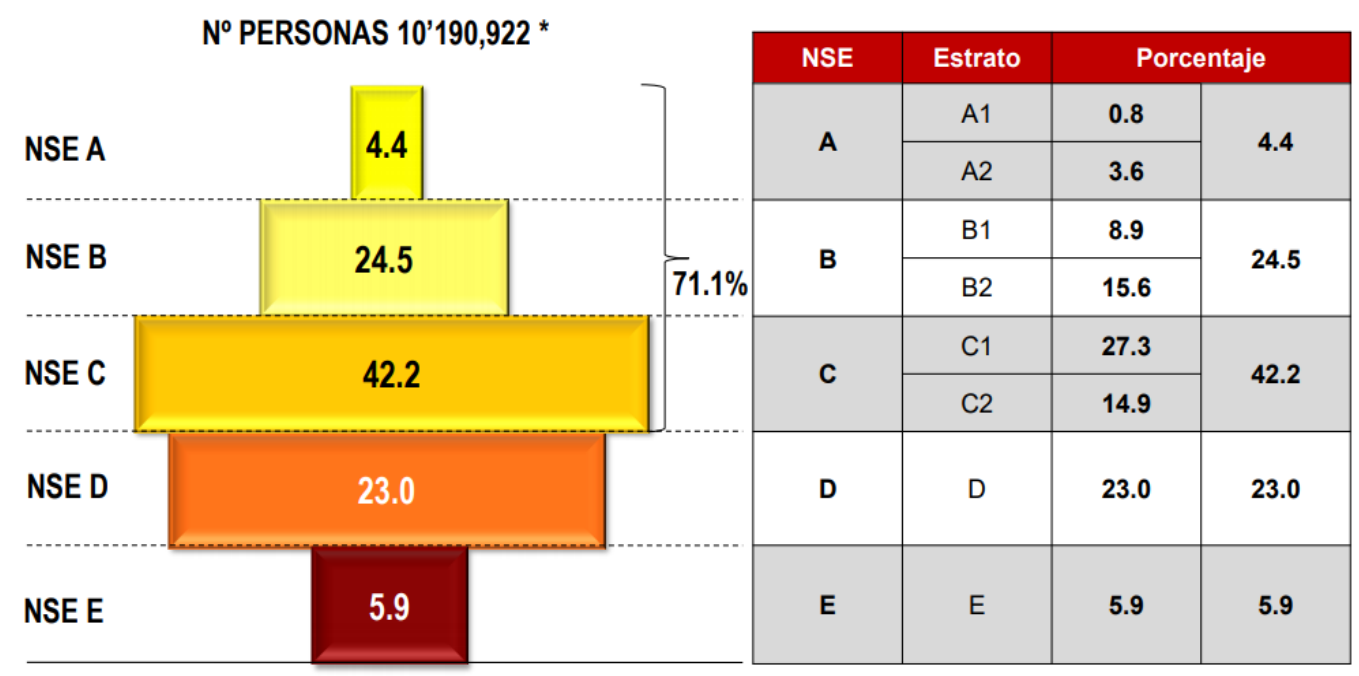

Figura 5. Distribución de hogares según NSE 2017 - Lima Metropolitana. Tomado de Niveles Socioeconómicos 2017 de la Asociación Peruana de Empresas de Investigación de Mercados (APEIM), agosto 2017. Recuperado de http://www.apeim.com.pe/wpcontent/themes/apeim/docs/nse/APEIM-NSE-2017.pdf. 
Como se observa los NSE B1 y B2 contiene al 24.5\% de los hogares que conforman Lima Metropolitana, lo cual permite identificar a este NSE como el target del proyecto a desarrollar, ya que gozan de ingresos más altos por lo que el costo de oportunidad de dejar de trabajar para cuidar a sus hijos es muy alto. Según el análisis esto representa una oportunidad para el proyecto.

A continuación, se muestra la Tabla 10 Con la Distribución de la PEA Ocupada, según sexo y nivel Educativo, $2001-2014$.

Tabla 10

Perú: Distribución de la PEA Ocupada, según sexo y nivel educativo, 2001 - 2014

Porcentaje)

\begin{tabular}{|c|c|c|c|c|c|c|c|c|c|c|c|c|c|c|}
\hline $\begin{array}{c}\text { Sexo I } \\
\text { Nivel educativo }\end{array}$ & 2001 & 2002 & 2003 & 2004 & 2005 & 2006 & 2007 & 2008 & 2009 & 2010 & 2011 & 2012 & 2013 & 2014 \\
\hline \multicolumn{15}{|l|}{ Perủ total } \\
\hline Sin nivel & 6.8 & 6.8 & 6.5 & 6.4 & 6.0 & 5.5 & 4.9 & 4.9 & 4.8 & 4.6 & 4.4 & 3.8 & 3.8 & 3.7 \\
\hline Primaria & 32.2 & 31.1 & 30.4 & 29.1 & 29.1 & 28.2 & 26.6 & 25.7 & 25.3 & 24.8 & 24.2 & 23.0 & 23.1 & 23.1 \\
\hline Secundaria & 40.0 & 40.1 & 40.7 & 41.4 & 41.5 & 41.7 & 41.4 & 41.8 & 41.1 & 41.8 & 41.4 & 41.5 & 42.2 & 42.6 \\
\hline Superior no universitaria & 10.5 & 10.9 & 11.4 & 11.8 & 12.0 & 12.5 & 13.1 & 13.6 & 14.3 & 14.6 & 15.3 & 15.2 & 14.7 & 14.2 \\
\hline Superior universitaria & 10.4 & 11.1 & 11.0 & 11.3 & 11.4 & 12.1 & 14.0 & 14.0 & 14.6 & 14.2 & 14.6 & 16.5 & 16.2 & 16.3 \\
\hline Total relativo & 100.0 & 100.0 & 100.0 & 100.0 & 100.0 & 100.0 & 100.0 & 100.0 & 100.0 & 100.0 & 100.0 & 100.0 & 100.0 & 100.0 \\
\hline PEA ocupada (Miles de personas) & $11,862.2$ & $12,033.9$ & $12,837.3$ & $13,059.8$ & $13,120.4$ & $13,683.0$ & $14,197.2$ & $14,459.2$ & $14,757.7$ & $15,089.9$ & $15,307.3$ & $15,541.5$ & $15,683.6$ & $15,796.9$ \\
\hline \multicolumn{15}{|l|}{ Hombre } \\
\hline Sin nivel & 3.0 & 2.9 & 2.9 & 2.6 & 2.4 & 2.1 & 2.0 & 1.9 & 1.8 & 1.7 & 1.9 & 1.6 & 1.6 & 1.5 \\
\hline Primaria & 31.4 & 30.0 & 29.3 & 27.9 & 27.7 & 26.8 & 25.1 & 24.4 & 23.7 & 23.2 & 22.8 & 21.6 & 21.6 & 21.6 \\
\hline Secundaria & 44.1 & 45.1 & 45.4 & 45.5 & 46.4 & 45.8 & 45.6 & 45.6 & 45.5 & 46.0 & 45.5 & 45.8 & 46.5 & 47.4 \\
\hline Superior no universitaria & 10.1 & 10.6 & 10.7 & 11.8 & 11.6 & 12.7 & 12.5 & 13.6 & 14.0 & 14.2 & 14.7 & 14.5 & 14.2 & 13.7 \\
\hline Superior universitaria & 11.4 & 11.4 & 11.7 & 12.2 & 11.8 & 12.7 & 14.7 & 14.5 & 14.9 & 14.8 & 15.1 & 16.6 & 16.1 & 15.7 \\
\hline Total relativo & 100.0 & 100.0 & 100.0 & 100.0 & 100.0 & 100.0 & 100.0 & 100.0 & 100.0 & 100.0 & 100.0 & 100.0 & 100.0 & 100.0 \\
\hline PEA ocupada (Miles de personas) & $6,866.5$ & $6,958.0$ & $7,270.7$ & $7,418.1$ & $7,483.2$ & $7,775.8$ & $7,989.9$ & $8,149.9$ & $8,269.6$ & $8,425.8$ & $8,553.8$ & $8,719.6$ & $8,795.1$ & $8,881.0$ \\
\hline \multicolumn{15}{|l|}{ Mujer } \\
\hline Sin nivel & 120 & 12.2 & 11.3 & 11.4 & 10.7 & 9.9 & 8.7 & 8.8 & 8.5 & 8.3 & 7.6 & 6.7 & 6.6 & 6.6 \\
\hline Primaria & 33.4 & 32.5 & 31.9 & 30.7 & 31.0 & 30.2 & 28.4 & 27.4 & 27.2 & 26.7 & 26.0 & 24.9 & 25.0 & 25.1 \\
\hline Secundaria & 34.3 & 33.2 & 34.6 & 35.9 & 35.0 & 36.4 & 35.9 & 36.8 & 35.5 & 36.5 & 36.3 & 36.0 & 36.8 & 36.3 \\
\hline Superior no universitaria & 11.1 & 11.4 & 12.3 & 11.7 & 12.5 & 12.2 & 13.9 & 13.6 & 14.5 & 15.1 & 16.0 & 16.1 & 15.3 & 14.8 \\
\hline Superior universitaria & 9.2 & 10.7 & 10.0 & 10.3 & 10.8 & 11.4 & 13.1 & 13.3 & 14.2 & 13.5 & 14.1 & 16.3 & 16.4 & 17.1 \\
\hline Total relativo & 100.0 & 100.0 & 100.0 & 100.0 & 100.0 & 100.0 & 100.0 & 100.0 & 100.0 & 100.0 & 100.0 & 100.0 & 100.0 & 100.0 \\
\hline PEA ocupada (Miles de personas) & $4,995.7$ & $5,075.9$ & $5,566.6$ & $5,641.7$ & $5,637.2$ & $5,907.2$ & $6,207.2$ & $6,309.3$ & $6,488.1$ & $6,664.1$ & $6,753.5$ & $6,821.9$ & $6,888.5$ & $6,915.9$ \\
\hline
\end{tabular}

Nota. Perú: Recuperado de Distribución de la PEA Ocupada, Según Sexo y Nivel Educativo, 2001 2014 (Porcentaje). Recuperado de

http://www.trabajo.gob.pe/archivos/file/estadisticas/peel/estadisticas/oferta_laboral/sexo/2014/peru_to tal_sexo_007_2001-2014.pdf

En la Tabla 10 se puede apreciar que la PEA ocupada conformada por mujeres con educación superior universitaria ha ido incrementándose a lo largo de los años. Lo cual evidencia que en la actualidad la mujer peruana (especialmente las que conforman los NSE destacados en el párrafo anterior) ha optado por desarrollarse profesionalmente y por encontrar un lugar dentro del mundo laboral, esto ha contribuido a que desempeñe un papel muy importante en la economía del hogar, ya que el sueldo que esta percibe forma parte del 
presupuesto familiar, por lo que difícilmente se puede prescindir de este ingreso. Según el análisis esto representa una oportunidad para el proyecto.

Por lo expuesto en los párrafos anteriores, la necesidad de generar un mayor ingreso económico que le permita a la familia tener un mejor estilo de vida en el creciente desarrollo sociocultural y económico de los últimos años, ligado a una mayor necesidad de liberación de tiempo y responsabilidades en el hogar que permitan potenciar y fortalecer el crecimiento profesional de la mujer; han propiciado la necesidad de tener que buscar alternativas respecto al cuidado de sus hijos pequeños. Lo cual representa una oportunidad para el proyecto.

Por otro lado, es preciso destacar que según los resultados del último estudio de la Organización para la Cooperación y Desarrollo Económicos (OCDE) basado en la prueba del Programa para la Evaluación Internacional de los Alumnos (PISA, por sus siglas en inglés) aplicada el 2015, el Perú ocupa el último lugar de Sudamérica en comprensión lectora y ciencia y el penúltimo lugar en matemáticas; por lo que resulta urgente contribuir con el desarrollo de las habilidades necesarias para que los infantes puedan aprender a leer.

A continuación, se muestra en la Figura 6 los resultados de la evaluación de la OCDE, donde se puede apreciar los resultados obtenidos por Perú.

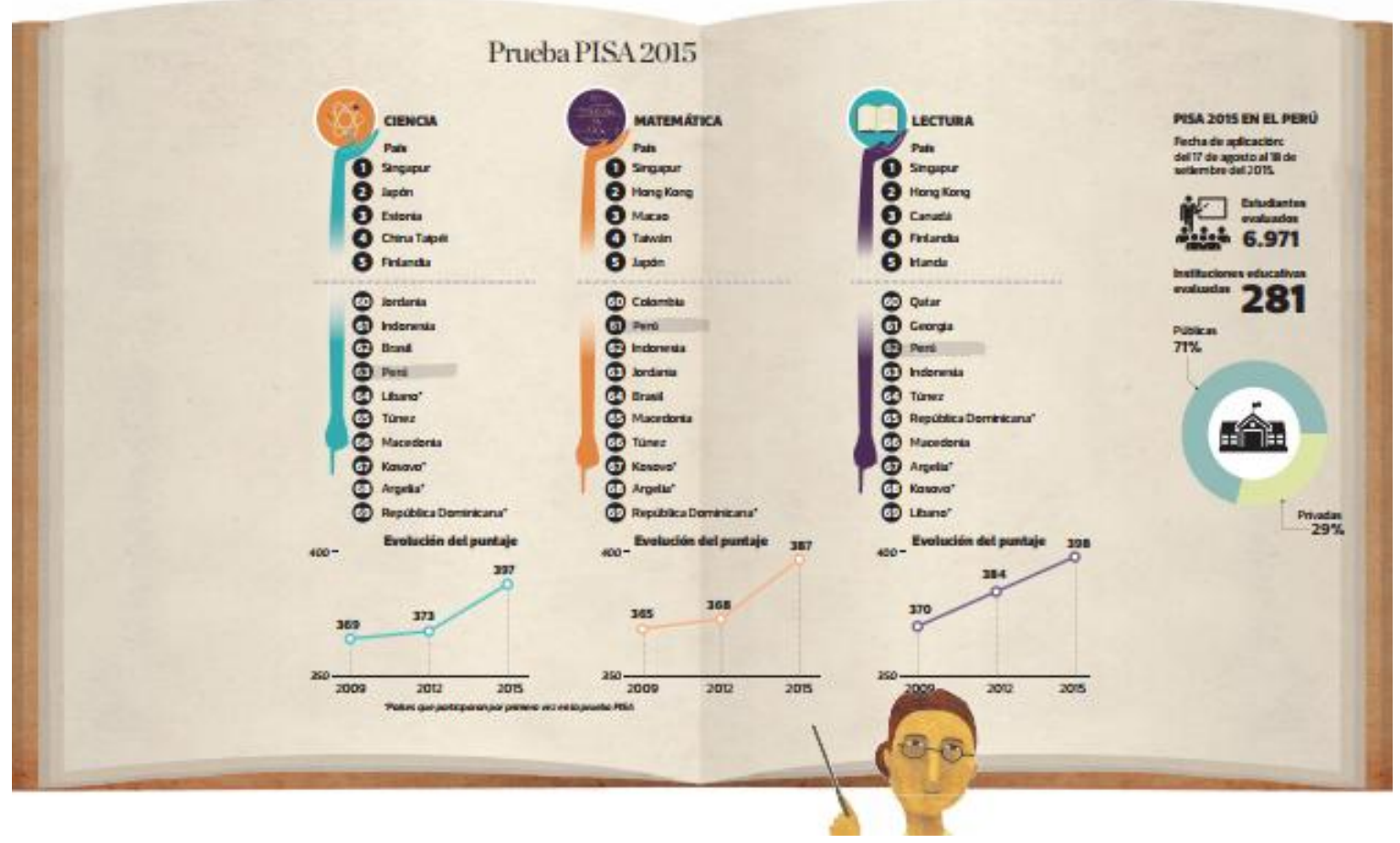

Figura 6. Evaluación OCDE. Tomado de "Perú sale del último lugar en la prueba PISA 2015" de Diario El comercio, 2016. Recuperado de https://elcomercio.pe/peru/peru-sale-lugar-prueba-pisa2015-152124 
Por lo expuesto en los párrafos anteriores ha surgido la necesidad de desarrollar en las cuna y guardería, la estimulación temprana de las habilidades blandas y cognitivas; asimismo es preciso destacar que las cunas y guarderías son lugares que están reguladas por el Ministerio de Educación, donde los padres pueden dejar a sus hijos con la tranquilidad y certeza que estos serán atendidos por personal capacitado y que a su vez le ayudarán a desarrollar diversas habilidades que faciliten el aprendizaje de los niños en la etapa escolar.

Así también, representa una oportunidad para el proyecto dado que en la sociedad actual la mujer juega un papel muy importante para la economía del hogar, adicionalmente valora mucho su desarrollo profesional y no está dispuesta o no puede prescindir de sus ingresos y dejar de trabajar para cuidar a sus hijos, por lo tanto, necesita de terceros que estén dispuestos a ayudarla en esa labor. Por otro lado, el cuidado de la primera infancia es muy importante porque es la etapa donde los niños forman las bases de las habilidades blandas y cognitivas que le permitirán tener un mejor desempeño en la edad escolar, por ello acompañar el cuidado de los niños con un programa de estimulación temprana resulta muy atractivo.

\subsubsection{Análisis legal y tributario}

Las instituciones educativas que presten servicio educativo público o particular gozan de algunas exoneraciones tributarias, como las que se encuentran inafectos al pago del impuesto general a las ventas - IGV, actualmente está gravado con el 18\% sobre las ventas en otros sectores; así también exonerado del impuesto a la Renta por la reinversión de utilidades. El sector educativo en el Perú es regulado y reglamentado bajo la jurisdicción del Ministerio de Educación - MINEDU.

Oportunidad:

Los beneficios de carácter tributario aplicados al sector educación, generan una oportunidad de negocio competitivo y eficiente ya que la exoneración de ciertos impuestos y tributos municipales permiten que las instituciones educativas puedan mejorar y expandir su oferta, de tal manera que al ingresar al mercado generen mayores beneficios a través de la venta de sus productos o servicios.

Ley General de Educación - Ley Nro. 28044 (Apéndice A)

Fue aprobada por unanimidad y promulgada como ley el 28 de julio de 2003 . La presente ley tiene por objeto establecer los lineamientos generales de la educación y del Sistema Educativo Peruano, las atribuciones y obligaciones del Estado y los derechos y responsabilidades de las personas y la sociedad en su función educadora. Rige todas las 
actividades educativas realizadas dentro del territorio nacional, desarrolladas por personas naturales o jurídicas, públicas o privadas, nacionales o extranjeras. (Minedu, 2003, p.1).

Oportunidad: La importancia de tener una ley que fortalezca los principios y lineamientos establecidos con el fin de salvaguardar el cumplimiento del proyecto educativo en cada uno de sus niveles, hace posible la oportunidad en el mejoramiento de la calidad y equidad de la educación.

Reglamento de la Ley N N $^{\mathrm{2}} 2044$, Ley General de Educación (aprobado por Decreto Supremo Nº11-2012-ED) (Minedu, n.d) - (Apéndice B)

El presente Reglamento desarrolla las disposiciones, criterios, procesos y procedimientos contenidos en la Ley No 28044, Ley General de Educación, que establece los lineamientos generales de la educación y del Sistema Educativo Peruano y regula las atribuciones y obligaciones del Estado, así como los derechos y responsabilidades de las personas y la sociedad en su función educadora.

Normas sobre organización y funcionamiento de las Cunas de Educación Inicial - Directiva No 073-2006-DINEBR-DEI. (Minedu, 2006) - (ver Apéndice C)

Establecer las normas y procedimientos sobre la planificación, organización, ejecución y evaluación de las acciones técnico-pedagógicas y de gestión de las Cunas de Educación Inicial. La Cuna, para el logro de sus fines y objetivos coordina con los programas dirigidos a la primera infancia que desarrollan el Ministerio de Educación, Ministerio de Salud, Ministerio de la Mujer y Desarrollo Social e instituciones relacionadas con la prestación de servicios de salud, nutrición, seguridad y saneamiento ambiental en pro del desarrollo integral de la niñez.

La Cuna es una institución educativa escolarizada del primer ciclo del nivel de Educación Inicial de la Educación Básica Regular (EBR) que brinda un servicio de carácter integral para la primera infancia desde los 90 días hasta los 2 años 11 meses de edad, con la finalidad de ofrecerles la posibilidad de desarrollarse en forma adecuada y oportuna respetando su nivel de madurez.

Oportunidad: Contar con una normativa para la organización y funcionamiento de cunas en el primer nivel educativo genera una oportunidad de ingresar al mercado con los estándares adecuados, seguros y formalmente constituido.

\subsubsection{Análisis tecnológico.}

Es sabido que en la actualidad la tecnología avanza a pasos acelerados, estos avances han contribuido a mejorar la vida del ser humano en muchos aspectos, para efectos de la 
presente tesis se va a profundizar en los avances tecnológicos relacionados a la comunicación y seguridad, debido a que el proyecto plantea ofrecer un sistema de videovigilancia a través de cámaras IP.

El internet es una herramienta muy valiosa para la interconexión y transmisión de datos al que se puede acceder de diversos dispositivos, tales como computadoras, laptops, teléfonos celulares inteligentes, tabletas. Según el INEI (2018) en el último trimestre del 2017, los hogares que tienen el servicio de internet ascienden a $29.5 \%$, este porcentaje se incrementa al 57.6\% si se considera únicamente a Lima Metropolitana. Asimismo, a población usuaria de internet en Lima Metropolitana representó 74.1\%.

La empresa mexicana TVC En Linea.com, especializada en brindar soluciones en seguridad, define sobre las cámaras IP lo siguiente:

Una Cámara IP (también conocidas como cámaras Web o de Red) son videocámaras especialmente diseñadas para enviar las señales (video, y en algunos casos audio) a través de Internet desde un explorador (por ejemplo, el Internet Explorer) o a través de concentrador (un HUB o un SWITCH) en una Red Local (LAN).

En las cámaras IP pueden integrarse aplicaciones como detección de presencia (incluso el envío de mail si detectan presencia), grabación de imágenes o secuencias en equipos informáticos (tanto en una red local o en una red externa (WAN), de manera que se pueda comprobar por qué ha saltado la detección de presencia y se graben imágenes de lo sucedido. (p.1)

Se deduce que a través de cualquier dispositivo que pueda conectarse a internet una persona puede ver a través de una cámara IP lo que sucede en cualquier lugar del mundo, siempre y cuando tenga los accesos a la dirección IP; para el proyecto esto se convierte en una oportunidad ya que es en una medida de seguridad y a la vez en una herramienta que permite generar confianza con los padres ya que estos tienen la posibilidad de ver en tiempo real los cuidados que reciben sus hijos y las actividades que realizan.

\subsubsection{Análisis ecológico.}

En el artículo Educación y huella ecológica de la revista Electrónica Actualidades Investigativas en Educación de Martínez Castillo, R. del 2008 refiere lo siguiente:

Los ecosistemas del mundo están siendo degradados a una velocidad sin precedentes en la historia humana. De ahí que el estudio de la problemática socioambiental es una necesidad dentro de las ciencias pedagógicas, por eso se analiza el concepto, sus causas y características. Al respecto, la huella ecológica debe examinar la estructura socioeconómica y política de los seres humanos en tanto que esta afecta a los 
ecosistemas y la misma sociedad. La dominación interna/externa a que está sometida nuestra realidad, impide el surgimiento de toda conciencia crítica. (p. 1)

En ese sentido, es deber de los seres humanos preocuparse por el medio ambiente; se debe pensar no solo en un trabajo de corrección sino también de control y sobre todo prevención, para ello es importante educar a los pequeños a respetar el medio ambiente y enseñarles a usar apropiadamente los recursos naturales y a manejar los residuos para reciclar. Este punto representa una oportunidad para el proyecto ya que permite contribuir con el cuidado del medio ambiente y además reducir costos.

Por otro lado, se han lanzado alertas mundiales sobre el uso de plomo en la fabricación de juguetes, accesorios para bebes e infantes, pinturas, útiles de escritorio entre otros artículos fabricados en China, según un estudio realizado por Greenpeace (2011) alrededor de un $30 \%$ de los juguetes chinos han mostrado altos niveles de metales pesados. En una nota descriptiva publicada por la Organización Mundial de la Salud OMS (2017) dice lo siguiente sobre los Efectos de la intoxicación por plomo en la salud de los niños:

El plomo tiene graves consecuencias en la salud de los niños. Si el grado de exposición es elevado, ataca al cerebro y al sistema nervioso central, pudiendo provocar coma, convulsiones e incluso la muerte. Los niños que sobreviven a una intoxicación grave pueden padecer diversas secuelas, como retraso mental o trastornos del comportamiento.

Se ha comprobado además que, en niveles de exposición más débiles sin síntomas evidentes, antes considerados exentos de riesgo, el plomo puede provocar alteraciones muy diversas en varios sistemas del organismo humano. En los niños puede afectar, en particular, al desarrollo del cerebro, lo que a su vez entraña una reducción del cociente intelectual, cambios de comportamiento, por ejemplo, disminución de la capacidad de concentración y aumento de las conductas antisociales- y un menor rendimiento escolar.

La exposición al plomo también puede causar anemia, hipertensión, disfunción renal, inmunotoxicidad y toxicidad reproductiva. Se cree que los efectos neurológicos y conductuales asociados al plomo son irreversibles.

Este punto representa una amenaza la cual puede ser controlada si se hace una adecuada evaluación de calidad de los productos antes de la compra y se trabaja con proveedores formales y que puedan ofrecer garantías a través de certificados de calidad. (p. 1) 
Por lo expuesto en los párrafos anteriores, es necesario crear conciencia sobre el cuidado del medio ambiente desde la primera infancia, se puede contribuir con el medio ambiente trabajando la prevención a partir de las actividades más cotidianas; asimismo es importante cuidar la salud de los niños evitando la exposición de estos a artículos contaminados que generalmente son fabricados bajo pésimos controles de calidad.

\subsection{Oportunidades}

Luego del análisis PESTEL realizado, se han encontrado Oportunidades que influyen sobre el proyecto, los cuales se detallan a continuación:

Político-Gubernamental: La política adoptada por el nuevo Ministro de Educación, el de continuar las políticas emprendidas en el sector y de puertas abiertas y dialogo a todos, resulta beneficioso para el proyecto, dado que se mantendría la norma establecida y ratificada con Resolución Ministerial 657-2017-Minedu (El Peruano, 2018, p.1), donde establece los lineamientos para el desarrollo del año escolar 2018 y la edad cronológica donde los menores deberán cumplir 3,4 y 5 años antes del 31 de marzo para ingresar al nivel inicial. Esto permitirá que padres con ocupación laboral permanente busquen alternativas como nidos y guarderías para el cuidado y aprendizaje de niños menores de 3 años.

Económico: Las proyecciones del PBI para el año 2018 tienden a un crecimiento y mejora respecto a periodos pasados, el cierre del primer trimestre ha sido positivo con un 3.8 por ciento, los cambios suscitados no han tenido mayor impacto a pesar de proyectarse inestabilidad o una crisis política, al contrario, se han recibido positivamente y se espera que sea un crecimiento sostenido y permanente con mayores beneficios para todos los peruanos; la oportunidad de enfrentar nuevos negocios en el sector donde se encuentra la educación privada por parte de hogares e instituciones es óptima gracias a la confianza empresarial que se viene mostrando.

Con respecto al análisis económico y la relación con el presente proyecto, este tendría un impacto positivo, a pesar de la crisis política, dado que el gobierno actual está realizando una reestructuración del aparato público y fiscal; así como el destrabe de proyectos y el impulso a las inversiones, lo que resultará en una aceleración del consumo privado y por ello a mejores condiciones en el mercado laboral a hombres y mujeres que llevará al incremento de la demanda y la oportunidad de abrirse en el mercado para un servicio como el que el proyecto ofrece.

Análisis Social: Las mujeres peruanas especialmente del nivel socioeconómico B, se preocupan más por su desarrollo profesional y consecuentemente tiene acceso a mayores y 
mejores oportunidades de empleo. El sueldo percibido por la mujer constituye parte del presupuesto familiar, por lo que el hogar no puede prescindir de ese ingreso. Este comportamiento genera una oportunidad al negocio ya que requerirá contar con un tercero para el cuidado de sus niños.

Legal y Tributario: Los beneficios de carácter tributario aplicados al sector educación, generan una oportunidad de negocio competitivo y eficiente ya que la exoneración de ciertos impuestos y tributos municipales permiten que las instituciones educativas puedan mejorar y expandir su oferta, de tal manera que al ingresar al mercado generen mayores beneficios a través de la venta de sus productos o servicios.

La importancia de tener una ley que fortalezca los principios y lineamientos establecidos con el fin de salvaguardar el cumplimiento del proyecto educativo en cada uno de sus niveles hace posible la oportunidad en el mejoramiento de la calidad y equidad de la educación. Contar con una normativa para la organización y funcionamiento de cunas en el primer nivel educativo genera una oportunidad de ingresar al mercado con los estándares adecuados, seguros y formalmente constituido.

Análisis Tecnológico: La tecnología proporciona herramientas de seguridad como las Cámaras IP, las cuales son de bajo costo y fácil instalación, estas permiten generar confianza en los padres ya que pueden ver en tiempo real y a través de su computador, tableta y/o Smartphone los cuidados que reciben sus hijos y las actividades que estos reciben.

Ecológico: El cuidado del medio ambiente y el uso responsable de los recursos permiten al proyecto ser socialmente 


\section{Capítulo III: Estudio de Mercado}

\subsection{Descripción del servicio o producto}

Este estudio plantea la puesta en marcha de un negocio que ofrecerá el servicio de una Guardería Infantil para niños de 3 a 36 meses; propone la aplicación del método Glen Doman (véase la descripción en la página 3) como mecanismo de aprendizaje que permitirá a los infantes desarrollar habilidades cognitivas, los avances serán evaluados de acuerdo a los rangos de edad y los tópicos detallados en el apéndice $\mathrm{R}$.

La guardería ofrecerá un lugar seguro ya que el proyecto plantea las instalaciones de cámaras IP, lo que permitirá a los padres ver en tiempo real las actividades que desarrollan los menores y los cuidados que recibirán.

La guardería contara con una página Web de banda ancha en donde el público interesado podrá apreciar los servicios que ofrece la guardería, beneficios, instalaciones, ubicación y un servicio de blog para comentarios; asimismo, se registrara en Facebook para poder realizar publicidad por este medio.

\subsection{Selección del segmento de mercado}

Para la segmentación sociodemográfica en este proyecto se utilizaron habitantes del nivel socioeconómico B que comprenden personas, hombres o mujeres jefes de familia de 25 años a más responsables de decidir sobre el cuidado de sus hijos a terceros. Según las características económicas de esta clase tienen ingresos mensuales aproximados de $\mathrm{S} / 3,000$ a $\mathrm{S} / 5000$, la mayoría tiene grado universitario y empleo de forma dependiente e independiente. Respecto a la variable geográfica, se ha tomado la zona financiera del distrito de San Isidro perteneciente a Lima Moderna.

En cuanto al sector que nos dirigimos sobre los aspectos psicográficos, el mercado corresponde a personas con estilos de vida proactivos progresistas y modernas que buscan permanentemente el progreso personal familiar y que buscan les faciliten las tareas del hogar. A precios de Lima Metropolitana, el gasto real promedio per cápita mensual (a soles constantes) ha pasado de S/. 711 en el 2013 a S/. 732 en el 2017. (INEI, 2018, p.13)

\subsection{Investigación Cualitativa}

La investigación cualitativa se efectuará en dos partes, la primera constará del análisis de tres focus group, lo cual permitirá obtener información, comprender la actitud, motivación y percepción de nuestros servicios de guardería; y luego del análisis de dos entrevistas de especialistas para rescatar opiniones, sentimientos y valoraciones que tienen los expertos en 
el negocio y metodología. Se puede indicar que ambas herramientas son relevantes para la implementación del plan de negocios.

Para este punto, se determinaron los siguientes objetivos de estudio:

Focus Group: Exploratoria

El objetivo principal de este estudio es conocer las opiniones e intereses compartidos por los clientes potenciales de nuestro mercado. Asimismo, esta herramienta permitirá obtener información de actitudes, experiencias e incluso saber las expectativas de nuestros posibles clientes, así como la frecuencia y los hábitos de compra del servicio a ofrecer (véase Apéndice S). Se realizarán 3 focus group, los cuales estarán distribuidos según se muestra en la Tabla 11.

Tabla 11

Distribución Muestral Para el Focus Group

\begin{tabular}{|c|c|c|c|c|}
\hline FG & Target & Genero & Condición Muestral & Edad \\
\hline 1 & TG1 & Hombre/Mujer & $\begin{array}{l}\text { Personas que actualmente utilizan el servicio de } \\
\text { guardería. }\end{array}$ & 25 años a más \\
\hline 2 & TG2 & Hombre/Mujer & $\begin{array}{l}\text { Personas que no utilizan el servicio de guardería, } \\
\text { pero tienen la necesidad de encargar el cuidado de } \\
\text { sus hijos a terceros. }\end{array}$ & 25 años a más \\
\hline
\end{tabular}

Entrevistas en Profundidad

Esta herramienta tiene por objetivo rescatar opiniones y experiencias que tienen los especialistas en el negocio y el sector educativo, tales como: un educador académico, auxiliares, directores de la competencia, y un especialista en la metodología Doman.

\subsubsection{Proceso de muestreo}

La técnica utilizada en nuestro estudio es de muestreo no probabilístico por cuotas ya que la selección no se hará aleatoriamente, así también se considera una muestra por criterio y conveniencia ya que a los participantes se les escogerán con criterios previamente establecidos. Adicionalmente, se utilizó una muestra no probabilística por que no se cuenta con un marco muestral apropiado, también se decidió por temas de tiempo y costos de asumir una muestra probabilística.

Para el FOCUS GROUP, se procedió a elegir la muestra de tres (3) focus group de acuerdo con la población objetivo, de cinco a seis participantes por cada grupo quienes fueron prácticos en sus repuestas evitando obtener resultados limitados, sesgados o incompletos que lleguen a terminar en conclusiones erróneas. Los integrantes de los focus group han cumplido con las siguientes características: 
- No haber participado en otros focus group sobre el mismo objeto o problema (6 meses antes).

- No han trabajado o trabajan en agencias de investigación de mercado o familiares en dichos lugares.

Para la Entrevista en Profundidad; la condición muestral consiste en contar con personas expertas en el tema del sector educativo. Se eligió a la directora de una guardería y a un experto en el tema y aplicación de la metodología Doman.

\subsubsection{Diseño de Instrumento}

Herramienta necesaria que permite obtener información de acuerdo a los objetivos del proyecto. El diseño de instrumento se ha desarrollado tanto para el Focus Group como para las Entrevistas en Profundidad.

Focus Group

Se definió la Guía de Pautas (ver Apéndice D). Se buscó a través de la investigación cualitativa del focus group entender la concepción de un servicio de Guardería, conocer acerca de los hábitos de cuidado y tenencia del bebe, aspectos generales del mercado, competencia, intención y expectativas del servicio, metodología a aplicar, concepto y ubicación del proyecto, precios, comunicación, imagen y posicionamiento, así también encontrar diferencias, atributos valorados, así como identificar rechazo de experiencias por servicios insatisfechos. Posteriormente se evaluó el nivel de aceptación del servicio a brindar, así como recabar información que los clientes consideran se debe brindar.

Entrevistas en Profundidad

Se definió una Guía de Pautas (ver Apéndice E y F) con preguntas abiertas y recomendaciones que nos permitirán conocer los siguientes aspectos:

- Características del negocio.

- Debilidades y fortalezas del sector educativo a nivel de infantes

- Las preferencias de los padres con respecto a servicios en la zona.

- Las preferencias de los padres con respecto a servicios adicionales que brinda.

- Metodología o técnicas que aplican.

- Horarios estratégicos o establecidos por ley

- Opinión y/o sugerencia acerca de un proyecto de guardería en zonas aledañas a San Isidro. 
El instrumento se diseñó con preguntas abiertas, de tal manera que los participantes pudieran expresar completamente sus ideas y estos nos permitan conocer aspectos relevantes para nuestro estudio.

Cada focus group conto con un moderador, un equipo de grabación, incentivo para los participantes y bocaditos. Cada focus group duro 1 hora 40 minutos aproximadamente, en los cuales se obtuvieron las siguientes conclusiones que se detallan en el punto 3.3.3.

\subsubsection{Análisis y procesamiento de datos.}

Se realizaron 3 focus group con la población objetivo; se tomó como referencia dos grupos para personas que no utilizan el servicio de guardería, pero tienen la necesidad de encargar el cuidado de sus hijos a terceros, y otro grupo para personas que hicieron uso de una guardería y que al momento ya no lo realizan. Los focus group fueron grabados y luego transcritos, estos se encuentran en los Apéndices G, H, I.

Resultados del primer Focus Group

El primer focus group se realizó el 28 de marzo con la participación de 5 personas del NSE B siendo trabajadores que laboran en la zona financiera de San Isidro. Dentro de los puntos más importantes y enriquecedores para el focus group se han considerado los siguientes:

Acerca de los Hábitos de cuidado y tenencia del bebe

- Los participantes no cuentan con un lugar en donde dejar el cuidado de sus hijos, pero tienen a personas cercanas o familiares de confianza a quienes encargan y que luego los retribuyen económicamente.

- Existe otro grupo de participantes que no cuentan con familiares cercanos a quienes puedan encargar a su niño o si lo tienen, estos trabajan y tienen otras actividades o no tienen paciencia para cuidarlos.

- Frente a la experiencia de dejarlo a terceros; el desprendimiento de sus hijos es difícil, pero los padres tienen la necesidad de seguir trabajando y continuar con sus actividades de crecimiento profesional.

- Una de las dificultades que se presentan con el apoyo familiar, son los imprevistos o temas de salud de la persona que está al cuidado de sus hijos y no pueden cumplir, generando un problema para los padres, los cuales deben recurrir a permisos o ausencias en el ámbito laboral.

- Todos los participantes conocen guarderías cercanas a sus viviendas, pero por desconfianza no se animan a hacer uso de ellos dado las noticias negativas y la 
lejanía a sus trabajos.

- Las referencias que tienen sobre guarderías, es que en su mayoría son viviendas acondicionadas para este tipo de negocio, que acrecienta más su desconfianza e inseguridad, ya que el tener casas de dos plantas donde se comparte vivienda y negocio es altamente riesgoso y de mucho temor para los padres.

- No conocen algún lugar cercano a la zona de labores, pero se muestran interesados si se presentara algún lugar que le ofrezcan las condiciones necesarias.

Metodología Doman

- Los participantes no conocen la metodología Doman, pero ante la explicación muestran su interés de conocer cómo se aplica.

Proyecto Guardería

- A los Participantes les interesa la idea de una guardería cercana a sus labores, el contar con Cámaras IP les parece muy buena idea porque les daría tranquilidad y confianza del lugar. Sugieren la entrega de videos de las actividades semanales.

- Otros atributos que esperan encontrar en una guardería son los niveles de seguridad en sus instalaciones y una infraestructura adecuada para los infantes.

- Frente al miedo de dejar a sus hijos con terceros, esperan de una guardería que cuente con personas altamente capacitadas y que tengan mucha paciencia.

- Los participantes además de los cuidados y seguridad que el lugar debe poseer, les atrae la idea de la interacción social de sus hijos y que su desarrollo sea jugando y educando.

- A los participantes les interesa que la guardería cuente con servicios adicionales como: alimentación, psicología, enfermería, entrega o envío de videos de actividades semanales de sus menores hijos.

- Dentro de los puntos que mencionan de importancia, es el medio de comunicación con los profesores, que sea de forma rápida; así también conocer el desarrollo y otra información relevante de sus hijos por lo menos una vez por semana.

- En cuanto a los horarios y frecuencia: Por la cercanía a su centro de labores, están de acuerdo con una frecuencia de asistencia de lunes a viernes y con el horario de 8:00am hasta las 7:00 pm.

- Dos de los participantes no estuvieron de acuerdo con la ubicación por las vías de acceso con transporte público; sin embargo, ante una demostración con el google map se vieron convencidos que tienen otras vías de acceso que son favorables 
para el lugar.

Precios

- El monto promedio que estaría dispuesto a pagar por el servicio requerido es de 900, utilizando los medios de pago a través de transferencias electrónicas o tarjeta de crédito/debito.

Resultados del segundo Focus Group

El segundo focus group está compuesto por tres mujeres y dos hombres, todos mayores de 30 años y con hijos. Todos los participantes laboran en el distrito de San Isidro en el Centro Empresarial y ninguno utiliza los servicios de una guardería para el cuidado de sus hijos menores de 36 meses.

Acerca de los hábitos de cuidado y tenencia del bebe

- En la mayoría de los casos los participantes del focus dejan a sus hijos con sus padres (en su mayoría adultos mayores), situación que complica los tiempos de los abuelos ya que es muy desgastante para ellos y también para los mismos participantes. Esta situación causa estrés en el núcleo familiar.

- La mayoría de los participantes toman la decisión acerca de los niños en consenso con la pareja; cuando los padres tienen que dejar a sus hijos con otras personas que nos son los habituales, solicitan muchas recomendaciones, pero tiene cierto grado de desconfianza así sean recomendados.

- Muchas veces tienen que pedir permiso en sus centros laborales por algunas contingencias que se pueden generar con los niños.

- Dentro de los principales frenos y temores para el cuidado de los niños a terceros están: desconfianza, agresividad, maltrato, paciencia, seguridad en sus instalaciones, el cómo van a estar, el cómo lo van a tratar, que tipo de persona lo va a cuidar, tendrá educación, valores?, se preocupará por sus alimentos?, etc.

- Evaluación de la competencia.

- En San Isidro no han visto ninguna guardería cerca a sus centros laborales, más sí por sus casas. También destacan que las guarderías que han visto son casas las cuales varían en tamaño y fachada.

- En algunos casos muestran su disconformidad con las guarderías que se encuentran distribuidas de la siguiente manera: el primer piso la guardería y el segundo piso la vivienda propiamente dicha. 


\section{Metodología Doman}

- Los padres no han escuchado el método Doman, quisieran investigarlo más para determinar cuál sería el ideal. Han escuchado acerca de la estimulación temprana y creen que está relacionado. Es importante considerar que los padres no conocen otros métodos de estimulación.

Proyecto Guardería

Los padres para cambiar el cuidado de sus hijos hacia alguna guardería en particular desean que esta tenga las siguientes características:

- Profesores capacitados en primeros auxilios.

- Buena infraestructura.

- El horario tendría que ser desde las 7:00 AM.

- Ubicación cercana al centro laboral.

- Que sea espaciosa.

- Deberían tener cámaras de seguridad.

- Estacionamientos.

- Los padres consideran que el cuidado de los profesores debería estar de acuerdo al promedio de edad, no es lo mismo el cuidado de menores de 12 meses a menores de 36 meses.

- La ubicación de la guardería en Santa Catalina les pareció buena en general, ya que es una zona cercana a San Isidro con vías de acceso.

- Los padres estarían dispuestos a realizar los pagos a través de cargos en cuenta de manera automática, tanto a la tarjeta de crédito como a la de débito, ya que no les gusta transportar dinero en efectivo.

- Consideran que la comunicación para mostrar la Guardería s a través de página web, correo electrónico, Facebook y recomendaciones.

Precio

- Los padres estarían dispuestos a pagar entre 1,200 y 1,400 soles por tiempo completo y de 600 a 800 soles por medio tiempo.

- En la mayoría de los casos, los padres quisieran investigar el mercado antes de tomar la decisión de inscribir a sus hijos en la guardería. Desearían ver el factor diferencial. 
Resultados del tercer focus group

Se entrevistaron a 4 mujeres de edad entre 25 y 40 años con hijos de edad entre 2 y 6 años. Todos los participantes laboran en el distrito de San Isidro en el Centro Empresarial, algunas entrevistadas tienen a sus hijos en cuna jardín, otras con empleada porque les da mayor seguridad.

Acerca de los hábitos de cuidado y tenencia del bebe

- Consideran como una ventaja la opción de una Guardería/Cuna/Jardín, ya que los estimulan en el habla, gateo, es decir, actividades de desarrollo de acuerdo con su edad y los niños se interrelacionan; Asimismo, indican que por lo general las nanas no cuentan con la capacitación para estimular a los niños.

- Algunas mamás indicaron que no cuentan con familiares que se puedan quedar con los niños porque también trabajan o no tienen paciencia para los niños.

- Las que tienen empleada cuando estas se enferman tienen que tomar días a cuenta de vacaciones para quedarse en casa con sus hijos.

- El 50\% de las participantes comparte la decisión del cuidado de sus hijos con el padre.

- Rotación de niñeras genera inseguridad en los niños; “cuando la niñera renunció le costó bastante al niño acostumbrarse con la nueva".

Metodología Doman

- Les pareció interesante el método Doman puesto que no lo conocían y lo ven como una forma divertida de aprender.

Proyecto Guardería

- Indican que sería ideal que en la guardería se de tolerancia para recoger a los niños unos 30 minutos después en caso de tratarse de una emergencia.

- Las características de la persona que cuida a niños deben gustarle su trabajo, tener paciencia para los niños y tener buena higiene; que transmita confianza.

- El personal de la guardería tiene que haber pasado por evaluación psicológica para evitar que personas agresivas o con problemas de conducta estén al cuidado de los niños. Asimismo, se debe revisar que no tengan denuncias policiales ni penales.

- La política de las guarderías deben centrar su compromiso en el mejoramiento continuo para un servicio de calidad.

- Contar con aprendizaje lúdico.

- Una buena infraestructura de la guardería es muy importante por seguridad y para 
permitir que los niños se desarrollen libremente.

- La cocina no debe estar muy cerca a las aulas o lugar donde descansan los niños y contar con baños separados por género.

- Que cuenten con cantidad de personal suficiente para que se den abasto en cuidar a los niños.

- Nutricionista para que se alimente correctamente a los niños y que atiendan todo el año de lunes a viernes de 7:00am a 7:00pm.

- Los participantes sugieren la firma de un compromiso por los padres de no enviar a sus hijos con enfermedades virales porque podrían contagiar a los demás.

- Sugieren contar con página web/intranet para recibir información de la guardería.

- Se debe contar con todos los métodos de pago.

Conclusiones de los focus group

- La mayoría de padres toman la decisión en consenso con la pareja; acerca de los niños cuando se trata de encargar a sus hijos a terceros.

- Los padres recurren a personas cercanas o familiares de confianza a quienes encargan el cuidado de sus hijos que es retribuido económicamente, esto debido a que no cuentan con un lugar de confianza en donde dejar a sus hijos.

- El cuidado de familiares de confianza o personas cercanas tiene la desventaja de que, en caso de ausencia por diferentes motivos, genere inconvenientes a los padres, ya que se tiene que recurrir a permisos o ausencia en los centros de labores.

- Estrés en el núcleo familiar cuando se encarga el cuidado de sus hijos menores a adultos mayores (desgaste, costumbre, tiempo, salud, exceso de consentimiento a los niños) y porque los padres deben revertir situaciones de engreimiento hacia los niños.

- La importancia de generar ingresos en el núcleo familiar se limita al no contar con familiares cercanos a quien puedan encargar a su niño, o si lo tienen, trabajan y están en otras actividades o no tienen paciencia cuidándolos.

- El no tener un lugar (no familiar) de entera confianza para encargar a terceros a sus menores hijos por temores de: desconfianza, agresividad, maltrato, paciencia, seguridad en sus instalaciones, personal capacitado, etc.

- Desconocimiento de guarderías cercanas a la zona en estudio.

- Referencias negativas de guarderías de otras zonas, en su mayoría por 
infraestructura (viviendas acondicionadas).

- Solo un $10 \%$ menciono tener conocimiento de metodologías de enseñanza para niños menores de 3 años.

- Adicional a los atributos de cuidados y enseñanza, los padres esperan encontrar un lugar con niveles de seguridad (cámaras on line) e infraestructura adecuada en sus instalaciones.

- El poder contar con un lugar de confianza cercano al centro de labores, y dado los horarios de oficina, a los padres les resulta beneficioso una frecuencia de lunes a viernes con horario extendido que permita el recojo de su niño sin contratiempos.

- Desconocimiento del método Doman, pero ante una buena explicación de las bondades y ventajas, resulta de interés para su aplicación.

- El interés de los padres porque sus hijos puedan estar bien cuidados y seguros, así como la idea de la interacción social y que su desarrollo sea jugando y educando mediante la metodología a aplicar (lo ven como un plus)

- Estratégica ubicación de la guardería por sus vías de accesos a la zona de SI y en sus alrededores otras empresas.

- La importancia de la selección del personal a cargo del cuidado de los niños (conocimiento, competencias, valores, hábitos, higiene, etc.)

- Interés por servicios adicionales

- Los padres estarían dispuestos a pagar por un servicio de Guardería entre 900 y 1400 soles por tiempo completo y de 600 a 800 soles por medio tiempo.

- Por seguridad prefieren que los pagos sean realizados vía transferencias electrónicas o tarjeta de crédito/debito ó débito automático.

- Comunicación rápida entre la guardería y padres a través de tecnología celular, whatsApp, correo electrónico.

- Información de avances periódicos sobre el desarrollo y otra información relevante de sus hijos.

- Los padres tienen la intención de confiar en este proyecto, en la medida que se cumplan y puedan ser evidenciados los requisitos propuestos en la exposición del proyecto.

Resultados de la Entrevista en Profundidad

Se realizaron 2 entrevistas a expertos de 1 hora cada una, los cuales fueron grabados y luego transcritos, estos se encuentran en los Apéndices J y K. 
En la primera entrevista con los expertos se puede concluir lo siguiente:

Entrevista en Profundidad - I

La entrevista fue realizada a la Licenciada en Educación Ludgarda Barriga y directora de la Cuna Guardería Optiland y al Staff de profesoras de su equipo, dicha guardería está Ubicada en la Calle de Pietro Torrigiani 380 San Borja.

Según la Lic. Ludgarda la idea de implementar la guardería nace a partir de la necesidad de las madres que trabajan y que no cuentan con una alternativa para el cuidado de sus hijos, Optiland trabaja con niños de 0 a 36 meses, aunque el bebe más pequeño que han recibido tenía 2 meses.

Trabajo Preoperativo

Buscar un local bien ubicado; y que tenga la capacidad instalada necesaria para iniciar el proyecto ha sido una de las tareas más complicadas, ya que Optiland tiene convenio con la empresa Optical Networks la cual tiene 5 sedes, por ello la cuna debía estar ubicada en un punto céntrico a dichas sedes.

Adecuación e implementación; para esta tarea se hizo una división de las aulas y luego un contratista se ocupó de realizar la adecuación (pintado y cambios) del local, posteriormente se evaluó a los proveedores de muebles y accesorios de cada nivel.

Contratación de personal; Se hizo la evaluación de las profesoras y auxiliares donde no solo se evaluó los conocimientos y experiencia sino la empatía de cada una.

Importancia de la educación inicial para infantes de 0 a 36 meses

Según la Lic. Ludgarda y su equipo los 5 primeros años de vida es la etapa más importante, la estimulación temprana es fundamental para el desarrollo físico y social de los infantes, y se debe procurar generar un desarrollo integral.

Un niño correctamente formado en los 5 primeros años tiene mayores posibilidades de éxito en la etapa escolar e incluso laboral.

Consejo para padres que trabajan y deben encargar el cuidado de sus hijos a terceros

La estimulación es importante, pero nada puede reemplazar el amor que deben recibir de los padres, no hay juguete, video o galleta que puede suplir el afecto que los padres deben brindar a los infantes. Asimismo, esto permite que los niños crezcan seguros e independientes.

Guardería en el futuro

El personal que cada vez sea más empático con los niños.

Los accesorios que sean acordes al tiempo y espacio de los niños-

La educación debe ser más libre y menos estructurada, fomentar el arte y la música. 
Distribución por edades

(a) De 0 a 8 meses, (b) De 9 a 14 meses, (c) De 15 a 24 meses, (d) De 24 a 36 meses

Número de niños por profesor y auxiliar.

Depende la edad de los niños, mientras más grandes los niños necesitan de menos personas por que son independientes.

Principales Problemas

- Los padres que llevan a los niños enfermos

- Los padres no comunican oportunamente de los cuidados especiales

- Los padres no llegan a tiempo a recoger a sus hijos

- Los padres no envían los útiles personales de los niños

- La exigencia de los padres por querer adelantarlos procesos de aprendizaje.

Temores más comunes de los padres por el cuidado de los niños

- El trato que reciben los padres.

- Que se enfermen.

- Que no atiendan sus necesidades.

- Que se golpeen entre niños.

- Que no coma todos sus alimentos.

Metodologías aplicadas a guarderías.

Emily Picler, aprendizaje lúdico y que permite trabajar con materiales domésticos. Montessori, requiere materiales especiales pero que se pueden fabricar con materiales y la experiencia de las profesoras.

Conocimiento acerca de la metodología de Glen Doman

No conocen a profundidad el método sin embargo refieren que los materiales que requiere para su aplicación son más especializados y costosos.

Comunicación con los padres

A través de la agenda de la guardería y por WhatsApp

Entrevista en Profundidad - II

La entrevista fue realizada a la Licenciada en Educación Rosmery Ocampo y directora del Nido Jardín Guardería "Rosmery Play Kids", dicho Nido está asociado al Programa Despegar - Del Método Doman Adaptado a la Educación Peruana, Ubicado en la Calle Cesar Canevaro 1326 San Juan de Miraflores. 
Según la directora, Lic. Rosmery, el establecimiento tiene más de 10 años en el rubro y nace la idea de aplicar el Método Doman nuevo en el Perú básicamente para los padres, pero termina siendo adaptado para las sesiones del nido-Guardería. Importancia de la educación inicial para infantes de 3 a 36 meses

Destaca la diferencia de un servicio de Guardería y lo que corresponde a un centro de Educación Inicial, básicamente la Guardería es el cuidado de los niños y se pueden incorporar servicios adicionales de estimulación temprana.

De la metodología de Glen Doman

Según la Lic. Rosmery señala que el método Doman está dirigido a padres. El Director y pionero de este programa en Perú el Sr. Leonardo Aguilar ha realizado estudios de esta metodología quien menciona que no hay mejor maestro que sus propios padres. Es una metodología que se adapta su aplicación a centros de guarderías y nidos, haciendo extensivo a personas que están al cuidado de los menores, tales como las niñeras u otras personas interesadas.

El éxito de esta metodología es respetar la capacidad del niño (cada niño es diferente), no se le presiona, no es una evaluación continua, sino más como una siembra de curiosidad de las cosas y se da a mediano plazo, no es un resultado inmediato.

La aplicación de este método se da en un $60 \%$, se rige en principios y debe respetarse horarios para que los niños eviten el aburrimiento, y sea mejor aprovechado.

Cualquier método se puede aplicar, pero lo importante es darlo con mucho amor.

Beneficio del método: Desarrollar internamente habilidades al niño, organización neuronal, estímulos visuales, de contacto experimental, actividades en general.

Doman= Organización cerebral Valoración del método a los padres:

Los padres no tienen mucha paciencia o el tiempo suficiente, a veces creen que el resultado debe ser inmediato, es un tira y jala con los padres, la idea es poder reforzar este método en sus casas.

¿Se cobra algo adicional por el método?

La Lic. Rosmery señala que desde hace 17 años viene trabajando con Leonardo Aguilar (Director-programa Despegar), Despegar es el nombre del programa con quien comparte y enseña la metodología. Es una franquicia, la capacitación tiene un costo para quien desea aprender el método por el cual recibe un certificado; sin embargo, para los niños es un servicio incluido en el cuidado, enseñanza y aplicación. 
Lo recomendable es establecer un horario y aplicar la metodología a los niños, a más información que escuchen, el cerebro va a procesar e internalizarlo.

Actualmente la guardería/nido que lidera la Lic. Rosmery los niños están agrupados según las edades, son 4 grupos de 15 niños y cada grupo con auxiliares que los acompaña.

Problemática con los niños: Se realizan reuniones en cada semana con los padres, chequeos constantes con los niños, en caso de enfermedades, si es de grado mayor se asiste y lleva a un centro médico, caso contrario se le atiende y acude de inmediato.

La Lic. Rosmery, pone como ejemplo y evidencia que el método es aplicable y tiene buenos resultados; su hija que hoy en día tiene 17 años ha leído 400 libros, creó un gusto por la lectura a través del método Doman.

"Los niños son vitaminas puras, las personas cercanas deben tener el cariño y el amor necesario para acogerlos"

Conclusiones de la Entrevista en Profundidad a Expertos

- El trabajo pre-operativo es básico para el inicio de este negocio; la ubicación, distribución de ambientes, ambientación, amoblamiento y sobre todo la contratación de profesoras y auxiliares, donde no solo se evalúa los conocimientos y experiencia, sino la empatía de cada una.

- La importancia de la educación inicial para infantes de 0 a 36 meses es la etapa más importante, la estimulación temprana es fundamental para el desarrollo físico y social de los infantes, y se debe procurar generar un desarrollo integral.

- Se busca que el personal sea cada vez más empático con los niños.

- La educación debe ser más libre y menos estructurada, se debe fomentar el arte y la música.

- El cuidado de los niños depende de la edad, mientras más grandes los niños necesitan de menos personas por que son más independientes.

- Los principales problemas muchas veces son causados por los mismos padres: Llevan a los niños enfermos, no comunican oportunamente de los cuidados especiales, no llegan a tiempo a recoger a sus hijos, no envían los útiles personales de los niños, la exigencia de los padres por querer adelantarlos con procesos de aprendizaje no acorde a su edad y obtener resultados inmediatos.

- Los temores más comunes que los padres transmiten por el cuidado de los niños: el trato que reciben, que se enfermen, que no atiendan sus necesidades, que se golpeen entre niños, que no coma todos sus alimentos. 
- Metodología más empleada en guarderías/nidos: Emily Picler y Montessori.

- El método Glenn Doman no es muy conocido; sin embargo, refieren que los materiales que requiere para su aplicación son más especializados.

- El éxito de la metodología Doman es respetar la capacidad del niño (cada niño es diferente), no se le presiona, no es una evaluación continua, sino más como una siembra de curiosidad de las cosas y se da a mediano plazo, no es un resultado inmediato

- La especialista con 17 años en el servicio educativo aplicando la metodología Doman y socia del Director fundador del programa Despegar avala su aplicación con buenos resultados en sus niños del nido/guardería y el reconocimiento de los padres. Pone como ejemplo y evidencia que el método es aplicable y tiene buenos resultados; su hija que hoy en día tiene 17 años ha leído 400 libros, creó un gusto por la lectura a través del método Doman.

- La aplicación del método Doman se da en un 60\%, se rige en principios y debe respetarse horarios para que los niños eviten el aburrimiento para un mejor aprovechamiento.

- Beneficio del método Doman: es desarrollar internamente habilidades al niño, organización neuronal, estímulos visuales, de contacto experimental, actividades en general.

- El programa Despegar es una franquicia, la capacitación y aprendizaje para profesores e interesados en el método tiene un costo por el cual reciben un certificado.

- La base del progreso y avance de los niños es la constancia y comunicación con los padres, se realizan reuniones en cada semana, chequeos con los niños.

- En caso de enfermedades, si es de grado mayor se asiste y lleva a un centro médico, caso contrario se le atiende y acude de inmediato.

- Los expertos recomiendan a los padres que trabajan y deben de encargar el cuidado de sus hijos a terceros, evaluar opciones de cercanía a sus hogares o trabajo, seguridad, formalidad del negocio, metodología de enseñanza, personal general para el cuidado de los niños y horario de servicio.

Conclusiones del estudio cualitativo

- Los participantes de los 3 focus group realizados, se muestran interesados en la propuesta del servicio de Guardería; sin embargo, tienen presente los temores que 
aqueja el cuidado de niños a terceros, se frenan ante la inseguridad y desconfianza, la informalidad en los negocios y la falta de capacitación en el personal de la guardería; ante ello, las estrategias se centraran en el capital humano altamente calificado (competencias y habilidades blandas) y la difusión y conocimiento del método Doman, así como su aplicación y beneficios.

- Las condiciones favorables para que el servicio de guardería se pueda dar, también radica en reducir el estrés en el núcleo familiar, los abuelos podrán hacer otras actividades, menos ausencia y/o permisos en el ambiente laboral, disciplina, crecimiento profesional sin tener que dejar de laborar.

- Existe la oportunidad de ingresar a este mercado donde no ha sido explotado en las zonas cercanas a empresas.

- La oferta informal carece de tecnología e infraestructura (viviendas acondicionadas sin reglamentación).

- Ante el poco conocimiento de la metodología Doman, la estrategia será la de mayor difusión en videos con presentaciones de alto impacto y en la página web mostrando las bondades y ventajas de este método, incluyendo el plus de la estimulación temprana.

- No hay metodología que funcione sin el amor y apoyo de los padres. La comunicación es importante en cada etapa de crecimiento. No hay mejor maestro que sus propios padres.

- Estratégica ubicación de la guardería por sus vías de accesos a la zona de SI y en sus alrededores otras empresas.

- Identificación de principales problemas y temores de los padres que afectan a los niños en una guardería, ante ello, mitigarlos con procesos establecidos.

- El éxito de la metodología Doman es respetar la capacidad del niño (cada niño es diferente). No es un resultado inmediato, se rigen en principios e indicadores de evaluación.

- La existencia del programa Despegar en el Perú para la enseñanza y capacitación del método Doman a los profesores, es beneficioso y añade valor al negocio.

- La experiencia de los expertos en el tema recomienda que para el éxito de un negocio educativo, el capital humano es básico e importante ya que a través de ello transmiten confianza, seguridad, protección y mucho amor, sea con la metodología que se quiera aplicar. 


\subsection{Investigación Cuantitativa}

Propósito del estudio

Validar el estudio cualitativo y cuantificar la información de las preferencias, gustos y expectativas de la población en estudio, así como determinar la aceptación o rechazo de los clientes potenciales sobre la idea de una Guardería Infantil para el cuidado de infantes.

En la Tabla 12 se puede apreciar los objetivos de la investigación cuantitativa.

Tabla 12

Objetivos de la Investigación

\begin{tabular}{cl}
\hline \multicolumn{1}{c}{ Objetivo General } & \multicolumn{1}{c}{ Objetivos Específicos } \\
\hline \multirow{2}{*}{ Acerca del público objetivo } & Perfil NSE, Rango de edad, Género, Profesión o actividad \\
& laboral, Lugar de residencia, Lugar de trabajo, Composición, \\
& Número y edades de niños en casa, Ingreso promedio mensual, \\
& Tenencia de seguro: EPS o Seguro médico particular. \\
\hline
\end{tabular}

Acerca de los Hábitos de cuidado Disponibilidad de familiares para el cuidado de menores en casa y tenencia del bebe para quienes Razones de preferencia para escoger una guardería tienen la necesidad de encargar el Atributos buscados y valorados en el servicio de una guardería cuidado de sus hijos a terceros. Medios utilizados para conocer el servicio de guardería Frecuencia del servicio ofrecido: veces por semana Frecuencia del servicio ofrecido: meses al año Horarios de atención Medios de comunicación con la guardería Pago por servicio de guardería Servicios adicionales recibidos Pagos por servicios adicionales Medios de pago que utiliza

Roles: Persona encargada de buscar alternativas para el cuidado de niños, decisión e influencia.

Principales frenos y temores para el cuidado de los niños a terceros.

Principales problemas presentados en el cuidado de los niños.

Capacidad de respuesta para atender emergencias (planes de contingencia).

Nivel de rotación del personal que presta el servicio.

Nivel de satisfacción del servicio recibido.

Evaluación de la Competencia

Guarderías más / menos conocidas en la zona

Negocio de guardería conocido como prestigioso o la mejor (razones)

Negocio de guardería descartado (razones)

Ventajas o desventajas del negocio prestigioso y descartado Nivel de fidelidad de los clientes. 
...Viene de

Objetivo General Objetivos Específicos

\begin{tabular}{|c|c|}
\hline Acerca de la Metodología & Nivel de conocimiento de la metodología. \\
\hline \multirow[t]{7}{*}{ Doman } & Medios de información del método \\
\hline & Ventajas percibidas Razones \\
\hline & Desventajas percibidas, Razones \\
\hline & Metodología de aprendizaje para infantes más conocidas \\
\hline & Personal especializado en la metodología Doman \\
\hline & Costo de implementación de la metodología Doman \\
\hline & Logística para la implementación del método Doman \\
\hline \multirow{16}{*}{$\begin{array}{l}\text { Acerca del proyecto de una } \\
\text { Guardería }\end{array}$} & Evaluación de la ubicación: ventajas, desventajas, razones \\
\hline & Lay out \\
\hline & Nombre del negocio \\
\hline & Logotipo \\
\hline & Pronunciación \\
\hline & Percepción del proyecto (ventajas/desventajas del proyecto) \\
\hline & Expectativas generales ideales para la infraestructura. \\
\hline & $\begin{array}{l}\text { Requisitos mínimos necesarios para el buen funcionamiento } \\
\text { del negocio. }\end{array}$ \\
\hline & Factibilidad para la instalación de Cámaras IP en el local. \\
\hline & $\begin{array}{l}\text { Disponibilidad de los padres para el acceso a tecnología e } \\
\text { internet en lugar de trabajo y horario laboral. }\end{array}$ \\
\hline & Niveles de precios dispuestos a pagar por el servicio ofrecido \\
\hline & Niveles de precios dispuestos a pagar por los servicios \\
\hline & $\begin{array}{l}\text { adicionales } \\
\text { Requisitos mínimos necesarios para la selección de personal }\end{array}$ \\
\hline & Servicios adicionales requeridos \\
\hline & Niveles de seguridad espectados \\
\hline & Número de niños asignados por cada profesor y auxiliar \\
\hline \multirow[t]{2}{*}{ Evaluación de Precios } & $\begin{array}{l}\text { Precio real de mercado vs precio ideal por el servicio de } \\
\text { guardería. }\end{array}$ \\
\hline & $\begin{array}{l}\text { Precio real de mercado vs precio ideal por los servicios } \\
\text { adicionales. }\end{array}$ \\
\hline \multirow[t]{4}{*}{ Comunicación } & Medios de comunicación utilizados para mostrar la guardería \\
\hline & Promociones. \\
\hline & Medios de comunicación con la guardería \\
\hline & Tonos y formas de comunicación con los padres \\
\hline \multirow[t]{3}{*}{ Intención } & De confiar el cuidado de sus hijos a una guardería \\
\hline & De recomendación \\
\hline & Medios de pago dispuesto a utilizar \\
\hline
\end{tabular}




\section{Metodología}

Se propone un estudio de carácter Cuantitativo de Diseño Concluyente, Descriptivo, Transversal e Individual o simple, llamada también diseño de investigación de encuesta por muestreo. Mediante esta técnica de encuesta se podrá obtener información cuantificable más precisa y certera que reduzca los riesgos en la toma de decisiones.

En la Tabla 13 se puede apreciar la ficha técnica de la investigación cuantitativa

Tabla 13

Ficha Técnica de la Investigación Cuantitativa

\begin{tabular}{ll}
\hline Población Meta & $\begin{array}{l}\text { Hombre o mujer jefe de familia de 25 años de edad a más, } \\
\text { perteneciente al nivel socioeconómico B; que trabajan en la zona } \\
\text { financiera de San Isidro, con hijos menores de 36 meses y que } \\
\text { tienen la necesidad de encargar el cuidado de sus hijos a terceros. }\end{array}$ \\
\hline Ámbito geográfico & San Isidro, La Victoria (Santa Catalina) - Lima \\
\hline Enfoque & $\begin{array}{l}\text { La investigación será descriptiva }{ }^{1} \text {, transversal }{ }^{2} \text { e individual o } \\
\text { simple. }\end{array}$ \\
\hline Técnica de investigación & Encuestas personales no auto administradas ${ }^{3}$ \\
\hline Instrumento & $\begin{array}{l}\text { Se utilizará un cuestionario estructurado y estandarizado con } \\
\text { preguntas cerradas }{ }^{4}, \text { elaboradas de acuerdo a los objetivos de la } \\
\text { investigación. }\end{array}$ \\
\hline Tamaño de la muestra & $\begin{array}{l}\text { 390 encuestas efectivas (*) } \\
(*) \text { Este tipo de estudio tendrá un margen de error del 5\% }\end{array}$ \\
\hline trabajando con un nivel de confianza del 95\%. \\
\hline Diseño & $\begin{array}{l}\text { No probabilístico por cuotas según segmentación de NSE, tenencia } \\
\text { de hijo y edad, apoyado en muestreo por juicio. }\end{array}$ \\
\hline Distribución de la muestra & $\begin{array}{l}\text { Se efectuarán encuestas aleatorias a trabajadores de las empresas } \\
\text { ubicadas en la zona financiera del distrito de San Isidro. }\end{array}$ \\
\hline Nivel de Supervisión & El trabajo de campo será desarrollado por los integrantes del grupo. \\
\hline La supervisión estará a cargo por el asesor de tesis. \\
\hline
\end{tabular}

\footnotetext{
${ }^{1}$ Investigación Descriptiva: Tipo de investigación de carácter conclusiva que tiene como objetivo principal la descripción de una situación determinada, por lo general características o funciones del mercado.

${ }^{2}$ Diseño Transversal simple: Tipo de diseño de investigación que incluye la recolección de información de una muestra dada de una población una sola vez.

${ }^{3}$ Encuestas personales no auto administradas: Tipo de método de encuesta llamada también encuesta face to face en el cual el entrevistador se encarga de administrar el cuestionario él mismo, registrando las respuestas del entrevistado que ha sido interceptado en el lugar.

${ }^{4}$ Preguntas cerradas: Preguntas que especifican previamente el conjunto de alternativas de respuestas y el formato de respuesta.
} 


\subsubsection{Proceso de muestreo}

La población objetivo está conformada por clientes potenciales del nivel socioeconómico del sector $\mathrm{B}$, hombre o mujer jefe de familia; con hijos en las edades comprendidas entre 03 y 36 meses de edad, que trabajan y que tienen la necesidad de encargar el cuidado de sus hijos a terceros; en edades de 25 años a más, y que laboran en la zona financiera del distrito de San Isidro.

La población de estudio es de 24729 personas. El proceso de determinación parte de trabajar con la población residente y la población flotante del distrito de San Isidro de los sectores 4 y 5 (ver Figura 7), así como estimar la proporción de las familias que tienen un hijo menor de 12 años, 20 \% según IPSOS APOYO en su artículo "estudio de la nueva ama de casa peruana / perfil ama de casa junio 2017 Ipsos apoyo página 16”, y que pertenecen al NSE B $24.5 \%$

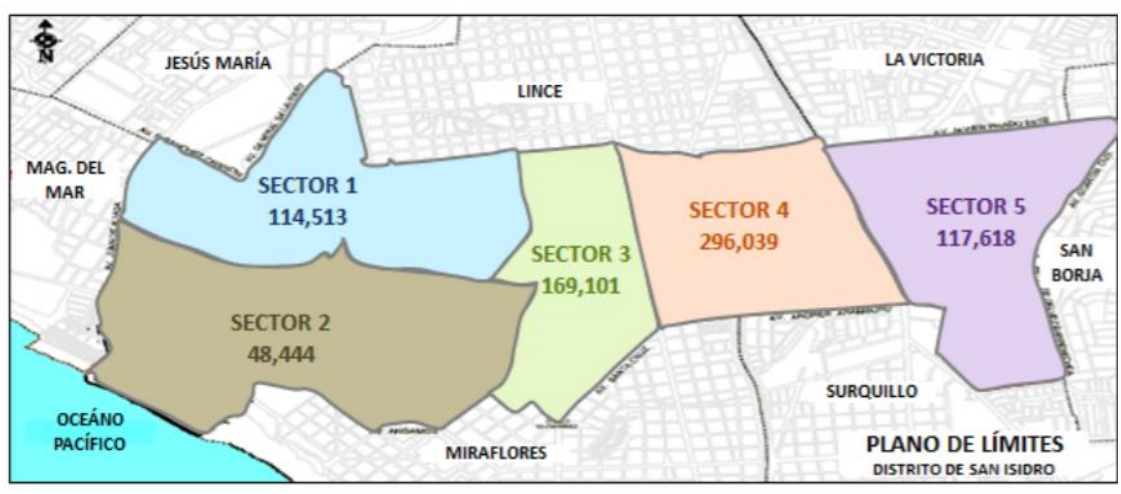

Figura 7. Plano de Límites y sectores del distrito de San Isidro. Tomado del Estudio "Cuantificar y Caracterizar a la Población Flotante del distrito de San Isidro" Desarrollado por la Empresa de Investigación Arellano Marketing Elaboración: Subgerencia de Desarrollo Corporativo.

El método usado para la muestra es no probabilístico con muestreo por cuotas apoyado en un muestreo por juicio; el cual permite obtener muestras representativas de la población por grupos o segmentos con características de control relevante con base en el juicio tales como: edad, tenencia de hijos, NSE. El tamaño de la muestra es de 390 personas que trabajan de forma dependiente e independiente en la zona financiera de San Isidro, trabajado con un nivel de confianza de $95 \%$ y un grado de error de 5\%; esta muestra es de tamaño suficiente lo que debe permitir tener estimaciones confiables de la población investigada.

Tamaño de la muestra

Para determinar el tamaño de la muestra se aplicaron los siguientes datos: 
Aplicando la fórmula de la muestra:

$$
\begin{aligned}
& \begin{array}{ll}
\hline \mathrm{P} & 0.5
\end{array} \\
& n=\frac{Z^{2} P Q}{e^{2}} \\
& \text { Q } \quad 0.5 \\
& \text { Confianza } \quad 95 \% \\
& \mathrm{Z} \quad 1.96 \\
& \begin{array}{lr}
\text { Error } & 5 \% \\
\hline \mathbf{n} & \mathbf{3 9 0} \\
\hline
\end{array}
\end{aligned}
$$

\subsubsection{Diseño de instrumento}

Para efectuar el diseño del cuestionario se tomó en cuenta los resultados de la investigación cualitativa como parte complementaria del estudio. Se tiene en cuenta los siguientes aspectos:

- Seleccionar al público objetivo

- Acerca de los hábitos de cuidado y tenencia de infantes para quienes tienen la necesidad de encargar el cuidado de sus hijos a terceros.

- Medir los atributos de importancia a evaluar para escoger una guardería

- Acerca de la zona

- Conocer la frecuencia de atención y horarios

- Nivel de fidelidad de los clientes

- Niveles de precios dispuestos a pagar

- Medios de comunicación utilizados para conocer el servicio

- Preferencia de medios de pagos a utilizar

- Medir la intención de la propuesta de nuestro servicio.

Las encuestas serán de tipo personales no auto administrado, para así obtener una muestra efectiva de 390 unidades. En la Tabla 14 se detalla la operacionalización de las variables y pasos efectuados para el diseño del cuestionario. 
Tabla 14

Operacionalización Para el Diseño del Cuestionario

\begin{tabular}{|c|c|c|c|}
\hline Objetivo & Variable & Dimensión/Pregunta & Indicador/medición \\
\hline \multirow{8}{*}{$\begin{array}{l}\text { Acerca del } \\
\text { público } \\
\text { objetivo }\end{array}$} & \multirow{4}{*}{ Datos generales } & Genero & Sexo \\
\hline & & Edad & Edad \\
\hline & & Lugar de procedencia & Distrito \\
\hline & & Ingreso promedio mensual & Rango de Ingresos percibidos \\
\hline & \multirow{4}{*}{ Filtro } & Tenencia de hijos & Tener hijos entre 3 y 36 meses \\
\hline & & Poder de decisión & $\begin{array}{l}\text { Quien decide sobre el cuidado de } \\
\text { sus hijos }\end{array}$ \\
\hline & & ¿Se encuentra trabajando actualmente? & Alternativa de respuesta/trabajo \\
\hline & & Se encuentra trabajando? & Modalidad de trabajo \\
\hline \multirow{5}{*}{$\begin{array}{l}\text { Acerca de los } \\
\text { Hábitos de } \\
\text { cuidado y } \\
\text { tenencia del } \\
\text { bebe para } \\
\text { quienes tienen } \\
\text { la necesidad de } \\
\text { encargar el } \\
\text { cuidado de sus } \\
\text { hijos a terceros }\end{array}$} & \multirow{2}{*}{$\begin{array}{l}\text { Atributos de } \\
\text { importancia }\end{array}$} & $\begin{array}{l}\text { Tiene acceso a internet durante su } \\
\text { horario laboral? }\end{array}$ & Tiene acceso a internet \\
\hline & & Dispositivo de acceso a internet & Tipo de dispositivo \\
\hline & \multirow[t]{3}{*}{$\begin{array}{l}\text { Hábitos de cuidado y } \\
\text { tenencia del bebe }\end{array}$} & $\begin{array}{l}\text { Quién se encarga del cuidado de sus } \\
\text { hijos menores de } 3 \text { años mientras } \\
\text { usted trabaja? }\end{array}$ & Disponibilidad para el cuidado \\
\hline & & $\begin{array}{l}\text { Motivo por el cual, al día de hoy no ha } \\
\text { dejado a su hijo al cuidado de una } \\
\text { guardería }\end{array}$ & Motivos: miedos, frenos \\
\hline & & $\begin{array}{l}\text { Atributos de importancia para escoger } \\
\text { una guardería }\end{array}$ & Escala de importancia \\
\hline \multirow{7}{*}{$\begin{array}{l}\text { Evaluación de } \\
\text { la Competencia }\end{array}$} & \multirow{7}{*}{ Competencia } & $\begin{array}{l}\text { Nivel de satisfacción por el servicio } \\
\text { recibido en la guardería }\end{array}$ & Grado de satisfacción \\
\hline & & $\begin{array}{l}\text { Los horarios del servicio de guardería } \\
\text { se adecuan a su horario de trabajo? } \\
\text { La guardería donde asiste su hijo, } \\
\text { aplica alguna metodología de } \\
\text { enseñanza y estimulación temprana } \\
\text { especializada? }\end{array}$ & $\begin{array}{l}\text { Conocimiento de metodologías } \\
\text { aplicadas }\end{array}$ \\
\hline & & $\begin{array}{l}\text { Con que frecuencia deja usted a su } \\
\text { hijo(a) en la guardería }\end{array}$ & Frecuencia veces por semana \\
\hline & & $\begin{array}{l}\text { Cuantos meses al año utiliza los } \\
\text { servicios de una guardería }\end{array}$ & Frecuencia veces por meses \\
\hline & & $\begin{array}{l}\text { ¿Qué servicios adicionales recibe en la } \\
\text { guardería? }\end{array}$ & Servicios adicionales \\
\hline & & Ubicación de guardería & Distrito de guardería \\
\hline & & $\begin{array}{l}\text { Cuánto paga mensual por el servicio } \\
\text { de una guardería }\end{array}$ & $\begin{array}{l}\text { Rango del importe por pago } \\
\text { mensual }\end{array}$ \\
\hline \multirow{2}{*}{$\begin{array}{l}\text { Acerca de la } \\
\text { Metodología } \\
\text { Doman }\end{array}$} & \multirow[b]{2}{*}{ Metodología Doman } & $\begin{array}{l}\text { Conoce el método Doman (Método de } \\
\text { Aprendizaje Americano? }\end{array}$ & $\begin{array}{l}\text { Nivel de conocimiento de } \\
\text { metodología }\end{array}$ \\
\hline & & $\begin{array}{l}\text { Ventajas/desventajas más importantes } \\
\text { en la aplicación del método Doman }\end{array}$ & Descripción, razones percibidas \\
\hline
\end{tabular}

Continua $a .$. 


\section{Acerca del proyecto de una Guardería \\ Propuesta de Guardería}

Existe la intención de una empresa en desarrollar una guardería infantil para niños de 3 a 36 meses de edad con un método de enseñanza y estimulación temprana especializada ¿Qué le parece la idea?

Esta guardería brindaría un servicio de video vigilancia a través de la instalación de cámaras IP, donde pueden ver en tiempo real las actividades y cuidados que reciben sus hijos, ¿Estaría de acuerdo?

La guardería estaría ubicada en la Urbanización Santa Catalina, la cual está cerca al centro financiero de San Isidro. ¿Estaría de acuerdo?

¿Qué horario le parecería adecuado para la atención de la guardería?

Esta guardería contaría con ambientes separados por edades, implementadas con materiales y juegos acordes, así mismo tendrá un comedor, lactario, cocina, SSHH habilitados con inodoros y tina de baño especiales para niños, ¿Qué le parece?

En una escala descendente donde, " 01 " es el más importante y " 06 " el menos importante, ¿determine qué servicios adicionales considera más importantes para la implementación en una Guardería qué tipo de servicio adicional le gustaría encontrar en la guardería? (Puede marcar más de una alternativa) porque no piden ranking?
Grado de necesidad/intención

Grado de acuerdo/desacuerdo

Grado de conformidad y/o acuerdo

Frecuencia de atención y horario

Grado de conformidad y/o acuerdo

Escala de importancia
¿Cuánto estaría dispuesto a pagar mensual por el servicio de una guardería que incluye el servicio de

Evaluación de Precios Precio

vídeo de vigilancia online y la aplicación de la metodología Doman?

Disposición de pagos

¿Cuánto estaría dispuesto a pagar mensual por cada servicio adicional?

¿Por qué medios le gustaría informarse de la guardería?

\begin{tabular}{ll} 
Comunicación & Comunicación \\
\hline $\begin{array}{l}\text { Intención de } \\
\text { compra }\end{array}$ & Interés de la propuesta \\
\hline
\end{tabular}
utilizar los servicios de la guardería?
Disposición de pago por servicio de guardería

Medios de pago

Disposición de pago por servicio adicional

Alternativas de medios de información

Grado de interés

\subsubsection{Análisis y procesamiento de datos}

Se procesaron 390 encuestas. Para el procesamiento de la data se utilizó el SPSS, software estadístico que se utiliza para realizar la captura y análisis de datos para la creación de tablas y gráficos; una vez que se llenó la matriz se hizo el análisis descriptivo respectivo para validar que en los campos no se hayan perdido datos o estén vacíos, de tal forma que la 
información contenga los campos llenos y completo al 100\%. Asimismo, se validó la consistencia y confiabilidad del instrumento.

Para el análisis de datos se utilizó la técnica estadística descriptiva (ver apéndice $O$ ), tablas de distribución de frecuencia acumuladas, cruces de tablas necesarios con categoría de control requeridos para la obtención de tablas y gráficos que ilustren los resultados de la investigación; así también se realizó el análisis sobre la demanda del servicio que el público estaría dispuesto a pagar y recibir.

Resultados:

A continuación, se detallan los resultados de los objetivos propuestos en la investigación de mercado.

Del cruce de la pregunta ¿Tiene acceso a internet durante su horario laboral? Con los rangos de edad de los encuestados se ha obtenido la siguiente información:

¿Tiene acceso a internet durante su horario laboral? (véase Figura 8)

Del Total de los encuestados el $97.4 \%$ si tiene acceso a internet durante su horario laboral, y la probabilidad de acceso a internet es directamente proporcional a la edad de los encuestados. Con esta información se concluye que el servicio de video vigilancia puede ser apreciada por el público objetivo.

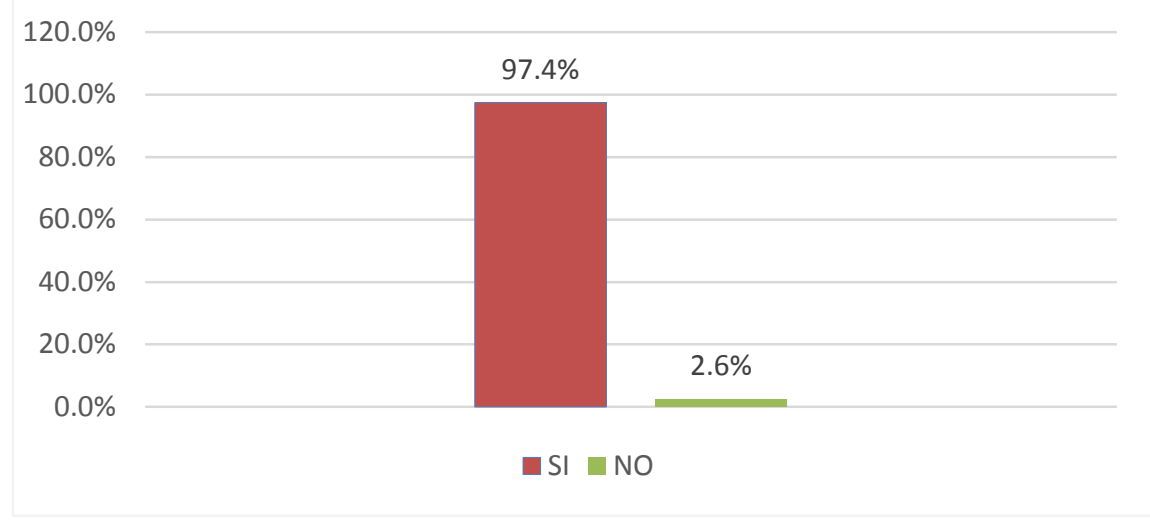

Figura 8. Acceso a internet durante horario laboral

¿A través de que dispositivo accede a internet? (véase Figura 9)

Del total de los encuestados que acceden a internet, en promedio el 90.8\% de personas tienen como dispositivo más utilizado el Smartphone, seguido del $81.1^{\prime} \%$ que utilizan una computadora y el 5.5\% los que utilizan una Tablet, esto ayudara a determinar que el sistema 
que se habilite para el servicio de video vigilancia debe ser compatible con el dispositivo de mayor uso.

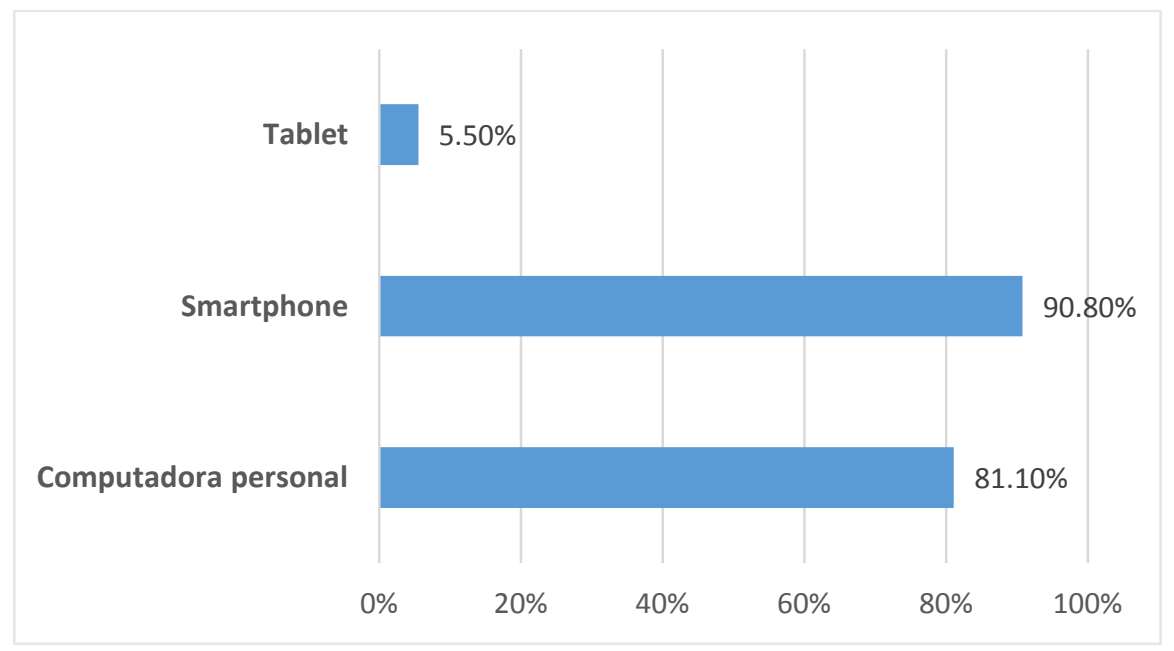

Figura 9. Dispositivo de accesos a internet

¿Quién se encarga del cuidado de sus hijos menores de 3 años mientras usted trabaja? (véase Figura 10)

De los encuestados, el $45.4 \%$ menciona que una Niñera esta al cuidado de los menores de tres años y el 29.2\% lo encarga a un familiar. Los que dejan al cuidado del esposo (a) y en una guardería, son los que menos encargan el cuidado de sus hijos menores.

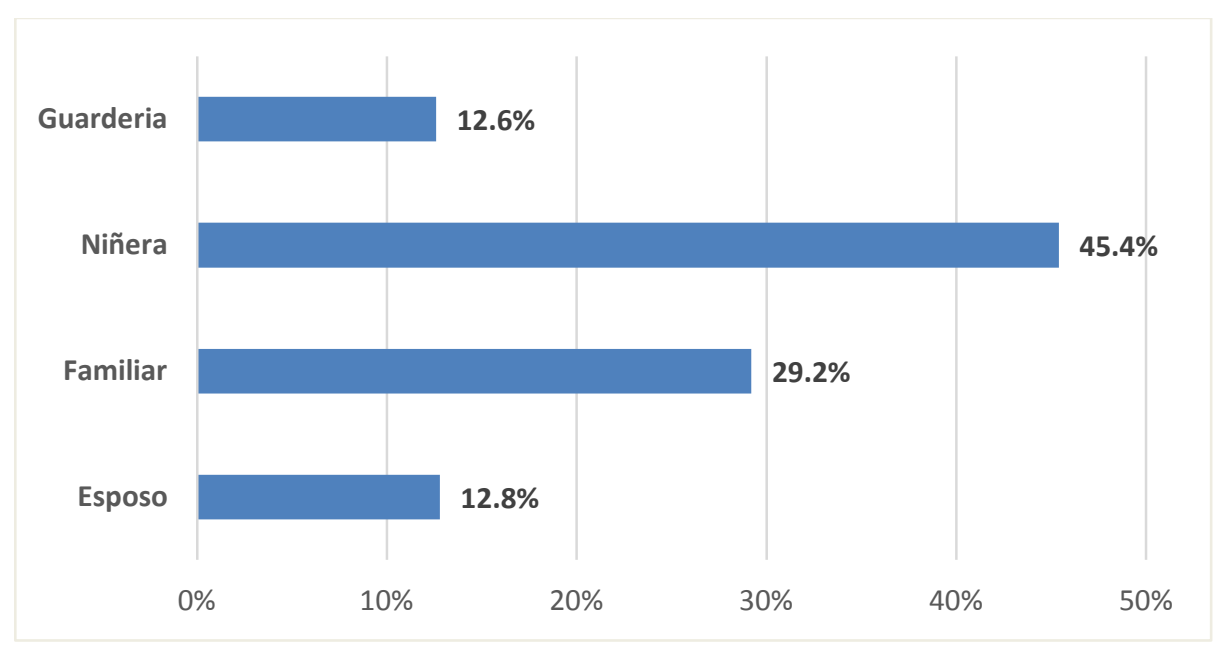

Figura 10. Encargo del cuidado de sus hijos menores de 3 años mientras usted trabaja 
¿Cuál es el motivo por el cual hasta el día de hoy no ha dejado a su hijo al cuidado de una guardería? (véase Figura 11)

El 56.9\% de los encuestados señala que el motivo principal es por la Seguridad que les puedan dar a los menores. El segundo motivo es la Desconfianza que tienen y que representa el $53.1 \%$, seguido del $41.9 \%$ por los Horarios reducidos que ofrecen las guarderías. El Alto costo y la mala experiencia con una Guardería no son motivos muy representativos.

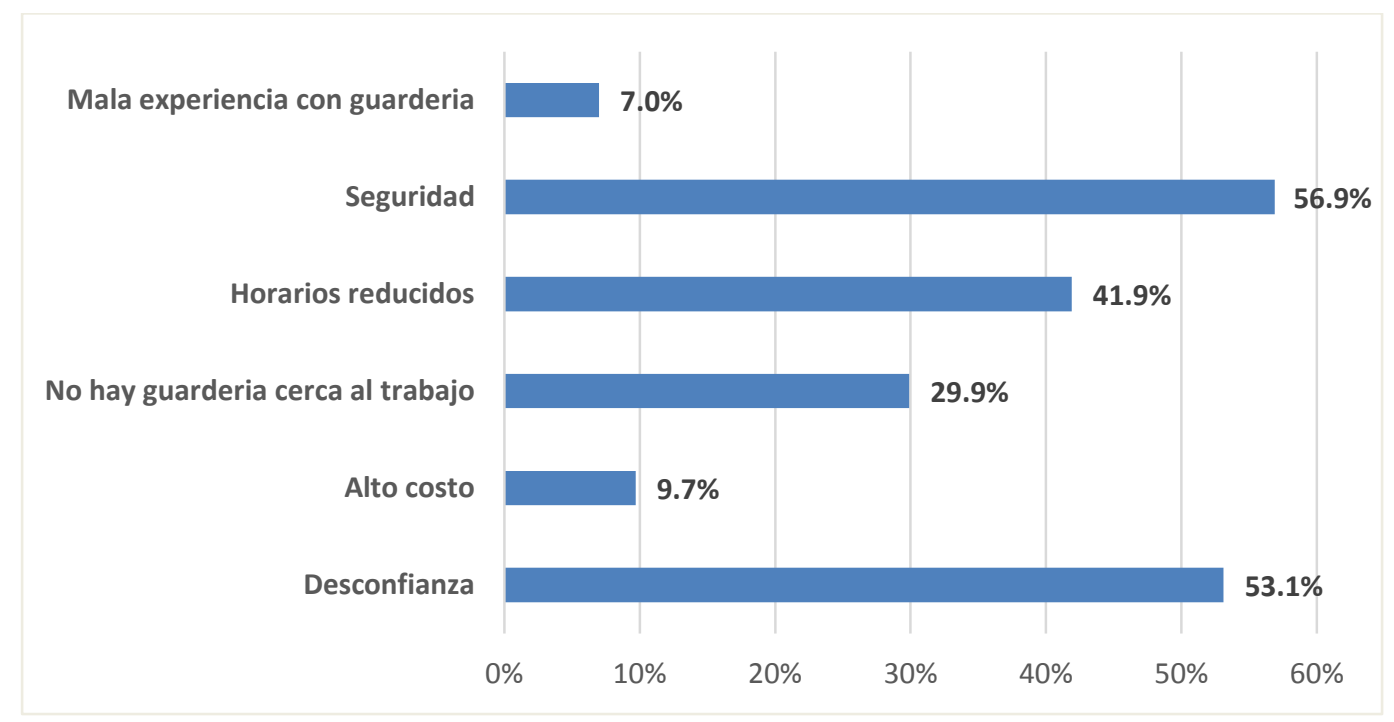

Figura 11. Motivo por el cual hasta el día de hoy no ha dejado a su hijo al cuidado de una guardería

En una escala descendente donde, "1" es el más importante y "6" el menos importante, determine que atributos considera más importantes para poder escoger una Guardería.

Los encuestados consideran que, para poder escoger una Guardería, determinarían como atributo más importante la Seguridad (58.1\%), como segundo atributo de importancia el Horario (30.8\%), seguido de la Ubicación (23.2\%). En la cuarta y quinta escala, el Precio (20.5\%) y la Recomendación (27\%), y ocupando la escala seis como atributo que considera menos importante, el Método de Enseñanza, lo que nos permite concluir que las personas buscarían mayor seguridad para sus hijos ante cualquier método de enseñanza que se les ofrezca. (véase Figura 12) 


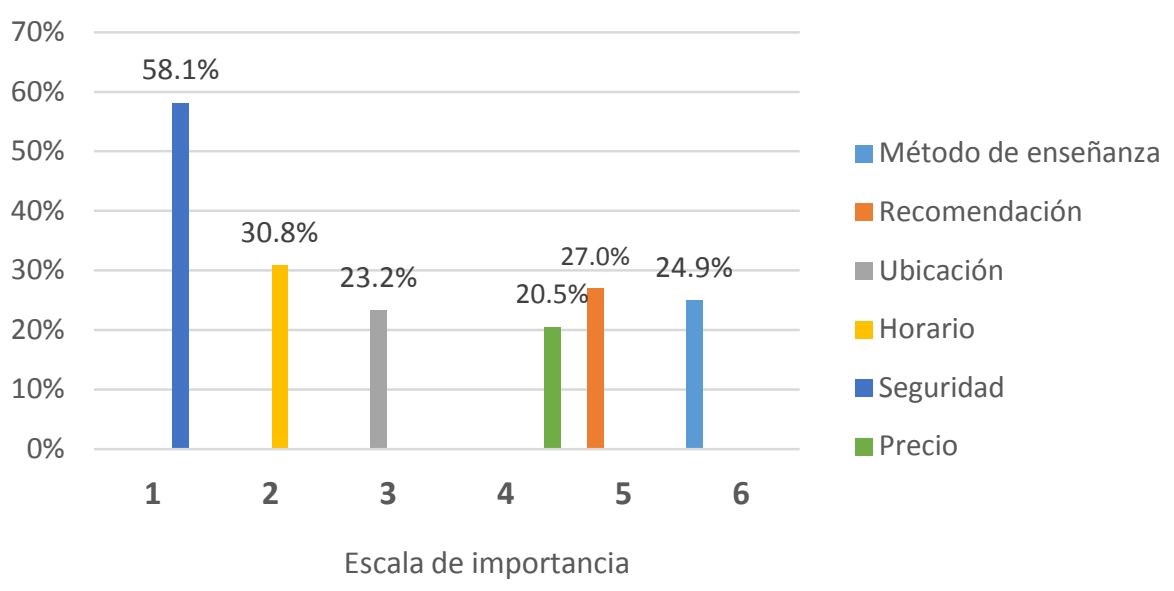

Figura 12. Atributos que considera más importantes para poder escoger una Guardería

¿Cuál es su nivel de satisfacción por el servicio recibido en la guardería? (véase Figura 13)

De los encuestados que respondieron que encargan el cuidado de sus hijos menores de 3 años a una Guardería mientras trabaja; podemos apreciar que el $67.3 \%$ de las personas encuestadas sienten satisfacción por el servicio recibido, el $24.5 \%$ considera un nivel de satisfacción indiferente Ni satisfecho, ni insatisfecho y solo un 8.2\% si se encuentra Muy satisfecho con el servicio recibo en una guardería.

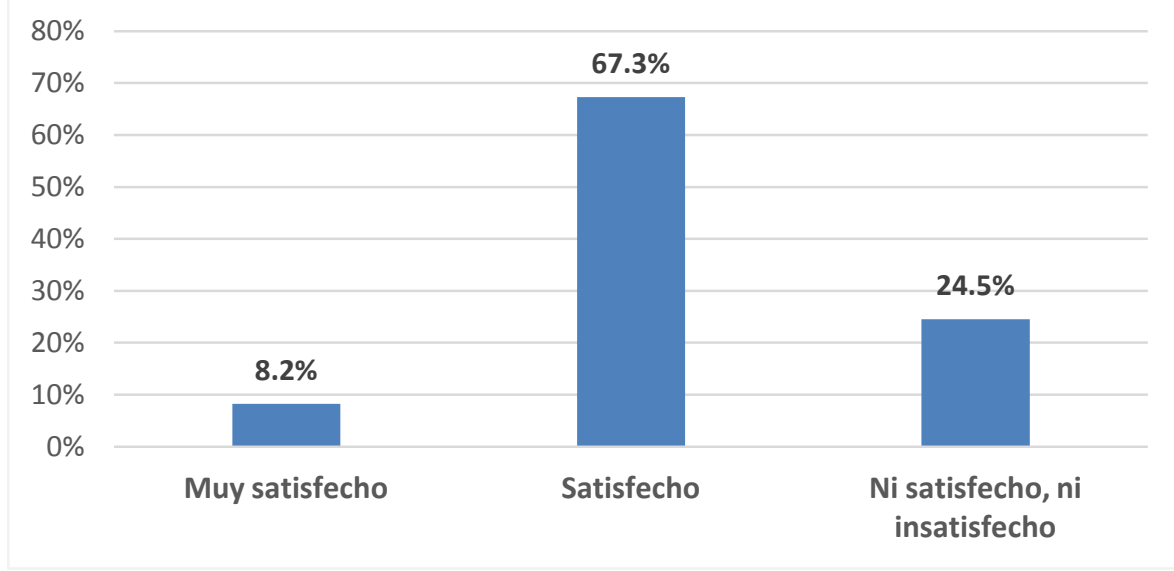

Figura 13. Nivel de satisfacción por el servicio recibido en la guardería

¿Los horarios del servicio de guardería, se adecuan a su horario de trabajo? (véase Figura 14) De los encuestados que respondieron que encargan el cuidado de sus hijos menores de 3 años a una Guardería mientras trabaja; el 59.2\% considera que el horario del servicio de guardería es Adecuado a su horario de trabajo; para el $24.5 \%$ le es indiferente, ni adecuado ni inadecuado, mientras que para un $14.3 \%$ de encuestados si considera Inadecuado el horario del servicio que recibe. 


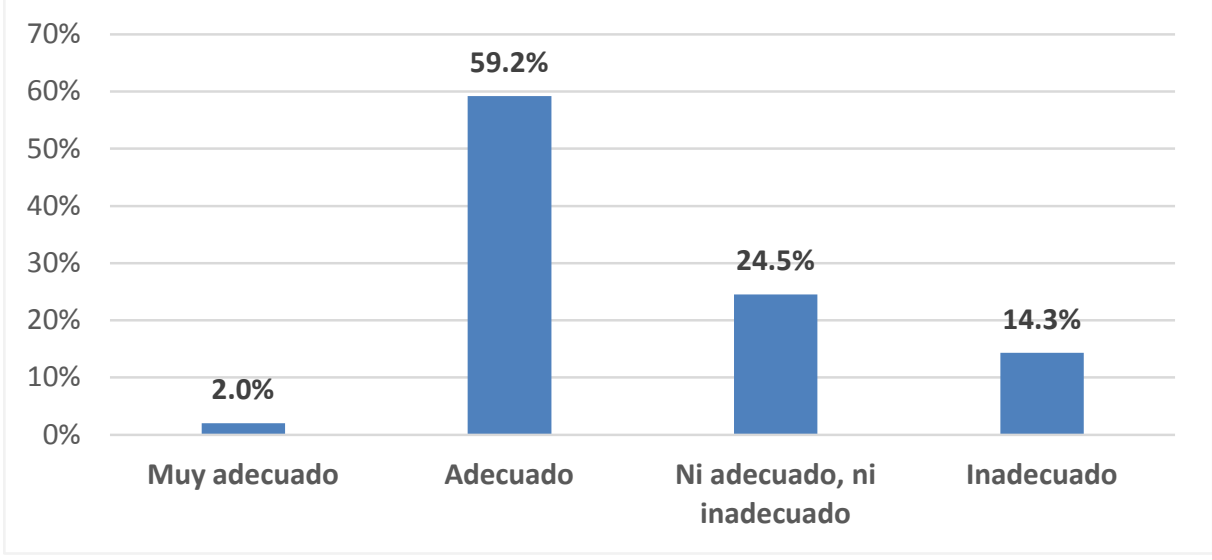

Figura 14. Respuesta a los horarios del servicio de guardería que se adecuan a su horario de trabajo.

La guardería donde asiste su hijo, ¿Aplica alguna metodología de enseñanza y estimulación temprana especializada? (véase Figura 15)

Podemos apreciar en la Figura 15 que el $42.9 \%$ de encuestados indica que en la guardería donde asiste su hijo NO aplican una metodología de enseñanza, mientras que el 32.7\% No recuerda alguna metodología aplicada y solo un $24.5 \%$ confirma que, si aplica una metodología de enseñanza especializada, siendo la de mayor recordación la Montessori con $75 \%$, seguido de Emilia Reggio con $25 \%$ de los que aplican (ver Tabla 15).

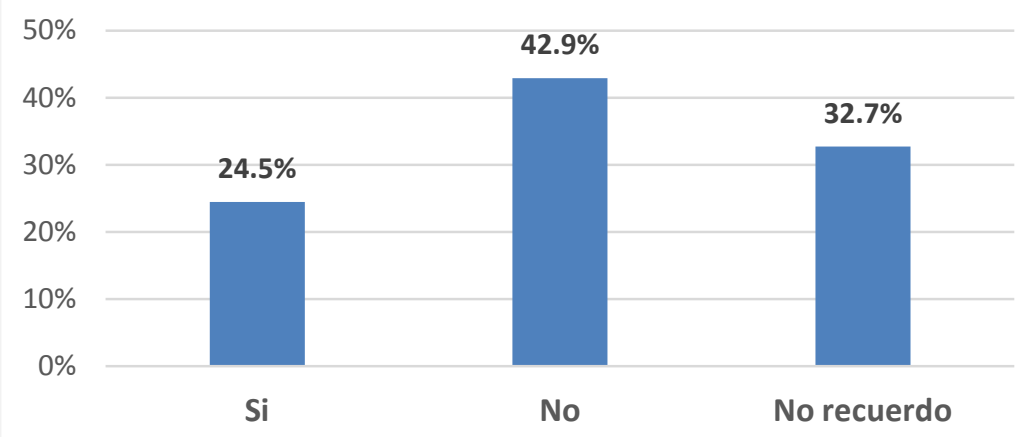

Figura 15. Metodología de enseñanza y estimulación temprana especializada que aplica en guardería.

Tabla 15

Tipos de Metodología que se Aplica en Otras Guarderías

\begin{tabular}{lc}
\hline \multicolumn{1}{c}{ ¿Si Aplica Metodología, cuál? } & Respuesta \\
\hline Montessori & $75 \%$ \\
Emilia Reggio & $25 \%$ \\
\hline
\end{tabular}


¿Con que frecuencia deja usted a su hijo(a) en la guardería? (véase Figura 16)

El $91.8 \%$ de los encuestados deja el cuidado de su hijo en una guardería 5 veces a la semana, mientras el $8.2 \%$ lo hace 3 veces por semana.

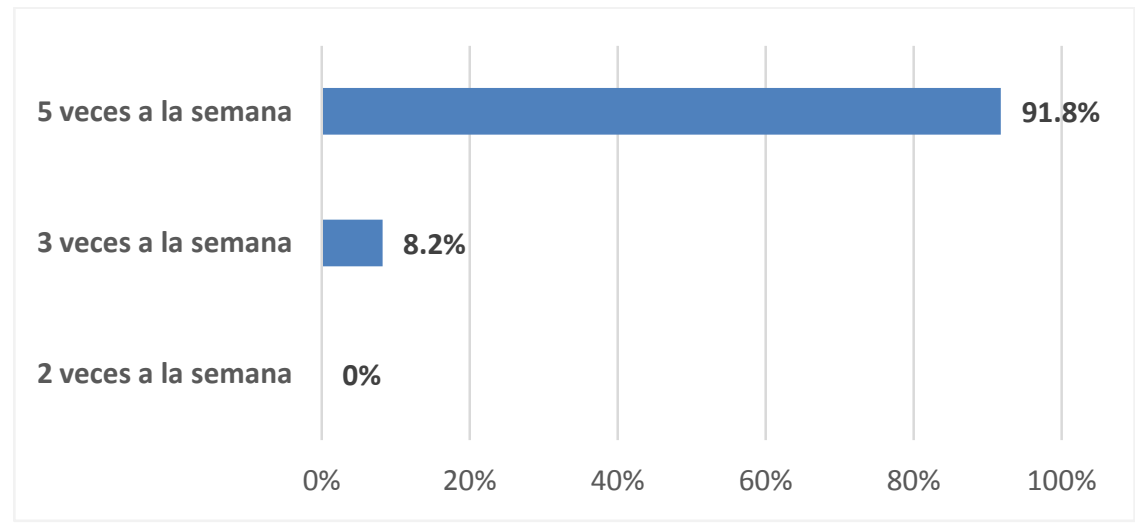

Figura 16. Frecuencia que deja a su hijo(a) en la guardería.

¿Cuantos meses al año utiliza los servicios de una guardería? (véase Figura 17)

El 59.2\% de los encuestados utiliza los servicios de guardería entre 10 y 11 meses, el 30.6\% menciona que utiliza 12 meses al año. Entre 6 y 9 meses y menos de 6 meses al año no son frecuencias muy representativas.

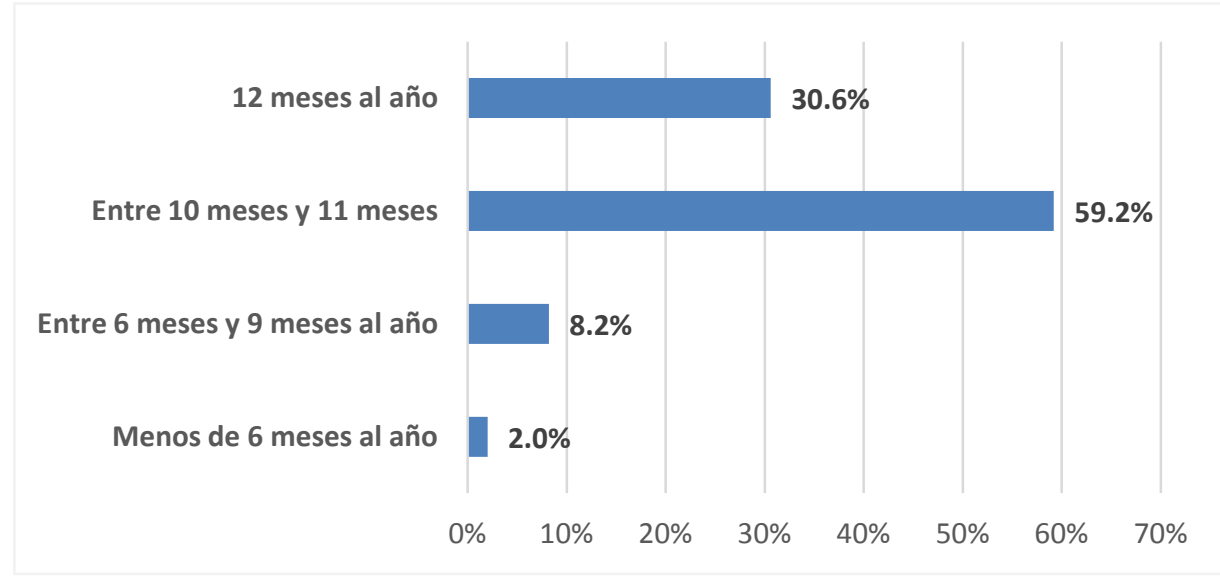

Figura 17. Frecuencia de meses al año que utiliza los servicios de una guardería

¿Qué servicios adicionales recibe en la guardería? (véase Figura 18)

Podemos apreciar que el $69.4 \%$ de encuestados que dejan el cuidado de su hijo en una guardería reciben como servicio adicional la Alimentación, el 63.3\% Estimulación temprana, el 44.9\% recibe el servicio de Talleres, así también la asistencia de Enfermería el 28.6\% y Terapia del lenguaje el $20.4 \%$. 


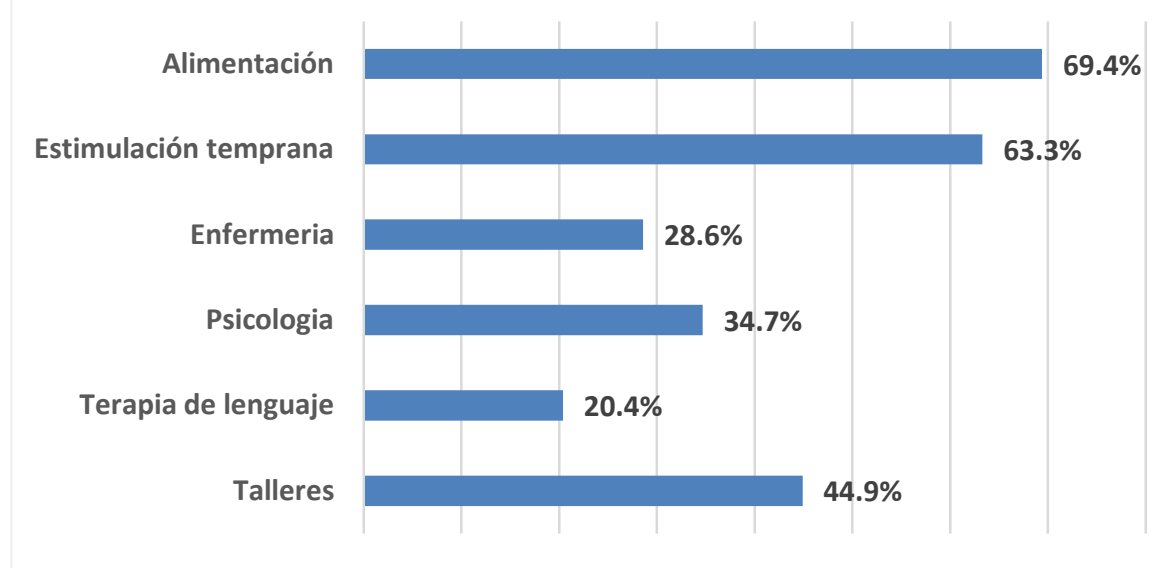

Figura 18. Servicios adicionales que recibe en la guardería.

¿Cuánto paga mensual por el servicio de una guardería? (véase Figura 19)

De nuestra muestra podemos ver que el $38.8 \%$ paga mensualmente por el servicio de guardería entre S/ 700 a S/ 900, el mismo porcentaje los que pagan de S/ 901 a S/ 1100.

Podemos observar también que el $10.2 \%$ es abarcado por los encuestados que pagan menos de S/ 700 y de S/ 1101 a S/ 1300.

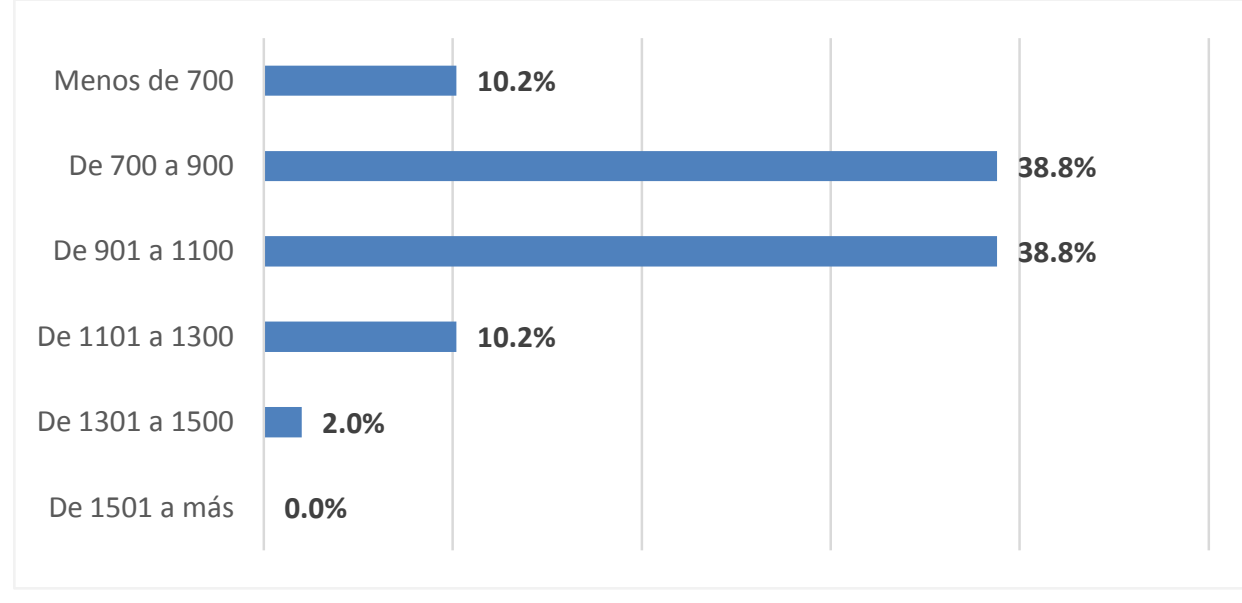

Figura 19. Importe mensual que pagan por el servicio de una guardería

Existe la intención de una empresa en desarrollar una guardería infantil para niños de 3 a 36 meses de edad con un método de enseñanza y estimulación temprana especializada ¿Qué le parece la idea? (véase Figura 20)

Luego de conocer la propuesta de un nuevo concepto de Guardería, el 55.9\% de los encuestados les parece Necesario la idea de desarrollar una guardería infantil para niños de 3 a 36 meses, al $40.3 \%$ le parece Muy necesario este tipo de empresa. 


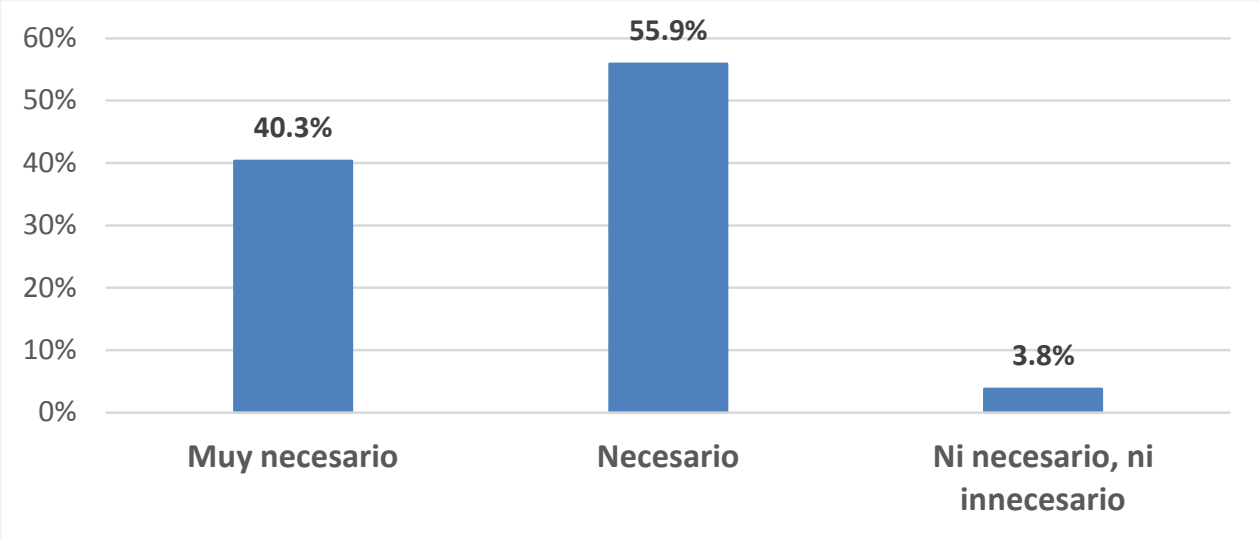

Figura 20. Intención de propuesta para un nuevo concepto de guardería.

Esta guardería brindaría un servicio de video vigilancia a través de la instalación de cámaras IP, donde pueden ver en tiempo real las actividades y cuidados que reciben sus hijos, ¿Estaría de acuerdo? (véase Figura 21)

El 51.8\% de los encuestados está Muy de acuerdo con la propuesta de servicio, de igual manera $46.9 \%$ se muestra de Acuerdo.

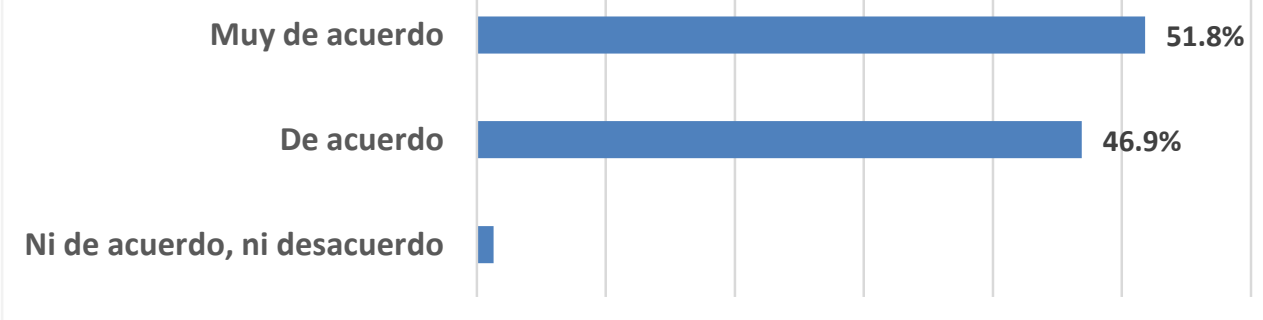

Figura 21. Conformidad sobre una Guardería que brindaría un servicio de video vigilancia

¿Conoce el método Doman (¿Método de Aprendizaje Americano? (véase Figura 22) Ante la pregunta realizada, podemos apreciar que el $84.1 \%$ NO conoce el método Doman, solo un $15.9 \%$ conoce este método de aprendizaje.

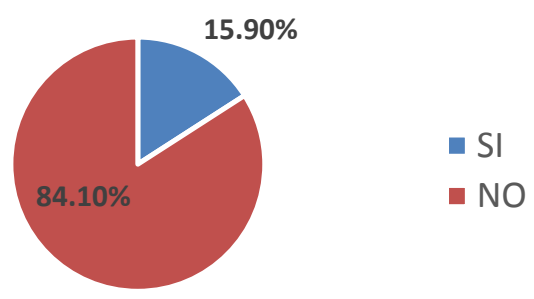

Figura 22. Conocimiento del Método Doman 
¿En su opinión cuales son las ventajas más importantes en la aplicación del método Doman? (véase Figura 23)

El 46.8\% de los encuestados opina que una de las ventajas más importante en la aplicación del método Doman es que Estimula la memoria y aprendizaje, el 29\% menciona que Contribuye al desarrollo cerebral, el 11.3\% opina que Favorece la concentración, el $8.1 \%$ Ayuda al desarrollo visual y auditivo, mientras que $4.8 \%$ menciona que Favorece la comunicación.

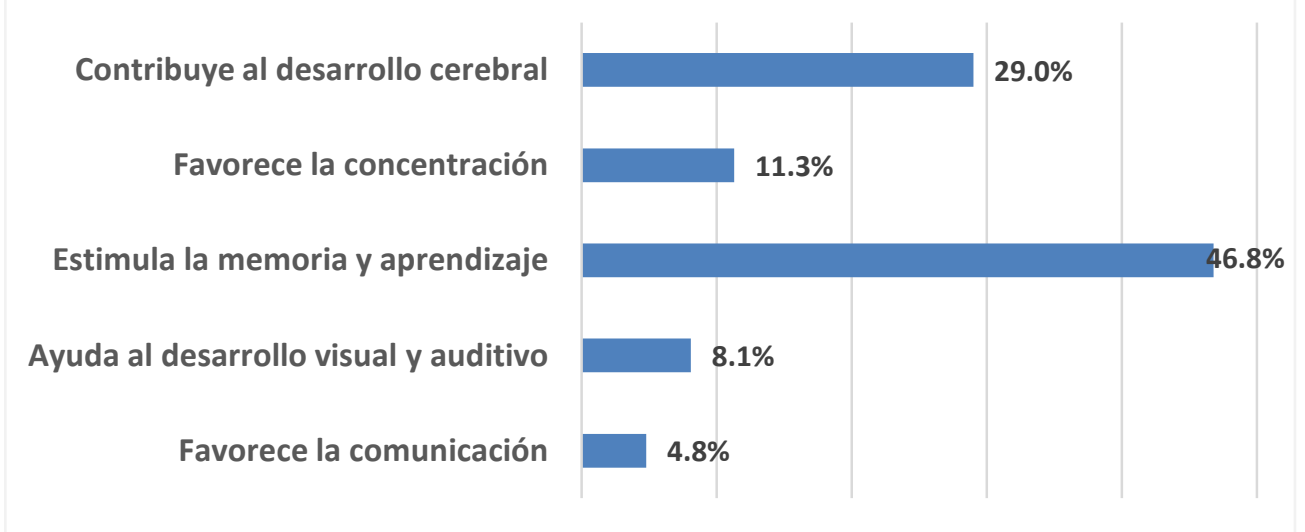

Figura 23. Ventajas más importantes en la aplicación del método Doman

La guardería estaría ubicada en la Urbanización Santa Catalina, la cual está cerca al centro empresarial de San Isidro. ¿Estaría de acuerdo? (véase Figura 24)

Ante esta pregunta realizada, el $61 \%$ de encuestados si estaría de Acuerdo y un $17.7 \%$ Muy de acuerdo. El 19.7\% le es indiferente (Ni de acuerdo, ni desacuerdo) la ubicación y un 1.5\% estaría en desacuerdo de la zona.

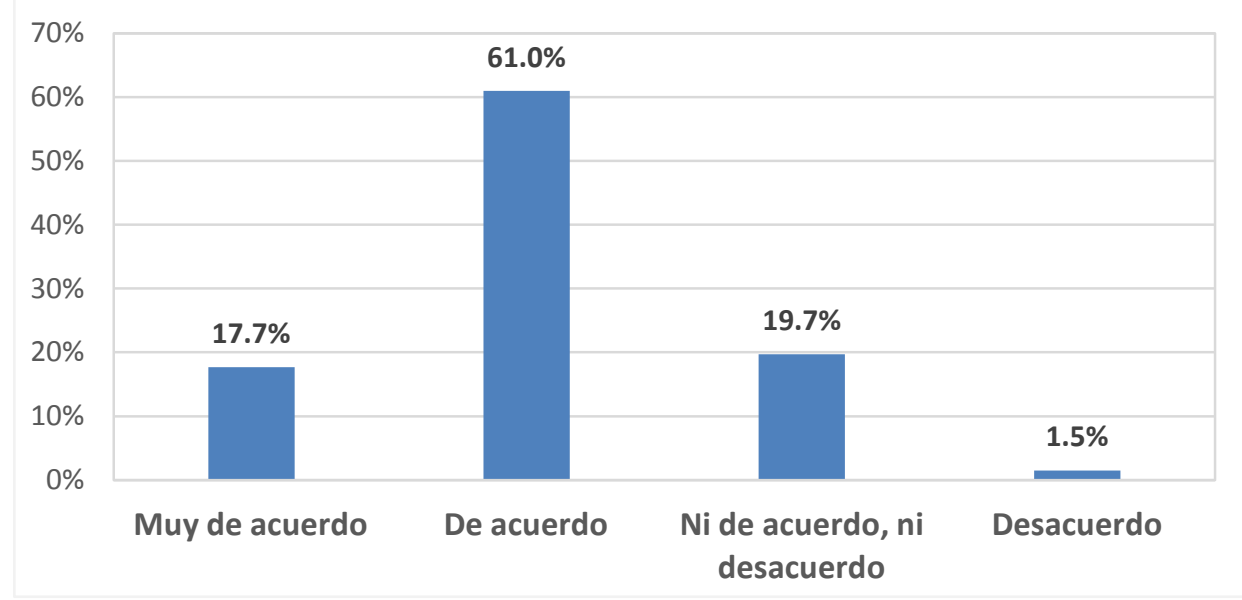

Figura 24. Conformidad de la zona de ubicación de la guardería. 
¿Qué horario le parecería adecuado para la atención de la guardería? (véase Figura 25) El 39.5\% le parece adecuado el horario de lunes a viernes de 8:00am a 7:00pm, el 31\% prefiere el horario de lunes a viernes de 8:00am a 6:00pm, mientras que un 17.2\% le parece adecuado el horario de lunes a viernes de 7:30am a 6:00pm y un 12.3\% el horario de lunes a viernes de 9:00am a 7:00pm.

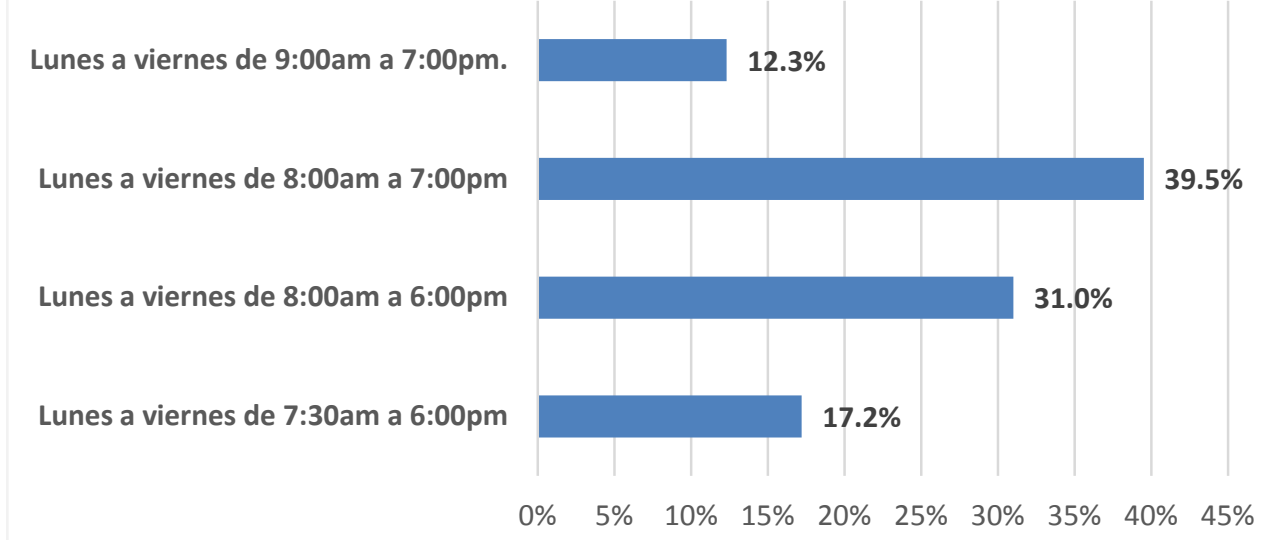

Figura 25. Horario que le parecería adecuado para la atención de la guardería

Esta guardería contaría con ambientes separados por edades, cada una implementadas con materiales y juegos acordes a las mismas, así mismo tendrá un comedor, lactario, cocina, SSHH habilitados con inodoros y tina de baño especiales para niños, ¿Qué le parece? (véase Figura 26)

El 53.6\% de los encuestados les parece y están Muy de acuerdo con la propuesta de esta guardería, así también el $45.4 \%$ se muestra de acuerdo a cada atributo con la cual contaría la guardería.

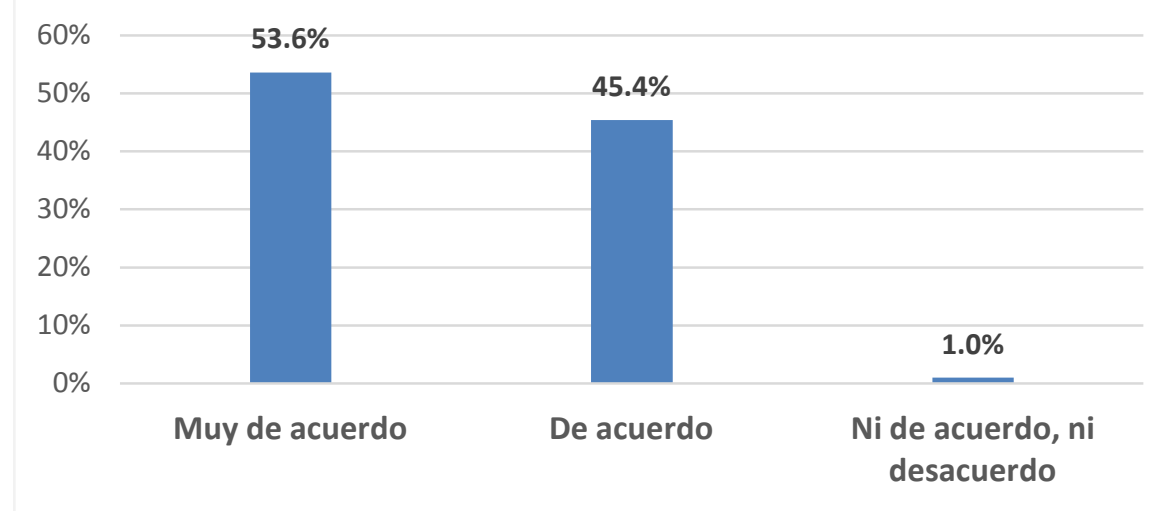

Figura 26. Distribución y ambientes de la guardería. 
¿Cuánto estaría dispuesto a pagar mensual por el servicio de una guardería que incluye el servicio de vídeo de vigilancia online y la aplicación de la metodología Doman?

De los encuestados, el 56.2\% estaría dispuesto a pagar de S/ 901 a S/1100 por el servicio mensual de una guardería, el 34.1\% lo haría por menos igual a S/900 y un 9\% pagaría de S/1101 a S/1300. (véase Figura 27)

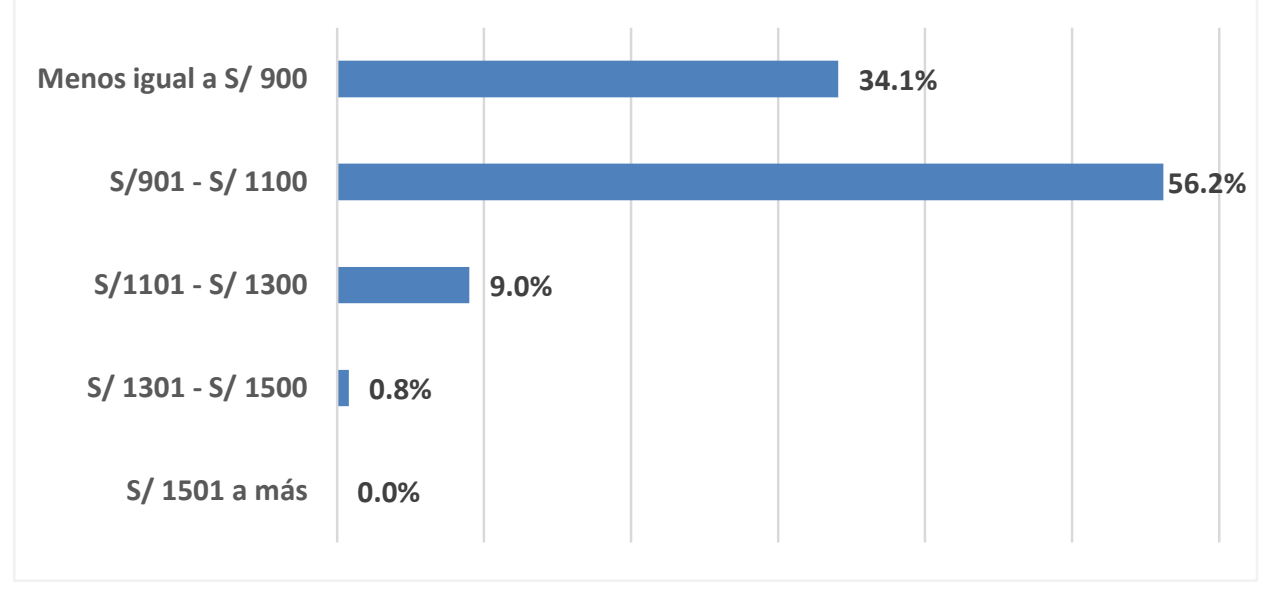

Figura 27. Disposición de pago mensual de guardería

¿Qué medio de pago utilizaría para el pago del servicio guardería? (véase Figura 28)

Podemos apreciar que el $51.5 \%$ y $51.3 \%$ de las personas encuestadas utilizaría el medio de pago de Abono en Cta. Cte. y Cargo en TC, el 47.7\% utilizaría el POS y un 25.6\% haría uso del medio en efectivo para el pago de servicio de guardería.

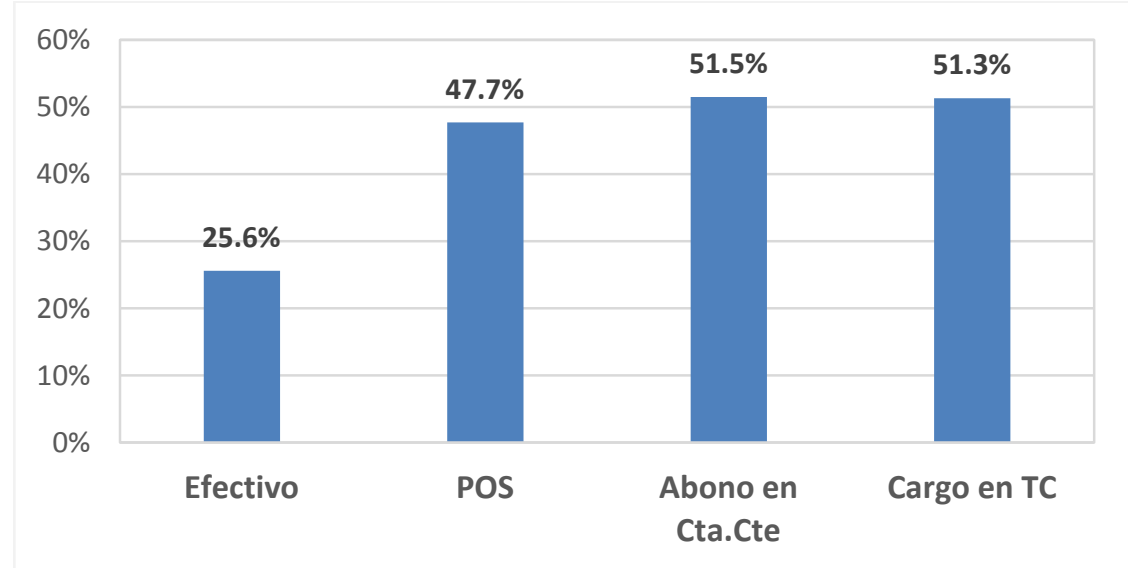

Figura 28. Preferencia de medios de pago que utilizar

En una escala descendente donde, “01” es el más importante y “06” el menos importante, ¿determine qué servicios adicionales considera más importantes para la implementación en una Guardería? (véase Figura 29) 
Los encuestados consideran que para la implementación en una Guardería el servicio adicional más importante sería la Alimentación (48.2\%), como segundo de importancia la Enfermería (30\%), seguido del Servicio Psicológico (29.7\%). En la cuarta y quinta escala, el servicio de Terapias (27.4\%) y Talleres (33.3\%), y finalmente ocupando la escala seis considerado el servicio de menos importancia como servicio adicional, la Organización de Cumpleaños (69\%).

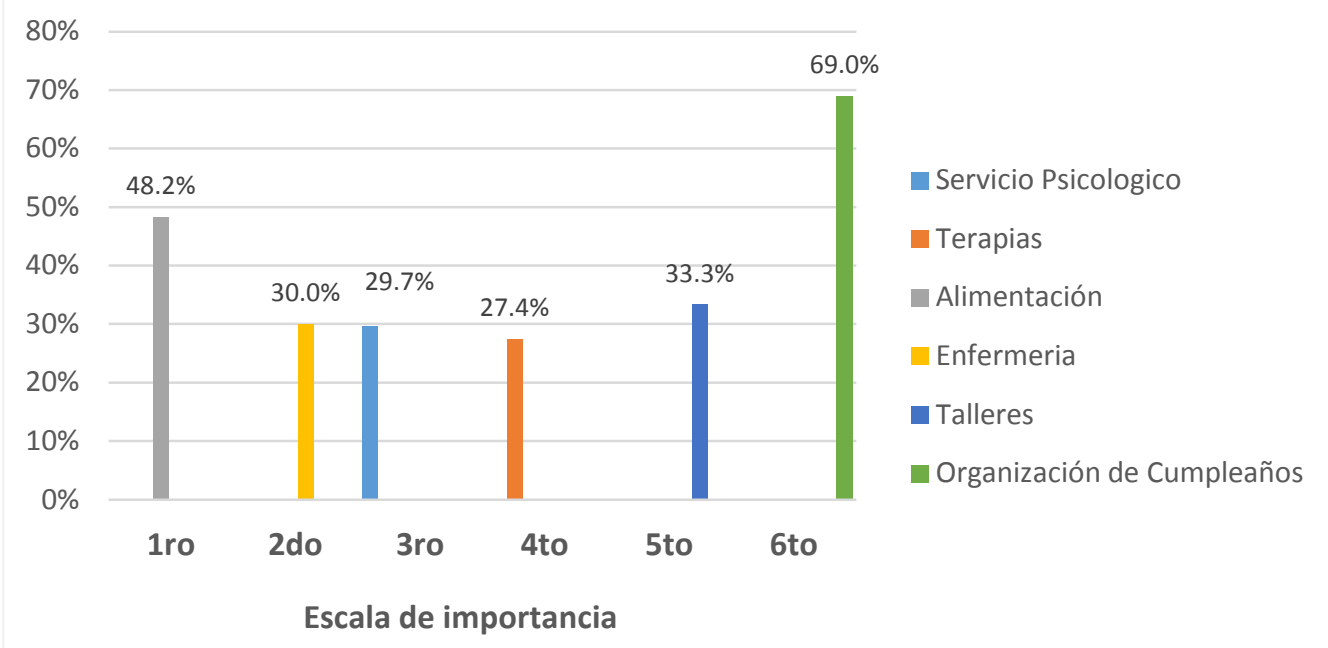

Figura 29. Servicios adicionales de importancia para la implementación de una guardería.

En base a su respuesta anterior, ¿Cuánto estaría dispuesto a pagar mensual por cada servicio adicional? (véase Figura 30)

El $68.7 \%$ de los encuestados indico estar dispuesto a pagar mensual menos de S/100 por servicio adicional, mientras que un 30\% lo haría por S/ 101 a S/200.

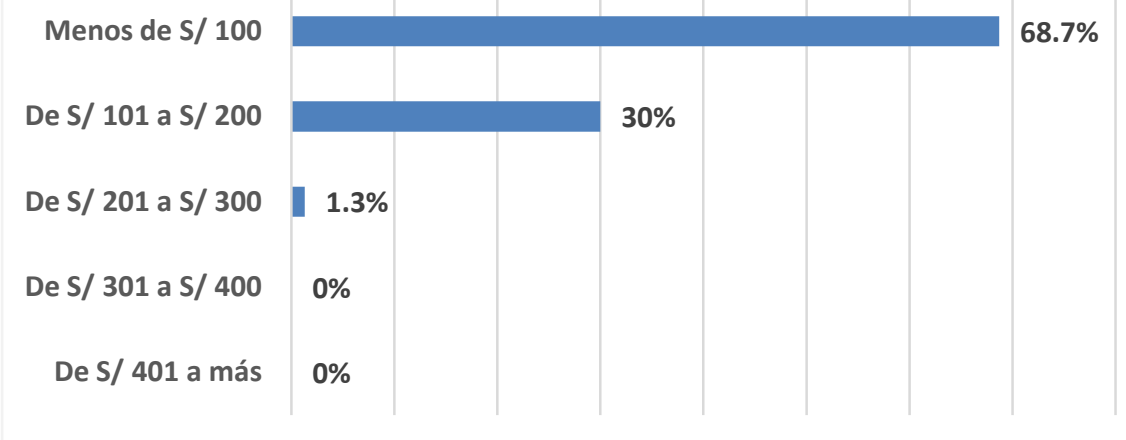

Figura 30. Disposición de pago mensual por servicio adicional 
¿Qué nombre le parecería más adecuado para esta guardería? (véase Figura 31)

Podemos apreciar que al $29.5 \%$ de encuestados le parece más adecuado el nombre para la guardería de My Happy World, al 28.2\% el nombre de Titinos Daycare, al 23.3\% prefiere Happy Daycare, y un $17.9 \%$ le parece más adecuado el nombre de Baby Land.

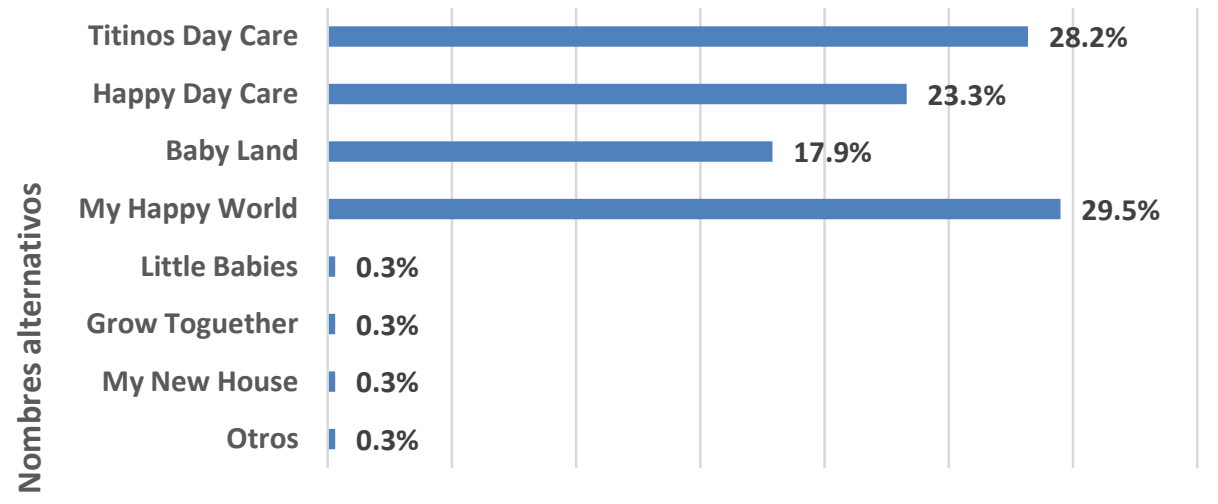

Figura 31. Preferencia del nombre para una guardería

¿Por qué medios le gustaría informarse de la guardería? (véase Figura 32)

El 59.5\% de encuestados prefiere informarse de este nuevo proyecto de negocio a través de Redes Sociales, seguido del 53.3\% que prefiere por Página Web, el 43.3\% sugiere informarse a través de Email, el $22.1 \%$ gustaría como medio de comunicación informarse por intermedio de Convenios con su Centro de Trabajo, y el 14.6\% a través de Revistas Especializadas.

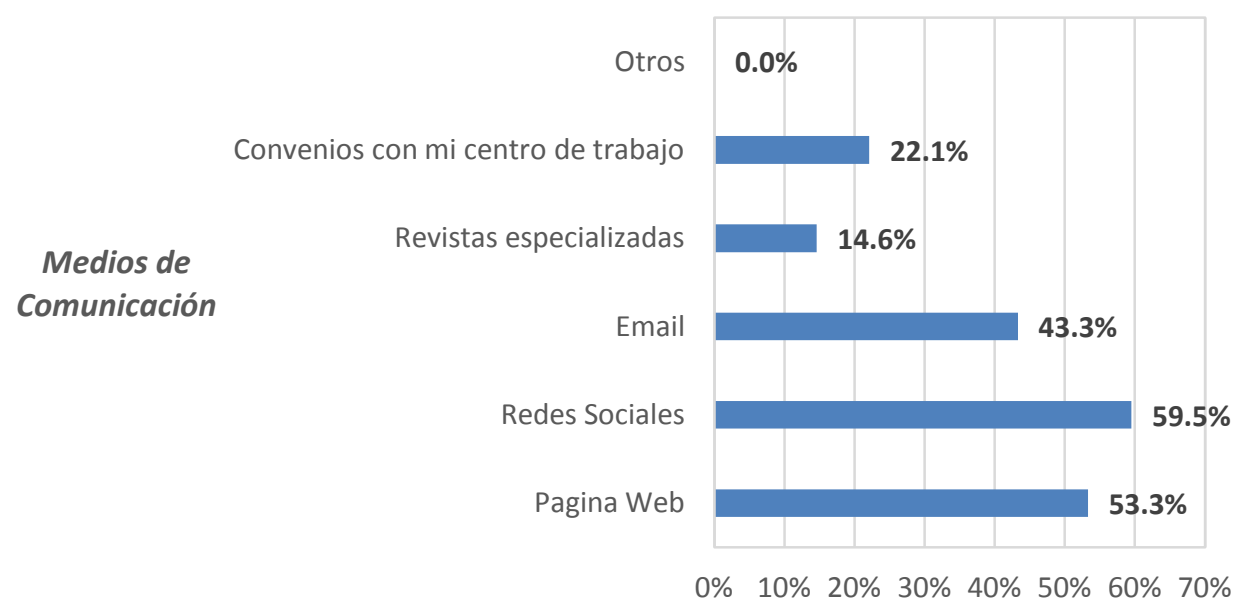

Figura 32. Medios de comunicación

Luego de haberse informado de este nuevo proyecto. ¿Qué tan dispuesto estaría usted a utilizar los servicios de la guardería? (véase Figura 33) 
De nuestra pregunta filtro, el 70.5\% Probablemente utilizaría los servicios de la Guardería, el $27.7 \%$ Definitivamente estarían dispuestos a utilizar los servicios, para el 1.3\% le es Indiferente y un $0.5 \%$ Probablemente no los utilizaría.

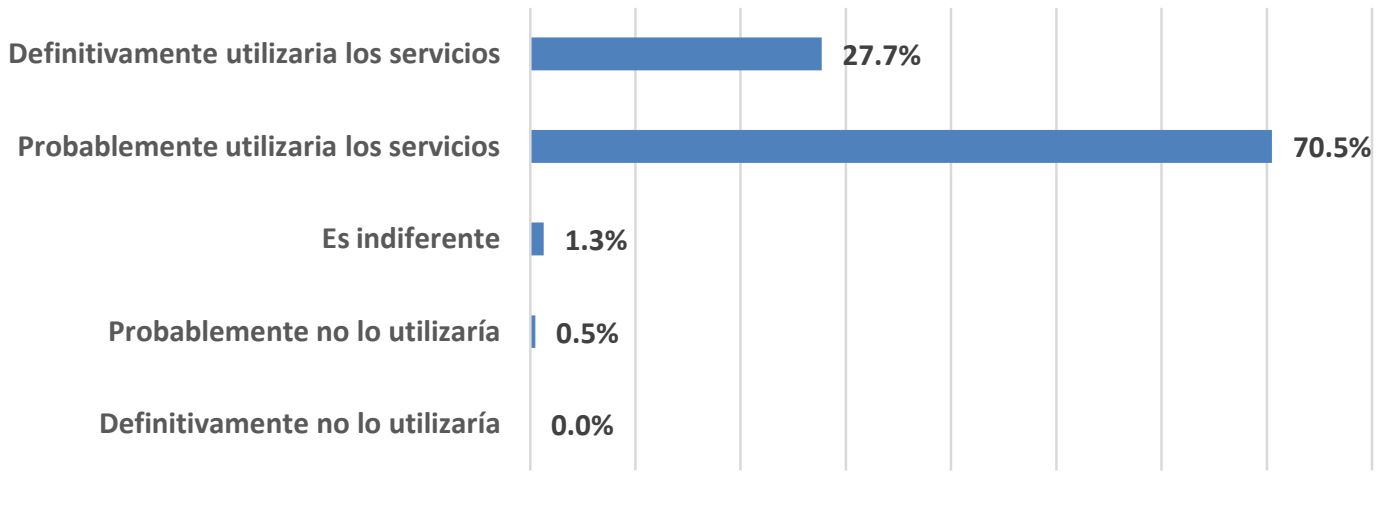

Figura 33. Disposición para el uso de servicio de una guardería

\subsection{Conclusiones del estudio cuantitativo}

- El $27.7 \%$ de los encuestados están muy interesados en utilizar los servicios de Titinos Daycare; sin embargo, uno de los motivos más resaltantes por el cual no hacen uso de servicios de una guardería, es por la falta de seguridad y desconfianza, más del 50\% de encuestados lo señalan, en base ello, las estrategias se centrarán en una estricta convocatoria del personal calificado y la difusión por recomendación (boca a boca).

- Inicialmente la empresa centrará sus actividades en el distrito de Santa Catalina La Victoria.

- Existen condiciones favorables para que el servicio de video vigilancia se pueda dar, el 97.4\% de encuestados señala lo beneficioso de esta herramienta para un mayor seguimiento.

- Titinos Daycare ve la oportunidad de ingresar a este mercado que aún no ha sido explotado en zonas cercanas a empresas.

- La oferta informal carece de tecnología e infraestructura.

- El horario extendido del servicio al cuidado de los menores, acorde a horarios de oficina, es también un atributo importante para los padres, ya que les permitirá trabajar sin preocupación y recogerlos sin apuros.

- A pesar de que el precio de mercado por servicio educativo se asemeja, los padres prefieren optar por la garantía y seguridad del servicio que les pueda brindar la empresa, más que un precio barato. 
- La metodología de enseñanza no es un factor determinante para decidir el servicio de guardería, el método Doman no es muy conocida en el mercado; sin embargo, en un mediano plazo sería un factor importante de recomendación dado los resultados y la experiencia de los niños.

- Dado que el público objetivo tiene fácil acceso a internet, más del 50\% de encuestados prefieren informarse sobre el servicio, horarios, precios, beneficios, etc. de la guardería; a través de redes sociales y página web. 


\section{Capítulo IV: Proyección del Mercado Objetivo}

\subsection{El ámbito de la proyección.}

El ámbito de proyección para este proyecto es el distrito de San Isidro, específicamente los sectores 4 y 5 de la Figura 34, donde consideramos a la población flotante y residente de los mismos.

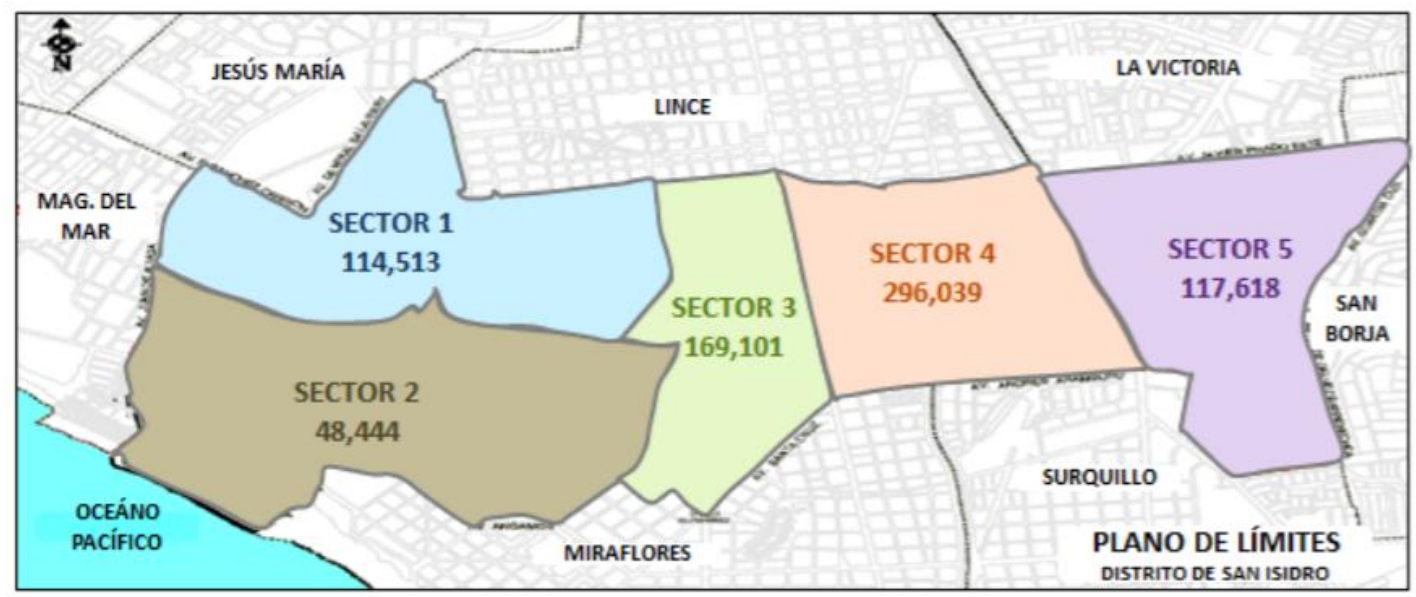

Figura 34. Mapa por sector del distrito de San Isidro. Tomado del estudio "Cuantificar y Caracterizar a la Población Flotante del distrito de San Isidro" Desarrollado por la Empresa de Investigación Arellano Marketing Elaboración: Subgerencia de Desarrollo Corporativo

\subsection{Selección del método de proyección.}

Para el presente proyecto de investigación se ha utilizado el Método de Pronóstico Visionario, dado que se hará tomando el resultado de la estimación directa del personal que trabaja en la municipalidad de San Isidro y corrigiéndola por antecedentes recopilados de una variable de fuentes atinentes al comportamiento de la economía, la natalidad, entre otras variables.

De acuerdo con Montemayor (2012) en el libro Métodos de pronósticos para negocios (2012) refiere que:

Pronostico visionario, todas las personas pueden realizar este tipo de pronóstico, sean expertas o no en el tema de interés; parte de la información que se tiene a la mano o de la experiencia, y con ello se realiza una conjetura de lo que va a suceder en el futuro, por ejemplo, cualquier persona podría dar un pronóstico de la temperatura que habrá en la ciudad de residencia al día siguiente, pero sería más difícil si a una persona cualquiera se le pidiera dar un pronóstico sobre el precio futuro de la acción de una compañía, la base de este método es la experiencia y el prestigio del experto a quien se le pide el pronóstico. (p. 8) 
Se detalla la población flotante del distrito de San Isidro como se aprecia en la Figura 35, la cual está conformada por personas mayores de 18 años que concurren diariamente al distrito por múltiples motivos, en promedio se estima que de lunes a viernes diariamente concurren al distrito. En la Tabla 16 podremos apreciar la cuantificación de dicha población.

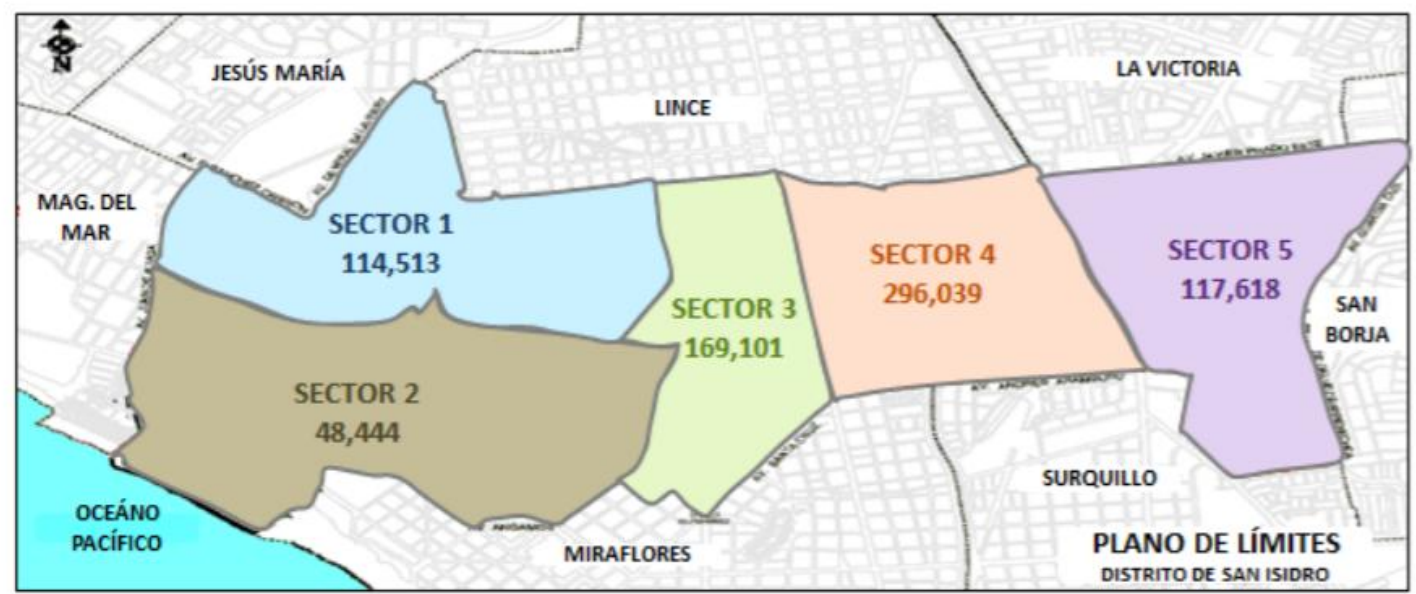

Figura 35. Mapa sectorial del distrito de San Isidro. Tomado del estudio "Cuantificar y Caracterizar a la Población Flotante del distrito de San Isidro utilizando el pronóstico visionario" Desarrollado por la Empresa de Investigación Arellano Marketing Elaboración: Subgerencia de Desarrollo Corporativo.

Tabla 16

San Isidro: Población Flotante 2016 en Miles

\begin{tabular}{lr}
\hline Sectores & $\begin{array}{l}\text { Población } \\
\text { Flotante }\end{array}$ \\
\hline Sector 1 & 114,513 \\
Sector 2 & 48,444 \\
Sector 3 & 169,101 \\
Sector 4 & 296,039 \\
Sector 5 & 117,618 \\
\hline Total & 745,715 \\
\hline
\end{tabular}

Nota. San Isidro. Población Flotante. Tomado de estudio "Cuantificar y Caracterizar a la Población Flotante del distrito de San Isidro" Desarrollado por la Empresa de Investigación Arellano Marketing Elaboración: Subgerencia de Desarrollo Corporativo

Asimismo, se cuenta con la proyección de la población residente en San Isidro proyectada por el INEI detallada en la Tabla 17, para poder determinar la demanda a partir del 2019 hasta el 2023. 
Tabla 17

Proyección de Crecimiento del Distrito y por Sectores en Miles

\begin{tabular}{crrrr}
\hline Sectores & $\begin{array}{c}\text { Población } \\
2007\end{array}$ & Porcentaje & $\begin{array}{c}\text { Población } \\
\text { Proyectada 2012 }\end{array}$ & $\begin{array}{c}\text { Población } \\
\text { Proyectada 2022 }\end{array}$ \\
\hline 1 & 13,327 & $23 \%$ & 14,162 & 16,658 \\
2 & 15,951 & $27 \%$ & 16,950 & 19,938 \\
3 & 8,457 & $15 \%$ & 8,987 & 10,571 \\
4 & 8,950 & $15 \%$ & 9,511 & 11,187 \\
5 & 10,462 & $18 \%$ & 11,117 & 13,077 \\
Otros & 909 & $2 \%$ & 966 & 1,136 \\
\hline Total & 58,056 & $100 \%$ & 61,692 & 72,567 \\
\hline
\end{tabular}

Nota: Tomado del Perfil Sociodemográfico - Censo 2007 INEI

\subsubsection{Mercado potencial.}

Según Fernández (2008) en el libro Segmentación de mercados define:

El mercado potencial, es el conjunto de consumidores que no forman parte del mercado real, pero en ocasiones si pueden formar parte del mercado disponible. Este grupo no consume el producto específico, debido a que no tiene las características del segmento o porque consume otro producto. Este concepto puede ser más claro con el siguiente ejemplo, los consumidores del mercado disponible que tiene las características para consumir el jabón líquido, pero utilizan uno en pasta.

Para la determinación del mercado potencial, se realizará tres cálculos:

Primero:

Se toma la tasa de crecimiento proyectada por el INEI, de los años 2012 al 2022, la cual da un $17.6 \%$ de crecimiento, calculo tomado del Tabla 16. Este porcentaje se extrapola a una tasa anual (1.76\%) para poder utilizarlo en la proyección de crecimiento en los cuales se realizaría el proyecto (2019 - 2023), según se muestra en la Tabla 18. Esta tasa se utilizará para la población residente en el sector 4 y 5, así como para la población flotante.

Tabla 18

Población Proyectada San Isidro en Miles

\begin{tabular}{crrrrr}
\hline Población / Años & \multicolumn{1}{c}{2019} & 2020 & \multicolumn{1}{c}{2021} & \multicolumn{1}{c}{2022} & 2023 \\
\hline $\begin{array}{c}\text { Población } \\
\text { Proyectada SI }\end{array}$ & 68,797 & 70,031 & 71,288 & 72,567 & 73,846 \\
Población Flotante & 435,885 & 443,556 & 451,363 & 459,307 & 467,391 \\
\hline Total Población & 504,682 & 513,587 & 522,651 & 531,874 & 541,237 \\
\hline
\end{tabular}


Segundo:

Del resultado obtenido en la Tabla 18, se aplicará el porcentaje de IPSOS APOYO (20\%), del perfil ama de casa a junio 2017, sobre la total población por año, mostrando un nuevo resultado en la Tabla 19.

Tabla 19

Población Total Proyectada Niños 0 - 4 Años Lima en Miles

\begin{tabular}{ll}
\hline \multicolumn{1}{c}{ Años } & Niños \\
\hline 2019 & 100,936 \\
2020 & 102,717 \\
2021 & 104,530 \\
2022 & 106,375 \\
2023 & 108,247 \\
\hline
\end{tabular}

Tercero:

Para obtener el mercado potencial al que se encuentra dirigido el proyecto, se tomará de los datos obtenidos en la Tabla 19 y de la fuente APEIM (2017), el porcentaje de 24.5 por ciento, que es el nivel socioeconómico B de Lima metropolitana. En la Tabla 20 se muestra los resultados.

Tabla 20

Mercado Potencial Proyectado de Niños 0 - 4 Años Lima

\begin{tabular}{cc}
\hline Años & Niños \\
\hline 2019 & 24,729 \\
2020 & 25,166 \\
2021 & 25,610 \\
2022 & 26,062 \\
2023 & 26,521 \\
\hline
\end{tabular}

\subsubsection{Mercado disponible.}

Según Fernández (2008) en el libro Segmentación de mercados define:

El mercado disponible, son todos aquellos consumidores que tienen una necesidad específica y cuentan con las características necesarias para consumir un producto. Un ejemplo de mercado disponible puede estar constituido por todos aquellos consumidores que tienen la necesidad de un jabón líquido para manos, y que además cuentan con las características de poder adquisitivo, costumbre, etc., para comprarlo. (p. 3) 
Se ha hecho uso de fuentes secundarias para poder determinar el mercado disponible, la fuente secundaria más real, fidedigna y confiable es la de INEI, donde indica que el $65.50 \%$ de padres, tienen la necesidad de dejar encargado a terceros, léase abuelos, guarderías, nidos, nanas a sus hijos, pues ambos padres trabajan. Se ha hecho uso de esta data secundaria dado que es la más actual y confiable que se ha tenido. También se ha podido tomar como elemento de castigo el estudio de fuente de información primaria que se ha realizado para este estudio en la pregunta número "4", sin embargo, se castiga mucho la demanda y además hay que tener en cuenta que este estudio ha sido no probabilístico basado en un juicio apoyado en conveniencia. Los resultados se pueden apreciar en la Tabla 21.

Tabla 21

Mercado Disponible SI Proyectados Niños 0 - 4 Años Lima en Miles

\begin{tabular}{lc}
\hline \multicolumn{1}{c}{ Años } & Niños \\
\hline 2019 & 16,198 \\
2020 & 16,484 \\
2021 & 16,774 \\
2022 & 17,070 \\
2023 & 17,371 \\
\hline
\end{tabular}

\subsubsection{Mercado efectivo.}

Según Fernández (2008) en el libro Segmentación de mercados define:

El mercado efectivo o real son todos aquellos consumidores del mercado disponible que compran un producto o servicio específico. El ejemplo seria todos aquellos consumidores que compran el jabón líquido. En esta primera clasificación es importante notar que no todos aquellos consumidores que tienen una necesidad y las características específicas para comprar un producto serán consumidores reales, pero si son consumidores disponibles. (p.3)

Según McDaniel y Gates (1999), en el libro Investigación de Mercados

Contemporánea menciona que:

Quizá la escala más empleada en la investigación comercial de mercados sea la “escala de intención de compra”. Lo más importante para los gerentes de mercado es determinar si los clientes comprarán el producto o no y, en caso afirmativo, qué porcentaje del mercado cabe obtener. Normalmente, los detallistas -e incluso las organizaciones no lucrativas- plantean la pregunta sobre intención de compra en relación con todos los productos y servicios nuevos o sus modificaciones. 
Las compañías de investigación de mercados llevan a cabo estudios que contienen una escala de intención de compra, pero el cliente no cuenta con datos históricos sobre su uso para tomarlos como base a fin de sopesar los datos. Una estimación razonable pero conservadora sería que el 70 por ciento de quienes indican que "van a comprar" el producto o servicio lo adquirirán, al igual que 35 por ciento de los que indican que "quizá lo compren", un 10 por ciento de los que comentan que "quizá no lo compren" y un 0 por ciento de los que dicen que "no lo comprarán". Es común que se observen pesos más altos en el mercado industrial. (p. 338,340)

En el presente trabajo, el mercado efectivo estará determinado por la pregunta 30 (ver Figura 36) del cuestionario y la subsecuente aplicación de McDaniels a la proyección del mercado disponible.

Pregunta 30. Luego de haberse informado de este nuevo proyecto. ¿Qué tan dispuesto estaría usted a utilizar los servicios de la guardería?

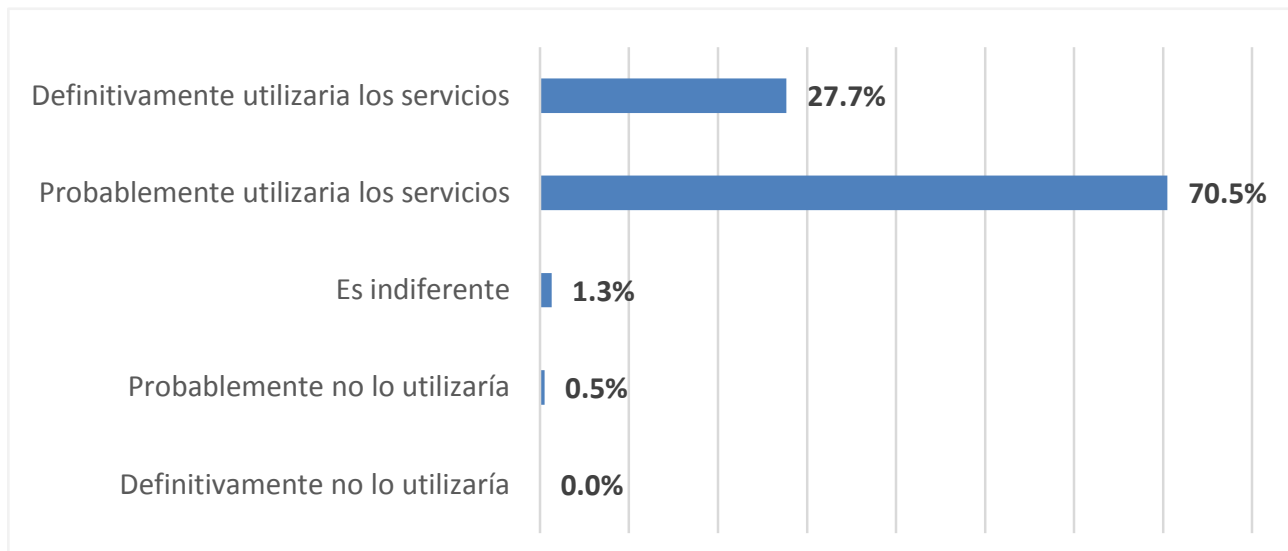

Figura 36. Probabilidad de que las personas encuestadas utilicen la guardería Fuente: Encuesta de Investigación de Mercados.

Teniendo presente que luego del resultado obtenido en las encuestas, se aplicara la teoría de McDaniels donde el porcentaje obtenido en la respuesta de "Definitivamente utilizaría los servicios" (28\%), se le asignó el 70\%; a la respuesta "Probablemente utilizaría los servicios" (71\%), se le asignó un 35\%; y a la respuesta de "Probablemente no iría" (1\%), se le asignó el 10\%, esta operación se muestra en la Tabla 22 como resultado de la aplicación y cálculo realizado: 
Tabla 22

Aplicación de la Teoría Mc Daniels

\begin{tabular}{rrr}
\hline $\begin{array}{c}\text { Porcentaje } \\
\text { encuesta }\end{array}$ & $\begin{array}{c}\text { Aplicación } \\
\text { McDaniels }\end{array}$ & Resultado \\
\hline $28 \%$ & $70 \%$ & $19.6 \%$ \\
$71 \%$ & $35 \%$ & $24.9 \%$ \\
$1 \%$ & $10 \%$ & $0.1 \%$ \\
\hline & Total & $\mathbf{4 4 . 6 0 \%}$ \\
\hline
\end{tabular}

En la Tabla 23 se muestra el resultado por año proyectado, el cual se halla del cálculo de la multiplicación del mercado disponible proyectado, por el resultado de la aplicación de McDaniels 44.6\%.

Tabla 23

Mercado Efectivo Proyectados Niños 0 - 4 Años Lima en Miles

\begin{tabular}{cc}
\hline Años & Niños \\
\hline 2019 & 7,224 \\
2020 & 7,352 \\
2021 & 7,481 \\
2022 & 7,613 \\
2023 & 7,747 \\
\hline
\end{tabular}

\subsubsection{Mercado objetivo.}

Según Fernández (2008) en el libro Segmentación de mercados define:

El mercado objetivo o mercado meta, puede definirse como el conjunto de consumidores que pertenecen al mercado disponible, que pueden formar parte del mercado real y potencial, y al cual se dirigen todos los esfuerzos y acciones mercadológicos de la empresa, con la finalidad de que todos ellos logren convertirse en consumidores reales del producto o servicio.

Dentro del mercado objetivo debemos considerar dos tipos de mercado: Primario, se refiere a todos aquellos consumidores directos, que tienen la decisión de compra y que realizan las actividades de selección y evaluación del producto o servicio. Secundario, se refiere a todos aquellos consumidores que, a pesar de tener contacto con el producto o servicio, no son decisores de compra, y en ocasiones tampoco realizan las actividades de evaluación del mismo. (p. 3) Para hallar el mercado objetivo, se utilizó el método Delphi, que también se conoce 
como método Delfos es un método práctico que es utilizado para la resolución y determinación de problemas de forma abierta; es una técnica de investigación que se utiliza con el propósito de realizar pronósticos y predicciones. En otras palabras, es un método de pronóstico sistemático que implica la interacción estructurada entre un grupo de expertos en un tema. La Técnica Delphi incluye típicamente al menos dos rondas de expertos respondiendo preguntas y dando justificación de sus respuestas, proporcionando la oportunidad entre las rondas de cambios y revisiones. Las múltiples rondas, que se obtuvo después de un criterio predefinido se alcanzan, y activa el grupo de expertos para llegar a un pronóstico de consenso sobre el tema que se discute.

Recuperado de https://conceptodefinicion.de/metodo-delphi/

Este método se aplicará para obtener el porcentaje de crecimiento por año detallado en la Tabla 24. Una vez tomado el porcentaje de crecimiento por año de la Tabla 24, se multiplica dicho porcentaje por los resultados obtenidos en la Tabla 23 del mercado efectivo. Los resultados obtenidos se observarán en la Tabla 25, el cual indica el target alcanzable proyectado por año.

Se entrevistaron a dos expertas en el rubro con ayuda de una guía de pautas (apéndice U, V) a la Licenciada Daniela Centurión quien es directora de la Cuna-Guardería "La Casita de Luna" con más de 10 años de experiencia en el rubro y a la Licenciada Lizbeth Alfaro quien es directora del Nido-Guardería "Virgen de la Merced" con más de 8 años de experiencia.

Tabla 24

Proyección de Crecimiento de la Guardería

\begin{tabular}{lr}
\hline \multicolumn{1}{c}{ Años } & $\begin{array}{l}\text { Crecimiento } \\
\text { Proyectado }\end{array}$ \\
\hline Primer año & $0.42 \%$ \\
Segundo año & $1.40 \%$ \\
Tercer año & $1.30 \%$ \\
Cuarto año & $1.15 \%$ \\
Quinto año & $1.08 \%$ \\
\hline
\end{tabular}

Tabla 25

Mercado Objetivo Proyectado Niños O -4 Años Lima

\begin{tabular}{lc}
\hline Años & Niños \\
\hline 2019 & 30 \\
2020 & 42 \\
2021 & 54 \\
2022 & 63 \\
2023 & 68 \\
\hline
\end{tabular}




\section{Capítulo V: Plan de Marketing}

\subsection{Estrategias de marketing}

Las diferentes características del mercado de guarderías en la zona de estudio, permite determinar que existe una oportunidad para que Titinos Daycare pueda alcanzar sus objetivos de venta con una estrategia de enfoque de alto valor, la misma que se evidencia en la diferenciación por la ubicación, infraestructura y horario extendido, los cuales generan confianza y seguridad en los padres, ya que al estar cerca de su centro de trabajo ahorran tiempo y emocionalmente sienten tranquilidad sobre el cuidado de sus hijos, lo que finalmente les permite mantener su productividad.

Objetivos de Marketing

A continuación, se presentan los objetivos generales y específicos, los cuales han sido planteados bajo la metodología SMART - Specific (específico), Measurable (Medible), Achievable (Alcanzable), Relevant (Relevante), Timel-bound (a Tiempo)

- Alcanzar un crecimiento ascendente y sostenible de ocupabilidad de las instalaciones, el cual debe ser mayor al 30\% para los años 2 y 3 (respecto al año 1) y mayor al $10 \%$ para los años 4 y 5 (respecto al año 3).

- Lograr ser la marca de referencia en guarderías al quinto año de funcionamiento (notoriedad de marca).

- Implementar desde el primer año un programa de referidos donde se alcance a contactar como mínimo un referido por cada cliente, en el plazo de 3 meses. Esto permite lograr fidelizar a los clientes y mantener la relación comercial a largo plazo.

- Realizar como mínimo una presentación mensual en empresas aledañas de la zona, ofreciendo convenios corporativos con beneficios para su personal donde se logre que por lo menos dos personas asistentes visiten las instalaciones de la guardería.

- Lograr la estandarización de calidad al tercer trimestre de funcionamiento, que generen una mejor experiencia en el cuidado de los infantes, para ello se trabajara en capacitar al personal en los procesos y protocolos con evaluaciones durante su permanencia.

- Conseguir un nivel de satisfacción de los clientes por encima del 70\% para el segundo año, el cual será medido a través de encuestas que se realizarán de forma semestral. 
- Crecer y expandir el concepto hacia otras zonas empresariales ubicadas dentro y fuera del distrito de San Isidro, al cierre del quinto año de funcionamiento.

\section{Público Objetivo}

Titinos Daycare es una guardería infantil cuyo público objetivo está conformado por hombre o mujer jefe de familia de 25 años de edad a más, perteneciente al nivel socioeconómico B; que trabajan en la zona financiera de San Isidro, con hijos menores de 36 meses y que tienen la necesidad de encargar el cuidado de sus hijos a terceros.

Titinos Daycare ofrece como parte del servicio la estimulación temprana para los infantes, el cual se desarrolla bajo la metodología Doman como un mecanismo de aprendizaje para desarrollar habilidades que les permitan a los infantes tener un desarrollo integral donde se estimulará el aspecto físico, cognitivo, linguiístico, artístico y emocional; así también, la finalidad es ofrecer horarios que puedan adaptarse a los requerimientos y necesidades de las familias modernas y/o trabajadores que tienen que postergar su crecimiento profesional a cambio de no descuidar el cuidado y seguridad de sus pequeños.

\subsubsection{Estrategia de producto}

El producto educativo es un conjunto de componentes tangibles e intangibles que incluyen recursos atractivos, infraestructura, actividades recreativas, metodología de trabajo, tecnología, imágenes y valores simbólicos, que son percibidos como una experiencia formativa, de calidad, seguridad y de excelencia educativa.

\section{Producto Principal (Servicio)}

El servicio principal de Titinos Daycare es ofrecer el cuidado permanente y seguro a infantes en un ambiente agradable y de armonía, centrándose en el mercado al cual se dirige, de quienes tienen la necesidad de encargar en horarios de oficina, el cuidado de sus menores a terceros con la finalidad de continuar diariamente con sus actividades laborales y profesionales, la misma que satisface las necesidades de auto realización, reconocimiento y seguridad, según la pirámide de Maslow que se muestra en la Figura 37. 


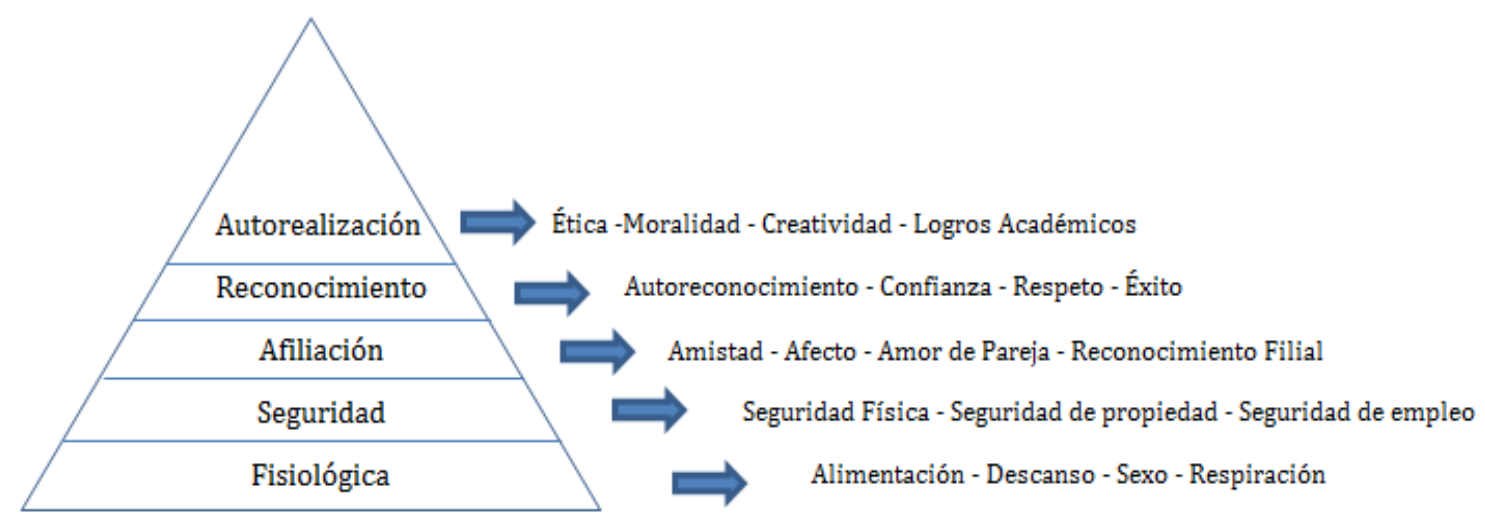

Figura 37. Pirámide de la Motivación de Abraham Maslow. Tomado de "Servicio y Mercadeo de Servicios" por Camacho, J., (2008). Recuperado de http://biblioteca.utec.edu.sv/siab/virtual/elibros_internet/55788.pdf

Plan de Producto

Teniendo en cuenta la estrategia de la empresa, esta se apoyará en:

- Diferenciación en la Oferta: Además de cuidados a los infantes, la empresa contará con espacios lúdicos y áreas complementarias, así como la “atmósfera de servicios" que supone un incentivo sensorial para los clientes.

- Diferenciación basada en la Entrega: Hace referencia a la prestación del servicio, es decir el trato que recibe el cliente por parte del personal desde el momento en el que ingresa a las instalaciones. El personal de la empresa usará uniforme para transmitir confianza y familiaridad. También se creará un manual de actuación donde se recogerán las pautas a seguir por el personal a la hora de atender a los clientes, así como el aspecto, el trato y la actitud.

\section{Definición del producto}

Se caracteriza por situarse en un entorno de zona financiera y por su ubicación cerca a la vía principal de San Isidro. El local se compone de espacio-ambiente como la zona de juegos, zona de comedor, zona de aseo e higiene, zona de descanso y zona de talleres; un espacio para la dirección y secretaría que podrá ser usado como sala para el personal educativo y un espacio de aseo para el personal general.

Para crear la "atmósfera de servicios" la decoración interior se basará de acuerdo con la reglamentación dada por el ministerio de educación. Ofrecerá unas instalaciones muy cuidadas con una decoración en tonos pasteles proporcionando un ambiente de armonía, orden y limpieza. 
La guardería dispone de cámaras IP (video vigilancia en tiempo real) ubicados en lugares estratégicos, así también el personal de la guardería mostrará visiblemente un fotocheck de identificación, las instalaciones serán en la planta del primer piso del local con puerta principal y de emergencia, los ambientes se identificarán por grupos de acuerdo a las edades (Durmientes, Gateadores, Caminantes y exploradores).

Las dimensiones del producto

El producto está conformado por elementos tangibles e intangibles, lo que da lugar a las cinco dimensiones del producto (véase Figura38)

- Beneficio básico: Es el servicio básico que busca el cliente. En el caso de la Guardería formación básica, cuidado, seguridad y entretenimiento.

- Producto genérico: Instalaciones que permiten la prestación del servicio fundamental, incluye ambientes adecuados según las edades de los infantes, lugar de descanso, comedor, cocina, espacio lúdico, recreativo, servicios higiénicos, sala de espera de padres y oficinas administrativa y académica.

- Producto esperado: Instalaciones que nos diferencien de los competidores. Esto estaría compartido por el equipamiento, horarios y tecnología propuesta.

- Producto aumentado: Atributos de diferenciación, cámaras IP, modelo educativo innovador, taller de padres, y convenio con programas educativos.

- Producto Potencial: Atributos que la empresa colocará en un futuro para adaptarse al cambio. Mejoras en tecnología de cámaras IP, nuevos talleres recreacionales y formación progresiva de cómo contribuir a la conservación del medio ambiente.

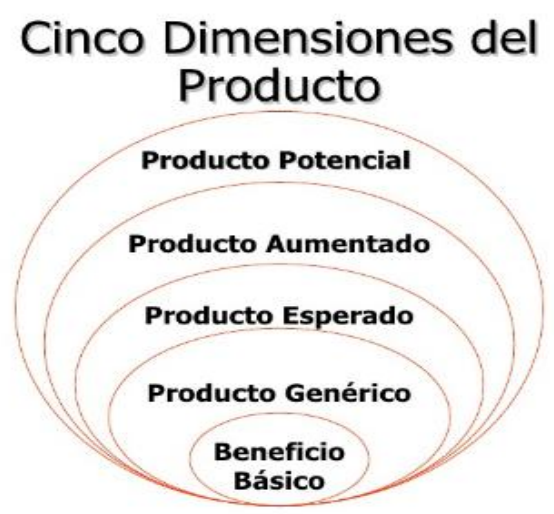

Figura 38. Cinco dimensiones de un producto. Tomado de Dirección de Marketing (p. No. 388) por Kotler P. y Keller K., 2006, España: PEARSON Prentice Hall, copyright 2006. 


\section{La Marca}

Para este proyecto de guardería, la creación de marca y la recordación son muy importantes para poder captar y mantener a un cliente. Al crear la marca de la guardería observaremos lo siguiente:

Identidad de la Marca:

- Grado: El grado es emocional, ya que en cada etapa de crecimiento y desarrollo del infante hay un motivo sentimental y de gratitud para los padres. La marca será emocional.

- Físico: La marca es una guardería localizado en la zona de Santa Catalina - La Victoria, con una infraestructura adecuada y segura, con una distribución por tipo de desplazamiento y edades de los infantes, ambientados con colores cálidos y alegres; así también, busca beneficiar a los infantes en el cuidado amoroso, atención y enseñanza especializada, así como para los padres en el crecimiento y realización profesional, y personal, ya que sienten la tranquilidad de que sus hijos están en un lugar seguro y de confianza.

- Personalidad

Tranquilidad: Disfrutar de un ambiente armonioso y cálido que este en sintonía con las actividades del día día. Mantener una distribución por edades permite un adecuado seguimiento y cuidado a los niños, así también el contar con acceso a tecnología para ver a sus niños en tiempo real será de tranquilidad para los padres. Seguridad: Un ambiente seguro y adecuado bajo las normas establecidas por el ente regulador que gozará de una infraestructura y mantenimiento constante, el personal que estará a su cuidado será empático y afectivo hacia los demás.

Sincero: Muestra y ofrece de forma responsable lo que realmente es.

Clima relación:

- El beneficio emocional: que hace sentir a los padres al ver a sus hijos bien cuidados, alegres y de crecimiento constante.

- Tipo de relación: Aspectos positivos que hacen sentir a los padres al encargar a sus niños en la guardería.

Mentalización:

Son los auto conceptos que el cliente se da con la marca, por ejemplo: me siento bien y tranquilo de saber que mi hijo está bien cuidado con esta marca; merezco auto realizarme, ser reconocido profesional y personalmente, me siento feliz con esta marca. 
Reflejo deseado:

El grupo objetivo desea recibir un servicio educativo y cuidados de calidad, en un lugar de calidad; no desean los tipos de guarderías informales sin las debidas normas de seguridad e infraestructura precaria y que no dan lo que ofrecen.

Universo cultural:

Mantener el crecimiento profesional y laboral sin descuidar a su entorno familiar, manteniendo una calidad de vida adecuada y de acuerdo con sus ingresos. Disfrutar del tiempo disponible o libre sin preocuparse por no tener a quien encargar el cuidado de su niño y la distancia que esta pueda tener de su centro de labores hacia la guardería.

Describir la imagen de la referencia:

- Si fuera una fruta, sería una manzana

- Si fuera un animal, sería un osito

- Si fuera una casa, sería una casa grande y bonita de colores vistosos.

- Si fuera un recuerdo familiar, sería la abuela consentidora de sus nietos.

Definición posicionamiento de marca:

Esta marca es mi mejor recuerdo

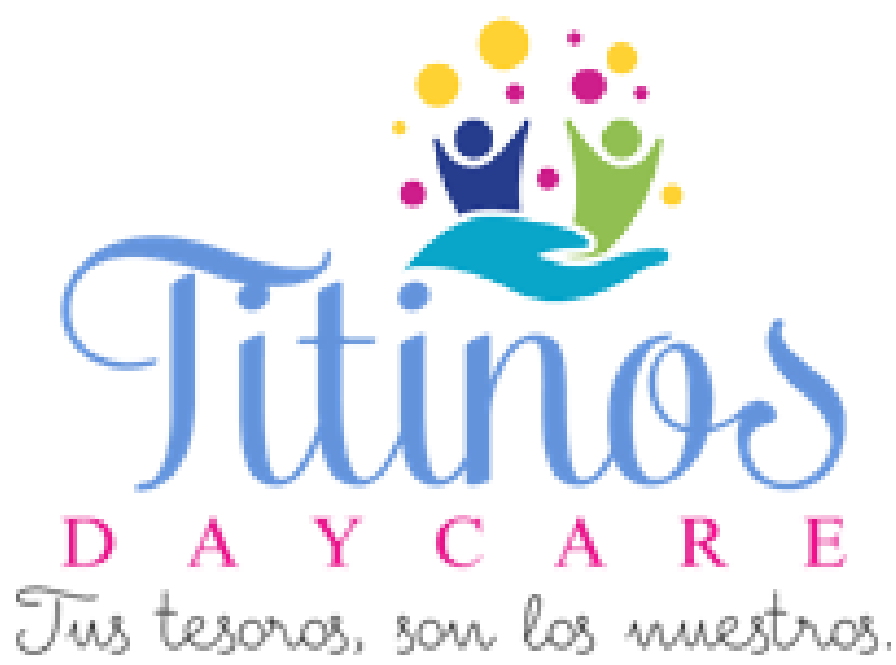

Figura 39. Logotipo de la marca Titinos Daycare.

Marca: La marca Titinos Daycare proviene de la palabra cariñosa con la que una abuela amorosa trataba a sus nietos. Así también ha sido elegido porque obtuvo una preferencia del $28 \%$ en el estudio realizado de la investigación de mercado.

Logotipo: Posee un concepto de protección. Está diseñado por una tipografía que tiene el nombre de la marca en letras y un gran peso visual de colores vistosos y alegres, 
predominando el turquesa y fucsia como nombre principal que simboliza a hombre y mujer; también incluye un dibujo de formas de niños felices sostenidos por la gráfica de una mano, el cual simboliza la protección, el sostenimiento y cuidado hacia los niños (véase la figura 39).

Slogan: Refuerza la filosofía de la guardería enfocado en el amor, cuidado y protección a los niños. "Tus tesoros, son los nuestros.”, frase que se muestra en la figura 39.

\subsubsection{Estrategia de precio}

Para la determinación del precio del producto que ofrece Titinos Daycare se utilizó la estrategia desnatada o descreme; el cual "consiste en que las empresas que introducen algún

tipo de innovación en el mercado suelen fijar inicialmente precios elevados para seleccionar y aprovechar al máximo el mercado" (Kotler, 2006, p. 461)

Así también, se sustenta en base a la evaluación de los costos en los que incurren, y los precios de los competidores directos del negocio según se muestra en la Tabla 26, el cual permitirá obtener rentabilidad. 
Tabla 26

Precios de la Competencia

\begin{tabular}{|c|c|c|c|c|c|c|c|}
\hline Institución & Primeros Pasos & Verde Limón & Star kids I y II & Palitroques & My world & Smart Kid & Mundo de Colores \\
\hline Tipo & $\begin{array}{l}\text { Cuna / Guardería, Nido } \\
\text { Jardín }\end{array}$ & Cuna / Guardería & Cuna, Nido, Guardería & $\begin{array}{l}\text { Cuna / Jardín / } \\
\text { Guardería }\end{array}$ & $\begin{array}{l}\text { Inicial / Jardín / } \\
\text { Guardería }\end{array}$ & Cuna / Jardín & $\begin{array}{l}\text { Cuna / Guardería, Nido } \\
\text { Jardín }\end{array}$ \\
\hline Modalidad & Particular & Particular & Particular & Particular & Particular & Particular & Particular \\
\hline Ubicación & Sta. Catalina La Victoria & Sta. Catalina La Victoria & Sta. Catalina La Victoria & San Isidro & Urb. Corpac. San Isidro & Urb. Corpac. San Isidro & Sta. Catalina La Victoria \\
\hline Metodología & No & No & Montessori & Optimist & Desarrollo Neuromotor & Optimist & Reggio Emilia \\
\hline Alimentación & $\mathrm{Si}$ & $\begin{array}{l}\text { En horario de } 7-4 \mathrm{pm} \mathrm{y} \\
7-7 \mathrm{pm}\end{array}$ & (Opcional) S/ 150 más & No & - & - & - \\
\hline Horario & 8:00 am. a $6: 00 \mathrm{pm}$ & $\begin{array}{l}\text { 7:00am-1:00pm, 7:00- } \\
\text { 4:00pm, 7:00am- } \\
\text { 7:00pm. }\end{array}$ & $\begin{array}{l}\text { Nido: 8:30am.-1.15pm/ } \\
\text { Guardería: } 1.15 \mathrm{pm}- \\
\text { 5:30pm. }\end{array}$ & $\begin{array}{l}\text { Nido: 8:30am.-1pm/ } \\
\text { Guardería: } 1 \mathrm{pm}- \\
\text { 5:30pm. }\end{array}$ & 8:00 am. a 2:00pm & $8: 00$ am. a $5: 30 \mathrm{pm}$ & 8:00 am. a 6:00pm \\
\hline Precios -Matricula & No - otorga materiales & $\begin{array}{l}\text { No cobra - otorga } \\
\text { materiales }\end{array}$ & No & S/ 650 inc. Materiales & S/ 500 inc. materiales & $\begin{array}{l}\text { S/ } 500 \text { no inc. } \\
\text { materiales }\end{array}$ & S/ 380 inc. materiales \\
\hline Precios - Pensión & S/ 700 & $\mathrm{~S} / 400, \mathrm{~S} / 650$ y $\mathrm{S} / 750$ & $\begin{array}{l}\mathrm{S} / 800+\mathrm{S} / 200 \\
\text { (guardería) }\end{array}$ & $\mathrm{S} / 850$ & $\mathrm{~S} / 850$ & $\mathrm{~S} / 850$ & $\mathrm{~S} / 500$ \\
\hline Niños & De 6 meses a 3 años & De 6 meses a 3 años & De 6 meses a 3 años & De 6 meses a 3 años & De 6 meses a 3 años & De 6 meses a 3 años & De 6 meses a 3 años \\
\hline Observación 1 & $\begin{array}{l}\text { De difícil acceso por } \\
\text { rejas cerradas en las } \\
\text { calles }\end{array}$ & $\begin{array}{l}\text { No destaca nombre del } \\
\text { negocio, de difícil } \\
\text { acceso por calle con } \\
\text { rejas a pesar de la } \\
\text { cercanía a la avenida } \\
\text { principal }\end{array}$ & $\begin{array}{l}\text { Local de colores } \\
\text { vistosos y diseño } \\
\text { adecuado, local } \\
\text { pequeño, cercano al } \\
\text { parque y de fácil } \\
\text { acceso. }\end{array}$ & $\begin{array}{l}\text { De fácil acceso a la } \\
\text { avenida principal, buena } \\
\text { ubicación entre avenidas } \\
\text { principales. }\end{array}$ & $\begin{array}{l}\text { De fácil acceso, } \\
\text { dificultad en horas punta } \\
\text { por gestión de tráfico. }\end{array}$ & $\begin{array}{l}\text { De fácil acceso, } \\
\text { dificultad en horas punta }\end{array}$ & $\begin{array}{l}\text { Escasa publicidad en el lugar, } \\
\text { de difícil acceso por rejas } \\
\text { cerradas en las calles }\end{array}$ \\
\hline Observación 2 & $\begin{array}{l}\text { Lugar visible con } \\
\text { publicidad, cerca de un } \\
\text { parque con cámaras de } \\
\text { seguridad en la zona, } \\
\text { calles sin mucho tráfico. }\end{array}$ & $\begin{array}{l}\text { Ubicación vistosa por } \\
\text { colores y diseño, } \\
\text { Publicidad en cartel en } \\
\text { avenida, zona tranquila, } \\
\text { frente a la Parroquia. }\end{array}$ & $\begin{array}{l}\text { Cercanía a empresas } \\
\text { como: Interbank, } \\
\text { Química Suiza, Grupo } \\
\text { Deltron, Ajinomoto, etc. }\end{array}$ & $\begin{array}{l}\text { Publicidad vistosa, local } \\
\text { de colores y diseño } \\
\text { adecuado al negocio. }\end{array}$ & $\begin{array}{l}\text { Local de colores } \\
\text { vistosos y diseño } \\
\text { adecuado al negocio, } \\
\text { cercano al parque. }\end{array}$ & $\begin{array}{l}\text { Local de colores } \\
\text { vistosos y diseño } \\
\text { adecuado al negocio, } \\
\text { cercano al parque. }\end{array}$ & $\begin{array}{l}\text { Zona aparente tranquila, sin } \\
\text { mayor tráfico en las calles, } \\
\text { frente a un parque }\end{array}$ \\
\hline
\end{tabular}


Del mismo modo; de la investigación del estudio de mercado realizado en el capítulo 3, se evaluó la intención de pago que los productos tendrán según se muestra en la Tabla 27 y Figura 40, así también se tomó como referencia la información recabada de las encuestas y sugerencias dadas en el focus group.

Tabla 27

Resultado de Intención de Pago - Investigación de Mercados

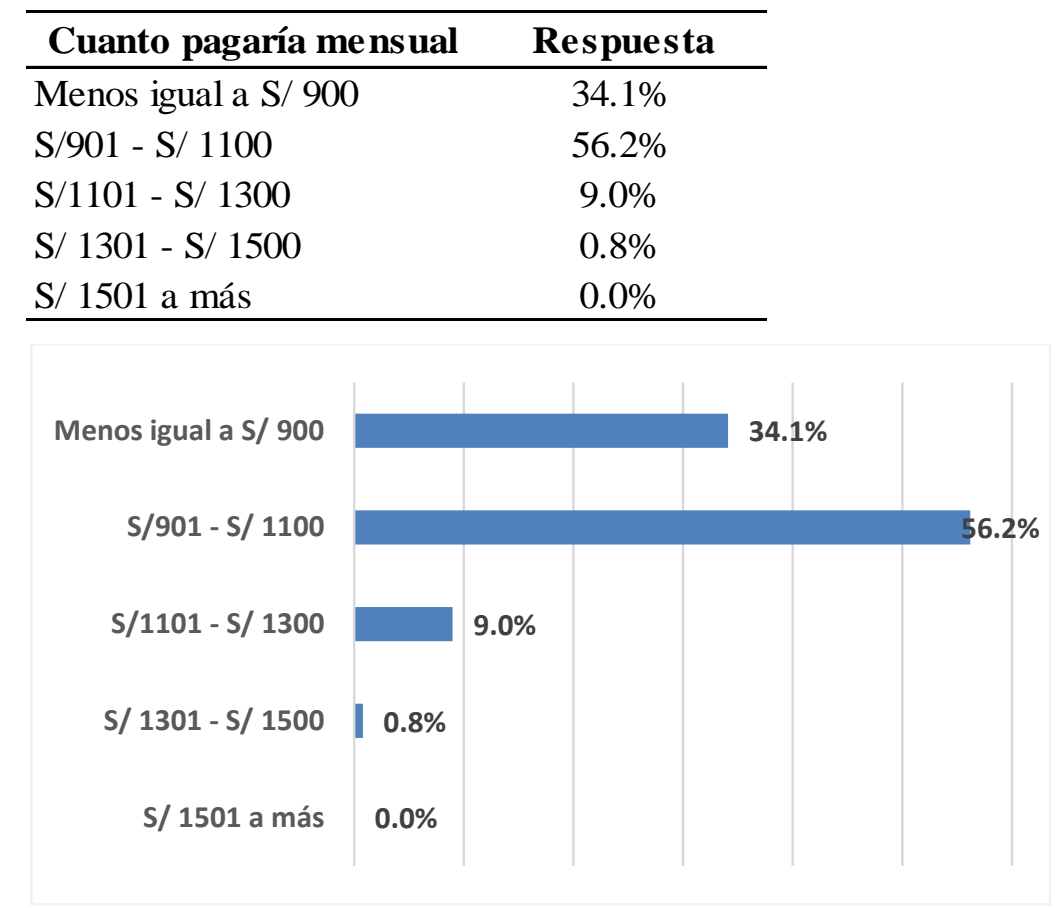

Figura 40. Resultado de intención de pago

Del mismo modo, el ofrecer un lugar donde integre 3 conceptos: (a) calidad en el servicio y seguridad, (b) ampliación de horarios, y (c) metodología innovadora, según la investigación de estudio realizada, gana credibilidad por la oferta de servicios que se ofrecerá en el establecimiento.

Con estas variables se buscó fijar un precio de introducción para el cliente, el cual sea atractivo para nuestro público objetivo y resulte en utilidades para la empresa. Cabe mencionar que los precios establecidos no pueden ser muy distintos al de la competencia ya que podría relacionarse el precio bajo con disminución en la calidad del producto.

En función a la estrategia fijada, concluimos que la estrategia de precios definida para Titinos Daycare es la que se muestra en la Tabla 28. 
Tabla 28

Estrategia de Precios Titinos Daycare

\begin{tabular}{ll}
\hline Institución & Titinos Daycare \\
\hline Tipo & Guardería \\
Modalidad & Particular \\
Ubicación & Sta. Catalina La Victoria \\
Metodología & Método Doman \\
Alimentación & No \\
Horario & $8: 00$ am. - 7:00pm. \\
Precios -Matricula & S/400 \\
Precios - Pensión & S/825 \\
Niños & De 3 meses a 3 años \\
Servicios incluidos & Estimulación temprana metodología Doman, Taller \\
& de escuela para padres. \\
& Acceso rápido, entrada por la vía expresa o Javier \\
Observación 1 & Prado. Instalaciones en el primer piso, vista frente al \\
& parque. \\
& Cercanía a empresas como: Interbank, Química \\
Observación 2 & Suiza, Grupo Deltron, Ajinomoto, etc. \\
& Estacionamiento público de amplias calles. \\
\hline
\end{tabular}

\subsubsection{Estrategia de plaza (distribución)}

En cuanto a la ubicación o plaza para este proyecto se consideró distintas variables; el factor primordial para la elección fue la ubicación del público objetivo y cercanía a sus centros de labores (ver Figura 41), la misma que se determinó en la zona empresarial y comercial del distrito de San Isidro.

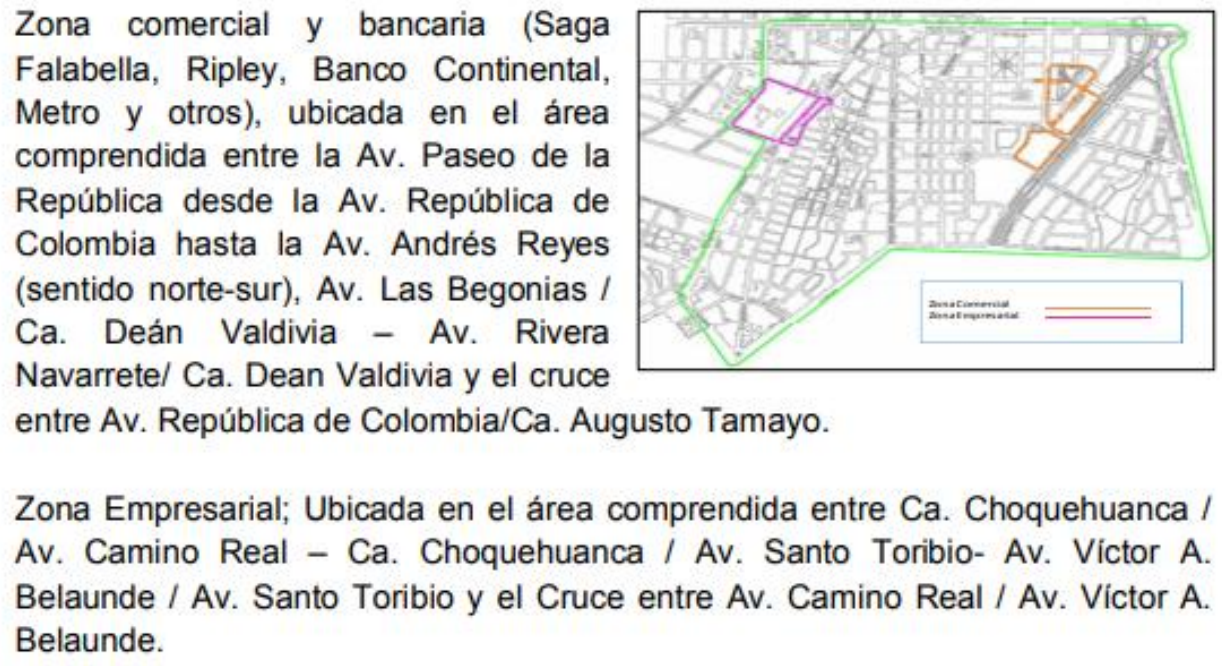

Figura 41. Ubicación de la plaza para el público objetivo. Tomado del Plan Urbano Distrital 20122022 - San Isidro 
En cuanto al canal de distribución, la estrategia que se va a emplear es la venta directa, ya que los consumidores deberán apersonarse a nuestro establecimiento, y por ende se logrará la relación directa entre el productor y consumidor.

Así también se emplearán herramientas como canal directo, a través de teléfonos de contacto (fijo y celular) o correo electrónico que estarán disponibles para las consultas e informes del servicio de guardería; así como las visitas programadas en la guardería o en los centros de trabajo de los interesados.

Titinos Daycare cuenta con una página web amigable con toda la información de horarios, servicios ofrecidos, beneficios y precios requeridos. La presencia activa en las redes sociales como Facebook, Instagram y el AdWords de Google potencializara la construcción de la marca abriendo un diálogo y cercanía con el posible comprador.

\subsubsection{Estrategia de promoción y publicidad}

A través de esta estrategia se busca lograr que el público objetivo pueda conocer las cualidades de la guardería y se sienta atraído por la idea de conocer las instalaciones, donde se les brindará información más detallada y se le mostrará todos los ambientes de la guardería.

Mensaje a difundir:

Hacer de conocimiento del público objetivo los servicios y ventajas competitivas que ofrece la Guardería Titinos Daycare respecto a:

- Infraestructura: Mostrar fotos y/o videos de las instalaciones y dar facilidades para que los padres puedan realizar visitas guiadas.

- Ubicación: A través del mapa satelital mostrar las vías de acceso y la cercanía que hay con la zona empresarial de San Isidro, (véase Figura 42) 


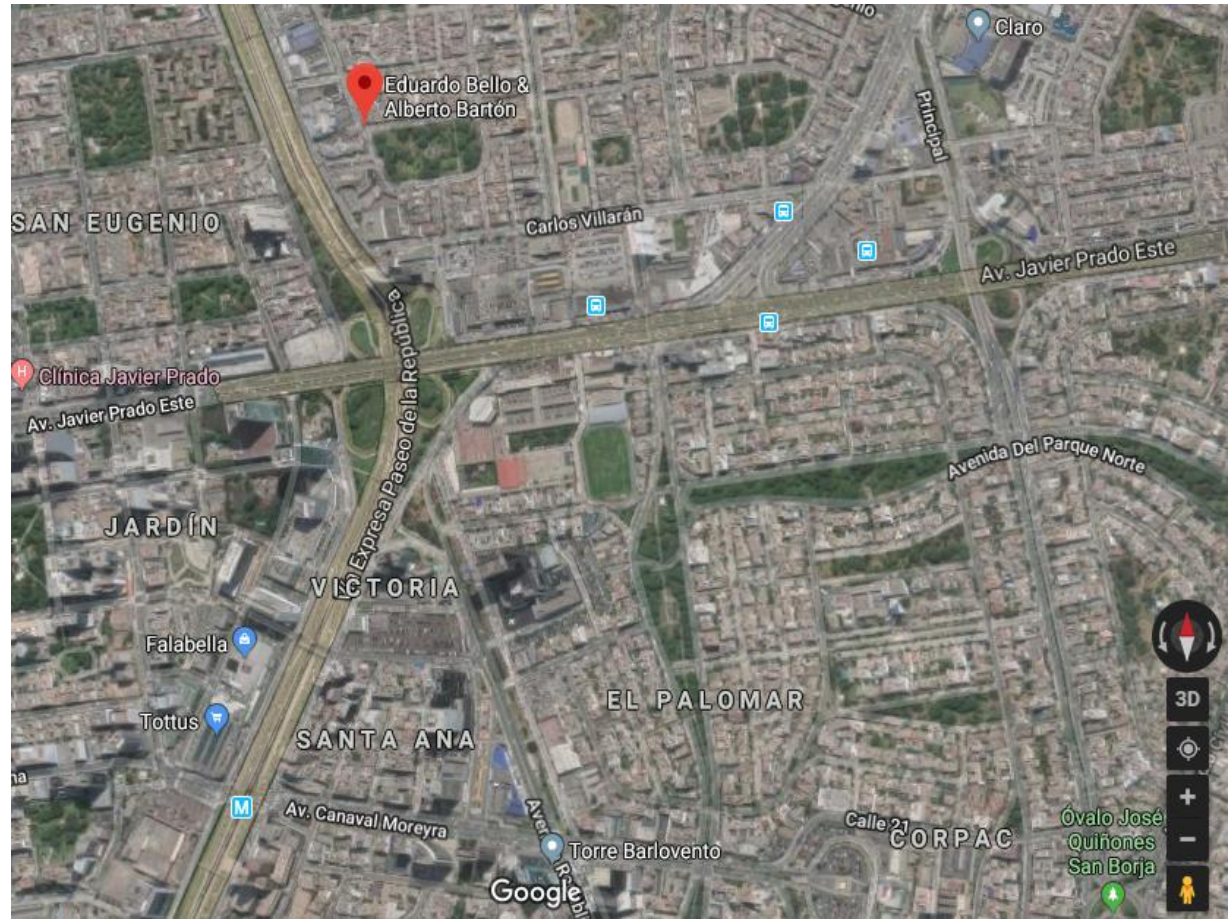

Figura 42. Estrategia de promoción y publicidad -Ubicación. Recuperado de https://www.google.com.pe/maps/place/Eduardo+Bello+\%26+Alberto+Bart\%C3\%B3n,+La+Victoria +15034/@-12.0973785,-

$77.0305827,3006 \mathrm{~m} /$ data $=! 3 \mathrm{~m} 1 ! 1 \mathrm{e} 3 ! 4 \mathrm{~m} 5 ! 3 \mathrm{~m} 4 ! 1 \mathrm{~s} 0 \times 9105 \mathrm{c} 862 \mathrm{e} 7580341: 0 x f 7 \mathrm{~d} 47303 \mathrm{db} 7 \mathrm{e} 0758 ! 8 \mathrm{~m} 2 ! 3 \mathrm{~d}$ $-12.0875542 ! 4 \mathrm{~d}-77.0232853$ ?hl=es-419\&authuser $=0$

- Horario: Ofrecer horario extendido; la ventaja de la cercanía a su centro de trabajo permite a los padres llevar y recoger a sus hijos sin contratiempos.

- Metodología de enseñanza: Poner en conocimiento a los padres sobre las ventajas que tiene la aplicación del método Doman en infantes menores de 3 años.

- Seguridad y Confianza: Poner en conocimiento a los padres sobre el servicio y la importancia de la video vigilancia en tiempo real y la opción de hacer seguimiento de las actividades y cuidados que reciben sus hijos a través de su Smartphone.

- Presentación: El personal deberá estar identificado a través del uniforme de la institución (ver Figura 43); y la información básica de todos ellos con su fotografía, será proporcionada a los padres al momento de la matrícula. 


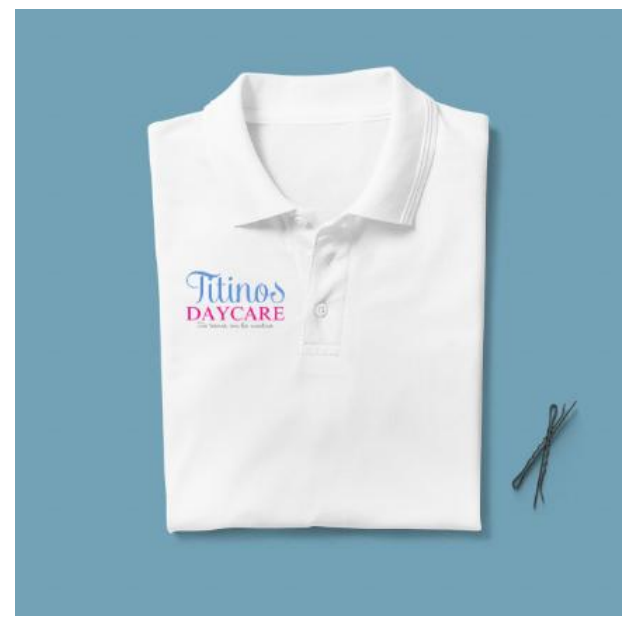

Figura 43. Estrategia de promoción y publicidad -Uniforme

- Filosofía Titinos Daycare: Difundir que la filosofía de la guardería está enfocada en el amor, cuidado y protección hacia los infantes, este ambiente genera confianza y mejora la capacidad de aprendizaje de los infantes; la palabra Titinos Daycare proviene de la palabra cariñosa con la que una abuela amorosa trataba a sus nietos, de allí la frase: "Tus tesoros, son los nuestros"

- Formas de difusión:

Convenios empresariales: Esta opción consiste en llegar a las personas que trabajan en las empresas ubicadas en la zona empresarial de San Isidro, a través de convenios empresariales firmados con las áreas de Recursos Humanos donde se les brindará descuentos y/u otros beneficios a sus trabajadores; para ello se plantea programar por lo menos una visita al mes a empresas.

Directamente: A los padres que decidan visitar las instalaciones se les brindará toda la información y se les mostrará los beneficios que pueden encontrar en Titinos Daycare.

Página Web y Redes Sociales: En la página web y en las redes sociales (ver Figura 44) se dan a conocer la misión, visión y valores de la guardería; así como los servicios y eventos que se realizan.

Volantes: Entregar volantes en las avenidas principales y cerca a los restaurantes ubicados en la zona empresarial de San Isidro, volantes con información concreta, de fácil y entretenida lectura (ver Figura 45).

Publicidad boca a boca: La opinión de un usuario satisfecho es valioso, por ello la importancia de trabajar en la formación del prestigio y diferenciación de la guardería; para ello Titinos Daycare implementará un programa de referidos. 


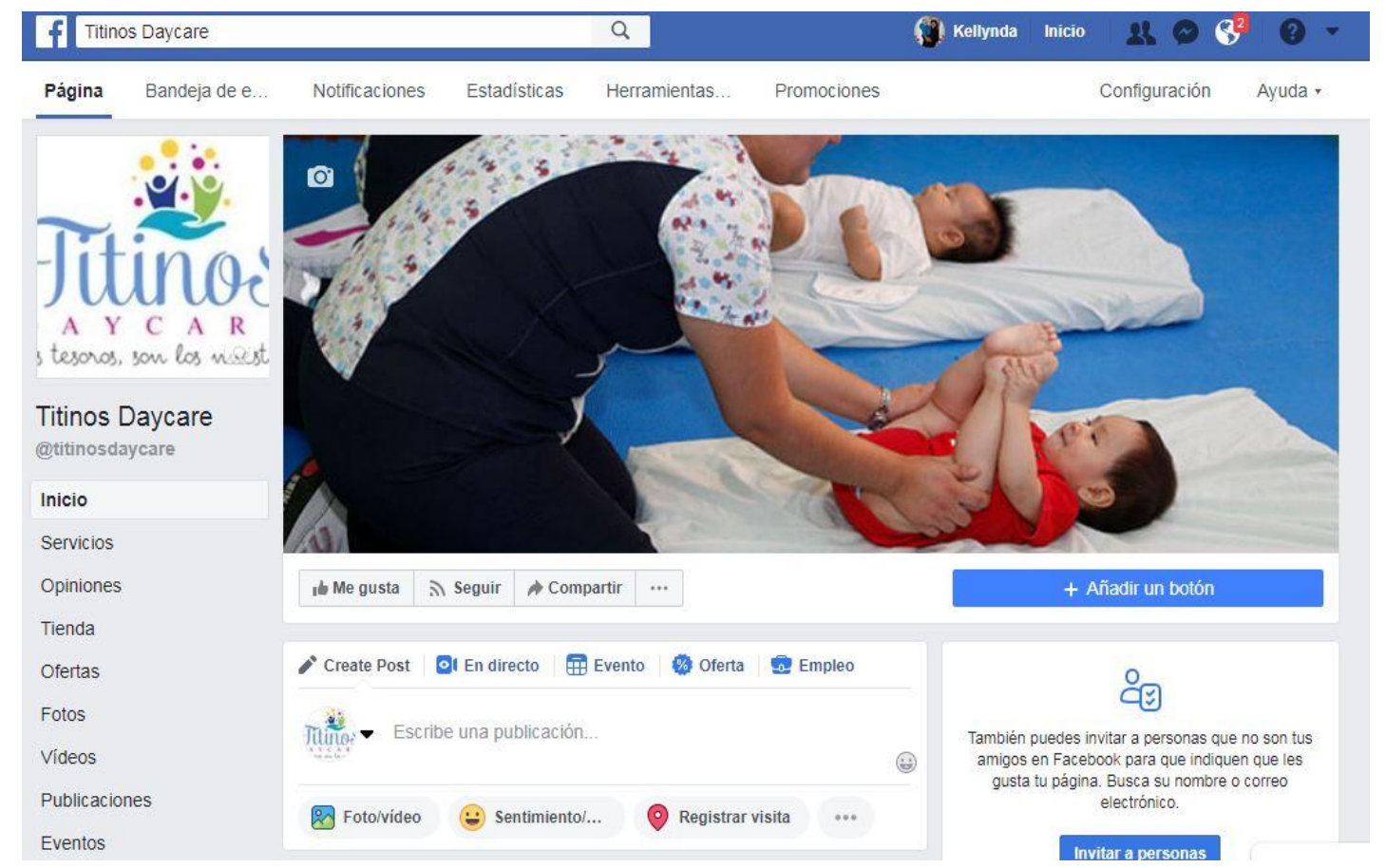

Figura 44. Titinos Daycare en redes sociales

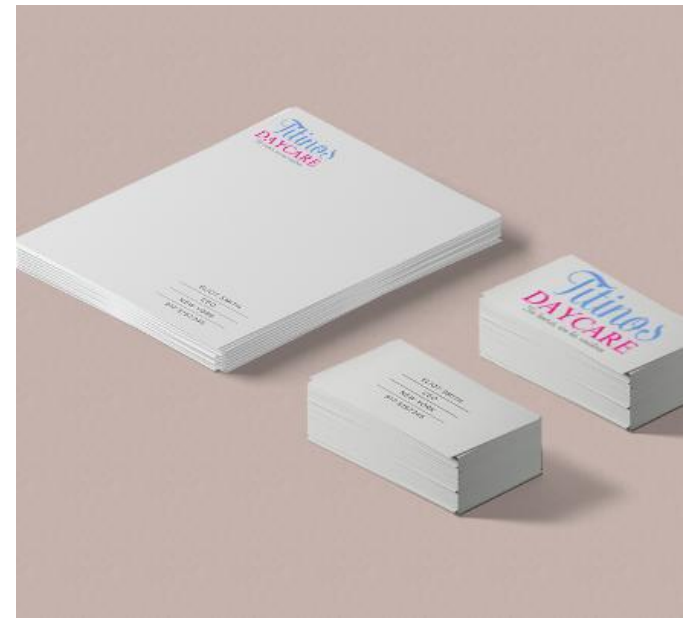

Figura 45. Estrategia de promoción y publicidad - Volantes

Material de Trabajo Promocional

Se plantea lo siguiente:

Para las presentaciones realizadas en las empresas que firmen convenio con Titinos Daycare se va a preparar una presentación de alto impacto, breve y con información importante; para la presentación que se efectúe a los padres que visiten la guardería, se va a preparar un folleto donde se refuerza los beneficios del método Doman (ver Figura 46). En 
ambas presentaciones, a los padres se van a entregar merchandising relacionado a artículos de oficina como lápices, post its, calendarios, posavasos, entre otros.

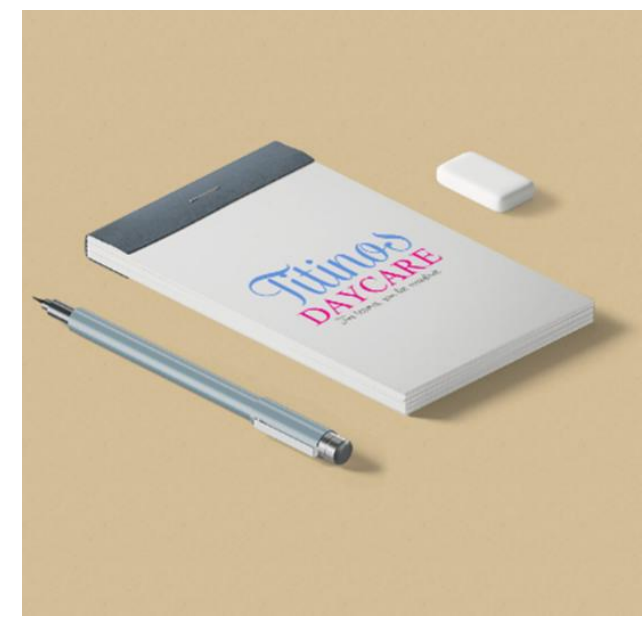

Figura 46. Estrategia de promoción y publicidad - Merchandising

Por último, los volantes repartidos en la vía pública contienen información resumida, donde el principal objetivo va a ser lograr que los padres entren en contacto directo con la guardería, por lo que el volante también debe contener los números de contacto y dirección de la guardería.

\subsubsection{Estrategia de personas.}

Titinos Daycare es una empresa de servicios, donde el capital humano es el recurso más importante de la guardería, ya que está orientado al cuidado y la formación de los infantes cuyos padres trabajan, siendo la principal tarea que van a tener los colaboradores que trabajen en la institución, la de generar un ambiente agradable y armonioso donde los infantes se sientan amados y logren un desarrollo integral.

Por lo expuesto, la estrategia seleccionada para la empresa es la de Empoderamiento, con ello se busca contar con el personal idóneo para cada posición, que desarrollen más competencia y conocimiento en las tareas que desempeñan, ya que tanto personal administrativo como académico va a tener contacto directo con los padres y es necesario proyectar seguridad, seriedad, confianza y empatía en cada nivel de comunicación.

Cada uno de los integrantes del equipo humano de Titinos Daycare representa la imagen de la institución por ello se ello es importante que se establezcan los procesos de reclutamiento, contratación, formación y retención definidos, los mismos que son descritos en la estrategia de procesos. 


\subsubsection{Estrategia de procesos.}

Titinos Daycare tiene por objetivo lograr la satisfacción y tranquilidad de los padres en un ambiente agradable y cómodo para los infantes; por ello se ha trabajado en el diseño de los procesos para estandarizar la prestación del servicio; los mismos que se irán actualizando cada vez que sea necesario. Asimismo, se ha creado un protocolo para maestros donde se han identificado las actividades más repetitivas y permite tener un discurso homogéneo ante determinadas consultas de los padres.

Es sumamente importante que todos los miembros de la institución se encuentren familiarizados con los procesos y libretos, ya que la percepción que se llevan los padres sobre la calidad del servicio depende mucho de estos, en ese sentido se han desarrollado los siguientes procesos:

- Proceso para reclutamiento, contratación, formación y retención

- Proceso para realizar presentaciones en empresas y visitantes.

\section{Reclutamiento, Selección}

Para Titinos Daycare es importante seleccionar al personal idóneo para las distintas áreas de la guardería, por ello se ha planteado realizar un proceso de selección muy exhaustivo, el cual se llevará a cabo de la siguiente manera.

1. Publicación de las ofertas laborales en sitios de confianza, como Bumeran, LinkedIn y bolsas de trabajo de Universidades.

2. Convenio de prácticas profesionales con universidades de prestigio.

3. Evaluación de Currículos Vitae de los postulantes.

4. Solicitar a los elegidos certificados de antecedentes policiales y penales.

5. Llamar a las referencias proporcionadas por los postulantes.

6. Evaluación psicológica a los que hayan pasado los filtros anteriores.

7. Entrevista a la terna finalista.

8. Elección y contratación.

Formación y Capacitación

Titinos Daycare va a aplicar el método de enseñanza Doman, para lo cual cuenta con un especialista certificado por el Instituto Para el Logro del Potencial Humano, el cual va a brindar capacitación permanente a las profesoras y asimismo va a programar las actividades a realizar en cada nivel.

Compensaciones 
Titinos Daycare va a ofrecer a sus trabajadores sueldos de acuerdo con el mercado, respetando más los beneficios sociales que de acuerdo a ley les corresponde, adicionalmente se les va a hacer la entrega de los uniformes sin costo alguno.

Finalmente es necesario crear una cultura organizacional donde el personal se sienta motivado y comprometido con el logro de los objetivos de Titinos Daycare.

- Proceso para inscripción y matriculas de bebes e infantes.

- Proceso de post venta

Estos dos últimos procesos se encuentran detallados paso a paso en el capítulo 7 .

Asimismo, se ha desarrollado los siguientes protocolos:

- Cuando los padres dejan a los infantes en la mañana

Auxiliar: Buenos días mamita o papito, hola "el nombre del alumno"

Padre: Buen día miss "el nombre del auxiliar"

Auxiliar: Revisa que entreguen la ropa de cambio, pañales, refrigerios, almuerzo y de ser el caso algún material especial solicitado. Luego da conformidad y pregunta si hay alguna indicación especial para el día.

Padre: responde y de haber una indicación especial detalla las indicaciones

Auxiliar: No se preocupe mamita o papito vamos a cuidar muy bien a "el nombre del alumno", ingresa a la guardería a su respectivo salón.

- Cuando los padres recogen a los infantes al final del día.

Auxiliar: Buenas noches mamita o papito, aquí esta nuestro tesoro "el nombre del alumno" Padre: Buenas noches miss "el nombre del auxiliar"

Auxiliar: Entrega las pertenencias del menor y comenta si ha comido, si se le bañó o no, si hubo algún síntoma de enfermedad y otra información relevante del día e indica que revise la agenda del menor donde las profesoras envían el detalle del día.

Padre: Se despide y en ocasiones puede solicitar conversar con la profesora.

Auxiliar: (si el padre solicita hablar con la profesora) le agenda una cita para el día siguiente durante el horario de la siesta de los infantes.

Finalmente se ha desarrollado un Blueprinting según se muestra en la Figura 47 donde se detalla el proceso para el desarrollo de las actividades diarias de la guardería. 


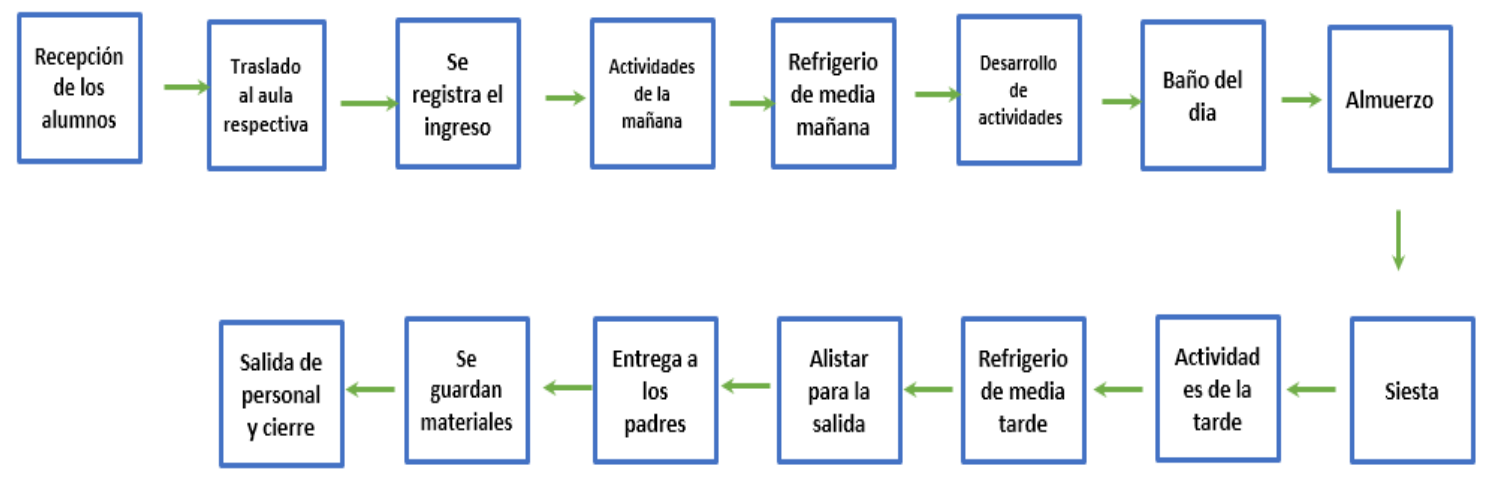

Figura 47. Blueprinting del servicio diario

\subsubsection{Estrategia de evidencias física.}

Titinos Daycare es una empresa de servicios cuyo recurso más importante es el capital humano; sin embargo, es necesario considerar que la primera impresión que van a tener los padres al visitar la guardería es la infraestructura y la decoración de esta, asimismo es muy importante generar un ambiente agradable para los infantes y para los maestros, donde se utilizan materiales de calidad. no tóxicos y que sean amigables con el medio ambiente. Se ha considerado conveniente que la guardería cuente con los siguientes ambientes:

- Fachada con el logo de Titinos Daycare en la parte superior y dibujos orientados a los infantes en las paredes.

- Frontis del local y estacionamiento siempre limpios.

- Hall limpio y ordenado con paredes decoradas con dibujos para infantes.

- Oficina limpia y ordenada, con sillas para adultos y material disponible para dar informes.

- Comedor limpio y ordenado, acondicionado con sillas para comer altas y con protección para evitar caídas.

- Cocina limpia y ordenada habilitada con un refrigerador, una cocina a gas, un horno microondas, un repostero, una mesa, un lavadero, una mesa y sillas para adultos.

- Lactario limpio y ordenado, habilitado con un lavadero de manos, un sofá, un refrigerador para guardar leche materna.

- Sala de descanso para durmientes habilitada con cunas las cuales deben contener sabanas y cubrecama limpias y en buen estado, una estación para cambio de pañales, armario con divisiones para cada bebe.

- Sala de gateadores alfombrada con pisos de goma, piscina de pelotas, módulos de 
psicomotricidad gruesa hechos de espuma de alta densidad.

- Sala de descanso para gateadores habilitada con cunas las cuales deben contener sabanas y cubrecama limpias y en buen estado, una estación para cambio de pañales, armario con divisiones para cada bebe.

- Sala de caminantes la cual esta acondicionado con pisos de goma, mesas y sillas diseñadas para su edad, juegos para estimular la psicomotricidad fina, área de lectura y títeres.

- Sala de exploradores habilitada con mesas y sillas diseñadas para su edad, juegos para estimular la psicomotricidad fina, área de lectura, área de música.

- Patio para caminantes y exploradores alfombrado y habilitado juegos como columpios, tobogán y carrusel.

- Patio general, la cual tiene un jardín con pasto natural y en época de verano se arma una piscina para infantes.

\subsection{Estrategia de ventas}

Es un pilar importante y fundamental para el proyecto, tiene como finalidad conseguir resultados económicos positivos y de crecimiento para que la empresa alcance la rentabilidad deseada en función de los objetivos de ventas propuestos.

\subsubsection{Plan de ventas}

El propósito es lograr una respuesta más sólida y rápida del consumidor e integrar el esfuerzo de las estrategias de marketing propuestas para el proyecto con la acción concreta de la venta.

Los objetivos específicos de la promoción de ventas son que el consumidor pruebe el producto o servicio, que logre un aumento en la cantidad y frecuencia del consumo, fortalecer la imagen y lograr fidelidad en el servicio.

Para lograr los objetivos de venta esperada, se trabajará primordialmente en:

- Volanteo y desarrollo de base de datos propia con un registro permanente de potenciales clientes.

- Conseguir referidos, siempre es mejor que hablen otras personas de nuestro negocio que nosotros mismos, un cliente satisfecho es el mejor vendedor.

- Incentivar las referencias de nuestros clientes hacia el negocio, ofreciéndoles un porcentaje de beneficio o algún servicio adicional de la guardería.

- Barridos promocionales para convenios con empresas o instituciones interesadas. 
Oferta de Valor Titinos Daycare

El servicio que ofrece Titinos Daycare permite que los clientes destinen su tiempo en actividades laborales, de crecimiento profesional y personales, las cuales consideran aportes valiosos en sus vidas y en su entorno familiar. Los servicios ya establecidos son:

- Servicio de Guardería en el horario de 8:00 am-7:00 pm. S/ 825 Soles mensuales más $\mathrm{S} / 400$ soles de derecho a matrícula (único pago de todo el ciclo)

- Servicio de Estimulación temprana bajo la metodología Doman, incluida en el costo de guardería.

Competidores:

Tomando en cuenta los resultados obtenidos en la investigación, el mercado objetivo de Titinos Daycare, no está siendo atendido por la competencia en la zona de estudio por el que existe una demanda insatisfecha la cual representa una opción de venta.

Objetivos de venta:

Al ser una empresa nueva en el mercado es necesario concentrar los esfuerzos de marketing durante el primer año de funcionamiento, asimismo previo al inicio de operaciones se va a ir trabajando en la captación de clientes a través de convenios empresariales, de los cuales se espera reunir un mínimo de diez para la apertura y luego del inicio de operaciones seguir trabajando en los convenios y adicionalmente impulsar el programa de referidos para que en cada mes se logre la captación de por lo menos un cliente y cerrar el primer año con 30 niños, en la Tabla 29 se ha realizado la proyección del número de infantes que se espera alcanzar durante el primer año de funcionamiento.

Tabla 29

Objetivos de Ventas en Ingreso de Infantes en Titinos Daycare Año 1

\begin{tabular}{|c|c|c|c|c|c|c|c|c|c|c|c|c|c|}
\hline Niños al año & & & & & & & & & & & & & \\
\hline & Ene & Feb & Mar & Abr & May & Jun & Jul & Ago & Sep & Oct & Nov & Dic & Año 1 \\
\hline Serv. Guardería & 10 & 11 & 14 & 15 & 17 & 19 & 21 & 22 & 24 & 27 & 30 & 30 & 240 \\
\hline Total niños & 10 & 11 & 14 & 15 & 17 & 19 & 21 & 22 & 24 & 27 & 30 & 30 & 240 \\
\hline
\end{tabular}

Plan de actividades:

Se realiza el plan para este proyecto en función a las actividades que se plantean aplicar con la finalidad de obtener mayor captación del servicio, tal como se detalla en la Tabla 30. 
Tabla 30

Plan de Actividades Titinos Daycare

\begin{tabular}{|c|c|c|}
\hline Numero & Responsable & Actividades \\
\hline \multirow{8}{*}{1} & \multirow{8}{*}{$\begin{array}{l}\text { Coordinador } \\
\text { de ventas }\end{array}$} & $\begin{array}{l}\text { Recibir de forma presencial a los potenciales clientes que soliciten } \\
\text { información del servicio. }\end{array}$ \\
\hline & & $\begin{array}{l}\text { Brindar toda la información requerida, así como los horarios de visita guiada } \\
\text { para las instalaciones. }\end{array}$ \\
\hline & & $\begin{array}{l}\text { Proporcionar los brochures indicando los precios, horarios y beneficios que } \\
\text { otorga Titinos. }\end{array}$ \\
\hline & & $\begin{array}{l}\text { Recepcionar las llamadas telefónicas de los clientes que soliciten } \\
\text { información, así como las inquietudes del servicio, siempre invitando a que } \\
\text { se acerque personalmente para una visita guiada a las instalaciones o visitar } \\
\text { la página web de Titinos. }\end{array}$ \\
\hline & & $\begin{array}{l}\text { Crear una base de datos de las atenciones por teléfono y presenciales con el } \\
\text { fin de hacerles seguimiento. }\end{array}$ \\
\hline & & $\begin{array}{l}\text { De estar en fecha de visita guiada, el Coordinador deberá guiar al cliente a } \\
\text { las instalaciones de la guardería haciendo mención a cada espacio } \\
\text { determinado para los niños y el equipamiento que posee, así como la } \\
\text { seguridad que brindara en caso decida por la opción Titinos. }\end{array}$ \\
\hline & & $\begin{array}{l}\text { De concretar la venta, deberá solicitar documentación del niño y los padres } \\
\text { para la validación correspondiente. }\end{array}$ \\
\hline & & $\begin{array}{l}\text { Proporcionar a los padres el Reglamento de estudios y ficha de matrícula, } \\
\text { donde se especifica información importante del servicio. }\end{array}$ \\
\hline
\end{tabular}

El marketing directo; consiste en la utilización de canales de comunicación con el cliente, basado en el uso de medios directos, unipersonales e interactivos (no utiliza intermediarios), generando una reacción en el receptor o el inicio de una comunicación directa y personal. Esta técnica relaciona el producto directamente con el consumidor, logrando su aceptación y posicionamiento.

Las acciones para el seguimiento y fidelización de los clientes serán:

- Sistema de base datos donde se almacenarán todos los datos de los clientes (datos personales, teléfonos, preferencias, aficiones, etc.)

- Campañas de e-mailing personalizado a los clientes saludándoles en fechas festivas como cumpleaños y otros, proporcionándoles trabajos o videos afectivos de sus menores hijos.

- Servicio de postventa, la empresa mantendrá contacto con el cliente en el transcurso del mes de aceptado el servicio para comprobar sus impresiones y sugerencias para posibles mejoras.

- Redes Sociales, a través de este medio se crearán diferentes cuentas como el 
Facebook, Instagram, etc. donde se facilitará información sobre la guardería, su creación, instalaciones, servicio que ofrece, etc. Se incluirá testimonios o experiencias de padres que tienen a sus hijos en la guardería. También se enviará información de índole nutricional, cuidados de los infantes y alguna otra información de importancia.

\subsubsection{Política de servicios y garantías}

- Para acceder al servicio que ofrece Titinos Daycare, el menor deberá presentar de forma obligatoria la cartilla de vacunación otorgado por centros de salud públicos o privados que incluyan todas las vacunas consideradas obligatorias por el Ministerio de Salud, así como los documentos de identidad de padres e infantes.

- Llenar y firmar el formato de personas autorizadas para el recojo del menor a la hora de salida (véase Figura 48).

- Asegurarnos de que todo el personal en contacto directo con los infantes tenga el perfil de servicio necesario y se encuentre en óptimas condiciones de salud

- Capacitar de manera constante al personal académico en temas educativos y al personal administrativo sobre la atención al cliente.

- Realizar encuestas semestrales para medir el nivel de satisfacción del servicio

\section{Cargos Obligatorios}

Se le solicitará al cliente que pague el derecho de matrícula y cuota que corresponda al servicio del mes que inicia.

Adicionalmente los padres deben cumplir con entregar los útiles de aseo, alimentación y materiales de trabajo. 
Formato 002 - Titinos Daycare

PERSONAS AUTORIZADAS DE RECOJO AL MENOR

Datos del alumno

APELLIDOS Y NOMBRES

FECHA DE NACIMIENTO:

EDAD (AÑOS Y MESES):

DIRECCIÓN:

Persona Autorizada 1

APELLIDOS Y NOMBRES:

DNI

PARENTESCO:

DIRECCIÓN

TELEFONOS

Persona Autorizada 2

APELLIDOS Y NOMBRES:

\begin{tabular}{|l|l|}
\hline APELLIDOS YNOMBRES: & \\
\hline DNI & \\
\hline PARENTESCO: & \\
\hline DIRECCIÓN & \\
\hline TELEFONOS & \\
\hline
\end{tabular}

Persona Autorizada 3

\begin{tabular}{|l|l|}
\hline APELLIDOS Y NOMBRES: & \\
\hline DNI & \\
\hline PARENTESCO: & \\
\hline DIRECCIÓN & \\
\hline TELEFONOS & \\
\hline
\end{tabular}

Yo, con DNI

Padre/Madre/Apoderado

del menor declaro que las personas antes indicadas estan debidamente

autorizados para el recojo de mi menor hijo.

La Victoria - Urbanización Santa Catalina. 01 de Enero del 2019

Firma Padre/Madre/Apoderado

Coordinador Titinos

Figura 48. Formato para Personas Autorizadas de Recojo del alumno 


\section{Capítulo VI: Pronóstico de Ventas}

\subsection{Fundamentos y Supuestos}

Los fundamentos y supuestos considerados para elaborar el pronóstico de ventas se determinaron en base a los resultados de la investigación de mercado, información sobre proyecciones de natalidad, población flotante, población residente, crecimiento del sector, PBI de economías emergentes y expectativas de crecimiento del sector económico del distrito de San Isidro.

Según el Ministerio de Economía y Finanzas, en el libro Marco Macroeconómico Multianual 2019 - 2022 (2018) menciona que:

En 2018-2022, el mundo crecería a una tasa promedio anual de 3.8\%. Esta proyección es similar a la presentada en el Informe de Actualización de Proyecciones Macroeconómicas 2018-2021 (IAPM) y superior a lo registrado en años previos (2012-2017: 3.5\%). Sin embargo, este escenario estará caracterizado por (i) un crecimiento diferenciado entre economías avanzadas y emergentes y (ii) la presencia de riesgos (como un mayor proteccionismo a nivel global y una salida de capitales en economías emergentes). En este contexto, el crecimiento del PBI de nuestros socios comerciales estaría alrededor de $3.8 \%$ en 2018 , 3.6\% en 2019 y 3.4\% en 2020-2022. (P. 30)

A continuación, se muestra la Figura 49 sobre la variación del PBI de las economías avanzadas y economías emergentes y en desarrollo de los próximos entre los años 2014 2022 (Var. \% real anual)

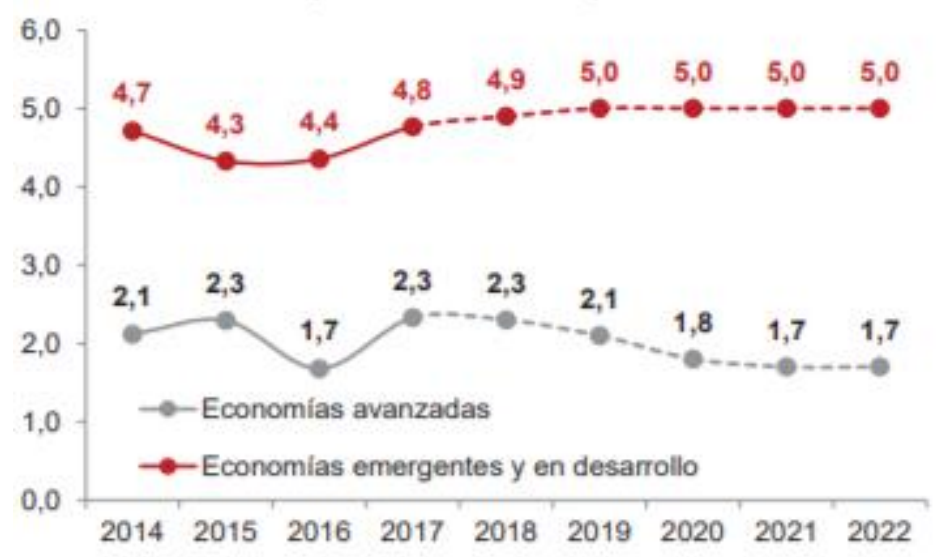

Figura 49. PBI de Economías avanzadas, y economías emergentes y desarrollo. Tomado del Marco Macroeconómico Multianual 2019 - 2022 por Ministerio de Economía y Finanzas (2018).

Recuperado de https://www.mef.gob.pe/contenidos/pol_econ/marco_macro/MMM_2019_2022.pdf. 


\subsection{Justificación}

Las diferentes características del mercado de guarderías en la zona de estudio, permite determinar que existe una oportunidad para que Titinos Daycare pueda alcanzar sus objetivos de venta con una estrategia de enfoque de alto valor, la misma que se evidencia en la diferenciación por la ubicación, infraestructura y horario extendido, los cuales generan confianza y seguridad en los padres, ya que al estar cerca de su centro de trabajo ahorran tiempo y emocionalmente sienten tranquilidad sobre el cuidado de sus hijos, lo que finalmente les permite mantener su productividad.

En función a las proyecciones del mercado objetivo y considerando las capacidades con las que cuenta el proyecto, se determinó el siguiente crecimiento por año tanto en porcentajes (ver Tabla 31) como en ingresos anuales (ver Tabla 32), estos se muestran a continuación:

Tabla 31

Proyección Crecimiento de la Guardería

\begin{tabular}{lr}
\hline \multicolumn{1}{c}{ Años } & $\begin{array}{c}\text { Crecimiento } \\
\text { Proyectado }\end{array}$ \\
\hline Primer año & $0.42 \%$ \\
Segundo año & $1.40 \%$ \\
Tercer año & $1.30 \%$ \\
Cuarto año & $1.15 \%$ \\
Quinto año & $1.08 \%$ \\
\hline
\end{tabular}

Tabla 32

Mercado Objetivo Proyectado Niños O-4 Años Lima

\begin{tabular}{ll}
\hline Años & Anual \\
\hline 2019 & 300,382 \\
2020 & 420,535 \\
2021 & 587,220 \\
2022 & 675,303 \\
2023 & 729,328 \\
\hline
\end{tabular}

\subsection{Análisis de los riesgos y aspectos críticos que impactan en el pronóstico}

El proyecto contempla factores externos y factores internos que podrían impactar en el pronóstico elaborado y que a continuación se detalla líneas abajo:

Factores externos

- Incursión de competencia. 
- Incremento periódico del alquiler.

- Flexibilización de la competencia con respecto a los precios.

- Inflación.

- Desarrollo de guarderías dentro de los centros laborales de San Isidro.

- Incremento de la remuneración mínima vital.

- Decrecimiento de la tasa de natalidad.

Factores internos

- Alta rotación laboral por deserción de colaboradores

- Falta de actualización del personal.

- Falta de fidelización con los clientes.

- Falta de incentivos la personal.

- Jornada laboral excesiva. 


\section{Capítulo VII: Ingeniería del Proyecto}

El presente capitulo contemplara el desarrollo de los aspectos técnicos y de infraestructura que permiten el proceso de la prestación del servicio hasta llegar al consumidor.

\subsection{Estudio de ingeniería}

Se describirá en forma detallada la localización, la determinación del tamaño y de los recursos necesarios que condicionarán la estructura organizativa de la empresa y su repercusión en los costes de esta, por ejemplo, recursos materiales, mobiliario, recursos humanos, recursos tecnológicos, procesos, y prevención de riesgos.

Dentro de los procesos a desarrollar serán:

- Proceso para selección de personal.

- Proceso para inscripción y matriculas de bebes e infantes.

- Proceso de post venta

\subsubsection{Modelamiento y selección de procesos productivos.}

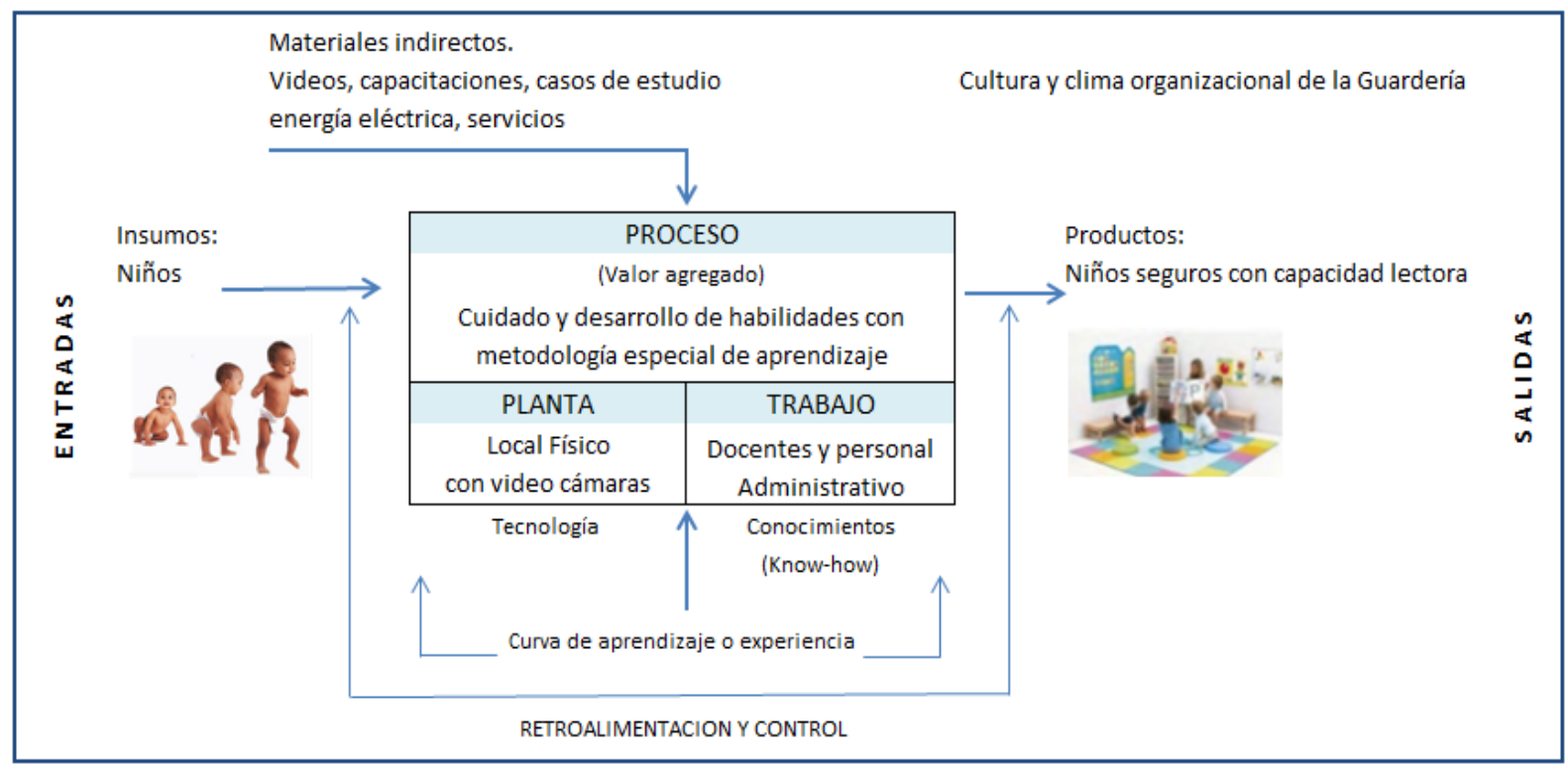

Figura 50. Diagrama general de entrada-proceso-salida para la Guardería Titinos Daycare

En la Figura 50. Se detalla el diagrama general de entrada-proceso-salida para el proceso del cuidado y desarrollo de habilidades con una metodología especial de aprendizaje, que toma como entrada niños y las convierte en niños con capacidad lectora y seguros, mediante el conocimiento y know-how de los docentes y especialistas, y el apoyo del 
personal administrativo desarrollado en el local de la Guardería. Los aspectos de importancia son el valor que se agregue en las actividades del proceso y la productividad que se consigna en el mismo.

Diagrama de proceso de selección de personal (véase Figura 51)

- Publicación de la oferta laboral y/o convenios de practicas

- Se revisa files de los postulantes interesados para el siguiente proceso

- Proceso de evaluación, se califica curriculum vitae de acuerdo al perfil requerido

- Files que no cumplen con el perfil se anula

- Files que cumplen con el perfil y requisitos se valida referencias

- Establecer contacto telefónico y validar referencias laborales

- Referencias no conformes, se archiva file

- Referencias positivas y conformes, se contacta al postulante para la evaluación psicológica.

- Postulante desaprueba evaluación, se archiva file

- Postulante que aprueba la evaluación psicológica pasa a entrevista y se le informa los términos de contrato.

- Postulante conforme con términos de contrato, se le solicita la documentación completa en original para su file de trabajo.

- Postulante que no cumple, se archiva file

- Se valida y comprueba documentos proporcionados

- File con documentos e información validados, es contratado bajo leyes laborales peruanas.

- Postulante firma contrato. 


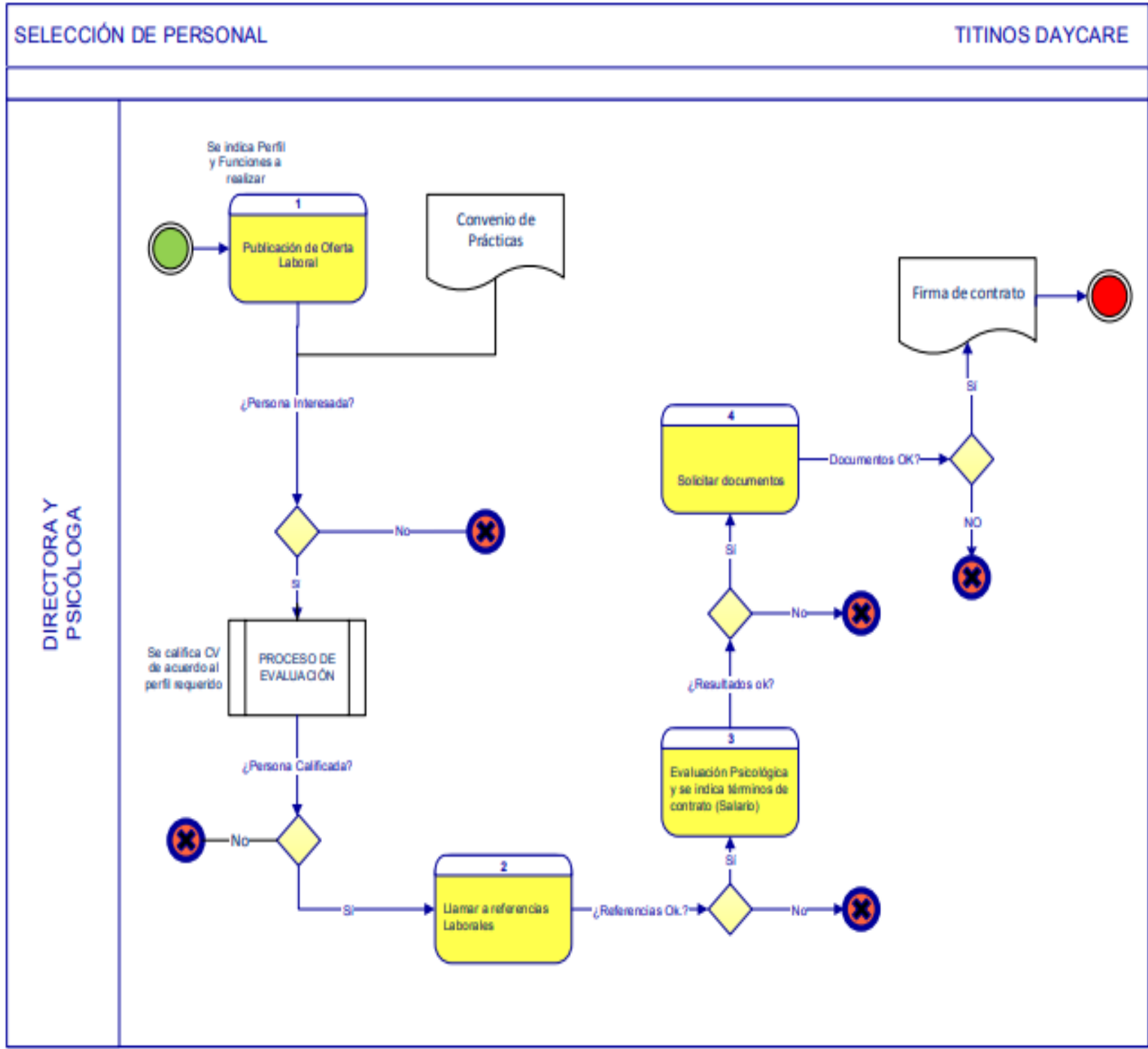

Figura 51. Flujograma de proceso de selección de personal

Diagrama de proceso para Inscripción y Matriculas de bebes e infantes (véase Figura 52)

- Padre de familia o interesado se acerca a local de Guardería

- Solicita información general del servicio de guardería

- Encargado de guardería entrega publicidad en folletos e información (tríptico)

- Brinda información de los servicios que ofrece, ventajas, beneficios, requisitos, costos y otros.

- De ser necesario informa horarios de visita guiada en las instalaciones del local

- De contar con cupos disponibles para la matricula, llena la ficha de matrícula con los requisitos previamente informados.

- De no contar con cupos, se le brinda fechas próximas de apertura 
- Con ficha de matrícula llenada y firmada, PPFF entrega documentos con los requisitos solicitados.

- Encargado de Guardería revisa y valida documentos solicitados

- Documentos incompletos o con observaciones, comunica

- Informa a PPFF situación documentaria por observaciones

- PPFF subsana observaciones documentarias

- Procede realizar pago de matricula

- PPFF no subsana observaciones, se archiva file

- Documentos completos y validados, pasa al siguiente proceso

- Realizar pago de matricula

- Encargado entrega comprobante y acuerdo de matrícula con la política e instrucciones del servicio.

- Registra en el sistema de niños matriculados 


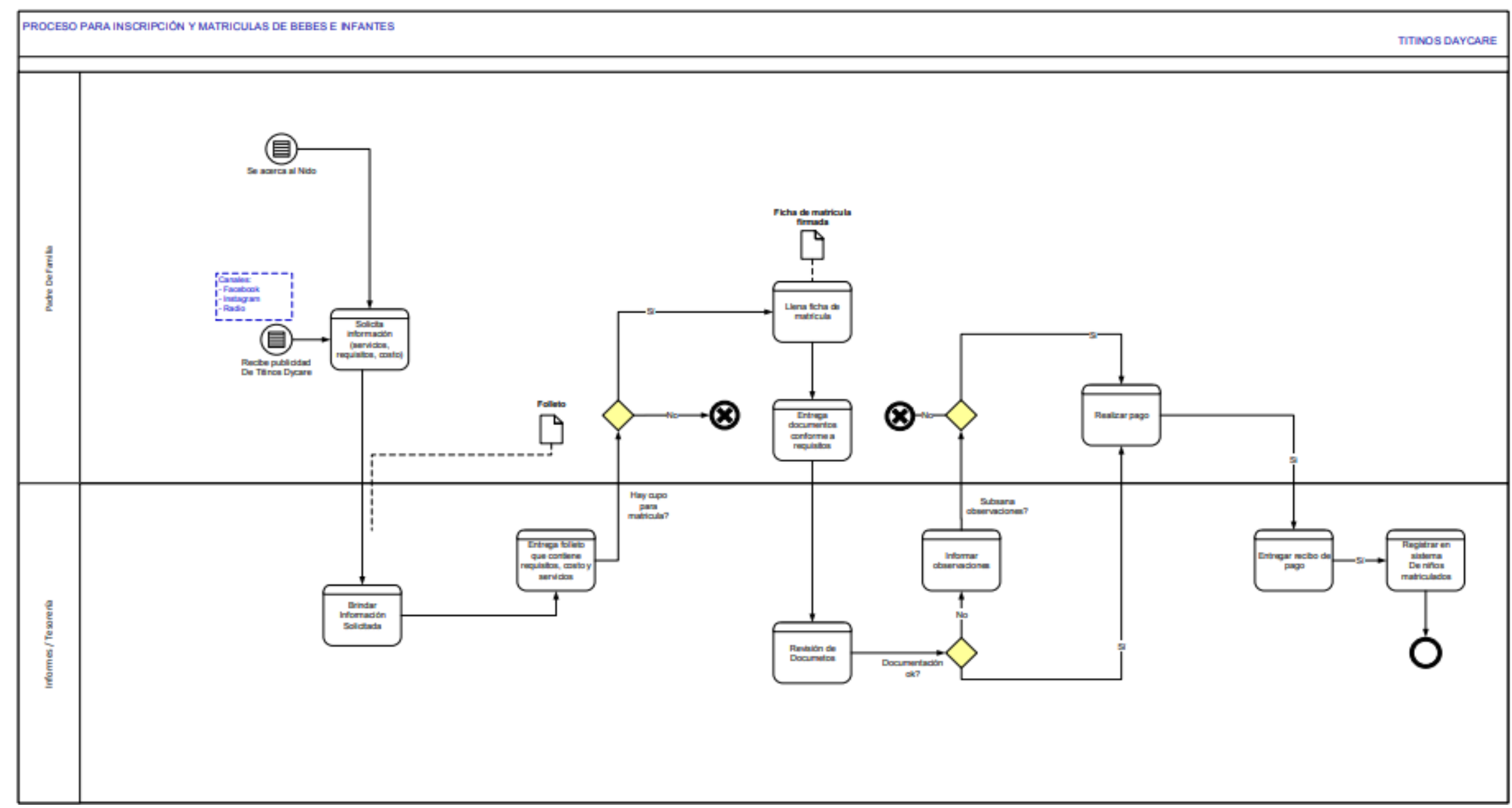

Figura 52. Flujograma del proceso para Inscripción y Matriculas de bebes e infantes. 
Diagrama del Proceso de post venta (véase Figura 53)

- Tener actualizado el registro de informes de padres y apoderados

- Comunicarse con el cliente para el seguimiento respectivo

- Si comunicación telefónica es fallido, enviar email

- Medir el nivel de satisfacción en la atención y cuidado del niño

- Si el cliente muestra satisfacción por el servicio aplicar estrategia de fidelización

- Solicitar recomendaciones y mejoras en el servicio

- Si cliente no se encuentra satisfecho con el servicio, realizar plan de acción y corrección.

- Encargado registra solicitud de reclamo por queja del cliente

- Empresa genera plan de acción para corregir y subsanar queja

- Empresa genera estrategias de fidelización (por ejm. actividad extracurricular como taller de padres) 


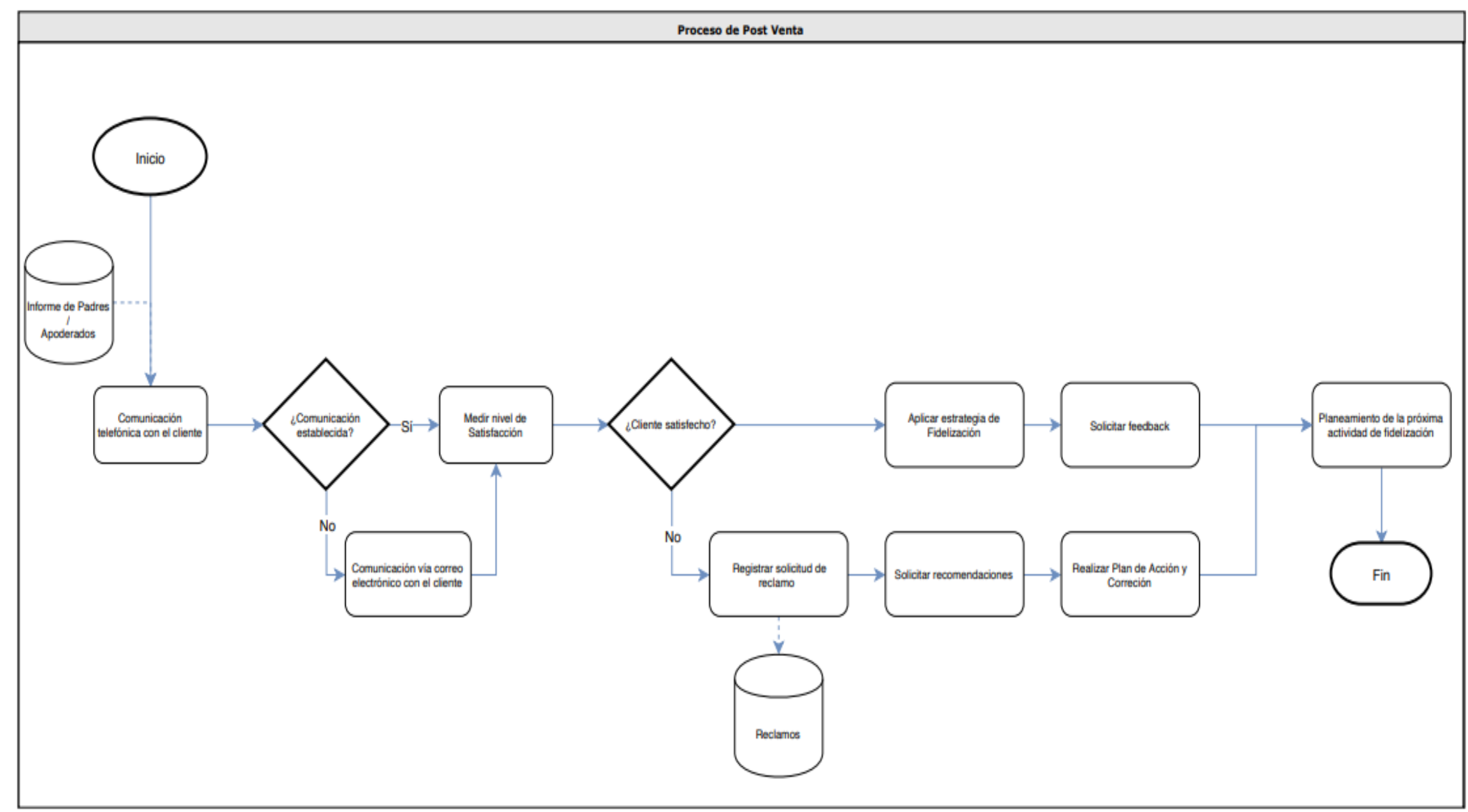

Figura 53. Flujograma del proceso de post venta 


\subsubsection{Selección de equipamiento}

Para este capítulo se ha determinado el equipamiento que requiere el local de operaciones y la oficina principal de Titinos Daycare (ver Tabla 33 y Tabla 34).

Tabla 33

Requerimiento de Muebles, Equipos y Enseres para la Guardería

\begin{tabular}{lc}
\hline \multicolumn{1}{c}{ Descripción de muebles, equipos y enseres } & Cant. /Unid. \\
\hline Refrigeradora de 150 Litros & 1 \\
Frigobar de 100 Litros & 1 \\
Cocina de 2 hornillas Eléctrica & 1 \\
Terma & 1 \\
Esterilizador de biberones eléctrico & 1 \\
Hervidor eléctrico & 1 \\
Horno microondas & 1 \\
Televisor de 50 Pulgadas - Smart TV & 1 \\
Cámaras IP & 7 \\
Sofá para lactario & 1 \\
Estantes para libros y juegos de cada sala & 4 \\
Cunas y colchones para durmientes y gateadores & 8 \\
Camas para caminantes y exploradores incluye colchón & 12 \\
Comedor para infantes con 5 sillas & 2 \\
Mesa para niños con 4 sillas & 5 \\
Mesa con 6 sillas para comedor (adultos) & 1 \\
Piscina de espuma con pelotas & 1 \\
Centro de estimulación de espuma- Psicomotricidad Gruesa & 4 \\
Kit de Juegos para psicomotricidad gruesa & 2 \\
Kit de Juegos para psicomotricidad fina & 2 \\
Flexipiso para los pisos & 1 \\
Tacho de residuos 40 Litros & 1 \\
Tazas & 6 \\
Termo con dispensador y azucarera & 1 \\
\hline
\end{tabular}


Tabla 34

Requerimiento de Muebles y Equipos de Administración y Ventas

\begin{tabular}{lc}
\hline $\begin{array}{c}\text { Descripción de Muebles y Equipos de } \\
\text { Administración y Ventas }\end{array}$ & $\begin{array}{c}\text { Cant. } \\
\text { /Unid. }\end{array}$ \\
\hline Computadoras personales & 2 \\
Impresora multifuncional laser & 1 \\
Cámaras IP & 3 \\
Ventilador de piso & 6 \\
Escritorio melamina & 1 \\
Silla ejecutiva & 2 \\
Silla de visita & 3 \\
Estantes para archivadores & 2 \\
Dispensador de agua & 1 \\
\hline
\end{tabular}

\subsubsection{Lay Out}

Para determinar la distribución del local donde operara Titinos Daycare, este se ha diseñado considerando una integración con todas las áreas como: zona de recepción y atención al público, la zona de operaciones, el área administrativa y académica; por tal, las necesidades de infraestructura se darán en los ambientes tal como se muestra en la Figura 54 La primera planta está distribuida de la siguiente manera:

- Exterior del nido, se encuentran las ubicaciones para los estacionamientos de los padres que dejan y recogen a sus hijos.

- Puertas de ingreso y salida tanto del personal que trabaja en la institución como los padres con sus hijos.

- Hall de espera para padres y recepción

- Sala de cunas: Durmientes, Bebes sin desplazamiento (90 días a 1 año)

- Sala de Gateadores y aprendiendo a caminar (1 a 2 años)

- Sala de Caminantes y exploradores (2 a 3 años)

- Lactario

- Sala de Higienización

- Servicios higiénicos para los niños

- Cocina-comedor

- Zona de descanso 1 (colchonetas)

- Zona de descanso 2 (colchonetas)

- Patio de recreación general 
- Cámaras de vigilancia

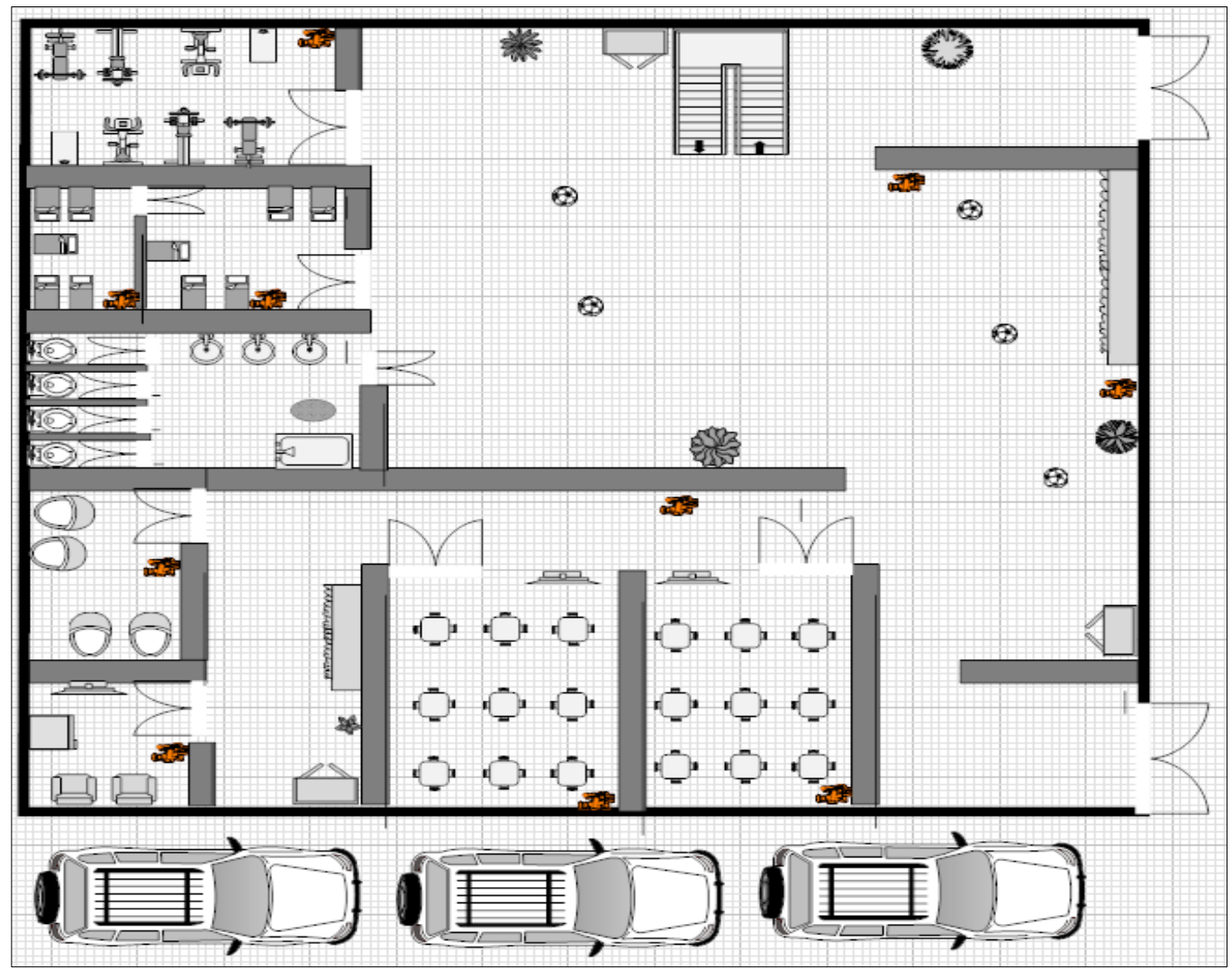

Figura 54. Lay out Titinos Daycare, primer nivel

La segunda planta (véase Figura 55) se encuentra distribuida de la siguiente manera:

- Depósito de material didáctico

- Oficina de Dirección y/o Administración

- Sala de reuniones

- Servicio higiénicos profesores y administrativo 


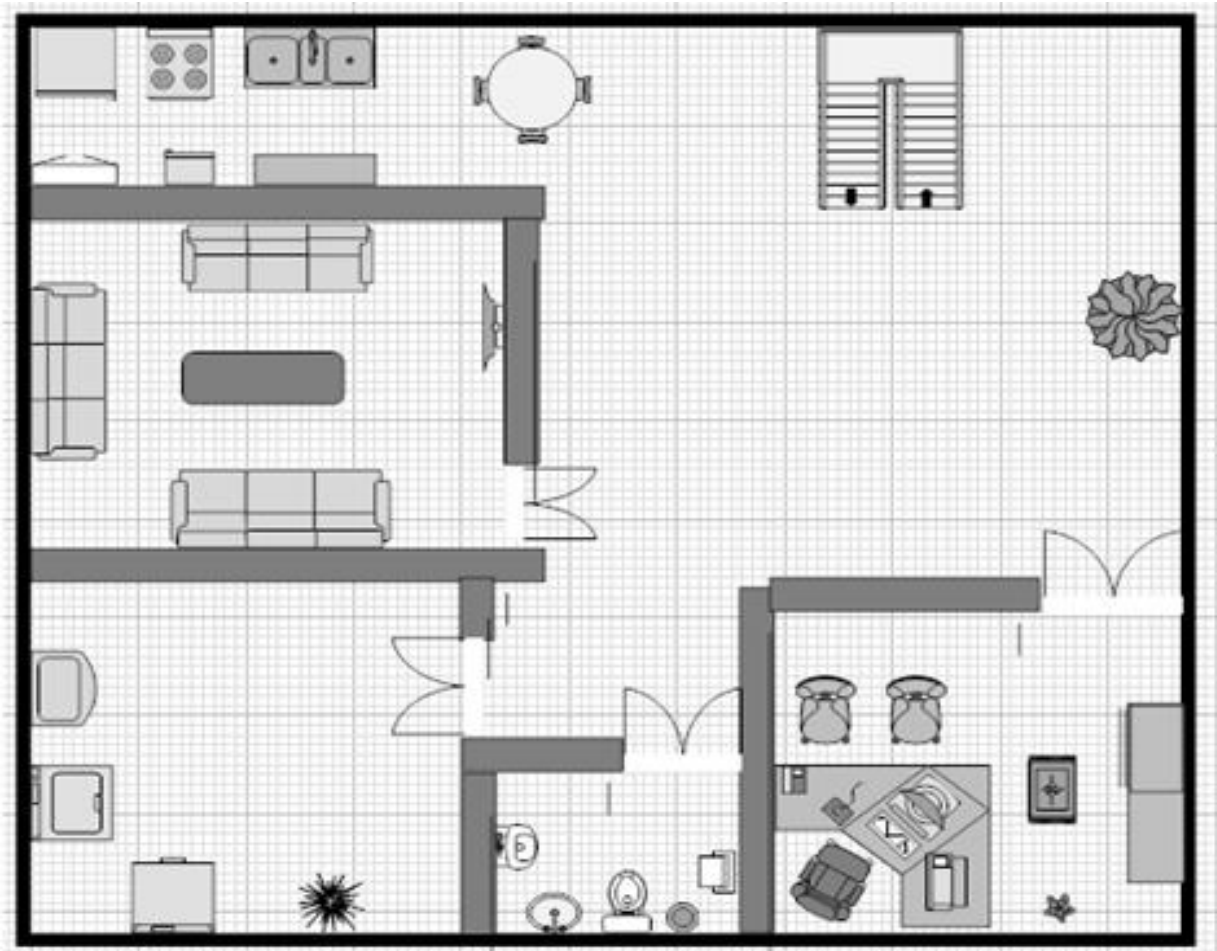

Figura 55. Lay out Titinos Daycare, Segundo nivel

\subsubsection{Distribución de equipos, muebles y enseres}

Para este proyecto se requiere desarrollar obras civiles con divisiones y acabados de colores pasteles y coloridos, el ambiente debe ser de buena ventilación e iluminado con cortinas que brinde calidez y seguridad al cliente interno y externo (véase Figura 56 y Figura 57). La distribución estará basada según las Normas Técnicas para el Diseño de Locales de Educación Básica Regular - Nivel Inicial como se detalla en la Tabla 35. 
Tabla 35

Descripción de los Espacios por Características de Desplazamiento Nivel Inicial

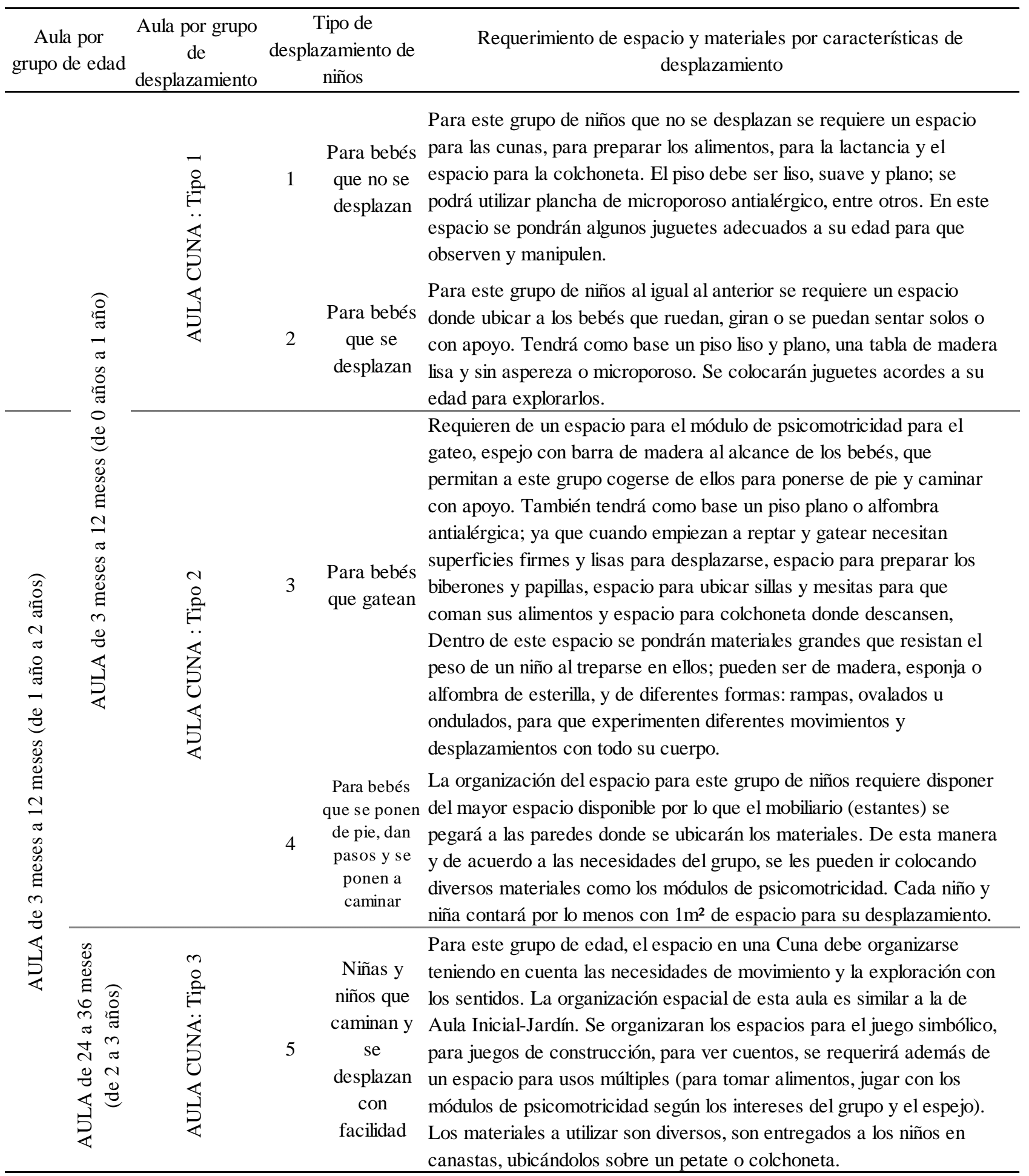

Nota. Descripción de los espacios por características de desplazamiento nivel Inicial: Cuna y Jardín.

Tomado de "Normas Técnicas para el Diseño de Locales de Educación Básica Regular: Nivel

Inicial, " (p. 29) por el Ministerio de Educación Viceministerio de Gestión Institucional Oficina de

Infraestructura Educativa, 2011. Recuperado de

http://www.minedu.gob.pe/files/107_201109011135.pdf 


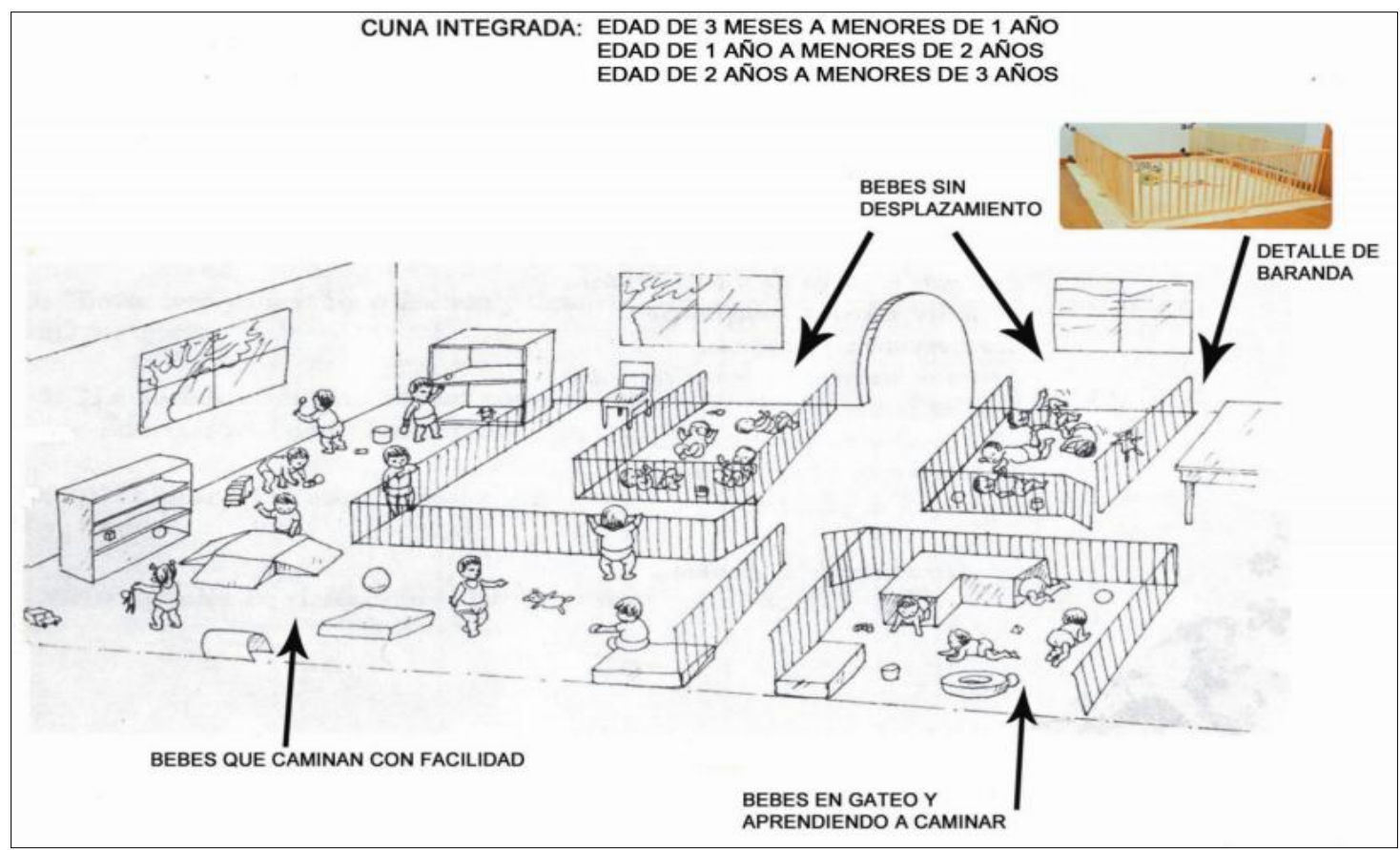

Figura 56. Distribución por tipo de desplazamiento de niños nivel Inicial: Cuna y Jardín. Tomado de “Normas Técnicas para el Diseño de Locales de Educación Básica Regular: Nivel Inicial," por el Ministerio de Educación Viceministerio de Gestión Institucional Oficina de Infraestructura Educativa, 2011. Recuperado de http://www.minedu.gob.pe/files/107_201109011135.pdf
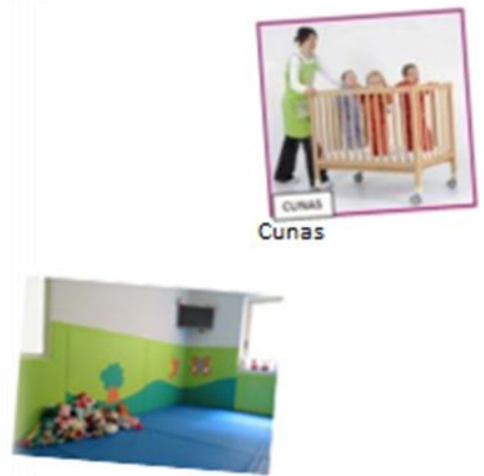

Area de juegos

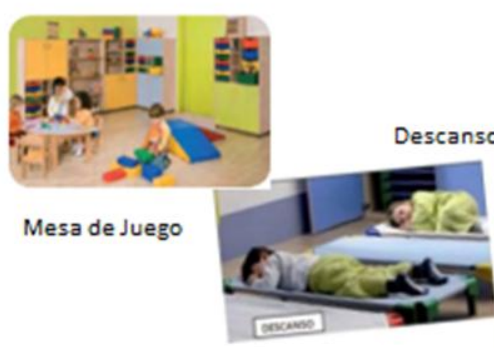

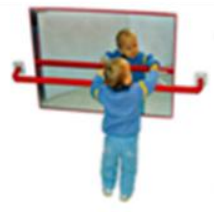

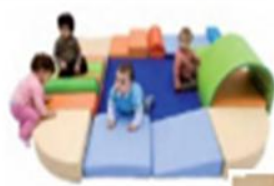

Bebes en gateo y aprendiendo

a caminar
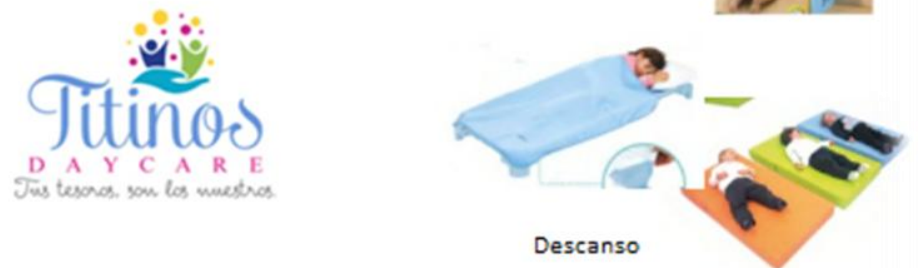

Bebes que caminan con facilidad
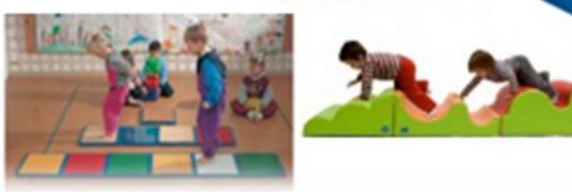

Figura 57. Distribución Titinos por tipo de desplazamiento de niños 


\subsection{Determinación del tamaño}

Para este proyecto se requiere contar con un establecimiento de $750 \mathrm{mts} 2$, que cumpla con la distribución de ambientes detallados, tales como:

- 03 salas o aulas por grupo de edad: Durmientes, Gateadores, Caminantes y exploradores.

- 01 sala de higienización

- 01 lactario

- 01 cocina - comedor

- 01 patio general

- 01 depósito de material didáctico

- 02 baños: profesores y niños

- 01 Hall de espera de padres

- 01 oficina de dirección - Administración

\subsubsection{Proyección de crecimiento}

El alquiler del local cuenta con dos niveles, el primer piso será ambientado exclusivamente para el servicio en sí, y en el segundo piso momentáneamente se acondicionará la oficina de la Administración. De acuerdo al crecimiento que tenga la empresa, se implementaran aulas para profesores, personal administrativo y zona de comedor para el personal en general.

\subsubsection{Recursos}

En este punto se busca determinar la composición óptima de los recursos que harán que el servicio se logre eficaz y eficientemente.

Recursos Humanos

Se requerirá la contratación de personal para la puesta en marcha de la empresa:

- 01 Director

- 04 Maestras

- 03 Auxiliares

- 01 Coordinador de ventas

- 01 Coordinador Administrativo

- 01 Mantenimiento y limpieza

- 01 Especialista Doman (Locación de servicios)

- 01Contador (Locación de servicios) 
El personal a contratar debe contar con experiencia en pedagogía y deben estar dentro del perfil requerido. Para efectos del funcionamiento en el primer año, solo se contratará el servicio de 02 maestras y 02 auxiliares, a partir del segundo año recién se contará con el personal completo.

Insumos

Los insumos son complementarios e importantes para la realización del servicio. Son obtenidos mediante la selección de proveedor (cartuchos de tinta, materiales de papelería, impresiones, fotocopiado, uniformes, artículos de limpieza, otros).

\subsubsection{Tecnología}

Para este punto, Titinos Daycare plantea contar con las siguientes herramientas tecnológicas:

- Cámaras IP que permitirán ver en tiempo real las actividades que realizan los niños (a modo de seguridad)

- Internet, cable TV y teléfono fijo.

- Portal web, plataforma que permitirá a los clientes mantenerse informados por los servicios que brinda la Guardería.

- Equipos móviles que permitirá estar comunicados con el personal en todo momento.

\subsubsection{Selección del tamaño real.}

Para el inicio de las operaciones se ha considerado usar el 100\% de la capacidad instalada en el primer piso, debidamente equipado y distribuido de acuerdo a las normas del MINEDU. En un plazo máximo de dos a tres años se aprovechará el ambiente del segundo piso con la instalación de nuevas salas de estudio para profesores y otros ambientes administrativos.

\section{3. $\quad$ Estudio de Localización}

Este punto define la ubicación más adecuada para el proyecto, ya que será la que posibilite maximizar el logro de los objetivos.

\subsubsection{Definición de factores locacionales.}

Se ha considerado que el distrito de La Victoria Santa Catalina (ver Figura 58) es una opción para el desarrollo de la Guardería, es un distrito colindante a las zonas con mayor afluencia de empresas importantes generadores de empleos y con grandes números de trabajadores. Así también, se considera como uno de los aspectos de importancia en el presente proyecto, el tiempo, factor crítico para el cumplimiento de expectativas favorables del cliente. Otro factor importante es el acceso de vías alternas para el transporte y el 
estacionamiento. En tal sentido, se tuvieron en cuenta los siguientes factores críticos para definir la localización del local principal:

- Transporte y vías de acceso fluido: la Guardería estará ubicado en una de las avenidas en paralelo a la vía expresa de la avenida Paseo de la Republica, entradas y salidas por la avenida Javier Prado y Canadá, además de la cercanía del paradero del Metropolitano lo cual facilita la accesibilidad y facilidad para los clientes.

- Costo del alquiler del local: Santa Catalina es una zona dónde el precio de los predios se ha revalorado, para el proyecto optaremos por alquilar un local de $700 \mathrm{mt} 2$, el mismo que será adecuado a los requerimientos del negocio.

- Proximidad a Clínicas y Centros Médicos: Para la guardería es importante contar con lugares cercanos por alguna emergencia que se presente.

- Cercanía a zonas empresariales, empresas medianas y pequeñas.

- Lugares de estacionamiento, cuenta con parques cercanos y espacios exclusivos para parqueo.

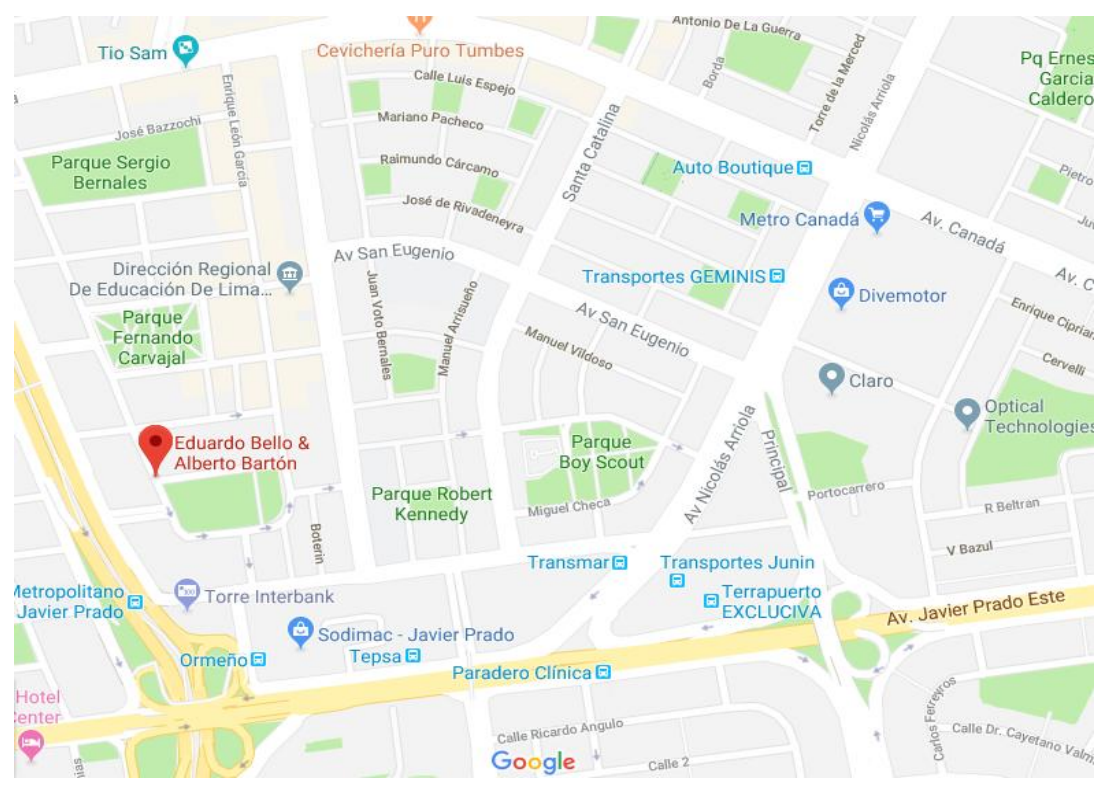

Figura 58. Ubicación del local. Recuperado de

https://www.google.com.pe/maps/place/Eduardo+Bello+\%26+Alberto+Bart\%C3\%B3n,+La+Victoria +15034/@-12.0875542,-

77.025474,17z/data=!3m1!4b1!4m5!3m4!1s0x9105c862e7580341:0xf7d47303db7e0758!8m2!3d$12.0875542 ! 4 \mathrm{~d}-77.0232853$ ?hl=es-419\&authuser $=0$ 


\subsubsection{Consideraciones legales}

1. Forma Societaria

Para este proyecto se adoptará la forma societaria de una Sociedad Anónima Cerrada por sus características, las cuales se encuentran normalizadas por la Ley General de Sociedades 26887.

Sociedad Anónima Cerrada (S.A.C.)

Ley N²6887 en el Título I, Artículo N²34:

La sociedad anónima puede sujetarse al régimen de la sociedad anónima cerrada cuando tiene no más de veinte accionistas y no tiene acciones inscritas en el Registro público del mercado de Valores. No se puede solicitar la inscripción en dicho registro de las acciones de una sociedad anónima cerrada (Ley General de Sociedades, 1997. P. 57)

Para realizar la constitución de la empresa se deberá seguir una serie de pasos los cuales están especificados en la página institucional de SUNARP (Ver Apéndice N)

2. Registro de Marcas y patentes

El registro de la marca “Titinos Daycare” estará a cargo y será tramitada a través de la Dirección de Signos Distintivos del Instituto Nacional de Defensa al Consumidor y a la Propiedad Intelectual (INDECOPI).

La duración del trámite de registro de la marca "Titinos Daycare” es de 120 días, a menos que haya oposición por una tercera persona. Esta gestión comprende desde que se presenta la solicitud en INDECOPI hasta la expedición del Certificado o título de la propiedad.

\subsubsection{1 identificación del marco legal.}

El presente proyecto se sustenta en el marco legal del Decreto Legislativo que aprueba la ley de promoción de la competitividad, formalización y desarrollo de micro y pequeña empresa y del acceso al empleo decente, Ley PYME - Decreto supremo No 007-2008-TR.

Las condiciones particulares se detallan en la Tabla 36 
Tabla 36

Características Establecidas para la Pequeña Empresa

\begin{tabular}{|c|c|}
\hline Características & Para la Pequeña Empresa \\
\hline Denominación & "Sociedad Anónima Cerrada", o de las siglas "S.A.C." \\
\hline Características & De 2 a 20 accionistas. \\
\hline Régimen Tributario & MYPE \\
\hline \multirow[t]{2}{*}{ Órganos } & Junta General de Accionistas, Directorio (opcional) y \\
\hline & Gerencia \\
\hline Capital Social & $\begin{array}{l}\text { Aportes en moneda nacional y/o extranjera y en } \\
\text { contribuciones tecnológicas intangibles. }\end{array}$ \\
\hline Duración & Determinado o Indeterminado \\
\hline \multirow[t]{2}{*}{ Transferencia } & La transferencia de acciones debe ser anotada en el Libro de \\
\hline & Matrícula de Acciones de la Sociedad \\
\hline Nro. de trabajadores & De cincuenta (50) hasta cien (100) trabajadores, inclusive \\
\hline \multirow[t]{2}{*}{ Ventas Anuales } & Hasta el monto máximo de 1,700 Unidades \\
\hline & Impositivas Tributarias (UIT) \\
\hline \multirow[t]{2}{*}{ Impuesto a la Renta } & Hasta 15 UIT $10 \%$ \\
\hline & Más de 15 UIT $29.5 \%$ \\
\hline Beneficios de los & Remuneración No menor a la RMV \\
\hline \multirow[t]{5}{*}{ trabajadores } & Jornada: 08 diárias o 48 horas semanales \\
\hline & Descanso semanal \\
\hline & Descanso vacacional 15 días calendarios \\
\hline & Compensación por tiempos de servicio \\
\hline & Gratificaciones \\
\hline
\end{tabular}

3. Licencias y autorizaciones

Para obtener la Licencia de Funcionamiento en la zona de Santa Catalina - La Victoria serán necesarios los requisitos aplicados según las normas legales:

- Ley No 28976, Ley Marco de Licencia de Funcionamiento

- Ordenanza No 256-2016/MLV - Actualización del Texto Único de Procedimientos Administrativos - TUPA. 
Para seguir lo establecido por las normas que se rigen, revisar el Apéndice $\mathrm{M}$ del presente proyecto para mayor detalle.

\subsubsection{2. $\quad$ ordenamiento jurídico de la empresa.}

Para esta empresa, el ordenamiento jurídico está sustentado en la ley de Promoción, formalización y desarrollo de micro y pequeña empresa y del acceso al empleo decente, publicada el 28 de junio del año 2008. Entre los alcances de la ley, se tienen los siguientes regímenes:

- Régimen Laboral de Micro y Pequeña Empresa

- Régimen MYPE Tributario del impuesto a la renta

- Aseguramiento en Salud y Sistema de Pensiones Sociales

- Instrumentos de Promoción para el Desarrollo y la Competitividad.

\subsection{Determinación de la localización óptima}

Para este proyecto se ha considerado tres ubicaciones estratégicas que se ven impactados en mayor o menor medida por los factores locacionales que a continuación detallamos:

- Facilidad de transporte

- Cercanías de zonas empresariales

- Proximidad a clínicas y centros médicos

- Vías de acceso

- Costo de Alquiler

Con el propósito de elegir la ubicación del local, se va a utilizar el método cualitativo por puntos, consiste en asignar valores ponderados de peso relativo a cada factor de localización, el peso debe sumar la base de 1 y la calificación dependerá del evaluador. En la Tabla 37 se muestran los valores obtenidos según calificación y peso asignado a cada factor. 
Tabla 37

Localización por el Método de Puntos para la Guardería Titinos Daycare

\begin{tabular}{lccccccc}
\hline \multirow{2}{*}{ Factores } & \multirow{2}{*}{ Pond. } & \multicolumn{2}{c}{ San Isidro } & \multicolumn{2}{c}{ La Victoria } & \multicolumn{2}{c}{ Lince } \\
\cline { 3 - 9 } & & & Calificación & Puntaje & Calificación & Puntaje & Calificación Puntaje \\
\hline Facilidad de transporte & 0.18 & 3 & 0.54 & 5 & 0.90 & 5 & 0.90 \\
Cercanías de zonas empresariales & 0.25 & 6 & 1.50 & 5 & 1.25 & 4 & 1.00 \\
Proximidad a clínicas y centros médicos & 0.12 & 6 & 0.72 & 4 & 0.48 & 5 & 0.60 \\
Vías de acceso & 0.25 & 4 & 1.00 & 6 & 1.50 & 3 & 0.75 \\
Costo de alquiler & 0.20 & 2 & 0.40 & 6 & 1.20 & 4 & 0.80 \\
Total & $\mathbf{1 . 0 0}$ & & $\mathbf{4 . 1 6}$ & & $\mathbf{5 . 3 3}$ & & $\mathbf{4 . 0 5}$ \\
\hline
\end{tabular}

De este análisis se obtiene como resultado que el Distrito de la Victoria es la más idónea para la implementación del proyecto dada la facilidad de vías de acceso que tiene, salidas y entradas por la Vía expresa, Av. Canadá y Av. Javier Prado, la cercanía a la zona empresarial y otras empresas de los alrededores lo hacen atractivo para el negocio por la mayor concentración de personas. El costo de alquiler es un factor muy importante ya que el precio y el tamaño del local forman parte de lo requerido para este negocio.

El local se situará en la Av. Eduardo Bello con Alberto Barton en Santa Catalina - La Victoria (véase Figura 59)

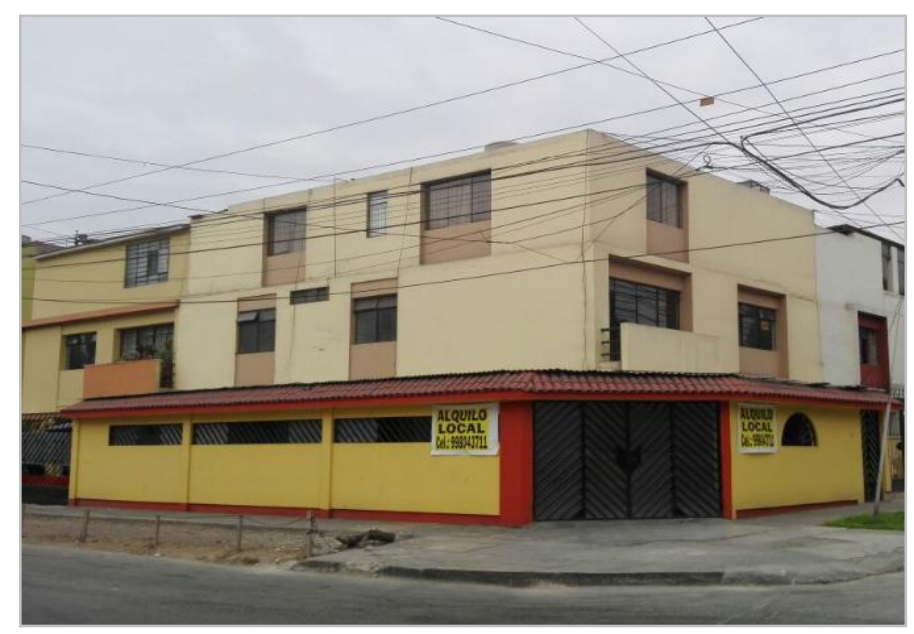

Figura 59. Fotografía Local Santa Catalina - La Victoria 


\section{Capítulo VIII: Aspectos Organizacionales}

\subsection{Caracterización de la cultura organizacional deseada}

Para poder establecer una organización solida es fundamental establecer las bases que definirán cuáles serán las mejores estrategias para lograr el éxito del proyecto; en ese sentido se empieza por definir la Visión, Misión y Principios que van a guiar el desarrollo de la organización.

\subsubsection{Visión}

Hitt, Ireland y Hoskisson, en el libro Administración Estratégica (2015) mencionan que:

La visión es una descripción de lo que quiere ser la empresa y, en términos generales, de lo que quiere lograr en última instancia. Por lo tanto, el enunciado de la visión articula la descripción ideal de una organización y configura el futuro que pretende alcanzar. En otras palabras, el enunciado de la visión dirige a la empresa hacia el lugar donde le gustaría estar en años por venir. Una visión efectiva también desafía a las personas y le exige al máximo. (p. 19)

En ese sentido para la definición de la visión de la guardería Titinos Daycare, se ha dado respuesta a las siguientes preguntas tal como se muestra en la Tabla 38: (a) ¿Qué queremos ser?, (b) ¿Qué valores necesitamos resaltar? (c) ¿Cómo queremos que nos vean? (d) ¿Qué consideramos como fundamental en el futuro de la organización?

Tabla 38

Preguntas y Respuestas para la Definición de la Visión

\begin{tabular}{ll}
\hline \multicolumn{1}{c}{ Pregunta } & \multicolumn{1}{c}{ Respuesta } \\
\hline ¿Qué queremos ser? & $\begin{array}{l}\text { La primera opción de guardería de los padres que trabajan } \\
\text { y tienen hijos menores de 36 meses. }\end{array}$ \\
¿Qué valores necesitamos resaltar? & Confianza y Seguridad. \\
¿Cómo queremos que nos vean? & Como un aliado estratégico para el cuidado de sus hijos. \\
¿Qué consideramos como fundamental & Generar empatía con los padres sobre en el cuidado de sus \\
en el futuro de la Organización? & hijos. \\
\hline
\end{tabular}

Siendo la respuesta a todas ellas la siguiente declaración de visión:

"Ser la primera opción de guardería de los padres que trabajan y tienen hijos menores de 36 meses".

\subsubsection{Misión.}

Fred R., en el libro Administración Estratégica (2013) asegura que:

La misión de la organización es la base de sus prioridades, estrategias, planes y 
asignación de tareas. Es el punto de partida para el diseño del trabajo gerencial y, sobre todo, para el diseño de las estructuras gerenciales. Aparentemente no hay nada más sencillo o más obvio que conocer cuál es el negocio de una empresa. (p. 46) En ese sentido se define que la misión de la guardería Titinos es la siguiente: "Somos una empresa que busca contribuir al desarrollo profesional y laboral de la mujer limeña mediante el cuidado y la estimulación temprana de sus hijos de 3 a 36 meses de edad aplicando el método Doman, brindándoles un ambiente seguro, con alta tecnología, que además sea agradable para los infantes y los colaboradores; y genere rentabilidad para los accionistas".

Para la definición de la misión se ha considerado los siguientes componentes esenciales:

- Clientes - La mujer limeña que trabaja en la zona empresarial de San Isidro.

- Servicios - Cuidado y estimulación temprana de sus hijos de 3 a 36 meses

- Mercados - Zona Financiera de San Isidro

- Tecnología - Sistema de video vigilancia con la instalación de cámaras IP.

- Preocupación por la supervivencia, el crecimiento y la rentabilidad - Asegurar el crecimiento y beneficiar a los clientes, colaboradores, accionistas, estado y por ende a la comunidad.

- Filosofía y Autoconcepto - Contribuir al desarrollo profesional y laboral de la mujer limeña.

- Preocupación por la imagen pública y empleados - Beneficiar a los clientes, colaboradores, accionistas y a la comunidad.

\subsubsection{Principios}

Titinos Daycare se basará en los siguientes principios:

- Responsabilidad: Titinos es una empresa que se ocupa del cuidado de los niños durante la primera infancia, es por ello que este principio es muy importante, el enfoque de este principio se divide de la siguiente manera:

- Responsabilidad Social: Contribuir con la sociedad brindando un cuidado y enseñanza especializada de calidad, así poder contribuir con el desarrollo integral de los niños, el desarrollo profesional y laboral de la mujer limeña y con la productividad de las empresas donde ellas trabajan.

- Responsabilidad personal: Ser muy rigurosos en los procesos de selección de personal para asegurar que el servicio prestado sea de calidad. Asimismo, es importante generar un ambiente laboral agradable para nuestros colaboradores, 
cumpliendo oportunamente con el pago de sus sueldos y todos los demás beneficios salariales. A los niños

- Seguridad: Titinos cuenta con una infraestructura segura para los niños y se realiza el correcto mantenimiento de cada uno de los ambientes; asimismo con ayuda de la tecnología cuenta con un sistema de video vigilancia donde los padres pueden ver en tiempo real las actividades y cuidados que reciben sus hijos.

- Respeto: Titinos está enfocado en lograr el desarrollo integral de los niños, para ello somos muy respetuosos de los tiempos de aprendizaje de cada uno de ellos; asimismo, tanto para los niños para los colaboradores brindamos un ambiente en las mejores condiciones de seguridad e higiene y por último se promueve la igualdad en todas las condiciones.

- Se promueve el respeto por las leyes, costumbres, creencias y por el medio ambiente.

- Calidez: Nuestro personal es muy empático con las necesidades afectivas de los niños, se brindan cuidados y enseñanzas, pero cada actividad que se desarrolla se busca que los niños se sientan a gusto y valorados.

- Comunicación: Titinos cuenta con diversos canales de comunicación tales como, Pagina Web, WhatsApp, Cuaderno de control y telefonía; se informa a los padres los avances y necesidades de sus hijos de forma clara y se reciben los comentarios y solicitudes de los padres.

\subsection{Formulación de estrategias del negocio}

La Guardería Titinos plantea brindar el servicio de cuidado de infantes de 3 a 36 meses, adicionalmente propone brindar la estimulación temprana el cual se utilizará como base el método Doman, así como un horario de servicio adaptado a horarios laborales de oficina u otros.

Esto lleva a establecer la estrategia de Enfoque de mejor valor ${ }^{5}$, cuya propuesta de valor se centra en la diferenciación, pues según la investigación de mercado realizada, los padres valoran mucho el tiempo, por el cual ofrecer un horario extendido de atención es muy atractivo para la intención de contar con este servicio, así también contar con alta tecnología en video cámaras resulta confiable ya que pueden observar a sus hijos en todo momento y en tiempo real; el método de enseñanza Doman no es muy conocido comercialmente; sin embargo, los beneficios que brinda a los infantes son altamente interesantes: (a) contribuye

\footnotetext{
${ }^{5}$ Estrategia de Enfoque de Mejor Valor: ofrece productos o servicios a una pequeña variedad de clientes con la mejor relación valor-precio disponible en el mercado, en ocasiones se conoce como "Diferenciación enfocada"
} 
al desarrollo cerebral, (b) favorece la concentración, (c) estimula la memoria y aprendizaje, (d) ayuda al desarrollo visual y auditivo, y (e) favorece la comunicación; dichos beneficios enriquecen la metodología y por ende la estimulación lectora en los niños.

\subsubsection{Análisis FODA}

De la información que hemos obtenido en el estudio de mercado cuantitativo y cualitativo se puede concluir de forma preliminar lo siguiente:

Fortalezas:

1. Ubicación estratégica, cercana a la zona empresarial más importante de Lima.

2. Contar con un especialista certificado en la metodología Doman.

3. Personal calificado y con experiencia en trabajos en guardería.

4. Ser una guardería formal que cuenta con autorización del Ministerio de Educación $\mathrm{y}$ con licencias de funcionamiento.

5. Infraestructura adecuada y acondicionado para el negocio

6. Confort en sus instalaciones.

7. Contar con horarios extendidos.

8. Alta tecnología en video cámaras para ver en tiempo real.

9. Vías de acceso y transporte.

10. Talleres de estimulación temprana, bajo la metodología Doman.

Oportunidades:

1. Crecimiento de la PEA femenina ocupada con nivel superior universitario, paso de $9.2 \%$ en el 2001 a $17.1 \%$ en el 2014 .

2. Factibilidad de acceso a internet a través de diferentes accesorios principalmente de los teléfonos celulares por parte de los padres.

3. Concentración del público objetivo en la zona propuesta para la guardería.

4. No existen guarderías especializadas en el método Doman en las zonas aledañas.

5. No existen guarderías con infraestructura adecuada en la zona, las que hay son casas adaptadas para una guardería.

6. Horarios de servicio de atención en guardería limitados o de tiempo corto.

7. Los ingresos percibidos por la mujer que trabaja forman parte del presupuesto. familiar, por lo que se reduce las probabilidades de dejar de trabajar para dedicarse al cuidado de sus hijos.

8. La existencia de empresas denominadas principales contribuyentes en la zona de Santa Catalina.

9. NSE elegido esta dentro del mayor poder adquisitivo. 
10. Cercanía a clínicas privadas para la atención de emergencias.

11. Los servicios de educación están exonerados de renta e IGV.

Debilidades:

1. Ser una empresa con curva de experiencia en el mercado.

2. Local no es propio.

3. No hay posicionamiento.

4. Bajo poder de negociación frente a proveedores

5. Limitación financiera.

6. Apalancamiento.

Amenazas:

1. Costo de alquiler en incremento.

2. Alto poder de negociación de los especialistas en la metodología Doman.

3. Poder de negociación de profesores especializados en niños menores.

4. Tiempos muy extensos para obtener la licencia de funcionamiento.

5. Competencia desarrollada en el sector.

6. Frenos de los padres por dejar a los niños de temprana edad.

Estrategias - FO

1. Aprovechar la ubicación de la zona para ganar mayor mercado. (F1,F4,F9,O1,03,O5,O7,O8)

2. Atender de forma personalizada con un grato ambiente y confort en sus instalaciones, con metodología especializada y horarios extendidos; aprovechando la concentración del público objetivo en la zona. (F1,F2,F3,F5,F6,F7,F9,O3,O6,O8)

3. Ofrecer un servicio de calidad y precio acorde con el mercado y el poder adquisitivo en crecimiento (F2,F3,F10,O1,O7,11)

4. Promocionar a través de la publicidad las características y bondades del producto/servicio a brindar con la finalidad de generar mayor demanda. (F2,F3,F7,F8,F10,O2,O4,O6,O8,O10)

Estrategias - DO

1. Fortalecer la poca experiencia en el rubro, contrarrestando con los atributos que se ofrecen como: infraestructura, metodología y horarios extendidos (D1,D3,O4,O5,O6)

2. Negociar el alquiler del local a largo plazo y aprovechar la zona empresarial y crecimiento de la PEA femenina (D2,O1,O8) 
Estrategias - FA

1. Brindar calidad en el servicio con una atención esmerada y profesional para asegurar y fidelizar a los clientes (F2,F3,A6)

2. Ofrecer comodidad y confort de las instalaciones y atributos que nos diferencie de otras guarderías que no los tienen (F2,F3,F5,F6,F7,F8,A5)

3. Negociar el costo del alquiler a largo plazo aprovechando la ubicación estratégica de la zona (F1, F4,F9,A1)

4. Mantener contratos de trabajo a mediano plazo con personal clave, para mantener la calidad de servicio que requiere la guardería $(\mathrm{F} 2, \mathrm{~F} 3, \mathrm{~A} 2, \mathrm{~A} 3)$

Estrategias - DA

1. Contar con personal de experiencia y capacitado, y con una buena infraestructura, refleja una imagen seria que permite la confianza y lealtad de los clientes (D1,A6)

2. Contar con proveedores mediano-pequeño para obtener cierto poder de negociación y reducir costos para enfrentar la competencia creciente (D4,A3,A5) 


\section{FORTALEZAS - $F$}

F1: Ubicación estratégica, cercana a la zona empresarial más importante de Lima.

F2: Contar con un especialista certificado en la metodología Doman.

F3: Personal calificado y con experiencia en trabajos de guardería

F4: Negocio formal con autorización del Ministerio de Educación y licencia de

funcionamiento.

F5:Infraestructura adecuada y acondicionado para el negocio

F6: Confort en sus instalaciones

7: Contar con horarios extendidos

8: Alta tecnología en video cámaras para ver en tiempo real

F9: Vías de acceso y transporte

F10:Talleres de estimulación temprana, bajo la metodología Doman

\section{OPORTUNIDADES - 0 \\ O1: Crecimiento de la PEA femenina ocupada con nivel superior} universitario, paso de $9.2 \%$ en el 2001 a $17.1 \%$ en el 2014

O2: Factibilidad de acceso a internet a través de diferentes accesorios

O3: Concentración del público objetivo en la zona propuesta para la guardería

O4: No existen guarderías es pecializadas en el método Doman en las zonas aledañas

05: No existen guarderías con infraestructura adecuada en la zona O6: Horarios de servicio de atención en guardería limitados o de tiempo corto

07: Los ingresos percibidos por la mujer que trabaja forman parte de presupuesto familiar, reduciendo las probabilidades de dejar de trabajar para dedicarse al cuidado de sus hijos

08: La existencia de empresas denominadas principales contribuyentes en la zona de Santa Catalina

O9: NSE elegido esta dentro del mayor poder adquisitivo

O10: Cercanía a clínicas privadas para la atención de emergencias.

O11: Los servicios de educación están exonerados de renta e IGV

\section{AMENAZAS - A}

A1: Costo de alquiler en incremento

A2: Alto poder de negociación de los especialistas en la metodología Doman

A3: Poder de negociación de profesores especializados en niños menores

A4: Tiempos muy extensos para obtener la licencia de funcionamiento A5: Competencia desarrollada en el sector

A6: Frenos de los padres por dejar a los niños de temprana edad

la zona para ganar mayor mercado.

F1,F4,F9, 01,03,05,07,08)

2. Atender de forma personalizada con un grato ambiente y confort en sus instalaciones, con metodologia especializada y horarios extendidos; aprovechando la concentración del publico objetivo en la zona.

( $\mathrm{F} 1, \mathrm{~F} 2, \mathrm{~F} 3, \mathrm{~F} 5, \mathrm{FG}, \mathrm{F} 7, \mathrm{Fg}, \mathrm{O3}, \mathrm{O6}, \mathrm{O} 8$ )

3. Ofrecer un servicio de calidad y precio acorde con el mercado y el poder adquisitivo en crecimiento $(\mathrm{F} 2, \mathrm{~F} 3, \mathrm{~F} 10, \mathrm{O} 1, \mathrm{O} 7,11)$

4. Promocionar a traves de la publicidad las características y bondades del producto/servicio a brindar con la finalidad de generar mayor demanda.

(F2,F3,F7,F8, F10,02,04,06,08,010)

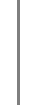

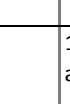

\section{Brindar calidad en el servicio con uTEGIAS - FA}

1. Brindar calidad en el servicio con una aten 2. Ofrecer comodidad $y$ confort de las instalaciones $y$ atributos de otras guarderias que no los tienen ( $F 2, F 3, F 5, F 6, F 7, F 8, A 5)$ estrategica de la zona (F1, F4,F9,A1)

4. Mantener contratos de trabajo a mediano plazo con personal clave, para mantener la calidad de servicio que requiere la guarderia $(F 2, F 3, A 2, A 3)$
3. Negociar el costo del alquiler a largo plazo aprovechando la ubicación

\section{DEBILIDADES -}

D1: Ser una empresa con curva de experiencia en el mercado.

D2: Local no es propio.

D3: No hay posicionamiento.

D4: Bajo poder de negociación frente a proveedores

D5: Limitación financiera.

D6: Apalancamiento.

ESTRATEGIAS - DO
$\begin{aligned} & \text { 1. Fortalecer la poca experiencia en el rubro, contrarrestando con los } \\ & \text { atributos que se ofrecen como: infraestructura, metodologia y horarios } \\ & \text { extendidos (D1,D3,04,05,06) }\end{aligned}$
extendidos (D1,D3,04,05,06)

2. Negociar el alquiler del local a largo plazo y a provechar la zona empresarial y crecimiento de la PEA femenina $(\mathrm{D} 2,01,08)$ 


\subsection{Determinación de las ventajas competitivas críticas}

Para el presente proyecto se han identificado las siguientes ventajas competitivas:

Los recursos tangibles

Está conformado por el capital físico y el capital financiero. En la Guardería Titinos, el capital físico se conforma por las características del establecimiento (tamaño, localización, remodelaciones y complementos utilizados para satisfacer las necesidades de sus clientes), mientras que el capital financiero está conformado por las capacidades económicas de la empresa (fuentes de financiación y capacidad de endeudamiento). La Guardería, al ser una empresa nueva contará con una capacidad financiera limitada.

Los recursos intangibles

Están basados en la imagen de marca, cultura y la metodología aplicada en la enseñanza. Los activos intangibles permanecen en su mayor parte invisibles en los estados financieros. La reputación es un recurso de importancia crucial. La propiedad del negocio es decir el know-how, es importante para la percepción de la calidad del servicio por parte de los clientes; en este sentido el desarrollo y puesta en valor del método Doman, constituye también una ventaja importante para la guardería.

\section{Los recursos humanos}

Aunque las personas son tangibles, los recursos que ofrecen a las empresas son sus destrezas, conocimientos y habilidades de razonamiento y de toma de decisiones. La Guardería Titinos contratara al personal según su perfil, calificación y la actitud que tenga hacia los clientes.

\section{* Cadena de Valor}

Para la Guardería Titinos Daycare se ha dividió las diversas unidades para poder fortalecer la cadena de valor tal como se muestra en la Figura 60.

Actividades primarias

Ventas

- Atención personalizas para cada cliente y/o empresa, asegurándole pronta respuesta a sus solicitudes y consultas.

- Guiado en las instalaciones de la Guardería para mayor observación y beneficios a ofrecer.

- Base de datos de personas interesadas en el servicio, así como tarifas y promociones que ofrece con empresas para convenios.

- Seguimiento constante y mínimo tiempo de espera sobre información del servicio. 
- Marketing

- Registro de la Guardería en revistas especializadas

- Registro de la Guardería en las diversas páginas webs dedicadas al sector educativo, cuidado de los niños y maternidad.

- Registro de la Guardería en Facebook como medio publicitario.

- Mantenimiento de la Pagina Web.

- Operaciones

- Recepción, brindar atención de calidad, el cliente es nuestra razón de ser y atenderlo es nuestro compromiso.

- Capacidad de respuesta de los empleados para cualquier pregunta, reclamo de parte del cliente, solucionando el problema en el menor tiempo posible.

- Establecer una comunicación fluida y clara con los padres de familia e interesados.

- Ofrecer en todo momento los beneficios que la empresa brinda.

- Buen manejo de quejas y reclamos.

- Logística - Mantenimiento

- Abastecimiento de insumos que permitan la prestación del servicio sin contratiempos.

- Control periódico de inventarios para analizar los costos de inventario en stock, así como la utilización de materiales e insumos de buena calidad.

- Buenas relaciones con los proveedores, para poder asegurar un buen abastecimiento y precios.

- Mantenimiento preventivo de los equipos, para evitar fallas.

- Personal capacitado para solución de problemas

- Mantener contacto con los proveedores de equipo para el abastecimiento de repuestos.

- Mantenimiento y limpieza constante en las instalaciones.

\section{Actividades secundarias}

\section{Recursos Humanos}

- Personal capacitado y con experiencia en el rubro para poder responder a los requerimientos de los clientes (PPFF).

- Capacitación y actualización constante sobre metodología de enseñanza.

- Beneficios laborales para nuestros empleados para así crear un buen ambiente 
laboral.

- Infraestructura

- Local acondicionado dentro de las normas establecidas por las autoridades del sector y de acuerdo a la zona con los servicios necesarios para la puesta en marcha.

- Ubicación estratégica y con accesibilidad a las vías principales.

- Zonas distribuidas de acuerdo a las edades de los niños.

Contabilidad y Finanzas

- Control de los ingresos y egresos de la guardería

- Análisis financiero continúo de la situación de la guardería

- Establecimiento de presupuesto.

\begin{tabular}{|c|c|c|c|c|c|}
\hline \multicolumn{5}{|c|}{ Cadena de Valor de la Empresa } & \\
\hline \multirow{6}{*}{ 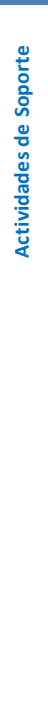 } & \multicolumn{4}{|c|}{$\begin{array}{l}\text { Recursos Humanos: Personal capacitado y con experiencia para su reclutamiento, } \\
\text { capacitación constante y buen clima laboral }\end{array}$} & \\
\hline & \multicolumn{4}{|c|}{$\begin{array}{l}\text { Infraestructura: Lugar estratégico y de ubicación accesible. Local acondicionado de acuerdo a las } \\
\text { normas establecidas y de ambiente agradable. }\end{array}$} & \\
\hline & \multicolumn{4}{|c|}{ Contabilidad y Finanzas: Análisis Financiero, control de ingresos y egresos, presupuestos } & \\
\hline & Venta & Marketing & Operaciones & Logística-Mantenimiento & del \\
\hline & $\begin{array}{l}\text { Atención al cliente, guías } \\
\text { in situ para la } \\
\text { observación de local } \\
\text { interior, ventas, } \\
\text { seguimiento y servicio de } \\
\text { post venta que permita la } \\
\text { satisfacción del cliente } \\
\text { por el servicio ofrecido. }\end{array}$ & $\begin{array}{l}\text { Revistas } \\
\text { especializadas, } \\
\text { difusión en } \\
\text { paginas web y } \\
\text { redes sociales } \\
\text { como medios } \\
\text { publicitarios }\end{array}$ & $\begin{array}{c}\text { Recepción (atención de } \\
\text { calidad y capacidad de } \\
\text { respuesta ante cualquier } \\
\text { pregunta o reclamo), } \\
\text { Maestros y Auxiliares } \\
\text { (supervisión constante y } \\
\text { comunicación ante } \\
\text { cualquier evento con los } \\
\text { niños) }\end{array}$ & $\begin{array}{l}\text { Abastecimiento de insumos, } \\
\text { control de inventarios, } \\
\text { buena relación con los } \\
\text { proveedores, mantenimiento } \\
\text { preventivo de equipos y } \\
\text { limpieza general }\end{array}$ & Servicio \\
\hline & & & des Primarias & & \\
\hline
\end{tabular}

Figura 60. Cadena de valor de la empresa - Adaptado del modelo de Michael Porter.

\subsection{Diseño de la estructura organizacional deseada}

El presente proyecto tendrá la estructura de una organización simple dividida por áreas. Este tipo de organización permitirá llevar un trabajo compartido y sistematizado con la finalidad de que cada área se involucre con el objetivo del negocio.

El director general es el encargado de todos los empleados de la empresa. El contador y el especialista Doman trabajarán bajo el esquema de locación de servicio. En la figura 61 se puede observar el diseño del organigrama de la guardería. 


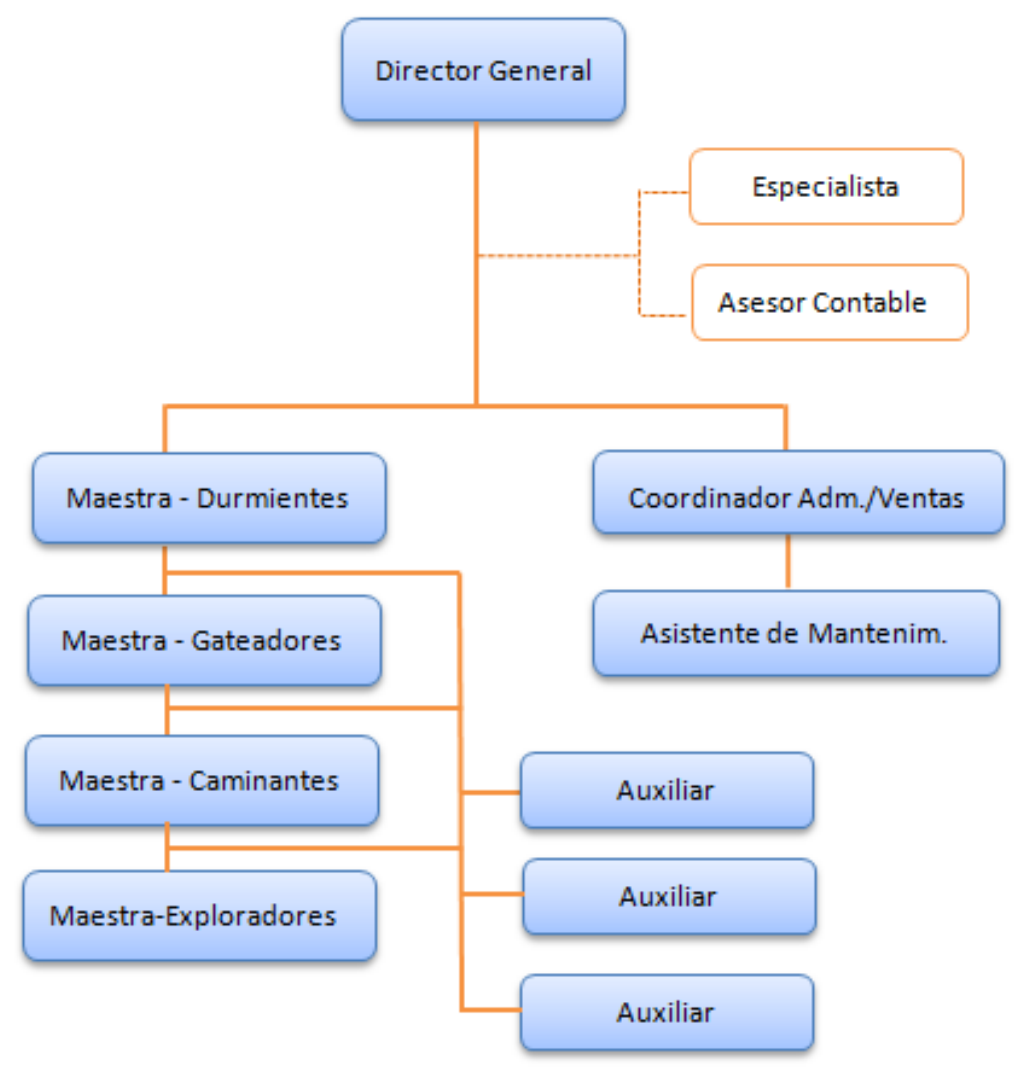

Figura 61. Organigrama Titinos Daycare

\subsection{Diseño de los perfiles de puestos clave}

"La Directora y el personal docente de la Cuna/Guardería deberán ser profesionales de

Educación Inicial, quienes recibirán el apoyo de los auxiliares de educación y

personal de servicio" (MINEDU. 2006, 9)

A continuación, se describen los perfiles y funciones requeridos para el staff de Titinos

Daycare, estas se mostrarán en las Figuras 62, 63, 64, 65, 66, 67 y 68).

Director (a): La Directora es la máxima autoridad de la Guardería, responsable de la gestión pedagógica, institucional y administrativa. 


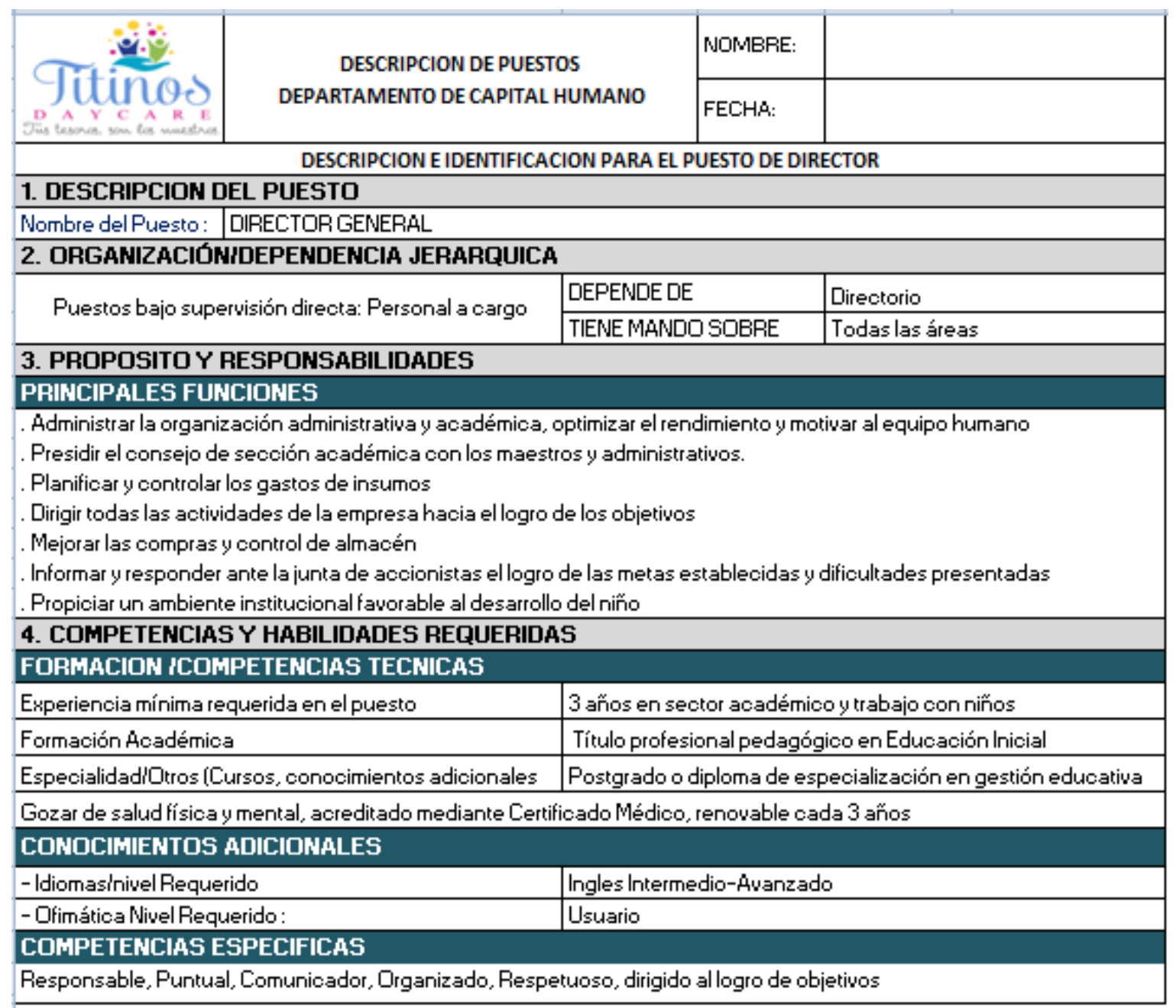

Figura 62. Perfil y funciones del Director General Titinos Daycare 


\begin{tabular}{|c|c|c|}
\hline \multicolumn{3}{|c|}{ DESCRIPCION E IDENTIFICACION PARA EL PUESTO DE COORDINADOR } \\
\hline \multicolumn{3}{|c|}{ 1. DESCRIPCION DEL PUESTO } \\
\hline \multicolumn{3}{|c|}{ COORDINADOR ADMINISTRATIVOY DEVENTAS } \\
\hline \multicolumn{3}{|l|}{ 2. ORGANIZACIÓN/DEPENDENCIA JERARQUICA } \\
\hline \multirow{2}{*}{ Puestos bajo supervisión directa: Personal a cargo } & DEPENDE DE & Director \\
\hline & TIENE MANDO SOBRE & Asistente Mantenimiento \\
\hline \multicolumn{3}{|l|}{ 3. PROPOSITOY RESPONSABILIDADES } \\
\hline \multicolumn{3}{|c|}{ Principales Funciones } \\
\hline \multicolumn{3}{|c|}{. Establece y coordina la búsqueda de nuevas alianzas o convenios con entidades publicas y/o privadas } \\
\hline \multicolumn{3}{|c|}{ Coordina con Maestros y Auxiliares el calendario académico } \\
\hline \multicolumn{3}{|c|}{ Coordina con Maestros y Auxiliares las actividades del calendario cívico escolar } \\
\hline \multicolumn{3}{|c|}{ Realizara los estudios de marketing para el diseño de nuevas estrategias de publicidad y del servicio } \\
\hline \multicolumn{3}{|c|}{ Se encargara de la supervisión de los programas académicos y administrativos. } \\
\hline \multicolumn{3}{|c|}{ Administra los medios de comunicación y redes sociales para mantener contacto con los clientes. } \\
\hline \multicolumn{3}{|c|}{ 4. COMPETENCIAS Y HABILIDADES REQUERIDAS } \\
\hline \multicolumn{3}{|l|}{ FORMACION /COMPETENCIAS TECNICAS } \\
\hline Experiencia mínima requerida en el puesto & \multicolumn{2}{|l|}{2 años en el puesto } \\
\hline Educación (grado, especialidad) & \multicolumn{2}{|c|}{ Título profesional en Administración/Marketing } \\
\hline Especialidad/Otros (Cursos, conocimientos adicionales & \multicolumn{2}{|c|}{ Atención al cliente, trabajo en equipo, marketing } \\
\hline \multicolumn{3}{|l|}{ CONOCIMIENTOS ADICIONALES } \\
\hline -Idiomas/nivel Requerido & \multicolumn{2}{|c|}{ Ingles Intermedio-Avanzado } \\
\hline - Ofimática Nivel Requerido: & \multicolumn{2}{|l|}{ Usuario } \\
\hline \multicolumn{3}{|c|}{ COMPETENCIAS ESPECIFICAS } \\
\hline \multicolumn{3}{|c|}{ Responsable, Creativo, Dinámico, Respetuoso, comunicador, orientado al logro de objetivos } \\
\hline
\end{tabular}

Figura 63. Perfil y funciones del Coordinador Administrativo y Ventas Titinos Daycare

\begin{tabular}{|c|c|c|}
\hline \multicolumn{3}{|c|}{ DESCRIPCION E IDENTIFICACION PARA EL PUESTO DE CONTADOR } \\
\hline \multicolumn{3}{|c|}{ 1. DESCRIPCION DEL PUESTO } \\
\hline \multicolumn{3}{|l|}{ CONTADOR } \\
\hline \multicolumn{3}{|l|}{ 2. ORGANIZACIÓN/DEPENDENCIA JERARQUICA } \\
\hline \multirow{2}{*}{ Puestos bajo supervisión directa: Personal a cargo } & DEPENDE DE & Administrador/Director \\
\hline & TIENE MANDO SOBRE & Ninguno \\
\hline \multicolumn{3}{|l|}{ 3. PROPOSITO Y RESPONSABILIDADES } \\
\hline \multicolumn{3}{|c|}{ Principales Funciones } \\
\hline $\begin{array}{l}\text {. Clasifica, registra y analiza información financiera } \\
\text {. Controlar gastos e ingresos presupuestales } \\
\text {. Liquidar planillas } \\
\text {. Prepara y certifica informes de Balances y EEFF a la } \\
\text {. Asesor asociado en materia crediticia }\end{array}$ & encia & \\
\hline \multicolumn{3}{|l|}{ 4. COMPETENCIAS Y HABILIDADES REQUERIDAS } \\
\hline \multicolumn{3}{|l|}{ FORMACION / COMPETENCIAS TECNICAS } \\
\hline Experiencia mínima requerida en el puesto & \multicolumn{2}{|c|}{2 años en actividades de contabilidad } \\
\hline Educación (grado, especialidad) & \multicolumn{2}{|c|}{ Título profesional en Contabilidad - Colegiado } \\
\hline Especialidad/Otros (Cursos, conocimientos adicionales & & \\
\hline \multicolumn{3}{|l|}{ COMPETENCIAS ESPECIFICAS } \\
\hline \multicolumn{3}{|l|}{ Analítico, Confiable, Respetuoso, Responsable } \\
\hline
\end{tabular}

Figura 64. Perfil y funciones del Contador Titinos Daycare 


\begin{tabular}{|c|c|c|}
\hline \multicolumn{3}{|c|}{ DESCRIPCION E IDENTIFICACION PARA EL PUESTO DE ESPECIALISTA } \\
\hline \multicolumn{3}{|c|}{ 1. DESCRIPCION DEL PUESTO } \\
\hline \multicolumn{3}{|l|}{ ESPECIALISTA DOMAN } \\
\hline \multicolumn{3}{|l|}{ 2. ORGANIZACIÓN/DEPENDENCIA JERARQUICA } \\
\hline \multirow{2}{*}{ Puestos bajo supervisión directa: Personal a cargo } & DEPENDE DE & Director/Coordinador \\
\hline & TIENE MANDO SOBRE & Ninguno \\
\hline \multicolumn{3}{|l|}{ 3. PROPOSITO Y RESPONSABILIDADES } \\
\hline \multicolumn{3}{|c|}{ Principales Funciones } \\
\hline \multicolumn{3}{|l|}{. Preparar programa anual de capacitación } \\
\hline \multicolumn{3}{|c|}{ Programar reuniones con profesores y auxiliares } \\
\hline \multicolumn{3}{|c|}{ Asesorar y reforzar la metodología al personal de la guardería } \\
\hline \multicolumn{3}{|c|}{ Proponer alternativas de mejora para la aplicación del método } \\
\hline \multicolumn{3}{|c|}{ 4. COMPETENCIAS Y HABILIDADES REQUERIDAS } \\
\hline \multicolumn{3}{|l|}{ FORMACION /COMPETENCIAS TECNICAS } \\
\hline Experiencia mínima requerida en el puesto & \multicolumn{2}{|c|}{2 años en actividades al puesto } \\
\hline Educación (grado, especialidad) & \multicolumn{2}{|l|}{ Psicólogo / Pedagogo } \\
\hline \multicolumn{3}{|l|}{ Especialidad/Otros (Cursos, conocimientos adicionales } \\
\hline \multicolumn{3}{|l|}{ COMPETENCIAS ESPECIFICAS } \\
\hline \multicolumn{3}{|l|}{ Paciente, Respetuoso, Responsable, buen carácter. } \\
\hline
\end{tabular}

Figura 65. Perfil y funciones del Especialista Titinos Daycare

\begin{tabular}{|c|c|c|c|}
\hline \multicolumn{4}{|c|}{ DESCRIPCION E IDENTIFICACION PARA EL PUESTO DE MAESTRO } \\
\hline \multicolumn{4}{|c|}{ 1. DESCRIPCION DEL PUESTO } \\
\hline Nombre del Puesto: & \multicolumn{3}{|l|}{ Maestro } \\
\hline \multicolumn{4}{|c|}{ 2. ORGANIZACIÓN/DEPENDENCIA JERARQUICA } \\
\hline \multirow{2}{*}{\multicolumn{2}{|c|}{ Puestos bajo supervisión directa: Personal a cargo }} & DEPENDE DE & Director \\
\hline & & TIENE MANDO SOBRE & Auxiliar \\
\hline \multicolumn{4}{|c|}{ 3. PROPOSITO Y RESPONSABILIDADES } \\
\hline \multicolumn{4}{|c|}{ Principales Funciones } \\
\hline \multirow{2}{*}{\multicolumn{4}{|c|}{$\begin{array}{l}\text { Responsable del cuidado y enseñanza de los niños } \\
\text { Programa las actividades de las clases a realizarse durante el día }\end{array}$}} \\
\hline & & & \\
\hline \multicolumn{4}{|c|}{. Evalúa el avance de rendimiento de los niños } \\
\hline \multicolumn{4}{|c|}{ Coordina y comunica de forma permanente con los padres } \\
\hline \multicolumn{4}{|c|}{ 4. COMPETENCIAS Y HABILIDADES REQUERIDAS } \\
\hline \multicolumn{4}{|c|}{ FORMACION /COMPETENCIAS TECNICAS } \\
\hline \multicolumn{2}{|c|}{ Experiencia mínima requerida en el puesto } & \multicolumn{2}{|c|}{3 años de experiencia en el sector educativo } \\
\hline \multicolumn{2}{|c|}{ Educación (grado, especialidad) } & \multicolumn{2}{|c|}{ Licenciado en Educación inicial } \\
\hline \multicolumn{2}{|c|}{ Especialidad/Otros (Cursos, conocimientos adicionales } & \multicolumn{2}{|c|}{ Metodología Doman } \\
\hline \multicolumn{4}{|c|}{ CONOCIMIENTOS ADICIONALES } \\
\hline \multicolumn{2}{|c|}{-Idiomas/nivel Requerido } & \multicolumn{2}{|l|}{ Ingles básico } \\
\hline \multicolumn{2}{|c|}{ - Ofimática Nivel Requerido: } & \multicolumn{2}{|l|}{ Usuario } \\
\hline \multicolumn{4}{|c|}{ COMPETENCIAS ESPECIFICAS } \\
\hline Paciente, Puntual, & Dedicado, Responsable, Comı & icador, Creativo. & \\
\hline
\end{tabular}

Figura 66. Perfil y funciones del Maestro Titinos Daycare 


\begin{tabular}{|c|c|c|}
\hline \multicolumn{3}{|c|}{ DESCRIPCION E IDENTIFICACION PARA EL PUESTO DE AUXILIAR } \\
\hline \multicolumn{3}{|c|}{ 1. DESCRIPCION DEL PUESTO } \\
\hline \multicolumn{3}{|l|}{ AUXILIAR } \\
\hline \multicolumn{3}{|l|}{ 2. ORGANIZACIÓN/DEPENDENCIA JERARQUICA } \\
\hline \multirow{2}{*}{ Puestos bajo supervisión directa: } & DEPENDE DE & Maestro \\
\hline & TIENE MANDO SOBRE & Ninguno \\
\hline \multicolumn{3}{|l|}{ 3. PROPOSITO Y RESPONSABILIDADES } \\
\hline \multicolumn{3}{|c|}{$\begin{array}{ll} & \text { Principales Funciones } \\
\end{array}$} \\
\hline \multicolumn{3}{|c|}{$\begin{array}{l}\text { Encargado de mantener los materiales para los niños } \\
\text { Responsable de velar por el cuidado de los niños } \\
\text { Dirige las actividades impartidas por los profesores } \\
\text { Coordina el horario de salida de los niños en coordinación con los padres }\end{array}$} \\
\hline \multicolumn{3}{|c|}{ 4. COMPETENCIAS Y HABILIDADES REQUERIDAS } \\
\hline \multicolumn{3}{|l|}{ FORMACION /COMPETENCIAS TECNICAS } \\
\hline Experiencia mínima requerida en el puesto & \multicolumn{2}{|c|}{1 año como auxiliar o al cuidado de niños } \\
\hline Educación (grado, especialidad) & \multicolumn{2}{|c|}{ Egresado de Instituto o universitario } \\
\hline Especialidad/Otros (Cursos, conocimientos adicionales & \multicolumn{2}{|c|}{ Pedagogía } \\
\hline \multicolumn{3}{|l|}{ CONOCIMIENTOS ADICIONALES } \\
\hline -Idiomas/nivel Requerido & \multicolumn{2}{|l|}{ Ingles básico } \\
\hline - Ofimática Nivel Requerido: & \multicolumn{2}{|l|}{ Usuario } \\
\hline \multicolumn{3}{|l|}{ COMPETENCIAS ESPECIFICAS } \\
\hline Paciente, Puntual, Dedicado, Responsable, Resp & uoso, Comunicado & tivo. \\
\hline
\end{tabular}

Figura 67. Perfil y funciones del Auxiliar Titinos Daycare

\begin{tabular}{|c|c|c|c|}
\hline \multicolumn{4}{|c|}{ DESCRIPCION E IDENTIFICACION PARA EL PUESTO DE ASISTENTE DE MANTENIMIENTO } \\
\hline \multicolumn{4}{|c|}{ 1. DESCRIPCION DEL PUESTO } \\
\hline Nombre del Puesto: & \multicolumn{3}{|l|}{ Asistente de Mantenimiento } \\
\hline \multicolumn{4}{|c|}{ 2. ORGANIZACIÓN/DEPENDENCIA JERARQUICA } \\
\hline \multirow{2}{*}{\multicolumn{2}{|c|}{ Puestos bajo supervisión directa: }} & DEPENDE DE & Coordinador Administrativo \\
\hline & & TIENE MANDO SOBRE & Ninguno \\
\hline \multicolumn{4}{|c|}{ 3. PROPOSITO Y RESPONSABILIDADES } \\
\hline \multicolumn{4}{|c|}{ Principales Funciones } \\
\hline \\
\hline \multicolumn{4}{|c|}{ Realizar mantenimiento preventivo de los equipos } \\
\hline \multicolumn{4}{|c|}{. Encargo de realizar la limpieza de todos los ambientes del local } \\
\hline \multicolumn{4}{|c|}{ Coordinar el abastecimiento de insumos para las áreas de la empresa } \\
\hline \multicolumn{4}{|c|}{ 4. COMPETENCIAS Y HABILIDADES REQUERIDAS } \\
\hline \multicolumn{4}{|c|}{ FORMACION /COMPETENCIAS TECNICAS } \\
\hline \multicolumn{2}{|c|}{ Experiencia mínima requerida en el puesto } & \multicolumn{2}{|l|}{1 año en el puesto } \\
\hline \multicolumn{2}{|c|}{ Educación (grado, especialidad) } & \multicolumn{2}{|c|}{ Egresado o estudiante de Instituto o universitario } \\
\hline \multicolumn{2}{|c|}{ Especialidad/Otros (Cursos, conocimientos adicionales } & \multicolumn{2}{|c|}{ Electricista, logistica } \\
\hline \multicolumn{4}{|c|}{ CONOCIMIENTOS ADICIONALES } \\
\hline \multicolumn{2}{|c|}{-Idiomas/nivel Requerido } & \multicolumn{2}{|l|}{ Ingles básico } \\
\hline \multicolumn{2}{|c|}{ - Ofimática Nivel Requerido: } & Usuario & \\
\hline \multicolumn{4}{|c|}{ COMPETENCIAS ESPECIFICAS } \\
\hline \multicolumn{4}{|c|}{ Ordenado, Responsable, Dedicado, Respetuoso, paciente. } \\
\hline
\end{tabular}

Figura 68. Perfil y funciones del Asistente de Mantenimiento Titinos Daycare 


\subsection{Remuneraciones, compensaciones e incentivos}

El personal de la empresa docente y administrativo se encontrarán en planilla y gozaran de beneficios sociales que les corresponde de acuerdo a ley. Para el caso del Especialista de la Metodología Doman y el Contador, tendrán un tipo de contrato de locación de servicios dado la naturaleza de sus actividades, las cuales serán por horas y en tiempos a requerimiento de la empresa.

Las remuneraciones del personal que laborara en la Guardería Titinos Daycare se detalla en la Figura 69.

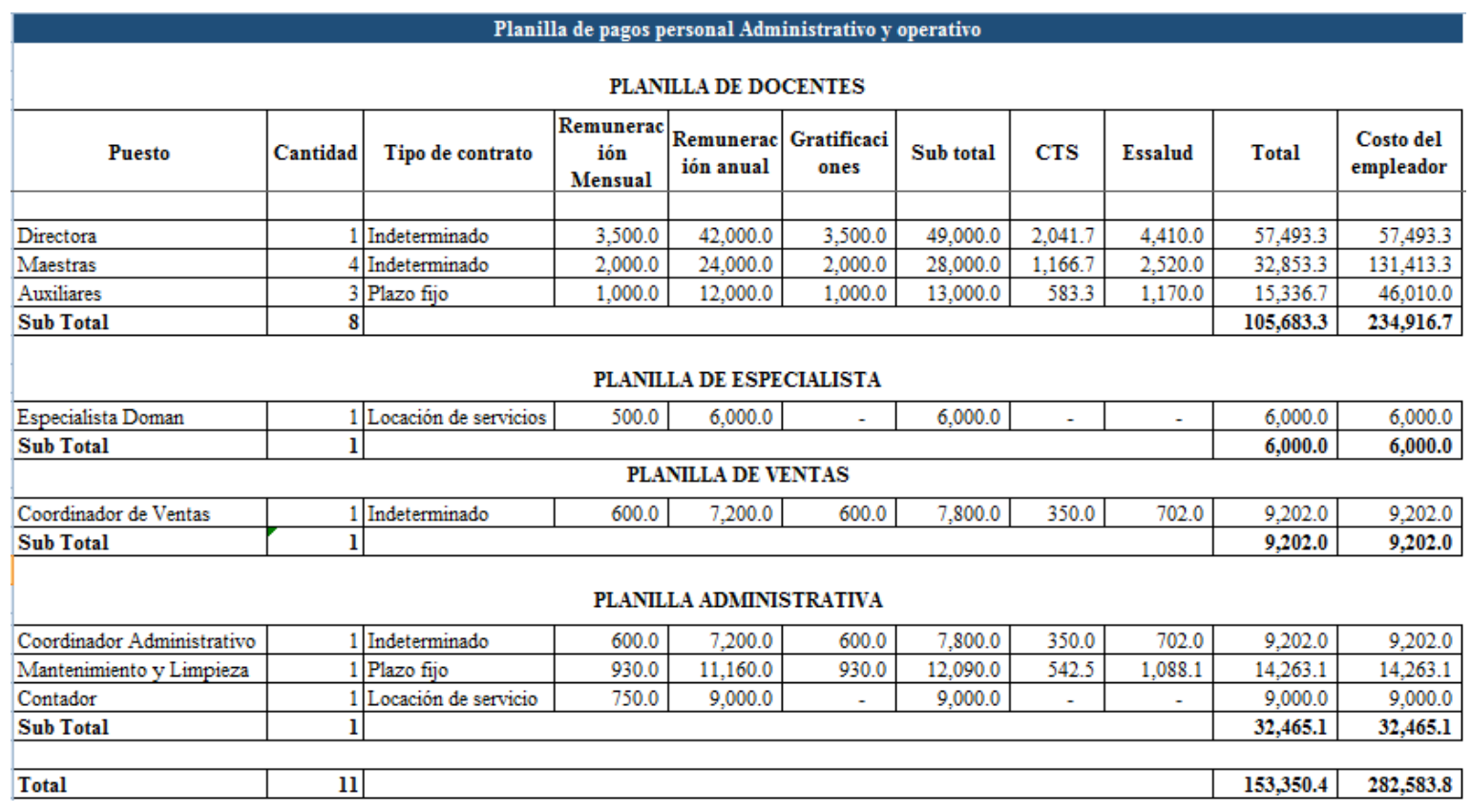

Figura 69. Planilla de Remuneraciones personal Titinos Daycare

\subsection{Política de recursos humanos}

REGLAMENTO DE ORGANIZACIÓN Y FUNCIÓN

ROF No 1 Generalidades

Artículo 1.1- Este reglamento es de carácter obligatorio y establece normas a las que deberán sujetarse todos los colaboradores dentro de la empresa.

Artículo 1.2.- Los asuntos que no estén especificados en este reglamento quedan bajo lo estipulado por la Ley de Trabajo.

Artículo 1.3.- Cada colaborador tendrá un jefe inmediato al cual tiene el deber de comunicar sus actividades.

Artículo 1.4.- El personal está obligado a cumplir con lo estipulado en el contrato de trabajo.

Articulo 1.5.- Es un requerimiento cumplir con las reglas de higiene y seguridad. 
Articulo 1.6.- Es obligación de todo trabajador permanecer constantemente en sus puestos.

Articulo 1.7.- Es deber de los jefes brindar encargos concretos y explicables.

Artículo 1.8.- Mostrarle las ventajas competitivas del negocio.

Artículo 1.9.- Fomentar participación gradual, sistemas de formación estratégica.

ROF N² Derechos del Colaborador

Artículo 2.1.- Se darán 15 días calendarios de vacaciones al transcurso de un año de labores.

Artículo 2.2.- Los trabajadores recibirán oportunamente los instrumentos necesarios, para desempañarse correctamente en su área de trabajo.

Artículo 2.3.- La empresa está obligada a brindar capacitación cada 3 meses para incrementar el nivel de desempeño y especializar el trabajo.

Artículo 2.4.- Todo trabajador tiene derecho a la manifestación sobre sus sanciones siempre y cuando se realicen con respeto.

Articulo 2.5.- Posibilidad de rotación, lo cual brindará capacidad integradora y Conocimiento del negocio.

Articulo 2.6.- Oportunidad de emprender (responsabilidades en la representación del negocio).

\section{ROF No 3 Jornada Laboral}

Articulo 3.1.- Al ingresar o salir a la empresa deberá registrar su hora de entrada y salida en el registro diario de asistencia.

Artículo 3.2.- La jornada laboral será de cinco días a la semana de acuerdo al turno que le corresponda; teniendo 10 min de tolerancia. Sin embargo si se diese el caso asistirán otros días de la semana no estipulados en el contrato de trabajo.

Articulo 3.3.- De no cumplir con el horario, ya sea con retardos o faltas se sancionará sobre pago de nómina y prestaciones. Esto se aplicará sólo si no excede tres faltas consecutivas sin previo aviso, si llegase a suceder queda automáticamente despedido(a).

Artículo 3.4.- Vacaciones y días festivos estarán sujetos a disposiciones oficiales y a cambios con previo aviso de parte del gobierno.

Artículo 3.5.- Las vacaciones serán acumulables.

Artículo 3.6.- Se brindará cena a los trabajadores; disponiendo de 25 min para el consumo de este.

ROF No 4 Higiene y Seguridad 
Artículo 4.1- El aseo de instalaciones se efectuará por el personal, en los días y horas correspondientes.

Artículo 4.2.- El personal queda obligado a someterse a exámenes médicos y psicométricos requeridos por la empresa.

Artículo 4.3.- Está prohibido que el personal masculino use aretes y/o tatuajes en áreas visibles; que tenga el cabello largo o luzca peinados extravagantes; en caso del personal femenino debe tener una presentación decorosa.

Artículo 4.4.- Es obligación del trabajador portar el uniforme completo y el fotocheck a simple vista; en el caso de las féminas deben vestirse con recato.

Artículo 4.5.- Es obligación del empleado avisar al departamento de seguridad cualquier situación o acción sospechosa.

ROF $N^{\circ} 5$ Prohibiciones a los empleados

Artículo 5.1.- No se permite el consumo de bebidas alcohólicas dentro de la guardería. Articulo 5.2.- No se permite el uso de narcóticos dentro de la empresa.

Artículo 5.3.- Se prohíbe estrictamente hacer uso de los alimentos, productos de limpieza, para uso personal del empleado. Así mismo el hurto de cualquier material de la empresa.

Articulo 5.4.- Está prohibido proporcionar cualquier información confidencial a personas ajenas a la empresa revelando políticas y sistemas propias de la misma.

Articulo 5.5.- Está prohibido actos que perjudiquen el prestigio de la empresa ofensas, daños o faltas de respeto a otros colaboradores y a las instalaciones.

Articulo 5.6.- No se permitirá escándalos personales y/o laborales en las instalaciones de la guardería.

\section{ROF No 6 Salarios}

Artículo 6.1.- El pago de honorarios y nómina se hará de acuerdo a lo establecido en el contrato con cada trabajador.

Artículo 6.2.- Se pagarán los días 30 de cada mes depositando en la cuenta de haberes del empleado.

Artículo 6.3.- En caso de renuncia se le liquidará de acuerdo a lo establecido por la ley del trabajo.

\section{ROF $N^{\circ} 7$ Sanciones}

Artículo 7.1.- Las faltas en que incurran los trabajadores ameritaran una sanción ya sea una amonestación verbal o por escrito o una suspensión laboral sin goce de salario. 
Artículo 7.2.- Si el trabajador no respeta sus 45 minutos de refrigerio, excediendo el tiempo, deberá reponer el tiempo perdido.

Articulo 7.3.- Quien no cumpla con la presentación personal correcta tendrá una llamada de atención al acumular tres será suspendido una semana.

Articulo 7.4.- Si el trabajador es sorprendido fuera de su puesto de trabajo, recibirá una llamada de atención, al recibir tres se le descontaran cuatro días de pago.

Articulo 7.5.- De no ser respetado este reglamento o algún artículo será sancionado de acuerdo a la gravedad de la falta.

Artículo 7.6.- El acoso sexual será una falta grave que llevará al despido sin goce de haber.

El propósito de este manual es generar un clima laboral favorable donde el trabajador se sienta bien en el cargo que realiza y aporte con creatividad y responsabilidad a la empresa, para así dar una buena percepción al cliente. 


\section{Capitulo IX: Planificación Financiera}

Con la finalidad de evaluar la viabilidad de poner en marcha el proyecto de implementar una guardería en la zona de Santa Catalina se ha realizado presupuestos de inversión inicial requerida, caculo del capital de trabajo, la elaboración de los presupuestos, la forma de financiamiento, determinar el costo de oportunidad, así como la proyección de Estados Financieros y Flujos de caja.

\subsection{La Inversión}

Se han realizado diversos presupuestos para determinar a cuánto asciende la inversión preoperativa que es necesaria para la implementación de la guardería Titinos Daycare, se ha considerado para este efecto la inversión a realizar en activos tangible, activos intangibles y en el capital de trabajo, en este punto se va a detallar dichos presupuestos.

\subsubsection{Inversión Preoperativa}

La inversión preoperativa se va a realizar en activo tangible e intangible, en ambos ítems dicha inversión asciende a S/ 96,274 (noventa y seis mil doscientos setenta y cuatro con 00/100 soles), el cual equivale al 59\% del total a invertir.

\subsubsection{Tangible}

Se presenta un resumen con el detalle de la inversión preoperativa Tangible a realizar el cual asciende a S/ 67828 (Sesenta y siete mil ochocientos veintiocho con 00/100 soles) equivalente al $42 \%$ de la inversión a realizar, esta inversión se va a ir depreciando en el tiempo; dicha inversión ha sido distribuido tal y como se muestra en la Tabla 39:

Tabla 39

Resumen de Inversión Preoperativa Tangible

\begin{tabular}{lrrr}
\hline \multicolumn{1}{c}{ Tangibles } & Costo Total & Costo sin IGV & \multicolumn{1}{c}{ IGV } \\
\hline Equipos y Muebles de Guardería & $30,118.00$ & $25,523.73$ & $4,594.27$ \\
Equipos y Muebles de Administracion y ventas & $7,710.00$ & $6,533.90$ & $1,176.10$ \\
Obras civiles & $30,000.00$ & $25,423.73$ & $4,576.27$ \\
\hline Total & $\mathbf{6 7 , 8 2 8 . 0 0}$ & $\mathbf{5 7 , 4 8 1 . 3 6}$ & $\mathbf{1 0 , 3 4 6 . 6 4}$ \\
\hline
\end{tabular}

A continuación, se muestra el detalle de cada uno de los conceptos:

La inversión que se va a realizar en equipos y muebles de guardería corresponde a la inversión a realizar en los equipos, muebles y enseres que van a ser directamente atribuibles al negocio tal y como se muestra en la Tabla 40. 
Tabla 40

Inversión Preoperativa Tangible - Equipos y Muebles de Guardería.

\begin{tabular}{|c|c|c|c|c|c|c|}
\hline Tipo de Bien I & Concepto & Cantidad & Costo Unt. & Costo Total & Costo sin IGV & IGV \\
\hline Equipos & 1 Refrigeradora de 150 Litros & 1 & $1,600.00$ & $1,600.00$ & $1,355.93$ & 244.07 \\
\hline Equipos & 2 Frigobar de 100 Litros & 1 & 500.00 & 500.00 & 423.73 & 76.27 \\
\hline Equipos & 3 Cocina de 2 hornillas Electrica & 1 & 700.00 & 700.00 & 593.22 & 106.78 \\
\hline Equipos & 4 Terma & 1 & 750.00 & 750.00 & 635.59 & 114.41 \\
\hline Equipos & 5 Esterilizador de biberones electrico & 1 & 600.00 & 600.00 & 508.47 & 91.53 \\
\hline Equipos & 6 Hervidor electrico & 1 & 100.00 & 100.00 & 84.75 & 15.25 \\
\hline Equipos & 7 Horno microondas & 1 & 500.00 & 500.00 & 423.73 & 76.27 \\
\hline Equipos & 8 Televisor de 50 Pulgadas - Smart TV & 1 & $2,000.00$ & $2,000.00$ & $1,694.92$ & 305.08 \\
\hline Equipos & 9 Camaras IP & 7 & 320.00 & $2,240.00$ & $1,898.31$ & 341.69 \\
\hline Muebles & 10 Sofa para lactario & 1 & 400.00 & 400.00 & 338.98 & 61.02 \\
\hline Muebles & 11 Estantes para libros y juegos de cada sala & 4 & 400.00 & $1,600.00$ & $1,355.93$ & 244.07 \\
\hline Muebles & 12 Cunas para durmientes y gateadores & 8 & 400.00 & $3,200.00$ & $2,711.86$ & 488.14 \\
\hline Muebles & 13 Colchones para cunas & 8 & 150.00 & $1,200.00$ & $1,016.95$ & 183.05 \\
\hline Muebles & 14 Camas para caminantes y exploradores incluye colchon & 12 & 450.00 & $5,400.00$ & $4,576.27$ & 823.73 \\
\hline Muebles & 15 Comedor para infantes con 5 sillas & 2 & 700.00 & $1,400.00$ & $1,186.44$ & 213.56 \\
\hline Muebles & 16 Mesa para niños con 4 sillas & 5 & 220.00 & $1,100.00$ & 932.20 & 167.80 \\
\hline Muebles & 17 Mesa con 6 sillas para comedor (adultos) & 1 & 600.00 & 600.00 & 508.47 & 91.53 \\
\hline Muebles & 18 Piscina de espuma con pelotas & 1 & 350.00 & 350.00 & 296.61 & 53.39 \\
\hline Muebles & 19 Centro de estimulación de espuma- Psicomotricidad Gruesa & 4 & 700.00 & $2,800.00$ & $2,372.88$ & 427.12 \\
\hline Muebles & 20 Kit de juegos para psicomotricidad gruesa & 2 & 250.00 & 500.00 & 423.73 & 76.27 \\
\hline Muebles & 21 Kit de juegos para psicomotricidad fina & 2 & 200.00 & 400.00 & 338.98 & 61.02 \\
\hline Enseres & 22 Termo con dispensador & 1 & 80.00 & 80.00 & 67.80 & 12.20 \\
\hline Enseres & 23 Flexipiso para los pisos & 1 & $2,000.00$ & $2,000.00$ & $1,694.92$ & 305.08 \\
\hline Enseres & 24 Tazas & 6 & 3.00 & 18.00 & 15.25 & 2.75 \\
\hline Enseres & 25 Azucarera & 1 & 10.00 & 10.00 & 8.47 & 1.53 \\
\hline Enseres & 26 Tacho de residuos 40 Litros & 1 & 70.00 & 70.00 & 59.32 & 10.68 \\
\hline \multicolumn{2}{|r|}{ Sub Total } & & & $30,118.00$ & $25,523.73$ & $4,594.27$ \\
\hline
\end{tabular}

La inversión que se va a realizar en equipos y muebles de administración y ventas corresponde a la inversión a realizar en los equipos muebles y enseres que van a ser indirectamente atribuibles al negocio tal y como se muestra en la Tabla 41. Tabla 41

Inversión Preoperativa Tangible - Equipos y Muebles de Administración y Ventas

\begin{tabular}{|c|c|c|c|c|c|c|c|}
\hline Tipo de Bien & $\mathbf{N}^{\circ}$ & Concepto & Cantidad & Costo Unt. & Costo Total & Costo sin IGV & IGV \\
\hline Equipos & 1 & Computadoras personales & 2.00 & $1,000.00$ & $2,000.00$ & $1,694.92$ & 305.08 \\
\hline Equipos & 2 & Impresora multifuncional laser & 1.00 & 800.00 & 800.00 & 677.97 & 122.03 \\
\hline Equipos & 3 & Camaras IP & 3.00 & 320.00 & 960.00 & 813.56 & 146.44 \\
\hline Equipos & 4 & Ventilador de piso & 6.00 & 500.00 & $3,000.00$ & $2,542.37$ & 457.63 \\
\hline Muebles & 5 & Escritorio melamine & 1.00 & 170.00 & 170.00 & 144.07 & 25.93 \\
\hline Muebles & 6 & Silla ejecutiva & 2.00 & 65.00 & 130.00 & 110.17 & 19.83 \\
\hline Muebles & 7 & Silla de visita & 3.00 & 150.00 & 450.00 & 381.36 & 68.64 \\
\hline Muebles & 8 & Estantes para archivadores & 2.00 & 100.00 & 200.00 & 169.49 & 30.51 \\
\hline \multicolumn{3}{|c|}{ Sub Total } & & & $7,710.00$ & $6,533.90$ & $1,176.10$ \\
\hline
\end{tabular}


La inversión que se va a realizar Obras Civiles, corresponde a la inversión que se debe realizar en la remodelación y acondicionamiento del inmueble con el objetivo de generar un ambiente agradable tanto para los infantes como para los niños, este concepto incluye realizar divisiones en draywall, acondicionamiento de servicios higiénicos, pintura de paredes con imágenes infantiles, este presupuesto fue realizado por un contratista especializado en realizar este tipo de trabajos para ello se muestra en la Tabla 42.

Tabla 42

Inversión Preoperativa Tangible - Equipos y Muebles de Administración y Ventas

\begin{tabular}{|c|c|c|c|c|c|c|c|}
\hline Tipo de Bien & $\mathrm{N}^{0}$ & Concepto & Cantidad & Costo Unt. & Costo Total & Costo sin IGV & IGV \\
\hline \multirow[t]{2}{*}{ Edificaciones } & & Remodelación y acondicionamiento & 1 & $30,000.00$ & $30,000.00$ & $25,423.73$ & $4,576.27$ \\
\hline & Sub T & & & & $30,000.00$ & $25,423.73$ & $4,576.27$ \\
\hline
\end{tabular}

\subsubsection{Intangible}

Se presenta un resumen con el detalle de la inversión preoperativa intangible a realizar el cual asciende a S/ 28455.84 (Veintiocho mil cuatrocientos cincuenta y cinco con 84/100 Soles) el cual equivale al 17\% de la inversión a realizar; dicha inversión va a generar una amortización a lo largo del tiempo y ha sido distribuido tal y como se muestra en la Tabla 43.

Tabla 43

Resumen de Inversión Preoperativa Intangible

\begin{tabular}{lrrr}
\hline \multicolumn{1}{c}{ Concepto } & Costo Total & Costo sin IGV & \multicolumn{1}{c}{ IGV } \\
\hline Constitucion de empresa & $2,555.84$ & $2,244.08$ & 311.76 \\
Gastos de marketing & $8,500.00$ & $7,203.39$ & $1,296.61$ \\
Otros gastos preoperativos & $17,390.00$ & $14,737.29$ & $2,652.71$ \\
\hline Total & $\mathbf{2 8 , 4 4 5 . 8 4}$ & $\mathbf{2 4 , 1 8 4 . 7 6}$ & $\mathbf{4 , 2 6 1 . 0 8}$ \\
\hline
\end{tabular}

A continuación, se muestra el detalle de cada uno de los conceptos:

Para la inversión a realizar en la constitución de la empresa se efectúan los desembolsos detallados en la Tabla 44. 
Tabla 44

Inversión Preoperativa Intangible - Constitución de Empresa

\begin{tabular}{|c|c|c|c|c|c|}
\hline Concepto & Cantidad & Costo Unt. & Costo Total & Costo sin IGV & IGV \\
\hline Solicitud de reserva de razón social & 1 & 4.00 & 4.00 & 4.00 & \\
\hline Reserva de nombre & 1 & 18.00 & 18.00 & 18.00 & \\
\hline Elaboración de la minuta & 1 & 450.00 & 450.00 & 381.36 & 68.64 \\
\hline Elevación a escritura pública de minuta & 1 & 45.00 & 45.00 & 38.14 & 6.86 \\
\hline \multicolumn{6}{|l|}{ Pago por derecho a inscripción } \\
\hline Derechos de calificacion & 1 & 38.88 & 38.88 & 38.88 & \\
\hline Derechos de calificacion & 1 & 12.96 & 12.96 & 12.96 & \\
\hline Derechos de inscripcion & 1 & 8.64 & 8.64 & 8.64 & \\
\hline Inscrpción de RUC & 1 & - & - & - & - \\
\hline Legalización de libros contables & 1 & 250.00 & 250.00 & 211.86 & 38.14 \\
\hline Legalización de libros societarios & 1 & 100.00 & 100.00 & 84.75 & 15.25 \\
\hline Autorizacion de Planillas de pago & 1 & - & - & - & - \\
\hline Búsqueda de antecedentes foneticos & 1 & 30.99 & 30.99 & 26.26 & 4.73 \\
\hline Busqueda de antecedentes figurativos & 1 & 38.46 & 38.46 & 32.59 & 5.87 \\
\hline Registro de marca & 1 & 520.56 & 520.56 & 441.15 & 79.41 \\
\hline Publicacion diario El Peruano & 1 & 19.47 & 19.47 & 16.50 & 2.97 \\
\hline Licencia Municipal & 1 & 139.30 & 139.30 & 139.30 & \\
\hline Permisos municipales para remodelacion & 1 & 290.30 & 290.30 & 290.30 & \\
\hline Certificado de defensa civil & 1 & 85.68 & 85.68 & 72.61 & 13.07 \\
\hline Certificado de seguridad en defensa civil & 1 & 503.60 & 503.60 & 426.78 & 76.82 \\
\hline $\begin{array}{c}\text { Sub Total } \\
\end{array}$ & & & $2,555.84$ & $2,244.08$ & 311.76 \\
\hline
\end{tabular}

Para la inversión inicial a realizar en el marketing de la empresa se efectúa los desembolsos detallados en la Tabla 45.

Tabla 45

Inversión Preoperativa Intangible - Otros

\begin{tabular}{|c|c|c|c|c|c|}
\hline & Cantidad & Costo Unt. & Costo Total & Costo sin IGV & IGV \\
\hline Tarjetas de visita & 1 & 150.00 & 150.00 & 127.12 & 22.88 \\
\hline Volantes & 1 & 700.00 & 700.00 & 593.22 & 106.78 \\
\hline Evento inaugural & 1 & $1,000.00$ & $1,000.00$ & 847.46 & 152.54 \\
\hline Invitaciones & 1 & 150.00 & 150.00 & 127.12 & 22.88 \\
\hline Marcha Blanca (2 semanas) & 1 & $6,500.00$ & $6,500.00$ & $5,508.47$ & 991.53 \\
\hline $\begin{array}{ll}\text { Sub Total } \\
\end{array}$ & & & $8,500.00$ & $7,203.39$ & $1,296.61$ \\
\hline
\end{tabular}

Asimismo, tenemos otros gastos que son necesarios para el inicio de funcionamiento de la guardería para los cuales se efectúa los desembolsos detallados en la Tabla 46. 
Tabla 46

Inversión Preoperativa Intangible - Otros

\begin{tabular}{|c|c|c|c|c|c|}
\hline & Cantidad & Costo Unt. & Costo Total & Costo sin IGV & IGV \\
\hline $\begin{array}{l}\text { Alquiler de local (Dos meses de garantía, mas } \\
\text { un mes adelantado de alquiler) }\end{array}$ & 3 & $5,000.00$ & $15,000.00$ & $12,711.86$ & $2,288.14$ \\
\hline Sistema operativo & 1 & 800.00 & 800.00 & 677.97 & 122.03 \\
\hline Antivirus & 1 & 90.00 & 90.00 & 76.27 & 13.73 \\
\hline Portal web & 1 & $1,500.00$ & $1,500.00$ & $1,271.19$ & 228.81 \\
\hline Sub Total & & & $17,390.00$ & $14,737.29$ & $2,652.71$ \\
\hline
\end{tabular}

\subsubsection{Inversión en capital de trabajo.}

Según Arlete Beltrán Barco en el libro Evaluación social de proyectos para países en desarrollo, "el capital de trabajo es un fondo que permite la adecuada operación del proyecto, cubriendo el desfase generado entre el momento en que se inicia el servicio y el momento en que este es entregado (y finalmente pagado)". (p. 53)

El método que se va a utilizar para este proyecto es el "método del porcentaje en la variación de ventas el cual supone que el capital de trabajo necesario es una porción del volumen de las ventas monetarias del proyecto; por ello, el cambio en el capital de trabajo se podrá estimar como una porción de la variación en el nivel de ventas" (p. 54)

A continuación, se presentan el cálculo de la inversión de capital de trabajo, para el cual se ha realizado el cálculo de forma mensual para el primer año y en de forma anual para los 4 años siguientes, tomando como monto a invertir el obtenido con el método del déficit acumulado máximo el cual asciende a S/ 67,004.68 (Sesenta y siete mil cuatro y 68/100 Soles); tal y como se muestra en las Tablas 47 y 48.

Tabla 47

Inversión Capital de Trabajo - Año 1

\begin{tabular}{|c|c|c|c|c|c|c|c|c|c|c|c|c|}
\hline Concepto & Enero & Febrero & Marzo & Abril & Mayo & Junio & Julio & Agosto & Septiembre & Octubre & Noviembre & Diciembre \\
\hline Ingresos Ventas & $12,250.00$ & $9,475.00$ & $12,750.00$ & $12,775.00$ & $14,825.00$ & $16,475.00$ & $18,125.00$ & $18,550.00$ & $20,600.00$ & $23,475.00$ & $25,950.00$ & $24,750,00$ \\
\hline Devolución del IGV - Sunat & - & & - & & 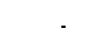 & $21,121.74$ & 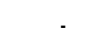 & & - & & & $6,000.11$ \\
\hline Total Ingresos & $12,250,00$ & $9,475,00$ & $12,750,00$ & $12,775,00$ & $14,825.00$ & $37,596,74$ & $18,125,00$ & $18,550,00$ & $20,600,00$ & $23,475.00$ & $25,950.00$ & $31,350,11$ \\
\hline Planilla Maestros & $-13,322.78$ & $-13,322,78$ & $-13,322,78$ & $-13,322.78$ & $-13,322.78$ & $-13,322.78$ & $-16,060,56$ & $-16,060.56$ & $-16,060.56$ & $-16,060,56$ & $-16,060.56$ & $-16,060.56$ \\
\hline Planilla de administracion & $-3,472.26$ & $-3,472.26$ & $-3,472.26$ & $-3,472.26$ & $-3,472.26$ & $-3,472.26$ & $-3,472.26$ & $-3,472.26$ & $-3,472.26$ & $-3,472.26$ & $-3,472.26$ & $-3,472.26$ \\
\hline Costos indirectos & $-6,972,68$ & $-6,936.82$ & $-6,992.70$ & $-6,993.12$ & $-7,028.10$ & $-7,056.25$ & $-7,084.40$ & $-7,091.65$ & $-7,126.63$ & $-7,175.68$ & $-7,217.90$ & $-7,197,43$ \\
\hline Total Gastos & $.23,767,12$ & $.23,731,86$ & $.23,787.73$ & $.23,788.16$ & $.23,823.14$ & $.23,851.29$ & $.26,617,22$ & $.26,624,47$ & $.26,659,44$ & $.26,708.49$ & $.26,750,72$ & $.26,730,24$ \\
\hline Costo total en desmbolsable & $-11,517.72$ & $-14,256.86$ & $-11,037.73$ & $-11,013.16$ & $-8,998.14$ & $13,745.45$ & $-8,492.22$ & $-8,074.47$ & $-6,059.44$ & $-3,233,49$ & -800.72 & $4,619,86$ \\
\hline Costo total en desmbolsable acumulado & $\cdot 11,517.72$ & $.25,774,58$ & $.36,812,31$ & $-47,825.47$ & $.56,823,61$ & $-43,078.16$ & $.51,570,37$ & $.59,644,84$ & $.65,704,28$ & $68,937,77$ & $69,738.49$ & $.65,118,62$ \\
\hline
\end{tabular}


Tabla 10

Inversión Capital de Trabajo - del Año 0 al Año 5

\begin{tabular}{lrrrrrr}
\hline \multicolumn{1}{c}{ Concepto } & Año 0 & \multicolumn{1}{c}{ Año 1 } & \multicolumn{1}{c}{ Año 2 } & \multicolumn{1}{c}{ Año 3 } & \multicolumn{1}{c}{ Año 4 } & \multicolumn{1}{c}{ Año 5 } \\
\hline Ingresos Ventas & & $210,000.00$ & $420,600.00$ & $588,000.00$ & $684,000.00$ & $736,400.00$ \\
Devolución del IGV - Sunat & & $27,721.85$ & $13,682.76$ & $14,196.84$ & $14,491.65$ & $14,652.57$ \\
Total Ingresos & & $\mathbf{2 3 7 , 7 2 1 . 8 5}$ & $\mathbf{4 3 4 , 2 8 2 . 7 6}$ & $\mathbf{6 0 2 , 1 9 6 . 8 4}$ & $\mathbf{6 9 8 , 4 9 1 . 6 5}$ & $\mathbf{7 5 1 , 0 5 2 . 5 7}$ \\
Planilla Maestros & & $-176,300.00$ & $-240,916.67$ & $-240,916.67$ & $-240,916.67$ & $-240,916.67$ \\
Planilla de administracion y ventas & & $-41,667.10$ & $-41,667.10$ & $-41,667.10$ & $-41,667.10$ & $-41,667.10$ \\
Costos indirectos & & $-84,873.37$ & $-88,466.42$ & $-91,322.43$ & $-92,960.29$ & $-93,854.28$ \\
Total Gastos & & $\mathbf{- 3 0 2 , 8 4 0 . 4 7}$ & $\mathbf{- 3 7 1 , 0 5 0 . 1 9}$ & $\mathbf{- 3 7 3 , 9 0 6 . 2 0}$ & $\mathbf{- 3 7 5 , 5 4 4 . 0 5}$ & $\mathbf{- 3 7 6 , 4 3 8 . 0 5}$ \\
\hline Costo total en desmbolsable & $-65,118.62$ & $63,232.57$ & $228,290.64$ & $322,947.60$ & $374,614.52$ \\
Costo total en desmbolsable acumulado & & & $\mathbf{- 1 , 8 8 6 . 0 5}$ & $\mathbf{2 2 6 , 4 0 4 . 5 9}$ & $\mathbf{5 4 9 , 3 5 2 . 1 9}$ & $\mathbf{9 2 3 , 9 6 6 . 7 1}$ \\
Deficit Acumulado Maximo & & & & &
\end{tabular}

\subsubsection{Costo del proyecto}

El costo total del proyecto asciende a S/ 163,278.52 (Ciento sesenta y tres mil doscientos setenta y ocho con 52/100 Soles), los cuales se han detallado en los puntos 9.1.1 y 9.1.2 y del cual se presenta un resumen en la Tabla 49

Tabla 49

Costo del Proyecto

\begin{tabular}{|c|c|c|}
\hline $\begin{array}{r}\text { Tangibles } \\
\end{array}$ & Costo Total & Porcentaje \\
\hline Equipos y Muebles de Guardería & $30,118.00$ & \\
\hline Obras civiles & $30,000.00$ & \\
\hline Equipos y Muebles de Administración y ventas & $7,710.00$ & \\
\hline Total & $67,828.00$ & $41.5 \%$ \\
\hline Intangibles & Costo Total & Porcentaje \\
\hline Constitución de empresa & $2,555.84$ & \\
\hline Gastos de Marketing & $8,500.00$ & \\
\hline Gastos pre operativos & $17,390.00$ & \\
\hline Total & $28,445.84$ & $17.5 \%$ \\
\hline $\begin{array}{c}\text { Capital de trabajo } \\
\end{array}$ & Total & Porcentaje \\
\hline Capital de trabajo Deficit Acum. Maximo & $67,004.68$ & $41.0 \%$ \\
\hline Inversión Total & $163,278.52$ & $100.0 \%$ \\
\hline
\end{tabular}

\subsection{Financiamiento}

Para iniciar la puesta en marcha del proyecto de implementar una Guardería Infantil se requiere contar con una inversión total de S/163,278.52, los cuales el 58.5\% van a ser obtenidos a través de un financiamiento propio, y el $41.5 \%$ será obtenido a través de un financiamiento externo proveniente de una empresa del sistema financiero peruano, se 
presenta la Tabla 50 con el esquema de financiamiento.

Tabla 50

Esquema de Financiamiento

\begin{tabular}{lrc}
\hline Forma de financiamiento & Importe en S/ & \% \\
\hline Financiamiento Externo & $67,828.00$ & $41.5 \%$ \\
Aporte de Capital & $95,450.52$ & $58.5 \%$ \\
\hline Total & $163,278.52$ & $100 \%$ \\
\hline
\end{tabular}

Es preciso destacar que el aporte de capital será cubierto por los accionistas, los mismos que por acuerdo de realizado en la minuta de constitución de empresa, solo pueden efectuar dicho aporte a través entregas en efectivo; este aporte va a formar parte del patrimonio de la empresa. Por otro lado, al ser una empresa nueva y no contar con historial crediticio, la capacidad de obtener financiamiento es limitada y las tasas son poco competitivas según lo consultado hasta en 4 bancos del sistema financiero peruano; dicho financiamiento va a ser ingresado solo en efectivo y va a formar parte del pasivo de la empresa.

\subsubsection{Endeudamiento y condiciones.}

Se ha logrado obtener el financiamiento de S/ 67,828; el cual equivale al 41.5\% de la inversión total del proyecto y está conformado por la inversión en activo tangible, se ha logrado obtener el financiamiento a una tasa efectiva anual (TEA) del 32\%, en el plazo de 60 meses. A continuación, se muestra la Tabla 51 donde se muestra el resumen de amortización de deuda por año y la Tabla 52 con el cronograma mensual de amortización de la deuda obtenida.

Tabla 51

Resumen de Amortización de la Deuda

\begin{tabular}{lrrrrr}
\hline $\mathbf{N}^{\circ}$ & Amortización & \multicolumn{1}{c}{ Interesés } & \multicolumn{1}{c}{ Cuota } & \multicolumn{1}{c}{ Saldo } & Escudo Fiscal \\
\hline Año 0 & & & & $67,828.00$ & \\
Año 1 & $7,217.03$ & $18,168.19$ & $25,385.22$ & $60,610.97$ & $5,359.62$ \\
Año 2 & $9,526.48$ & $15,858.74$ & $25,385.22$ & $51,084.49$ & $4,678.33$ \\
Año 3 & $12,574.95$ & 12,810 & $25,385.22$ & $38,509.54$ & $3,779.03$ \\
Año 4 & $16,598.94$ & $8,786.28$ & $25,385.22$ & $21,910.60$ & $2,591.95$ \\
Año 5 & $21,910.60$ & $3,474.62$ & $25,385.22$ & 0.00 & $1,025.01$ \\
\hline Total & $\mathbf{6 7 , 8 2 8 . 0 0}$ & $\mathbf{5 9 , 0 9 8 . 0 9}$ & $\mathbf{1 2 6 , 9 2 6 . 0 9}$ & & $\mathbf{1 7 , 4 3 3 . 9 4}$ \\
\hline
\end{tabular}


Tabla 52

Cronograma de Amortización de la Deuda 


\begin{tabular}{|c|c|c|c|c|c|}
\hline Periodo & Amortizacion & Intereses & Cuota & Saldo & Escudo Fiscal \\
\hline 0 & & & & $67,828.00$ & \\
\hline 1 & 527.87 & $1,587.56$ & $2,115.43$ & $67,300.13$ & 468.33 \\
\hline 2 & 540.23 & $1,575.21$ & $2,115.43$ & $66,759.90$ & 464.69 \\
\hline 3 & 552.87 & $1,562.56$ & $2,115.43$ & $66,207.02$ & 460.96 \\
\hline 4 & 565.81 & $1,549.62$ & $2,115.43$ & $65,641.21$ & 457.14 \\
\hline 5 & 579.06 & $1,536.38$ & $2,115.43$ & $65,062.15$ & 453.23 \\
\hline 6 & 592.61 & $1,522.82$ & $2,115.43$ & $64,469.54$ & 449.23 \\
\hline 7 & 606.48 & $1,508.95$ & $2,115.43$ & $63,863.06$ & 445.14 \\
\hline 8 & 620.68 & $1,494.76$ & $2,115.43$ & $63,242.39$ & 440.95 \\
\hline 9 & 635.20 & $1,480.23$ & $2,115.43$ & $62,607.18$ & 436.67 \\
\hline 10 & 650.07 & $1,465.36$ & $2,115.43$ & $61,957.11$ & 432.28 \\
\hline 11 & 665.29 & $1,450.15$ & $2,115.43$ & $61,291.83$ & 427.79 \\
\hline 12 & 680.86 & $1,434.58$ & $2,115.43$ & $60,610.97$ & 423.20 \\
\hline 13 & 696.79 & $1,418.64$ & $2,115.43$ & $59,914.18$ & 418.50 \\
\hline 14 & 713.10 & $1,402.33$ & $2,115.43$ & $59,201.07$ & 413.69 \\
\hline 15 & 729.79 & $1,385.64$ & $2,115.43$ & $58,471.28$ & 408.76 \\
\hline 16 & 746.87 & $1,368.56$ & $2,115.43$ & $57,724.41$ & 403.73 \\
\hline 17 & 764.36 & $1,351.08$ & $2,115.43$ & $56,960.05$ & 398.57 \\
\hline 18 & 782.25 & $1,333.19$ & $2,115.43$ & $56,177.81$ & 393.29 \\
\hline 19 & 800.55 & $1,314.88$ & $2,115.43$ & $55,377.25$ & 387.89 \\
\hline 20 & 819.29 & $1,296.14$ & $2,115.43$ & $54,557.96$ & 382.36 \\
\hline 21 & 838.47 & $1,276.97$ & $2,115.43$ & $53,719.49$ & 376.71 \\
\hline 22 & 858.09 & $1,257.34$ & $2,115.43$ & $52,861.40$ & 370.92 \\
\hline 23 & 878.18 & $1,237.26$ & $2,115.43$ & $51,983.22$ & 364.99 \\
\hline 24 & 898.73 & $1,216.70$ & $2,115.43$ & $51,084.49$ & 358.93 \\
\hline 25 & 919.77 & $1,195.67$ & $2,115.43$ & $50,164.72$ & 352.72 \\
\hline 27 & 963.33 & $1,152.11$ & $2,115.43$ & $48,260.10$ & 339.87 \\
\hline 28 & 985.87 & $1,129.56$ & $2,115.43$ & $47,274.23$ & 333.22 \\
\hline 29 & $1,008.95$ & $1,106.49$ & $2,115.43$ & $46,265.28$ & 326.41 \\
\hline 30 & $1,032.56$ & $1,082.87$ & $2,115.43$ & $45,232.71$ & 319.45 \\
\hline 31 & $1,056.73$ & $1,058.70$ & $2,115.43$ & $44,175.98$ & 312.32 \\
\hline 32 & $1,081.47$ & $1,033.97$ & $2,115.43$ & $43,094.52$ & 305.02 \\
\hline 33 & $1,106.78$ & $1,008.66$ & $2,115.43$ & $41,987.74$ & 297.55 \\
\hline 34 & $1,132.68$ & 982.75 & $2,115.43$ & $40,855.06$ & 289.91 \\
\hline 35 & $1,159.19$ & 956.24 & $2,115.43$ & $39,695.86$ & 282.09 \\
\hline 36 & $1,186.33$ & 929.11 & $2,115.43$ & $38,509.54$ & 274.09 \\
\hline 37 & $1,214.09$ & 901.34 & $2,115.43$ & $37,295.44$ & 265.90 \\
\hline 38 & $1,242.51$ & 872.93 & $2,115.43$ & $36,052.94$ & 257.51 \\
\hline 39 & $1,271.59$ & 843.84 & $2,115.43$ & $34,781.34$ & 248.93 \\
\hline 40 & $1,301.35$ & 814.08 & $2,115.43$ & $33,479.99$ & 240.15 \\
\hline 41 & $1,331.81$ & 783.62 & $2,115.43$ & $32,148.18$ & 231.17 \\
\hline 42 & $1,362.98$ & 752.45 & $2,115.43$ & $30,785.19$ & 221.97 \\
\hline 43 & $1,394.89$ & 720.55 & $2,115.43$ & $29,390.31$ & 212.56 \\
\hline 44 & $1,427.53$ & 687.90 & $2,115.43$ & $27,962.77$ & 202.93 \\
\hline 45 & $1,460.95$ & 654.49 & $2,115.43$ & $26,501.83$ & 193.07 \\
\hline 46 & $1,495.14$ & 620.29 & $2,115.43$ & $25,006.68$ & 182.99 \\
\hline 47 & $1,530.14$ & 585.30 & $2,115.43$ & $23,476.55$ & 172.66 \\
\hline 48 & $1,565.95$ & 549.48 & $2,115.43$ & $21,910.60$ & 162.10 \\
\hline 49 & $1,602.60$ & 512.83 & $2,115.43$ & $20,308.00$ & 151.29 \\
\hline 50 & $1,640.11$ & 475.32 & $2,115.43$ & $18,667.88$ & 140.22 \\
\hline 51 & $1,678.50$ & 436.93 & $2,115.43$ & $16,989.38$ & 128.90 \\
\hline 52 & $1,717.79$ & 397.65 & $2,115.43$ & $15,271.60$ & 117.31 \\
\hline 53 & $1,757.99$ & 357.44 & $2,115.43$ & $13,513.60$ & 105.45 \\
\hline 54 & $1,799.14$ & 316.30 & $2,115.43$ & $11,714.47$ & 93.31 \\
\hline 55 & $1,841.25$ & 274.19 & $2,115.43$ & $9,873.22$ & 80.88 \\
\hline 56 & $1,884.35$ & 231.09 & $2,115.43$ & $7,988.87$ & 68.17 \\
\hline 57 & $1,928.45$ & 186.99 & $2,115.43$ & $6,060.42$ & 55.16 \\
\hline 58 & $1,973.59$ & 141.85 & $2,115.43$ & $4,086.83$ & 41.85 \\
\hline 59 & $2,019.78$ & 95.66 & $2,115.43$ & $2,067.05$ & 28.22 \\
\hline 60 & $2,067.05$ & 48.38 & $2,115.43$ & 0.00 & 14.27 \\
\hline
\end{tabular}




\subsubsection{Capital y costo de oportunidad.}

El aporte de capital que será cubierto por los accionistas asciende a S/ 95,450.52 (noventa y cinco mil cuatrocientos cincuenta y 52/100 Soles) el cual equivalente al $58.5 \%$ del costo del proyecto.

Para calcular el costo de oportunidad del proyecto se utiliza la tasa libre de riesgo de los Bonos soberanos americanos, el rendimiento de la bolsa de valores de Nueva York como el rendimiento del mercado, para ambos casos se utiliza el promedio aritmético desde el año 1928 hasta el 2017. Dado que no existe información de empresas de educación que cotizan en bolsa en el mercado local se ha tomado el beta desapalancado del sector educación de Estados Unidos, el cual se procede a apalancar utilizando la ecuación de Hamada (Beta $\mathbf{l}=$ Beta u * $(\mathbf{1}+((\mathbf{D} / \mathbf{E}) *(\mathbf{1 - t}))))$ según se muestra en la Tabla 53; por otro lado para poder añadir el riesgo de una empresa nueva en un mercado emergente añadimos es Size Premium y el Riesgo país de Perú.

\section{Tabla 53}

Ecuación de Hamada -Beta Apalancado

\begin{tabular}{lr}
\hline Beta u (desapalancado) & 0.89 \\
$\mathrm{D}$ & $41.54 \%$ \\
$\mathrm{E}$ & $58.46 \%$ \\
$\mathrm{t}$ & $29.50 \%$ \\
\hline COK Beta u & 1.33663901 \\
\hline
\end{tabular}

Asimismo, en la Tabla 54 se va a proceder a calcular el COK o CAPM con Beta desapalancado y en la Tabla 55 el COK con Beta apalancado, para ello se va a utilizar la siguiente fórmula: $\mathbf{C O K}=\mathbf{R f}+$ Beta $*(\mathbf{R m}-\mathbf{R f})+$ Size premium + Riesgo País Tabla 54

Cok-Beta Desapalancado ( $\beta u)$

\begin{tabular}{lr}
\hline Tasa Libre de Riesgo - RF & $5.15 \%$ \\
Rendimiento de Mercado & $11.53 \%$ \\
Beta u (desapalancado) & 0.89 \\
Size Premium & $6.46 \%$ \\
Riesgo País & $1.69 \%$ \\
\hline COK Beta u & $\mathbf{1 8 . 9 9 \%}$ \\
\hline
\end{tabular}


Tabla 55

Cok-Beta Apalancado $(\beta l)$

\begin{tabular}{lr}
\hline Tasa Libre de Riesgo - RF & $5.15 \%$ \\
Rendimiento de Mercado & $11.53 \%$ \\
Beta l (apalancado) & 1.34 \\
Size Premium & $6.46 \%$ \\
Riesgo País & $1.69 \%$ \\
\hline COK Beta l & $\mathbf{2 1 . 8 3 \%}$ \\
\hline
\end{tabular}

\subsubsection{Costo de capital promedio ponderado.}

El Costo de capital promedio ponderado también conocido como WACC que san las siglas del nombre en inglés Weighted Average Cost of Capital, pondera los costos de cada una de las fuentes de capital, independientemente si se trata de financiamiento propio o financiamiento de terceros; la fórmula utilizada para realizar dicho calculo es $\mathbf{W A C C}=$ $\mathbf{D} /(\mathbf{E}+\mathbf{D}) \times$ rd + (1-Tax $)+\mathbf{E} /(\mathbf{E}+\mathbf{D}) \times$ re; en la Tabla 56 se muestra el cálculo del WACC del proyecto.

Tabla 56

WACC - Beta Apalancado $(\beta l)$

\section{Capital Structure}

Debt to Total Capitalization $\quad 41.54 \%$

\begin{tabular}{ll} 
Equity to Total Capitalization & $58.46 \%$ \\
\hline Debt / Equity & $\mathbf{7 1 . 0 6 \%}$
\end{tabular}

\section{Cost of Equity}

Tasa Libre de Riesgo - RF

Rendimiento de Mercado

Beta 1 (apalancado)

Size Premium

Riesgo País $\frac{1.69 \%}{\mathbf{1 . 8 3 \%}}$

COK Beta I

\section{Cost of Debt}

Costo de la deuda

Tasa de impuesto $29.50 \%$ 


\subsection{Presupuestos Base}

\subsubsection{Presupuesto de ventas}

Se ha realizado un presupuesto de las ventas considerando la capacidad instalada de la infraestructura y adicionalmente la determinación del público objetivo el cual ha sido hallado en el Capítulo III. Hay que considerar que el precio al público para el año 1 y 2 asciende a S/ 825, y del año 3 al 5 el precio es de S/ 900; adicionalmente se realiza el cobro de una matrícula al ingreso a la guardería, este monto asciende a S/ 400. A continuación, se muestra el presupuesto de las ventas proyectada de forma mensual para el primer año como se muestra en la Tabla 57 y de forma anual tal como se muestra en la Tabla 58 para los cinco primeros años.

\section{Tabla 57}

Presupuesto de Ventas del Año 1

\begin{tabular}{|c|c|c|c|c|c|c|c|c|c|c|c|c|}
\hline Concepto & Enero & Febrero & Marzo & Abril & Mayo & Junio & Julio & Agosto & Septiembre & Octubre & Noviembre & Diciembre \\
\hline Numero de Niños al Año & 10.00 & 11.00 & 14.00 & 15.00 & 17.00 & 19.00 & 21.00 & 22.00 & 24.00 & 27.00 & 30.00 & 30.00 \\
\hline Matriculas & $4,000.00$ & 400.00 & $1,200.00$ & 400.00 & 800.00 & 800.00 & 800.00 & 400.00 & 800.00 & $1,200.00$ & $1,200.00$ & - \\
\hline Ventas & $8,250.00$ & $9,075.00$ & $11,550.00$ & $12,375.00$ & $14,025.00$ & $15,675.00$ & $17,325.00$ & $18,150.00$ & $19,800.00$ & $22,275.00$ & $24,750.00$ & $24,750.00$ \\
\hline IGV & - & - & - & - & - & - & - & - & - & - & - & - \\
\hline Pago en efectivo & $4,900.00$ & $3,790.00$ & $5,100.00$ & $5,110.00$ & $5,930.00$ & $6,590.00$ & $7,250.00$ & $7,420.00$ & $8,240.00$ & $9,390.00$ & $10,380.00$ & $9,900.00$ \\
\hline Pago con Tarjeta Visa & $7,350.00$ & $5,685.00$ & $7,650.00$ & $7,665.00$ & $8,995.00$ & $9,885.00$ & $10,875.00$ & $11,130.00$ & $12,360.00$ & $14,085.00$ & $15,570.00$ & $14,550.00$ \\
\hline
\end{tabular}

Tabla 58

Presupuesto de Ventas del Año lal Año 5

\begin{tabular}{lrrrrr}
\hline \multicolumn{1}{c}{ Concepto } & \multicolumn{1}{c}{ Año 1 } & \multicolumn{1}{c}{ Año 2 } & \multicolumn{1}{c}{ Año 3 } & \multicolumn{1}{c}{ Año 4 } & \multicolumn{1}{c}{ Año 5 } \\
\hline Número de Niños al Año & 240.00 & 504.00 & 648.00 & 756.00 & 816.00 \\
Matrículas & $12,000.00$ & $4,800.00$ & $4,800.00$ & $3,600.00$ & $2,000.00$ \\
Ventas & $198,000.00$ & $415,800.00$ & $583,200.00$ & $680,400.00$ & $734,400.00$ \\
IGV & - & - & - & - & - \\
& & & & & \\
Pago en efectivo & $84,000.00$ & $168,240.00$ & $235,200.00$ & $273,600.00$ & $294,560.00$ \\
Pago con Tarjeta Visa & $126,000.00$ & $252,360.00$ & $352,800.00$ & $410,400.00$ & $441,840.00$ \\
\hline
\end{tabular}




\subsubsection{Presupuesto de costos de servicios.}

A continuación, se muestra el presupuesto de costo de servicios de forma mensual para el primer año como se muestra en la Tabla 59 y de forma anual tal como se muestra en la Tabla 60 para los cinco primeros años.

Tabla 59

Presupuesto de Costo de Servicios del Año 1

\begin{tabular}{|c|c|c|c|c|c|c|c|c|c|c|c|c|}
\hline Concepto & Enero & Febrero & Marzo & Abril & Mayo & Junio & Julio & Agosto & Septiembre & Octubre & Noviembre & Diciembre \\
\hline 1. Costos directos & $13,322.78$ & $13,322.78$ & $13,322.78$ & $13,322.78$ & $13,322.78$ & $13,322.78$ & $16,060.56$ & $16,060.56$ & $16,060.56$ & $16,060.56$ & $16,060.56$ & $16,060.56$ \\
\hline Planilla de Maestros & $13,322.78$ & $13,322.78$ & $13,322.78$ & $13,322.78$ & $13,322.78$ & $13,322.78$ & $16,060.56$ & $16,060.56$ & $16,060.56$ & $16,060.56$ & $16,060.56$ & $16,060.56$ \\
\hline 2. Costos indirectos & $4,237,88$ & $4,247.61$ & $4,247,61$ & $4,247.61$ & $4,247.61$ & $4,247.61$ & $4,247.61$ & $4,247.61$ & $4,247.61$ & $4,247.61$ & $4,247.61$ & $4,247.61$ \\
\hline Gastos indirectos & $3,460.22$ & $3,469.95$ & $3,469.95$ & $3,469.95$ & $3,469.95$ & $3,469.95$ & $3,469.95$ & $3,469.95$ & $3,469.95$ & $3,469.95$ & $3,469.95$ & $3,469.95$ \\
\hline Depreciacion y Amortizacion & 777.66 & 777.66 & 777.66 & 777.66 & 777.66 & 777.66 & 777.66 & 777.66 & 777.66 & 777.66 & 777.66 & 777.66 \\
\hline 3. Gastos de administracion y ventas & $6,212,08$ & $6,164,74$ & $6,220.61$ & $6,221,04$ & $6,256,01$ & $6,284.16$ & $6,312.31$ & $6,319.56$ & $6,354.54$ & $6,403,59$ & $6,45,82$ & $6,425,34$ \\
\hline Planilla Administrativa & $3,472.26$ & $3,472.26$ & $3,472.26$ & $3,472.26$ & $3,472.26$ & $3,472.26$ & $3,472.26$ & $3,472.26$ & $3,472.26$ & $3,472.26$ & $3,472.26$ & $3,472.26$ \\
\hline Gastos indirectos & $2,481.48$ & $2,434.13$ & $2,490.01$ & $2,490.43$ & $2,525.41$ & $2,553.56$ & $2,581.71$ & $2,588.96$ & $2,623.94$ & $2,672.99$ & $2,715.21$ & $2,694.74$ \\
\hline Depreciacion y Amortizacion & 258.35 & 258.35 & 258.35 & 258.35 & 258.35 & 258.35 & 258.35 & 258.35 & 258.35 & 258.35 & 258.35 & 258.35 \\
\hline 4. Gastos financieros & $1,038.41$ & $1,027.73$ & $1,016,88$ & $1,005.87$ & 994.69 & 983,34 & 971.82 & 960.12 & 948.24 & 936.17 & 923.93 & 911.49 \\
\hline Total Costo & $24,811.14$ & $24,762,85$ & $24,807,88$ & $24,797,30$ & $24,821,09$ & $24,837,89$ & $27,592,30$ & $27,587.85$ & $27,610.94$ & $27,647.93$ & $27,677.91$ & $27,645.00$ \\
\hline
\end{tabular}

Tabla 60

Presupuesto de Costo de Servicios del Año lal Año 5

\begin{tabular}{lrrrrr}
\hline \multicolumn{1}{c}{ Concepto } & \multicolumn{1}{c}{ Año 1 } & \multicolumn{1}{c}{ Año 2 } & \multicolumn{1}{c}{ Año 3 } & \multicolumn{1}{c}{ Año 4 } & \multicolumn{1}{c}{ Año 5 } \\
\hline 1. Costos directos & $\mathbf{1 7 6 , 3 0 0 . 0 0}$ & $\mathbf{2 4 0 , 9 1 6 . 6 7}$ & $\mathbf{2 4 0 , 9 1 6 . 6 7}$ & $\mathbf{2 4 0 , 9 1 6 . 6 7}$ & $\mathbf{2 4 0 , 9 1 6 . 6 7}$ \\
Planilla de Maestros & $176,300.00$ & $240,916.67$ & $240,916.67$ & $240,916.67$ & $240,916.67$ \\
2. Costos indirectos & $\mathbf{5 0 , 9 6 1 . 5 8}$ & $\mathbf{5 0 , 9 6 1 . 5 8}$ & $\mathbf{5 0 , 9 6 1 . 5 8}$ & $\mathbf{5 0 , 9 6 1 . 5 8}$ & $\mathbf{5 0 , 9 6 1 . 5 8}$ \\
Gastos indirectos & $41,629.72$ & $41,629.72$ & $41,629.72$ & $41,629.72$ & $41,629.72$ \\
Depreciacion y Amortizacion & $9,331.86$ & $9,331.86$ & $9,331.86$ & $9,331.86$ & $9,331.86$ \\
3. Gastos de administracion y ventas & $\mathbf{7 5 , 6 1 9 . 7 9}$ & $\mathbf{7 9 , 2 1 2 . 8 4}$ & $\mathbf{8 2 , 0 6 8 . 8 5}$ & $\mathbf{8 3 , 7 0 6 . 7 1}$ & $\mathbf{8 4 , 6 0 0 . 7 1}$ \\
Planilla Administrativa & $41,667.10$ & $41,667.10$ & $41,667.10$ & $41,667.10$ & $41,667.10$ \\
Gastos indirectos & $30,852.55$ & $34,445.60$ & $37,301.61$ & $38,939.47$ & $39,833.46$ \\
Depreciacion y Amortizacion & $3,100.14$ & $3,100.14$ & $3,100.14$ & $3,100.14$ & $3,100.14$ \\
4. Gastos financieros & $\mathbf{1 1 , 7 1 8 . 7 0}$ & $\mathbf{9 , 8 9 5 . 7 6}$ & $\mathbf{7 , 7 0 8 . 2 3}$ & $\mathbf{5 , 0 8 3 . 2 0}$ & $\mathbf{1 , 9 3 3 . 1 5}$ \\
\hline Total Costo & $\mathbf{3 1 4 , 6 0 0 . 0 8}$ & $\mathbf{3 8 0 , 9 8 6 . 8 5}$ & $\mathbf{3 8 1 , 6 5 5 . 3 3}$ & $\mathbf{3 8 0 , 6 6 8 . 1 5}$ & $\mathbf{3 7 8 , 4 1 2 . 1 1}$ \\
\hline
\end{tabular}

\subsubsection{Presupuesto de compras}

A continuación, se muestra el presupuesto de compras el cual se ha dividido en compras del área operativa (académica) y de administración y de ventas, se presenta de forma mensual para el primer año como se muestra en la Tabla 61 y de forma anual tal como se muestra en la Tabla 62 para los cinco primeros años. 
Tabla 61

Presupuesto de Compras del Año 1

\begin{tabular}{|c|c|c|c|c|c|c|c|c|c|c|c|c|}
\hline Concepto & Enero & Febrero & Marzo & Abril & Mayo & Junio & Julio & Agosto & Septiembre & Octubre & Noviembre & Diciembre \\
\hline \multicolumn{13}{|l|}{ Gastos indirectos Area Académica } \\
\hline Extintor & 35.31 & 35.31 & 35.31 & 35.31 & 35.31 & 35.31 & 35.31 & 35.31 & 35.31 & 35.31 & 35.31 & 35.31 \\
\hline Recarga de extintor & 11.30 & 11.30 & 11.30 & 11.30 & 11.30 & 11.30 & 11.30 & 11.30 & 11.30 & 11.30 & 11.30 & 11.30 \\
\hline Uniformes & 28.25 & 28.25 & 28.25 & 28.25 & 28.25 & 28.25 & 28.25 & 28.25 & 28.25 & 28.25 & 28.25 & 28.25 \\
\hline Alquiler Local & $2,966.10$ & $2,966.10$ & $2,966.10$ & $2,966.10$ & $2,966.10$ & $2,966.10$ & $2,966.10$ & $2,966.10$ & $2,966.10$ & $2,966.10$ & $2,966.10$ & $2,966.10$ \\
\hline Arbitrios & 14.83 & 14.83 & 14.83 & 14.83 & 14.83 & 14.83 & 14.83 & 14.83 & 14.83 & 14.83 & 14.83 & 14.83 \\
\hline Energía Eléctrica & 177.97 & 177.97 & 177.97 & 177.97 & 177.97 & 177.97 & 177.97 & 177.97 & 177.97 & 177.97 & 177.97 & 177.97 \\
\hline Agua & 59.32 & 59.32 & 59.32 & 59.32 & 59.32 & 59.32 & 59.32 & 59.32 & 59.32 & 59.32 & 59.32 & 59.32 \\
\hline Teléfono + Internet + cable TV & 106.78 & 106.78 & 106.78 & 106.78 & 106.78 & 106.78 & 106.78 & 106.78 & 106.78 & 106.78 & 106.78 & 106.78 \\
\hline Botiquin & 2.97 & 12.70 & 12.70 & 12.70 & 12.70 & 12.70 & 12.70 & 12.70 & 12.70 & 12.70 & 12.70 & 12.70 \\
\hline Desinfectante & 15.93 & 15.93 & 15.93 & 15.93 & 15.93 & 15.93 & 15.93 & 15.93 & 15.93 & 15.93 & 15.93 & 15.93 \\
\hline Contenedor de basura grande c/tapa & 41.47 & 41.47 & 41.47 & 41.47 & 41.47 & 41.47 & 41.47 & 41.47 & 41.47 & 41.47 & 41.47 & 41.47 \\
\hline \multicolumn{13}{|l|}{ Gastos Administracion y ventas } \\
\hline Archivador & 12.97 & 12.97 & 12.97 & 12.97 & 12.97 & 12.97 & 12.97 & 12.97 & 12.97 & 12.97 & 12.97 & 12.97 \\
\hline Clips & 1.08 & 1.08 & 1.08 & 1.08 & 1.08 & 1.08 & 1.08 & 1.08 & 1.08 & 1.08 & 1.08 & 1.08 \\
\hline Papel Bond & 33.90 & 33.90 & 33.90 & 33.90 & 33.90 & 33.90 & 33.90 & 33.90 & 33.90 & 33.90 & 33.90 & 33.90 \\
\hline Sobre Manila & 3.18 & 3.18 & 3.18 & 3.18 & 3.18 & 3.18 & 3.18 & 3.18 & 3.18 & 3.18 & 3.18 & 3.18 \\
\hline Cinta Adhesiva & 1.43 & 1.43 & 1.43 & 1.43 & 1.43 & 1.43 & 1.43 & 1.43 & 1.43 & 1.43 & 1.43 & 1.43 \\
\hline Bolígrafo & 2.03 & 2.03 & 2.03 & 2.03 & 2.03 & 2.03 & 2.03 & 2.03 & 2.03 & 2.03 & 2.03 & 2.03 \\
\hline Corrector & 3.19 & 3.19 & 3.19 & 3.19 & 3.19 & 3.19 & 3.19 & 3.19 & 3.19 & 3.19 & 3.19 & 3.19 \\
\hline Grapas & 2.39 & 2.39 & 2.39 & 2.39 & 2.39 & 2.39 & 2.39 & 2.39 & 2.39 & 2.39 & 2.39 & 2.39 \\
\hline Block cuadriculado & 5.59 & 5.59 & 5.59 & 5.59 & 5.59 & 5.59 & 5.59 & 5.59 & 5.59 & 5.59 & 5.59 & 5.59 \\
\hline Resaltador & 1.10 & 1.10 & 1.10 & 1.10 & 1.10 & 1.10 & 1.10 & 1.10 & 1.10 & 1.10 & 1.10 & 1.10 \\
\hline Cartucho Tinta Negra & 177.97 & 177.97 & 177.97 & 177.97 & 177.97 & 177.97 & 177.97 & 177.97 & 177.97 & 177.97 & 177.97 & 177.97 \\
\hline Cartucho Tinta Color & 203.39 & 203.39 & 203.39 & 203.39 & 203.39 & 203.39 & 203.39 & 203.39 & 203.39 & 203.39 & 203.39 & 203.39 \\
\hline Teléfono Movil & 59.32 & 59.32 & 59.32 & 59.32 & 59.32 & 59.32 & 59.32 & 59.32 & 59.32 & 59.32 & 59.32 & 59.32 \\
\hline Publicidad y marchandising & 42.37 & 42.37 & 42.37 & 42.37 & 42.37 & 42.37 & 42.37 & 42.37 & 42.37 & 42.37 & 42.37 & 42.37 \\
\hline Extintor & 35.31 & 35.31 & 35.31 & 35.31 & 35.31 & 35.31 & 35.31 & 35.31 & 35.31 & 35.31 & 35.31 & 35.31 \\
\hline Recarga de extintor & 11.30 & 11.30 & 11.30 & 11.30 & 11.30 & 11.30 & 11.30 & 11.30 & 11.30 & 11.30 & 11.30 & 11.30 \\
\hline Uniformes & 18.36 & 18.36 & 18.36 & 18.36 & 18.36 & 18.36 & 18.36 & 18.36 & 18.36 & 18.36 & 18.36 & 18.36 \\
\hline Alquiler Local & $1,271.19$ & $1,271.19$ & $1,271.19$ & $1,271.19$ & $1,271.19$ & $1,271.19$ & $1,271.19$ & $1,271.19$ & $1,271.19$ & $1,271.19$ & $1,271.19$ & $1,271.19$ \\
\hline Arbitrios & 6.36 & 6.36 & 6.36 & 6.36 & 6.36 & 6.36 & 6.36 & 6.36 & 6.36 & 6.36 & 6.36 & 6.36 \\
\hline Energía Eléctrica & 76.27 & 76.27 & 76.27 & 76.27 & 76.27 & 76.27 & 76.27 & 76.27 & 76.27 & 76.27 & 76.27 & 76.27 \\
\hline Agua & 25.42 & 25.42 & 25.42 & 25.42 & 25.42 & 25.42 & 25.42 & 25.42 & 25.42 & 25.42 & 25.42 & 25.42 \\
\hline Teléfono + Internet + cable TV & 45.76 & 45.76 & 45.76 & 45.76 & 45.76 & 45.76 & 45.76 & 45.76 & 45.76 & 45.76 & 45.76 & 45.76 \\
\hline Bolsa Basura grande & 90.17 & 90.17 & 90.17 & 90.17 & 90.17 & 90.17 & 90.17 & 90.17 & 90.17 & 90.17 & 90.17 & 90.17 \\
\hline Escoba & 10.68 & 10.68 & 10.68 & 10.68 & 10.68 & 10.68 & 10.68 & 10.68 & 10.68 & 10.68 & 10.68 & 10.68 \\
\hline Recogedor & 3.62 & 3.62 & 3.62 & 3.62 & 3.62 & 3.62 & 3.62 & 3.62 & 3.62 & 3.62 & 3.62 & 3.62 \\
\hline Desinfectante & 6.83 & 6.83 & 6.83 & 6.83 & 6.83 & 6.83 & 6.83 & 6.83 & 6.83 & 6.83 & 6.83 & 6.83 \\
\hline Contenedor de basura grande c/tapa & 17.77 & 17.77 & 17.77 & 17.77 & 17.77 & 17.77 & 17.77 & 17.77 & 17.77 & 17.77 & 17.77 & 17.77 \\
\hline Jabón Espuma & 32.45 & 32.45 & 32.45 & 32.45 & 32.45 & 32.45 & 32.45 & 32.45 & 32.45 & 32.45 & 32.45 & 32.45 \\
\hline Papel higienico elite & 23.61 & 23.61 & 23.61 & 23.61 & 23.61 & 23.61 & 23.61 & 23.61 & 23.61 & 23.61 & 23.61 & 23.61 \\
\hline Kimberly papel toalla Scott & 32.95 & 32.95 & 32.95 & 32.95 & 32.95 & 32.95 & 32.95 & 32.95 & 32.95 & 32.95 & 32.95 & 32.95 \\
\hline Acido Muriático & 7.24 & 7.24 & 7.24 & 7.24 & 7.24 & 7.24 & 7.24 & 7.24 & 7.24 & 7.24 & 7.24 & 7.24 \\
\hline Desatorador de inodoro & 2.29 & 2.29 & 2.29 & 2.29 & 2.29 & 2.29 & 2.29 & 2.29 & 2.29 & 2.29 & 2.29 & 2.29 \\
\hline Total compras sin IGV & $5,727.70$ & $5, \mathbf{5 3 7 . 4 3}$ & $5, \mathbf{5 3 7 . 4 3}$ & $5,737.43$ & $5,737.43$ & $5,737.43$ & $5, \mathbf{5 3 7 . 4 3}$ & $\begin{array}{l}5,737.43 \\
\end{array}$ & $5,737.43$ & $5,737.43$ & $5,737.43$ & $5,737.43$ \\
\hline IGV & $1,030.99$ & $1,032.74$ & $1,032.74$ & $1,032.74$ & $1,032.74$ & $1,032.74$ & $1,032.74$ & $1,032.74$ & $1,032.74$ & $1,032.74$ & $1,032.74$ & $1,032.74$ \\
\hline Total compras inc. IGV & $6,758.68$ & $6,770.17$ & $6,770.17$ & $6,770.17$ & $6,770.17$ & $6,770.17$ & $6,770.17$ & $6,770.17$ & $6,770.17$ & $6,770.17$ & $6,770.17$ & $6,770.17$ \\
\hline
\end{tabular}


Tabla 62

Presupuesto de Compras del Año lal Año 5

\begin{tabular}{|c|c|c|c|c|c|}
\hline Concepto & Año 1 & Ã̃̃o 2 & Año 3 & Año 4 & Año 5 \\
\hline \multicolumn{6}{|l|}{ Gastos indirectos Area Académica } \\
\hline Extintor & 423.73 & 423.73 & 423.73 & 423.73 & 423.73 \\
\hline Recarga de extintor & 135.59 & 135.59 & 135.59 & 135.59 & 135.59 \\
\hline Uniformes & 339.00 & 339.00 & 339.00 & 339.00 & 339.00 \\
\hline Alquiler Local & $35,593.22$ & $35,593.22$ & $35,593.22$ & $35,593.22$ & $35,593.22$ \\
\hline Arbitrios & 177.97 & 177.97 & 177.97 & 177.97 & 177.97 \\
\hline Energía Eléctrica & $2,135.59$ & $2,135.59$ & $2,135.59$ & $2,135.59$ & $2,135.59$ \\
\hline Agua & 711.86 & 711.86 & 711.86 & 711.86 & 711.86 \\
\hline Teléfono + Internet + cable TV & $1,281.36$ & $1,281.36$ & $1,281.36$ & $1,281.36$ & $1,281.36$ \\
\hline Botiquin & 142.67 & 142.67 & 142.67 & 142.67 & 142.67 \\
\hline Desinfectante & 191.14 & 191.14 & 191.14 & 191.14 & 191.14 \\
\hline Contenedor de basura grande c/tapa & 497.59 & 497.59 & 497.59 & 497.59 & 497.59 \\
\hline \multicolumn{6}{|l|}{ Gastos Administracion y ventas } \\
\hline Archivador & 155.59 & 155.59 & 155.59 & 155.59 & 155.59 \\
\hline Clips & 12.92 & 12.92 & 12.92 & 12.92 & 12.92 \\
\hline Papel Bond & 406.78 & 406.78 & 406.78 & 406.78 & 406.78 \\
\hline Sobre Manila & 38.14 & 38.14 & 38.14 & 38.14 & 38.14 \\
\hline Cinta Adhesiva & 17.19 & 17.19 & 17.19 & 17.19 & 17.19 \\
\hline Bolígrafo & 24.41 & 24.41 & 24.41 & 24.41 & 24.41 \\
\hline Corrector & 38.24 & 38.24 & 38.24 & 38.24 & 38.24 \\
\hline Grapas & 28.68 & 28.68 & 28.68 & 28.68 & 28.68 \\
\hline Block cuadriculado & 67.12 & 67.12 & 67.12 & 67.12 & 67.12 \\
\hline Resaltador & 13.22 & 13.22 & 13.22 & 13.22 & 13.22 \\
\hline Cartucho Tinta Negra & $2,135.59$ & $2,135.59$ & $2,135.59$ & $2,135.59$ & $2,135.59$ \\
\hline Cartucho Tinta Color & $2,440.68$ & $2,440.68$ & $2,440.68$ & $2,440.68$ & $2,440.68$ \\
\hline Teléfono Movil & 711.86 & 711.86 & 711.86 & 711.86 & 711.86 \\
\hline Publicidad y marchandising & 508.47 & 508.47 & 508.47 & 508.47 & 508.47 \\
\hline Extintor & 423.73 & 423.73 & 423.73 & 423.73 & 423.73 \\
\hline Recarga de extintor & 135.59 & 135.59 & 135.59 & 135.59 & 135.59 \\
\hline Uniformes & 220.34 & 220.34 & 220.34 & 220.34 & 220.34 \\
\hline Alquiler Local & $15,254.24$ & $15,254.24$ & $15,254.24$ & $15,254.24$ & $15,254.24$ \\
\hline Arbitrios & 76.27 & 76.27 & 76.27 & 76.27 & 76.27 \\
\hline Energía Eléctrica & 915.25 & 915.25 & 915.25 & 915.25 & 915.25 \\
\hline Agua & 305.08 & 305.08 & 305.08 & 305.08 & 305.08 \\
\hline Teléfono + Internet + cable TV & 549.15 & 549.15 & 549.15 & 549.15 & 549.15 \\
\hline Bolsa Basura grande & $1,082.03$ & $1,082.03$ & $1,082.03$ & $1,082.03$ & $1,082.03$ \\
\hline Escoba & 128.14 & 128.14 & 128.14 & 128.14 & 128.14 \\
\hline Recogedor & 43.42 & 43.42 & 43.42 & 43.42 & 43.42 \\
\hline Desinfectante & 81.92 & 81.92 & 81.92 & 81.92 & 81.92 \\
\hline Contenedor de basura grande c/tapa & 213.25 & 213.25 & 213.25 & 213.25 & 213.25 \\
\hline Jabón Espuma & 389.35 & 389.35 & 389.35 & 389.35 & 389.35 \\
\hline Papel higienico elite & 283.32 & 283.32 & 283.32 & 283.32 & 283.32 \\
\hline Kimberly papel toalla Scott & 395.39 & 395.39 & 395.39 & 395.39 & 395.39 \\
\hline Acido Muriático & 86.92 & 86.92 & 86.92 & 86.92 & 86.92 \\
\hline Desatorador de inodoro & 27.46 & 27.46 & 27.46 & 27.46 & 27.46 \\
\hline Total compras sin IGV & $68,839.46$ & $68,839.46$ & $68,839.46$ & $68,839.46$ & $68,839.46$ \\
\hline IGV & $12,391.10$ & $12,391.10$ & $12,391.10$ & $12,391.10$ & $12,391.10$ \\
\hline Total compras inc. IGV & $81,230.56$ & $81,230.56$ & $81,230.56$ & $81,230.56$ & $81,230.56$ \\
\hline
\end{tabular}




\subsubsection{Presupuesto de costo de ventas.}

A continuación, se muestra el presupuesto del costo de ventas del servicio el cual se presenta de forma mensual para el primer año como se muestra en la Tabla 63 y de forma anual tal como se muestra en la Tabla 64 para los cinco primeros años.

Tabla 63

Presupuesto de Costo de Ventas del Año 1

\begin{tabular}{|c|c|c|c|c|c|c|c|c|c|c|c|c|}
\hline Concepto & Enero & Febrero & Marzo & Abril & Mayo & Junio & Julio & Agosto & Septiembre & Octubre & Noviembre & Diciembre \\
\hline Planilla Académica & $12,822,78$ & $12,822.78$ & $12,822.78$ & $12,822.78$ & $12,822.78$ & $12,822.78$ & $15,560.56$ & $15,560.56$ & $15,560.56$ & $15,560.56$ & $15,560.56$ & $15,560.56$ \\
\hline Directora & $4,791.11$ & $4,791.11$ & $4,791.11$ & $4,791.11$ & $4,791.11$ & $4,791.11$ & $4,791.11$ & 4,791.11 & 4,791.11 & $4,791.11$ & $4,791.11$ & $4,791.11$ \\
\hline Maestras & $5,475.56$ & $5,475.56$ & $5,475.56$ & $5,475.56$ & $5,475.56$ & $5,475.56$ & $8,213.33$ & $8,213,33$ & $8,213.33$ & $8,213.33$ & $8,213.33$ & $8,213,33$ \\
\hline Auxiliares & $2,556.11$ & $2,556.11$ & $2,556.11$ & $2,556.11$ & $2,556.11$ & $2,556.11$ & $2,556.11$ & $2,556.11$ & $2,556.11$ & $2,556.11$ & $2,556.11$ & $2,556.11$ \\
\hline Planilla Especialista & 500.00 & 500.00 & 500,00 & 500.00 & 500.00 & 500.00 & 500,00 & 500.00 & 500.00 & 500.00 & 500.00 & 500,00 \\
\hline Especialista Doman & 500.00 & 500.00 & 500.00 & 500.00 & 500.00 & 500.00 & 500.00 & 500.00 & 500.00 & 500.00 & 500.00 & 500.00 \\
\hline Gastos indirectos Area Académica & $3,460.22$ & $3,469.95$ & $3,469.95$ & $3,469,95$ & $3,469,95$ & $3,469,95$ & $3,469,95$ & $3,469,95$ & $3,469,95$ & $3,469,95$ & $3,469.95$ & $3,469,95$ \\
\hline Extintor & 35.31 & 35.31 & 35.31 & 35.31 & 35.31 & 35.31 & 35.31 & 35.31 & 35.31 & 35.31 & 35.31 & 35.31 \\
\hline Recarga de extintor & 11.30 & 11.30 & 11.30 & 11.30 & 11.30 & 11.30 & 11.30 & 11.30 & 11.30 & 11.30 & 11.30 & 11.30 \\
\hline Uniformes & 28.25 & 28.25 & 28.25 & 28.25 & 28.25 & 28.25 & 28.25 & 28.25 & 28.25 & 28.25 & 28.25 & 28.25 \\
\hline Alquiler Local & $2,966.10$ & $2,966.10$ & $2,966.10$ & $2,966.10$ & $2,966.10$ & $2,966.10$ & $2,966.10$ & $2,966.10$ & $2,966.10$ & $2,966.10$ & $2,966.10$ & $2,966.10$ \\
\hline Arbitrios & 14.83 & 14.83 & 14.83 & 14.83 & 14.83 & 14.83 & 14.83 & 14.83 & 14.83 & 14.83 & 14.83 & 14.83 \\
\hline Energía Eléctrica & 177.97 & 177.97 & 177.97 & 177.97 & 177.97 & 177.97 & 177.97 & 177.97 & 177.97 & 177.97 & 177.97 & 177.97 \\
\hline Agua & 59.32 & 59.32 & 59.32 & 59,32 & 59.32 & 59.32 & 59.32 & 59.32 & 59.32 & 59.32 & 59.32 & 59,32 \\
\hline Teléfono + Internet + cable TV & 106.78 & 106.78 & 106.78 & 106.78 & 106.78 & 106.78 & 106.78 & 106.78 & 106.78 & 106.78 & 106.78 & 106.78 \\
\hline Botiquin & 2.97 & 12.70 & 12.70 & 12.70 & 12.70 & 12.70 & 12.70 & 12.70 & 12.70 & 12.70 & 12.70 & 12.70 \\
\hline Desinfectante & 15.93 & 15.93 & 15.93 & 15.93 & 15.93 & 15.93 & 15.93 & 15.93 & 15.93 & 15.93 & 15.93 & 15.93 \\
\hline Contenedor de basura grande cltapa & 41.47 & 41.47 & 41.47 & 41.47 & 41.47 & 41.47 & 41.47 & 41.47 & 41.47 & 41.47 & 41.47 & 41.47 \\
\hline Total costo de ventas & $16,783.00$ & $16,792.73$ & $16,792.73$ & $16,792.73$ & $16,792.73$ & $16,792.73$ & $19,530.51$ & $19,530.51$ & $19,530,51$ & $19,530,51$ & $19,530,51$ & $19,530,51$ \\
\hline
\end{tabular}


Tabla 64

Presupuesto de Costo de Ventas del Año lal Año 5

\begin{tabular}{lrrrrr}
\hline Concepto & \multicolumn{1}{c}{ Año 1 } & \multicolumn{1}{c}{ Año 2 } & \multicolumn{1}{c}{ Año 3 } & \multicolumn{1}{c}{ Año 4 } & \multicolumn{1}{c}{ Año 5 } \\
\hline Planilla Académica & $\mathbf{1 7 0 , 3 0 0 . 0 0}$ & $\mathbf{2 3 4 , 9 1 6 . 6 7}$ & $\mathbf{2 3 4 , 9 1 6 . 6 7}$ & $\mathbf{2 3 4 , 9 1 6 . 6 7}$ & $\mathbf{2 3 4 , 9 1 6 . 6 7}$ \\
Directora & $57,493.33$ & $57,493.33$ & $57,493.33$ & $57,493.33$ & $57,493.33$ \\
Maestras & $82,133.33$ & $131,413.33$ & $131,413.33$ & $131,413.33$ & $131,413.33$ \\
Auxiliares & $30,673.33$ & $46,010.00$ & $46,010.00$ & $46,010.00$ & $46,010.00$ \\
Planilla Especialista & $\mathbf{6 , 0 0 0 . 0 0}$ & $\mathbf{6 , 0 0 0 . 0 0}$ & $\mathbf{6 , 0 0 0 . 0 0}$ & $\mathbf{6 , 0 0 0 . 0 0}$ & $\mathbf{6 , 0 0 0 . 0 0}$ \\
Especialista Doman & $\mathbf{6 , 0 0 0 . 0 0}$ & $6,000.00$ & $6,000.00$ & $6,000.00$ & $6,000.00$ \\
Gastos indirectos Area Académica & $\mathbf{4 1 , 6 2 9 . 7 2}$ & $\mathbf{4 1 , 6 2 9 . 7 2}$ & $\mathbf{4 1 , 6 2 9 . 7 2}$ & $\mathbf{4 1 , 6 2 9 . 7 2}$ & $\mathbf{4 1 , 6 2 9 . 7 2}$ \\
Extintor & 423.73 & 423.73 & 423.73 & 423.73 & 423.73 \\
Recarga de extintor & 135.59 & 135.59 & 135.59 & 135.59 & 135.59 \\
Uniformes & 339.00 & 339.00 & 339.00 & 339.00 & 339.00 \\
Alquiler Local & $35,593.22$ & $35,593.22$ & $35,593.22$ & $35,593.22$ & $35,593.22$ \\
Arbitrios & 177.97 & 177.97 & 177.97 & 177.97 & 177.97 \\
Energía Eléctrica & $2,135.59$ & $2,135.59$ & $2,135.59$ & $2,135.59$ & $2,135.59$ \\
Agua & 711.86 & 711.86 & 711.86 & 711.86 & 711.86 \\
Teléfono + Internet + cable TV & $1,281.36$ & $1,281.36$ & $1,281.36$ & $1,281.36$ & $1,281.36$ \\
Botiquin & 142.67 & 142.67 & 142.67 & 142.67 & 142.67 \\
Desinfectante & 191.14 & 191.14 & 191.14 & 191.14 & 191.14 \\
Contenedor de basura grande c/tapa & 497.59 & 497.59 & 497.59 & 497.59 & 497.59 \\
\hline Total costo de ventas & $\mathbf{2 1 7 , 9 2 9 . 7 2}$ & $\mathbf{2 8 2 , 5 4 6 . 3 8}$ & $\mathbf{2 8 2 , 5 4 6 . 3 8}$ & $\mathbf{2 8 2 , 5 4 6 . 3 8}$ & $\mathbf{2 8 2 , 5 4 6 . 3 8}$ \\
\hline
\end{tabular}

\subsubsection{Presupuesto de gastos administrativos y de ventas.}

A continuación, se muestra el presupuesto de los gastos de administración y de ventas el cual se presenta de forma mensual para el primer año como se muestra en la Tabla 65 y de forma anual tal como se muestra en la Tabla 66 para los cinco primeros años. 
Tabla 65

Presupuesto de Gastos Administrativos y de Ventas del Año 1

\begin{tabular}{|c|c|c|c|c|c|c|c|c|c|c|c|c|}
\hline Concepto & Enero & Febrero & Marzo & Abril & Mayo & Junio & Julio & Agosto & Septiembre & Octubre & Noviembre & Diciembre \\
\hline Planilla ventas & 766.83 & 766.83 & 766.83 & 766.83 & 766.83 & 766.83 & 766.83 & 766.83 & 766.83 & 766.83 & 766.83 & 766.83 \\
\hline Coordinador de Ventas & 766.83 & 766.83 & 766.83 & 766.83 & 766.83 & 766.83 & 766.83 & 766.83 & 766.83 & 766.83 & 766.83 & 766.83 \\
\hline Planilla Administrativa & $2,705.43$ & $2,705.43$ & $2,705.43$ & $2,705.43$ & $2,705.43$ & $2,705.43$ & $2,705.43$ & $2,705.43$ & $2,705.43$ & $2,705.43$ & $2,705.43$ & $2,705.43$ \\
\hline Coordinador Administrativo & 766.83 & 766.83 & 766.83 & 766.83 & 766.83 & 766.83 & 766.83 & 766.83 & 766.83 & 766.83 & 766.83 & 766.83 \\
\hline Mantenimiento y Limpieza & $1,188.59$ & $1,188.59$ & $1,188.59$ & $1,188.59$ & $1,188.59$ & $1,188.59$ & $1,188.59$ & $1,188.59$ & $1,188.59$ & $1,188.59$ & $1,188.59$ & $1,188.59$ \\
\hline Contador & 750.00 & 750.00 & 750.00 & 750.00 & 750.00 & 750.00 & 750.00 & 750.00 & 750.00 & 750.00 & 750.00 & 750.00 \\
\hline Servicios Visa & 214.00 & 166.65 & 222.53 & 222.95 & 257.93 & 286.08 & 314.23 & 321.48 & 356.46 & 405.51 & 447.73 & 427.26 \\
\hline Comision Tarjeta Debito & 197.79 & 152.98 & 205.86 & 206.27 & 239.36 & 266.01 & 292.65 & 299.51 & 332.61 & 379.03 & 418.99 & 399.61 \\
\hline Comision Tarjeta crédito & 11.21 & 8.67 & 11.67 & 11.69 & 13.56 & 15.07 & 16.58 & 16.97 & 18.85 & 21.48 & 23.74 & 22.65 \\
\hline Estado de cuenta & 5.00 & 5.00 & 5.00 & 5.00 & 5.00 & 5.00 & 5.00 & 5.00 & 5.00 & 5.00 & 5.00 & 5.00 \\
\hline Gastos Administracion y ventas & $2,267.48$ & $2,267.48$ & $2,267.48$ & $2,267.48$ & $2,267.48$ & $2,267.48$ & $2,267.48$ & $2,267.48$ & $2,267.48$ & $2,267.48$ & $2,267.48$ & $2,267.48$ \\
\hline Archivador & 12.97 & 12.97 & 12.97 & 12.97 & 12.97 & 12.97 & 12.97 & 12.97 & 12.97 & 12.97 & 12.97 & 12.97 \\
\hline Clips & 1.08 & 1.08 & 1.08 & 1.08 & 1.08 & 1.08 & 1.08 & 1.08 & 1.08 & 1.08 & 1.08 & 1.08 \\
\hline Papel Bond & 33.90 & 33.90 & 33.90 & 33.90 & 33.90 & 33.90 & 33.90 & 33.90 & 33.90 & 33.90 & 33.90 & 33.90 \\
\hline Sobre Manila & 3.18 & 3.18 & 3.18 & 3.18 & 3.18 & 3.18 & 3.18 & 3.18 & 3.18 & 3.18 & 3.18 & 3.18 \\
\hline Cinta Adhesiva & 1.43 & 1.43 & 1.43 & 1.43 & 1.43 & 1.43 & 1.43 & 1.43 & 1.43 & 1.43 & 1.43 & 1.43 \\
\hline Bolígrafo & 2.03 & 2.03 & 2.03 & 2.03 & 2.03 & 2.03 & 2.03 & 2.03 & 2.03 & 2.03 & 2.03 & 2.03 \\
\hline Corrector & 3.19 & 3.19 & 3.19 & 3.19 & 3.19 & 3.19 & 3.19 & 3.19 & 3.19 & 3.19 & 3.19 & 3.19 \\
\hline Grapas & 2.39 & 2.39 & 2.39 & 2.39 & 2.39 & 2.39 & 2.39 & 2.39 & 2.39 & 2.39 & 2.39 & 2.39 \\
\hline Block cuadriculado & 5.59 & 5.59 & 5.59 & 5.59 & 5.59 & 5.59 & 5.59 & 5.59 & 5.59 & 5.59 & 5.59 & 5.59 \\
\hline Resaltador & 1.10 & 1.10 & 1.10 & 1.10 & 1.10 & 1.10 & 1.10 & 1.10 & 1.10 & 1.10 & 1.10 & 1.10 \\
\hline Cartucho Tinta Negra & 177.97 & 177.97 & 177.97 & 177.97 & 177.97 & 177.97 & 177.97 & 177.97 & 177.97 & 177.97 & 177.97 & 177.97 \\
\hline Cartucho Tinta Color & 203.39 & 203.39 & 203.39 & 203.39 & 203.39 & 203.39 & 203.39 & 203.39 & 203.39 & 203.39 & 203.39 & 203.39 \\
\hline Teléfono Movil & 59.32 & 59.32 & 59.32 & 59.32 & 59.32 & 59.32 & 59.32 & 59.32 & 59.32 & 59.32 & 59.32 & 59.32 \\
\hline Publicidad y marchandising & 42.37 & 42.37 & 42.37 & 42.37 & 42.37 & 42.37 & 42.37 & 42.37 & 42.37 & 42.37 & 42.37 & 42.37 \\
\hline Extintor & 35.31 & 35.31 & 35.31 & 35.31 & 35.31 & 35.31 & 35.31 & 35.31 & 35.31 & 35.31 & 35.31 & 35.31 \\
\hline Recarga de extintor & 11.30 & 11.30 & 11.30 & 11.30 & 11.30 & 11.30 & 11.30 & 11.30 & 11.30 & 11.30 & 11.30 & 11.30 \\
\hline Uniformes & 18.36 & 18.36 & 18.36 & 18.36 & 18.36 & 18.36 & 18.36 & 18.36 & 18.36 & 18.36 & 18.36 & 18.36 \\
\hline Alquiler Local & $1,271.19$ & $1,271.19$ & $1,271.19$ & $1,271.19$ & $1,271.19$ & $1,271.19$ & $1,271.19$ & $1,271.19$ & $1,271.19$ & $1,271.19$ & $1,271.19$ & $1,271.19$ \\
\hline Arbitrios & 6.36 & 6.36 & 6.36 & 6.36 & 6.36 & 6.36 & 6.36 & 6.36 & 6.36 & 6.36 & 6.36 & 6.36 \\
\hline Energía Eléctrica & 76.27 & 76.27 & 76.27 & 76.27 & 76.27 & 76.27 & 76.27 & 76.27 & 76.27 & 76.27 & 76.27 & 76.27 \\
\hline Agua & 25.42 & 25.42 & 25.42 & 25.42 & 25.42 & 25.42 & 25.42 & 25.42 & 25.42 & 25.42 & 25.42 & 25.42 \\
\hline Teléfono + Internet + cable TV & 45.76 & 45.76 & 45.76 & 45.76 & 45.76 & 45.76 & 45.76 & 45.76 & 45.76 & 45.76 & 45.76 & 45.76 \\
\hline Bolsa Basura grande & 90.17 & 90.17 & 90.17 & 90.17 & 90.17 & 90.17 & 90.17 & 90.17 & 90.17 & 90.17 & 90.17 & 90.17 \\
\hline Escoba & 10.68 & 10.68 & 10.68 & 10.68 & 10.68 & 10.68 & 10.68 & 10.68 & 10.68 & 10.68 & 10.68 & 10.68 \\
\hline Recogedor & 3.62 & 3.62 & 3.62 & 3.62 & 3.62 & 3.62 & 3.62 & 3.62 & 3.62 & 3.62 & 3.62 & 3.62 \\
\hline Desinfectante & 6.83 & 6.83 & 6.83 & 6.83 & 6.83 & 6.83 & 6.83 & 6.83 & 6.83 & 6.83 & 6.83 & 6.83 \\
\hline Contenedor de basura grande c/tapa & 17.77 & 17.77 & 17.77 & 17.77 & 17.77 & 17.77 & 17.77 & 17.77 & 17.77 & 17.77 & 17.77 & 17.77 \\
\hline Jabón Espuma & 32.45 & 32.45 & 32.45 & 32.45 & 32.45 & 32.45 & 32.45 & 32.45 & 32.45 & 32.45 & 32.45 & 32.45 \\
\hline Papel higienico elite & 23.61 & 23.61 & 23.61 & 23.61 & 23.61 & 23.61 & 23.61 & 23.61 & 23.61 & 23.61 & 23.61 & 23.61 \\
\hline Kimberly papel toalla Scott & 32.95 & 32.95 & 32.95 & 32.95 & 32.95 & 32.95 & 32.95 & 32.95 & 32.95 & 32.95 & 32.95 & 32.95 \\
\hline Acido Muriático & 7.24 & 7.24 & 7.24 & 7.24 & 7.24 & 7.24 & 7.24 & 7.24 & 7.24 & 7.24 & 7.24 & 7.24 \\
\hline Desatorador de inodoro & 2.29 & 2.29 & 2.29 & 2.29 & 2.29 & 2.29 & 2.29 & 2.29 & 2.29 & 2.29 & 2.29 & 2.29 \\
\hline Total Gastos Administracion y ventas & $5,953.73$ & $5,906.39$ & $5,962.26$ & $5,962.69$ & $5,997.67$ & $6,025.82$ & 6,053.97 & $6,061.22$ & $6,096.19$ & $6,145.24$ & 6,187.47 & $6,167.00$ \\
\hline
\end{tabular}


Tabla 66

Presupuesto de Gastos Administrativos y de Ventas del Año 1 al Año 5

\begin{tabular}{|c|c|c|c|c|c|}
\hline Concepto & Año 1 & Año 2 & Año 3 & Año 4 & Año 5 \\
\hline Planilla ventas & $9,202.00$ & $9,202.00$ & $9,202.00$ & $9,202.00$ & $9,202.00$ \\
\hline Coordinador de Ventas & $9,202.00$ & $9,202.00$ & $9,202.00$ & $9,202.00$ & $9,202.00$ \\
\hline Planilla Administrativa & $32,465.10$ & $32,465.10$ & $32,465.10$ & $32,465.10$ & $32,465.10$ \\
\hline Coordinador Administrativo & $9,202.00$ & $9,202.00$ & $9,202.00$ & $9,202.00$ & $9,202.00$ \\
\hline Mantenimiento y Limpieza & $14,263.10$ & $14,263.10$ & $14,263.10$ & $14,263.10$ & $14,263.10$ \\
\hline Contador & $9,000.00$ & $9,000.00$ & $9,000.00$ & $9,000.00$ & $9,000.00$ \\
\hline Servicios Visa & $3,642.81$ & $7,235.86$ & $10,091.87$ & $11,729.72$ & $12,623.72$ \\
\hline Comision Tarjeta Debito & $3,390.66$ & $6,791.01$ & $9,493.85$ & $11,043.86$ & $11,889.91$ \\
\hline Comision Tarjeta crédito & 192.15 & 384.85 & 538.02 & 625.86 & 673.81 \\
\hline Estado de cuenta & 60.00 & 60.00 & 60.00 & 60.00 & 60.00 \\
\hline Gastos Administracion y ventas & $27,209.74$ & $27,209.74$ & $27,209.74$ & $27,209.74$ & $27,209.74$ \\
\hline Archivador & 155.59 & 155.59 & 155.59 & 155.59 & 155.59 \\
\hline Clips & 12.92 & 12.92 & 12.92 & 12.92 & 12.92 \\
\hline Papel Bond & 406.78 & 406.78 & 406.78 & 406.78 & 406.78 \\
\hline Sobre Manila & 38.14 & 38.14 & 38.14 & 38.14 & 38.14 \\
\hline Cinta Adhesiva & 17.19 & 17.19 & 17.19 & 17.19 & 17.19 \\
\hline Bolígrafo & 24.41 & 24.41 & 24.41 & 24.41 & 24.41 \\
\hline Corrector & 38.24 & 38.24 & 38.24 & 38.24 & 38.24 \\
\hline Grapas & 28.68 & 28.68 & 28.68 & 28.68 & 28.68 \\
\hline Block cuadriculado & 67.12 & 67.12 & 67.12 & 67.12 & 67.12 \\
\hline Resaltador & 13.22 & 13.22 & 13.22 & 13.22 & 13.22 \\
\hline Cartucho Tinta Negra & $2,135.59$ & $2,135.59$ & $2,135.59$ & $2,135.59$ & $2,135.59$ \\
\hline Cartucho Tinta Color & $2,440.68$ & $2,440.68$ & $2,440.68$ & $2,440.68$ & $2,440.68$ \\
\hline Teléfono Movil & 711.86 & 711.86 & 711.86 & 711.86 & 711.86 \\
\hline Publicidad y marchandising & 508.47 & 508.47 & 508.47 & 508.47 & 508.47 \\
\hline Extintor & 423.73 & 423.73 & 423.73 & 423.73 & 423.73 \\
\hline Recarga de extintor & 135.59 & 135.59 & 135.59 & 135.59 & 135.59 \\
\hline Uniformes & 220.34 & 220.34 & 220.34 & 220.34 & 220.34 \\
\hline Alquiler Local & $15,254.24$ & $15,254.24$ & $15,254.24$ & $15,254.24$ & $15,254.24$ \\
\hline Arbitrios & 76.27 & 76.27 & 76.27 & 76.27 & 76.27 \\
\hline Energía Eléctrica & 915.25 & 915.25 & 915.25 & 915.25 & 915.25 \\
\hline Agua & 305.08 & 305.08 & 305.08 & 305.08 & 305.08 \\
\hline Teléfono + Internet + cable TV & 549.15 & 549.15 & 549.15 & 549.15 & 549.15 \\
\hline Bolsa Basura grande & $1,082.03$ & $1,082.03$ & $1,082.03$ & $1,082.03$ & $1,082.03$ \\
\hline Escoba & 128.14 & 128.14 & 128.14 & 128.14 & 128.14 \\
\hline Recogedor & 43.42 & 43.42 & 43.42 & 43.42 & 43.42 \\
\hline Desinfectante & 81.92 & 81.92 & 81.92 & 81.92 & 81.92 \\
\hline Contenedor de basura grande c/tapa & 213.25 & 213.25 & 213.25 & 213.25 & 213.25 \\
\hline Jabón Espuma & 389.35 & 389.35 & 389.35 & 389.35 & 389.35 \\
\hline Papel higienico elite & 283.32 & 283.32 & 283.32 & 283.32 & 283.32 \\
\hline Kimberly papel toalla Scott & 395.39 & 395.39 & 395.39 & 395.39 & 395.39 \\
\hline Acido Muriático & 86.92 & 86.92 & 86.92 & 86.92 & 86.92 \\
\hline Desatorador de inodoro & 27.46 & 27.46 & 27.46 & 27.46 & 27.46 \\
\hline Total Gastos Administracion y ventas & $72,519.65$ & $76,112.70$ & $78,968.71$ & $80,606.57$ & $81,500.56$ \\
\hline
\end{tabular}




\subsubsection{Presupuesto de gastos financieros.}

A continuación, se muestra el presupuesto de los gastos financieros el cual se presenta de forma mensual para el primer año como se muestra en la Tabla 67 y de forma anual tal como se muestra en la Tabla 68 para los cinco primeros años.

Tabla 67

Presupuesto de Gastos Financieros del Año 1

\begin{tabular}{|c|c|c|c|c|c|c|c|c|c|c|c|c|}
\hline Concepto & Enero & Febrero & Marzo & Abril & Mayo & Junio & Julio & Agosto & Septiembre & Octubre & Noviembre & Diciembre \\
\hline Intererses & $1,587.56$ & $1,575.21$ & $1,562.56$ & $1,549.62$ & $1,536.38$ & $1,522.82$ & $1,508.95$ & $1,494.76$ & $1,480.23$ & $1,465.36$ & $1,450,15$ & $1,434,58$ \\
\hline
\end{tabular}

Tabla 68

Presupuesto de Gastos Financieros del Año 1 al Año 5

\begin{tabular}{llllll}
\hline \multicolumn{1}{c}{ Concepto } & Año 1 & Año 2 & Año 3 & Año4 & Año5 \\
\hline Intereses & $18,168.19$ & $15,858.74$ & $12,810.27$ & $8,786.28$ & $3,474.62$ \\
\hline
\end{tabular}

\subsection{Presupuestos de Resultados}

\subsubsection{Estado de ganancias y pérdidas proyectado}

Luego de haber realizado los presupuestos detallados en este capítulo se procede a realizar el Estado de Ganancias y Pérdidas proyectado, este estado financiero nos ayuda a determinar el resultado de una gestión y no acumula saldos de ejercicios anteriores. Para el proyecto se puede apreciar que el resultado de la gestión del año uno es negativo lo que significa que hay perdidas, este escenario no debe causar preocupación ya que durante el primer año la captación de clientes es lenta y se está trabajando en lograr un posicionamiento. Es importante destacar que la administración tributaria peruana permite compensar las pérdidas de ejercicios anteriores a partir del año donde se obtiene utilidad, en el caso del proyecto esto ocurre a partir del segundo año.

A continuación, se muestra el Estado de ganancias y pérdidas proyectado el cual se presenta de forma mensual para el primer año como se muestra en la Tabla 69 y de forma anual tal como se muestra en la Tabla 70 para los cinco primeros años. 
Tabla 69

Estado de Ganancias y Pérdidas Proyectado del Año 1

\begin{tabular}{|c|c|c|c|c|c|c|c|c|c|c|c|c|}
\hline Concepto & Enero & Febrer0 & Marzo & Abril & Mayo & Junio & Julio & Agosto & Septiembre & Octubre & Noviembre & Diciembre \\
\hline Ventas & $12,250.00$ & $9,475.00$ & $12,750.00$ & $12,775.00$ & $14,825.00$ & $16,475.00$ & $18,125.00$ & $18,550.00$ & $20,600.00$ & $23,475.00$ & $25,950.00$ & $24,750.00$ \\
\hline Costo de ventas & $-16,783.00$ & $-16,792.73$ & $-16,792.73$ & $-16,792.73$ & $-16,792.73$ & $-16,792.73$ & $-19,530.51$ & $-19,530.51$ & $-19,530.51$ & $-19,530.51$ & $-19,530.51$ & $-19,530.51$ \\
\hline Utilidad Bruta & $-4,533,00$ & $-7,317,73$ & $-4,042.73$ & $-4,017,73$ & $\cdot 1,967.73$ & .317 .73 & $\cdot 1,405.51$ & .980 .51 & $1,069.49$ & $3,944.49$ & $6,419.49$ & $5,219.49$ \\
\hline Gastos de Administracion y Ventas & $-5,953.73$ & $-5,906.39$ & $-5,962.26$ & $-5,962.69$ & $-5,997.67$ & $-6,025.82$ & $-6,053.97$ & $-6,061.22$ & $-6,096.19$ & $-6,145.24$ & $-6,187.47$ & $-6,167,00$ \\
\hline Depreciacion & -634.22 & -634.22 & -634.22 & -634.22 & -634.22 & -634.22 & -634.22 & -634.22 & -634.22 & -634.22 & -634.22 & -634.22 \\
\hline Amortizacion de intangibles & -401.78 & -401.78 & -401.78 & -401.78 & -401.78 & -401.78 & -401.78 & -401.78 & -401.78 & -401.78 & -401.78 & -401.78 \\
\hline Gastos financieros & $-1,587.56$ & $-1,575.21$ & $-1,562.56$ & $-1,549.62$ & $-1,536.38$ & $-1,522.82$ & $-1,508.95$ & $-1,494.76$ & $-1,480.23$ & $-1,465.36$ & $-1,450.15$ & $-1,434.58$ \\
\hline Utilidad antes de impuestos & $-13,110,29$ & $\cdot 15,835,33$ & $\cdot 12,603.56$ & $\cdot 12,566,04$ & $\cdot 10,537.78$ & $8.8902,37$ & $\cdot 10,004.43$ & $.9,572,49$ & $-7,542.94$ & $-4,702.12$ & $-2,254,13$ & $-3,418,08$ \\
\hline Arrastre de Perdida & $-13,110.29$ & $\cdot 28,945,62$ & $-41,549,18$ & $.54,115.23$ & $.64,653.00$ & $.73,555,38$ & $.83,559,81$ & $.93,132,30$ & $\cdot 100,675.23$ & $-105,377.35$ & $\cdot 107,631.48$ & $\cdot 111,049.56$ \\
\hline Impuesto a la renta & & - & & - & - & 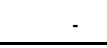 & - & - & & - & - & - \\
\hline Utilidad Neta & $\cdot 13,110,29$ & $\cdot 15,835,33$ & $\cdot 12,603.56$ & $\cdot 12,566,04$ & $\cdot 10,537,78$ & $.8,902,37$ & $\cdot 10,004.43$ & $.9,572.49$ & $.7,542.94$ & $-4,702.12$ & $-2,254.13$ & $.3,418,08$ \\
\hline
\end{tabular}

Tabla 70

Estado de Ganancias y Pérdidas Proyectado del Año 1 al Año 5

\begin{tabular}{lrrrrr}
\hline \multicolumn{1}{c}{ Concepto } & \multicolumn{1}{c}{ Año 1 } & \multicolumn{1}{c}{ Año 2 } & \multicolumn{1}{c}{ Año 3 } & \multicolumn{1}{c}{ Año 4 } & \multicolumn{1}{c}{ Año 5 } \\
\hline Ventas & $210,000.00$ & $420,600.00$ & $588,000.00$ & $684,000.00$ & $736,400.00$ \\
Costo de ventas & $-217,929.72$ & $-282,546.38$ & $-282,546.38$ & $-282,546.38$ & $-282,546.38$ \\
Utilidad Bruta & $\mathbf{- 7 , 9 2 9 . 7 2}$ & $\mathbf{1 3 8 , 0 5 3 . 6 2}$ & $\mathbf{3 0 5 , 4 5 3 . 6 2}$ & $\mathbf{4 0 1 , 4 5 3 . 6 2}$ & $\mathbf{4 5 3 , 8 5 3 . 6 2}$ \\
Gastos de Administración y Ventas & $-72,519.65$ & $-76,112.70$ & $-78,968.71$ & $-80,606.57$ & $-81,500.56$ \\
Depreciación & $-7,610.68$ & $-7,610.68$ & $-7,610.68$ & $-7,610.68$ & $-7,610.68$ \\
Amortización de intangibles & $-4,821.33$ & $-4,821.33$ & $-4,821.33$ & $-4,821.33$ & $-4,821.33$ \\
Gastos financieros & $-18,168.19$ & $-15,858.74$ & $-12,810.27$ & $-8,786.28$ & $-3,474.62$ \\
Utilidad antes de impuestos & $\mathbf{- 1 1 1 , 0 4 9 . 5 6}$ & $\mathbf{3 3 , 6 5 0 . 1 7}$ & $\mathbf{2 0 1 , 2 4 2 . 6 3}$ & $\mathbf{2 9 9 , 6 2 8 . 7 6}$ & $\mathbf{3 5 6 , 4 4 6 . 4 3}$ \\
Arrastre de Pérdida & $-\mathbf{7 7 , 3 9 9 . 3 9}$ & $\mathbf{1 2 3 , 8 4 3 . 2 4}$ & & \\
Impuesto a la renta & - & - & $36,533.76$ & $88,390.49$ & $105,151.70$ \\
\hline Utilidad Neta & $\mathbf{- 1 1 1 , 0 4 9 . 5 6}$ & $\mathbf{3 3 , 6 5 0 . 1 7}$ & $\mathbf{1 6 4 , 7 0 8 . 8 8}$ & $\mathbf{2 1 1 , 2 3 8 . 2 8}$ & $\mathbf{2 5 1 , 2 9 4 . 7 3}$ \\
\hline
\end{tabular}

\subsubsection{Balance proyectado}

Se presenta el Balance General proyectado de Titinos Daycare, cabe destacar que el

Balance General es un estado financiero donde se muestran los saldos a valor histórico de las transacciones que realiza la empresa, está conformada por tres elementos los cuales son:

- Activo: Está conformado por el efectivo y los bienes tangibles y/o intangibles que posee la entidad a través de los cuales se pueden generar ingresos económicos futuros.

- $\quad$ Pasivo: Está conformado por las obligaciones contraídas con terceros, las cuales van a generar desembolsos económicos futuros.

- $\quad$ Patrimonio: Representa los aportes realizados por los accionistas más los resultados obtenidos durante el ejercicio y los Resultados acumulados de ejercicios anteriores. 
A continuación, se muestra el Balance General proyectado el cual se presenta de forma mensual para el primer año como se muestra en la Tabla 71 y de forma anual tal como se muestra en la Tabla 72 para los cinco primeros años.

Tabla 71

Balance General Proyectado del Año 1

\begin{tabular}{|c|c|c|c|c|c|c|c|c|c|c|c|c|}
\hline Concepto & Enero & Febrer0 & Marzo & Abril & Mayo & Junio & Julio & Agosto & Septiembre & Octubre & Noviembre & Diciembre \\
\hline Activo Corriente & $69,088,35$ & $53,748.79$ & $41,628,36$ & $29,532.50$ & $19,451.67$ & $10,992.69$ & $1,417.77$ & $.7,739,39$ & $\cdot 14,881.53$ & -19,197.72 & $\cdot 21,081.13$ & $-24,144,07$ \\
\hline Caja & $53,333,90$ & $36,932.51$ & 23,740.19 & $10,572.36$ & -586.74 & $10,992.69$ & 329.37 & $-9,917.49$ & $-18,155,63$ & $-23,576.65$ & $-26,572.49$ & $-24,144,07$ \\
\hline IGVCredito Fiscal & $15,754.45$ & $16,816.28$ & $17,888.17$ & $18,960.14$ & $20,038.41$ & - & $1,088.40$ & $2,178.10$ & $3,274.10$ & $4,378.93$ & $5,491.36$ & - \\
\hline Activo no Corriente & $80,552.00$ & $79,516,00$ & $78,480.00$ & $77,444,00$ & $76,408.00$ & $75,372,00$ & $74,336,00$ & $73,300.00$ & $72,263.99$ & $71,227.99$ & 70,191.99 & $69,155.99$ \\
\hline Activo Fijo neto & $57,481.36$ & $57,481.36$ & $57,481.36$ & $57,481.36$ & $57,481.36$ & $57,481.36$ & $57,481.36$ & $57,481.36$ & $57,481,36$ & $57,481.36$ & $57,481.36$ & $57,481.36$ \\
\hline Intangibles neto & $24,106.64$ & $24,106.64$ & $24,106.64$ & $24,106.64$ & $24,106.64$ & $24,106.64$ & $24,106.64$ & $24,106.64$ & $24,106.64$ & $24,106.64$ & $24,106.64$ & $24,106.64$ \\
\hline Depreciación Acumulada & -634.22 & $-1,268.45$ & $-1,902,67$ & $-2,536.89$ & $-3,171,12$ & $-3,805.34$ & $-4,439.56$ & $-5,073,79$ & $-5,708,01$ & $-6,342.23$ & $-6,976.45$ & $-7,610.68$ \\
\hline Amortizacion Acumulada & -401.78 & -803.55 & $-1,205.33$ & $-1,607.11$ & $-2,008.89$ & $-2,410.66$ & $-2,812.44$ & $-3,214,22$ & $-3,616.00$ & $-4,017.77$ & $-4,419.55$ & $-4,821,33$ \\
\hline Total Activos & 149,640 & 133,265 & 120,108 & 106,976 & 95,860 & 86,365 & 75,754 & 65,561 & 57,382 & 52,030 & 49,111 & 45,012 \\
\hline Pasivo Corriente & 527.87 & 540.23 & $\mathbf{5 5 2 . 8 7}$ & 565.81 & $\mathbf{5 7 9 , 0 6}$ & 592.61 & 606.48 & 620.68 & 635.20 & 650.07 & 665.29 & 680.86 \\
\hline Obligaciones con Bancos & 527.87 & 540.23 & 552.87 & 565.81 & 579.06 & 592.61 & 606.48 & 620.68 & 635.20 & 650.07 & 665.29 & 680.86 \\
\hline Pasivo no Corriente & $66,772.25$ & $66,219,67$ & $65,654,15$ & $65,075.40$ & $64,483.10$ & $63,876.93$ & $63,256,58$ & $62,621.71$ & $61,971.98$ & $61,307.04$ & $60,626.54$ & $59,930.11$ \\
\hline Obligaciones con Bancos & $66,772.25$ & $66,219.67$ & $65,654.15$ & $65,075.40$ & $64,483.10$ & $63,876.93$ & $63,256.58$ & $62,621.71$ & $61,971.98$ & $61,307,04$ & $60,626.54$ & $59,930.11$ \\
\hline Total Pasivo & $67,300.13$ & $66,759.90$ & $66,207,02$ & $65,641.21$ & $65,062.15$ & $64,469.54$ & $63,863,06$ & $63,242,39$ & $62,607.18$ & $61,957.11$ & $61,291.83$ & $60,610.97$ \\
\hline \multicolumn{13}{|l|}{ Patrimonio } \\
\hline Capital social & $95,450,52$ & $95,450.52$ & $95,450.52$ & $95,450.52$ & $95,450.52$ & $95,450.52$ & $95,450,52$ & $95,450.52$ & $95,450,52$ & $95,450,52$ & $95,450.52$ & $95,450.52$ \\
\hline Resultado acumulados & & $-13,110.29$ & $-28,945,62$ & $-41,549.18$ & $-54,115.23$ & $-64,653,00$ & $-73,555,38$ & $-83,559.81$ & $-93,132,30$ & $-100,675.23$ & $-105,377.35$ & $-107,631.48$ \\
\hline Resultado del ejercicio & $-13,110.29$ & $-15,835,33$ & $-12,603.56$ & $-12,566.04$ & $-10,537.78$ & $-8,902.37$ & $-10,004.43$ & $-9,572,49$ & $-7,542,94$ & $-4,702.12$ & $-2,254.13$ & $-3,418.08$ \\
\hline Total Patrimonio & $82,340,22$ & $66,504.89$ & $53,901,33$ & $41,335.29$ & $30,797.51$ & $21,895.14$ & $11,890.71$ & $2,318.22$ & $.5,224,72$ & $.9,926,84$ & -12,180,96 & -15,599,05 \\
\hline
\end{tabular}

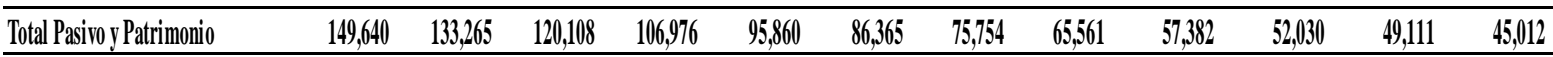


Tabla 72

Balance General Proyectado del Año 0 al Año 5

\begin{tabular}{|c|c|c|c|c|c|c|}
\hline Concepto & Año 0 & Año 1 & Año 2 & Año 3 & Año 4 & Año 5 \\
\hline Activo Corriente & $81,690.52$ & $-24,144.07$ & $12,411.63$ & $176,977.56$ & $384,048.90$ & $625,865.04$ \\
\hline Caja & $67,004.68$ & $-24,144.07$ & $12,411.63$ & $176,977.56$ & $384,048.90$ & $625,865.04$ \\
\hline IGV Credito Fiscal & $14,685.84$ & - & - & - & - & - \\
\hline Activo no Corriente & $81,588.00$ & $69,155.99$ & $56,723.99$ & $44,291.98$ & $31,859.97$ & $19,427.97$ \\
\hline Activo Fijo neto & $57,481.36$ & $57,481.36$ & $57,481.36$ & $57,481.36$ & $57,481.36$ & $57,481.36$ \\
\hline Intangibles neto & $24,106.64$ & $24,106.64$ & $24,106.64$ & $24,106.64$ & $24,106.64$ & $24,106.64$ \\
\hline Depreciación Acumulada & & $-7,610.68$ & $-15,221.36$ & $-22,832.03$ & $-30,442.71$ & $-38,053.39$ \\
\hline Amortizacion Acumulada & & $-4,821.33$ & $-9,642.66$ & $-14,463.99$ & $-19,285.32$ & $-24,106.64$ \\
\hline Total Activos & 163,279 & 45,012 & 69,136 & 221,270 & 415,909 & 645,293 \\
\hline Pasivo Corriente & - & $7,217.03$ & $9,526.48$ & $12,574.95$ & $16,598.94$ & $21,910.60$ \\
\hline Obligaciones con Bancos & & $7,217.03$ & $9,526.48$ & $12,574.95$ & $16,598.94$ & $21,910.60$ \\
\hline Pasivo no Corriente & $67,828.00$ & $53,393.94$ & $41,558.01$ & $25,934.58$ & $5,311.66$ & $-21,910.60$ \\
\hline Obligaciones con Bancos & $67,828.00$ & $53,393.94$ & $41,558.01$ & $25,934.58$ & $5,311.66$ & $-21,910.60$ \\
\hline Total Pasivo & $67,828.00$ & $60,610.97$ & $51,084.49$ & $38,509.54$ & $21,910.60$ & 0.00 \\
\hline \multicolumn{7}{|l|}{ Patrimonio } \\
\hline Capital social & $95,450.52$ & $95,450.52$ & $95,450.52$ & $95,450.52$ & $95,450.52$ & $95,450.52$ \\
\hline Resultado acumulados & & & $-111,049.56$ & $-77,399.39$ & $87,309.49$ & $298,547.76$ \\
\hline Resultado del ejercicio & & $-111,049.56$ & $33,650.17$ & $164,708.88$ & $211,238.28$ & $251,294.73$ \\
\hline Total Patrimonio & $95,450.52$ & $-15,599.05$ & $18,051.12$ & $182,760.00$ & $393,998.28$ & $645,293.01$ \\
\hline Total Pasivo y Patrimonio & 163,279 & 45,012 & 69,136 & 221,270 & 415,909 & 645,293 \\
\hline
\end{tabular}

\subsubsection{Flujo de caja proyectado}

El flujo de caja nos muestra el movimiento del activo líquido de la empresa, para poder realizar este flujo proyectado nos hemos basado en los diversos presupuestos proyectados de ingresos y egresos. Para los ingresos además de la proyección de las ventas, se ha tomado en cuenta y las devoluciones del IGV solicitadas a SUNAT. El capital de trabajo ha sido proyectado con el método del porcentaje en la variación de ventas, y se está considerando el financiamiento obtenido de una entidad financiera. A continuación, se muestra el flujo de caja proyectado el cual se presenta de forma anual en la Tabla 73 para los cinco primeros años de vida del proyecto. 
Tabla 73

Flujo de Caja Proyectado del Año 1 al Año 5

\begin{tabular}{|c|c|c|c|c|c|c|}
\hline & Año 0 & Año 1 & Año 2 & Añ̃ 3 & Año 4 & Año 5 \\
\hline Ingresos & & $237,721.85$ & $434,282.76$ & $602,196.84$ & $698,491.65$ & $751,052.57$ \\
\hline Planilla & & $-217,967.10$ & $-282,583.77$ & $-282,583.77$ & $-282,583.77$ & $-282,583.77$ \\
\hline Gastos Indirectos & & $-81,230.56$ & $-81,230.56$ & $-81,230.56$ & $-81,230.56$ & $-81,230.56$ \\
\hline Comisión VISA & & $-4,287.72$ & $-8,527.51$ & $-11,897.60$ & $-13,830.27$ & $-14,885.19$ \\
\hline Impuesto a la renta & & & & $-36,533.76$ & $-88,390.49$ & $-105,151.70$ \\
\hline Flujo Operativo & & $-65,763.53$ & $61,940.92$ & $189,951.15$ & $232,456.56$ & $267,201.36$ \\
\hline Activos Fijos & $-67,828.00$ & & & & & \\
\hline Activos Intangibles & $-28,445.84$ & & & & & \\
\hline Capital de Trabajo & $-67,004.68$ & $-55,402.98$ & $-21,421.39$ & $-3,425.41$ & -257.76 & - \\
\hline Recuperación de K de W & & & & & & $147,512.22$ \\
\hline Valor Residual del activo & & & & & & $19,427.97$ \\
\hline Flujo de Inversiones & -163278.515 & $-55,402.98$ & $-21,421.39$ & $-3,425.41$ & -257.76 & $166,940.18$ \\
\hline Servicio de Deuda & $67,828.00$ & $-20,025.60$ & $-20,706.89$ & $-21,606.19$ & $-22,793.27$ & $-24,360.21$ \\
\hline Flujo Financiero & -95450.5154 & $-141,192.12$ & $19,812.63$ & $164,919.55$ & $209,405.54$ & $409,781.34$ \\
\hline
\end{tabular}




\section{Capítulo X: Evaluación Económico-Financiera}

La Evaluación económico financiero incluye el análisis de los flujos Netos de Efectivo los que constituirán la disponibilidad real de efectivo por cada período de evaluación de nuestro proyecto, y que al confrontarlos con la inversión inicial nos permitirá determinar el Valor Presente Neto, la Tasa Interna de Retorno y otros indicadores financieros, asimismo se ha realizado el análisis de sensibilidad y de escenarios.

\subsection{Evaluación Financiera}

Se ha realizado el cálculo de los indicadores de rentabilidad, para ello se ha analizado la TIR, el VAN, el ROE, el ROA y algunos ratios financieros que son aplicables al proyecto.

Para efectos del cálculo de la TIR y el VAN se va a trabajar con el flujo de caja proyectado en el capítulo anterior, y para el cálculo del ROE, ROA y otros ratios, se va a utilizar el Estado de ganancias y pérdidas, y el Balance general realizados en el capítulo anterior.

\subsubsection{TIR}

La TIR es un indicador de la rentabilidad que genera la inversión del proyecto, adicionalmente la TIR es la tasa de descuento que hace que el VAN sea igual a cero, se debe tener en cuenta que, si la TIR obtenida es mayor o igual al COK, el proyecto es rentable; es preciso recordar que el COK de este proyecto es $21.83 \%$. Para efectos del análisis del proyecto de implementación de una guardería se ha realizado el cálculo en función al flujo económico (TIRE) y al flujo financiero (TIRF), asimismo para el cálculo se hace uso de la siguiente formula $I+\sum_{\mathrm{i}=1}^{\mathrm{n}} \frac{\mathrm{FC}}{(1+\mathrm{d})^{\mathrm{i}}}=\oint_{\text {y se toman los flujos obtenidos en la Tabla } 74 \text { y se }}$ obtienen los resultados mostrados en la Tabla 75

Tabla 74

Flujos de Caja Proyectados

\begin{tabular}{lcccccc}
\hline & Año 0 & Año 1 & \multicolumn{1}{c}{ Año 2 } & \multicolumn{1}{c}{ Año 3 } & \multicolumn{1}{c}{ Año 4 } & Año 5 \\
\hline Flujo Económico & $-163,279$ & $-121,167$ & 40,520 & 186,526 & 232,199 & 434,142 \\
Servicio de Deuda & 67,828 & $-20,026$ & $-20,707$ & $-21,606$ & $-22,793$ & $-24,360$ \\
\hline Flujo Financiero & $\mathbf{- 9 5 , 4 5 1}$ & $\mathbf{- 1 4 1 , 1 9 2}$ & $\mathbf{1 9 , 8 1 3}$ & $\mathbf{1 6 4 , 9 2 0}$ & $\mathbf{2 0 9 , 4 0 6}$ & $\mathbf{4 0 9 , 7 8 1}$ \\
\hline
\end{tabular}


Tabla 75

Resultados del Cálculo de la TIR

\begin{tabular}{cc}
\hline TIRE & TIRF \\
\hline $36.73 \%$ & $40.94 \%$ \\
\hline
\end{tabular}

Como se puede apreciar en ambos casos se obtiene una TIR mayor al COK por lo que se concluye que el proyecto es rentable y puede implementarse; adicionalmente se puede ver que la TIR financiera es mayor a la económica, lo cual indica que un proyecto que cuenta con financiamiento es más rentable para el inversionista.

\subsubsection{VAN}

El VAN es un indicador de la rentabilidad que se expresa en unidades monetarias, consiste en traer a valor presente todos los flujos que genera un proyecto, hay que tener en cuenta que, si el VAN obtenido es mayor o igual a Cero, el proyecto es rentable y puede aceptarse. Para efectos del análisis del proyecto de implementación de una guardería se ha realizado el cálculo en función al flujo económico con deuda y sin deuda (VANE) y al flujo financiero (VANF), asimismo para el cálculo se hace uso de la siguiente fórmula:

VPN $=\mathrm{I}+\sum_{\mathrm{i}=1}^{\mathrm{n}} \frac{\mathrm{FC}_{\mathrm{i}}}{(1+\mathrm{d})^{\mathrm{i}}}$ y se toman los flujos obtenidos en la Tabla 76 y se obtienen los resultados mostrados en la Tabla 77.

Tabla 76

Flujos de Caja Proyectados

\begin{tabular}{lcccccc}
\hline & Año 0 & Año 1 & \multicolumn{1}{c}{ Año 2 } & Año 3 & \multicolumn{1}{c}{ Año 4 } & Año 5 \\
\hline Flujo Económico & $-163,279$ & $-121,167$ & 40,520 & 186,526 & 232,199 & 434,142 \\
Servicio de Deuda & 67,828 & $-20,026$ & $-20,707$ & $-21,606$ & $-22,793$ & $-24,360$ \\
\hline Flujo Financiero & $\mathbf{- 9 5 , 4 5 1}$ & $\mathbf{- 1 4 1 , 1 9 2}$ & $\mathbf{1 9 , 8 1 3}$ & $\mathbf{1 6 4 , 9 2 0}$ & $\mathbf{2 0 9 , 4 0 6}$ & $\mathbf{4 0 9 , 7 8 1}$ \\
\hline
\end{tabular}

Tabla 77

Resultados del Cálculo del VAN

\begin{tabular}{ccc}
\hline $\begin{array}{c}\text { VANE } \\
\text { (s/deuda) }\end{array}$ & $\begin{array}{c}\text { VANE } \\
\text { (c/deuda) }\end{array}$ & VANF \\
\hline 172,066 & 131,150 & 140,899 \\
\hline
\end{tabular}

Como se puede apreciar, en todos los casos se obtiene un VAN mayor a Cero, por lo que se concluye que el proyecto es rentable y puede implementarse. 


\subsubsection{ROE Y ROA}

Estos indicadores ayudan a medir la gestión de la administración de la guardería, para ello se va a analizar como esta genera utilidades a partir de la inversión de los accionistas y el total de activos del que dispone el proyecto. La data para el cálculo de estos resultados ha sido hallada de los Estados financieros proyectados.

El ROE es un indicador de la rentabilidad obtenida sobre la inversión de los accionistas, para el cálculo del ROE se va a tomar en cuenta la siguiente formula $\frac{\text { UTLLIDAD }}{\text { PATRIMONIO - UT. EJERC. }}$.

El ROA es un indicador de la rentabilidad obtenida sobre el total de activos del que dispone la guardería, para el cálculo del ROA se va a tomar en cuenta la siguiente formula. UTILIDAD ACT. TOTAL .

Luego de realizar dicho calculo en los primeros 5 años, se han obtenido los resultados que se muestran en la Tabla 78.

Tabla 78

Resultados del Cálculo del ROE y ROA

\begin{tabular}{crrrrr}
\hline Indicador & \multicolumn{1}{c}{ Año 1 } & \multicolumn{1}{c}{ Año 2 } & \multicolumn{1}{c}{ Año 3 } & \multicolumn{1}{c}{ Año 4 } & \multicolumn{1}{c}{ Año 5 } \\
\hline ROE & -1.16 & 0.35 & 1.73 & 2.21 & 2.63 \\
ROA & -2.47 & 0.49 & 0.74 & 0.51 & 0.39 \\
\hline
\end{tabular}

Como se puede apreciar el primer año existe una perdida financiera; sin embargo, a partir del segundo año el indicador nos genera resultados positivos los cuales confirman que el proyecto es rentable y puede ponerse en marcha.

\subsection{4 Índice Beneficio - Costo}

Es un indicador que expresa la relación entre el total de los beneficios actualizados y costos actualizados, más la inversión inicial. Éste no expresa el resultado total de los beneficios obtenidos por el proyecto, por este motivo se tiene que recurrir al cálculo del VAN. Para efectos del análisis del proyecto de implementación de una guardería se ha realizado el cálculo en función al flujo económico con deuda y sin deuda (VANE) y al flujo

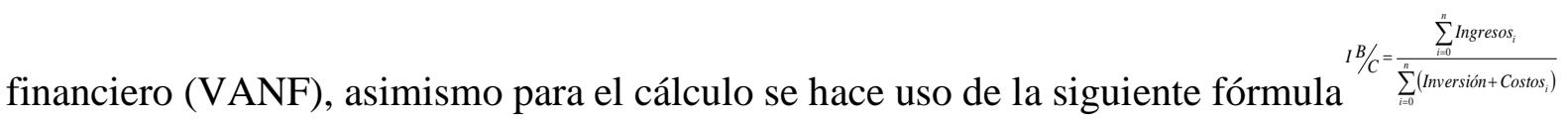
, el proyecto puede ser aceptado cuando el I B/C es mayor o igual a 1; para el cálculo se toman los flujos de la Tabla 79 y se obtienen los resultados mostrados en la Tabla 80. 
Tabla 79

Flujos de Caja Proyectados

\begin{tabular}{lrrrrrr}
\hline & Año 0 & \multicolumn{1}{c}{ Año 1 } & \multicolumn{1}{c}{ Año 2 } & \multicolumn{1}{c}{ Año 3 } & \multicolumn{1}{c}{ Año 4 } & Añ் 5 \\
\hline Flujo Económico & $-163,279$ & $-121,167$ & 40,520 & 186,526 & 232,199 & 434,142 \\
Servicio de Deuda & 67,828 & $-20,026$ & $-20,707$ & $-21,606$ & $-22,793$ & $-24,360$ \\
\hline Flujo Financiero & $\mathbf{- 9 5 , 4 5 1}$ & $\mathbf{- 1 4 1 , 1 9 2}$ & $\mathbf{1 9 , 8 1 3}$ & $\mathbf{1 6 4 , 9 2 0}$ & $\mathbf{2 0 9 , 4 0 6}$ & $\mathbf{4 0 9 , 7 8 1}$ \\
\hline
\end{tabular}

Tabla 80

Resultados del Cálculo del Índice B/C

\begin{tabular}{ccc}
\hline $\begin{array}{c}\mathbf{B} / \mathbf{C ~ E} \\
\text { (s/deuda) }\end{array}$ & $\begin{array}{c}\text { B/C E } \\
\text { (c/deuda) }\end{array}$ & B/C F \\
\hline 2.05 & 1.80 & 2.48 \\
\hline
\end{tabular}

Como se puede apreciar en todos los casos se obtiene un I B/C mayor a 1, por lo que se concluye que el proyecto es rentable y puede implementarse.

\subsection{Análisis de Riesgo}

Consiste en evaluar la consistencia del proyecto cuando algunas de las variables que se han proyectado, varían.

\subsubsection{Análisis de sensibilidad.}

Se ha realizado un análisis de sensibilidad a 3 variables:

Variación en el precio de los años 1 y 2, es preciso destacar que el precio propuesto para dichos años asciende a S/ 825 mensuales; se puede observar que una reducción en S/ 125 $(15 \%)$ del precio hace que el proyecto ya no sea rentable para el accionista si se evalúa la TIR, el VAN y el I B/C, el proyecto resiste una reducción de S/ 85 (10\%) en el precio después del cual aún sigue siendo rentable y atractivo para el inversionista. En la Tabla 81 se presenta el resumen del análisis realizado a esta variable.

Tabla 81

Sensibilidad al Precio de los Años 1 y 2

\begin{tabular}{rrrrrrrrrr}
\hline \multirow{2}{*}{ PRECIO } & $\begin{array}{c}\text { VANE } \\
\text { (s/deuda })\end{array}$ & \multicolumn{1}{c}{ TIRE } & \multicolumn{1}{c}{ B/C $/$ deuda $)$} & \multicolumn{1}{c}{$\begin{array}{c}\text { VANE } \\
\text { (s/deuda })\end{array}$} & $\begin{array}{c}\text { TIRE } \\
\text { (c/deuda })\end{array}$ & $\begin{array}{c}\text { B/C E } \\
\text { (c/deuda })\end{array}$ & $\begin{array}{c}\text { VANF } \\
\text { (c/deuda) }\end{array}$ & TIRF & B/C F \\
\hline 700 & $-12,372$ & $18.27 \%$ & 0.96 & $-41,661$ & $18.27 \%$ & 0.85 & $-29,149$ & $18.33 \%$ & 0.87 \\
720 & 17,824 & $20.10 \%$ & 1.07 & $-12,615$ & $20.10 \%$ & 0.95 & -86 & $20.36 \%$ & 1.00 \\
765 & 84,769 & $25.38 \%$ & 1.38 & 51,002 & $25.38 \%$ & 1.23 & 63,275 & $26.45 \%$ & 1.41 \\
$\mathbf{8 2 5}$ & $\mathbf{1 7 2 , 0 6 6}$ & $\mathbf{3 6 . 7 3 \%}$ & $\mathbf{2 . 0 5}$ & $\mathbf{1 3 1 , 1 5 0}$ & $\mathbf{3 6 . 7 3 \%}$ & $\mathbf{1 . 8 0}$ & $\mathbf{1 4 0 , 8 9 9}$ & $\mathbf{4 0 . 9 4 \%}$ & $\mathbf{2 . 4 8}$ \\
850 & 207,837 & $44.21 \%$ & 2.49 & 162,255 & $44.21 \%$ & 2.17 & 168,290 & $51.84 \%$ & 3.36 \\
875 & 243,280 & $54.73 \%$ & 3.12 & 191,194 & $54.73 \%$ & 2.67 & 187,641 & $69.91 \%$ & 5.00 \\
900 & 278,413 & $70.67 \%$ & 4.08 & 216,653 & $70.67 \%$ & 3.39 & 179,581 & $107.86 \%$ & 8.92 \\
\hline
\end{tabular}


Variación en el precio del año 3 al 5, es preciso destacar que el precio propuesto para dichos años asciende a S/ 900 mensuales; se puede observar que una reducción de hasta S/ 180 en el precio (20\%), el proyecto aún sigue siendo rentable y atractivo para el inversionista, por lo que se concluye que el proyecto no es muy sensible a la variación de precios a partir del año 3. En la Tabla 82 se presenta el resumen del análisis realizado a esta variable.

Tabla 82

Sensibilidad al Precio del Año 3 al 5

\begin{tabular}{|c|c|c|c|c|c|c|c|c|c|}
\hline PRECIO & $\begin{array}{c}\text { VANE } \\
\text { (s/deuda) }\end{array}$ & $\begin{array}{c}\text { TIRE } \\
\text { (s/deuda) }\end{array}$ & $\begin{array}{c}\text { B/CE } \\
\text { (s/deuda) }\end{array}$ & $\begin{array}{c}\text { VANE } \\
\text { (c/deuda) }\end{array}$ & $\begin{array}{c}\text { TIRE } \\
\text { (c/deuda) }\end{array}$ & $\begin{array}{c}\text { B/CE } \\
\text { (c/deuda) }\end{array}$ & VANF & TIRF & $\mathrm{B} / \mathrm{CF}$ \\
\hline 720 & 39,093 & $23.67 \%$ & 1.24 & 11,918 & $23.67 \%$ & 1.07 & 20,430 & $25.09 \%$ & 1.21 \\
\hline 765 & 72,337 & $27.30 \%$ & 1.44 & 41,727 & $27.30 \%$ & 1.26 & 50,548 & $29.53 \%$ & 1.53 \\
\hline 855 & 138,824 & $33.79 \%$ & 1.85 & 101,342 & $33.79 \%$ & 1.62 & 110,782 & $37.40 \%$ & 2.16 \\
\hline 900 & 172,066 & $36.73 \%$ & 2.05 & 131,150 & $36.73 \%$ & 1.80 & 140,899 & $40.94 \%$ & 2.48 \\
\hline 950 & 209,002 & $39.81 \%$ & 2.28 & 164,268 & $39.81 \%$ & 2.01 & 174,361 & $44.62 \%$ & 2.83 \\
\hline 975 & 227,470 & $41.27 \%$ & 2.39 & 180,828 & $41.27 \%$ & 2.11 & 191,092 & $46.37 \%$ & 3.00 \\
\hline
\end{tabular}

Variación en costo de alquiler, es preciso destacar que el precio presupuestado para dicho concepto asciende a S/ 5,000 mensuales; se puede observar que con un incremento hasta de S/ 2,000 en el costo de alquiler, el proyecto aún sigue siendo rentable y atractivo para el inversionista, por lo que se concluye que el proyecto no es muy sensible a la variación de precios de alquiler. En la Tabla 83 se presenta el resumen del análisis realizado a esta variable.

Tabla 83

Sensibilidad al Precio de Alquiler

\begin{tabular}{rrrrrrrrrr}
\hline \multirow{2}{*}{ ALQUILER } & $\begin{array}{c}\text { VANE } \\
\text { (s/deuda) }\end{array}$ & $\begin{array}{c}\text { TIRE } \\
\text { (s/deuda) }\end{array}$ & $\begin{array}{c}\text { B/C E } \\
\text { (s/deuda) }\end{array}$ & $\begin{array}{c}\text { VANE } \\
\text { (c/deuda) }\end{array}$ & $\begin{array}{c}\text { TIRE } \\
\text { (c/deuda) }\end{array}$ & $\begin{array}{c}\text { B/C E } \\
\text { (c/deuda) }\end{array}$ & VANF & TIRF & B/C F \\
\hline 4,000 & 226,351 & $47.47 \%$ & 2.70 & 178,138 & $47.47 \%$ & 2.34 & 182,456 & $56.73 \%$ & 3.81 \\
4,500 & 199,179 & $41.56 \%$ & 2.35 & 154,964 & $41.56 \%$ & 2.05 & 162,773 & $47.73 \%$ & 3.03 \\
$\mathbf{5 , 0 0 0}$ & $\mathbf{1 7 2 , 0 6 6}$ & $\mathbf{3 6 . 7 3 \%}$ & $\mathbf{2 . 0 5}$ & $\mathbf{1 3 1 , 1 5 0}$ & $\mathbf{3 6 . 7 3 \%}$ & $\mathbf{1 . 8 0}$ & $\mathbf{1 4 0 , 8 9 9}$ & $\mathbf{4 0 . 9 4 \%}$ & $\mathbf{2 . 4 8}$ \\
5,500 & 145,012 & $32.71 \%$ & 1.81 & 106,863 & $32.71 \%$ & 1.60 & 117,716 & $35.61 \%$ & 2.06 \\
6,000 & 118,015 & $29.31 \%$ & 1.61 & 82,223 & $29.31 \%$ & 1.42 & 93,697 & $31.30 \%$ & 1.74 \\
7,000 & 64,193 & $23.87 \%$ & 1.29 & 32,202 & $23.87 \%$ & 1.14 & 44,159 & $24.72 \%$ & 1.28 \\
\hline
\end{tabular}

\subsubsection{Análisis de escenarios.}

Se realiza un análisis de una variable externa, para ello se ha tomado el crecimiento del PBI, donde se han supuesto 3 escenarios: optimista, normal y pesimista; para el escenario optimista se va a suponer que el PBI va a tener un crecimiento sostenido de $8 \%$ anual 
durante los próximos 5 años, para el escenario normal se va trabajar con los flujos que se han obtenido de las proyecciones realizadas para este proyecto y para el escenario pesimista se va suponer que el PBI va a tener una caída sostenida de 5\% anual durante los próximos 5 años. A continuación, se muestra la Tabla 84 donde se puede apreciar los escenarios del flujo económico.

Tabla 84

Escenarios del Flujo Económico

\begin{tabular}{ccccccc}
\hline Escenario & Año 0 & Año 1 & Año 2 & Año 3 & Año 4 & Año 5 \\
\hline Flujo Económico Optimista & $-163,278.52$ & $-111,473.19$ & $43,761.09$ & $201,447.80$ & $250,774.71$ & $468,872.86$ \\
Flujo Económico Normal & $-163,278.52$ & $-121,166.51$ & $40,519.53$ & $186,525.74$ & $232,198.81$ & $434,141.54$ \\
Flujo Económico Pesimista & $-163,278.52$ & $-127,224.84$ & $38,493.55$ & $177,199.46$ & $220,588.87$ & $412,434.46$ \\
\hline
\end{tabular}

Es seguida se procede a calcular el VAN y la TIR de estos flujos tal y como se muestra en la Tabla 85 donde también se observa la ponderación de los escenarios.

Tabla 85

Escenarios del VAN y TIR Económico (con Deuda)

\begin{tabular}{cccc}
\hline Escenario & Probabilidad & VAN & TIR \\
\hline Optimista & $30 \%$ & $170,576.97$ & $40.9 \%$ \\
Normal & $60 \%$ & $131,149.66$ & $36.7 \%$ \\
Pesimista & $10 \%$ & $106,507.60$ & $34.1 \%$ \\
\hline
\end{tabular}

Posteriormente se halla el VAN y la TIR promedio, la varianza y la desviación estándar tal y como se muestra la Tabla 86.

Tabla 86

VAN y TIR Promedio, la Varianza y la Desviación Estándar

\begin{tabular}{lr}
\hline VAN promedio & $140,513.65$ \\
Varianza & $439,392,669.69$ \\
Desviación & $20,961.70$ \\
TIR promedio & $37.71 \%$ \\
Varianza & $0.05 \%$ \\
Desviación & $2.20 \%$ \\
\hline
\end{tabular}

De este cálculo se puede concluir que:

- Existe un $67.5 \%$ de probabilidad de que el VAN del proyecto se encuentre entre: $119,551.95$ y $161,475.34$.

- Existe un $95 \%$ de probabilidad de que el VAN del proyecto se encuentre entre: $98,590.26$ y $182,437.04$ 
- Existe $67.5 \%$ de probabilidad que la TIR se encuentre entre: $35.51 \%$ y $39.91 \%$

- Existe el 95\% de probabilidad de que la TIR se encuentre entre: $33.31 \%$ y $42.11 \%$ Por lo tanto, se puede decir que existe casi la certeza de que el proyecto es viable. 


\section{Capitulo IX: Conclusiones y Recomendaciones}

\section{Conclusiones}

- Los temores más comunes de los padres es la inseguridad y desconfianza que representan las guarderías actualmente; por ello, el acceso vía on line a la guardería mediante las cámaras IP representa una forma de aliviar dichos temores.

- Inicialmente los padres les dan más valor a los factores como la ubicación, horarios, seguridad e infraestructura; por ello, es necesario desarrollar estrategias de comunicación para poner en valor los beneficios de método Doman y hacer de este el factor diferenciador de la guardería.

- Los padres utilizarían el servicio 5 veces a la semana, hasta 11 meses al año. Por lo expuesto se concluye que no hay estacionalidad en el negocio.

- Al ser una empresa nueva y no tener un historial crediticio, las tasas de financiamiento son altas.

- El VAN es mayor a 1 y la TIR del proyecto es mayor al COK, el proyecto según estos indicadores financieros es rentable para los inversionistas.

- El proyecto es sensible a la variación de precios durante el año 1 y 2.

- El proyecto no es muy sensible a la variación del precio del año 3 en adelante.

- El proyecto no es muy sensible a un incremento en el costo de alquiler.

- En el análisis realizado, en un escenario pesimista el proyecto aún continúa siendo rentable.

\section{Recomendaciones}

- Se recomienda la implementación del proyecto ya que, según los estudios, análisis y proyecciones realizadas en este proyecto, se evidencia que es rentable para el accionista y contribuye con el desarrollo profesional y económico de las familias modernas.

- Mantener y/o mejorar los estándares de calidad del servicio proporcionado a lo largo del tiempo.

- Aplicar el plan de marketing desarrollado en este proyecto.

- Patentar ante Indecopi el nombre y el logo del proyecto. 


\section{Referencias}

Andina Agencia Peruana de Noticias (2014). “Unesco resalta avances en educación logrados por Perú” Recuperado de http://www.andina.com.pe/agencia/noticia-unesco-resaltaavances-educacion-logrados-peru-529897.aspx

Andina, Agencia Peruana de Noticias (2016). Primer tramo de incremento salarial para docentes será a inicios del 2017. Recuperado de https://andina.pe/agencia/noticiaprimer-tramo-incremento-salarial-para-docentes-sera-a-inicios-del-2017-626829.aspx

Andina Agencia Peruana de Noticias (2018). Gobierno debe cerrar brechas sociales y reconciliar a población con autoridades. Recuperado de http://andina.pe/agencia/noticia-gobierno-debe-cerrar-brechas-sociales-y-reconciliara-poblacion-autoridades-704890.aspx

Andina, Agencia Peruana de Noticias (2015). Banco Mundial: Perú es una de las economías de mejor desempeño en América Latina. Recuperado de http://andina.pe/agencia/noticia.aspx $? \mathrm{id}=577710$

APEIM (2017). Niveles Socioeconómicos 2017. Recuperado de http://www.apeim.com.pe/wp-content/themes/apeim/docs/nse/APEIM-NSE-2017.pdf

APEIM. (2017). Niveles Socioeconómicos 2017. Recuperado de https://www.studocu.com/en/document/universidad-de-lima/economia/lecturenotes/apeim-nse-2017-nse/1324223/view

Banco Central de Reserva del Perú (2017, diciembre). Reporte de Inflación, Panorama actual y proyecciones macroeconómicas 2017-2019. Recuperado de http://www.bcrp.gob.pe/docs/Publicaciones/ReporteInflacion/2017/diciembre/reporte-de-inflacion-diciembre-2017.pdf

Banco Mundial en Perú (2017). Perú Panorama general. Recuperado de http://www.bancomundial.org/es/country/peru/overview

Camacho, J., (2008)

Pirámide de la Motivación de Abraham Maslow. "Servicio y Mercadeo de Servicios". Recuperado de http://biblioteca.utec.edu.sv/siab/virtual/elibros_internet/55788.pdf

Cornachione, M. L. (2006). Psicología del Desarrollo, Adultez Aspectos Biológicos, Psicológicos y Sociales. Recuperado de https://books.google.com.pe/books?id=3BznIWWshLEC\&printsec=frontcover\&hl=es $\# \mathrm{v}=$ onepage $\& \mathrm{q} \& \mathrm{f}=$ false 
CPI - Compañía Peruana de Estudios de Mercados y Opinión Pública SAC. (2017). Perú: Población 2017. Recuperado de http://www.cpi.pe/images/upload/paginaweb/archivo/26/mr_poblacion_peru_2017.pd

Correo, Diario, (2015, Mayo). Ciudad, Existe un déficit de guarderías en la capital.

Recuperado de https://diariocorreo.pe/ciudad/existe-un-deficit-de-guarderias-en-lacapital-589661/

D`Alessio, F. (2012). Administración de las Operaciones Productivas, Un enfoque en procesos para la gerencia. México: PEARSON

El comercio, Diario (2017). Entre los últimos de la región: ¿Cuánto invierte el Perú en el sector educación?. Recuperado de https://elcomercio.pe/peru/peru-paises-invierteeducacion-region-noticia-454487

El comercio, Diario (2016). Perú sale del último lugar en la prueba PISA 2015. Recuperado de https://elcomercio.pe/peru/peru-sale-lugar-prueba-pisa-2015-152124

El comercio, Diario (2016). Colegios privados triplican en número a los públicos.

Recuperado de https://elcomercio.pe/lima/colegios-privados-triplican-numeropublicos-265818

El comercio, Diario (2017). En Lima y Callao solo hay 624 guarderías autorizadas.

Recuperado de https://elcomercio.pe/lima/sucesos/lima-y-callao-hay-624-guarderiasautorizadas-428352

El comercio, Diario (2017). Cunas y guarderías: ¿qué las diferencia y cómo reconocer las autorizadas?. Recuperado de https://elcomercio.pe/lima/sucesos/cunas-guarderiasdiferencia-reconocer-autorizadas-42824

El Comercio, Diario (2017, Junio). Sucesos, zona ejecutiva. Recuperado de https://elcomercio.pe/lima/sucesos/lima-y-callao-hay-624-guarderias-autorizadas428352

El Peruano, Diario Oficial (2018, febrero). Resolución Ministerial No. 070-2018-MINEDU. Recuperado de http://busquedas.elperuano.pe/normaslegales/modifican-el-numeral7211-de-las-orientaciones-para-el-d-resolucion-ministerial-no-070-2018-minedu1619228-1/

El Mundo (2011). Greenpeace detecta altos niveles de metales pesados en un $30 \%$ de los juguetes en China. Recuperado de http://www.elmundo.es/elmundo/2011/12/08/ciencia/1323330781.html 
Elisa Guerra (2013) Método Filadelfia. Recuperado de https://www.elisaguerra.info/metodofiladelfia.html

Fondo de Población de las Naciones Unidas - Perú / UNFPA, (2015). Adultos Mayores en el Perú. Recuperado de http://www.unfpa.org.pe/publicaciones/publicacionesperu/UNFPA-Ficha-AdultosMayores-Peru.pdf

Fernández R. (2008).

Segmentación de Mercados. 3ra. edición (p. 3)

Fred, D. (2008). Conceptos de Administración estratégica. $11^{\mathrm{a}}$ ed. Mexico: PEARSON Educación, pp. 168-247

GfK Conecta SAC. (2016) Uso de Internet. Recuperado de http://www.gfk.com/fileadmin/user_upload/dyna_content/PE/GfK_OP_Octubre_2015 _-_Uso_de_Internet_2.pdf

Kotler, P. and Keller, K. (2006).

Dirección de Marketing. 12a ed. España: PEARSON Prentice Hall, pp. 145-741

Instituto Nacional de Estadística e Informática - INEI (2018). Aumentan Hogares que Tienen Servicio de Internet de Octubre a Diciembre De 2017 Recuperado de https://www.inei.gob.pe/media/MenuRecursivo/noticias/nota-de-prensa-n-050-2018inei.pdf

Instituto Nacional de Estadística e Informática (2018). Comportamiento de la Economía Peruana en el cuarto trimestre de 2017. Recuperado de https://www.inei.gob.pe/media/MenuRecursivo/boletines/01-informe-tecnicon01_producto-bruto-interno-trimestral_-ivtrim2017.pdf

Instituto Nacional de Estadística e Informática - INEI (2018). Evolución de La Pobreza Monetaria 2007-2017 Informe técnico Recuperado de https://www.inei.gob.pe/media/cifras_de_pobreza/informe_tecnico_pobreza_monetari a_2007-2017.pdf

Instituto Nacional de Estadística e Informática - INEI, (2018, Enero). Notas de prensa. Recuperado de https://www.inei.gob.pe/prensa/noticias/durante-el-ano-2017-elempleo-crecio-15-en-lima-metropolitana-10510/

Instituto Nacional de Estadística e Informática - INEI, (2017, Noviembre). Notas de prensa. Recuperado de https://www.inei.gob.pe/prensa/noticias/en-el-trimestre-agosto- 
setiembre-octubre-de-2017-se-crearon-88-mil-300-nuevos-empleos-en-limametropolitana-10073/

Instituto Nacional de Estadística e Informática - INEI, (2017, Agosto). Evolución de los Indicadores de Empleo e Ingresos por Departamento, 2007- 2016. Recuperado de http://www.inei.gob.pe/media/MenuRecursivo/publicaciones_digitales/Est/Lib1441/li bro.pdf

Laura, G. (2013). Diseño de un sistema de video-monitoreo IP para la sala de manufactura del centro de tecnologías avanzadas de manufactura (cetam) (Tesis de grado). Recuperado de http://tesis.pucp.edu.pe/repositorio/bitstream/handle/123456789/5078/LAURA_GIGI_SI STEMA_VIDEO_MONITOREO_MANUFACTURA_TECNOLOGIAS_AVANZADAS_M ANUFACTURA.pdf? sequence $=1$

Martínez Castillo, R. (2008). Educación y huella ecológica. Revista Electrónica "Actualidades Investigativas en Educación", 8 (1), 1-28. Recuperado de http://www.redalyc.org/pdf/447/44780103.pdf

Ministerio de Educación - MINEDU (2003). Ley General de Educación Ley Nro. 28044. Recuperado de http://www.minedu.gob.pe/p/ley_general_de_educacion_28044.pdf Ministerio de Educación - MINEDU (n.d). Reglamento de la Ley 28044 - Ley General de Educación. Recuperado de http://www.ccec.edu.pe/files/pdfs/Reglamento-Ley-N28044.pdf

Ministerio de Educación - MINEDU (n.d). Directiva No 073-2006-DINEBR-DEI. Recuperado en http://www.minedu.gob.pe/normatividad/directivas/dir073-2006DINEBR-DEI.pdf

Ministerio de Economía y Finanzas (2016). Notas de Prensa, el MEF publica el Marco Macroeconómico Multianual 2017 - 2019, aprobado en sesión de Consejo de Ministros del 27 de abril. Recuperado de https://www.mef.gob.pe/es/comunicados-ynotas-de-prensa/100-notas-de-prensa-y-comunicados/4427-ministerio-de-economia-yfinanzas-publica-el-marco-macroeconomico-multianual-2017--2019-aprobado-ensesion-de-consejo-de-ministros-del-27-de-abril

Ministerio de Trabajo y Promoción del Empleo (2015). Distribución de la PEA Ocupada, según sexo y nivel educativo, 2001 - 2014. Recuperado de http://www.trabajo.gob.pe/archivos/file/estadisticas/peel/estadisticas/oferta_laboral/se xo/2014/peru_total_sexo_007_2001-2014.pdf 
Ministerio de Educación del Perú - MINEDU (2013). ESTUDIO DE EDUCACIÓN INICIAL: Un acercamiento a los aprendizajes de las niñas y los niños de cinco años de edad. Recuperado de http://umc.minedu.gob.pe/wp-content/uploads/2016/08/archivofinal.pdf

Montemayor, J. (2012). Métodos de pronósticos para negocios. Recuperado de https://www.editorialdigitaltec.com/materialadicional/P196_Montemayor_Metodosde pronosticosparanegocios.cap1.pdf

McDaniel C. and Gates, R. (2011). Investigación de Mercados. $8^{\mathrm{a}}$ ed. México: CENGAGE Learning, pp. 416-438

Municipalidad de San Isidro, 2012, Plan Urbano Distrital de San Isidro 2012-2022, Recuperado de: http://www.msi.gob.pe/portal/repositorio/desarrollourbano/PLAN_URBANO_MSI\%202012-2022_Version_Final.pdf

Ministerio de Educación-Vice Ministerio de Gestión Institucional Oficina de Infraestructura Educativa (2011). Descripción de los espacios por características de desplazamiento nivel Inicial: Cuna y Jardín -Normas Técnicas para el Diseño de Locales de Educación Básica Regular: Nivel Inicial. Recuperado de http://www.minedu.gob.pe/files/107_201109011135.pdf

Organización de las Naciones Unidas para la Educación, la Ciencia y la Cultura - UNESCO (2011). La UNESCO y “Toda persona tiene derecho a la educación”. Recuperado de http://unesdoc.unesco.org/images/0021/002127/212715s.pdf

Organización Mundial de la Salud - OMS (2017). Intoxicación por plomo y salud.

Recuperado de http://www.who.int/mediacentre/factsheets/fs379/es/

Pérez Cepeda, María de los Ángeles, (2018)

Matriz del Perfil Competitivo (En línea)

Recuperado de https://www.zonaeconomica.com/matriz-del-perfil-competitivo

Programa de las Naciones Unidas para el Desarrollo - PNUD, (2015). Trabajo al Servicio del Desarrollo Humano 2015. Recuperado de http://hdr.undp.org/sites/default/files/hdr_2015_report_sp.pdf Programa Nacional CUNA MAS, (2016, Julio). Tag Archives: Programas Sociales.

Recuperado de http://www.cunamas.gob.pe/?tag=programas-sociales

Proyecto Optimist (2018). Fomento Educación Infantil. Recuperado de https://www.fomento.edu/publicaciones/proyecto-optimist 
SEMANAeconómica.com (2018). Economía Peruana PBI. Recuperado de http://semanaeconomica.com/article/economia/macroeconomia/261938-bancomundial-mantuvo-estimado-en-el-2018-pbi-del-peru-creceria-3-8-este-ano/

Unicef, (2016). Estado Mundial de la Infancia 2016. Una Oportunidad para cada niño.

Recuperado de https://www.unicef.org/spanish/publications/files/UNICEF_SOWC_2016_Spanish.pd f 


\section{Apéndice A}

\section{Ley General de Educación}

LEY GENERAL DE EDUCACIÓN

Ley Nro. 28044

TÍTULO III

LA ESTRUCTURA DEL SISTEMA EDUCATIVO

CAPÍTULO II

LA EDUCACIÓN BÁSICA

\section{Artículo 36 ${ }^{\circ}$ - Educación Básica Regular}

La Educación Básica Regular es la modalidad que abarca los niveles de Educación Inicial, Primaria y Secundaria. Está dirigida a los niños y adolescentes que pasan, oportunamente, por el proceso educativo de acuerdo con su evolución física, afectiva y cognitiva, desde el momento de su nacimiento.

La Educación Básica Regular comprende:

a) Nivel de Educación Inicial

La Educación Inicial constituye el primer nivel de la Educación Básica Regular, atiende a niños de 0 a 2 años en forma no escolarizada y de 3 a 5 años en forma escolarizada. El Estado asume, cuando lo requieran, también sus necesidades de salud y nutrición a través de una acción intersectorial. Se articula con el nivel de Educación Primaria asegurando coherencia pedagógica y curricular, pero conserva su especificidad y autonomía administrativa y de gestión.

Con participación de la familia y de la comunidad, la Educación Inicial cumple la finalidad de promover prácticas de crianza que contribuyan al desarrollo integral de los niños, tomando en cuenta su crecimiento socioafectivo y cognitivo, la expresión oral y artística y la sicomotricidad y el respeto de sus derechos.

\section{LA INSTITUCIÓN EDUCATIVA}

\section{Artículo $71^{\circ}$.- Tipos de gestión de las Instituciones Educativas}

Las Instituciones Educativas, por el tipo de gestión, son:

a) Públicas de gestión directa por autoridades educativas del Sector Educación o de otros sectores e instituciones del Estado.

b) Públicas de gestión privada, por convenio, con entidades sin fines de lucro que prestan servicios educativos gratuitos.

c) De gestión privada conforme al artículo $72^{\circ}$.

\section{Artículo $72^{\circ}$.- Las Instituciones Educativas Privadas}

Las Instituciones Educativas Privadas son personas jurídicas de derecho privado, creadas por iniciativa de personas naturales o jurídicas, autorizadas por las instancias descentralizadas del Sector Educación. El Estado en concordancia con la libertad de enseñanza y la promoción de la pluralidad de la oferta educativa, reconoce, valora y supervisa la educación privada.

En lo que les corresponda, son funciones de la Institución Educativa Privada las establecidas en el artículo $68^{\circ}$. Sin perjuicio de ello:

a) Se constituyen y definen su régimen legal de acuerdo a las normas vigentes.

b) Organizan y conducen su gestión administrativa y económico-financiera, estableciendo sus regímenes: económico, de pensiones y de personal docente y administrativo.

c) Participan en la medición de la calidad de la educación de acuerdo a los criterios establecidos por el Instituto de Evaluación, Acreditación y Certificación de la calidad educativa. 
d) Garantizan la participación de los padres de los alumnos a través de la Asociación de Padres de Familia, e individualmente, en el proceso educativo de sus hijos.

Las instituciones educativas privadas pueden contribuir a la educación pública con sus recursos, instalaciones y equipos, así como con el intercambio de experiencias de innovación.

EL FINANCIAMIENTO DE LA EDUCACIÓN PÚBLICA

Artículo $8^{\circ}$.- La regulación tributaria

Las donaciones con fines educativos gozan de exoneración y beneficios tributarios en la forma y dentro de los límites que fija la ley. Las instituciones educativas públicas y privadas gozan de inafectación de todo impuesto creado o por crearse, directo o indirecto que pudiera afectar bienes, servicios o actividades propias de la finalidad educativa y cultural, de acuerdo a lo establecido en la Constitución Política del Perú. En materia de aranceles de importación, la legislación específica establece un régimen especial para determinados bienes destinados a la educación. 


\title{
Apéndice B
}

\author{
Reglamento de la Ley $\mathbf{N}^{\circ} 28044$ - Ley General de Educación \\ REGLAMENTO DE LA LEY No 28044 - LEY GENERAL DE EDUCACIÓN \\ CAPÍTULO III \\ SUBCAPÍTULO I
}

DE LA EDUCACIÓN INICIAL

\begin{abstract}
Artículo $5^{\circ}$.- De la organización del nivel de Educación inicial
El nivel de Educación Inicial está organizado en dos ciclos: el primero atiende a niños de 0 a 2 años y el segundo, a niños de 3 a 5 años. La atención a los niños se realiza en función de su edad y de sus características de desarrollo individual.
\end{abstract}

\section{Artículo 56 ${ }^{\circ}$. De las formas de atención}

La Educación Inicial responde a la diversidad familiar, social, cultural, lingüística y ecológica del país, ofreciendo servicios en forma escolarizada y no escolarizada a niños y niñas menores de 6 años. La definición de una u otra forma de atención se determina teniendo en cuenta las características y demandas de las familias y el contexto. Ambas formas de atención garantizan los logros de aprendizaje esperados para el nivel, considerando factores de calidad, equidad e inclusión educativa, así como la atención en su lengua materna y a la discapacidad.

\section{Artículo 58 ${ }^{\circ}$ - Instituciones educativas escolarizadas}

La forma escolarizada de Educación Inicial comprende las siguientes instituciones:

a) Cuna. En las cunas, los niños y niñas menores de 3 años reciben una atención integral durante un tiempo no menor de cinco días a la semana, en horarios de ocho horas diarias como máximo. La permanencia diaria del niño en la cuna estará sujeta a las necesidades de la familia. El servicio funciona todo el año. Esta atención se brinda a través de un espacio rigurosamente organizado que ofrece a los niños un máximo de estabilidad y seguridad para crecer y desplegar sus capacidades de organización del movimiento y desplazamiento, exploración, comunicación, autonomía e iniciativa. La atención es realizada por personal profesional y técnico (auxiliar) preparado y especializado para garantizar la calidad del servicio.

Para el funcionamiento de una cuna se necesitará garantizar las condiciones de infraestructura, mobiliario y material educativo. Asimismo, el personal a cargo de la atención de los niños deberá haber realizado la formación especializada para este tipo de servicio.

b) Jardín. Atiende a niños y niñas de 3 a 5 años de edad. Se adecúan a las características y necesidades específicas de los niños, las familias y el medio. Están bajo responsabilidad de profesionales de Educación Inicial con el apoyo de auxiliares de educación.

c) Cuna-Jardín. Atiende en un mismo local escolar a niños menores de 6 años de edad. 


\section{Apéndice C}

\section{DIRECTIVA No 073-2006-DINEBR-DEI \\ NORMAS SOBRE ORGANIZACIÓN Y FUNCIONAMIENTO DE LAS CUNAS DE EDUCACIÓN INICIAL}

\section{FINALIDAD}

Establecer las normas y procedimientos sobre la planificación, organización, ejecución y evaluación de las acciones técnico-pedagógicas y de gestión de Cunas de Educación Inicial.

\section{OBJETIVOS}

2.1 Promover una atención educativa de calidad para los menores de tres años que asisten a las instituciones educativas públicas o privadas denominadas Cunas, afianzando la eficacia del trabajo pedagógico con participación de la familia y la comunidad.

2.2 Actualizar y orientar el proceso de creación, organización, funcionamiento y evaluación técnicopedagógica y de gestión de las Cunas pública y privada.

2.3 Determinar criterios de gestión pedagógica, institucional y administrativa que permita a las Direcciones Regionales de Educación (DRE) y Unidades de Gestión Educativa Local (UGEL), regular, supervisar y asesorar las actividades y servicios que ofrecen las Cunas.

2.4 Mejorar la calidad del servicio que se brinda y el desempeño laborar del personal que labora en las Cunas.

III. BASE LEGAL

(...)

\section{ALCANCES}

$(\ldots)$

\section{DISPOSICIONES GENERALES}

5.1 La Cuna es una institución educativa escolarizada del primer ciclo del nivel de Educación Inicial de la Educación Básica Regular (EBR) que brinda un servicio de carácter integral para la primera infancia desde los 90 días hasta los 2 años 11 meses de edad, con la finalidad de ofrecerles la posibilidad de desarrollarse en forma adecuada y oportuna respetando su nivel de madurez.

(...)

5.4 Son objetivos de las Cunas:

a. Brindar atención temprana a la niñez menor de 3 años con el fin de contribuir a su desarrollo integral y satisfacer sus necesidades de cuidado y educación.

b. Sensibilizar a la comunidad, los gobiernos locales y otras instituciones públicas y privadas para que promuevan acciones a favor de los niños menores de 3 años.

(...)

\section{DISPOSICIONES ESPECÍFICAS}

6.1. Del enfoque técnico pedagógico (...)

6.2 De la creación y autorización de funcionamiento (...)

6.3 Del funcionamiento (...)

6.3.6 La capacidad de niños por cada Cuna, tanto de Gestión Pública como Privada, se establecerá al otorgar el permiso de funcionamiento. El número se deducirá teniendo en cuenta lo establecido en la presente Directiva.

6.3.7 Cada auxiliar de educación atenderá no menos de 8 niños, en función a las necesidades del servicio educativo, debiendo estar veinticinco (25) minutos antes del ingreso y permanecer hasta la salida correspondiente.

(...)

6.5 De la Infraestructura (local, equipamiento y mobiliario) 
6.5.1 La infraestructura se rige por las normas técnicas elaboradas por la Oficina de Infraestructura Educativa (OINFE) del Ministerio de Educación y teniendo en cuenta lo establecido en la presente Directiva.

6.5.2 En todos los casos, los ambientes mínimos son: aulas para cada grupo de edad, servicios higiénicos para niños independientes de los adultos, sala de higienización, cocina, sala multiusos y espacios amplios que permitan el juego al aire libre.

6.5.3 El local destinado para el funcionamiento de una Cuna es de uso exclusivo, con acceso independiente desde el exterior y con salidas de emergencia visibles, así como zonas de seguridad debidamente establecidas y señalizadas, teniendo en cuenta lo siguiente:

a. El área mínima necesaria por cada niño al interior de las aulas, salas o patio es de dos metros cuadrados $\left(2 \mathrm{~m}^{2}\right)$. b. Aulas ventiladas e iluminadas con luz natural. c. Los pisos de mayólica, madera pulida, parquet o vinílico y las paredes lisas, revocadas y pintadas. Los materiales utilizados no serán tóxicos ni dañinos a la salud.

6.5.4 Las aulas estarán ubicadas sólo en el primer piso. Los pisos restantes serán únicamente para uso administrativo. Por ningún motivo se autoriza la construcción y el funcionamiento del servicio de Cuna en otros pisos.

$(\ldots)$

6.6. De la Organización

6.6.1 Las Cunas públicas polidocentes, con más de un aula por grupo de edad, contarán con la siguiente organización: Dirección, Personal docente, auxiliar, de servicio (Limpieza-Cocina)

$(\ldots)$

6.6.5 Del personal docente:

6.6.6 Son requisitos para ser profesoras de Cuna:

a. Poseer título profesional pedagógico en la especialidad de Educación Inicial.

b. Disposición para el trabajo con menores de tres años, padres de familia y comunidad.

c. Estar inscrita en el Colegio de Profesores del Perú.

d. Gozar de salud física y mental, acreditada Certificado Médico, renovable cada 3 años.

e. No tener antecedentes penales.

6.6.7 De las auxiliares de educación que trabajan en las Cunas:

Las auxiliares de educación contribuyen a la creación de un ambiente favorable para el aprendizaje y el servicio que se brinda en las Cunas. (...)

6.6.8 Son requisitos para ser auxiliar de Cuna: (a). Poseer formación especializada en Educación Inicial o con estudios en atención integral al niño menor de 3 años. (b). Acreditar un año de experiencia en el trabajo con menores de tres años, como mínimo. (c). Gozar de salud física y mental, acreditado Certificado Médico, renovable cada 3 años. (d). No tener antecedentes penales.

6.6.9 Del personal de servicio

El personal de servicio brinda apoyo en la creación de un ambiente favorable para el aprendizaje en las Cunas. (...)

6.6.10 Son requisitos para trabajar como personal de servicio:

a. Tener secundaria completa, b. Gozar de salud física y mental, acreditado Certificado, Médico, renovable cada 3 años, c. No tener antecedentes penales.

$(\ldots)$

VII. DISPOSICIONES COMPLEMENTARIAS

7.1 Las Cunas están sujetas a lo dispuesto en el Decreto Supremo No 013-2004-ED, Reglamento de Educación Básica Regular, y demás normas específicas que dicte el Ministerio de Educación, en coherencia con la Ley $N^{\circ} 28044$, Ley General de Educación, modificada por las Leyes No. 28123 y $\mathrm{N}^{\circ}$ 28302. San Borja, 24 de Abril del 2006 


\title{
Apéndice D
}

\section{Guía de Pautas para Focus Group - Proyecto Guardería Infantil}

\author{
I. Saludo y Presentación \\ II. Calentamiento \\ III. Estudio en Profundidad \\ IV. Cierre
}

I. Saludo y Presentación. -

Buenas tardes / noches mi nombre es ...... en primer lugar les agradecemos que dediquen su tiempo a conversar con nosotros, asimismo queremos comentarles que somos egresados de la Escuela de Postgrado de la Universidad San Ignacio de Loyola y que estamos elaborando nuestro proyecto de Tesis para obtener el grado de MBA.

El día de hoy seré el moderador de este Focus group / entrevista, antes de iniciar le solicito cordialmente que apaguen sus celulares dado que para hacer más enriquecedora sus respuestas, es necesario poder enfocarnos en el tema. Me gustaría que cada uno se vaya presentando, yo tomaré nota de sus nombres en estos stickers y se los entregaré para que se los coloquen en el pecho para que se haga más fácil la identificación de cada uno.

II. Calentamiento. -

Desearíamos conversar con ustedes hoy porque queremos conocer mejor sus experiencias sobre el cuidado de sus hijos

Se hace de su conocimiento que su nombres e información personal serán estrictamente confidenciales. Tan solo utilizaremos la información que ustedes nos suministren para elaborar nuestro proyecto. Así que, por favor, no duden en expresar sus opiniones abiertamente.

Asimismo, esta entrevista será grabada para lo cual solicitamos su autorización. ¿Aceptan participar en el grupo focal / la entrevista y que esta sea grabada?

¡Estupendo! Antes de empezar les reitero que las ideas, experiencias y opiniones de todos son importantes y por lo tanto, desearíamos escucharlos a todos.

III. Estudio en Profundidad. -

Público Objetivo

1. 1 ¿Nos podrían indicar dónde viven?

2. ¿Qué edad tienen?

3. ¿Dónde trabajan o a que se dedican?

4. ¿En qué distrito trabaja?

5. ¿Cuántas personas viven en el hogar?

6. ¿Cuántos hijos tienen?

7. ¿Qué edades tienen?

8. ¿Cuenta con EPS o Seguro médico particular?

Acerca de los Hábitos de cuidado y tenencia del bebe.

1. ¿Quién decide sobre el cuidado de sus hijos?

2. ¿Quién se encarga del cuidado de sus hijos mientras usted trabaja?

3. ¿Qué características ustedes buscarían en la persona que cuida a sus hijos

4. ¿Qué tan complicado ha sido dejar a sus hijos con sus padres o familiares?

5. ¿Qué excusas les dieron sus padres o familiares para no poder cuidar a sus hijos?

6. ¿Qué tan complicado fue buscar a una niñera? Profundizar.

7. ¿Cuáles son los temores de dejar a sus hijos con la niñera?

8. ¿Estaría dispuesto a dejar a sus hijos en una Guardería? Profundizar. 
9. ¿Qué atributos buscaron en la Guardería? Profundizar.

10. ¿Cuántos días a la semana utilizaría el servicio de la Guardería?

11. ¿Qué medio de pago utilizaría para pagar por el servicio de una guardería?

Competencia

1. ¿Conoce alguna Guardería?

2. ¿Cuáles son las referencias que tiene sobre dichas guarderías?

3. Si hace uso de los servicios de una guardería ¿Cuáles serían los factores que los llevarían a cambiar de Guardería? Profundizar.

Metodología Doman

1. ¿Han escuchado de la Metodología Doman? Profundizar.

2. Explicar el método

3. ¿Qué les parece el método?

4. ¿Cuáles creen que sean las ventajas / desventajas del método? Profundizar.

5. ¿Qué otros métodos de enseñanza conocen? Profundizar.

Proyecto Guardería

Explicar el concepto del proyecto y la ubicación de la Guardería.

1. ¿Qué percepción tienen acerca del proyecto? Profundizar.

2. ¿Qué les parece la ubicación de la Guardería?

3. ¿Cuáles serían las ventajas / desventajas que encontrarían? Profundizar.

4. ¿Cómo les gustaría que sea la distribución de la Guardería?

5. ¿Qué características les gustaría que tenga la Guardería? Profundizar.

6. ¿Qué otros servicios adicionales para el cuidado y método de enseñanza le gustarían que su hijo reciba?

7. ¿Cuántos niños considera usted que deberían estar a cargo de cada profesor? Profundizar.

8. ¿Qué niveles de seguridad considera necesario para una Guardería?

9. ¿Qué nombre le pondrían a la Guardería? Dar opciones.

Precios

1. ¿Cuánto estaría dispuesto a pagar por el servicio de Guardería?

2. ¿Qué medios de pago le gustaría tener disponibles?

Comunicación

1. ¿Cuáles creen que serían los mejores medios de comunicación para mostrar la Guardería?

2. ¿Cuáles serían los medios de comunicación que les gustaría tener con la Guardería? Intención

Después de haber escuchado el proyecto de Guardería:

1. ¿Tendría la intención de confiarnos la educación de su hijo? ¿Por qué?

2. ¿Recomendaría la Guardería a sus amistades?

III. Cierre. -

Gracias. Sus respuestas y comentarios han sido muy útiles e informativas. Les agradecemos enormemente la información que nos han suministrado. ¿Desean hacernos alguna pregunta o sugerencia?

Muchas Gracias. 


\section{Apéndice $\mathbf{E}$}

\section{Guía de Pautas para entrevista en profundidad a experto-Especialista Método Doman}

Buenas tardes/ noches estimado señor (a) , queremos agradecerle el tiempo brindado para poder realizar esta entrevista, asimismo comentarle que somos egresados de la Escuela de Postgrado de la Universidad San Ignacio de Loyola y que estamos elaborando nuestro proyecto de Tesis para obtener el grado de MBA, y nos gustaría conocer mejor su experiencia como experto en el tema de

Esta entrevista será grabada, esperamos no tenga inconveniente ya que su información es muy importante y valiosa para realizar nuestro proyecto.

1. Nos puede contar su experiencia profesional

2. Cuáles son sus expectativas en los próximos 5 años?

3. Qué opinión tiene acerca de la Educación Inicial, específicamente en las edades de 3 a 36 meses en nuestro País?

4. En su opinión, que metodologías son las más empleadas en los nidos y/o guarderías de Lima?

- Cuál considera la mejor? Porque V/D

- Cual ya se encuentra desfasada? Porque V/D

- Cuál es la que se aplica con mayor demanda?

- Cuál es la que requiere mayor inversión?

5. De las metodologías que usted nos indica cual considera ideal para los Niños menores de 3 años?

6. Que nos puede contar acerca de la metodología Glenn Doman?, es importante su aplicación a niños menores de 3 años? Porque

7. Qué clase de educación/incentivo necesita un niño/niña de 3 a 36 meses?, es necesario segmentarlo por edades? Porque..

- 3 a 12 meses

- 12 a 24 meses

- 24 a 36 meses?

8. Que recomendaría a los padres que trabajan y deben dejar el cuidado de sus hijos a terceros?

9. Qué cualidades debe tener la persona que los cuidaría, si desean utilizar los servicios de una nana?

10. Qué opina sobre la capacitación a estas nanas y también a las madres sobre la metodología Doman.

11. Que servicios debe tener la guardería que aplica la Metodología Glenn Doman (características especiales?: espacio, infraestructura, materiales, diseños, si los padres deciden utilizar los servicios de esta para el cuidado de sus hijos?

12. Que tan factible es la implementación de este método en términos de tiempo y costos.

13. Algo que desee agregar para enriquecer nuestro conocimiento 


\section{Apéndice F}

\section{Guía de Pautas para entrevista en profundidad a expertos - Dueño/Director de una Guardería}

Buenas tardes/ noches estimado señor (a) , queremos agradecerle el tiempo brindado para poder realizar esta entrevista, asimismo comentarle que somos egresados de la Escuela de Postgrado de la Universidad San Ignacio de Loyola y que estamos elaborando nuestro proyecto de Tesis para obtener el grado de MBA, y nos gustaría conocer mejor su experiencia como experto en el tema de

Esta entrevista será grabada, esperamos no tenga inconveniente ya que su información es muy importante y valiosa para realizar nuestro proyecto.

1. Nos puede contar su experiencia profesional

2. ¿Cuáles son sus expectativas en los próximos 5 años?

3. ¿Qué opinión tiene acerca de la Educación Inicial, específicamente en las edades de 3 a 36 meses en nuestro País?

4. ¿En su opinión, que metodologías son las más empleadas en los nidos y/o guarderías de Lima?

- ¿Cuál considera la mejor? Porque V/D

- ¿Cual ya se encuentra desfasada? Porque V/D

- ¿Cuál es la que se aplica con mayor demanda?

- ¿Cuál es la que requiere mayor inversión?

5. ¿De las metodologías que usted nos indica cual considera ideal para los Niños menores de 3 años?

6. ¿Conoce acerca de la metodología Glenn Doman? cual es su opinión.

7. ¿Que recomendaría a los padres que trabajan y deben dejar el cuidado de sus hijos a terceros?

8. ¿Cuál es su opinión sobre las guarderías en la actualidad y como lo ve a futuro?

9. Como distribuye a los niños para su cuidado?, esta segmentado por edades u otro factor?

10. Cuantos niños están a cargo de un profesor y auxiliar?

11. Que servicios ustedes ofrecen en su guardería? Y que otros servicios desearía o proyecta implementar a futuro?

12. Cuáles son los frenos o temores de los padres con los que se ha tenido que enfrentar en el día a día.

13. Que situaciones considera usted como problemas más comunes en el cuidado de los niños y como se manejan estas situaciones.

14. Que tan factible es la implementación de una guardería en términos de tiempo y costos.

15. Algo que desee agregar para enriquecer nuestro conocimiento 


\section{Apéndice G}

\section{Transcripción de variables FOCUS GROUP 1}

Personas que no utilizan el servicio de guardería, pero tienen la necesidad de encargar el cuidado de sus hijos a terceros

\section{Integrantes:}

Edith Meyhuay - 36 años - Contadora

Ana Quispe - 29 años - Administradora

July Agüero - 32 años - Administración Hotelera

Ruthy Castillo - 36 años - Contadora

Edwin Cardenas - 30 - Administrador

FACILITADOR: Buenas noches con todos muchas gracias por venir. Se dio los nombres de los integrantes del grupo y sus cargos. Se explicó que el motivo del focus group era para un plan de negocios para la obtención del grado de Magister. También se les indico la necesidad de que la información obtenida sea sincera y que sean lo más explícitos posible.

Bueno vamos a conversar sobre el cuidado de sus hijos, sabemos que cada uno de ustedes tiene niños y como ustedes son los especialistas en el tema de cuidado entonces quisiéramos saber sus opiniones, porque nos interesan mucho para el proyecto que estamos realizando. Asimismo decirles que no hay opiniones malas ni opiniones buenas, todas las opiniones son importantes porque van a enriquecer el proyecto que estamos realizando. ¿Hay alguna consulta o algo que quisieran añadir antes de comenzar la entrevista? ¿No? Entonces comencemos.

Quisiera comenzar preguntándoles cuántos hijos tienen y las edades de sus niños.

EDITH: Mi nombre es Edith y quiero agradecerle por estar aquí y compartir opiniones que en realidad son enriquecedoras para nosotros mamás y papas con hijos de niños pequeños. En mi caso tengo mellizos son los únicos que tengo y no tendré más tampoco. (Risas...) Ellos tienen dos años.

FACILITADOR: Muchas gracias. Ana cuéntanos, ¿cuántos hijos tienes?

ANA: Yo tengo 3 hijos he, la mayor de 3 años y medio, el segundo de un año y 10 meses y mi bebe de 4 meses.

FACILITADOR: ¡Wao que valiente! (Risas...). Muchas gracias Ana.

FACILITADOR: July, ¿Nos comentas por favor?

JULY: Si bueno, mi niño es único, va a cumplir este año 3 añitos.

FACILITADOR: ¿3 añitos...? muchas gracias.

FACILITADOR: ¿Edwin?

EDWIN: Hola Kelly, Yo tengo una pequeña que se llama Vania, tiene 1 año y 7 meses.

RUTI: Si yo tengo 2 niñas, una de 1 añito y 3 añitos.

FACILITADOR: Muchas gracias!. Bueno quisiera preguntarles como hacen ustedes con el cuidado de sus hijos porque sabemos que todos ustedes trabajan, entonces, ¿cómo hacen para venir a trabajar y dejar a sus niños? ¿Nos podrían comentar sus experiencias?, ¿Quién gusta comenzar?

RUTI: Bueno yo actualmente la dejo con una amiga, una gran amiga, bueno siempre busco una que tenga paciencia con los niños porque yo sé que son a veces inquietas e irritadas, yo creo que mi amiga la tiene y por eso confío mucho en ella.

ANA: Yo dejo a mis hijos con mi tía en la casa de mis abuelos. Mi tía es una persona bastante paciente y como a estudiando un poco de educación inicial entonces los estimula bastante, yo le pedí a ella por favor los vea. Ella ahorita está en casa y me ayuda más que todo para que no los griten, porque los niños se asustan es por eso que a veces tampoco no los dejo así nada en más en otro lado. 
EDWIN: Bueno en mi caso mi esposa lo está cuidado por momentos. Si bien es cierto que yo le comente que es bien trabajoso pero también disfruta bastante y yo prefiero que ella los cuide por el momento.

FACILITADOR: ¿De alguna manera ella trabajaba antes?

EDWIN: Si, ella es enfermera y por el momento no está ejerciendo por el tema del niño, pero nosotros hemos planificado que cuando cumpla los 2 años ya nuevamente va a reincorporarse.

JULY: Bueno en mi caso hay una señora que le decimos la nona que cuida a los niños, si salgo de terminar de mi trabajo bajo y la nona ya lo tiene al niño, pero si es una persona que la conozco, con quien me siento en confianza y aparte que puede ser lo positivo es que es un libro abierto, le enseña varias cosas a pesar de su edad y si tiene paciencia.

EDITH: Bueno en mi caso fue una situación muy complicada dejar a mis hijos porque los deje cinco meses porque tenía que trabajar. Yo lo dejo con mi suegro actualmente y con sus hermanas, en realidad también busco eso, una persona de confianza pero también personas que sepan orientar a los niños, porque están en una edad bien complicada, porque son esponjas y absorben lo bueno y malo. Lo bueno de que lo dejes con familiares es que los cuidan, tienen cuidado, ven sus alimentos y todo eso pero lo malo es que demasiado los engríen entonces eso es lo que a mí me ha pasado, que yo los crio de tal forma y como es el abuelo o la abuela lo malcría. Entonces eso es mi pequeña dificultad que yo tengo por eso es que me gustaría buscar un lugar en donde sepa orientar al niño FACILITADOR: ¿Otras opciones?

EDITH: Exacto.

FACILITADOR: Haber, nos gustaría que nos comenten como ha sido su experiencia en dejar con otras personas a sus hijos, ósea para volver a trabajar. En el caso de Edwin no porque confía enteramente en su esposa. (Risas...)

EDWIN: Lo que pasa es que mis suegros sus padres están trabajando entonces están todo el día ocupados de su tiempo y llegan a las 7 o 8 de la noche. Entonces definitivamente mi esposa tiene que cuidarlos, bueno su hermanos, mis cuñados también trabajan. Entonces dejarlos en una guardería, tantas cosas que vemos en las noticias hoy en día no lo veo confiable pero bueno ese es en mi caso. FACILITADOR: Y para las otras personas como ha sido su experiencia en dejar a sus hijos bajo el cuidado de terceros, llámese tíos amigos, conocidos. Ha sido difícil, fácil, de repente complicado. Cuál es la experiencia que han tenido al dejar a sus niños.

EDITH: Lo que pasa es que cuando son bebes lo puedes dejar de repente un momento que lo cuide pero cuando son más grandecitos ya se dan cuenta, o sea, cuando están acostumbrado a estar con mi suegra o con mis hermanas, yo les dejo con otra persona y lloran no quiere entonces es difícil que los deje, entonces digamos que entre comillas mi pobre suegra se está quedando con mis hijos porque no puedo dejarlo con otra persona, no se acostumbra y es eso por lo menos ese es mi caso.

FACILITADOR: ¿Y tú experiencia como mamá el dejarlo con ella, con tu suegra?

EDITH: Por eso te decía que para mí fue difícil dejarlos, uno porque le dice mamá July de cariño, es su mamá July y a veces me dice mama July y es porque no paro en mi casa, yo los dejo dormidos y los encuentro dormidos. Y como te digo, antes yo no me sentía mal porque me decía: como mamá estoy fallando porque los estoy dejando mucho tiempo con mi suegra y que la verdad mi esposo es igual también, pero ya con el tiempo y un poquitos más grandes ya se están dando cuenta. Ahora ya lloran, me acuerdo cuando eran bebes no se daban mucha cuenta. Decía: ¿mamá dónde vas? A trabajar y me tenía que escapar porque lloraban y como madre sientes que se te estruja el corazón entonces que vas a hacer, tengo mis responsabilidades en mi caso.

RUTI: Yo igual, lloran cuando hay un desprendimiento, cuando uno los deja y tiene que salir. Uno llora, uno sufre al verlos sufrir a nuestros hijos, pero tenemos que trabajar no nos queda de otra forma que dejarlos con otra persona, al final los engaña y ya se quedan calmados. (Risas...) 
FACILITADOR: Este... July, ¿algo que comentar?

JULY: Bueno en mi caso cierta vez lo dejo con una amiga de mi mamá porque este se fue a jugar con un perrito chiquito y se hizo una herida y dije no, seguramente independientemente cuando esta chiquita yo soy la que asumo la responsabilidad. Si a mi niño por ejemplo le va bien es mi responsabilidad y se le va mal también es mi responsabilidad. Es así.

RUTI: totalmente de acuerdo.

FACILITADOR: ¿Anita?

ANA: Bueno mi experiencia al dejarlos bueno, son muy pequeños entonces mi tía las ve, mi hija mayor va al colegio, no hay problema pero cuando vengo de trabajar por la tarde y los tres llegan y entonces un poco de preocupación porque la mayor ya es un poquito más independiente, mi hijito el segundo, un año y 10 meses esta que sube y baja en las escaleras, que se trepa, más la bebe, entonces un poco como que me da temor. Pero ya como que pedirle pues simplemente a Dios que los cuide porque llega un momento en que llora la bebe y llora él porque también es bebe. Por ahí que llegan mis tías o mis primas de la universidad, por favor y ya pues no, con el dolor y todo, pero bueno se tiene que quedar pues para seguir adelante a trabajar.

FACILITADOR: Y Edwin en tu caso ¿han conversado con tu esposa a cerca de como seria esa situación? O sea, ¿Cuando ya vuelva a trabajar?

EDWIN: Yo le había sugerido que lo cuide mi suegro, como hay otra persona que también les cuida pues ¿no? y digo porque ellos si tiene ese espacio por decirlo así, ellos paran todo el día ocupados llegando a las 8 de trabajar, pero por ese lado no me apoyan mucho, pero ya ahora ya ella se cómo conoce más a mi suegra y mi suegro ya lo dejamos por ratos y a veces se los lleva al supermercado y ya no tienen más tiempo, pero si de alguna forma hemos conversado que ya cuando tenga dos años ella pueda laborar, y si no es mi suegra, va a tener que adaptarse con mi mama o una de las dos... pero más que nada mi suegro se enfoca en que cada uno tiene sus responsabilidades y si bien es cierto ellos ya han criado o educado a sus hijos no es como que justo que vuelvan a hacerlo por eso yo admiro cuando van y la apoyan, me parece muy bien, yo también quiero que suceda eso en mi caso, pero uno tiene que seguir y también creo que para una mamá es bien especial que pase el tiempo con su hijito los primeros meses, por eso las escucho y debe ser difícil haber dejado, definitivamente, pero hay situaciones y situaciones. Pero quizá para el próximo bebe ya tendrá que trabajar y dejarlo nomas, ya sería otra experiencia para nosotros.

FACILITADOR: Y cuáles, si han tenido algún inconveniente con las personas que les cuida a los niños. No sé... que no hayan podido cuidarlos ese día. O que hayan tenido que viajar, o que se halla enfermado. ¿Han tenido ese tipo de inconvenientes?

EDITH: En mi caso yo lo he pasado con mi suegra, que se ha enfermado, digamos que no es tan joven y sufre de la presión y me dice que se siente mal y que tiene que ir al hospital, "madre santa ahora que hago con mis hijos”. Mi mamá trabaja. ¿Y qué puedo hacer en este caso? ¿Con quién más la puedo dejar? Ahí tiene la mamá, porque los hijos no piden papá, es mamá porque la mamá es quien lava su ropita, la que va y cocina, la verdad que no lo puede hacer la suegra y como dice él (Edwin), tuve suerte con mi suegra porque para mi suerte mi esposo es hijo único. O sea son sus únicos nietos en cambio de parte de mi mamá ya tiene nietos entonces dice que ya ha criado nietos y más que son 2 , se pone nerviosa. Entonces me ha pasado eso. Como dice con la vergüenza así en la cara a llamar a la jefa y decirle que no puedo ir a trabajar. Que hacemos con lo hijos, a veces esa es la parte que a uno le fastidia pues, así es.

FACILITADOR: ¿Anita?

ANA: En mi experiencia, mi tía se enfermó, le dio la gripe, le dio feo y le decía "me estas mintiendo" y no le paraba y no le cortaba y tuve que llamar a mi mamá en este caso mi mamá es una mamá joven pero ella no quiero mucho cuidar como que ya se ha casado es por eso que tiene otro compromiso 
entonces como que no puede mucho, pero en estos casos le explico "pero por favor mi tía está mal", gracias a Dios me poyo pero en ese momento si de repente algo pasaba, que se yo, porque mis abuelos ven a mis hijos, ellos no tienen la responsabilidad de cuidarlos pero como están en la casa igual juegan, están con ellos, pero yo no les puedo dejar a mis abuelos porque son sus bisnietos, jamás, no podría.

FACILITADOR: ¿July?

FACILITADOR: Si has tenido algún inconveniente en alguna oportunidad con el personal que te cuidaba a tu hijo.

JULY: Lo positivo es de que cuando estaba bebito tenía bastante leche para lactar, entonces le dejaba, pero aparte lo que yo más me he puesto triste que el bebé, pero al regreso de nuevo, en esa etapa si trabajaba full time y tenía un día libre, pero día de semana y ese día de semana lo llevaba al teatro porque era como que no te he tenido los demás días pero te tengo un día. Y todo el día era para él era mamá que salía, no estaba en casa.

FACILITADOR: Edwin, el caso de tu esposa no creo que hayas tenido algún inconveniente o ¿sí? EDWIN: En realidad no, es que la mamá tiene que de alguna forma ver si se enferma o llevarlo al doctor, pero siempre hay bastante comunicación y ver si hay que llevarlo a la clínica o algo así.

FACILITADOR: igual me imagino que si ella llegara a enfermarse te verías en la obligación de pedir permiso en tu trabajo porque no tienes como comentabas el apoyo de tus suegros.

EDWIN: Claro, si es una emergencia que amerite de alguna forma solicitar un permiso sí. Si es un tema que lo puede manejar mi esposa con ayuda de repente de mi mamá o alguna persona bien. Pero si ya es una emergencia netamente si tendría que comunicarlo para pedir permiso.

RUTI: Bueno yo siempre recuro a mi hermana o a mi suegra, ellas son mi opción o mi cuñada, cualquier de los dos busco, porque son las personas que yo veo que auxilian a mis hijos y sé que van a estar bien con ellos y esa es mi prioridad, que ellos van a estar bien.

FACILITADOR: Bueno sabemos que ninguna de ustedes utiliza una guardería. ¿Ustedes le dan a una retribución económica a la persona por el cuidado de sus hijos?

TODOS: Claro que sí.

FACILITADOR: y es en efectivo me imagino.

TODOS: Si, así es.

FACILITADOR: Como sabemos ustedes trabajan en la zona de San Isidro. Queríamos preguntarle si ustedes conocen una guardería cercana a su centro de trabajo.

RUTY: Cerca al trabajo no, no conozco.

JULY: Bueno como es un área comercial no.

ANA: No, pero sería muy bueno.

RUTY: Por lo menos no estoy informada.

JULY: ¿En el colegio san Agustín?

FACILITADOR: Bueno, es colegio y creo que es a partir de inicial en el colegio san Agustín.

FACILITADOR: Yo en este punto voy a pasar a comentarles, como les había explicado al inicio de esta reunión nosotros estamos iniciando un proyecto de tesis que es una guardería infantil para niños entre 3 meses y 36 meses que vendrían a ser 3 años, que es más o menos la edad que sus hijos tienen y es por eso que los hemos invitado. Entonces me gustaría explicarles algunas de las características que nosotros hemos ideado para esta guardería y conocer sus opiniones. Si después de esta explicación quizás ustedes cambien de opinión o quizá no. Bueno en primer lugar la ubicación, esta guardería está ubicada en la zona de Santa Catalina que corresponde al distrito de la victoria (se les muestra un mapa de ubicación), esta exactamente a la espalda de química Suiza ¿no sé si se ubican? Esta es para nosotros un punto estratégico porque es accesible, no tiene el tráfico de San Isidro y tiene algunas 
ventajas por el tema de estacionamiento. Entonces me gustaría saber que les parece esta ubicación; les es accesible, no se si no podrían llegar, ¿qué les parece la ubicación?

JULY: A mí me parece bien porque esta área no esta tan concurrida, tengo entendido que hay parques, parques grandes, y las personas también, no lo veo muy movido como es San Isidro, un área familiar. FACILITADOR: ¿Alguien más que guste en darnos su opinión?

ANA: Para mí el acceso para llegar ahí, yo no tomo un carro, me voy a trabajar, para entrar ahí no hay muchos carros creo, es una zona un poco difícil.

FACILITADOR: Para ti, ¿no sería muy accesible?

ANA: No.

FACILITADOR: Claro, si no transita transporte público por ahí

RUTY: Claro, es puro taxi o tu auto nada más.

FACILITADOR: Bueno, esta guardería tiene proyectado en aplicar una metodología de estimulación temprana, esta metodología es la metodología DOMAN. ¿En qué consiste esta metodología?, es estimular al niño de forma integral para que vaya desarrollándose, desarrolle la visión, desarrolle el sentido del acto y poco a poco se inicia el tema de la lectura con el niño, entonces, ¿cómo es esto? Se trabaja a través de fichas y se le dice, por ejemplo. Aquí dice papá no se le dice que esto es p, es a, es p, es a, dice papá, entonces el niño por repetición va a aprender que eso es papá, luego se le introduce otra palabrita. El niño va a aprender a diferencia al papá de mamá, de la de mamá y pelota y eso le ayuda al niño a que a medida que vaya creciendo, primero lea palabras pequeñas, luego pueda leer una frase corta y luego ir aumentando las palabras hasta poder leer un texto. Este método inicia con la estimulación, la estimulación inicialmente de poder familiarizarse con el ambiente, hay que darle un niño un ambiente agradable, que sea fácil para que él pueda sentirse confiado y que el sobre todo él pueda tener claridad para concentrarse en lo que pueda aprender. ¿Qué les parece este método? EDITH: Por ejemplo, eso dice que empiece del gateo, pero si en el caso de mis hijos que ya tienen 2 años, ¿cómo harían para que esa parte que ha perdido desde que era pequeño se pueda recuperar? FACILITADOR: El tema del método es que, el especialista dice que lo más recomendable es empezar antes, pero si empieza después igual puede adelantar, si bien es cierto entre comillas quedaría en desventaja con el niño que inicio antes pero también va a tener muy buenos resultados con el método, entonces es más o menos la ventaja, que igual siempre es un buen momento para iniciar. EDITH: O sea no es netamente que van y los cuidan, sino que aparte le dan algo adicional que es lo que tú nos dices.

FACILITADOR: Exacto.

EDWIN: Me imagino que si ustedes están pensando un rango de edades de 0 a 3 por decirlo así. El especialista va a ir desarrollando va air trabajando según la edad, porque ustedes van a atener niños de diferentes edades o meses entonces imagino que trabajar con este grupo, con el otro, no es que un niño puede ir avanzando más o menos, sin ustedes trabajan como van llegando.

FACILITADOR: Claro, el proyecto y eso es a nivel hay estudios psicológicos con respecto a esto. Es la separación de niños por edades, como bien indica Edwin las necesidades de un niño de 3 meses no son las misma que la de un niño de 2 años y menos que las de uno de 3 años. Entonces si hay una separación por edades; primero están los del mes lactantes que son los que generalmente están durmiendo, hay que estimularle las manitos para que las abran porque tiene las manitos cerradas inicialmente. Se les estimula primero el tacto, luego están los gateadores que están a partir de sexto o séptimo mes, entonces ya estos niños que necesitan otro tipo de estimulación, entonces ya hay que hacerlos sentar, hay que enseñarle a probar comidas. Entonces es otro tipo de cuidado. Están los niños caminantes que ya necesitan un espacio más abierto y otro tipo de cuidados porque no puedes tener enchufes, no puedes tener ese tipo de cosas, hay que preparar el ambiente para que ellos puedan aprender a caminar para que ellos se sientan libres y seguros a la hora de caminar. Y luego están los 
bebes exploradores que son los niños de 2 a 3 años, que estos años son los que ya no están dependientes entre comillas, se les da un poquito más de libertad y se trabaja con ellos otro tipo de estimulación, entonces si hemos considerado el tema de la separación por edades de acuerdo a las necesidades de cada niño. Entonces que opinan de esta separación por así llamarlo.

ANA: Esta bien por la necesidad de cada niño, me imagino que los ambientes también un poco separados porque si yo dejaría a mi bebe, por ejemplo, que tienen 4 meses y medio y yo sé que a las 11 de la mañana tiene su siesta entonces si esta con los niños más grandes no lo va a dejar dormir. Y eso también les conviene a los que cuidan porque así pueden dedicarle ese tiempo a cuidar otros niños y también que mi hijito tenga su siesta.

RUTI: Claro porque a esa edad todavía hacen siesta, a los 3 hacen siesta

FACILITADOR: Que otras cualidades les gustaría encontrar en una guardería, que no sé, si por ejemplo tuviesen que decidir por ya no dejarlo con la persona que actualmente las cuidan y tuviesen que elegir una guardería. ¿Qué cualidades les gustaría encontrar en una guardería?

JULY: La transparencia.

RUTI: Que jueguen más con el niño porque uno no juega mucho con el niño, es que uno para juega, juegan solitos, que jueguen con el niño y en ese juego que lo vallan educando, por ejemplo, que se le puede enseñar, que se me ocurre a mi hija de 3 añitos que recoja los juguetes. Por ejemplo si hemos jugado y llega el momento de recogerlo, tienes tu tachito ahí y recoges los juguetitos. Una cosa así, jugando y educando.

JULY: En mi caso hacen una canción a guardar, a guardar.

RUTI: Es una forma que juegas pero de alguna forma están enseñando y cuando terminas de jugar estas guardando los juguetes.

EDITH: Por ejemplo yo no tengo eso y cuando estoy en mi casa y no puedo enseñarle y pongo mi video, como pedir pipi, y vamos a pedir pi pi. Es como si le estuviera explicando y es que no sé a veces porque no sé cómo le tengo que poner. Entonces me dice, mamá ponme la canción del popo y el pipi y está mirando, entonces de repente eso, pongo el televisor pones una persona y empezando presentan a la profesora, porque yo tengo que ver hasta su rostro porque una que el niño no lo quiere, se da cuenta.

ANA: Yo buscaría contactar una guardería muy aparte sabemos que el ambiente, tiene que tener seguro y todo eso. Pero más que todo yo quería personas capacitada que hayan recibido profesoras. Sus charlas de estimulación y sobre todo paciencia porque los niños saben, así como mi tía los cuida y ellos quieren ir a la casa de mi abuelita, para ellos es su guardería, ellos me piden así como a mí me han dicho o por ejemplo mi hija cuando fue al colegio o a su estimulación yo veía que ella se despedía de mi rapidito y entraba, o sea eso me da la seguridad a mí de que la están tratando bien y de que ella quiere estar ahí, de que la tratan bien con amor y va advertirse y aprende. Eso es lo que más quisiera, lo que yo no quisiera es que le pegaran o personal que no tenga paciencia que les grite como dijo él, todo lo de las noticias lo que uno ve.

RUTI: Que las golpeen es el terror de un padre, que la golpeen, el solo hecho de ver que la están atacando a tu hijo y tú vas al colegio y que lo golpeen entonces, nos aterra o sea, que tenga full paciencia.

EDITH: Y lo que pasa es que el cliente aparte del papá también es el niño porque el niño sabe y se da cuenta, el niño de un momento a otro cambia su forma de ser, esta triste, llora y uno sabe que es lo que está pasando en su interior no se le puede engañar.

JULY: Claro sobre todo en personas que sean profesionales pero que acompañen y que tengan valores y tal vez si se cayó un foco y no nos enteramos. Y una profesora después de que había dicho no se lo cuente. Entonces por ejemplo la nona ha habido casos, como uno es un ser humano se nos puede caer una taza y el niño puede pasar por ahí, uno no va querer que son cosas casuales entonces pero me 
cuenta, que sea transparente, como que hay una interacción el niño es sincero entonces la persona que también que la cuida también aprende, no se olvida de decirle, entonces también las personas que están capacitadas profesionalmente también tiene que tener. Si paso bueno, contar con la verdad, a lo hecho pecho.

ANA: Si claro, eso también. Porque es lo que va a aprender el niño.

RUTI: Claro porque si no, lo ocultas, estas ocultando estas mintiendo. Nos quedamos callados no decimos nada. Y no se ve bien, normal.

FACILITADOR: Y que opinan de una guardería que tenga cámaras IP y ustedes a través de su celular su computadora su tablero cualquier tipo se sientan a ver y puedan monitorear su cuidado y nuestra clase.

RUTI: Excelente idea.

EDWIN: Es que lo que pasa es que fuera de un tema económico, los padres quieren ver eso seguridad para sus hijos partiendo de ahí y personalmente si yo eligiera una guardería vería si la infraestructura y si tiene cámara de seguridad. No porque desconfié de las personas, pero siempre yo tengo que ver la forma de que realmente lo están tratando bien a mi hijo puede ser que lo estén maltratando y si es un bebito de 6 meses, ellos no van a hablar como van a expresar sus emociones. Un niño de 3 años es distinto entonces para mí el tema de las ideas de las cámaras es de que tenemos la tecnología y la podemos usar. Creo que sería bastante brillante, de tal forma que puedan tener tranquilidad los padres. FACILITADOR: Eh, bueno que otros niveles de seguridad aparte de las cámaras les gustaría encontrar en una guardería. Bueno también infraestructura que creo que menciono Edwin también. ¿Qué otras cositas?

EDITH: De repente infraestructura, ver como son las aulas, si son amplias como están los estantes, si están bien puestos, si esta solo fijado, si tiene extintor, si tuene cosas así. Porque en realidad si tuviera cocina donde está la cocina. Yo me daría una vuelta por todo el nido.

RUTI: Claro, en todo caso los enchufes, si los estantes son pequeños, porque si se cuelgan se le viene encima.

FACILITADOR: Bueno como sabemos que una guardería no necesariamente es el cuidado de uno a uno, no es un profesor para cada niño, entonces cual creen ustedes que sería la cantidad ideal en la que un profesor o un auxiliar deba ocuparse, o sea un grupo ideal de 3 niños 4 niños 5 niños, no sé. Que numero creen ustedes que sería el ideal.

ANA: Dependiendo de la edad.

RUTY: dependiendo de la edad porque imagínate si tienes un grupo de 5 niños y hay 3 o 4 inquietos que no están ahí, yo creo que es dominio de escena de la profesora.

ANA: dependiendo, si son de 2 años para arriba. Yo pienso que lo puede manejar una profesora entre 8.

EDITH: Lo que pasa es que en esa edad son más inquietos.

ANA: Claro, pero siempre van con un auxiliar.

EDITH: Porque si no, no podría.

RUTY: una profesora, para mi serian 5 niños y que tenga su auxiliar.

ANA: Es que dependiendo de la edad porque los que están gateando o aprendiendo a caminar definitivamente ellos van a necesitar muchas amas atención

FACILITADOR: dadas todas las explicaciones que le hemos dado acerca proyecto como son; la ubicación, el método, el tema de las cámaras IP, ¿ustedes se animar a dejar a la personas que actualmente cuidan a los bebes por una guardería?

ANA: yo sí, porque también entiendo que mi hijo en este caso también necesita estimularse con otros niños, a aprender, a compartir. Porque en la casa ellos están solos. Mi hija mayor se va al colegio y 
con la bebe todavía no puede jugar entonces se siente solo, todo eso le choca entonces yo sí. A mí me gustaría.

JULY: la etapa de sociabilización es importante.

EDITH: también porque mi suegro no lo va a cuidar siempre, entonces tengo que buscar alguna opción. Lo que pasa es que el niño en la casa también lo malcrían. Y en la guardería es diferente porque aparte que sociabilizan con los demás niños, los educan.

ANA: y Los niños hacen más caso a la profesora que a la mamá.

ANA: a las mamas nos hacen las mañas y a las profesores si les hacen caso. "mi miss" dice (risas)

FACILITADOR: Cuanto seria lo que ustedes estarían dispuestos a pagar por este servicio.

EDWIN: ¿El servicio es diario? ¿De lunes a viernes?

FACILITADOR: Claro, con qué frecuencia y cuanto seria. Porque por ejemplo algunas personas pueden necesitarlo 2 o 3 veces por semanas otros todos los días.

EDITH: Hay esa opción.

FACILITADOR: o sea, ¿cuál sería la frecuencia y cuanto estarían dispuestos a pagar por ese servicio?

EDITH: Y en el caso de que sean hermanitos ¿hay descuento? (Risas...)

ANA: ¿De qué hora a qué hora es?

FACILITADOR: Estamos proponiendo inicialmente un horario de 8 de la mañana a 6:30 de la tarde.

RUTY: ¿de lunes a viernes?

FACILITADOR: Es que lo que queremos es precisamente es saber la necesidad que ustedes pudieran tener entonces para nosotros poder usar esa información y nosotros poder plantear las posibles alternativas.

FACILITADOR: Ustedes que horarios preferirían, o sea según los horarios de trabajo de sus labores, que horario sugerirían ustedes poner, normalmente uno puede decir de 8 a 5 de la tarde pero la otra persona no porque trabaja hasta las 6 de la tarde. Ustedes que horarios quisieran de repente e que una guardería pudiera tener de acuerdo a sus requerimientos.

EDITH: Bueno, digamos que como está cerca de donde uno labora podría ser de 8 hasta las 6:30 porque si fuera de mi casa no llego. No hay forma. Algo así podría ser.

ANA: De 8 a 6 o 6:30, en el horario de trabajo.

FACILITADOR: ¿Y con qué frecuencia utilizarían el servicio?

TODOS: De lunes a viernes.

FACILITADOR: ¿Y cuanto estarían dispuestos a pagar?

EDWIN: ¿No tienes un rango? ¿No hay un rango?

FACILITADOR: Claro, más o menos las guarderías por las zonas de san Isidro están cobrando sobre los mil soles. Entonces esto es un promedio básico, entonces de ese importe ¿cuánto estarían de acuerdo a pagar?

FACILITADOR: Si lo ponemos entre 1000 - 1200, de 1200 a 1300 y de 1300 a 15000 digamos que ese podría ser el rango, más o menos ¿cuál podría ser? Según las características que Kelly a mencionado al respecto al tema de seguridad en las cámaras, el tipo de metodología, porque una guardería normalmente es para el cuidado, pero aquí es una aplicación utilizar una metodología adicional para una estimulación de sus hijos, teniendo en cuenta eso, proximidad de su trabajo que de repente pueda hacer más rápido el poder dejarlos y poder de alguna forma recogerlos, en base a esas características ustedes en base al rango que le hemos dado de repente podemos hablar de 900 a 1500. En ese rango más o menos ustedes como se agruparían, si yo le pongo de 900 a 1000 sería el número 1, así las 3 más que he dicho. 1234 más o menos ustedes como se acomodarían. Por no decir montos de repente hablamos 1234 .

ANA: Uno. 
EDITH: Bueno en mi caso como te digo tengo 2 niños. O sea si fuera 1 yo pago lo que pides. Uno tiene que pensar un poquito más.

RUTY: yo 2.

FACILITADOR: Y si ustedes decidieran, por ejemplo, ir o requerir el servicio de una guardería, cuáles serían sus temores, lo dejan al cuidado con otras personas porque tienen esa facilidad, pero si no lo tuvieran y se presenta esto, algo cercano a su trabajo. Cuáles serían sus temores o cuales seria ese freno que puede decir, mejor busco a mi hermana o busco a alguien para que lo cuide. ¿Cuáles seria ese limitante para poder decidir si va o no?

ANA: Para mí es la desconfianza, el cómo van a estar el cómo lo van a tratar, eso es lo primordial. Es que se ven en las noticas tantas cosas. Entonces es para mí es lo que, por eso busco a alguien a algún familiar porque definitivamente tu familia lo quiere tus hijos lo quieren, hay un amor, por más que les hagan perder la paciencia, están ahí en cambio un desconocido eso es lo que me frenaría, pero ya conociendo a la persona como dice Edith, viéndole la cara porque a veces nosotros, la información desde que tú ves a la persona, que te transmite, conociendo a la profesora ya de repente me da más seguridad,

RUTI: Claro es eso, la profesora, como yo la percibo a la persona yo, según eso yo dejo a mis hijas. Sino no, no sé. Como uno dice soy madre y tengo el sexto sentido desarrollado. Entonces yo de solo ver a la persona, yo digo esta persona si le va a hacer bien a mis hijas, si las va a ayudar y esa persona no. O sea, el solo verla a la persona, me inspira algo. Si es bien para que cuide a mis hijas porque si no, no.

EDITH: Yo opino lo mismo porque digo, de repente pago todo lo que de la guardería y llevo a mi hijo y no se acostumbra y empieza a llorar y para mí no va a hacer una facilidad dejarlo porque todo los días voy a tener que sufrir porque él va a estar llore que llore todos los días, te hacen entrar y la verdad que no. Para mí es eso, lo más importante es la persona que va a dar la clase, yo tengo que verla, porque yo conozco a mi hijo y yo sé si le va a gustar o no, porque el mira, yo ya lo conozco y además son dos y no están tan chiquitos y cuando están ya más o menos más grandecito ya se dan cuenta de todo y perciben y aparte todo lo que viene, salen tantas noticias que la verdad que yo no soporto, lo maltratan y yo lo cambio, te indigna lo que pueda pasar.

FACILITADOR: bueno si, se ven todas las cosas en las noticias, básicamente las noticias. Bueno, volviendo al tema del pago que mediad de pago les gustaría encontrar, porque sabemos que o ejemplo ahorita ustedes también mencionaba un pago en efectivo a las personas que les ayudan. ANA: Un POS.

EDITH: O una transferencia.

EDWIN: Por temas de tiempo

JULY: Por parte de la seguridad también.

FACILITADOR: con respecto a los medios de comunicación, generalmente con las personas que cuidan a su hijos en si la comunicación es más directa, que otros medios de comunicación les gustara encontrar con los profesores a los cuales les dejara encargado en la guardería, que otros medios de comunicación les es fácil utilizar.

EDITH: Teléfono, WhatsApp mensajes

ANA: Claro, el WhatsApp

EDWIN: Y que ellos puedan responder cuando le llamen rápido porque si no estás un poquito intranquilo.

ANA: O que la comunicación que sea cada semana o cada fin de semana, el cómo va tu hijo porque cada niño es distinto porque a uno le puede caer mal la comida u otro, sufre de alguna alegría, cada niño es distinto y que nos mantengan comunicado. 
JULY: O de repente puede ser también una ayuda psicológica de cómo van avanzando, si evaluación, puede ser un plus.

FACILITADOR: Y se les ocurre algún otro servicio como el que mencionaba Anita el tema de la comida, el tema de la lonchera o el tema psicológico, ¿se les ocurre alguna otro servicio adicional que podría ser un plus para el proyecto?

EDITH: Y por ejemplo si el niño se pone le da fiebre o convulsiona o algo así, ustedes en este caso que harían, o sea, lo llevan a un seguro, una enfermería o tópico.

ANA: Claro porque... ¿Cuenta con un seguro han visto eso?

FACILITADOR: Eso sería muy importante

ANA: Bueno, ya en colegio mi sobrina de 10 años. Pero mi hermano vive en Italia y mi sobrina esta acá, allá lo maneja de forma distinta, allá todo es seguro, pero acá no se sienten seguros, a nosotros no llaman a los papas o a los tíos, en ese caso a los tíos, y ya pues nosotros tenemos que buscar a que clínica lo vamos a llevar, pero tampoco tiene seguro entonces, pero cuando el accidente es dentro del lugar, la guardería tiene que asumirlo, la institución.

EDITH: Y yo digo también, la profesora o el profesor tiene esa preparación como para darse cuenta de que un niño se está sintiendo mal o que de repente no esté convulsionando.

FACILITADOR: Bueno debería ser

ANA: Debería tener cierto botiquín el tema del termómetro.

EDWIN: Quien podría atenderlo para un tipo de emergencia.

RUTI: Un tipo de emergencia digamos, como un servicio de enfermería para medir la temperatura o fiebre.

RUTI: Claro cuando es leve, pero cuando es leve pero cuando es por ejemplo una emergencia uno mismo tiene que llevarlo rápido a acudir la emergencia. Pero si se cayó y se raspo se le puede curar. EDITH: Y como decía la sinceridad, que cuando venga la mamá y le diga que sea golpeado porque de repente o no sé da ni cuenta, pero ya sabe. Hace poco escuche un caso de una chica que estaba bañando a un bebe no avisó de que el niño se había golpeado en la tina, y en la noche dice que empezó a convulsionar y se murió. Y no dijo nada, la chica sabia y ¿porque no avisó? Entonces esas pequeñas cosas que uno no le da importancia es bueno comunicarlas a los papás

ANA: Claro para tomar acciones en el momento.

EDWIN: Yo tengo una pregunta, si bien es cierto van a haber las cámaras que pueden estar conectadas pero no todo el tiempo vamos a estar así viéndolo. Puede que se haya caído lo hayan empujado o le haya pasado algo, sería bueno en tener un acceso de repente, brindarnos algún video o algo porque quiero saber qué hace mi hijo o mi hija durante el día. O sea, yo no voy estar con el celular porque todos estamos trabajando, si se podría quedar grabado algo.

ANA: Es que a veces esas cosas, por ejemplo a mi hija mayor le ha pasado que una niñita le golpeo porque no todos tiene la misma educación, entonces yo fui y dije quien le golpeo pero no me dicen, no me dicen el nombre, porque ya con la mamá, no quieren crean ellos conflictos con la yo con niña y con la mamá. Hay ciertas cosas que dependiendo también ellos como lo manejas y son reservados, porque en si es verdad porque cuando yo voy a ver quién es y de ahí en la reunión.

FACILITADOR: más o menos recapitulando, con los servicios adicionales sabemos que aparte de la comida con un servicio de menú, un servicio de psicología un servicio de enfermería, y un servicio de entrega de videos semanal de las actividades que realizan, un resumen.

EDWIN: Porque eso le da de alguna forma credibilidad a tu guardería, porque hoy en día el marketing es mas de boca a boca, y siempre los clientes dicen yo conozco una guardería en la cual cuidan bien a mi hijo, me mandan videos y yo puedo ver lo que hace mi hijo y que las otras guarderías no tienen y eso puedo ser un plus un valor agregado, y eso es lo que los padres buscan “¿a mira si cuál es?” yo 
creo entonces que la guardería podría tener más acogida, todos esos detalles que se puedan agregar obviamente en el inicio no se ven pero a futuro sí.

FACILITADOR: Bueno, ¿si hay alguna otra opinión algo más que quieran añadir?

EDITH: Promociones.

FACILITADOR: Claro esa también es la idea que pueda haber promociones.

ANA: A los que tiene uno les cobran los descuentos de 2

EDITH: Y los recomendados también.

FACILITADOR: Eso es una muy bien idea para una promoción.

EDITH: Si mi hermana me dice que esta guardería va pues yo voy. Que tiene cámara y todo.

FACILITADOR: Bueno muchísimas gracias por su participación han sido de verdad muy útiles todo lo que ustedes nos han podido comentar sobre sus experiencias y sobre todo lo que esperarían del servicio sabemos que ustedes no utilizan el servicio de la guardería, agradecemos mucho su tiempo sabemos que son personas muy ocupadas y valoramos bastante que hayan tomado unos minutos para conversar con nosotros. Eso es todo. Gracias!!. 


\section{Apéndice $\mathbf{H}$}

\section{Transcripción de variables FOCUS GROUP 2}

Personas que no utilizan el servicio de guardería, pero tienen la necesidad de encargar el cuidado de sus hijos a terceros

Integrantes:

ALDO: Padre de dos hijos hombre y mujer de año y medio, y uno por cumplir 3 años.

SORAYA: Madre de una hija de año y medio.

SHEYLA: Madre de un hijo de un año.

JOSE: Padre de un hijo de dos años.

DIANA: Madre de una hija de seis meses.

FACILITADOR: Buenas noches con todos muchas gracias por venir (presentación). Se dio los nombres de los integrantes del grupo y número de hijos. Se explicó que el motivo del focus group era para un plan de negocios para la obtención del grado de Magister. También se les indico la necesidad de que la información obtenida sea sincera y que sean lo más explícitos posible.

FACILITADOR: Básicamente vamos a hablar acerca de los hábitos del bebé por ejemplo, ¿Diana Cómo haces con el cuidado de tu hijo mientras trabajas? ¿Dónde se queda? ¿Qué es lo que haces? DIANA: Bueno cuando nació Camila yo he podido tener una licencia. Es mi primera hija entonces este año acaba toda la tensión, Pero ya al regresar al trabajo me cuesta, tengo a mis papás que me ayudan porque viven cerca y me lo cuidan, pero es algo que desgasta.

FACILITADOR: ¿en qué parte te desgasta?

SHEYLA: desgasta por parte de llevarlos, estar pendientes porque mis papás también necesitan ayuda.

FACILITADOR: ¿tu José Cómo haces en este caso?

JOSE: Yo tengo mi empleada que en la mañana limpia y mi mamá ayuda a cuidarlo y en la tarde y después de almuerzo mi mamá se retira y la empleada se encarga simplemente de atender al niño. FACILITADOR: ¿Cómo ves el tema ahí de tu mamá como soporte?

JOSE: si nos apoyan felices porque es su nieto, pero si hay veces que se complica porque tienen que ir a la clínica o tienen otras actividades.

FACILITADOR: en tu caso Sheyla ¿cómo haces con esta situación con el cuidado de tus hijos? SHEYLA: en principio me apoyaba mi hermana, pero la disponibilidad de su tiempo también se fue complicando, entonces me vi en la necesidad de ver otras opciones y hay veces que tiene otras actividades que hacer y tengo que ver cómo me ocupo. Tengo que pedir vacaciones y es un poco complicado, mis padres son muy adultos y no podría darles esa tarea.

FACILITADOR: ¿Soraya en tu caso como haces?

SORAYA: Bueno yo soy madre soltera entonces voy a la casa de mi madre donde hay una nana y lo dejó mientras mi mamá la supervisa. El problema es que tengo que hacer un viaje de su casa al trabajo largo y eso le genera un cuadro de estrés, esa es básicamente mi rutina diaria.

FACILITADOR: ¿Y cómo acabas el día normalmente?

SORAYA: es un poco complicado ahora porque ya mi mamá me está pidiendo que tiene que ocuparse de su tarea, entonces estoy buscando una guardería donde pueda llevarlo al bebé cerca de donde trabajo o de dónde vivo para después poder recogerla o mandar la empleada para que lo haga. FACILITADOR: ¿tu Aldo?

ALDO: al principio era fácil, me ayudaba mi suegra porque tenía una nana cuando eran muy pequeñas y no caminaban, pero ya cuando los bebés han crecido ahora es un poco más difícil. Mi suegra es un poco mayor, la empleada no tiene cuatro ojos como para ver a los dos entonces me encuentro dándole vueltas para tomar una decisión. 
FACILITADOR: y con este tema, ¿cómo es el nivel de estrés que manejan tú y tu pareja?

ALDO: Tranquilos dentro de todo porque está mi suegra, pero siempre teniéndola en cuenta porque nos está apoyando bastante.

FACILITADOR: en este caso, ¿ustedes son los que toman la decisión del cuidado de sus hijos o es una decisión que toman en pareja, Aldo en tu caso?

ALDO: La verdad es que yo pongo mi opinión, pero priorizó la tranquilidad de mi esposa.

SORAYA: soy yo la que decido, pero igual recibo algunos consejos, pero yo soy la que tomó la decisión.

SHEYLA: en mi caso conversamos con mi pareja para ver cuál es la mejor decisión.

JOSE: en mi caso es familiar.

DIANA: la decisión la tomamos con mi esposo.

FACILITADOR: en este caso la decisión no lo toma una persona sino en parejas o con su familia.

Bien, ahora cuando ustedes han tenido que dejar al cuidado de sus hijos con terceros, ¿qué es lo que ha sido fácil o difícil? ¿Bueno o malo? Me gustaría que me cuenten un poco de esa experiencia.

ALDO: lo difícil es construir confianza con esa persona porque cuando ganas confianza con esa persona todo se hace más fácil.

FACILITADOR: En este caso como son situaciones puntuales ¿Cómo construir esa confianza cuando normalmente no conoces a esa persona?

ALDO: un factor clave es el tiempo qué, tan responsable es esta persona con su trabajo, sus valores. Sería un poco difícil dejarlo los primeros días, pero ya con el tiempo se haría un poco más fácil.

DIANA: es difícil encontrar a alguien con buen criterio que no esté en mi familia para que cuando al bebé le pase algo pueda saber qué hacer.

FACILITADOR: ¿tendrías entonces un poco de miedo por no saber si la persona está preparada?

DIANA: Claro si no puede responder rápidamente a situaciones complejas.

FACILITADOR: ¿En tu caso Soraya?

SORAYA: en mi caso tuve suerte porque encontré una persona de confianza, pero a pesar de tener confianza y todo no tiene la instrucción como para cuidar completamente al niño es por eso que decidí ponerla en un nido porque la chica no es una nana, sino que hace una doble función, mi madre ya es mayor de edad y es por eso que mi hija está en una guardería ahora y los fines de semana la pasa con sus abuelos.

FACILITADOR: y en tu caso José, ¿cómo has hecho ante una situación complicada donde no tenías tu nivel de seguridad y confianza establecida?

JOSE: Normalmente la persona que la cuida por las tardes es una persona de confianza para mí y para mi mamá entonces en el día en la mañana la cuida mi mamá o mi suegra o mi cuñada. En mi caso ninguno podemos pedimos permiso, yo o mi esposa nunca lo hemos dejado con otra persona. Lo difícil es tener que pedir permiso y llegar tarde al trabajo o faltar en estas situaciones.

FACILITADOR: ¿en tu caso Sheyla como ha sido?

SHEYLA: en los casos que mi hermana no ha podido yo me he tenido que valer por una recomendación. Más allá de buscar en una guardería en otro lugar, para mí una recomendación es fundamental entonces en casos de extremos eso me ha ayudado bastante.

FACILITADOR: ¿esa recomendación de quién venía?

SHEYLA: venía de mi hermana o de un familiar directo porque no tengo un círculo social en donde tengan bebés y me puedan recomendar. Otro punto importante es saber sus costumbres y valores porque es lo que le va a transmitir al bebé.

FACILITADOR: Bien, ¿qué atributos buscarías si tienen que buscar una guardería?

SORAYA: yo desconozco el tratamiento o el procedimiento lo que tienen las guarderías, pero me interesaría saber qué cantidad de niños va a manejar cada adulto en la guardería o cada auxiliar. Me 
gustaría también tener el monitoreo de mi hija a través de mi celular poder verla en tiempo real, cuántas profesoras van a asistir a los niños, la distancia a mi trabajo porque hay tráfico diario, el horario también no sería full time sino más o menos hasta las 6 .

FACILITADOR: ¿cuál sería el horario de ingreso para ti?

SORAYA: sería bien temprano 7 de la mañana por ejemplo y a la salida por lo menos a las 5 de la tarde para poder recoger la saliendo del trabajo.

FACILITADOR: Perfecto, Sheyla en tu caso, ¿qué buscarías en una guardería?

SHEYLA: un tema importante sobre el tema de las horas que se vaya a quedar el niño en la guardería o el tiempo que le vayan a dedicar. Si bien es cierto no es una atención directa, he visto casos en donde las profesoras no se dan abasto por la gran cantidad de niños. Otro también es el lugar para poder recogerla temprano y no tenga problemas con el tráfico, otro tema también es el espacio donde se vayan a quedar, qué tan cómodo es para que pueda satisfacer todas sus necesidades. Espacio y tiempo.

FACILITADOR: ¿Cómo sería el caso de los horarios? ¿Qué horarios buscarías?

SHEYLA: Tendría que ser un horario fijo, depende también de cuán cerca está a mi trabajo para poder controlar mis horarios. Podría ser hasta las 6:30.

FACILITADOR: ¿En tu caso Aldo?

ALDO: la primera premisa sería seguridad, que tiene varios frentes como la infraestructura o los cuidados que puedan haber y también que los que los cuidan sean profesionales.

FACILITADOR: ¿A qué te refieres con que serían profesionales?

ALDO: que la profesora o la tutora sean personas capacitadas en temas de educación, en primeros auxilios, que haya una nutricionista que se encargue de las comidas.

FACILITADOR: ¿Y cuál sería un horario bueno para ti?

ALDO: acoplarse con mi horario de oficina para poder dejarlo a la entrada y recogerlos saliendo de mi trabajo más o menos de 7 de la mañana a 7 de la noche.

FACILITADOR: ¿en tu caso Diana?

DIANA: coincido con las demás con el tema de seguridad, también que me dé tranquilidad en caso de algún accidente como por ejemplo que pueda existir un centro médico cerca una enfermera que los asista, que haya un nivel de enseñanza de acuerdo a la edad de mi hija, que pueda aprender, un lugar limpio y bastante oxigenado y que sean seguros.

FACILITADOR: ¿Y cuál sería un horario bueno para ti?

DIANA: entre 7:30 a 4:00 o 5 de la tarde.

FACILITADOR: En tu caso José, ¿qué atributo buscarías?

JOSE: creo que una buena infraestructura con cuidados en las esquinas y enchufes Porque mi hijo ya es un niño grande entonces para que no se choque con las esquinas. Otro punto es que los profesores o tutores sean calificados y que hayan pasado por un test psicológico, que estén aptos para tratar con niños porque se necesita paciencia y un cuidado especial.

FACILITADOR: ¿Y cuál sería un buen horario para ti?

JOSE: para mí sería un buen horario, un medio turno en la tarde de preferencia.

FACILITADOR: ¿y con qué frecuencia utilizarlo? ¿Todos los días? ¿Dos veces por semana o que sea inter diario?

SORAYA: para mí de lunes a viernes.

SHEYLA: en mi caso inter diario para ir conociendo la guardería y ver qué tan confiable es y mientras tanto seguir con el apoyo de mi hermano hasta que se acostumbre. Dos veces por semana o 3 veces por semana.

FACILITADOR: ¿En tu caso Diana?

DIANA: en mi caso también serían dos veces por semana. 
JOSE: En mi caso de lunes a viernes.

FACILITADOR: pasando a otra pregunta ¿ustedes qué medio de pago utilizarían o con qué medio de pago les gustaría utilizar? ¿En efectivo en tarjeta en un depósito en el banco, que método les gustaría? DIANA: Una transferencia interbancaria porque es más práctico ahora.

ALDO: y también tarjeta de crédito.

JOSE: yo agregaría una opción Qué sería un cargo de cuenta automático

FACILITADOR: Ahora déjenme mostrarles donde va a quedar la guardería, En qué zona se encuentra. Entonces la ubicación se encuentra en la parte de Santa Catalina entre Química Suiza e Interbank es una zona aledaña al lugar donde ustedes trabajan. Ahora Quisiera saber si ustedes han visto guarderías en San Isidro o han visto guarderías cerca a sus casas.

ALDO: yo vivo en surco y para llegar a San Isidro tengo que pasar por San Borja y en San Borja hay pero en San Isidro no he visto.

SORAYA: Yo vivo en San Borja Y sí he visto porque estaba buscando. En San Isidro no he visto muchas porque es una zona más comercial o si es que hay son muy caros y ya tienen los cupos llenos. SHEYLA: Yo vivo en Magdalena Y sí he visto varias guarderías. En San Isidro No mucho más he visto colegios, pero sería lo ideal buscar un lugar que esté en mi ruta rumbo a mi trabajo.

JOSE: yo he visto alguno relativamente cerca a mi casa Y por San Isidro la verdad que no he visto por ahí seguro algún colegio, pero no más.

DIANA: Igual yo en San Isidro no he encontrado, pero por donde vivo si hay alguno.

FACILITADOR: $¿ y$ en las guarderías que han podido ver han visto alguna ventaja o desventaja de repente se acercaron a preguntar?

ALDO: yo me limité solamente a ver la fachada y que hay publicidad, que la casa es bastante grande pero no he entrado a preguntar.

FACILITADOR: en tu caso SORAYA, ¿qué ventajas o desventajas has podido ver?

SORAYA: lo que yo he visto es que tienen a niños de distintas edades Por ende en la entrada es un poco caótico entonces lo que yo estaba buscando es una guardería para más pequeños y que sea más personalizado.

FACILITADOR: ¿Lo dices por el tema de los estacionamientos?

SORAYA: Si porque las profesoras vienen hasta el auto a recoger a los niños he visto niños de 5 y 6 entonces no sé si una guardería o un nido, yo lo que quiero es una guardería.

SHEYLA: no he entrado a preguntar pero lo que he visto es que son casas adaptadas para hacer guardería o nido y ahí hay un poco de temor, porque no sé qué tan útil es, si la adaptación de la infraestructura es la correcta. No he entrado para ver si la infraestructura tiene todo lo necesario. JOSE: si, fuimos a uno pero lo que no me gustó fue que en el primer piso está la guardería y en el segundo piso viven personas, entonces ahí tenemos que tener mucho cuidado porque no sabemos Qué clase de personas son.

DIANA: lo que yo he visto es que son muchas casonas viejas y no están bien adaptadas. Son como casonas.

FACILITADOR: yo les voy a hablar un poco del método para estimular a niños. No sé si han escuchado del método DOMAN utilizado en algunas de las guarderías usan. Les voy a mostrar un video introductorio para que vean de qué se trata.

FACILITADOR: ¿Qué les parece el método lo habían escuchado antes? Empezamos por ti Diana. DIANA: no lo había escuchado antes pero me gustaría probarlo para ver cómo se desarrolla.

FACILITADOR: ¿no conocías otro método de enseñanza?

DIANA: No había investigado otros métodos porque está un poco chiquito mi hijo 
JOSE: en mi caso nunca lo había escuchado, pero me gustaría más escuchar o Investigar sobre este método para ver cuáles son los beneficios.

SHEYLA: en mi caso no había escuchado este método, pero sé que se estila utilizar la estimulación temprana, pero no sé si esta metodología se refiere a eso o está relacionado con eso.

FACILITADOR: en tu caso Soraya habías escuchado sobre este método antes o de repente otros métodos.

SORAYA: he escuchado sobre la estimulación temprana, pero en casa a través de videos para niños de uno o dos años pero sí me interesaría saber cómo a este método, si lo podría aplicar a mi hija. FACILITADOR: en este caso el método es visual, lo ideal es que se aplique a los meses de nacido, pero también se usa a partir de 4 años hacia adelante. Es un método repetitivo que el niño va aprendiendo a cada momento a través de imágenes.

ALDO: yo como nombre técnico, como método no lo escuchado, pero sí he visto psicólogas o profesoras que usan el tema de las tarjetas que es bastante parecido a lo que es este método.

FACILITADOR: ¿han visto ustedes alguna ventaja y desventaja de este método?

ALDO: yo creo que como menciona se busca esta estimulación de que escuche y entienda más rápido a las cosas, creo que esa sería la base de la estimulación.

SORAYA: también creo que va a depender de la edad del niño

FACILITADOR: Cómo saben este es un proyecto de guardería, ahora me gustaría que me comenten ¿cómo les gustaría que fuera la distribución de la guardería?

ALDO: qué prima la higiene y los espacios acordé al número del alumnado que tengan áreas para comer áreas para juegos y áreas para aprender.

DIANA: me gustaría que todo fuese en el primer piso, que haya divisiones de acuerdo a las edades y que haya en espacios especiales para sus actividades.

SORAYA: tenga primer piso, pero en la realidad no sucede porque la guardería justamente quieren más espacio entonces abarcan también el segundo piso para dar más ambientes y satisfacer a los usuarios, pero yo preferiría que sea todo en el primer piso. Me parece importante también el lugar de descanso de ellos más allá del tema de aprendizaje, me gustaría saber el tema del ambiente donde va a descansar.

FACILITADOR: finalmente, ¿ustedes cuántos niños consideran Qué debe tener cada auxiliar?

DIANA: Depende de la edad. Si es menor de un año deberían ser 3 por cada auxiliar.

JOSE: viendo mí caso que es de 2 años creo que podría ser de 4 a 5 niños.

SHEYLA: yo creo también que podría ser de 4 a 5 sabiendo que también tienen personal de apoyo que van intercalando según el número de niños.

SORAYA: en mi caso serían 3 niños por cada auxiliar.

ALDO: en mi caso estoy en un promedio de 2 años, entonces también sería de 4 a 5 .

FACILITADOR: volvemos un poquito a la imaginación ¿Qué nombre le gustaría para una guardería?

SHEYLA: los nombres más o menos por lo que veo están orientados al crecimiento como "pequeña casa" pero un hombre particular no sé.

FACILITADOR: ¿pero te gustaría que esté asociado al crecimiento?

SHEYLA: Que mi hijo lo relacione y que se sienta identificado con el espacio.

ALDO: algo que se asocie el crecimiento seguro.

DIANA: algo fácil de pronunciar como "casa feliz" por ejemplo y fácil de recordar.

JOSE: algo alegre que llame la atención que impacte más que al niño al papá (risas). Porque el que va a pasar y va a ver el letrero es el papá y no el niño.

SORAYA: Me gustaría que la fachada de la guardería donde la voy a dejar me de esa tranquilidad por lo menos visual y estructuralmente con color, que cuando mi hija baje del carro ella se sienta feliz. El nombre no sé tanto pero que ella no lo sienta algo ajeno. 
FACILITADOR: ¿cuánto ustedes estarían dispuestos a pagar por un servicio de guardería en base a todos los requisitos que ustedes están mencionando?

SHEYLA: si fuese de tiempo completo estaríamos hablando en un promedio de 1200 aproximadamente.

FACILITADOR: ¿Y en este caso qué medio de pago utilizarías?

SHEYLA: Las tres opciones que mencionaron.

JOSE: en mi caso sería entre 600 y 800 porque estoy buscando algo a medio tiempo.

DIANA: me gustaría saber si es posible un costo por día, no sé, seria hasta 1000 soles por mes unas 3 veces por semana.

ALDO: yo haría una referencia de cuánto me costaba una nana que es más o menos 1000 a 1200, más la alimentación se sería 1000 a 1400 entendiendo que haya alimentación y un servicio full Day.

SORAYA: en mi caso no la tendría al bebé todo el día en la guardería, entonces yo cálculo que sería en 800 soles más o menos con un método de pago interbancario.

FACILITADOR: ahora pasemos a la etapa de comunicación, Entonces ustedes para conocer la guardería. ¿Qué métodos les gustaría que utilice la guardería para que se vea conocer? y aparte, ¿qué método de comunicación quisieras tener para mantenerte comunicado con la guardería?

DIANA: me gustaría estar en contacto para ver las novedades de la guardería, principalmente tener la publicidad de las mejoras que hacen.

ALDO: ¿Cómo encontrarla? pues primero buscar y lo primero que encuentres en Google sea esa guardería ya se vía web o vía redes sociales.

JOSE: en mi caso igual, que tenga redes sociales y que pueda ver fotos de mi hijo y también con sus compañeritos jugando, porque esas fotos no las voy a poder tomar yo entonces me gustaría sacar de ahí las fotos. Con la comunicación de la guardería me gustaría tener algún teléfono para alguna emergencia.

SORAYA: todo lo que dicen mis compañeros estoy de acuerdo, con las actividades de mi hijo tendría que hablar directamente con la auxiliar o profesora.

SHEYLA: también lo que ha mencionado mis compañeros, pero si es un poco más personalizado estaría bien por correo o algún número al cual me puedan llamar o yo llamarlos.

FACILITADOR: después de haber escuchado el proyecto. ¿A ustedes les gustaría adquirir el servicio de la guardería? teniendo en cuenta la ubicación en Santa Catalina y el método a utilizar y ¿recomendaría el servicio a sus conocidos?

ALDO: siendo sincero habría que hacer una búsqueda para comparar este futuro local versus los existentes para poder tomar una decisión en precios y en ubicación.

SORAYA: más allá de todo lo que se ha dicho me gustaría que tenga audio videos, que yo desde mi trabajo pueda visualizar a través de mi celular en vivo. Yo lo contrataría con la premisa que acabo de mencionar y si la guardería tiene un costo adicional por los audios videos yo lo asumiría, porque para mí es importante ese tipo de contacto.

SHEYLA: primero investigar y qué es lo que ofrece el mercado para ver qué valor agregado me ofrece, cuál es el elemento diferenciador porque si no sería uno más de los que ya existen. 


\section{Apéndice I}

\section{Transcripción de variables FOCUS GROUP 3 - Personas que utilizan el servicio de guardería Integrantes:}

ZULENKA: Madre de dos niños: uno de 6 años y uno va a cumplir 3 años

MILUSKA: Madre de una niña y tiene 2 años.

ALISSON: Madre de dos niños: uno de 5 años y de 2 años.

ANGGIE: Madre 1 niño de 2 años y medio

*Quinto invitado se retiró por emergencia.

FACILITADOR: Buenas noches con todos muchas gracias por venir (presentación). Se dio los nombres de los integrantes del grupo y número de hijos. Se explicó que el motivo del focus group era para un plan de negocios para la obtención del grado de Magister. También se les indico la necesidad de que la información obtenida sea sincera y que sean lo más explícitos posible.

FACILITADOR: Quisiera saber cómo hacen con el cuidado de sus hijos mientras ustedes trabajan. Yo se que ustedes trabajan en San Isidro, pero como hacen con el cuidado de los hijos, que es lo que hacen normalmente. Comiencen como quieran por favor:

ANGGIE: Ya, yo. Bueno inicialmente los dejaba con mis papas, después contrate a una empleada, pero las empleadas se aburren rápido entonces prácticamente no tienen la paciencia y uno también se siente un poco preocupado, tiene que ser alguien con referencias, se aburren, entonces hay que estar cambiando y eso es negativo.

FACILITADOR: ¿Por qué cree que se aburren las empleadas?

ANGGIE: porque están de repente acostumbradas a hacer una sola cosa, cuando se les dice que tienen que atender, jugar o hacer otras cosas más, no quieren. Entonces la idea es como que los niños avancen un poco mientras ella va haciendo otras cosas.

ALLISON: Por un tema de seguridad, no confió en las empleadas, los metí a los dos a la cuna, a la cuna del jardín. El pro es que tiene una correcta estimulación tanto para el habla, el gateo o ciertas cosas que quieras de acuerdo a la edad, de acuerdo al tiempo pasar. Para el desarrollo para ellos. Yo por un tema de confianza los metí a la cuna.

FACILITADOR: ¿Prefieres tenerlos en la cuna que a la empleada?

ALLISON: Si porque la empleada puede estar viendo novelas y mientras que en la cuna lo pueden estar estimulando a desarrollar algo de su cuerpo, algo del habla, quitarle el pañal, que se yo.

ZULENKA: Yo tuve apoyo de mi mamá y el mayor estuvo en el mes de 3 para 4 en un nido pero con el menor no ha sido posible, entonces yo he tenido que contratar una nana pero la verdad es que eso te da una ventaja, te da una tranquilidad, pero al a ves siento que la nana no es suficiente. Es una chica buena, lo cuida y todo, lo tiene bien, pero... Algo parecido lo que menciona Angie, que ahora que los niños son más despiertos, necesitan más estimulación, entonces necesitan otro tipo de ejercicio que ella no lo puede hacer, en este caso, de repente por falta de conocimiento.

FACILITADOR: Okey, perfecto, muy bien, muy buenas respuestas. ¿Miluska?

MILUSKA: Bueno en principio recibí ayuda de mi familia, pero por motivos de independizarme y laborales necesitaba que pueda compartir con otros niños de su edad, entonces me intereso en la guardería en la que lo puse a él porque también se interesaba en la estimulación temprana, entonces tú pagas y por lo menos una persona quiere pagar lo menos posible y lo menos posible no es una persona educada que le pueda dar esos servicios extras que lo podría brindar una guardería.

FACILITADOR: Perfecto, muy bien, en verdad es muy buena información. Ponemos otra pregunta, en el caso cuando están trabajando, ya me han contado que actualmente si es que no prefieren la guardería, no quieren la empleada ¿quién estaría al cargo e sus hijos si es que no tuvieran el tema de la 
guardería en esos momentos?, se puede haber complicado la guardería, de repente han cerrado o el tema de la empleada que pudo haber faltado, ¿quién se haría cargo de los hijos mientras ustedes trabajan?

ANGGIE: Lo ideal sería que en la guardería uno pueda llamar y que, si en algún momento porque no hay un lugar fijo para salir, te puedan dar un poco de tolerancia, te puedas quedar un poco más de tiempo por el tráfico y uno demora en llegar. Por mi parte mis padres me pueden apoyar, pero no va a ser siempre, puede ser un tema de emergencia pero lo ideal es que las guarderías tengan un horario que se adecue al horario laboral de hoy en día y con esa tolerancia, de repente poder comunicar, llamar si en algún momento uno va a ir más tarde.

ALLISON: Claro por algo ha dicho que si no tuviéramos ni guardería ni empleada. En mi caso nadie. ANGGIE: Si no tuviéramos como le comentaba, serian mis papás, alguna que otra oportunidad, no es que vaya a ser siempre.

FACILITADOR: ¿A ti se te complica dejarlo? ¿O no tienes con quien dejarlo en todo caso?

ALLISON: No, mi mamá trabaja, mis hermanos igual, mi papá les tiene pánico a los bebes así que no hay quien. Tendría que renunciar.

FACILITADOR: Ya, entonces tú también dependes mucho de la guardería.

ALLISON: Si, o de una persona o de un nido, o de una cuna.

FACILITADOR: Porque tú no confías en la nana como has dicho.

ALLISON: No, porque pasan muchas coas, he visto temas de maltratos a los niños, los niños cuando son bebes todavía no saben hablar, no saben expresarte lo que ha pasado más que un cierto rechazo que podría ver, pero no puedes ver que está pasando más allá. A menos que le pongas cámaras de seguridad a tu casa o algún tema de esos que ya sería invertir 3 veces más lo que normalmente uno tiene presupuesto. Así que en mi caso nadie podría cuidarlo más que yo. A menos que haya como dice Anggie un caso de emergencia. Sino o guardería o en mi caso ninguna chica.

ZULENKA: Bueno yo no puedo tener la ayuda en de mi mamá que a veces pasa, porque se me enferma la chica o no va o por algún motivo... o llamo para pedir vacaciones a cuenta, porque uno tiene que trabajar. Por una emergencia a veces es así, o por ahí mi jefe me puede apoyar y decir "bueno ya trabaja desde tu casa" pero también me puede decir, porque es un problema "tienes que estar al pendiente con el trabajo que necesitan de ti o que mandes información" entonces no es sencillo, es un día bien pesado porque me ha pasado.

FACILITADOR: ¿Tienes un trabajo flexible que te permite tomarte unas vacaciones en cualquier momento como en estos casos?

ZULENKA: No, es una excepción, pero trato en lo posible de negociar con mi jefe porque si realmente yo no voy a estar, si la chica no está y él bebe esta y se pone mal y tengo que llevarlo al doctor entonces no voy a estar conectada con la computadora. Entonces tampoco voy a estar disponible, porque no voy a estar todo el día, no es que solo sean unas horas, no voy a estar todo el día porque tampoco no tengo con quien se quede. Entonces si es un problema eso de estar pidiendo, a veces ya yo pido que me descuenten el día.

FACILITADOR: Okey, perfecto.

MILUSKA: En mi caso si no sería la guardería ni la nana, sería la abuelita paterna por un tema de que ella tiene la disposición y le agradan los niños. Pero no me agrada y no confió yo por un tema de qué educación le podría brindar un ancianito y aparte que no tiene mucha movilidad. Puede tener la disposición o le pueden gustar los niños, puede querer estar con él, pero a veces los ancianos no tienen la movilidad y de repente tienen otros pensamientos que mi hijo tenga.

FACILITADOR: Aja, son buenos puntos. ¿ustedes son las que deciden sobre el cuidado o también entra la pareja en este caso?

ANGGIE: En mi caso es compartida 
ALLISON: Si, bueno sí.

MILUSKA: Si.

ZULENKA: Si, pero bueno en mi caso no se involucra mucho en que persona, o sea confía mucho en mi criterio.

FACILITADOR: Entonces en este caso, ¿tú eres la que decide sobre el cuidado y donde se queda tu hijo?

ZULENKA: Si

FACILITADOR: Y por ejemplo me han tocado un poco el tema en que confían y desconfían de las personas, pero vamos a tratar de ver un perfil o desarrollar un perfil acá y que características ustedes podrían buscar en la persona que cuidara sus hijos, me han hablado de que tiene temores, pero ¿un perfil ideal para ustedes para que pueda cuidar a sus hijos y no estén solos?

ANGGIE: Una persona con educación, que tenga educación, que sepa hablar bien, que trasmita confianza, que sea recomendada o en la guardería que haya trabajo buen tiempo y que trate bien a los niños, que tiene que gustarle los niños porque a veces hay nanas que son aburridas, no les gustan los niños y a veces se fastidian y transmiten ese fastidio a los niños y una persona limpia e higiénica también.

FACILITADOR: Ya, perfecto.

ALLISON: En mi caso yo preferiría que sea una técnica, que haya estudiado como para auxiliar de niños, de infantes, que tenga proactividad dependiendo de las necesidades de mi hijo, si ve que mi hijo está muy pasivo en ciertas cosas que me lo active, que no se quede quieta, que no se quede en un solo lugar, que transmita paz para ciertas situaciones. En el caso de mi hijo, mi hijo tiene una dependencia con su madre al $100 \%$. Entonces yo necesito una persona, no que remplace mi lugar, sino que al menos le dé la confianza que yo le doy para que él se desarrolle normalmente. Entonces que no le tenga temor al niño, a las reacciones del niño. Eso para mí es importante.

FACILITADOR: Okey, perfecto.

MILUSKA: A mí me agradaría que una guardería más allá que tenga un personal capacitado, sino que sea una cuestión de la guardería como empresa por ejemplo porque toda empresa tiene una forma de ser lucrativo, para existir, pero también puede tener una política dentro de una guardería para pronto educar a los niños en paz, porque esta sociedad es muy violenta, y me agradaría que desde pequeño lo estimulen a ser tranquilo, no ser ansioso, cosa que si yo flaqueo. Sería bueno que lo estimulen en ese sentido y que esas personas sean pasen un test psicológico en el que no sean agresivas y que no tengan antecedentes de violencia física o psicológica en casa, creo que es importante un filtro en ese sentido o denuncias a nivel policial ya que eso constataría que esas personas tienden a ser violentas y ya de por si es conflictivo con uno mismo.

FACILITADOR: Eso de frente lo descartaría. ¿Tú buscarías en el perfil, personas que tengan ese filtro de que no tengan ninguna denuncia o alguna clase de problemas no?

MILUSKA: Si, que sean muy espirituales, es ponerte en conexión con la naturaleza, contigo. Y enseñarle a un niño eso sería muy interesante para ver cómo crece porque a veces nosotros encontramos eso cuando tenemos 20 o 30 años y de pequeño sería muy importante que un niño este con su alma.

ALLISON: bueno, yo creo que es en el caso de cuando tú contrates a alguien, a una sola persona al cuidado de tu hijo, si tú pagas para que tu hijo entre a una guardería, lamentablemente tu como mamá que estas pagando por el servicio, no te dan la chance de estar investigando el cuidado de tu hijo. MILUSKA: Claro, por eso sería muy interesante, pero eso sí, lo de los filtros y el perfil, sí. ZULENKA: Yo creo que tendrías que buscar, porque también tendrías que tener en cuenta que sería para niños más grandecitos que puedan porque el tema de la espiritualidad no lo tienen muy claro. MILUSKA: Sería interesante, si aún no existe la guardería. 
MILUSKA: Pero creo que son una esponjita, entonces de repente el tema de la espiritualidad no lo van a entender, no van a entender que es un alma, pero creo que tanto subestimamos lo que no entienden, que al final quizá puedan entender algo.

ANNGIE: Tengo una amiga que tiene una cuna que justo ella se relaciona con temas así. Hacen imposición de manos y tienen una orientación así.

FACILITADOR: ¿A ustedes les gustaría un perfil de esos?

ANGGIE: A mí personalmente no

ALLISON: No

ZULENKA: No

ANGGIE: No, yo no busco eso, pero estoy de acuerdo con lo que dice Miluska con la parte del filtro.

FACILITADOR: ¿Y tú que buscas en esa parte, en la parte del perfil para ti cual sería?

ZULENKA: A mí me importa mucho, bueno la parte del análisis que ella menciona Miluska me parece importante, eso de todas maneras es importante, pero también que sea una persona, para mí, que se sepa ganarse al niño rápidamente porque los niños, no todos los niños son iguales; hay niños que son confiados, hay otros niños que son desconfiados por algún estimulo que habrá tenido que vaya a saber cuál fue. O de repente la misma personalidad del niño, es así desconfiado. Y que lo haga despertar su creatividad y haga mucho el aprendizaje con juegos, pero sobre todo que estos juegos ayuden mucho a desarrollar su creatividad. A mí me gusta mucho.

FACILITADOR: ¿Te vas más por la parte lúdica?

ZULENKA: Si, a mí me gusta mucho el tema lúdico, es más. A mí me encanta jugar con mis hijos diferentes cosas y que dentro del juego yo les enseño. A mí me encanta particularmente. Pero si bien es cierto son niños pequeños pero justamente cuando son pequeños es donde empiezan a ver hasta dónde pueden llegar y es importante, a mí me parece importante que puedan tener un tipo de limite, sin llegar a la violencia, pero que si sepan "okey, esto de acá está permitido, pero de aquí ten cuidado" claro, también acompañado de un por qué, porque los niños entienden, si tu le dices "¡no! Por esto". Pero si le dices solo un "NO" para mí es un llamado a negarse porque el niño es rebelde.

FACILITADOR: Bien, muy buena respuesta, pero seguimos avanzando, tengo 2 tipos de perfiles; la parte mágica, religiosa, la parte de seguridad y la parte lúdica de cómo serían los perfiles que les gustaría a ustedes. Ahora por ejemplo me gustaría saber, cuando han tenido que dejar a sus hijos con terceros, de esas raras veces que han tenido que hacerlo, quisiera saber si ha sido fácil, difícil, bueno, malo, complicado, lo que ustedes hayan sentido esas veces, reacciones muy puntuales porque entiendo que tienen a la nana, tiene a la cuna, entonces en esas situaciones que no se ha podido ¿cómo es que se han sentido ustedes?

ANGGIE: Yo lo he dejado con mi mamá en una oportunidad, las abuelas tienden a ser más engreidoras, entonces la disciplina que imparte uno en casa, como que desautorizan un poco, porque los abuelos piensan que saben más, como te han criado, son tus padres, entonces piensan que saben más que tú, entonces le dejo a mi hijo y a veces le da solo las cosas que él quiere y no le da lo que debe de comer. Entonces lo que no hizo con los hijos ahora lo quiere hacer con los nietos, entonces cuando ya mi hijo va a mi casa ya está con esas otras costumbres "yo no quiero esto, quiero otra cosa" entonces eso es un poco lo que tienden a hacer los abuelos, tenemos confianza y todo, pero esa parte es la que no me gusta, los engríen demasiado.

FACILITADOR: Esa parte es lo malo para ti, que son engreidores.

ANGGIE: $\mathrm{Si}$, porque tienden un poco a desautorizar.

ALLISON: ¿Pero tu pregunta es al punto del niño o al punto de la reacción de la mamá?

FACILITADOR: La reacción de la mamá, como han visto esa situación, he tenido que dejar a mi hijo con un tercero entonces ¿cómo se han sentido? ¿Fue fácil? 
ANGGIE: Mas o menos porque pienso que va a suceder lo del cambio de actitudes de mi hijo. Porque pienso que cuando llegue a casa va a pasar eso y pienso que se va a repetir.

ALLISON: Yo en mi caso he tenido experiencias totalmente diferentes. Con el mayor, estamos hablando de terceros, no mamá, no papá, no nana. En mi caso cuando tuve a mi hijo mayor yo estaba en la universidad, todavía no había acabado la universidad y me pasó que en tiempo de exámenes lamentablemente mi mamá no podía llegar, mi papá no se podía quedar con los bebes, mi hermano tampoco y pues tuve que dejar a mi hijo con una prima de tercer grado, en el caso del mayor, como mi hija también tenía hijos, no chiquitos pero tenía hijos y le hacían jugar y el feliz, y yo me fui tranquila. En el caso del segundo, crucé la puerta me subí a carro y a los 10 segundos ya me estaban llamando porque no lo podía dejar. Entonces en ningún caso puedes desprenderte de tu hijo por algún tipo de emergencia, siempre te de miedo, siempre te da temor porque de repente no pueden darle de comer, no pueden cambiarle el pañal, o cosas que le pueden pasar a tu niño en ese momento. En el caso del segundo fue más difícil porque ese temor del niño de alejarse de la mamá y hace que la mamá también lo sienta y sienta temor de dejar al niño, entonces hace que ya no quieras y te haga regresar para que te quedes con tu hijo, o te lo lleves o hagas lo que sea. En el caso de mi segundo hijo fue horrible porque cada niño es diferente... En el caso del segundo, como nació con este problema, siempre para el fui yo. Entonces ya en el momento del desprendimiento es más difícil, eso es en mi caso. De acuerdo a los que te haya pasado puede ser más fácil o más difícil de que el niño sea más independiente o no.

MILUSKA: Bueno en mi caso si es que no es ni en la guardería ni con la nana, se quedaría con su abuela.

FACILITADOR: En un caso de un tercero? O no has tenido esa oportunidad?

MILUSKA: No, no he tenido.

ZULENKA: Yo tampoco he tenido, no sé, me imagino en esa situación y no sé. Es difícil esa situación.

FACILITADOR: Si, son situaciones complejas, porque si te fallara la guardería, la nana, con las personas que estamos acostumbrados, ver esas reacciones, que pueden hacer. Por ejemplo, ya sea con la nana, o con las cunas, ¿han tenido algún problema o inconveniente al momento de dejar a sus hijos? ¿Algún ejemplo que tenga?

ALLISON: ¿Al momento de dejarlos?

FACILITADOR: Si, por ejemplo, cuando lo has dejado por ejemplo en la cuna o en la guardería, ¿has tenido algún problema con los encargados, te han dicho algo? ¿Algo ha podido suceder ahí?

ALLISON: Si, la guardería donde está mi hijo ahorita, son dos profesoras titulares y son 4 auxiliares. Una entra desde las 8 de la mañana hasta las 11 y a las 11 entra la otra acompañando a la segunda hasta las 4 o 5 de la tarde. En el salón de mi hijo este año son 25 niños, entonces 25 niños por 4 auxiliares porque la profesora es la que esta adelante haciendo la clase, donde le cuenta cuentos, le hace la estimulación y lo demás y las auxiliares son las que cambian los pañales, llevan al baño, control de esfínteres y todo eso. Entonces imagínate tú 6 o 7 niños, con diferentes personalidades, contando que todos estén sanos, porque cuando están en las guarderías todos los niños se enferman de todo, entonces imagínate que tengas a solo 2 niños con gripe y los otros auxiliares 3 tengan tos, y el otro tenga otra cosa, entonces al final tu hijo te regresa a casa con todas las enfermedades del mundo y es un problema. Por ejemplo, a mí me pasa porque cuando llego al nido, lo primero que quieres es que tu hijo tenga la atención al 100\% de la auxiliar. Para mí el problema es que no se dan abasto en ningún nido, a menos que sean $100 \%$ personalizado, obviamente eso no lo podría pagar, pero cuando es en el caso de nido o de cunas por así decirlo que tienen mucha cantidad de niños, para mí, nunca se dan abasto, nunca, son 5 niños o 4 niños por persona y pues cada niño tiene una personalidad diferente, algunos tranquilos y otro le pueden tocarle 5 terremotos. Entonces ese es el problema. 
ANGGIE: Ellos (las guarderías) se dedican a crecer sin importar la calidad.

ALLISON: Entonces, por más que haya profesoras, supervisoras, médicos y todo lo que tú quieras, no es suficiente para la cantidad de niños por lo menos por el tiempo de adaptación que existe. Empieza el año e inician en marzo entonces tienen un tiempo de adaptación porque piden a los papás que estén presentes una hora, después a medio hora y así va bajando hasta que por fin haces el desprendimiento de tu hijo todo el horario regular. Entonces en el periodo de adaptación que es una serie de llantos desde que llegan hasta que el niño se queda sin aliento, en ese periodo de adaptación ellos no se dan abasto porque cuando ya pasan 3 o 4 meses todos los niños ya están quietecitos, ya los tienen más controlados, pero en el tiempo de adaptación no tienen el suficiente personal, Para mí en ningún nido. FACILITADOR: ¿Entonces aquí la parte inconveniente es el tiempo de adaptación?

ANGGIE: Es que el tiempo de adaptación ¿Por qué? Porque hay niños que lo dejan en la guardería desde los 3 meses y hay niños que los dejan recién desde los 3 años. El niño que tiene 3 meses porque ni cuenta se porque apenas es un lactante, está durmiendo y toma su leche todo el día. Entonces, el niño que tiene 3 años y ha estado con su mamá, con su papá, con su familia y de pronto lo llevas a otro lugar donde hay personas desconocidas y tú simplemente te vas, ese es el niño que te va a llorar, te va a hacer la pataleta, se te va a aferrar a la puerta. Entonces para mí el personal no se da abasto, en ningún lado.

FACILITADOR: Y ustedes chicas, ¿han podido tener problemas?

ANGGIE: El inconveniente que he tenido, es con la higiene, por ejemplo, el realizar como está haciendo las cosas. Me ha pasado que tuve una chica que estaba preparando el biberón y en eso vi que metió la cuchara y se la metió a la boca, entonces lo que pasa es que se quedan los gérmenes en la cuchara y pone la cuchara en el biberón, entonces esas cosas son muy agradables porque pueden adquirir enfermedades, entonces tiene que haber un cuidado con el tema del higiene que es importante, el tema de los pañales y todo eso por lo que son niños más pequeños.

FACILITADOR: Tú vas más por el tema de la higiene, o sea ¿el inconveniente que tú has tenido es por el lado de la higiene?

ANGGIE: Si, por ejemplo, también deben tener un instinto maternal porque hay mujeres que no les gustan los niños, entonces trabajan seguramente por necesidad, pero no le gustan los niños, entonces tiene que gustarle los niños y transmitirle esa confianza para que ellos también se acostumbren. Como le digo, yo tenía una chica, pero la veía como que aburrida con los niños, entonces es una persona que va a estar poco tiempo, seguro le sale algún otro trabajo y se va a ir.

FACILITADOR: Okey.

ZULENKA: Mi problema en el caso de que la criatura se encariña con el personal que la cuida porque está más tiempo que uno. Entonces el niño tiene una percepción de que tiene una mamá y tiene una persona que le da la comida, que le cambia el pañal, que lo hace jugar, entonces cuando se te va esa persona tiene que venir otra persona y también es un proceso de adaptación y es difícil sobre todo cuando el niño es más grandecito. Entonces ese sufrimiento que tiene el niño es lo que no me gusta, porque pasa en la realidad. A mí me paso que tuve que hacer un cambio, la persona se tuvo que retirar y para que entre la otra persona fue bien difícil porque ya el niño se había acostumbrado. Entonces es fuerte para la criatura porque la consideran parte de su familia.

FACILITADOR: ¿Que tanta rotación has tenido de nanas?

ZULENKA: Si pies, no me duran mucho porque a veces consiguen otra cosa o se quieren regresar a su tierra, a veces hay la posibilidad que me recomienden un nana con experiencia pero a veces pasa, se enfermó un familiar, tienen que regresar con su mamá o algo paso con sus hijos porque también algunas son personas ya mayores. Para mi hijo mayor, ha tenido 3 nanas, el menor recién ha tenido un cambio entonces lo que yo he visto con el mayor no quiero que le pase al menor.

FACILITADOR: Okey, perfecto. ¿Miluska algo más? 
MILUZKA: A mí me paso un tema con la infraestructura de la guardería, como es el caso en que algunas guarderías utilizan una casa para hacerlas guardería entonces ocurre que esta casa era grande y espaciosa pero que tenía una piscina y la tapaban con una tolva. Entonces los niños pequeños abarcaban un espacio, pero mientras fueron creciendo ya abarcaban más espacio, sobre todo porque la casa era amplia entonces ellos corrían hasta que descubrieron que había una piscina, entonces todos se pusieron alrededor de la piscina porque para un niño pequeño ver una piscina es algo nuevo, entonces el problema que lima es muy húmeda y tener una piscina en invierno y a los niños que lo mandan súper abrigado.

FACILITADOR: ¿En tu caso entonces lo sacaste?

MILUSKA: Claro, eso fue una alarma para sacarlo de ahí.

FACILITADOR: Bien chicas, lo que quería consultarles era, en caso de que tuvieran que cambiar de guardería o que tuvieran que cambiar de nana, que buscarían, cuáles serían los atributos, que primarían para tomar una decisión de quizá, dejar la nana y buscar una guardería o en caso de que este en una guardería ver la posibilidad de cambiarla.

ANGGIE: Yo si quisiera una guardería porque la experiencia que he tenido con la nana NO es buena. Lo deje con ella y me fui a trabajar, tenía que hacer un tema de mi trabajo cerca a mi casa, entonces cuando llego y abro la puerta veo a mi hijo comiendo frente al televisor de bien cerca, él tiene miopía y no puede estar tan cerca de la televisión, ninguna persona debe estar tan cerca y un niño mucho menos. Ahora, a la chica la encontré en la computadora chateando en el Messenger. Entonces es el problema que yo tengo, no confió porque les pasa eso, se distraen y dejan a los niños como cualquier cosa. Me gustaría una guardería porque el niño va a socializar con otros niños y va a empezar a hacer actividades y no a estar pegado frente al televisor FACILITADOR: ¿Pero qué buscarías en la guardería?

ANGGIE: Buscaría primero que interactúe con otros niños, él ya tiene una edad para ya interactuar un poco más cerca con otros niños.

FACILITADOR: ¿Que atributos buscarías en la guardería?

ANGGIE: Que le enseñen, por ejemplo, que él pueda dibujar, pueda pintar, que este con otros niños, que tenga un espacio más grande para que puedan jugar, que este más desenvuelto porque es un poco tímido. Entonces que sea un poco más suelto, que sea más inquieto como todo niño porque él es muy tranquilo entonces debería jugar un poco más.

ALLISON: En mi caso lo que buscaría para cambiarlo de guardería; uno seria que la guardería tenga espacio suficiente para las vías de escape en caso de emergencia, que estén preparados para cualquier temblor, contenedores necesarios con alimentos, pañales y útiles de emergencia para los niños, porque si bien es cierto puede pasar cualquier cosa, a los niños los sacan y tiene que pasar un buen tiempo para que el papá, mamá o la persona encargada llegue para recogerlos. Mientras que eso pasa el niño no se puede quedar sobre todo si es bebe, no se puede quedar sin alimento o sin cambiar el pañal porque de repente se hace una herida o se pone histérico y aumenta la desesperación de los demás y las profesoras. Dos, que el espacio sea grande, tres; que cada salón sea ventilado por un tema de las enfermedades. A veces las guarderías son casas que las acoplan a cunas, entonces lo que yo buscaría es que tenga ventilación por todos lados para que pueda correr normalmente el aire y así se ventilen y no sean tan propensos a las enfermedades, cuatro, que haya más personal dentro del aula o sea que no sean 4 o 5 niños por cada adulto, que sean de repente cada 2 niños un adulto.

FACILITADOR: ¿Esa sería tu prioridad’

ALLISON: Para mí sí, yo creo que una persona se puede hacer cargo de 2 niños, que podría manejar con 2 adultos por lo menos 3 niños que obviamente si el espacio es grande, si tiene más de un piso que haya seguridad, que no se puedan escapar porque los niños son muy curiosos abren las puertas salen corriendo y les puede pasar cualquier cosa. El tema de seguridad prima sobre todas las cosas, 
que haya una persona encargada en el caso de la guardería dónde está mi hijo mayor. Que tenga un horario razonable, que sea como un horario de oficina porque normalmente las cunas algunas son hasta el mediodía, otras son hasta las 2 de la tarde y la máxima que encontraba es hasta las 5:30 y 6:00 de la tarde entonces, siendo realistas aquí nadie sale del trabajo a las 5 o 4 o 3 o 12 del día entonces eso te obliga no solamente a pagar la guardería sino a pagar una persona extra.

FACILITADOR: es un paquete muy grande el que has hecho (risas). Miluska o Zulenka, ¿algo que agregar a lo que ha expresado Allison?

MILUSKA: creo que a mí me agrada mucho lo que dijo Alisson, el tema del horario porque considero como que como profesionales tenemos mucha responsabilidad entonces a veces tú quieres salir y no te dejan salir. Entonces por el tema de la carrera lo que significa para mí me gustaría una propuesta que por lo menos sea hasta las 7:00 o 6:30 y en Casos excepcionales que se queden hasta las 8 pero eso es de forma excepcional, si me tienen que cobrar más que me cobren y aparte de eso, el horario no creo que tampoco sea como una cárcel si no creo que me gustaría o sería muy atractivo que una guardería que tenga una razón de ser que tengan corazón y me gustaría mucho que haya alguien que sea bilingüe o poliglota que pueda hablarles en otro idioma ya que a los 2 años o un año los niños escuchan a otra persona hablando otro idioma y lo toman como suyo o a relacionarse cómo los niños interactúan.

ANGGIE: Yo agregaría la parte psicológica que es básico porque hay niños que vienen con problemas de su casa entonces en esos casos también ayudarnos para informarles a los padres.

ALLISON: Yo no sé si les ha pasado pero en el caso de una cuna hay una psicóloga previo a que el niño ingrese a las clases regulares o a las sesiones regulares, la psicóloga te entrevista a ti y lo primero que te pregunta es si estás con el papá del niño, o sea si tienen una familia realmente constituida, si son católicos o qué religión tienen porque también hay niños que si tú lo estás criando en tu casa de una religión distinta entonces hay que respetarla sea quien esté. Entonces te pregunta cómo es la relación con el papá de niño con la mamá, si eres padre soltero o madre soltera, cómo es todo ese tema y eso es básico.

ANGGIE: he visto ejemplos de niños donde los padres están juntos y tienen un niño que tiene un perfil agresivo, de jalar el pelo a la niña, entonces eso no te ayuda. Mucho mejor es observar al niño hacer y un diagnóstico, hacer una evaluación a los niños bastante compleja y ahí se van dando la nueva información.

FACILIDOR: ¿en tu caso Zulenka?

ZULENKA: Para mí es importante la atención una persona que se encargue de mi bebé. También es muy importante el tipo de alimentación, yo soy una vegetariana y mi niño quiero que también lo sea entonces si yo lo llevó a una cuna no sé si hay que llevarle comida o ahí cocinan no sé.

ZULENKA: El tema El horario es importante porque si me dicen que recoja mi hijo a las 5 de la tarde definitivamente no voy a poder entonces tiene que estar cerca de mi trabajo para que yo pueda llegar creo que es bien importante.

FACILITADOR: Y por ejemplo en el caso de la guardería ¿qué método de pago utilizan? ¿Qué tipo de pago hacen?

ZULENKA: Claro es dinero, no es tarjeta de crédito.

ANGGIE: Sería factible con tarjeta de crédito o débito.

ALLISON: En mi caso es descuento por planilla porque mi esposo es del estado, mi esposo es marino entonces le hacen el descuento automático de la Marina. Pero si son civiles, ellos si tiene que pagar en efectivo, no se aceptan ningún medio de pago que no sea efectivo.

MILUSKA: si, en efectivo también, pero sería interesante que la guardería acepte débito o crédito o un depósito a cuenta. 
ZULENKA: Una cosa que me pasa mi es que aparte del abono yo tengo que pagarle su seguro, tengo que estar guardando dinero para la CTS porque es por ley porque tienen un contrato para las personas que trabajan en el hogar. Entonces a mí se me complica porque si fuera todo de golpe me afecta económicamente, entonces tengo que estar viendo eso.

ANGGIE: Yo no tengo una referencia sobre una guardería, pero sería bueno que atiendan todo el año. FACILITADOR: Y por ejemplo las personas que usan la guardería, ¿han visto otras guarderías donde tiene a sus bebes? ¿Por la zona si han visto alguna con una ventaja o desventaja, les gustaría algo más?

ALLISON: yo no estoy satisfecha al $100 \%$ porque para mí hay muchos niños para tan poco personal y eso llega a consecuencias a tu hijo, que un día regreso con alguna herida, o que le jalan el pelo o se cayó. Por otro lado, si he visto cunas por mi casa, pero son casas adaptadas a cunas y no me gusta. En cambio, en la cuna donde mi hijo esta ahora es un buen espacio, de un solo piso, campo amplio, salones separados, corredores de emergencia, eso es lo principal. Que tengan un espacio amplio, entonces eso es uno del os beneficios que he visto en esta cuna y no he visto en las demás.

FACILITADOR: ¿y tú que has visto Miluska?

MILUSKA: Yo he visto otras guarderías, pero no me han parecido atractivas por el hecho de que son casas $\mathrm{Y}$ en parte también porque son pequeñas y porque no tienen ningún filtro de ingreso Entonces por aceptar dinero pueden aceptar a cualquier niño puede tener pueden ser niños problemas o con algún tipo de trauma.

FACILITADOR: ¿tú que buscarías entonces?

MILUSKA: yo más que Todo un ambiente Pacífico que tenga la infraestructura Adecuada para que no se lastimen Eso me parece importante y Que tengan flexibilidad en los horarios y que le enseñen. MILUSKA: Yo discrepo un poco, yo creo que está bien ser inclusivo Explicarles a los niños que existen diferentes tipos de niños y ser solidarios con ellos pero no me parecería muy atractivo porque puede generar un impacto.

ANGGIE: yo voy a contar una experiencia. Tengo 1 sobrinos que tuvieron una compañera con síndrome de Down Ellos comenzaron desde inicial, desde pequeños Entonces esa niña a pesar de tener esa enfermedad se ha desarrollado muy bien Sus compañeros le han ayudado a ella a desarrollarse bien incluso tuvo su fiesta de quince años donde todos sus compañeros asistieron.

Entonces eso a ellos les enseñó a madurar hacer más solidarios darse cuenta de que ellos son privilegiados al no tener esa enfermedad

FACILITADOR: Interesante todos eso puntos que se mencionaron. Ahora, ¿ustedes han escuchado del método DOMAN? Voy a mostrarles in video para que sepan a grandes rasgos cual es este método. FACILITADOR: ¿Qué métodos han visto que han utilizado en las guarderías donde están sus niños? ANGGIE: Yo he visto algo parecido por ejemplo me ha pasado con mis sobrinas Qué le ponía en la dirección de la casa en una pizarra porque la memoria es gráfica Todo lo que aprendí a la entrada por lo visual y así iban aprendiendo más Y así fue como si grabaron La dirección Incluso el teléfono y no Se olvidaron más

ALLISON: Yo conozco el método Montessori Y era que en casa se le tenía que hablar de manera positiva todo decirle de manera positiva. Entonces creo que por esa parte le llegaba mejor a los niños. ZULENKA: No conozco yo no conozco un método con nombre y apellido.

MILUSKA: Yo tampoco.

ANGGIE: He visto otros más o menos como que aprenden números con los cubos Como que aprenden jugando es algo mucho más creativo que hace que el niño capel atención más rápido Y que aprenda.

FACILITADOR: ¿Que les pareció este método?

ZULENKA: Y la verdad Qué interesante no sabía qué se podía hacer eso con niños tan pequeños. 
FACILITADOR: ¿vieron alguna desventaja del método?

ALLISON: No podría quizá identificar ahora un defecto por lo mismo que la información ha sido un poco corta Pero lo que sí me gustaría es saber el proceso de cómo la niña aprende mediante la imagen de la dirección de su casa, por ejemplo. Quizá requiera un poco más de información sobre las repeticiones por ejemplo según la edad, cuanto tiempo tardaría el niño.

FACILITADOR: como ya sabes, este es un proyecto de una guardería. Entonces ahora les voy a mostrar la ubicación exacta de la guardería. Entonces, la guardería se va a ubicar en la zona central de San Isidro, más o menos Química Suiza, por el edificio Interbank. Así que en nuestra guardería aplicaríamos el método Doman teniendo en cuenta toda la información que ahora ustedes nos están brindando. Ahora que ya conocen más sobre la guardería, me gustaría saber ¿cómo les gustaría que fuese la distribución de la guardería?

ANGGIE: Me gustaría que sea en un piso con un baño por cada salón para niños y otro para niñas, que la cocina este separado de las aulas, que el patio de juegos este con horarios distintos por la edad de los niños.

MILUSKA: A mí me gustaría Que sea de un piso, que tenga salones especiales para los niños y que tenga áreas verdes para que ellos puedan jugar.

ALLISON: Me gustaría que la cocina esté separada de las Águilas en caso de que la guardería tenga ese paquete de alimentación, Para mí también debería haber un pediatra Porque en algún momento puede tener un problema algún niño y me parece que para eso temas Se necesita auxilio inmediato Como por ejemplo ponerle crema si se raspó o alguna venda si se cayó.

ZULENKA: Para mí lo más importante es el tema de los horarios. Si la guardería tiene un segundo piso pues hay que ver la manera de tapar la entrada a ese segundo piso.

FACILITADOR: ¿Qué niveles de seguridad buscaría en una guardería? Quizá con la infraestructura O con el área del personal.

ANGGIE: Tiene que haber ventilación por el tema de los olores que puede haber.

ZULENKA: En el invierno para mí también porque debería tener un ambiente adecuado Porque los niños se enferman muy rápido con el frío.

ALLISON: En mi caso Yo creo que todo Debería ser de cemento Porque hay lugares que los dividen con material drywall.

MILUSKA: yo no tendría ningún problema con el drywall pero si quisiera que tenga áreas verdes. Con respecto a la seguridad me gustaría que tengan cuidado con Los enchufes Porque en mi caso soy una de las afectadas cuando era niña así que me parece importante.

FACILITADOR: ¿Y con respecto a el monto a pagar? ¿Qué precios estarían dispuestas a pagar?

MILUSKA: Hasta 1550 podría pagarlo.

ANGGIE: creo que debería ser también por edades, porque los bebes testan en una etapa distinta. Son muchos los gastos que hay que hacer por un bebe y los niños más grandes ya no usan pañal, pero son más traviesos. Una niñera por ejemplo tiene a cobrar más cuando son bebes que cuando son niños más grandes por lo mismo que necesitan más cuidado.

ALLISON: En mi caso es distinto porque más caro me cobran cuando los niños son más grandes. Por el mismo hecho de que son más Inquietos un poco malcriados entonces por eso es que me cobran más. FACILITADOR: ¿entonces cuanto sería el rango que pagarían ustedes?

ZULENKA: Yo podría pagar hasta 1800 soles es lo máximo que podría pagar. Pero con todos esos atributos, lo de la comida, la seguridad, La disponibilidad del horario también por qué estamos hablando de que el niño por lo menos se va a quedar hasta las 7 de la noche.

ALLISON: Un punto importante para mí es que los padres deben de firmar un acuerdo por escrito de no manda a sus niños Si es que están enfermos.

FACILITADOR: ¿Y cuál sería el método de pago como el que ustedes sentirían más cómodas? 
ALLISON: Todos los métodos de pago.

ZULENKA: Por débito.

MILUSKA: Que haya la posibilidad que lo carguen a tu tarjeta.

ANGGIE: Otra cosa que me gustaría en particular es que los niños tengan lockers con sus nombres para cada uno.

FACILITADOR: Vamos a hablar sobre el tema de la comunicación ¿Cuál Creen ustedes que sería el medio de comunicación de una guardería? ¿Cómo se debería dar a conocer la guardería?

ANGGIE: Yo creo que sería suficiente con el Facebook y por correo. Para mí sí sería el Facebook para las promociones y publicidad, por ejemplo

FACILITADOR: Y para mantenerse comunicado con la guardería, que medios les gustaría tener?

ALLISON: El teléfono y el celular de la guardería y de la profesora. Y por ahí también grupo

WhatsApp donde se puedan coordinar algunos pagos y actividades que se realizan durante el año para los niños y las llamadas directamente con la profesora.

ZULENKA: A mí lo que sí me gustaría es acerca de cuándo a los niños les mandan a hacer actividades en casa Cómo enseñarle el disfraz al niño, pero como yo no tengo disponibilidad de tiempo para hacerlo quizá podría la profesora o las auxiliares facilitarme ese tipo de actividades porque no dispongo en tiempo como para hacer el disfraz por ejemplo.

FACILITADOR: Entonces, a partir de toda la información que les acabo de brindar ¿Ustedes estarían dispuestas a contrataran a la guardería?

ALLISON: Para mí el contra sería que no tiene dónde estacionarse. Normalmente los trabajadores de Interbank de química Suiza de DELTRON Y todos los negocios que están por ahí cogen el estacionamiento de atrás.

FACILITADOR: Voy a aclarar algo con respecto a ese tema, Que la guardería tiene un estacionamiento para 8 cocheras Y además estamos hablando de una doble vía por ambos lados. Entonces ahí de repente cambia un poco la manera de ver a la guardería con respecto al estacionamiento y a la ubicación.

ALLISON: ¿Desde qué hora seria la atención? Porque hay personas que recién a las 7 salen de trabajar, otras a las 8 .

ZULENKA: Si los horarios de recepción de los niños van a ser fijos o amplios porque no todos entramos a trabajar a la misma hora.

FACILITADOR: El horario que estamos proponiendo nosotros de 7 de la mañana a 7 de la noche.

ALLISON: Yo si contrataría el servicio.

MILUSKA: Si, si cumple todo lo que hemos dicho.

ANGGIE: ¿Pero hay tolerancias?

FACILITADOR: $\mathrm{Si}$, siempre hay tolerancias.

ALLISON: ¿Y cada cuanta hora les estarían dando alimentos a los niños?

FACILITADOR: Esa es una muy buena pregunta y la vamos recién la vamos a tomar en consideración.

ALLISON: Para esto deberías tener por lo menos unos 3 turnos de personal porque trabajar con niños es más estresante de lo normal.

FACILITADOR: Y con todo lo que hemos conversado ¿ustedes recomendarían a sus amistades esta guardería?

ZULENKA: Yo sí, si es buena. Porque hay muchas mamás que al igual que yo quieren que le solucionen ese tema

FACILITADOR: Bueno chicas gracias por todo su tiempo. Estoy muy agradecido por la información brindada. 


\title{
Apéndice J
}

\section{Transcripción de variables ENTREVISTA A EXPERTOS I Entrevista a Directora Cuna Guardería Optiland y Staff de profesora}

\author{
Nombre: Lic. en Educación Ludgarda Barriga \\ Cargo: Directora de la Cuna Guardería Optiland y Staff de profesoras. \\ Lugar: Calle de Pietro Torriani 380 San Borja
}

ENTREVISTADOR: Estoy aquí con la miss Leonarda Barriga y con las misses que trabajan con ella para poder realizar la entrevista a expertos en temas de guarderías. Entonces, voy a comenzar la entrevista con la miss Leonarda que nos va a contar brevemente como nace la idea de implementar el proyecto de la guardería que ella maneja que es la guardería OPTILAND.

LIC. BARRIGA: Hola hijita como estas, mira este proyecto nace viendo la necesidad fundamental de todas las mujeres, de las personas que trabajan en la empresa Optical. Cuando se hizo una encuesta habían de 100 trabajadoras, el $80 \%$ eran mujeres que estaban en la edad reproductiva, de esas $80 \%$ el $60 \%$ ya tenían niños menores de 3 años y el resto estaban embarazadas tenían bebes muy pequeños y esas eran las problemáticas o la necesidad urgente de la empresa.

Nace esta idea a raíz de esto, para que llegue a hacerse realidad lo que nosotros tenemos, se ha pasado por muchas etapas, plantear como solventar el gasto de una guardería, ese era la prioridad, en donde ponerla, para que, las sedes para que puedan traer a sus hijos, de acuerdo a eso se hizo un estudio, se elaboró este proyecto y ver de dónde nace la matriz de nuestra cuna guardería. No solo tenemos acá, que es guardería cuna que es de los cero meses hasta los 3 años, sino que también nosotros damos una educación integral de acuerdo a las edades, a los bebes los vamos trabajando sensorialmente, motrizmente, vamos despertando en ellos otro tipo de conocimientos, así sean pequeñitos ellos van a adquiriendo en la edad de 2, 3,4 o 5 meses, ellos van despertando todas sus destrezas motoras, auditiva, visión, es un mundo trabajar con ellos. Yo soy profesora de primaria, yo estoy gateando alrededor de ellas. Pero estoy aprendiendo no sabes cuánto.

ENTREVISTADOR: Si me imagino miss.

MISS BARRIGA: Nosotros acá, cuando hicimos el proyecto, mucho depende de cuánto la empresa quiso invertir en la cuna porque aparte de que hay que inscribir el local hay que implementar la cuna, que necesitábamos, que cantidad de niños podíamos atender de acuerdo al local, se abrió este local, vimos otros, dijimos bueno este está bonito pero no iba a pasar de 20 niños, bueno cuando agarramos este vimos acá entramos 30, apretaditos 35 y es ese el foco que tenemos acerca de 30 niños, entonces ya estamos a nuestra capacidad máxima en la cuna, gracias a dios y a la virgen que nos ilumino que hemos tenido la suerte de contar con un equipo de chicas que son muy profesionales en su campo y realmente que las auxiliares son chicas muy cariñosas, muy cuidadosas con los bebes que es lo que se quiere, un poco maternales. Sino para que quiero soldaditos. Basta conmigo, no solamente estamos atendiendo a los hijos de la empresa, sino por ahí tenemos uno o dos niñitos que son de la comunidad, que son vecinos que se han enterado de que quieren, y muchos me piden no solamente cuna o guardería, me piden primaria o jardín. ¿No tienes 4 o 5 años?, me preguntan. No tenemos por ahora, primero queremos pisar bien, después vamos a crecer. Es más, mira, uno de nuestros objetivos acá que tenemos es crean un espacio donde funcione la guardería. Ese es nuestro primer objetivo, que sirva de enseñanza atención y cuidado de los hijos de nosotros colaboradores de Optical Network. Tranquilizar y minimizar las preocupaciones de Optical. Tú sabes que cuando los papás en el trabajo no sabemos dónde está nuestros hijos, como están cuidados, quienes lo tienen, donde los tienen, y no estamos tranquilos, y iqué pasa? Nuestro trabajo se ve mellado porque no podemos dar el $100 \%$, siempre vamos a estar preocupados, mecánicamente trabajando, pero tu cabeza está en otra, quien los 
mira, donde está, como esta. Entonces aquí tiene la facilidad, la oportunidad de que aparte de que es cero costos, los niños están bien cuidados. Ustedes también los pueden monitorear desde sus celulares o computadoras, porque la cuna tiene un circuito cerrado de cámaras donde los papás pueden acceder a las cámaras.

ENTREVISTADOR: Ok. Yo quería un poquito que nos comente sobre su opinión en general de la educación inicial, para esta etapa de cero a 3 años.

MISS BARRIGA: Es fundamental, si el niño no está bien trabajadito, no recibe las estimulaciones de acuerdo a las edades, como cualquier niñito de la calle va a aprender según como ha sido criado, su entorno social dice mucho, los niños pequeños necesitan ir a su edad de vida a un jardín, a centro de estimulación.

ENTREVISTADOR: Entonces es fundamental.

MISS BARRIGA: Sí, es fundamental. Si es posible que los padres tengan las facilidades de llevarlos a cunas a guarderías o a centros de repente, no todo el día, si ellos disponen del tiempo de estar en casa que los lleven a centros que le den estimulación temprano. Ustedes han llevado sus cursos de estimulación temprana, Cintya que ella trabaja con los más pequeñitos, de acuerdo a las edades te pueden ir hablando cada una de ellas. Daniela por ejemplo que ella trabaja con niños de un añito. ENTREVISTADOR: Haber miss ustedes nos pueden comentar más o menos ¿cuáles son las necesidades de los niños de un añito?

MISS DANIELA: Primero para ayudar un poquito al panorama que me decías de la estimulación temprana, primero hay que aprovechar los 5 primeros años de vida de los niños, porque es el momento más importante. Es decir, Es donde el cerebro está más fresquito, es como una esponjita, así decía Maria Montessori donde los niños absorben toda la información si hablamos de los términos clínicos y psicológicos, podríamos decir que el cerebro pasa por un momento que se llama plasticidad neuronal, es el momento en donde el niño absorbe esa información esa la sinapsis mucho más rápida, entonces la estimulación temprano es realmente favorable durante los 5 primeros años de vida por que el niño recibe la información mucho más rápido que lo normal de otros niños, más adelante, mientras más temprano adquiera esos conocimientos mucho mejor, y con respecto las necesidades de los niños que en realidad en toda cuna se necesita pues, básicamente es tener un desarrollo integral ¿qué es lo que quiere decir? Enfocarnos en todas las áreas de la persona, no solamente en lo cognitivo como antes era, en la escuela antigua todo era muy mecánico, muy que el niño se tiene que sentar, que el niño se tiene que mover, solamente el niño recibe la información, entonces en este caso para lograr el desarrollo integral en el niño es importante que sea una información como un feedback como una retroalimentación, tu les das un información al niño, sin forzarlo y el niño responde a esa información, no es que el niño queda ahí, y entonces los niños comparten absolutamente todo con las experiencias significativas que son; el entorno social, ambiental, entonces, se trabaja las diferentes áreas del ser humano, que son las cognitivas, el área social, el are de lenguaje, el psicomotriz, que abarca lo que es psicomotricidad fina, psicomotricidad gruesa. Entonces lo primordial es eso, y sobre todo estimular al niño a ser un niño independiente, un niño social, un niño que sea fuerte para la vida, porque si nosotros llegamos a lograr todo esto, vamos a tener niños exitosos, que puedan valerse por sí mismos porque hay momentos donde mamá o papá no van a estar entonces si se llega a lograr todo eso, van a tener una etapa educativa en la primaria y en la secundaria muy favorable.

ENTREVISTADOR:¿Y qué recomendaría usted a los padres que trabajan y tienen que dejar a sus hijos al cuidado de terceros?, quizá una alternativa sea la guardería, hay también padres que dejarlos con nanas o derrápenle un familiar. ¿Qué consejo o cual es la opinión que usted tiene sobre eso? MISS DANIELA: Bueno, Yo considero que la estimulación temprana es favorable, más no todo el día porque el niño de por si se cimienta en la personalidad con el afecto, quien se lo brinda con los principales ejes son los padres, si el padre le brinda la seguridad y el afecto que necesita entonces ese 
niño va a ser un niño muy seguro de sí y va a poder trabajar completamente. Entonces en lo personal yo pienso que si es importante la estimulación temprana, pero hasta un cierto tiempo, no todo el día porque a veces el niño se sobre estimula, no tiene ese factor principal que es el afecto de los padres que eso lo más importante porque al final el afecto, no se puede comprar con absolutamente nada, ni con los videos, ni con las galletas, ni con los regalos, ni con los juguetes.

ENTREVISTADOR: Y cuál es la opinión que tendrían de una guardería, como es en el momento actual y que cosas le faltaría, no sé si en términos legales o sociales para que pueda ser en el futuro ¿No sé si me dejo entender?

MISS CINTHYA: O sea ahorita, en la actualidad, una guardería y ¿que podría ser? ¿En la estructura? MISS CINTHYA: Bueno a mi parecer, Yo creo que mientas más vamos avanzado, si la Directora no tiene bien establecido el personal que va a ir a buscar a esa guardería, ya no vas a encontrar esa cariño, esa paciencia, ¿por qué? porque una persona puede ser muy profesional y no tienes esa conectividad con los niños, ese apego, ese cariño, puede tener impecablemente su curriculum, pero si no tiene esa conectividad con los niños de nada sirve.

ENTREVISTADOR: ¿Empatía?

MISS DANIELA: Más que nada vocación.

MISS KENYA: Si hablamos en la parte de infraestructura, si te proyectas para un futuro tienes que tener espacio, los accesorios, los materiales, que sean acorde a cada niño y a cada edad. Ojo, hay que tener también en cuenta que cuna es otra cosa, guardería es otra cosa, jardín es otra cosa. Entonces acá funcionan 2 cosas importantes, una porque lo que están enseñando de 0 a 3 , y otra enseñanza en un aula pedagógica, no solamente es cuidar, muchas veces escuchamos a los papás que dicen, solo cuidan. Como le digo a un compañero, yo no he estudiado 5 años para cuidar un niño, yo he estudiado para enseñar y a su vez tener en cuenta lo cuidados básicos de los niños, todo es una fusión.

MISS CINTHYA: La educación inicial se divide en 2 ciclos. el primer ciclo es de 0 meses hasta los 3 años. Entonces ahí es donde quieras o no, es más difícil porque son niños más pequeños a los cuales uno les brinda conocimientos. Actividades pequeñas donde ellos van a ir aprendiendo y esas actividades significativas, para ellos es muy importantes porque uno no trabaja con niños, trabaja cerebros. Y esa es la diferencia

MISS DANIELA: Y forma personas al final.

MISS KENYA: El objetivo final es formar a personas.

MISS DANIELA: Ahora por ejemplo están implementando la educación a otro ritmo, me decías también como podría ser a futuro y pienso que tendría que ser seguir trabajando con darle educación algo más libre.

MISS DANIELA: Más libertad, más arte, más música, más libertad de que los niños puedan expresarse libremente, pintar, ensuciarse, sin tener el foco antiguo, no que no se ensucie, de que no se embarre, que no coma así, que coma acá. Que mejor no se junte con este amigo. No hay que obligarlos demasiado.

MISS KENYA: Lo que paso que la educación tradicional de antes era así. Ya siéntense y todo lo que el profesor escribe, todo tenemos que hacerlo entonces no, hay que dejar a los niños tengan esa expresión esa libertad donde ellos crean sus propios juegos.

LIC. BARRIGA: Acá, lo dejamos así, por ejemplo las miro y les digo ¿a qué hora comienzan a hacer algo? Miss están haciendo, recreando, ellos tienen su hora de venir de entrar de jugar, entonces es cierto ¿qué estás haciendo Cinthya? Miss están jugando se están saludando y se están abrazando. MISS DANIELA: ¿Que guarden los juguetes? No, porque los juguetes los guardamos en la caja entonces el otro mira, no es necesidad de plantearle, guardas acá y guardas acá. Entonces ellos ya lo saben. Entonces ven a uno, adquieren el conocimiento del otro, entonces sin querer, sin tener algo estructurado, ellos ya logran hacer muchas cosas en realidad, empatía, sociabilización, comunicación, 
hasta el mundo matemático. Que, porque este es el lobo, el lobo hace "uuhhh" pero acá hay 2. Entonces para ellos desarrollar muchas cosas.

LIC. BARRIGA: Es que eso no saben los papás. Entonces para nosotros lograr que un niño te entregue, por ejemplo uno de 6 o 7 meses, una pelota le dices dame y él bebe te mira y te lo da. Para nosotros es una alegría.

MISS CINTHYA: O que simplemente gateen.

MISS DANIELA: Porque sin querer ese contacto que ha hecho con la miss es sociabilización, o sea, y ese contacto es principal porque ya lo logra con la miss entonces ya lo puede lograr con el otro compañero.

MISS KENYA: Entonces el niño va air sociabilizando, por ejemplo, cuando están conmigo yo no solo dejo que el niño este conmigo y con los auxiliares, no, los niños tiene que conocer a todas porque ese niño va a crecer y va a estar con otras misses, el niño tiene que estar con todos. Tienen que ver, cuando estamos en un sitio por ejemplo y llega otra persona, hay niños que lloran porque no están acostumbrados porque el papá le dice algo.

LIC. BARRIGA: El problema no es el niño, el problema son los padres, que no se ensucie, que no quiero que lo besen a mi hijo, no quiero que lo estén abrazando, es una cosa si hay papás que dicen ¿qué tiene? Yo estoy mirando que lo están besando que lo están abrazando no. No quiero. Entonces uno dice por dios.

MISS DANIELA: Y al final los signos de cómo han avanzado y de los logros se ven al tiempo, por ejemplo, nosotros tenemos niños que ya están más de un año con nosotros y hay niños que eran muy ariscos. Yo tengo casos y ahora son niños muy sociales muy empáticos, abraza, besa, entones se ve el logro nosotros podemos decir que hay muchos logros dentro de la cuna porque tenemos niños que ya están más de un año con nosotros prácticamente hacen el aniversario con nosotros.

LIC. BARRIGA: Algunos se han ido, ya están en jardín que han entrado con nosotros en febrero porque el 1ero de marzo han entrado a sus jardines, nos da muchísima pena, pero nuestros logros son las respuestas de los papás por el WhatsApp, felices porque las profesoras han dicho que han recibido unos niños muy preparados, sociales líderes, muchos de 3 años hacen cosas que no hacen los demás. Eso es un logro para nosotros. Nosotros felices. Qué bien que los papás.

LIC. BARRIGA: Y ahora ellos dicen "nos damos cuenta todo lo bueno que recibieron en la cuna", ellos decían "ellos están saltando, ¿qué van a hacer saltando todo el día?" Pero para nosotros era lograr un objetivo, saltan un mes. Pero ya sabemos que se va a lograr saltando, corriendo, caminando. MISS KENYA: La enseñanza es todo jugando, así sea en cuna o sea en jardín. Todo es jugando. Jugando ellos aprenden.

ENTREVISTADOR: Y cuál es la distribución que se hace con los niños porque nos comentaban, que no es lo mismo el cuidado de un bebe de 3 meses o 4 meses, que el de un niño de 3 años. O sea ¿cuál es la distribución ideal?

LIC. BARRIGA: Yo los tengo acá de cero a 8 meses, lo tiene la miss Cinthya, bueno generalmente no los traen a los 0 meses generalmente los traen a los 2 meses y medio, con dos meses son bebes muy pequeñitos que siempre hay que seguirles sus sueños, cuando duermen, porque son tan pequeñitos no hablan y no hacen más que gestos o que si lloran es que tiene hambre o están sucios o les duele algo y ahí van siguiendo sus etapas de desarrollo hasta los 6 meses 9 meses cuando el niño de 6 meses ya logro sentarse, ahí gatean y ya pasa a la profesora de 9 meses que es Kenya de los 9 meses o 10 meses ella los afianza lo que es el gateo y comienza lo que es prepáralos para caminar, todo su proceso de motricidad ya más fina, más gruesa, cuando ya logran estabilizar su caminar, logran también relacionarse con los demás niños, ya pasan con la miss Daniela que ella ya los trabaja a partir de año y medio hasta los 2 años y 2 meses ya pasan donde Carla que son niños más independientes. Carla ya hace la secuencia de quitarle el pañal porque hasta esa edad porque acá cuando vienen de 
pequeñitos ya están maduros, ya están independientes ya razonan ya eligen y también es más fácil quitarles el pañal. Su control de esfínteres ya los hace Daniela que anda quitar el pañal y los lleva a baño de niños que ya también tienen que ir al baño y hacen.

ENTREVISTADOR: Miss y ¿Cuál es el número ideal de niños para que puedan estar, por cada miss y por cada auxiliar?

LIC. BARRIGA: Mire eso es relativo, puede ser que hayan 10 niños, eso es manejo de la profesora, pueden haber profesoras que son pilas que pueden trabajar con 10 o 12 niños y hay también profesoras que también de acuerdo a la cantidad de niños, también de acuerdo la edad, o al material que tengas porque hay niños que son engreídos, berrinchudos, que necesitan más cuidado, que hace, tengo que cuidarlos más sin disminuir la carga de niños pero lo normal una maestra con su auxiliar esta con 10 niños que es lo que tenemos acá, cada profesora tiene, en el caso de Daniela tiene 2 auxiliares en el caso de Cinthya tiene 2 auxiliares, Kenya tiene 1 auxiliar porque no tiene muchos bebes pero si en el caso ella tenga más niños va a tener que contar con otra auxiliar más. Pero carlita si tiene un auxiliar porque ellos son niños más grandes, más independientes, no hay que estar dándoles de comer en la boquita, ya solos logran comer a los 2 años,

ENTREVISTADOR: Y respecto al tema de la guardería como tal con que cosas se han encontrado en el día a día. Positivas o negativas. Problemas.

MISS BARRIGA: Acá mis misses te van a hablar cantidad por montones.

MISS CINTHYA: Bueno, yo tengo bastantes problemas que a veces las mamás, yo las puedo entender porque ellas trabajan, pero quieras o no eres mamá y a veces los mandan enfermos o están con fiebre o están con vómitos entonces es algo contradictorio. Mi querer ayudarla y ayudar al bebe también puede ser que se enfermen los demás entonces a veces ahí es fastidioso porque me los envían enfermos, otra cosa es que a veces no me envían las cosas que se pide, entonces yo tengo que estar ahí peleando que me envíen ropa, pañales cosas del niño.

MISS KENYA: También con el tema del horario, por más que tengas 2 años o estén más grandecitos, igual ellos esperan a sus papás.

MISS KENYA: Son como un reloj porque mientras llega la horade salida, ellos ya están en la ventana y están mirando.

MISS DANIELA: Y si se sienten solos peor porque ya ahí si rompen en llanto.

MISS KENYA: Porque está viendo que sus compañeritos se están yendo, entonces ellos por más pequeños que sean ellos entienden entonces eso hay que respetar también son pequeños, pero también son seres humanos y se les tiene que respetar.

MISS CINTHYA: ¿Y eso es por qué? Porque, no muchos saben, pero en si la estimulación temprana ¿porque sale eso? Porque nace esta estimulación temprana porque eran para que trabajen madre e hijos. Era para que hubiera esa conexión. La estimulación temprana no es que vengan los niños, se crea la estimulación temprana para que el padre y el niño tengan esa conexión y trabajen a la par. Pero se hace el cambio porque los padres tienen que trabajar y dejan a sus niños, entonces como dice la miss, los niños llegan a cierta hora, ya se cansan, se saturan, entonces a veces los papis yo me imagino que por el trabajo o diferentes cosas es que no llegan a su hora.

LIC. BARRIGA: Y no solo los bebes de 2 años o 1 año, lo bebes más pequeños ya saben que ya sienten ya porque no hacemos secuencias, ellos ya saben que tiene que irse con mama y cuando no viene a la hora lloran, no quieren nada, llega un momento en que en su cabecita ellos quieren a su mamá y su mamá, y lloran y lloran, y no quieren con nadie, con nada se quieren calmar, estamos, Dios mío que venga rápido y no es porque lo queramos sacar sino porque los bebes quieren a los papás, acá todos somos mamás y llega un momento en que tu hijo quiere estar.

MISS DANIELA: Yo creo que este factor que hemos visto a lo largo de todo este tiempo, se tiene que dar no solo con la profesora, sino también con los padres principalmente que es el respetar el proceso 
de aprendizaje de los niños, no exigir, no miss pero mi hijo ya tiene 2 años ya tiene que hacer pichi, ya tiene que ir al baño, si pero si el niño no siente, no está preparado, forzarlo es peor, porque le voy a crear un trauma, porque no va a querer, de repente va generar algo posteriormente y así con varias situaciones. Es importante respetar el proceso de aprendizaje del niño y no forzarlo y decirle pero miss ya quiero que camine, tranquila, este proceso va a darse sea como sea el niño va a caminar, sea como sea va a dejar el papá, sea como sea el niño va a aprender el color rojo, sea como sea va a aprender, porque no necesariamente tengo que yo imponerle algo, sino que el niño va a aprender justamente como te decía, en la sociabilización en el ambiente, viendo al otro compañero, cuando él ya tenga ese proceso, esa madurez, y diga este momento es mi momento, no teníamos ningún apuro en adelantar ningún proceso de aprendizaje.

MISS KENYA: Es algo innato, al final el niño va a hacer la acción, al final lo va a hacer, hay niños a veces demora su madurez, y hay otros que si adelantan porque no hay que comparar porque al final acabo al niño hay que respetar su maduración, entonces hay que respetar más que nada los papás deben entender eso, respetar mucho, porque la final lo van a lograr.

LIC. BARRIGA: Puede demorar un poquito más, pero lo va a hacer.

MISS DANIELA: Algunos son hábiles en esto, algunos son hábiles en otro, y al final van a llegar al desarrollo integral que es lo que se quiere, con objetivo principal.

MISS CINTHYA: Por ejemplo, mis bebitos que normalmente estar boca abajo, hay niños que no soportan estar boca abajo y gritan y lloran, y yo a veces me pongo así porque la mamá pensara me lo está haciendo llorar, está llorando porque no lo cargan, yo al bebe por momentos se pone boca abajo, por momentos está parado, por momentos está sentado hasta que él solo se sienta tranquilo al estar boca abajo. Y hay niños que obviamente lo hacen mucho más rápido, otros no, otros se privan están llora y llora, y yo tengo que calmarlos para que se tranquilicen.

MISS BARRIGA: Se les pone un ratito después otra vez, se le sienta hasta que él logre y ya se quede ahí calladito.

MISS BARRIGA: Llegar a ese logro, y esta hora, y eso es bastante para nosotros y para el niño es mucho.

ENTREVISTADOR: Bueno con las preguntas aparte de esos problemas que ustedes nos manifiestan, ¿cuáles son los otros temores que quizá los papas les hayan manifestado? Yo sé que los papas a veces venimos y decimos miss no haga esto no haga lo otro. $\mathrm{O}$ ¿cuáles son los temores los papas comúnmente tienen que les hayan manifestado?

LIC. BARRIGA: ¿Con los niños?

ENTREVISTADOR: Si con los niños o con el cuidado.

LIC. BARRIGA: Con los temores, de acuerdo a su desarrollo, aquí muerden, jalan, empujan. Más temores no los tienen porque los niños de acuerdo a su etapa ¿qué hacen Danielita? ¿Piñizcan? MISS DANIELA: Yo creo que el temor más que anda con los niños es uno, el trato de la profesora con mi hijo y eso es una cosa que acá en la cuna se perdió.

MISS CINTHYA: Cuando iniciamos la cuna, todos, porque todos los papás decían ¿que como era? O sea muchas ideas, pero yo creo que a pasar del tiempo se ha roto ese esquema, ya los padres ya están seguros, bien convencidos que saben muy bien la cuna es un hogar para los niños, ellos se sientes protegidos, es lo que ellos plasman cada vez que lo vienen a recoger, o cada vez que los dejan en la cuna porque saben porque ellos observan que es niño está entrando tranquilo, que ese niño ya cambiando de lo que entraba, ahora entra feliz y hay niños que a veces los papis lo viene a recoger y no se quieren ir y le niño le dicen no. Así le dicen, y se sientan y no se quieren mover.

MISS DANIELA: Otra de las cosas que también he visto con los papas por ejemplo es que "miss por favor no se enferme", (risas) entonces por favor miss por favor esto. Entonces en la etapa de los niños es eso, justamente proponer que los niños sean libres. Obviamente que no lo vamos a bañar si están 
resfriados o que le vamos a dar cosas heladas, esos netamente están en las necesidades del niño y en los cuidados pero si es un temor que tiene los papás, que se enfermen o que por ejemplo entre ellos se golpeen y les hagan un daño hay unas cositas ahí que hay que respetar y que es un proceso que necesariamente se van dar no solamente aquí sino también en el colegio.

MISS KENYA: Claro, los papás de hecho siempre tienen ese temor. De que se peguen y se jalen, si mis niños que son más pequeños ya están que se empujar, se agarran, pero es parte del proceso es un proceso que es normal porque son egocéntricos, aparte de eso, ellos están descubriendo sus emociones, sus sentimientos y es como que uno aprende algo recién y no sabe cómo reaccionar, entonces imagínese que ellos lo están descubriendo ellos recién lo están descubriendo ellos lo están aprendiendo, entonces esas emociones, esos sentimientos cuando recién los explora es como que no saben qué hacer y están jalando, pegando y es parte. Como le dije a una mamá, es normal le digo, pero luego eso va pasando con el tiempo o lo van a dejar y saber manejar.

MISS DANIELA: Y lo último es que coma todo, porque eso si es importante, porque los papas dicen pero miss no me ha comido hoy día, señora pero si come todos los días de repente esta comida no le gusto, entonces no nos vamos a morir porque el niño no coma hoy. Entonces esa es una de las preocupaciones de los papás, sino come o si come y que comió, no esto no le dé, el otro, eso básicamente.

ENTREVISTADOR: Respecto a las metodologías de enseñanza que aplican, o bueno aquí o de repente también conocen de sus experiencias anteriores o como teoría quizás ¿cuáles son esas metodologías que se aplican a los niños de esta edad de cero a 36 meses?

MISS KENYA: Yo aplico el de Emmi Pikler en cuna.

TODOS: El de Emmi Pikler o Maria Montessori.

MISS CINTHYA: En cuna si es Emmi pikler o Maria Montessori pero mayormente con mis niños yo trato de aplicar Pikler porque si bien es cierto la metodología de Pikler es libre, el niño aprende jugando, entonces para mi sobre todos en esa edad es fundamental que el niño aprenda ¿porque? Porque de algo de un material simple, básico ellos aprenden, por ejemplo yo le doy una taza, ese niñito va a aprender, ese bebito va a aprender que de esa taza va a poder tomar agua, va a prender por ejemplo o va a descubrir que puede poner torres o puede ver. O sea, solamente del juego de ese material tú estás haciendo que ese niño cree, invente cosas a su nivel obviamente entonces para mi es fundamental porque aparte del bienestar o el cuidado personal yo estoy trabajando sus cerebritos entonces por eso es importante.

ENTREVISTADOR: ¿Que edades es la que usted cubre?

MISS CINTHYA: Yo tengo ahorita pequeños desde cero meses hasta nueve meses ENTREVISTADOR: Para más o menos guiarnos con la aplicación.

MISS DANIELA: Ah, pero Emmi Pikler trabaja todo lo que es cuna hasta los 3 años, puede ser Emmi Pikler, Montessori y en realidad a la vez está la teoría Piaget, todo lo que es el área cognitiva, Del Bosque para lo que es el área de lenguaje entonces, por ahí y obviamente que la experiencia de cada una de las profesoras ya es para nosotros, no una teoría sino una marera de trabajo porque ya a través de la experiencia que se ha tenido se ven las necesidades del niño, ves todos otros momentos que has tenido que pueden haber sido similares y que pueden ayudarte obviamente con todos los conocimientos pero eso es solamente, digamos como un cerrojo como una guía, más nada lo demás es la experiencia y sobre todo quien hace la metodología son los niños porque en base a las necesidades e interés del niño se trabaja

ENTREVISTADOR: Ya miss y quisiera saber, ¿ustedes han escuchado sobre la metodología Glen Doman?

TODAS: $\mathrm{Si}$.

ENTREVISTADOR: ¿Y qué opinan sobre esa metodología? 
MISS CINTHYA: A ver, pero eso se toma según la necesidad, o sea, según la necesidad del niño porque normalmente para estimulación temprana se trabaja con ese tipo, la mayoría de los centros trabaja con ese tipo pero en mi caso opte lo que es Emmili Pikler ¿por qué? Porque si bien es cierto con esta metodología tienes que tener material, trabajas bastante lo que es materiales en cambio mi trabajo o lo que yo trato de enseñarles, es con lo que yo tengo a mi alrededor, lo que yo trabajo entonces trato de no comprar cosas tal vez caras o material caro, solamente la estimulación que se hace se hace con el material que está a mi mano, que está a mi alcance, un material que es más concreto.

ENTREVISTADOR: Bueno miss, muchísimas gracias por toda su experiencia, por todo lo que han comentado de verdad me han enriquecido como profesional, como mamá y entiendo muchísimo más su trabajo muchas gracias por todo, creo que es todo, no tengo más preguntas no sé si ¿quisieran añadir algo que quizás no les haya preguntado, pero por su experiencia es muy relevante con el tema de la guardería?

MISS DANIELA: Creo que más que nada siempre cuando se dé el desarrollo integral los espacios el juego libre, y el respetar el proceso de aprendizaje que es lo más importante, que se debe de rescatar en una guardería y el lugar, si tu hijo entra feliz es porque está tranquilo, porque está bien porque sabe que hay amor a dentro. Sino no quisiera entrar.

MISS KENYA: Y parte como dicen si también el papá ayuda tanto en casa, como dicen nosotros podemos hacer todo lo bonito con el niño, pero si eso no trabaja también en casa, ni el papá tampoco ayuda, no trabajamos en conjunto porque la educación en si es en conjunto. Padres y docentes y el niño, si no hay ese conjunto, si no hay eso entonces cada uno por separado y el niño lo siente, el niño lo sabe.

ENTREVISTADOR: Y hablando del tema de la comunicación, ¿cuáles son los mejores medios para comunicarse con los papás?, porque como sabemos los papás están trabajando, entonces ¿qué medios de utilizan para poder hacer una comunicación efectiva con ellos?

MISS DANIELA: Principalmente con ellos nosotros tenemos las agendas o el WhatsApp.

MISS CINTHYA: El problema con las agendas es que a veces no las leen, ese es problema yo creo o uno de los problemas que hay en cuna. Hay papis que piensan que por ser cuna, solamente se ocupan de recibir el cuidado, yo recibo a mi niña y veo que reciben el cuidado, ya no leo esa agenda pero, como papa como yo sé lo que ha hecho ese niño en su día a día, no sé nada no sé si almorzó bien, si como bien si lo bañaron o sea no sé pero por eso yo tengo que leer una agenda ese es el medio por el cual la miss con el papá van a poder conversar. Está bien, yo puedo crean un grupo, pero son para invitaciones generales por ejemplo, yo a veces no tengo tiempo para leer, y a veces yo estoy ocupada y me dicen miss dele a tal hora tal medicina y yo estoy con los bebes y me está reventando el teléfono o sea no es. Entonces si o si 15 minutos, miss tal medicina le tiene que dar a tal hora porque yo llego y lo primero que hace un niño que viene a mi aula reviso mi agenda, si lo firmo a perfecto, si me escribió algo, si yo veo que ni me firma ni me escribe es porque me está diciendo que el niño no le interesa.

ENTREVISTADOR: Muchísimas gracias miss, les agradezco mucho el tiempo, es de mucha ayuda. Muchas gracias. Para la próxima voy a venir temprano. (Risas). 


\section{Apéndice K}

\section{Transcripción de variables ENTREVISTA A EXPERTOS II}

\section{Entrevista a Fundadora y Directora Nido Jardín Guardería "Rosmery Play Kids"}

Nombre: Lic. Rosmery Ocampo

Cargo: Directora de "Rosmery Play Kids" y Asociada al programa Despegar - Del Método Doman

Adaptado a la Educación Peruana

ENTREVISTADOR: La primera pregunta es en base a tu experiencia, basado en tu negocio; cómo ves la parte de la educación inicial sobre todo en los niños de 3 años o menos de 3 meses. ¿Cuál es tu experiencia o tu opinión en base a la parte de educación inicial?

LIC. ROSMERY: Bueno, una cosa es un servicio de guardería que es muy distinto a un centro de Educación Inicial, son servicios diferentes. Una guardería se encarga básicamente de cuidar a los niños y algunas pueden presentar algún servicio funcional como: incorporación de estimulación temprana, otro puede ser el tema del aprestamiento. Pero guardería en sí, es el cuidado de niños.

Ahora, en los nidos lo que se hace según la directora y promotora, es aplicar el método tradicional a lo que la institución está sujeto o aplicar otros métodos como el MONTESSORI o el método DOMAN en sí. Lo que hacemos nosotros es una adaptación porque el método DOMAN madre es especialmente dirigido a padres; no es para colegios. Según el fundador GLENN DOMAN, el método DOMAN se da a padres porque para los principios que él ha estudiado, no hay mejor maestro que su propio padre, sin embargo, eso no se da en nuestra realidad, porque los padres tenemos que trabajar, tenemos horarios muy complicados para hacer maestros de nuestros hijos. Por eso es que lo que hace el director de nuestro programa que es LEONARDO AGUILAR es una adaptación a la educación a nuestra realidad peruana. Entonces si bien es cierto la idea de LEONARDO es aplicar lo más que se pueda según las horas que tenemos, muy apretadas con los chicos, aplicar lo más que se pueda, en si el método se dará en un $60 \%$, no se dará en todo porque se deben regir y priorizar ciertos patrones que se deben presentar y los horarios nosotros tenemos 7 horas o 6 horas a los chicos, entonces para aplicar exclusivamente el método es, mientras el niño este despierto se tiene que hacer todo eso, es por eso que nosotros lo que hacemos es una adaptación.

ENTREVISTADOR: ¿funciona? ¿Dentro de lo que me cuentas?

LIC. ROSMERY: Exacto, lo bueno del método DOMAN es que se respeta la capacidad de cada niño, no es un método que usted puede enseñar a un niño y al mes siguiente lo evalúas, es un método que siembra, siembra y siembra y en un determinado momento te da frutos. ¿Cuándo? Eso se respeta. La naturaleza de cada niño y la capacidad de cada niño no es un método que se siembra y cosecha en corto plazo, es a mediado y a largo plazo, pero para eso primero tenemos los 5 primeros años de los chicos que son esenciales y fundamentales. ¿Por qué? Porque bien, se conoce esa frase que es como unas esponjas, y eso es cierto, los niños pueden aprender 5, 6 y 7 idiomas dependiendo a quien le hable todos los días. Si tiene una nana sueca, si tiene un papa americano, si tiene a la abuela rusa, aprende todos los idiomas porque así está preparado el cerebro humano, así como también está preparado para leer de manera muy temprana y de manera global. El niño no lee a, e, i, o, u, ma, me, mi, mo, mu, el niño lee de manera global, palabras concretas y completas. Entonces eso nos demuestra que los niños si tiene toda la capacidad.

ENTREVISTADOR: Y ¿has encontrado barreras en cuanto a la aplicación de este método o con los papás de alguna forma?

LIC. ROSMERY: Este método no es nuevo, este método tiene más de 50 años y GLENN DOMAN para hacer este proyecto, esta manera de enseñar a los niños, ha tenido que viajar todo el mundo y visitar todas las culturas, el puede haberse ido a lo más recóndito de la amazonia en Brasil y puede 
haber estudiado a las tribus y ven como tiene al bebe desde recién nacido y como lo ponen a prueba para que él bebe solito se mueva en el cuerpo de la madre cuando nace y busque su propio alimento, desde ahí. Barreras en sí, no. Los padres desde que vienen y escuchan del método, han buscado por internet, definitivamente algunos tienen nociones y otros tienen curiosidad por ver si es que eso funciona o no, pienso que cualquier método si uno le da al niño con amor el niño lo va aprender, cualquier método. No es que el método doman sea mejor que el tradicional, no. Todo método es bueno siempre y cuanto se da con amor.

ENTREVISTADOR: ¿Y qué beneficio crees que puede haber aplicado este método?

LIC. ROSMERY: El método DOMAN básicamente se basa en desarrollar internamente al niño, o sea organizarlo, el método DOMAN en síntesis es organización neuronal, así es. ¿Porque? Por qué los estímulos que nosotros le damos, tanto visuales como auditivos de manera de contacto, de manera experimental al niño, esto que va a hacer que el cerebro desarrolle, los ejercicios que hace, las actividades que hace, las canciones, la música, todo el estímulo que reciben, va a ser que es celebro desarrolle, entonces el resumen del método es que el cerebro va a ser mayores interconexiones, va a organizarse mejor. Método Doman - organización cerebral.

ENTREVISTADOR: Y los papás o las personas que vienen, ¿valoran esa aplicación?

LIC. ROSMERY: ¡Muchos si!, como también tenemos opiniones de repente de algunos papás que no han tenido la paciencia, ese es uno del obstáculo, pero por sobre todas las cosas nosotros lo que hacemos es tratar al niño con amor, siempre! A veces los papás tiene alguna manera de pensar diferente, pero mientras nosotros tratemos con amor al niño el niño va a decir cuánto lo amamos y cuanto le enseñamos, el hecho de que a nosotros mismos nos han formado de manera muchas veces de rigor de que con un trato no tan adecuado olviden eso y ellas traten de corregir al niño algunas conductas que se tiene que corregir, enseñarles a los niños de la manera correcta, motivándolos, diciendo siempre que deben hacer lo bueno, lo positivo y no mencionándoles las palabras negativas, como malcriado, sucio, cochino y cosas así que emocionalmente no lo ayudan. Es una guerra constante, es un tira y jala constante porque es difícil a veces romper lo que a nosotros nos ha formado pero está ahí la voluntad de que cada vez si cometiste cada día un porcentaje de errores, de 20 errores al día siguiente te propongas cometer menos errores. Cada niño nos enseña a tener más paciencia, a corregir nuestros errores, a quererlos más, cada niño, desde el más difícil hasta el más tiernito nos enseña.

ENTREVISTADOR: Y al haber aplicado este método en tu negocio ¿tú cobras algo adicional? O es parte de la formación que le da, porque para eso te capacitaste también.

LIC. ROSMERY: Yo trabajé con Leonardo desde que mi hijita mayor, ya tiene 18 años y medio, entonces desde que lo conocí compartí con él estas expectativas. Lo conocí siendo estudiante de psicología, de ahí me enseñó, me formó en 2 años casi todo este tema del método DOMAN y de ahí él ha investigado, él ha viajado a Europa a capacitarse por otros métodos más. Siempre lo he admirado, siempre he admirado como quiere a los niños y como él forma a los niños por eso es que siempre tuve la inquietud desde que me independicé, de querer dar algo diferente, y es así como el forma un grupo para enseñar a niños y forma su marca DESPEGAR.

ENTREVISTADOR: Ah, con el directamente?

LIC. ROSMERY: Si, con él, entonces quien distribuyen todos los colegios, el comparte esto que él ha aprendido y que él se ha formado de manera sola porque no hay ningún instituto que te diga a ti, "nosotros promocionamos la marca despegar, el método DOMAN". No. Como le digo, el método DOMAN es exclusivo para padres, y les da a padres que tienen casualmente niños con dificultades, niños con capacidades diferentes. Niños con síndrome de Down, con autismo, con retardo, entonces es dirigido para ellos. Entonces es así como con Leonardo hacemos la conexión para que brinde este nuevo método a los colegios y se forma la marca despegar y es así como nosotros pertenecemos a esta 
red. Es así, o sea, cobra porque los colegios se capaciten, las maestras, los directores, y nosotros brindemos este método.

ENTREVISTADOR: Los papás cuando dejan a sus niños, ¿ellos tienen algunos temores? ¿Tienen alguna desconfianza? ¿Esto es guardería, o nido?

LIC. ROSMERY: Solo es nido, para guardería solo hay hasta las 3 de la tarde, para casos muy especiales, tienen un horario que trabajan hasta las $2 \mathrm{pm}$ y pueden venir a las $3 \mathrm{pm}$. Más horas no me atrevería tener más niños porque lo cierto es que, por más que no implique que haya peligro, tendríamos que acolchar todo para saber que el niño si se tropieza no se va a lastimar, porque, si, hay situaciones extremas y a nosotras nos ha pasado, más que extremas. Porque el cuidado, así sea un grupo de pequeño de niños es suma mente delicado, el trabajo con niños pienso yo, porque son 23 años lo que ya trabajo con niños, desde los 16 años y ahora ya voy a cumplir 40 años y es mi vida entera, más de la mitad de mi vida está con ellos. Entonces es muy complejo. Y es de mucho cuidado y por ejemplo; no puedo irme así nada más a la puerta a despedirlos o a recibirlos, yo tengo que estar con el grupo. De ahí formarlos y de ahí distribuirlos a cada uno y yo me quedo con mi grupo, las chicas cada uno con su grupo de edades.

ENTREVISTADOR: ¿Cuántos niños por grupo?

LIC. ROSMERY: Son 4 grupos, son 15 máximos por grupo.

ENTREVISTADOR: ¿Es una sola persona o con asistentes?

LIC. ROSMERY: Grupos grandes mayores de niños mayores de 4 años son solos, y grupos de 3 años para abajo si con auxiliares.

ENTREVISTADOR: ah ya, ¿Siempre de la mano no?

LIC. ROSMERY: Siempre, que vomitó, que se ensució, que se le cayó, entonces siempre hay que asistir a los menores de 3 , pero los demás si son niños más independientes.

ENTREVISTADOR: Y que le recomendarías a los papás, que de alguna forma por el trabajo o porque el Papá o Mamá trabaja y tienen que dejarlo en algún lado, ya sea en un nido o en una guardería, ¿qué les dirías sobre eso? Si sienten el respaldo, que no se preocupen, que están bien cuidados, en base a lo que tú ofreces.

LIC. ROSMERY: Si, yo les diría de que si puedo recibir a los niños, puedo recibirlos, pero no sé si más salta mi lado materno, pero les diría que no hay mejor lugar estar en su propio hogar inclusive y es así porque en otros países en otras realidades, los niños no van al nido, los niños van a guarderías porque la guardería en otros pides es como si fuese su casa entonces ahí hacen actividades; no algo marcado en programaciones sino ahí juegan, todo es jugar y jugar, y no saben leer, no saben escribir, y es que eso es lo que necesita un niño .En cambio acá está un poco maltratado ese tema, mal instruido, mal llevado, entonces el niño en una guardería tiene que jugar.

ENTREVISTADOR: ¿Y has tenido problemas a veces con algún Papá porque un niño se cae o se golpea o se ha enfermado?

LIC. ROSMERY: Siempre pasa, siempre pasa, ese es el pan de cada día inclusive, que se golpeó que se tropezó, para eso nosotros hacemos una reunión entre la segunda y la tercera semana y el día inclusive de la matricula se le dice la verdad de la milanesa, los niños se golpean se tropiezan, quitan, hay niños que pegan va a pasar un sinfín, pero por sobre todas las cosas nuestra prioridad es cuidar. Si se golpeó lo vamos a asistir, dependiendo del grado del golpe, de muchos factores, no lo vamos a dejar, no vamos a llamar a la Mamá para que se lo lleve. Tenemos que esperar a la mama si vemos que es de un grado mayor tenemos que llevarlo a un lugar donde asistirlo, pero la prioridad es el niño, entonces de que pasas si, si ha pasado. Pasa en todos los colegios, pero ya es tener como qué sentido común para reaccionar y acudirlo al niño, hemos tenido todos los casos; se han desmayado, han perdido la conciencia, no por golpe, sino que vinieron ya con fiebre de la casa, estuvieron medios idos. O sea, como que ya vimos que estaba que se desvanecía, han convulsionado inclusive, pero cada 
una de esas experiencias nos enseña y en la siguiente reunión tenemos que hablarlos con los Papás, siempre hay que hacerles chequeos a los niños. Nunca hay que decir que eso, que si se queja de dolor de cabeza es por nada, es engreído, no es, no es. Algo de cierto tiene lo que dice el niño. La prioridad es el niño y el padre debería saberlo, como también hay padres que no le toman importancia a eso y vemos que no caminan bien se tropiezan se para cayendo, entonces hay algo que no está bien en su desarrollo y hay Papás que no hacen caso a eso y hay papas que si lo hacen. Acuden al hospital, buscan cita, buscan neurólogo, porque esa es la idea, porque no queremos que pasen situaciones extremas, lo que menos queremos es eso, y por eso es nuestras recomendaciones van más allá como de maestra van más de madre.

ENTREVISTADOR: Claro!, para cerrar, ¿tu consideras que este tu proyecto, no sé cuántos años tiene tu proyecto?

LIC. ROSMERY: Aquí en San Juan tengo 10 años.

ENTREVISTADORA: 10 años, y dentro de toda experiencia de estos 10 años, siempre has aplicado el método doman entiendo por los que me comentas, que has trabajado con el director. Entonces tú si consideras que este método es aplicable de alguna forma ayudar a los niños a pesar de existir otras metodologías que se aplican en colegios. En nidos incluso como el MONTESSORI, que es el más conocido de alguna forma.

LIC. ROSMERY: Si, yo desde mi experiencia de madre, porque acá soy Mamá inclusive de todos los niños y es tanto así el amor hacia ellos y de ellos hacia mí que no dicen miss, dicen mamá entonces, yo pienso que si ayuda mucho y ayuda a muchos niños, como se respeta cada capacidad, cada niño es individual y es diferente al otro niño, entonces se valora cada progreso del niño por más minúsculo que sea. Entonces el método me ha ayudado a mí como madre, a que mi hija mayor que ya tiene 18 años sea una fanática de la lectura, le encanta la lectura, a sus 18 años se habrá leído como 400 libros, y libros. Y en el colegio me decían que era la única que visita la biblioteca, y cosas así y yo me siento muy feliz porque se por información de todos lo que he ido leyendo, investigado según el método, de que sí. Si tú respeta la capacidad de cada niño de aprender y respetas su forma natural de aprender a leer a crear a dibujar, a pintar. Si respetas el niño va a crecer feliz y le va a gustar hacer lo que hace. Entonces en el caso de mi hija ella no se alfabetizó, ella creó un gusto por la lectura, y ¿cómo lo creó? Con este método. ¿Cómo les enseñamos a leer? Con etiquetas, full etiquetas ¿cómo les enseñamos a pintar? Empezando a segmentar. Como les enseñamos y así cada cosa es con amor, en realidad todos los métodos son buenos pero en realidad el amor y la emoción es la clave y el ingrediente principal para que les guste, porque si es con presión, mucho disciplina y vamos a estar evaluando con un balotario de todos los meses como lo hacen en la mayoría de colegios, que priorizan más el aprestamiento en base a "lo aprende o lo aprende con rigor" entonces, no es la manera correcta para mí como madre, y como maestra también, este método a mí me ha enseñado mucho, vamos en un $10 \%$ pero con lo que aplicamos y con lo que damos en realidad felices porque si, los padres los que han sabido apreciar esto, que son en realidad la mayoría de Papás, si nos han dicho que sus hijos están muy bien en los colegios en donde están, y los que ya han terminado inclusive. Yo tengo niños que a están en los 20 años y si ya están son felices, haciendo lo que hacen.

ENTREVISTADOR: Digamos que les ha servido como base o información para que ahora sigan una vida, una carrera.

LIC. ROSMERY: Exacto!, y lo bueno es que el complemento de lo que los niños van estudiando, por ejemplo cada mes les enseñamos un tema cultural. Este mes hablamos del planeta tierra, del ambiente, de la contaminación. De dinosaurios, todo lo que son de los dinosaurios; que comían como vivan, que paso con ellos, de ahí al otro mes vamos a hablar de don quijote de la mancha, lo que es las aventuras, y al otro mes cuentos chinos, y así sucesivamente. Que nos garantiza el que ellos reciban información cultural diferente, nos garantiza que internamente el cerebro, a mayores palabras que escuche, mayor 
información que tenga, la interconexión entre neurona y neurona va a hacer mucho más amplia va a tener mayor interconexión neuronal, esto va a hacer que tenga mayores redes. Y eso es lo único que logra eso es la oxigenación cerebral que con los ejercicios y la información auditiva. Toda la información, no hay otra cosa. El Enfagrow y nada por el estilo, es la oxigenación y lo otro es la información que le dan, la base de datos. Eso son lo prioritario, lo que el método DOMAN exige a los padres que deben hacer no.

ENTREVISTADOR: ¿Algo que me quisieras agregar, algo con respecto a esto? Ya para cerrar la entrevista.

LIC. ROSMERY: Estoy feliz de tener a los chicos todos estos años trabajando y en cada año aprendo más de ellos, cada día en realidad, ellos son los maestros. Los maestros del amor, de la compasión, de la felicidad, de la vida. Ellos son vitamina pura de ser feliz. Ellos quizá ven todo perfecto. De que yo soy maga, payasa, soy mamá, soy todo, soy actriz para ellos, entonces quizá los adultos ven lo negativo, los errores, juzgan y todo. Pero yo en mi mundo de niños soy feliz, después lo demás tomo lo que necesito y lo que no, bueno lo deshecho, pero en el mundo de los niños, es todo felicidad. Ellos ven todo perfecto, ellos no son malos, son puritos, entonces del ellos viene para mí, mi vitamina. Se termina el final en un caos, pero lo que he vivido con ellos cada día no hay precio, lo que pagan sus papas no es, lo que pagan ellos es lo más reconfortante.

ENTREVISTADOR: Los padres pagan una mensualidad, ¿tú les cobras algo adicional por este método? ¿Les indicas a ellos?

LIC. ROSMERY: No, nosotros pagamos una franquicia para entrar, una cuota de ingreso, que implica que capacitan todos los años, durante todos los años que yo esté dentro de este programa del método DOMAN y todos los años los profesores van. Se actualizan, se capacitan, pero no por ellos, somos unos de los más bajos, cobramos menos. Deberían cobrar más pero como estamos en una casa alquilada, es antigua, tenemos muchas cosas en contra, por la infraestructura, pero por otro lado mis fortalezas son que por más que cobre menos que los otros colegios, por más que tengamos métodos que brindamos de menú diferente, lo importante es que mis profesores tengan sus niños todo el mes, cada mes hasta fines de año pagar los alquileres de todos los meses durante todo el año y todo lo implique al servicio de contabilidad y todo eso y lo que quede después, de seguir comprando materiales. De alguna manera si puedo decir de que como es mi prioridad los niños, me gusta comprar algo que les va a gustar, algo que no se va a romper tan fácilmente, cosas que son caras pero duran bastante si se sabe cuidar y si se les enseña a los niños que los cuide y va a durar mucho tiempo, y eso por ejemplo cuando viven los Papás yo les digo que sí, de que invierto mucho en materiales, y los Papás lo ven. Y cuando van a otros colegios les digo que vallan ustedes a otros colegios y pregúntele porque el niño necesita para aprender para que juegue, muchos materiales, pregúntele que tiene para jugar. Porque entienda que el niño va a venir acá a crear, a jugar a divertirse. Nosotros somos las jefas de los grupos, La niña mayor y ellos van a hacer su juego dirigidos por nosotros, nosotros les vamos a enseñar a jugar, a compartir, a tolerar, a esperar, a respetar, a querer, a disculpar, eso tienen que aprender, es como una casa, pero el material es muy básico también, para que el niño, de magia y de imaginación tampoco es, tiene que aprender con estos materiales completos también, entonces por eso es que me esmero si hay inclusive más que otros lugares, que no invierten mucho en materiales. Yo sí, puedo decir que, si yo invierto y de ahí lo demás yo no lo tomo como un negocio, porque si lo viera en ese aspecto en realidad tendría otra cosa, pero no, no lo veo como un negocio, para mi es mi vocación en realidad.

ENTREVISTADOR: Bueno, porque la mayoría pues siempre busca eso no?

LIC. ROSMERY: Mientras tenga para pagar todo yo estoy tranquilo

ENTREVISTADOR: ¡Qué bueno!, ok Rosmery, muchas gracias de verdad que nos va a servir mucho tu explicación. 


\section{Apéndice L}

\section{Formato de encuesta de estudio cuantitativo}

\section{Encuesta}

Buen día, somos egresados de la Escuela de Postgrado de la Universidad San Ignacio de Loyola, estamos efectuando una investigación de mercado, para lo cual le solicitamos su disposición por cinco minutos y que sus respuestas sean sinceras. Agradecemos su colaboración de antemano.

¿Actualmente Tiene hijos entre 3 y 36 meses?

a) $\mathrm{Si}$

b) No (Fin de la encuesta)

¿Es Usted quien decide sobre el cuidado de sus hijos?

a) $\mathrm{Si}$

b) No (Fin de la encuesta)

1. ¿Se encuentra trabajando actualmente (Dependiente o Independiente)?
a) Sí
b) No

2. ¿Tiene acceso a internet durante su horario laboral?

a) Sí

b) No (Pasar a la pregunta 4)

3. ¿A través de que dispositivo accede a internet?? (Puede escoger más de una opción como respuesta)

a) Computadora personal/Laptop

b) Smartphone

c) Tablet

d) Otros (Especifique)

4. ¿Quién se encarga del cuidado de sus hijos menores de 3 años mientras usted trabaja?

a) Su esposo(a)

b) Un familiar especificar

c) Una niñera

d) Una guardería (pasar a la pregunta 7 si marca esta opción

5. Cuál es el motivo por el cual hasta el día de hoy no ha dejado a su hijo al cuidado de una guardería? (Puede escoger más de una opción como respuesta)

a) Por desconfianza

b) Alto costo

c) No hay guardería cerca de mi trabajo

d) Horarios reducidos

e) Seguridad

f) Mala experiencia con una guardería

6. En una escala descendente donde, " 1 " es el más importante y "6" el menos importante, determine que atributos considera más importantes para poder escoger una Guardería.

(Responder y pasar a la pregunta 15 )

\begin{tabular}{|ll|l|}
\hline 1. & Método enseñanza & \\
\hline 2. & Recomendación & \\
\hline 3. & Ubicación & \\
\hline 4. & Horario & \\
\hline 5. & Seguridad & \\
\hline 6. & Precio & \\
\hline 7. & Otros especifique & \\
\hline
\end{tabular}

7. ¿Cuál es su nivel de satisfacción por el servicio recibido en la guardería?

\begin{tabular}{|c|c|c|c|c|}
\hline \multicolumn{5}{|c|}{ Grado de Satisfacción } \\
\hline a) & b) & c) & d) & e) \\
\hline $\begin{array}{c}\text { Muy } \\
\text { Satisfecho }\end{array}$ & Satisfecho & $\begin{array}{c}\text { Ni satisfecho } \\
\text { ni insatisfecho }\end{array}$ & Insatisfecho & $\begin{array}{c}\text { Muy } \\
\text { insatisfecho }\end{array}$ \\
\hline
\end{tabular}

8. ¿Los horarios del servicio de guardería, se adecuan a su horario de trabajo?

\begin{tabular}{|c|c|c|c|c|}
\hline \multicolumn{5}{|c|}{ Grado de Adecuación } \\
\hline a) & b) & c) & d) & e) \\
\hline $\begin{array}{c}\text { Muy } \\
\text { adecuado }\end{array}$ & Adecuado & $\begin{array}{c}\text { Ni adecuado ni } \\
\text { inadecuado }\end{array}$ & Inadecuado & $\begin{array}{c}\text { Muy } \\
\text { inadecuado }\end{array}$ \\
\hline
\end{tabular}

9. La guardería donde asiste su hijo, ¿Aplica alguna metodología de enseñanza y estimulación temprana especializada?
a) $\mathrm{Si}$ (especifique cual)
b) No
c) No recuerdo

10. Con que frecuencia deja usted a su hijo(a) en la guardería?
a) 2 veces a la seman
b) 3 veces a la semana
c) 5 veces a la semana

11. Cuantos meses al año utiliza los servicios de una guardería?
a) Menos de 6 meses al año
b) Entre 6 meses del año y 9 meses
c) Entre 10 meses y 11 meses
d) 12 meses al año

12. ¿Qué servicios adicionales recibe en la guardería? (Puede escoger más de una opción como respuesta)
a) Alimentación
b) Estimulación temprana
c) Enfermería
d) Psicología
e) Terapia de lenguaje
f) Talleres (arte, baile, teatro)

13. ¿Cuál es el nombre de la guardería que utiliza su hijo y en qué distrito está ubicado?

\begin{tabular}{|l|l|}
\hline Nombre & \\
\hline Distrito & \\
\hline
\end{tabular}

14. ¿Cuánto paga mensual por el servicio de una guardería?
a) Menos de $\mathrm{S} / 700$
b) $\mathrm{De} S / 700$ a $\mathrm{S} / 900$
c) $\mathrm{De} S / 901-\mathrm{S} / 1100$
d) $\mathrm{De} S / 1101-\mathrm{S} / 1300$
e) $\mathrm{De} S / 1301-\mathrm{S} / 1500$
f) De S/ 1501 a más

\section{CONCEPTO}

15. Existe la intención de una empresa en desarrollar una guardería infantil para niños de 3 a 36 meses de edad con un método de enseñanza y estimulación temprana especializada Qué le parece la idea?

\begin{tabular}{|c|c|c|c|c|}
\hline \multicolumn{5}{|c|}{ Grado de Necesidad } \\
\hline a) & b) & c) & d) & e) \\
\hline $\begin{array}{c}\text { Muy } \\
\text { Necesario }\end{array}$ & Necesario & $\begin{array}{c}\text { Ni necesario ni } \\
\text { innecesario }\end{array}$ & Innecesario & $\begin{array}{c}\text { Muy } \\
\text { innecesario }\end{array}$ \\
\hline
\end{tabular}

16. Esta guardería brindaría un servicio de video vigilancia a través de la instalación de cámaras IP, donde pueden ver en tiempo real las actividades y cuidados que reciben sus hijos, ¿Estaría de acuerdo?

\begin{tabular}{|c|c|c|c|c|}
\hline \multicolumn{5}{|c|}{ Grado de acuerdo } \\
\hline a) & b) & c) & d) & e) \\
\hline $\begin{array}{c}\text { Muy De } \\
\text { acuerdo }\end{array}$ & $\begin{array}{c}\text { De } \\
\text { acuerdo }\end{array}$ & $\begin{array}{c}\text { Ni de acuerdo } \\
\text { ni desacuerdo }\end{array}$ & Desacuerdo & $\begin{array}{c}\text { Muy } \\
\text { Desacuerdo }\end{array}$ \\
\hline
\end{tabular}

17. ¿Conoce el método Doman (Método de Aprendizaje Americano?

a) $\mathrm{Si}$

b) No (pase a la pregunta 19 ) 
18. ¿En su opinión cuales son las ventajas más importantes en la aplicación del método Doman?
a) Contribuye al desarrollo cerebral
b) Favorece la concentración
c) Estimula la memoria y aprendizaje
d) Ayuda al desarrollo visual y auditivo
e) Favorece la comunicación

19. La guardería estaría ubicada en la Urbanización Santa Catalina, la cual está cerca al centro empresarial de San Isidro. ¿Estaría de acuerdo?

\begin{tabular}{|c|c|c|c|c|}
\hline \multicolumn{5}{|c|}{ Grado de acuerdo } \\
\hline a) & b) & c) & d) & e) \\
\hline $\begin{array}{c}\text { Muy De } \\
\text { acuerdo }\end{array}$ & $\begin{array}{c}\text { De } \\
\text { acuerdo }\end{array}$ & $\begin{array}{c}\text { Ni de acuendo } \\
\text { ni desacuerdo }\end{array}$ & Desacuendo & $\begin{array}{c}\text { Muy } \\
\text { Desacuerdo }\end{array}$ \\
\hline
\end{tabular}

20. ¿Qué horario le parecería adecuado para la atención de la guardería?

a) Lunes a Viernes 7:30 am - 6:00 pm

b) Lunes a Viernes 8:00 am - 6:00 pm

c) Lunes a Viernes 8:00 am - 7:00 pm

d) Lunes a Viernes 9:00 am - 7:00 pm

21. Esta guardería contaría con ambientes separados por edades, cada una implementadas con materiales y juegos acordes a las mismas, así mismo tendrá un comedor, lactario, cocina, $\mathrm{SSHH}$ habilitados con inodoros y tina de baño especiales para niños, ¿Qué le parece?

\begin{tabular}{|c|c|c|c|c|}
\hline \multicolumn{5}{|c|}{ Grado de acuerdo } \\
\hline a) & b) & c) & d) & e) \\
\hline $\begin{array}{c}\text { Muy De } \\
\text { acuerdo }\end{array}$ & $\begin{array}{c}\text { De } \\
\text { acuerdo }\end{array}$ & $\begin{array}{c}\text { Ni de acuendo } \\
\text { ni desacuerdo }\end{array}$ & Desacuerdo & $\begin{array}{c}\text { Muy } \\
\text { Desacuerdo }\end{array}$ \\
\hline
\end{tabular}

22. ¿Cuánto estaría dispuesto a pagar mensual por el servicio de una guardería que incluye el servicio de vídeo de vigilancia online y la aplicación de la metodología Doman?
a) Menos o igual a $\mathrm{S} / 900$
b) $\mathrm{S} / 901-\mathrm{S} / 1100$
c) $\mathrm{S} / 1101-\mathrm{S} / 1300$
d) $\mathrm{S} / 1301-\mathrm{S} / 1500$
e) S/ 1501 a más

23. ¿Qué medio de pago utilizaría para el pago del servicio guardería? (Puede marcar más de una alternativa)

\begin{tabular}{|l|l|}
\hline Efectivo & \\
\hline POS & \\
\hline Abono en Cta. Cte. & \\
\hline Cargo en TC. & \\
\hline
\end{tabular}

24 En una escala descendente donde, "01" es el más importante y " 06 " el menos importante, determine qué servicios adicionales considera más importantes para la implementación en una Guardería ?

\begin{tabular}{|rl|l|}
\hline 1. & Servicio Psicológico & \\
\hline 2. & Terapias & \\
\hline 3. & Alimentación & \\
\hline 4. & Enfermería & \\
\hline 5. & Talleres de arte, baile, & \\
\hline 6. & Organización de cumpleaños & \\
\hline 7. & Otros & \\
\hline
\end{tabular}

25 En base a su respuesta anterior, ¿Cuanto estaría dispuesto a pagar mensual por cada servicio adicional?
a) Menos de $\mathrm{S} / 100$
b) $\mathrm{S} / 101$ a $\mathrm{S} / 200$
c) $\mathrm{S} / 201$ a S/ 300
d) $\mathrm{S} / 301$ a S/ 400
e) S/401 a más

26 ¿Qué nombre le parecería más adecuado para esta guardería? (Marcar solo una alternativa)
a) Titinos Day Care
b) Happy Day Care
c) Baby Land
d) My Happy World
e) Otro (especificar)

27 Por qué medios le gustaría informarse de la guardería? (Puede marcar más de una alternativa)
a) Pagina Web
b) Redes sociales
c) E-mail
d) Revistas especializadas
e) Convenios con mi centro de trabajo
f) Otros..........................

28 Luego de haberse informado de este nuevo proyecto. ¿Qué tan dispuesto estaría usted a utilizar los servicios de la guardería?
a) Definitivamente utilizaría los servicios
b) Probablemente utilizaría los servicios
c) Es indiferente (Fin de la encuesta)
d) Probablemente no iría (Fin de la encuesta)
e) Definitivamente no iría (Fin de la encuesta)

Datos de control

Nombre:

Sexo:

Distrito:

Profesión:

Rango de Edad:

$$
25-35
$$

$36-46$

47 a más

29 ¿Cuántas habitaciones/dormitorios exclusivos para dormir tiene dentro de su hogar?
a) 0-1 habitación
b) 2-4 habitaciones
c) 5-6 habitaciones
d) 7 a más habitaciones

30 ¿Cuántos focos tiene dentro de su hogar?
a) 1-2 focos
b) 3-5 focos
c) 6-8 focos
d) 9 a más focos

31 ¿Cuántos baños tiene dentro de su hogar?
a) 1-2 baños
b) 3-4 baños
c) 5 a más baños

32 Sus ingresos se encuentran en el rango de:
a) Menos de $\mathrm{S} / 3000$
b) $\mathrm{De} \mathrm{S} / 3001 \mathrm{a} \mathrm{S} / 5000$
c) De S/ 5001 a mas 


\section{Apéndice M}

\section{Pasos para constituir una empresa o sociedad}
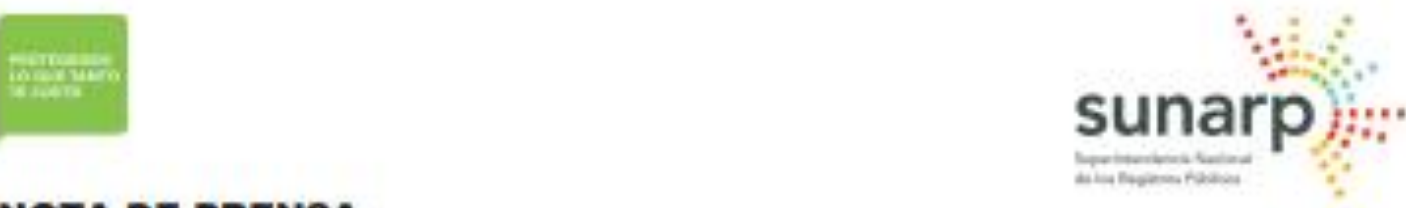

\section{NOTA DE PRENSA}

ofioina General de Comunicaciones

\section{CONSIIUUY TUEMPRESA EN SEIS PASOS}

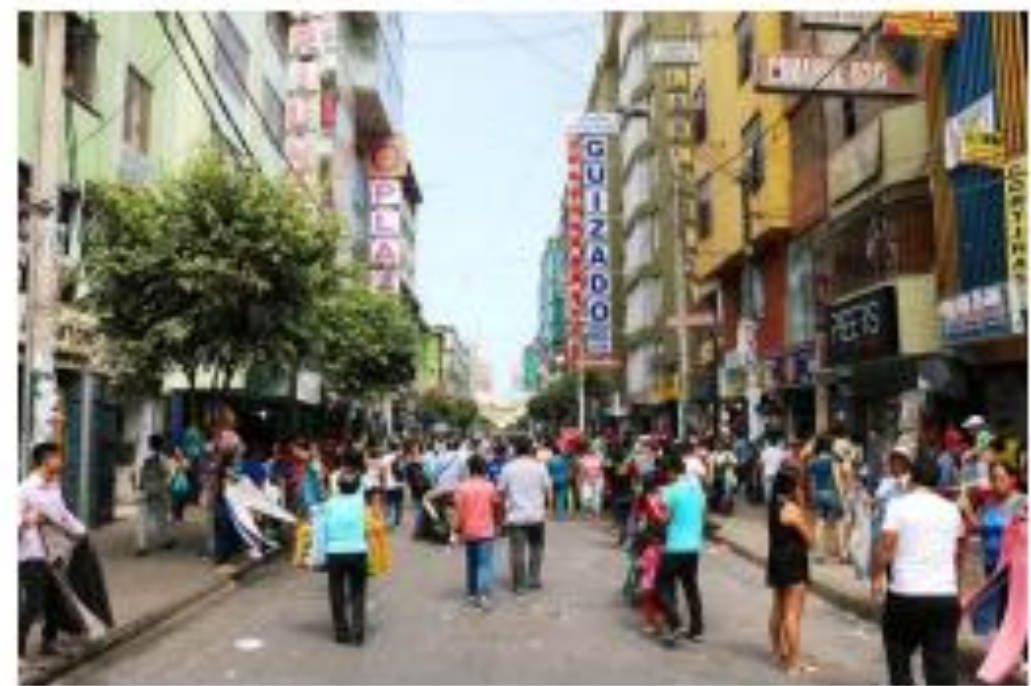

Consthuir una empresa o sociedad es un proceso a travla del cual una persona o grupo de personas regiatran su empresa ante el Estado para que este les ofrezca las beneficios de ser formales.

Autes de iniciar of proceso de consthucibn de una emcresa o socisdad debes evaluar el tipo de negocio que deseas montar, el capital inicial y como bu vas a financiar, asi como la aceptacidn que tendra entre ion poeibles clertes $\gamma$, por supuesto, las oblipacienes tributarias que deberis aaumir.

Puedes desamolar tu actividad empresarial como persona individual a sociedad, ya sea como Empresa Individual de Responsabilidad Limitada (ERL) o como uno de los tipos societarios requlades en la LeV general de Sociedades (Sociedad Anónima de Responsabiliad Limicada, Sociedad Ansnima Cerrada. Sociedad Andinima Abierta, ecc.)

A continuacibn te explcamos los pasces que debes sequr para constituir una emcresa o scoiedas.

1. Bussqueda y resarva de nembre. La reserva de nombre es el paso previo a la consitucion de una empresa o sociedad. No es un tramte cblioatorio pero sí recomendable pora facilrar la inscripcion de la empresa o sociedad en el Fegiatio de Personas Juridicas de la Sunamp. Durante la caificacidon de la Reserva de Nombre, el registrador publico fiene que verícar si existe alguna iqualdad o coincidenda con coro nombre denominacidn, completa o abreviada, o raadn scocial de una empresa o sociedad preenistente o que este govando de la preferencia registral.

2. Elaboracib́n de la Minuta de Constitucibn de la Empresa o Sociedad. A traves de esie documemb ef thalar de a empresa o los miembios de la sociedad manfiestan su voluntad de conetisir la persona juridioe. El acto consitutivo consta dei pacto social y los estatuba. Asimismo, se nombra a los primerce aderinistradorea, de acuardo a las caracterioficas de la persona juridica. 


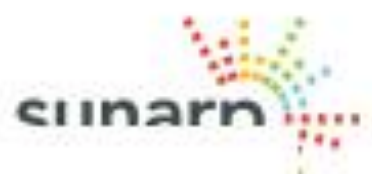

3. Aporte de capital. Podid aportarse dinero, el cual se acredfara con el documento eapedido por una entidad del satema financiero nacional; o bienes (inmuebles o muebles, en estos uttimos ge enfenden los derechos de credito) los que se acreditatn con la inscripción de la transiterencia a Grvor de la empresa a sociedad, con la indicación de la tranaterencia en la escrtura publica o con ef infome de vabrizacibn detalodo y ef ofterio empieado para su valuacibn, segón sea ef cosso.

4. Elaboracide de Escritura Püblica ante et notario. Una vez redactado ef acto constintivo, es necesario levario a una notarla para que un notario público lo reviee y lo eleve a Escritura Pibloc De esta manera se generara la Escritura Pibica de constoución. Este documertb debe estar firmaso y sellado por es notario y tener ia firma ded thular o los socios, inchuidos los conyuges de ser ed caso. Bl costo y el tiempo det trímile dependerán de la notaria que efijas.

5. Inscripción de la empresa o sociedad en el Rejister de Persenas Juridicas de la Sunarp. Ya sea en ed Fegistro de Sociedades, para las sociedades andnimas cerradas, abiertas, sociedad comercial de responaabilidad limiradar, o en el Registro de Empresa Individual de Fesponsablidad Limtada. En la Sunarp obtendrs un asiento registral de inscripoion de la empresa a sociedad como persona juridica. Este procedimiento nomalmente es realizado por el notario. El plazo de calncación es de 24 horaz desde la presentación del tílo.

Recuerda que la Persona Juridica exesle a partir de su inscripoión en los Registros Publicos.

6. Inscripción al RUC para Parsona Juridica. El Registro Único de Contribuyentes (RUC) es ef nùmero que iderb́foa como contribuyenie a una Persona Juridica o Persona Nahural. El RUC contiene los datos de identficación de las actividades econdmicas y es emindo por la Sunat.

Beneficles de tener un negocio formal

- Tendrata la libertad de exponer tu marca legaimente, sin problemas con las autoridades.

- Podras crecer y emplear gente que obeenga beneficios des Estado.

- Ser formal te permile, ademas, acceder a prestamos bancarios.

- Fomar parte del ecoeistema comercial del país y contribuir con el crecimiemb de emprendedones rempresarios quienes. como $\mathrm{D}$, buscan iener estabildad economica y social.

\title{
Inscripción digital
}

Tambien puedes constbuir e inscribir a empresa a sociedad en el Pegistro de Personas Junidicas de la Bunarp mediante el SID-Sunarp. platafomia digtal a travts de la cual se puede iniclar al procedimients regatral electionicamente sin necesidad de lenar fomularios flabos ni acudir a una of cina de la sunarp.

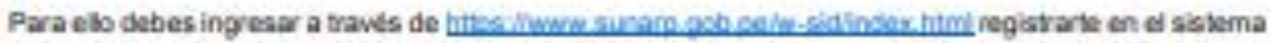

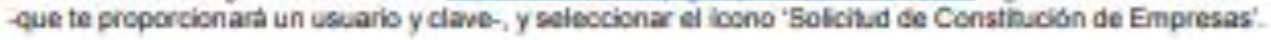

Entre las muchas vertajas de emplear et SID-Sunarp, destacan:

- Eliminacion del soporte papel en el procedimienis registral.

- Maycr rapidez en el trimile notarial yrogistral, dado que la Sunarp registra la empresa o sociedad en un promedio menor a 24 horas e incluso cotener su respectivo FuJC.

- Comunicación inmediata al comeo electiónico del ciudad ano sobre el estatus del trabaio notarial y eogiatral.

Santiago de Surco, 4 de agosto do 2018

OFICINA GENERAL DE COMUNICACIONES - SUNARP

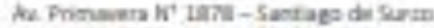

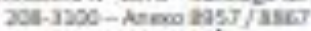

www:asnurp gab pe 


\section{Apéndice N}

\section{Requisitos para obtener la licencia de funcionamiento en el Distrito de la Victoria}

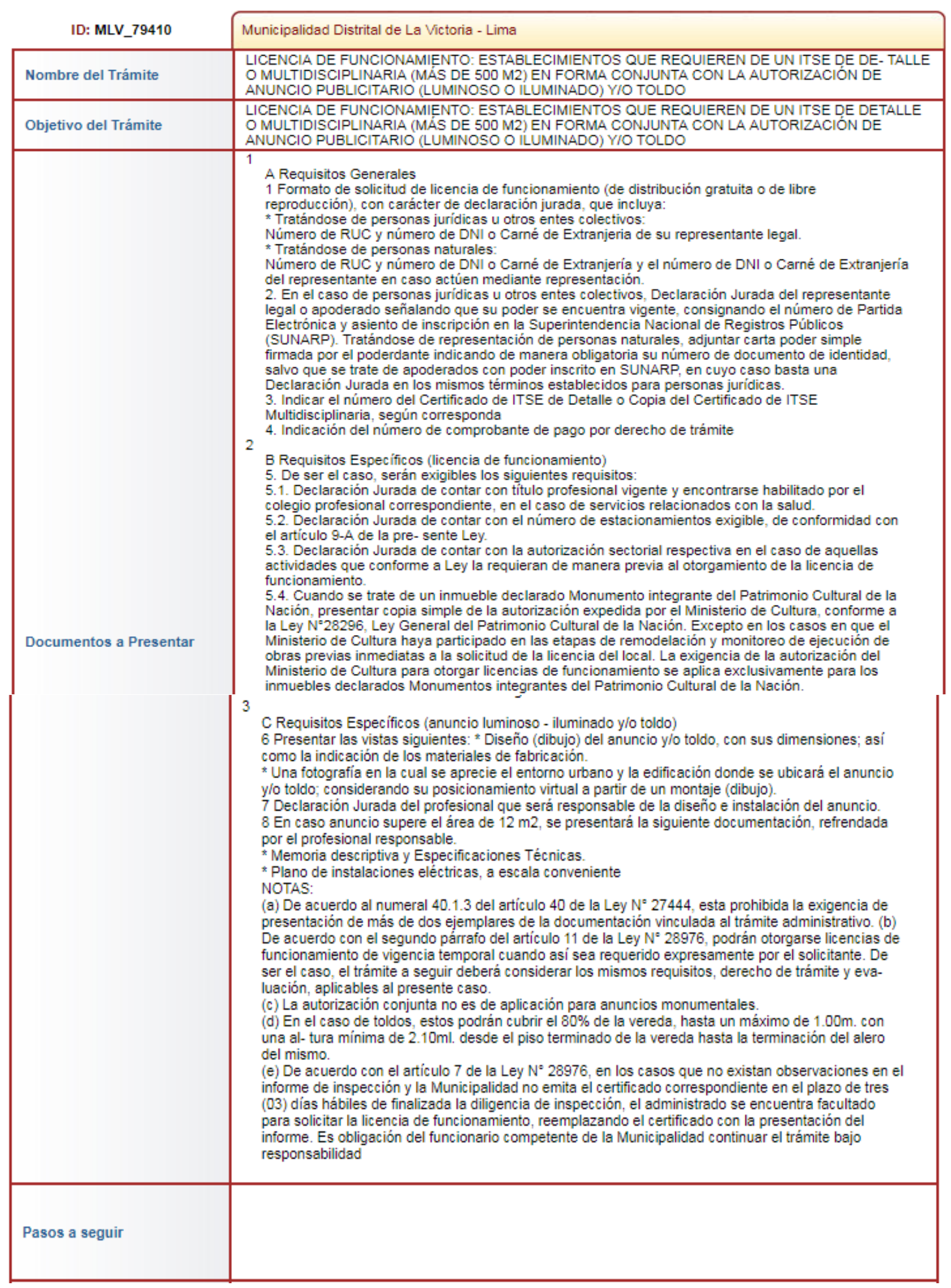




\begin{tabular}{|c|c|}
\hline Donde se realiza el trámite & 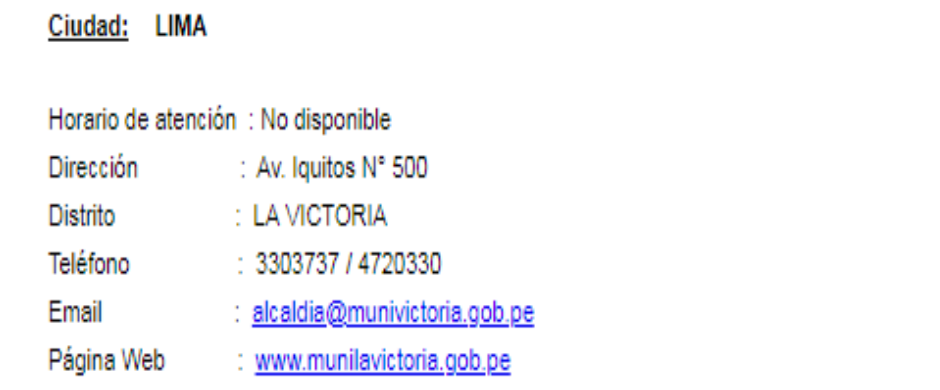 \\
\hline $\begin{array}{l}\text { Costo } \\
\text { Costo UIT S./4150 }\end{array}$ & S/ 108.70 \\
\hline Calificación & $\begin{array}{l}\text { Silencio Positivo - } 15 \text { días } \\
\text { Cuando transcurrido el plazo la institución no ha emitido un pronunciamiento expreso al trámite o } \\
\text { servicio solicitado, este se da como aprobado. }\end{array}$ \\
\hline Inicio del Trámite & Trámite Documentario \\
\hline Unidad que evalúa el trámite & Subgerente de Comercialización y Promoción Empresarial \\
\hline $\begin{array}{l}\text { Informes sobre el estado del } \\
\text { Trámite }\end{array}$ & Subgerente de Comercialización y Promoción Empresarial \\
\hline $\begin{array}{l}\text { Instancia que resuelve el } \\
\text { Trámite }\end{array}$ & Subgerente de Comercialización y Promoción Empresarial \\
\hline
\end{tabular}




\begin{tabular}{|c|c|}
\hline $\begin{array}{l}\text { Instancia que resuelve } \\
\text { recurso impugnatorio }\end{array}$ & $\begin{array}{l}\text { Reconsideración } \\
\text { Subgerente de Comercialización y Promoción Empresarial Plazo máximo para presentar el recurso: } 15 \text { días } \\
\text { hábiles Plazo máximo para resolver: } 30 \text { días hábiles } \\
\text { Apelación } \\
\text { Gerente de Desarrollo Económico Plazo máximo para presentar el recurso: } 15 \text { días hábiles Plazo máximo } \\
\text { para resolver: } 30 \text { días hábiles }\end{array}$ \\
\hline Base Legal & 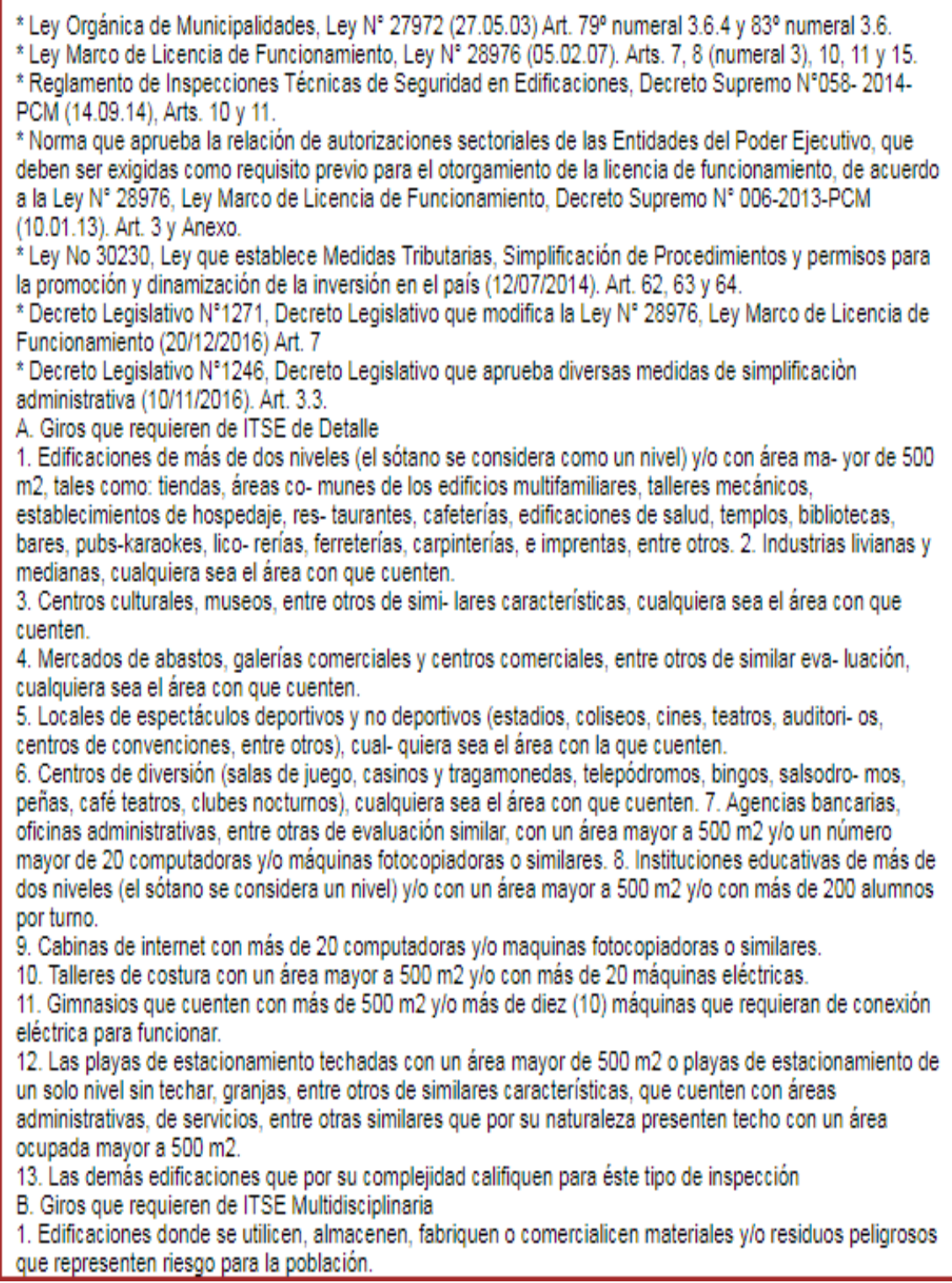 \\
\hline
\end{tabular}

Fuente: http://www.serviciosalciudadano.gob.pe/tramites/10063/6_1_9_0.htm 


\section{Apéndice $\mathbf{P}$}

\section{Transcripción de variables ENTREVISTA A EXPERTOS III}

\section{Entrevista a Directora del "Nido GuarderíaVirgen de la Merced"}

Nombre: Lic. Lizbeth Chavez Alfaro

Cargo: Directora del "Nido Guardería Virgen de la Merced"

ENTREVISTADOR: ¿Buenos días?, tiene un lindo lugar para niños.

Lic. Lizbeth Chavez Alfaro: Gracias, nuestro punto de partida es que nuestros niños disfruten su primera infancia en este lugar pues representa su segundo hogar.

ENTREVISTADOR: Claro, que bonito concepto tienen como parte de la educación que imparten. ¿Siguiendo con lo que me comenta, cuénteme por favor como es que han realizado la distribución de sus instalaciones para darles esa experiencia de segundo hogar que menciona?

Lic. Lizbeth Chavez Alfaro: Bueno, nosotros empezamos en una casita vecina en esta misma cuadra, ahí atendíamos a niños de 3 y 4 años de edad impartiendo clases y también dando los servicios de guardería. Sin embargo, luego de un tiempo de abrir nuestras instalaciones, quisimos aumentar el rango de edades a atender, pero el lugar nos resultaba pequeño. En el anterior local contábamos con 4 aulas que eran distribuidas para el salón de niños de 3 años, el salón de 4 años, el aula de usos múltiples y la oficina administrativa, teníamos también una cocina, un pequeño patio y 3 baños, uno para niños, otro para niñas y el último para los adultos. Ahora con el crecimiento que hemos tenido, contamos con 5 aulas, un aula de usos múltiples, un patio amplio, una oficina para las misses, auxiliares y psicóloga, una oficina para la dirección, una cocina con comedor amplio y 5 baños. Ahora, con todo este espacio los niños disfrutan y se divierten porque no solo tenemos actividades con niños de sus mismas edades, sino que tenemos actividades que involucran a todas las edades porque promovemos que nuestros alumnos se conozcan entre sí.

ENTREVISTADOR: ¿En cuanto a los permisos con la Municipalidad y problemas de ruidos con los vecinos, le ha sido fácil adaptar el Nido a la zona?

Lic. Lizbeth Chavez Alfaro: Al inicio tuvimos algunos inconvenientes con la Municipalidad pues en esta zona no podía operar ningún negocio por el tipo de zonificación, pero justo el cambio a zona comercial esta estaba en trámite por lo que pudimos iniciar operaciones. En cuanto a los vecinos, muchos de estos subarrendaban habitaciones dentro de sus casas y otras se estaban convirtiendo en edificios multifamiliares, la mayor cantidad de público generó una mayor demanda y movimiento en la zona. Con el cambio de zonificación y nuestra apertura, se aperturaron nuevos negocios también. ENTREVISTADOR: Ya que me cuenta del crecimiento del nido-guardería, ¿cómo es que deciden que es momento de seguir creciendo?

Lic. Lizbeth Chavez Alfaro: Teniendo la experiencia de la apertura de nuestro nido-guardería, y siguiendo una clara línea en la educación de nuestros niños, hicimos una encuesta a los padres de los niños que ya atendíamos y en los alrededores del nido, lo que nos arrojó que había necesidad de un nido-guardería con nuestras características, pero con un rango de atención mayor tanto en edades como en horario. Muchos de los padres de nuestros niños, tenían más hijitos de edades próximas y necesitaban tener a los niños en un solo lugar. Por lo que decidimos que debíamos ampliar el rango de edad e implementar la currícula que se pide para las edades de 2 y 5 años.

ENTREVISTADOR: ¿Tuvieron que hacer muchos cambios para la implementación de estos cambios? Me refiero a la continuidad del servicio.

Lic. Lizbeth Chavez Alfaro: Los cambios los empezamos a planificar a mediados del año escolar, para que, al término del mismo, empecemos a hacer las modificaciones que decidimos hacer. Necesitamos mucho capital, pero abrimos las vacantes con tiempo para que el dinero de las nuevas matrículas de los niños ingresantes, nos ayudaran con apalancamiento del nuevo lugar del nido- guardería. Las que 
sí vivieron los cambios de manera directa, fueron las misses y auxiliares, pues durante las vacaciones de verano de los niños, hicimos trabajos conjuntos para recrear el lugar que nuestros niños esperarían ver al inicio de clases.

ENTREVISTADOR: ¿Aparte de estas interrupciones en el servicio de comunicación, han tenido algún evento en que su calidad en el servicio haya disminuido?

Lic. Lizbeth Chavez Alfaro: Normalmente tratamos de dar el mejor servicio, sin embargo, tuvimos un incidente con nuestra anterior asistente, que por alguna razón no entregaba los mensajes a las misses ni a mi persona a tiempo, generando malestar entre los padres pues pensaban que no se atendían sus solicitudes por desinterés. No identificamos el problema rápidamente porque los padres no se quejaban de manera directa con nosotros, sino lo comentaban entre ellos mismos por lo que nos obligamos a enviar un comunicado de disculpas y con un renovado compromiso en nuestra atención, la verdad, esta es la única vez en la que he llegado a pensar que el negocio se iría cuesta abajo. Ahora nuestros ojos están bien abiertos, pues es claro que ahora ningún negocio subsiste si no pone atención a la calidad de su atención.

ENTREVISTADOR: Comprendo el temor que este impase generó. Imagino que mayor temor debe existir cuando algún niño se golpea o enferma dentro de sus instalaciones. ¿Cómo suelen resolver estos temas frente a los padres?

Lic. Lizbeth Chavez Alfaro: Cuando un incidente médico es leve, enviamos la comunicación por la agenda, instrumento que exigimos que se firme de manera diaria tanto por parte de los padres como por parte de nuestra institución. Si el niño sufriera algún golpe que consideramos requiere atención, llamamos a los padres para confirmar su autorización para que su menor hijo salga del nido y sea atendido en la clínica cercana, en esos casos voy yo misma a acompañar al menor. Hasta el momento, todas nuestras intervenciones en este campo han resultado exitosas, esperemos que sea así siempre. ENTREVISTADOR: Coménteme por favor la diferencia de actividades que realiza durante el nido versus la guardería.

Lic. Lizbeth Chavez Alfaro: Básicamente al inicio del año escolar creamos un clima de confianza, para que se sientan cómodos expresando sus palabritas de manera activa, para nosotros esto es muy significativo. Esta primera etapa nos permite conocer sus intereses y habilidades, lo cual nos va a ayudar a estimular su aprendizaje y realizar reforzamientos durante el año. A inicio de año realizamos una reunión con los padres para comprometernos mutuamente a cumplir con nuestros deberes con los niños, pues en ambos lugares se debe reforzar tanto los nuevos conocimientos como los valores. En el nido, brindamos una enseñanza de calidad que sigue una línea de aprendizaje autónomo a través de la estimulación respetando el ritmo individual de cada niño. Al tener a nuestras maestras comprometidas con el desarrollo integral de sus niños, permiten que estén alertas sobre sus necesidades y características particulares para inspirarles confianza y seguridad al vivir las diferentes experiencias que programamos para ellos.

En la guardería se desarrollan capacidades del niño en el que muestra un mayor interés en tanto los padres se liberan de sus actividades laborales.

ENTREVISTADOR: Al darme este detalle, cree que esta forma de trabajo que tienen los diferencia de su competencia o creen que hay algún valor agregado frente a otros?

Lic. Lizbeth Chavez Alfaro: Estoy segura que nuestro sistema educativo y forma interna de trabajo nos posiciona en una de las mejores propuestas de nuestro distrito. Nos capacitamos constantemente, y buscamos ir mejorando y actualizando nuestros procedimientos.

ENTREVISTADOR: ¿Como parte de esa mejora, alguna vez ha considerado la educación a través del Método Doman?

Lic. Lizbeth Chavez Alfaro: Nosotros no lo hacemos de manera directa con los niños en clase pues son varios niños por aula y consideramos que ese método requiere ser personalizado ya que los niños 
no tienen la misma rapidez de aprendizaje. Sí es cierto que tenemos fichas de figuras con sus respectivos nombres debajo de ellas, pero es difícil captar la atención de todos niños a la vez para que relaciones las figuras con las letras que corresponden con el nombre. Lo que sí hacemos, es comentarlo con los padres para que, a manera de juego, lo realicen en casa y estimulen el aprendizaje de los niños y se despierte el interés por la lectura. Una de las profesoras, dio una charla a los padres y les mostró de manera práctica la manera en que debe reforzarse el uso de las fichas con los niños, todos los padres se interesaron, pero en el tiempo hemos sabido que no lo han implementado.

ENTREVISTADOR: Ok, y los padres, ¿están conformes con la educación que ustedes brindan a sus hijos?

Lic. Lizbeth Chavez Alfaro: Considero que sí pues siempre tenemos niños felices que quieren regresar rápido de sus vacaciones para estar con nosotros. Para nosotros eso es un buen indicador.

ENTREVISTADOR: ¿Y cree que la matrícula, la pensión y gastos por materiales van acorde con lo que brindan?

Lic. Lizbeth Chavez Alfaro: Tenemos una estrategia clara para decidir sobre el monto a cobrar cada año en cada uno de los rubros que menciona. Esta se plantea con un año de anticipación aproximadamente pues nos planteamos metas a corto, mediano y largo plazo. Una vez estudiadas estas metas, las valorizamos y las volcamos en las pensiones, y cada vez que el Nido tiene como logro una de sus metas cumplidas, comparte la información con los padres de nuestros niños para que perciban la mejora y sientan que su dinero realmente está siendo utilizado de manera directa en su hijo. Así mismo, al presentar a las misses, exponemos también sus logros académicos para que se evidencie la inversión en docentes de primer nivel.

ENTREVISTADOR: ¿Cómo ha visto la implementación de esta técnica en otras instituciones educativas?

Lic. Lizbeth Chavez Alfaro: He notado que algunos Jardines lo han implementado, sin embargo, no he visto de manera directa el éxito de la técnica. Insisto en que ese tipo de educación debe ser personalizada para que haya una buena visualización de la imagen y de la palabra. Quizá implemente esta técnica más adelante que pueda contratar más personal y reducir la cantidad de alumnos por aula, pero por el momento la infraestructura no me lo permite.

ENTREVISTADOR: Resumiendo un poco la entrevista, ¿cuáles serían los factores de éxito que usted considera para una guardería?

Lic. Lizbeth Chavez Alfaro: Los más importantes según mi experiencia serian una adecuada visión del precio a cobrar, el servicio que nosotros brindamos a nuestros niños, así como el servicio diferenciado que hacemos. Entro otras muchas variables, pero creo que son las principales.

ENTREVISTADOR: Finalmente para elaborar un buen pronóstico de ventas que datos considerarías para tener éxito.

Lic. Lizbeth Chavez Alfaro: Es una buena pregunta, déjame pensar un momento ... Te podría decir la tasa de natalidad, como va a ir el sector en los próximos años, cuál sería el crecimiento del país también. Como te dije anteriormente hay muchos más factores. Pero en base a mi experiencia el primer año es el más complicado y de ahí uno tiene un crecimiento en promedio de $35 \%$ los dos siguientes años y esto va disminuyendo conforme vas alcanzando el máximo de niños.

ENTREVISTADOR: Gracias por tan agradable conversación. Tengo mucha información clara y precisa respecto a su negocio.

Lic. Lizbeth Chavez Alfaro: Que bueno que le he ayudado y espero que, de encontrar puntos de mejora, me los pueda poner en conocimiento para fortalecer la base de los niños que vienen a estudiar. ENTREVISTADOR: Claro que sí, le agradezco su tiempo y gentileza.

Lic. Lizbeth Chavez Alfaro: Gracias a ustedes. 


\title{
Apéndice Q
}

\section{Transcripción de variables ENTREVISTA A EXPERTOS IV Entrevista a Directora del nido guardería "La Casita de Luna"}

\author{
Nombre: Lic. Daniella Centurion
}

Cargo: Directora del nido guardería "La Casita de Luna"

ENTREVISTADOR: Buenos días Miss Daniella, gracias por recibirnos en las instalaciones del Nido

Guardería La Casita de Luna y permitirme realizarle una entrevista respecto a todo lo que concierne al rubro de guarderías.

Lic. Daniella Centurion: Gracias a ustedes por considerarnos dentro de los expertos a entrevistar en el rubro educativo para niños que se inician en un proceso formativo en manos de profesionales.

ENTREVISTADOR: Tenemos muy buenos comentarios de padres que han tenido a sus hijos recibiendo estimulación desde muy pequeños en sus instalaciones, que por cierto quisiera comentarle, que desde mi ingreso he percibido un ambiente muy agradable.

Lic. Daniella Centurion: Eso mismo es lo que procuramos reflejar no solo a visitas como la tuya, sino en la convivencia diaria con los niños y sus papitos.

ENTREVISTADOR: ¿Comencemos con la entrevista, coménteme cómo así es que decide iniciar un proyecto tan ambicioso como el de una guardería?

Lic. Daniella Centurion: Todo empezó como un sueño, uno en el que yo ayudaría de manera directa en la educación de niños de mi país, una educación que tuviera una estimulación adecuada para aprovechar al máximo la capacidad de aprendizaje de los niños más pequeñitos.

ENTREVISTADOR: ¿Comprendo, y cómo es que empieza a ejecutar su sueño?

Lic. Daniella Centurion: Bueno, los estudios que hicimos previo a nuestra apertura, por un lado nos indicaron que había una necesidad de tener una guardería en la zona puesto que las más cercanas, no tenían suficientes vacantes para cubrir la demanda que existía, y por otro lado, nos demostró el descontento de los padres respecto a la debida estimulación y educación que recibían sus hijos frente al pago mensual requerido por estas instituciones. Aquí quisiera comentarte que esta zona tiene mayor demanda de vacantes, puesto que muchas constructoras han ido interesándose en viviendas de los alrededores para demolerlas e iniciar la construcción de edificios, esto ha traído como consecuencia, que muchas parejas jóvenes con bebés en camino o niños pequeños se interesen en estos inmuebles y se trasladen a los alrededores.

ENTREVISTADOR: Ok, y ya que me comenta de las nuevas construcciones en la zona, ¿cómo es que esta propiedad ha sido acondicionada?

Lic. Daniella Centurion: En un inicio no contábamos con el presupuesto suficiente por lo que decidimos buscar ayuda entre personas de mi entorno a las que les pudiera interesar mi proyecto, pero al no ser suficiente el capital reunido, tuvimos que recurrir al crédito bancario. Sobre la marcha de la implementación del local, la búsqueda de los permisos y licencias, y la contratación de personal calificado, decidí abrir las vacantes de manera pública ya que gran cantidad de vecinos tocaban el timbre para pedirnos información respecto al rango de edades que recibiríamos en la guardería, el tipo de estimulación que trabajaríamos, y la corriente educativa que seguiríamos. La aceptación y las ganas fueron tales, que con la ayuda de los papitos el sueño se pudo concretar y llenar nuestras primeras aulas. Dicho esto, iniciamos clases y servicio de guardería con las aulas para niños de 1, 2 y 3 años, ya con el transcurrir del tiempo, implementamos estimulación temprana y guardería para bebés desde los 4 meses a 12 meses, y realizamos una ampliación en el número de aulas para niños con edades de 4 y 5 años. 
ENTREVISTADOR: La felicito por el gran crecimiento que ha tenido en el tiempo. Coménteme más respecto al tipo de educación que reciben los niños en sus diferentes etapas.

Lic. Daniella Centurion: Gracias por tus palabras. Te comento que básicamente trabajamos en todas las edades el interés por los descubrimientos, desde los más chiquitos hasta los más grandecitos pues buscamos que la curiosidad innata de cada uno los ayude a explorar desde las cosas más sencillas. Claro, esto sin descuidar los estímulos visuales, sonoros y táctiles a través del juego que desarrollamos de acuerdo a la edad de nuestros niños, esto lo complementamos con adecuados movimientos para el desarrollo físico, hacemos seguimiento de su desarrollo emocional y social, y trabajamos de manera personalizada de las habilidades cognitivas. Así mismo, las misses tienen un rol muy importante en todo momento del día, pues al ser ellas quienes enseñan a través del ejemplo, los niños aprenden mucho más al replicar el actuar de las misses porque tienden a imitarlas.

ENTREVISTADOR: Ya que me comenta de las profesoras, ¿cómo es que las llega a seleccionar? Lic. Daniella Centurion: Ellas pasan un riguroso proceso de selección pues necesitamos profesoras y auxiliares de primer nivel ya que es de mucha responsabilidad trabajar con niños pequeños. Y no hemos pensado solo en las evaluaciones para estos profesionales, sino también para aquellos que complementan nuestros servicios, como nuestro departamento psicológico, nutrición, tópico administrativo, seguridad y limpieza. Todo nuestro personal, debe rigurosamente, tener estas características: paciente, actitud flexible y positiva, dedicado, respetuoso, empático y motivador. Una vez que pasa por nuestros filtros y queda seleccionado trabajamos de manera constante en mantenerlos actualizados en sus respectivos campos a través de cursos o talleres, y motivados luego de sesiones de coaching; de esta manera hemos venido trabajando durante estos años obteniendo muy buenos resultados pues un profesional que se ilusiona a diario por su trabajo da lo mejor de sí. ENTREVISTADOR: Interesante lo que menciona. ¿Cuál es la opinión de los padres del trabajo que realizan?

Lic. Daniella Centurion: Muy buena, los padres están muy contentos. En realidad, nosotros fomentamos la comunicación y participación activa de los padres a través de reuniones uno a uno con la maestra, teléfonos o a través de correo electrónico. Inclusive, cada inicio de bimestre convocamos a reunión con los padres y maestras para comentar sobre lo que se planteará para el trabajo en clases. La primera de estas reuniones sirve también para que los padres creen relación con las maestras y presenten sus dudas o indicaciones especiales en casos puntuales de salud o comportamiento, enseñamos el uso de la agenda, detallamos el calendario escolar y manejo del reporte de avances de los niños. A los padres les gusta mucho nuestra primera reunión pues, con ayuda de un proyector, mostramos las primeras fotos de la adaptación de los niños, los primeros trabajos hechos en clase y la interacción con sus compañeros en clase y recreo. Además, que se hace una presentación entre los padres a través de una divertida dinámica ya que se acompañarán durante todo el año escolar. Al final del año tenemos una última reunión, esta es un compartir entre maestras, padres e hijos donde se comparten anécdotas del año de manera visual.

ENTREVISTADOR: ¿Y cómo hacen con aquellos padres que trabajan y no pueden asistir? Lic. Daniella Centurion: Procuramos hacer las reuniones tarde en la noche para tener la mayor cantidad de asistentes posibles, sin embargo, para que la información llegue de manera directa, pedimos que de no poder ambos padres, se acerque uno de ellos, de tampoco poder, pedimos envíen un representante. Aun así, enviamos los resúmenes de las reuniones a través de un correo electrónico general. Continuamente enviamos información por ese mismo medio sobre temas de interés relacionados con la edad de sus hijos sea de carácter lúdico, médico, conductual o cognitivo. ENTREVISTADOR: ¿El trabajar con niños que tienen meses de nacido debe ser muy demandante, qué clase de actividades son las que realizan hasta antes del primer año de edad? 
Lic. Daniella Centurion: El juego es la mejor forma de relacionarse con un bebé, el jugar llama su atención y consigues que te observe, te escuche y lo ayuda a aprender. Además, que es importantísimo para su desarrollo integral. No todos los juegos funcionan en el llamado de su atención la primera vez que se ejecutan, el secreto es la repetición, esto hará que el bebé comprenda lo que uno hace, le causará gracia y querrá verlo una y otra vez, e inclusive dar la sensación de que quiere hacerlo con uno. Lo fundamental es tener una gama de juegos, los cuales pueden ser cambiados dependiendo el temperamento y estado de ánimo del niño.

ENTREVISTADOR: ¿Según su experiencia y por lo que me está comentando cuales serían factores a considerar para la diferenciación de las guarderías?

Lic. Daniella Centurion: De acuerdo a lo observado y mi experiencia consideraría el local, el servicio al cliente y como me diferencio respecto a mi servicio brindado. Por supuesto que debe haber otras, pero estas son las que más considero.

ENTREVISTADOR: ¿Quisiera hacerte una última pregunta, cuales consideras que son buenas variables para realizar un buen pronóstico de ventas?

Lic. Daniella Centurion: Buena pregunta, según mi criterio y recalco mi experiencia te podría decir la población de tu distrito, la economía del país y la tasa de natalidad. Puede haber otras más por supuesto. Recuerda que el primer año es uno de los más difíciles hasta que los padres te recomienden, se conservador. Es mi mejor consejo.

ENTREVISTADOR: Miss Daniella muchas gracias por todo su tiempo brindado, he podido sacar muy buenas conclusiones. Le molestaría si después vuelvo a visitarla si es que me surgieran algunas dudas.

Lic. Daniella Centurion: Por supuesto que no. Encantada de ayudarte. Me agrado mucho que me consideres para la entrevista como experta en el rubro. 


\section{Apéndice R}

Tópicos de evaluación que permiten medir el avance de la metodología en los niños de acuerdo a los rangos de edad.

Nombre del Infante:

Responsable de la evaluación:

Área / Actividades
Edad:

Fecha:

SI

NO

Observaciones

\section{MESES}

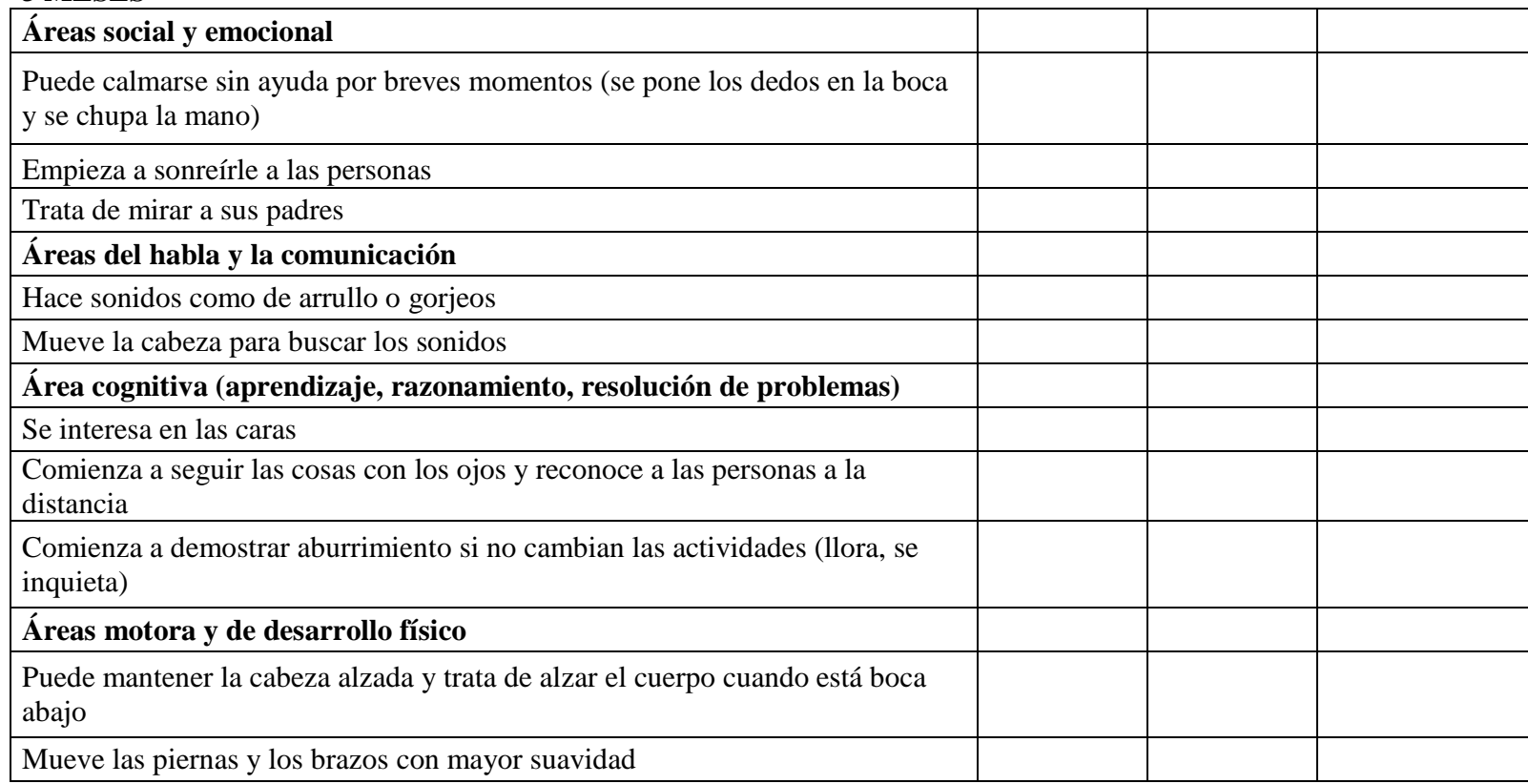


Nombre del Infante:

Responsable de la evaluación:
Edad:

Fecha:

SI

NO

Observaciones

\section{MESES}

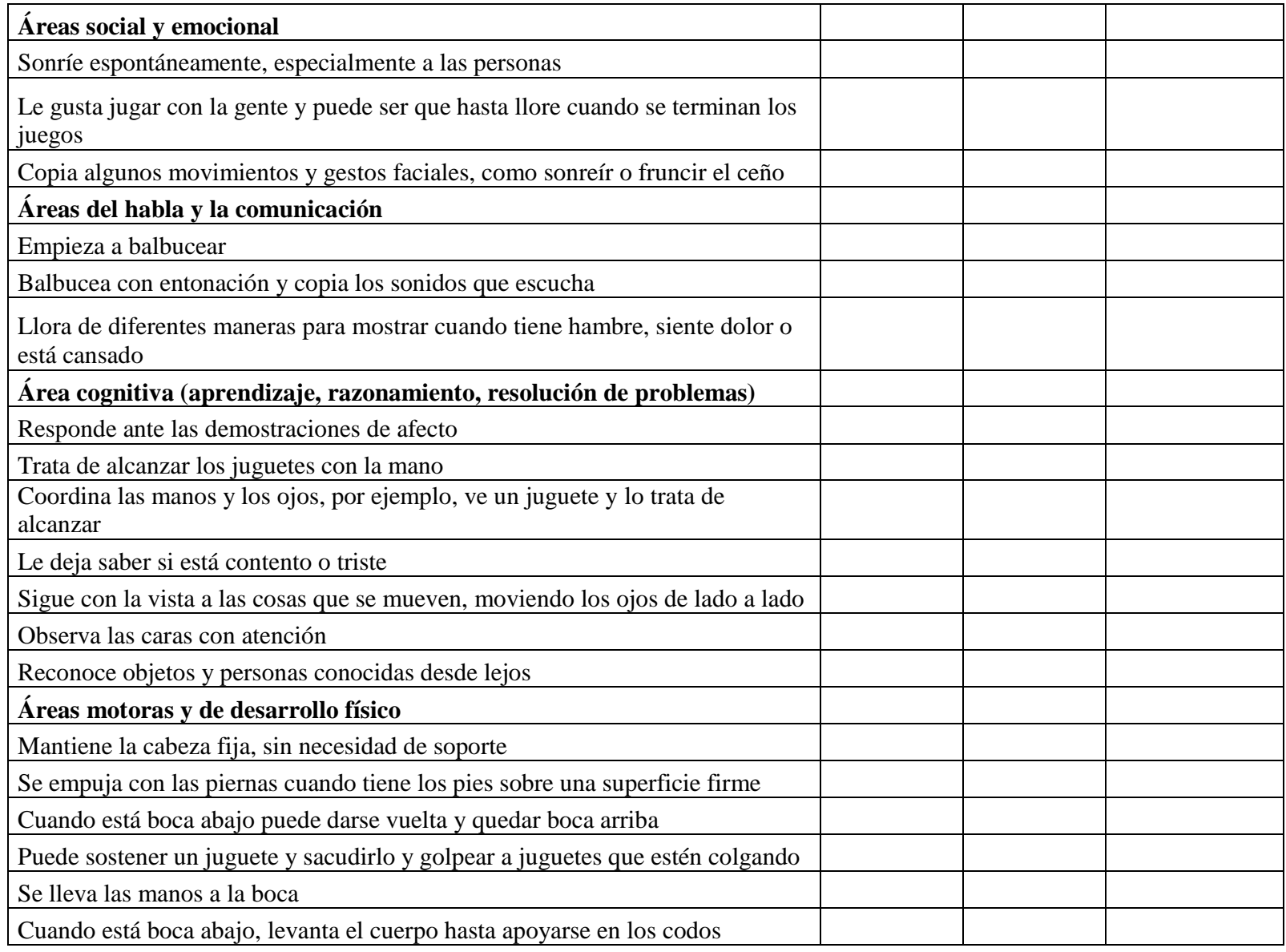


Nombre del Infante:

Responsable de la evaluación:

Área / Actividades
Edad:

Fecha:

\section{MESES}

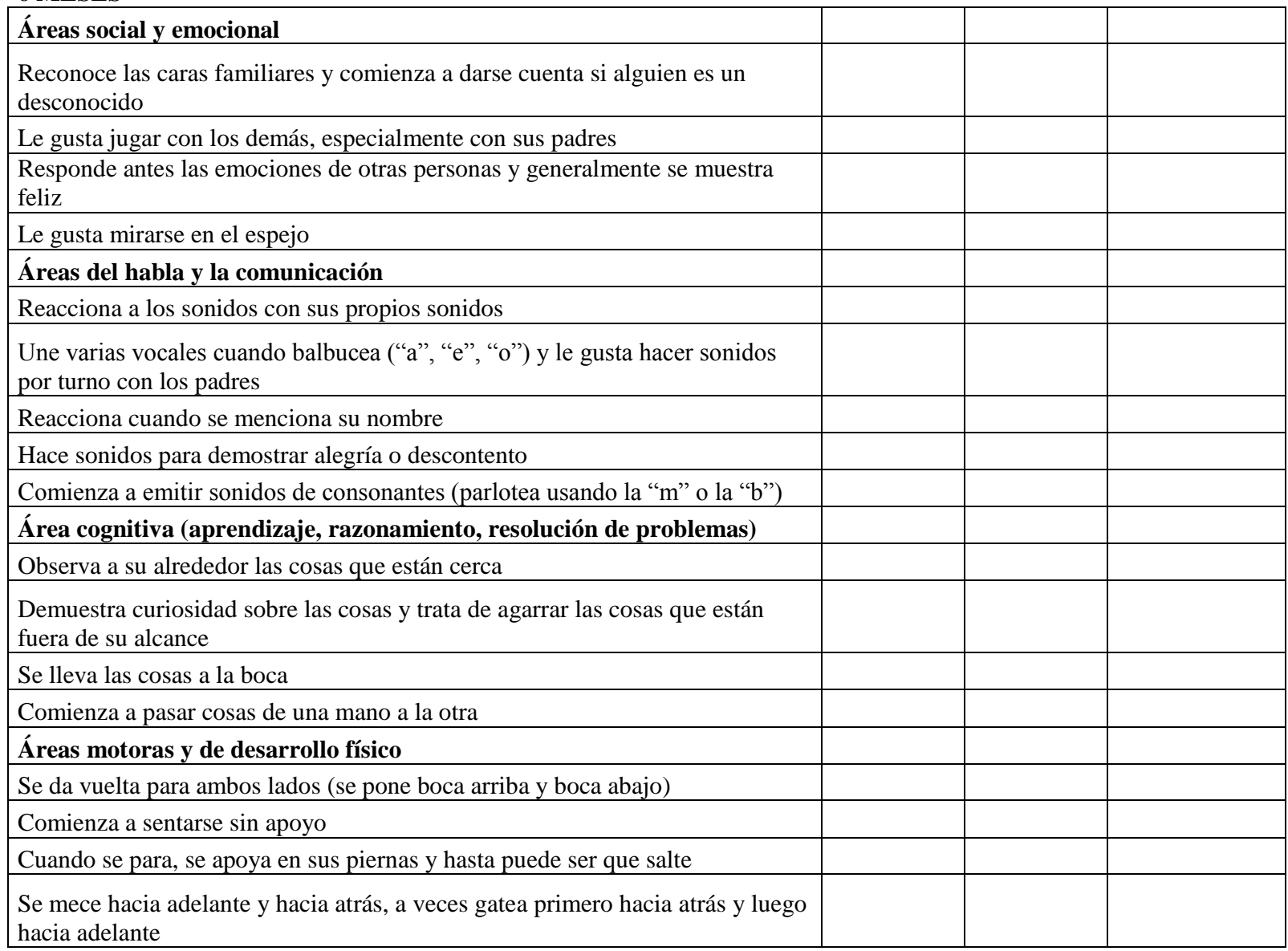


Nombre del Infante:

Responsable de la evaluación:
Edad:

Fecha:

SI

NO

Observaciones

\section{MESES}

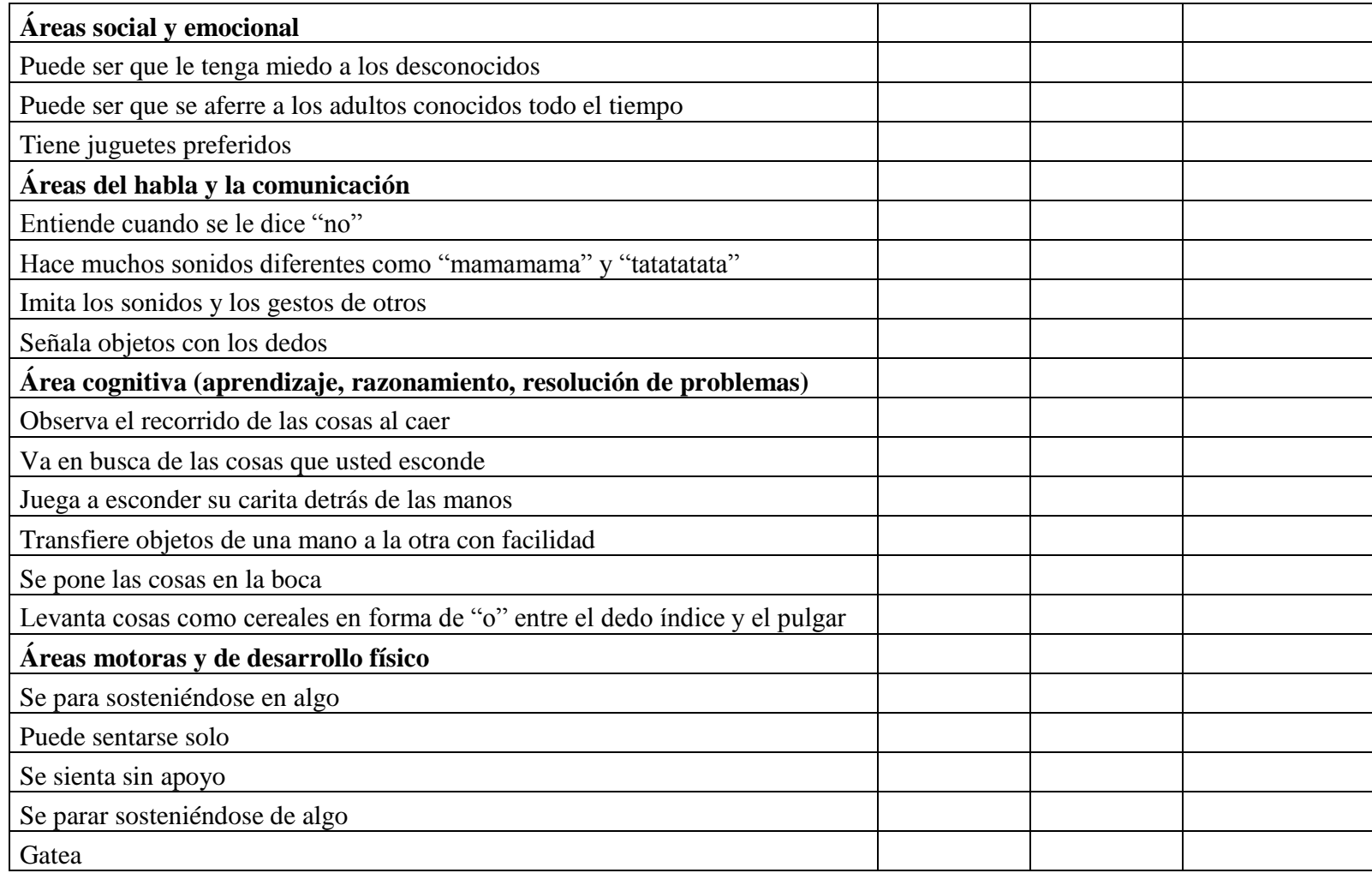


Nombre del Infante:

Responsable de la evaluación:
Edad:

Fecha:

SI

NO

Observaciones

\section{MESES}

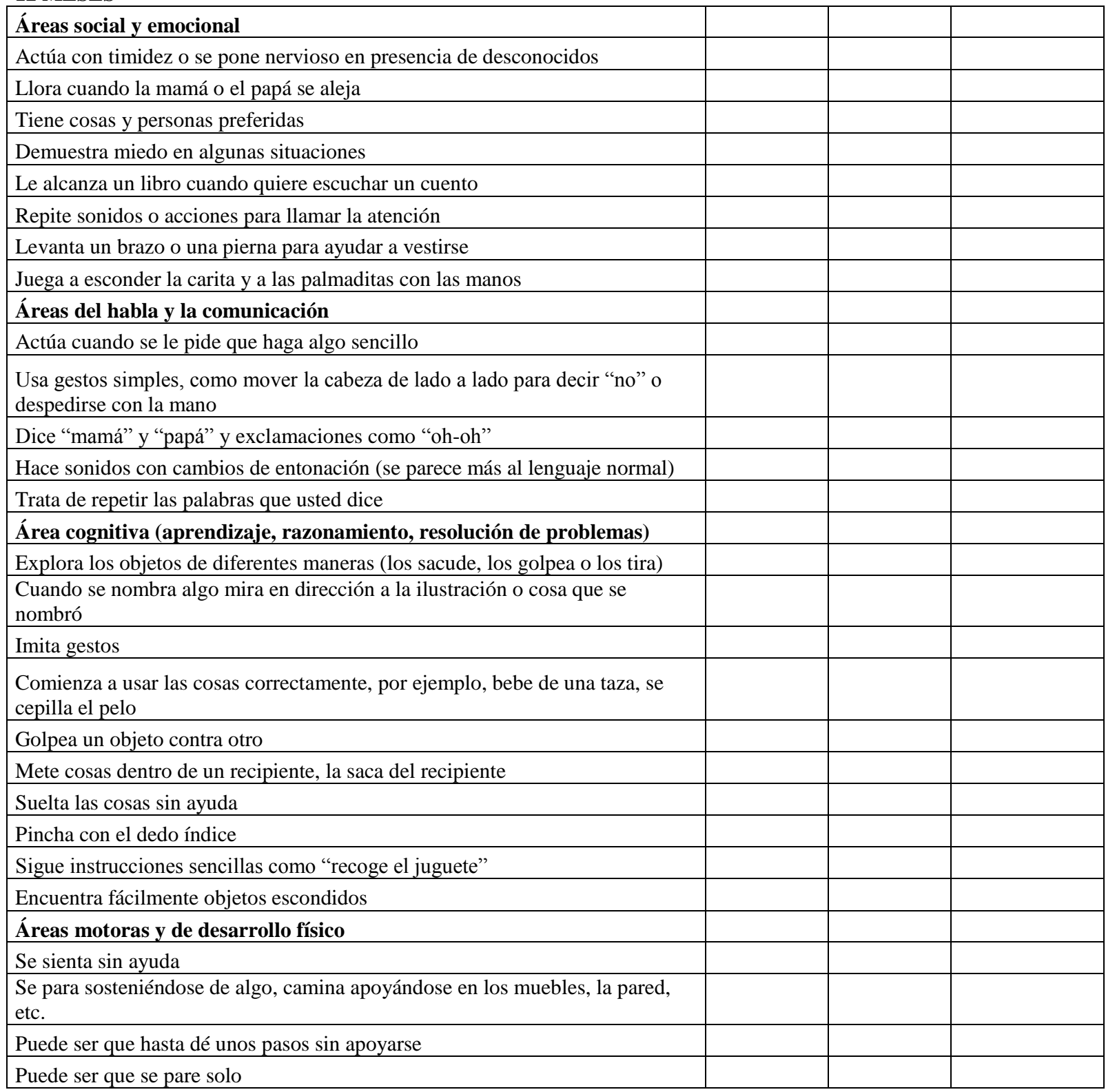


Nombre del Infante:

Responsable de la evaluación:
Edad:

Fecha:

SI

NO

Observaciones

\section{MESES}

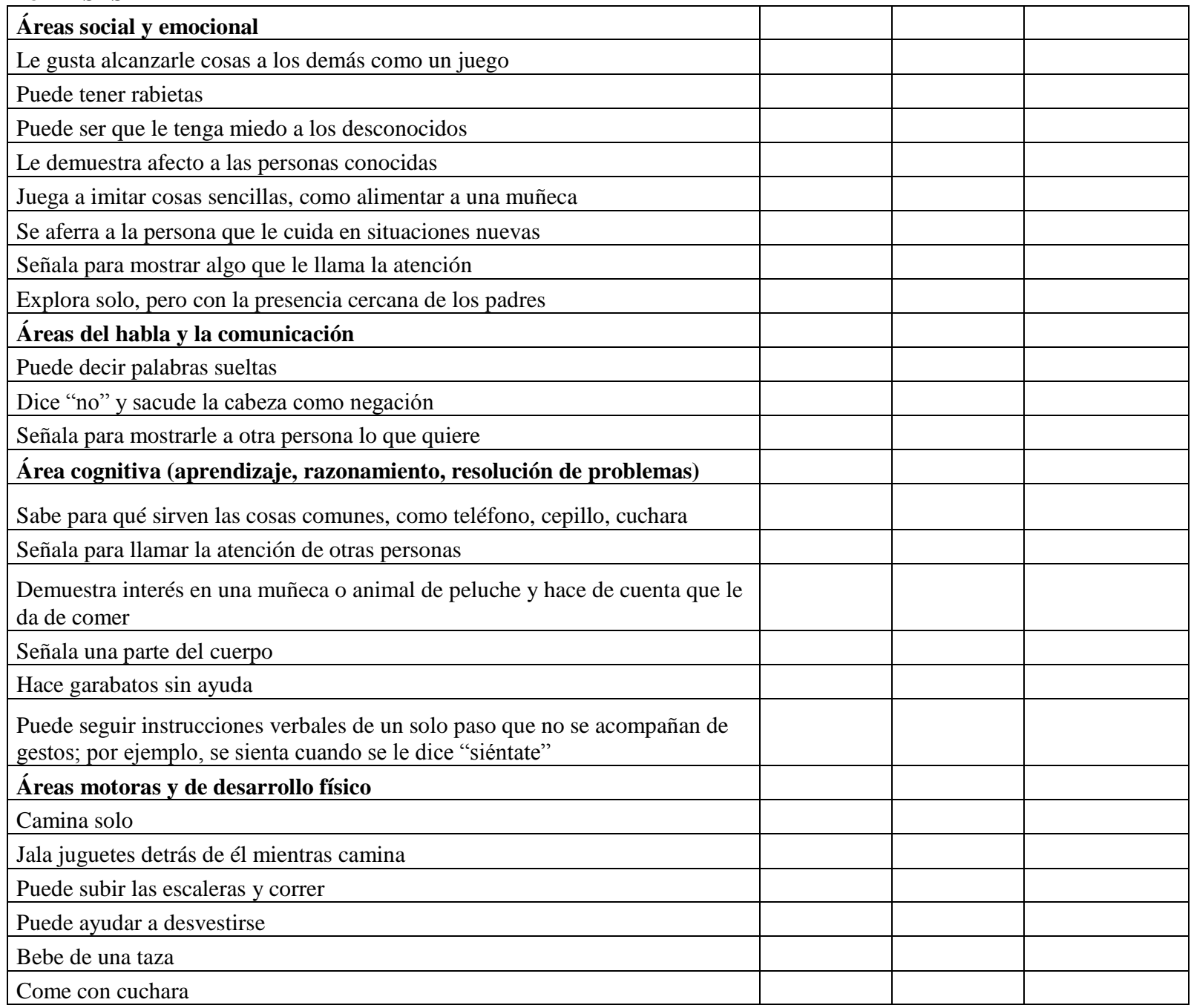


Nombre del Infante:

Responsable de la evaluación:
Edad:

Fecha:

SI

NO

Observaciones

\section{MESES}

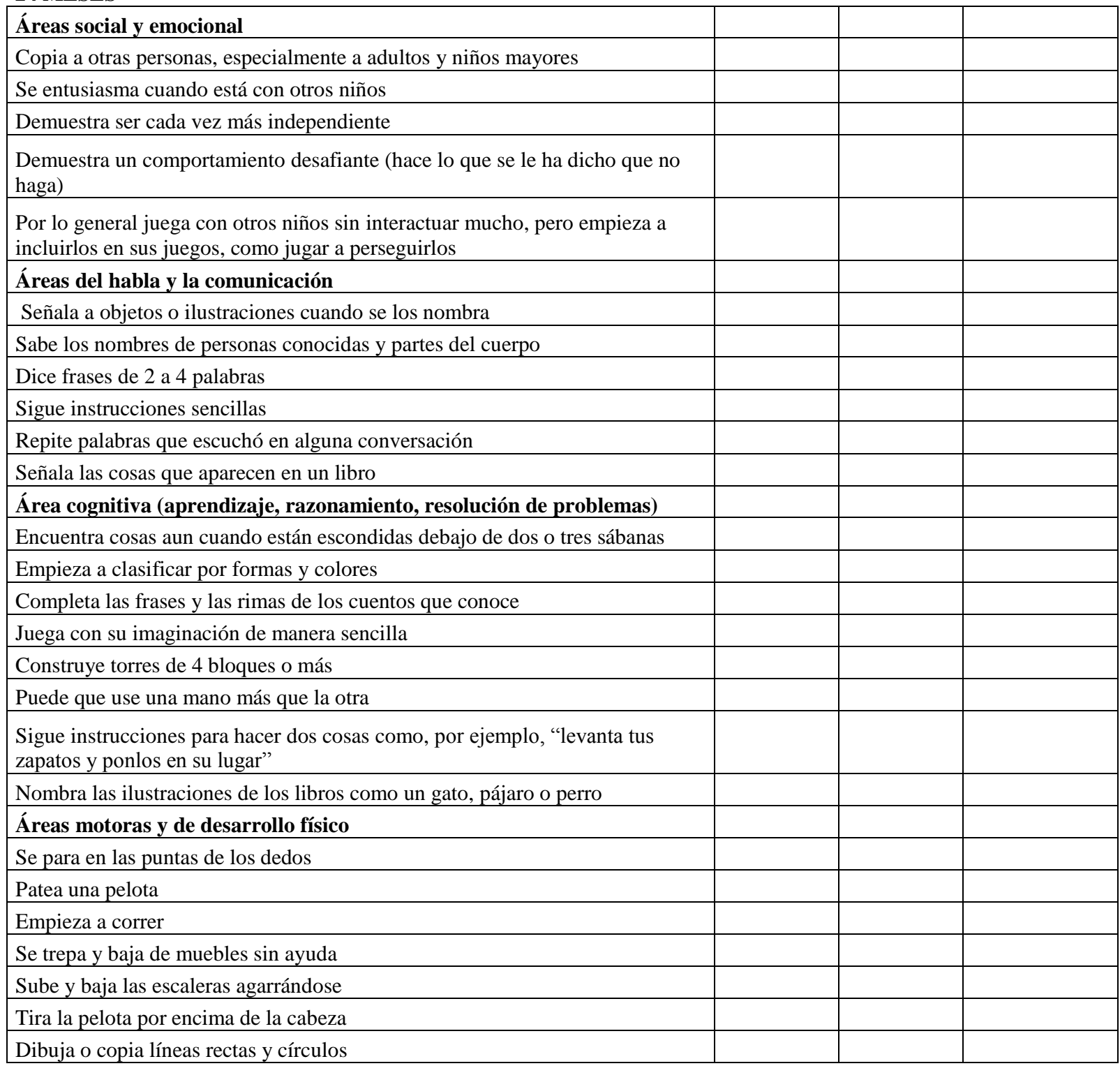


Nombre del Infante:

Responsable de la evaluación:

Área / Actividades
Edad:

Fecha:

Observaciones

\section{MESES}

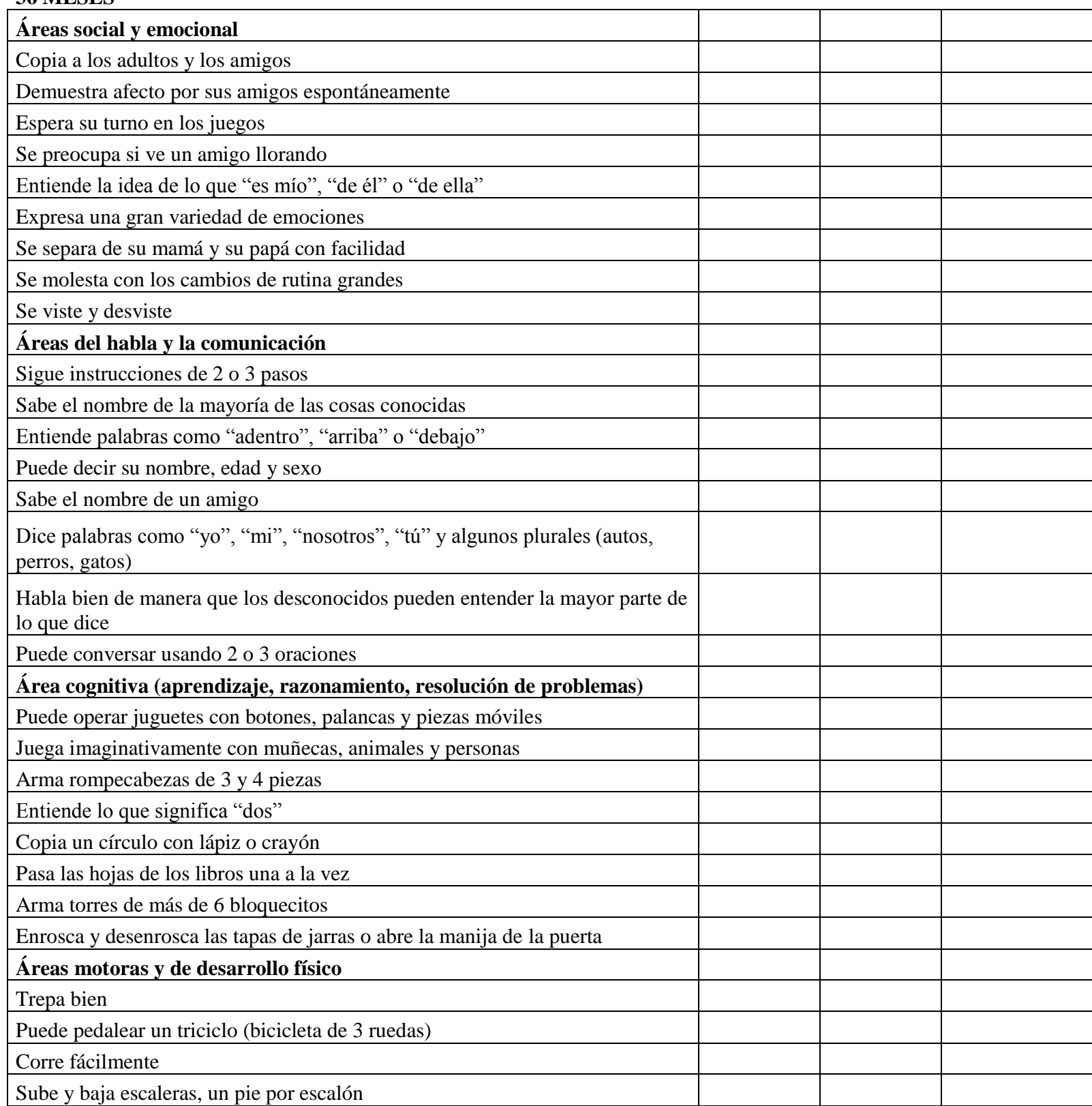




\section{Apéndice S}

Focus Group: Tabla de preguntas que permite conocer opiniones, intereses, experiencias, expectativas y hábitos de compra compartidos por clientes potenciales del mercado.

\begin{tabular}{ll}
\hline \multicolumn{1}{c}{ Pregunta } & \multicolumn{1}{c}{ Respuesta } \\
\hline ¿Quién decide sobre el cuidado de & La mayoría de los participantes toman la decisión acerca de los \\
sus hijos? & niños en consenso con la pareja; cuando se trata de encargar a \\
& sus hijos a otras personas que nos son los habituales, estos \\
& solicitan muchas recomendaciones, pero tienen cierto grado de \\
& desconfianza así sean recomendados.
\end{tabular}

¿Quién se encarga del cuidado de sus Los participantes no cuentan con un lugar en donde dejar el hijos mientras usted trabaja? cuidado de sus hijos, pero tienen a personas cercanas o familiares de confianza a quienes encargan, y que luego los retribuyen económicamente.

¿Qué tan complicado ha sido dejar a Los imprevistos o temas de salud de la persona que está al sus hijos con sus padres o familiares? cuidado de sus hijos y no pueden cumplir, generando un problema para los padres, los cuales deben recurrir a permisos $o$ ausencias en el trabajo.

Los abuelos en su gran mayoría son muy consentidores, llegando a malcriar al niño, situación que debe ser revertida en casa por los padres.

Algunos de los familiares son adultos mayores, situación que complica los tiempos de los abuelos ya que es muy desgastante para ellos y también para los mismos padres, esta situación causa estrés en el núcleo familiar.

La rotación de niñeras (si los tiene) genera inseguridad en los niños; "cuando la niñera renunció le costó bastante al niño acostumbrarse con la nueva niñera".

¿Qué excusas les dieron sus padres o $\quad$ El no contar con familiares cercanos a quien puedan encargar a familiares para no poder cuidar a sus su niño, o si lo tienen, trabajan y están en otras actividades o hijos? no tienen paciencia cuidando niños.

¿Cuáles son los temores de dejar a sus hijos con terceros?

\footnotetext{
Desconfianza, agresividad, el cómo van a estar, el cómo lo van a tratar, que tipo de persona lo va a cuidar, tendrá educación?, se preocupará por sus alimentos?, etc. Que no tengan paciencia o se aburra con los niños, lugar y espacio donde va a estar, si el lugar es seguro o no; ante ello, se espera de una guardería cuente con personas altamente capacitadas, que tengan mucha paciencia y sobre todo valores.
} 


\begin{tabular}{ll}
\hline \multicolumn{1}{c}{ Pregunta } & \multicolumn{1}{c}{ Respuesta } \\
\hline ¿Estaría dispuesto a dejar a sus hijos & El desprendimiento de los hijos es difícil, pero ante la \\
en una Guardería? Profundizar & necesidad de seguir trabajando y continuar con sus actividades \\
de crecimiento profesional, si. & \\
& Los participantes no conocen algún lugar de guardería cercano \\
a su zona de labores, pero se muestran interesados si se \\
presentara alguna opción que le ofrezcan las condiciones \\
necesarias para el cuidado de sus hijos. \\
Inciden mucho en que el personal de la guardería tenga que \\
seguir un proceso de evaluación psicológica para evitar \\
agresividad o problemas de conducta estando al cuidado de los \\
niños. Asimismo, revisar que no tengan denuncias policiales ni \\
penales.
\end{tabular}

¿Qué atributos buscaron en la Guardería? Profundizar.
Otros atributos que esperan encontrar en una guardería son los niveles de seguridad en sus instalaciones y una infraestructura adecuada para los infantes, así también la estimulación motora, impartir valores a los niños, que debería considerarse como base fundamental para el cuidado de los niños.
¿Cuántos días a la semana utilizaría el servicio de la Guardería?
Por la cercanía a su centro de labores, están de acuerdo con una frecuencia de asistencia de lunes a viernes y con el horario de 8:00am hasta las 7:00 pm. (algunos mencionan la posibilidad de que sea desde las 7.00am)

Todos los participantes conocen guarderías cercanas a sus viviendas (varían en tamaño y fachada), pero por desconfianza no se animan a hacer uso de ellos dado las noticias negativas y la lejanía a sus trabajos.

En San Isidro no han visto ninguna guardería cerca a sus centros laborales.

En su mayoría, son casas acondicionadas para el tipo de negocio, poco reglamentarias que conllevan a la inseguridad y desconfianza.

Muestran su disconformidad de guarderías que se encuentran distribuidas: el primer piso la guardería en sí, y el segundo piso la vivienda propiamente dicha.

El orden y limpieza, así como la uniformidad del personal es muy importante por el cual puede sumar o restar seriedad. 
...Viene de

\begin{tabular}{ll}
\hline \multicolumn{1}{c}{ Pregunta } & \multicolumn{1}{c}{ Respuesta } \\
\hline ¿Han escuchado de la & Los participantes no conocen la metodología Doman, pero ante la \\
Metodología Doman? & $\begin{array}{l}\text { explicación muestran su interés en saber más y del cómo se aplica. } \\
\text { Profundizar. }\end{array}$ \\
& $\begin{array}{l}\text { Los padres quisieran investigar más sobre el método, han escuchado } \\
\text { acerca de la estimulación temprana y creen que está relacionado. }\end{array}$ \\
& $\begin{array}{l}\text { Es importante considerar que el 10\% de los participantes menciono el } \\
\text { método Montessori, el resto desconoce algún otro método. }\end{array}$
\end{tabular}

Explicar el método

Ante la explicación verbal y audiovisual sobre las ventajas y bondades que brinda la metodología, los asistentes se muestran interesados.

\begin{tabular}{ll}
\hline Explicar el concepto del proy & proyecto y la ubicación de la Guardería \\
\hline ¿Qué percepción tienen & A los participantes les interesa la idea de una guardería cercana a sus \\
acerca del proyecto? & labores, el contar con Cámaras IP les parece muy buena idea porque \\
Profundizar. & $\begin{array}{l}\text { les daría tranquilidad y confianza del lugar. Sugieren la entrega de } \\
\text { videos de las actividades semanales }\end{array}$
\end{tabular}

Les pareció interesante el método Doman puesto que no lo conocían y lo ven como una forma divertida de aprender.

¿Qué les parece la ubicación La ubicación de la guardería en Santa Catalina les pareció buena en de la Guardería? general, ya que es una zona cercana a San Isidro con vías de acceso.

¿Qué características les gustaría que tenga la Guardería?

Profundizar.
Los participantes además de los cuidados y seguridad que el lugar debe poseer, les atrae la idea de la interacción social de sus hijos y que su desarrollo sea jugando y educando mediante la metodología a aplicar.

Las características de la persona que cuida a niños deben de gustarle su trabajo, es decir, tener paciencia y sepa orientar a los niños, tener buena higiene, que transmita confianza, tranquilidad y protección.

Profesores capacitados en primeros auxilios, buena infraestructura, horario desde 7:00 AM., ubicación cercana al centro laboral, que sea espaciosa, contar con cámaras de seguridad, estacionamientos; mencionan que sería ideal que en la guardería se de tolerancia para recoger a los niños unos 30 minutos después en caso de tratarse de una emergencia.

¿Qué otros servicios adicionales para el cuidado y método de enseñanza le A los participantes les interesa que la guardería cuente con servicios adicionales como: alimentación, psicología, enfermería, entrega o envío de videos de actividades semanales de sus menores hijos. gustarían que su hijo reciba? 
...Viene de

\begin{tabular}{ll}
\hline \multicolumn{1}{c}{ Pregunta } & \multicolumn{1}{c}{ Respuesta } \\
\hline $\begin{array}{l}\text { ¿Cuántos niños considera } \\
\text { usted que deberían estar a } \\
\text { cargo de cada profesor? }\end{array}$ & De acuerdo a la edad, no es lo mismo el cuidado de menores de 12 \\
& \\
\hline
\end{tabular}

¿Qué niveles de seguridad Una buena infraestructura de la guardería es muy importante por considera necesario para una seguridad y para permitir que los niños se desarrollen libremente.

Guardería?

La cocina no debe estar muy cerca a las aulas o lugar donde descansan los niños y contar con baños separados x género.

¿Cuánto estaría dispuesto a $\quad$ El monto promedio que estaría dispuesto a pagar por el servicio pagar por el servicio de requerido es entre 900 y 1400 soles por tiempo completo y de 600 a Guardería? 800 soles por medio tiempo.

¿Qué medios de pago le A través de transferencias electrónicas o tarjeta de crédito/debito, gustaría tener disponibles? débito automático (cargos en cuenta de manera automática), ya que no les gusta transportar dinero en efectivo.

¿Cuáles creen que serían los Vía correo electrónico, Facebook, página web y recomendaciones. mejores medios de comunicación para mostrar

la Guardería?

¿Cuáles serían los medios de $\quad$ El medio de comunicación con la guardería y sobre todo con los comunicación que les profesores a través del celular, whatsApp, correo electrónico; que sea gustaría tener con la de forma rápida, así también conocer el desarrollo y otra información Guardería? relevante de sus hijos por lo menos una vez por semana.

¿Tendría la intención de $\quad$ En la medida que se cumplan y puedan ser evidenciados con los confiarnos la educación de requisitos propuestos en la exposición del proyecto (cercanía, su hijo? ¿Por qué? seguridad, cámaras, metodología de enseñanza, infraestructura, horarios, precios, etc.), si tendrían la intención de confiar en este proyecto.

Consideran como una ventaja la opción de una guardería, ya que los estimulan en el habla, gateo; es decir, actividades de desarrollo e interrelación de acuerdo con la edad de niños.

¿Recomendaría la Guardería Si los resultados de la propuesta son óptimos y adecuados para los a sus amistades? niños, si los recomendaría. 


\section{Apéndice T}

\section{Materiales usados para el desarrollo de la investigación de mercado}

Video que explica la metodología Doman.

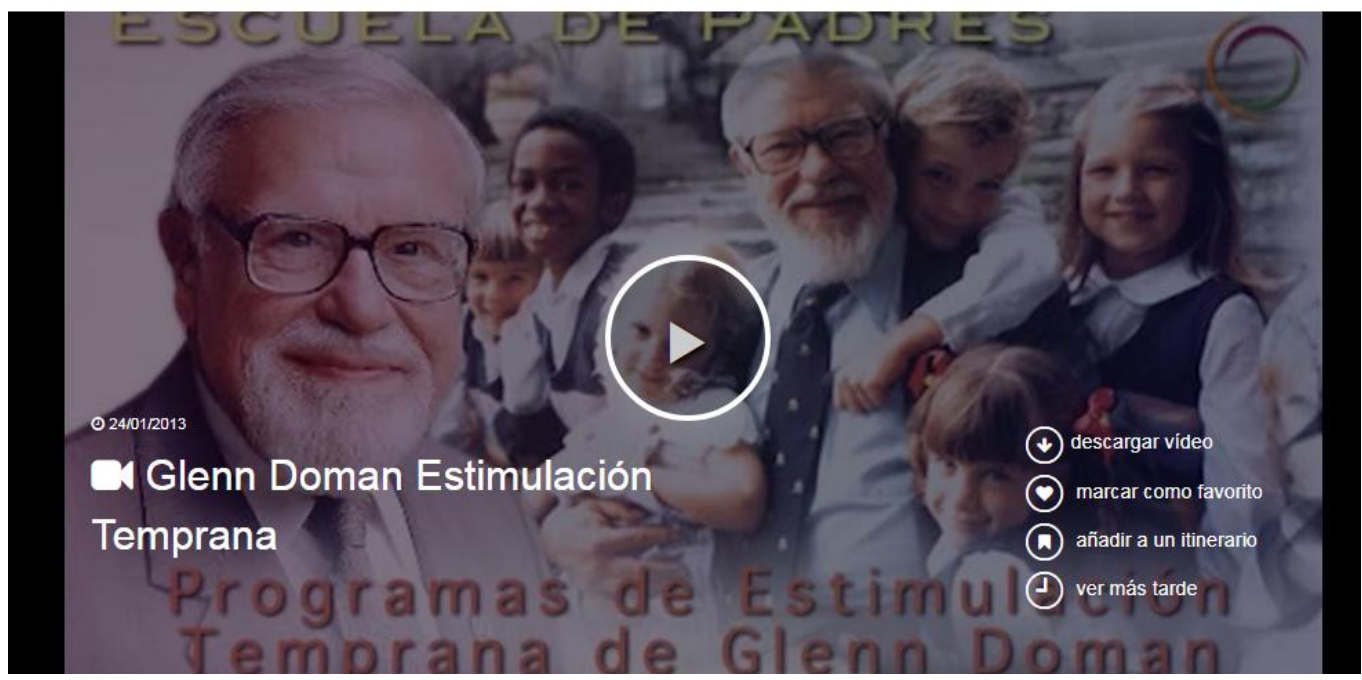

Fuente: Recuperado de https://www.think1.tv/es/video/estimulacion-temprana-glenn-doman-es

\section{Ubicación}

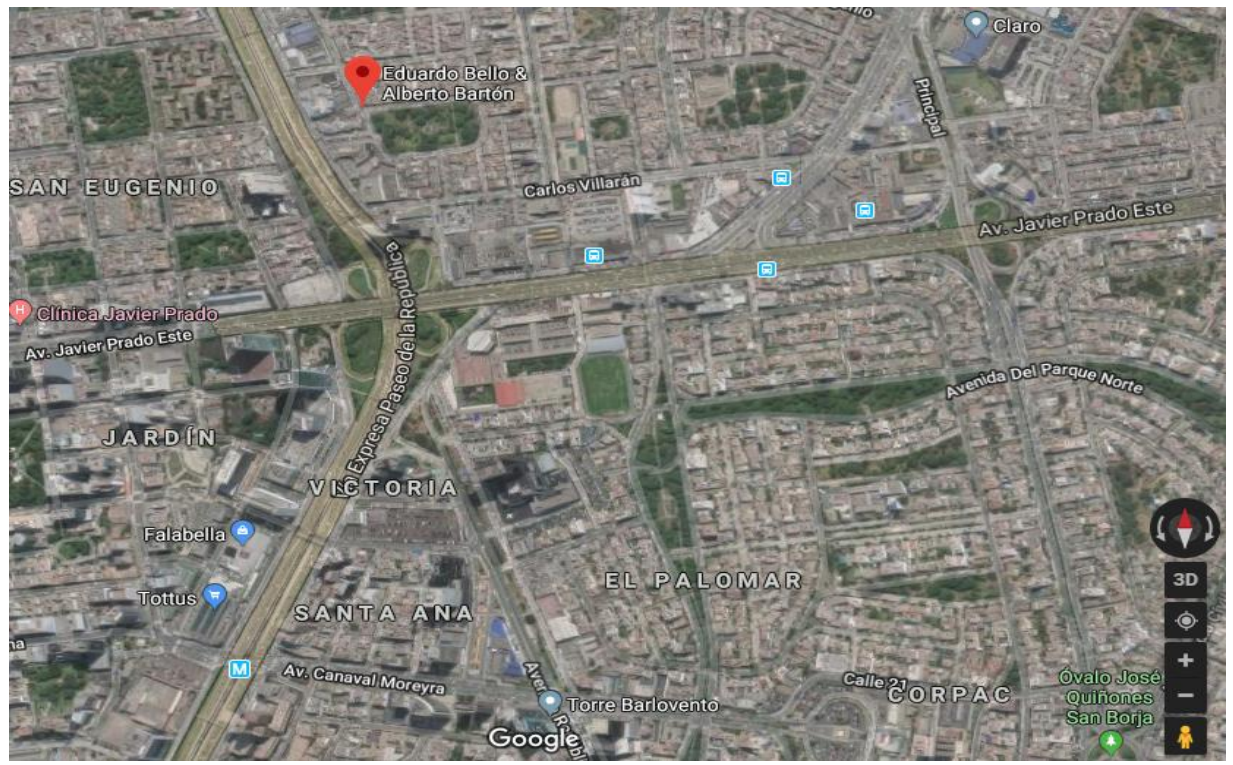

Fuente: Recuperado de

https://www.google.com.pe/maps/place/Eduardo+Bello+\%26+Alberto+Bart\%C3\%B3n,+La+Victoria +15034/@-12.0973785,-

$77.0305827,3006 \mathrm{~m} / \mathrm{data}=! 3 \mathrm{~m} 1$ !1e3!4m5!3m4!1 s0x9105c862e7580341:0xf7d47303db7e0758!8m2!3d $-12.0875542 ! 4 \mathrm{~d}-77.0232853$ ?hl=es-419\&authuser $=0$ 


\section{Infraestructura}
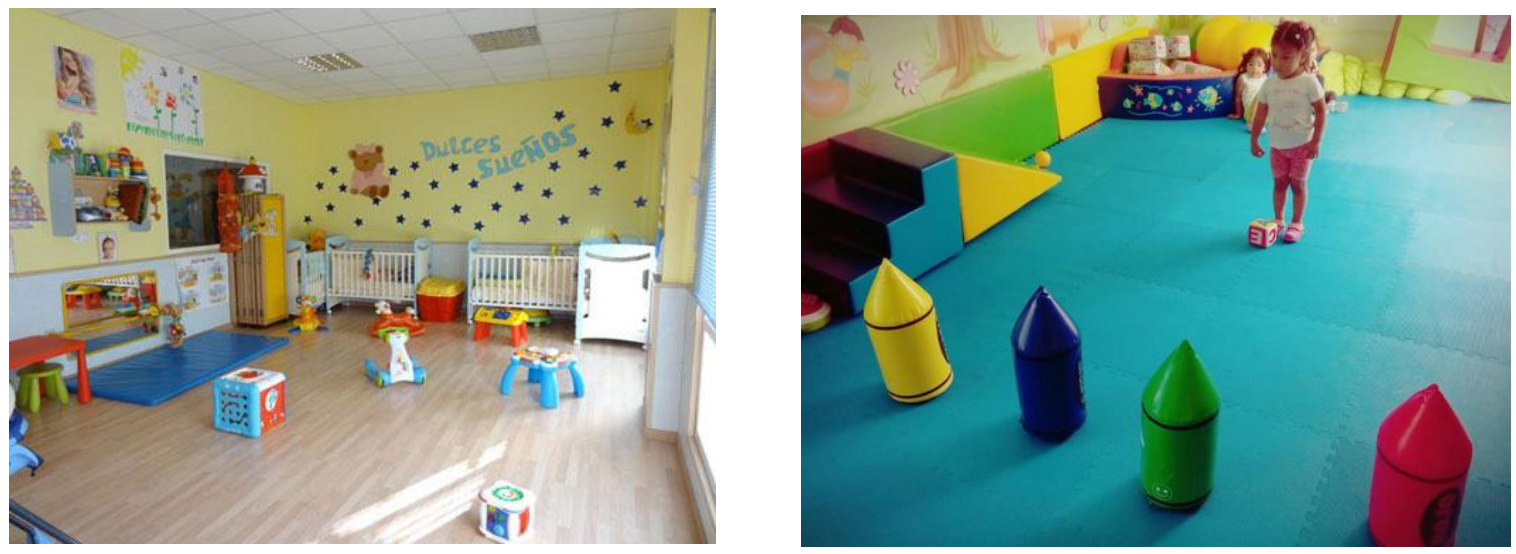

\section{Ambiente separado por edades}
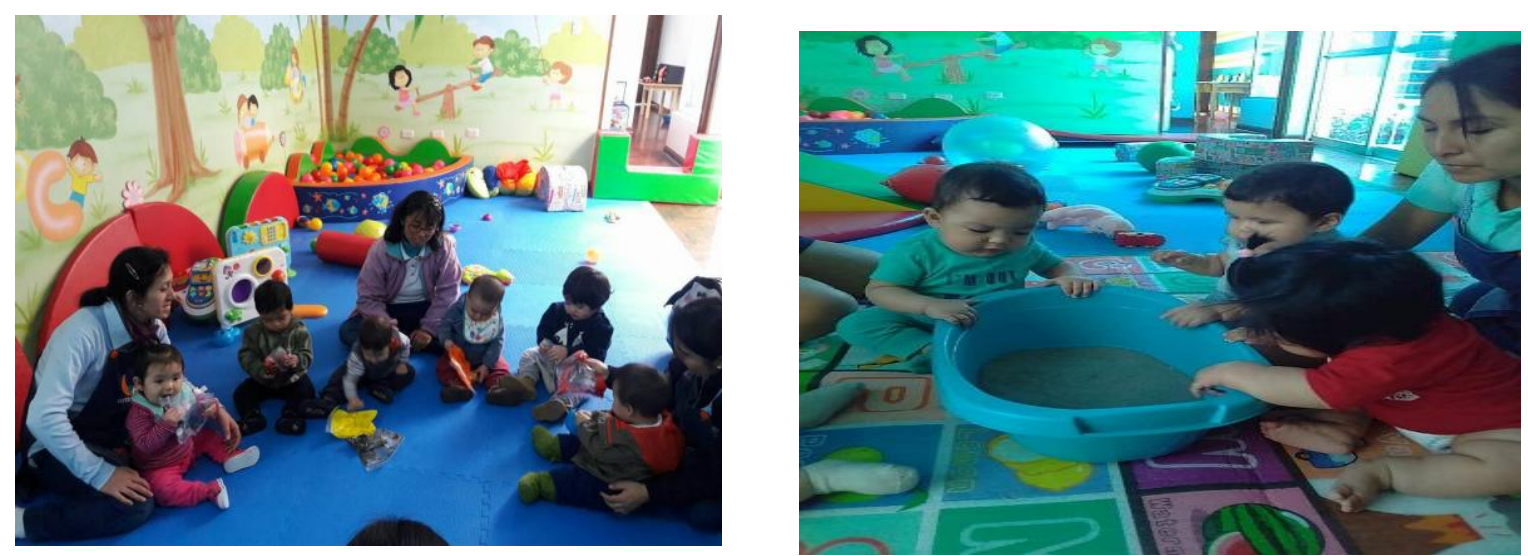

Estimulación temprana

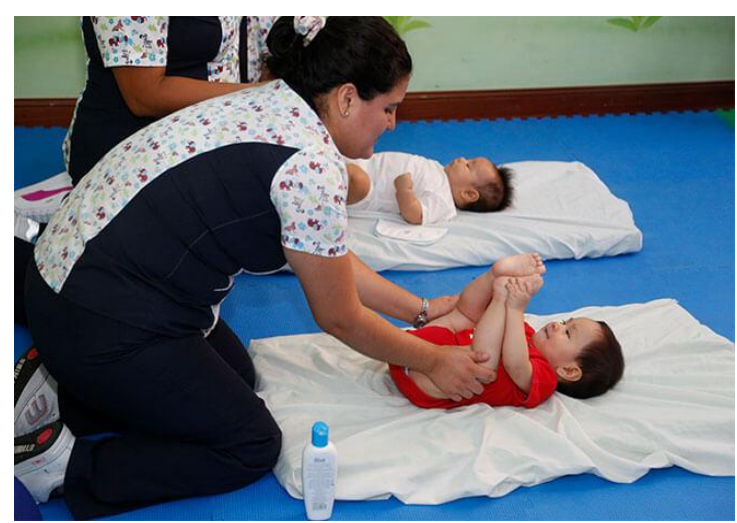




\section{Apéndice U}

\section{Guía de Pautas para entrevista en profundidad a expertos - Dueño/Director de una Guardería}

Buenas tardes/ noches estimado señor (a) , queremos agradecerle el tiempo brindado para poder realizar esta entrevista, asimismo comentarle que somos egresados de la Escuela de Postgrado de la Universidad San Ignacio de Loyola y que estamos elaborando nuestro proyecto de Tesis para obtener el grado de MBA, y nos gustaría conocer mejor su experiencia como experto en el tema de

Esta entrevista será grabada, esperamos no tenga inconveniente ya que su información es muy importante y valiosa para realizar nuestro proyecto.

16. ¿Siguiendo con lo que me comenta, cuénteme por favor como es que han realizado la distribución de sus instalaciones para darles esa experiencia de segundo hogar que menciona?

17. ¿En cuanto a los permisos con la Municipalidad y problemas de ruidos con los vecinos, le ha sido fácil adaptar el Nido a la zona?

18. Ya que me cuenta del crecimiento del nido-guardería, ¿cómo es que deciden que es momento de seguir creciendo?

19. ¿Tuvieron que hacer muchos cambios para la implementación de estos cambios? Me refiero a la continuidad del servicio.

20. ¿Aparte de estas interrupciones en el servicio de comunicación, han tenido algún evento en que su calidad en el servicio haya disminuido?

21. Comprendo el temor que este impase generó. Imagino que mayor temor debe existir cuando algún niño se golpea o enferma dentro de sus instalaciones. ¿Cómo suelen resolver estos temas frente a los padres?

22. Coménteme por favor la diferencia de actividades que realiza durante el nido versus la guardería.

23. ¿Al darme este detalle, cree que esta forma de trabajo que tienen la diferencia de su competencia o creen que hay algún valor agregado frente a otros?

24. ¿Como parte de esa mejora, alguna vez ha considerado la educación a través del Método Doman?

25. Ok, y los padres, ¿están conformes con la educación que ustedes brindan a sus hijos?

26. ¿Y cree que la matrícula, la pensión y gastos por materiales van acorde con lo que brindan?

27. ¿Cómo ha visto la implementación de esta técnica en otras instituciones educativas?

28. Resumiendo, un poco la entrevista, ¿cuáles serían los factores de éxito que usted considera para una guardería?

29. Finalmente, para elaborar un buen pronóstico de ventas que datos considerarías para tener éxito.

30. Gracias por tan agradable conversación. Tengo mucha información clara y precisa respecto a su negocio.

31. Claro que sí, le agradezco su tiempo y gentileza. 


\section{Apéndice V}

\section{Guía de Pautas para entrevista en profundidad a expertos - Dueño/Director de una Guardería}

Buenas tardes/ noches estimado señor (a) , queremos agradecerle el tiempo brindado para poder realizar esta entrevista, asimismo comentarle que somos egresados de la Escuela de Postgrado de la Universidad San Ignacio de Loyola y que estamos elaborando nuestro proyecto de Tesis para obtener el grado de MBA, y nos gustaría conocer mejor su experiencia como experto en el tema de.

Esta entrevista será grabada, esperamos no tenga inconveniente ya que su información es muy importante y valiosa para realizar nuestro proyecto.

14. ¿Comencemos con la entrevista, coménteme cómo así es que decide iniciar un proyecto tan ambicioso como el de una guardería?

15. ¿Comprendo, y cómo es que empieza a ejecutar su sueño?

16. Ok, y ya que me comenta de las nuevas construcciones en la zona, ¿cómo es que esta propiedad ha sido acondicionada?

17. La felicito por el gran crecimiento que ha tenido en el tiempo. Coménteme más respecto al tipo de educación que reciben los niños en sus diferentes etapas.

18. Ya que me comenta de las profesoras, ¿cómo es que las llega a seleccionar?

19. Interesante lo que menciona. ¿Cuál es la opinión de los padres del trabajo que realizan?

20. ¿Y cómo hacen con aquellos padres que trabajan y no pueden asistir?

21. ¿El trabajar con niños que tienen meses de nacido debe ser muy demandante, qué clase de actividades son las que realizan hasta antes del primer año de edad?

22. ¿Según su experiencia y por lo que me está comentando cuales serían factores a considerar para la diferenciación de las guarderías?

23. ¿Quisiera hacerte una última pregunta, cuales consideras que son buenas variables para realizar un buen pronóstico de ventas?

24. Miss Daniela muchas gracias por todo su tiempo brindado, he podido sacar muy buenas conclusiones. Le molestaría si después vuelvo a visitarla si es que me surgieran algunas dudas. 